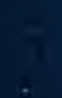

s. 



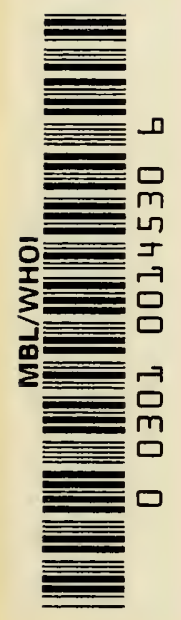



THE WATER RELATIONS

OF PLANTS 
THE BRITISH ECOLOGICAL SOCIETY SYMPOSIUM NUMBER THREE 


\title{
THE WATER RELATIONS OF PLANTS
}

\author{
A Symposium of \\ THE BRITISH ECOLOGICAL SOCIETY
}

London, 5-8 April 1961

\author{
Edited by \\ A.J.RUTTER \\ B.Sc. Ph.D. \\ Imperial College of Science \\ and Technology, London \\ and \\ F.H.WHITEHEA D \\ M.A. D.Phil. \\ Imperial College of Science \\ and Teclinology, London
}

JOHN WILEY \& SONS INC

NEW YORK 
(C) BLACKWELL SCIENTIFIC PUBLICATIONS I 963

This book is copyright. It may not be reproduced by any means in whole or in part without permission. Application with regard to copyright should be addressed to the publishers.

FIRST PUBLISHED I 963

Printed in Great Britain 


\section{CONTENTS}

PREFACE

\section{WATER AND WATER MOVEMENT IN THE ENVIRONMENT}

Chimatic Diagrams as a Means to Comprehend the Various

Climatic Types For Ecological and Agricultural

Purposes

H.Walter, Botanisches Institut, Stuttgart-Hohenheim, West Germany

Potential Water Deficit as a Climatic Discriminant

F.H.W. Green, Speyside Research Station, Nature Conservancy, Achantoul, Aviemore, Invernesshire, Scotland

The Role of Evaporation in the Surface Energy Balance

M.J. Blackwell, Meteorological Office, Agricultural Research Unit, School of Agriculture, University of Cambridge

Dew: Facts and Fallacies

J.L. Monteith, Rothansted Experimental Station, Harpenden, Herts.

The Effect of Dissolved Salts on Water Movement

D.A. Rose, Rothansted Experimental Station, Harpenden, Herts.

MOdel Tests on the Ecological Effect of Vapour Movement in Soll due to Temperature Gradients

W.R. Müller-Stoll \& G. Lerch, Botanisches Institut, Pädagog.

Hochschule, Potsdam, East Germany

PHYSIOLOGICAL STUDIES OF WATER BALANCE AND MOVEMENT IN PLANTS

The Pathway of Water Movement Across the Root Cortex and Leaf Mesophyll of Transpiring Plants

P.E. Weatherley, Botany Department, University of Aberdeen,

Scotland 
Water Saturation Deficit and its Development in Young and Old Leaves

Jiři Čatský, Institute of Biology, Czechoslovak Academy of

Sciences, Praha, Czechoslovakia

WATER RELATIONS IN NATURAL CONDITIONS

On the Distribution of the Precipitation in a Spruce

Stand: An Attempted Analysis

M.G. Stålfelt, University of Stockholm, Sweden

Measurement and Significance of Throughfall in Forest STANDS

E. R. C. Reynolds \& L. Leyton, Department of Forestry,

University of Oxford

The Behaviour of Norway Spruce (Picea abies (L.) Karst) in

Central Jutland, Denmark, in the Summer of 1955

E. B. Oksbjerg, Royal Forestry College, Stockholm, Sweden

Climate and Water Relations of Plants in the Sub-Alpine REGION

Walter Tranquillini, Forschungsstelle fïr Lawinenvorbengúng, Innsbruck, Austria

Investigations on the Water Relations of SAND-DUne Plants Under Natural Conditions

A.J. Willis \& R.L. Jefferies, Department of Botany, University of Bristol

Water Relations of Some Psammophytes with Respect to Their Distribution

Milena Rychnovská \& Jan Kvèt, Geobotanical Laboratory of the Czechslovak Academy of Sciences, Brno, Czechoslovakia

The Water Supply of Desert Plants

H. Walter, Botanisches Institut, Stuttgart-Hohenheim, West Germany 
Seasonal Dimorphism of Desert and Mediterranean

Chamaephytes and its Significance as a Factor in their WATER ECONOMY

G. Orshan, The Hebrew University, Jerusalem, Israel

\section{RELATION OF GROWTH AND DISTRIBUTION TO WATER}

On the Problem of the Relationship Between Hydration of Leaf Tissue and Intensity of Photosynthesis and RESPIRATION

B. Slavik, Institute of Biology, Czechoslovak Academy of Sciences, Praha, Czechoslovakia

The Effects of Exposure on Growth and Development

F.H. Whitehead, Imperial College, London

Growth and Water use of Vegetables in a Greenhouse

J.F. Bierhuizen, Institunt voor Cultuurtechnick en Waterhuishouding, Wageningen, Netherlands

Photosynthesis and Growth of a Five-year-old Stand of Poplar Trees in Relation to Water Economy of the Site

H. Polster, Institute of Forest Science, Tharandt, East Germany

Hydrature and Plant Production

K. Kreeb, Botaniscles Institut, Stuttgart-Hohenheim, West Germany

A Comparison Between the Water Relations of Species with Contrasting Types of Geographical Distribution in the BRITISH ISLES

Margaret S. Jarvis, Institute of Physiological Botany of the University of Uppsala, Uppsala, Sweden

The Effect of Soil Type on the Relation Between Soil/ Water Regime and Growth of Seedlings of Quercus petraea (Matt.) Liebl.

P. G. Jarvis, Institute of Physiological Botany of the University of Uppsala, Uppsala, Sweden 
viii CONTENTS

Formulae for the Ecological Reaction of Crop Yields

W.C. Visser, Institunt voor Cultumrtechnick en Waterhnishouding, Wageningen, Netherlands

The Growth Response of Sugar Beet to Similar Irrigation Cycles Under Different Weather Conditions

B. Orchard, Rothamsted Experimental Station, Harpenden, Herts.

Cropping Pattern and Water Relations

W.C. Visser, Institunt voor Cultunrtechnick en Waterhuishouding, Wageningen, Netherlands

Water Relations of Forest Trees

E.E. Gaertner, Professional Agrologist, Petawara Forest, Chalk River, Ontario, Canada 


\section{PREFACE}

It is a striking illustration of the current world-wide interest in the investigation of plant water relations that it should have been possible for the British Ecological Society to organize a symposium on this topic in I961, barely two years after a similar one had been held in Madrid, under the auspices of Unesco*, and that a different set of contributors of international reputation should have been available to sustain the symposium. It is true that the Madrid symposium was mainly concerned with the problems of arid lands, and this volume is to an extent complementary in that it lays greater emphasis on temperate vegetation. The authors of the Reviews of Research $\uparrow$ which preceded the Madrid symposium, performed a most valuable task in giving a systematic account of the soil-plant-air system through which water moves and the relation of the physiology and growth of plants to the water factor. But already it has become possible to add, in this volume, new information on subjects of fundamental importance to plant water relations, such as evaporation, dew formation and water movement through soil and plant. In addition investigations from very varied standpoints of the relationship of water balance to growth and development represent a valuable contribution to the understanding of the biological problems involved.

As a result of some late withdrawals of papers, matched by some fortunate late contributions, the plan of arrangement of topics in the symposium was somewhat disturbed, and in preparing the proceedings for publication the opportunity has been taken to re-arrange the contributions in a more logical order.

The first section on Water in the Environment contains papers from both geographical and physical points of view. It is followed by two studies of water in the plant, one of which presents new evidence on the path of water movement while the other critically re-examines a technique, the determination of leaf water deficit (or relative turgidity, its

* UNESCO, Arid Zone Research Series, No. I6, I96I.

† Ibid, No. Is, 1960 . 
complement) which has been widely used in ecological studies for more than 30 years. As is appropriate for an ecological society, there then follows a considerable section devoted to investigations in natural vegetation, ranging from coniferous forest and sub-alpine vegetation, to psammophytes and desert plants. Much work in recent years has been directed to the accurate measurement or estimation of transpiration because of its significance to mankind in water conservation and in forecasting catchment yields and floods. To the botanist, how ever, transpiration has greater significance. In the first place it represents a process which dissipates, often with apparent extravagance, the water in the soil on which growth and survival depend. Secondly, the life processes of the plant are related in a complex way to the balance between the demand of the atmosphere for water and the ability of the soil to supply it. From both points of view the success of the plant is related to its ability to regulate its transpiration and its potential on the gradient between soil source and air sink. The ultimate concern of studies on water relations is surely to analyse all aspects of the growth, development, reproduction and survival of plants as they are affected by, or as they affect, the potentials, movement and balance of water in the system. Although we are far from fully understanding the responses of plants to water, our ultimate interest in growth and development has been recognized by reserving for the final section investigations on the relation of growth to climate, soil water and the potential of water in the plant.

The symposium was held at Imperial College, London, by invitation of the Rector and Professor W. O. James F.R.s., from 5 to 8 April, I96r. The conveners wish to record here the thanks which were expressed at the closing session to the College authorities and staff, and the many willing and able helpers who contributed so largely to the smooth running of the meeting and the enjoyment of all present.

A.J. RutTer F.H. WHTEHEAD 
WATER AND WATER MOVEMENT IN THE ENVIRONMENT 



\title{
CLIMATIC DIAGRAMS AS A MEANS TO COMPREHEND THE VARIOUS CLIMATIC TYPES FOR ECOLOGICAL AND AGRICULTURAL PURPOSES
}

\author{
H. WALTER \\ Botanisches Institut, Stuttgart-Hohenheim, W. Germany
}

A very close correlation exists between vegetation and climate. Therefore everyone who is interested in vegetation should be equally interested in climate.

It is very difficult, however, to get an exact idea of climate. We constantly use the word 'climate', but what is climate? It is possible to define climate as the weather, changing in a certain manner during the course of a year, taken as an average of many years, as a single year may be abnormal.

What is the weather? It is the effect of all weather or climatic elements as temperature, rainfall, humidity, radiation, etc., combined at a certain moment. Therefore, to get the actual clinnate, it is necessary to summarise the effects of all these climatic elements in order to get the weather for the entire year. But no climatologist tells us how to do this. It is only possible to get the tables for each climatic element. We also have many exact maps of the distribution of the annual temperature or the annual rainfall, the temperature of the coldest or hottest month, the rainy seasons, the humidity, the evapotranspiration, etc., but all this does not yet fully constitute the climate. As basis for climatic maps the climatologist employs chiefly the maps of vegetation and also the climatic types are named after the vegetation, for example, desert climate, steppe climate, forest climate, alpine climate, etc.

Climate is a unity. It is not possible to express climate by a figure or by formulae, even by the most complicated ones, because it is necessary to know the seasonal rhythm of the most important factors. Therefore we have to use a diagram, quasi as a picture of the climatic type.

During the year 1954-55 I was a guest professor at Ankara in Anatolia and I desired a quick overall picture of the different climatic types of Anatolia. I obtained the meteorological tables from approximately 66 meteorological stations with long-term observations, but it was very difficult to get a synopsis of the climatic regions. I decided to use the diagram method and I remembered a suggestion given by $\mathrm{H}$. Gaussen at the International Botanical Congress in Paris in 1954 to use the same units 
of length for $10^{\circ} \mathrm{C}$ and $20 \mathrm{~mm}$ of rainfall respectively. Using this scale, $10^{\circ} \mathrm{C}$ equal to $20 \mathrm{~mm}$, Gaussen established for the Mediterranean region a strictly arid period prevailing when the rainfall curve goes below the temperature curve and a humid period when the rainfall curve rises above the temperature curve (Fig. I, climatic diagram of Ankara). I applied this method to the climate of Ankara and the diagram showed the actual dry period beginning with June and ending in the second half of October. When I checked the method for tropical summer rain regions (South

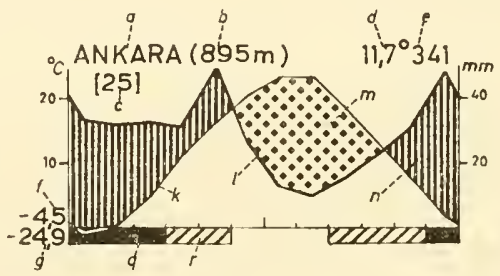

FIG. I

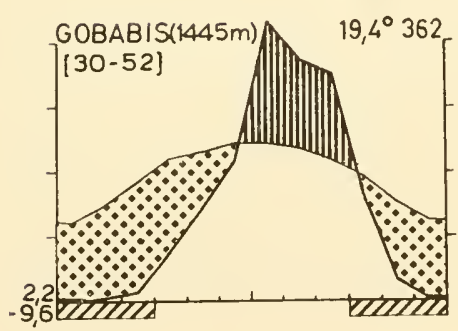

Fig. 2

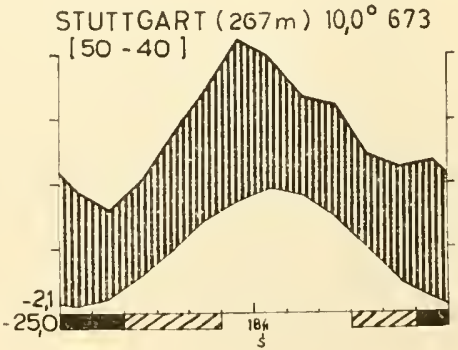

FYG. 3

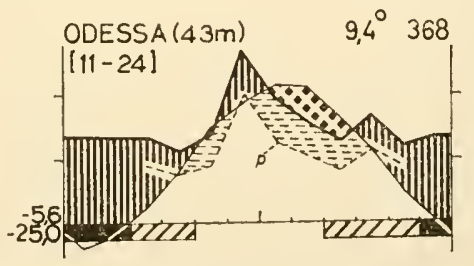

FIG. 4 


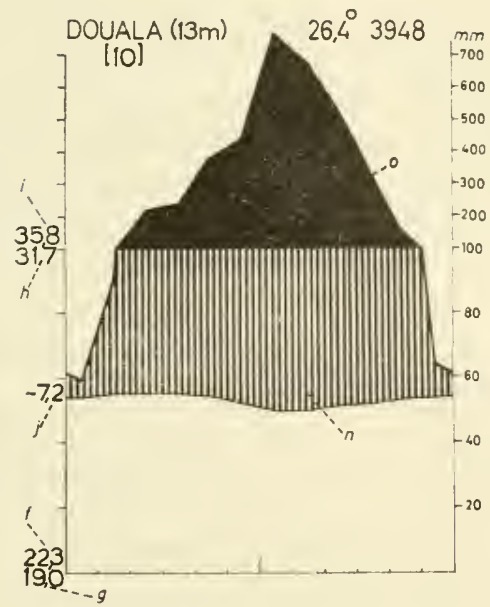

FIG. 5

FIGURES I-5. Explanation of climatic diagrams.

a-Station.

$\mathrm{b}$ - Altitude.

c-Number of years of observation (the first stands for temperature, the second for precipitation).

$\mathrm{d}$-Mean annual temperature in ${ }^{\circ} \mathrm{C}$.

e-Mean annual amount of precipitation in $\mathrm{mm}$.

f-Mean daily minimum of the coldest month.

$\mathrm{g}$-Absolute minimum.

$\mathrm{h}$-Mean daily maximum of the hottest month.

i-Absolute maximum.

j-Mean daily range of temperature.

$\mathrm{k}$-Monthly means of temperature (thin line) in ${ }^{\circ} \mathrm{C}$.

1-Monthly means of precipitation (thick line) in $\mathrm{mm}$.

$\mathrm{m}$-Arid period (dotted area).

n-Humid period (hatched area).

o-Perhumid area (black area), mean monthly rainfall over $100 \mathrm{~mm}$ (scale reduced ten times).

p-Additional precipitation curve $\left(10^{\circ} \mathrm{C}=30 \mathrm{~mm}\right)$ showing the less extreme dry period.

q-Months with a mean daily mininum below $0^{\circ} \mathrm{C}$.

r-Months with an absolute minimum below $0^{\circ} \mathrm{C}$.

$s-$ Mean number of frost-free days. 
West Africa) and temperate regions of which I knew the exact climate (Stuttgart, etc.), it worked out as well (Figs. 2 and 3 ).

The only exception was the temperate steppe climate with a summer maximum of rainfall. The diagram of Odessa shows a short arid period in the spring and a little longer arid period in July and August. This was a contradiction as the whole summer in Odessa is dry, though not as dry as in the Mediterranean region. In these cases it proved to be useful to draw an additional rainfall curve with a scale of $10^{\circ} \mathrm{C}$ equal to $30 \mathrm{~mm}(\mathrm{I}: 3)$ and to distinguish an extreme drought period and a less extreme dry period (Fig. 4, climatic diagram of Odessa).

Comparison between the curve of the monthly mean temperature and monthly mean rainfall is allowable because evaporation is mostly proportional to temperature. To get the water balance it is necessary to know the ratio of the evaporation to rainfall. As evaporation values are published only for very few stations, temperature values have to be utilised instead of the missing evaporation values. This is only possible, however, when the temperatures are above $0^{\circ} \mathrm{C}$, as below $0^{\circ} \mathrm{C}$ the evaporation is negligible.

Many authors have used the ratio of precipitation to temperature in order to obtain a picture of the water balance (Lang, de Martonne, Köppen, Angström, Church and Gueffroy, Thornthwaite, etc.). The formulae they used are, more or less, complicated. But the ratio of the temperature to rainfall does not much deviate from $I: 2$ or $I: 3$ as used by us. For the drawing of thousands of diagrams the ratio must be a simple one, therefore we employ mostly only the ratio $\mathrm{I}: 2$ and distinguish between an extreme drought period and a less extreme dry period if desirable, by employing the ratio $\mathrm{I}: 3$.

The horizontal extension of the different areas on the diagrams shows us the duration of the periods, the vertical extension, the intensity of humidity or aridity respectively.

But it is not enough to characterise unfavourable seasons caused by water shortage. To get an idea of the climate or the climatic type, we also have to know the unfavourable season, caused by cold. Therefore the months with a mean daily minimum below $0^{\circ} \mathrm{C}$ are indicated by black blocks. This is the average cold season of the year. The months with only an absolute minimum below $0^{\circ} \mathrm{C}$ are hatched (Figs. I-4). During this season frost was observed, but frost may not occur every year, sometimes only in exceptionally cold years. Some additional climatic data are provided by figures. Complete diagrams are shown in Figs. I-4. In the tropics the monthly rainfall may be extremely high and in order to simplify the diagram, the scale for rainfall above $100 \mathrm{~mm}$ per month is reduced ten times. 
This area is shown in black (Fig. 5, climatic diagram of Douala) and is a perhumid season.

In the equatorial region the temperature shows a much larger daily than seasonal variation. Therefore it is necessary to give additional figures: the mean daily maximum of the hottest month, the absolute maximum temperature and the amplitude of the mean daily variation of the temperature (Fig. 5).

The diagrams of all 66 meteorological stations of Anatolia were drawn and attached to a large wall map of Anatolia. At a glance one could see the distribution of the main climatic types without any interpolation. This was also accomplished for Iraq during a visit to Baghdad. Later on the same method was applied to Africa, while the maps were published in Germany. Since they proved to be very useful, we decided to prepare a world atlas of the climatic diagrams. The first part is already published by VEB Gustav Fischer-Verlag Jena and comprises the complete Southern Hemisphere, India, the Near East, the Iberian Peninsula and Western Europe. Maps of the other parts of the world are in preparation and will be published next year.

It is impossible to show the diagrams of all stations on the maps or climatic cartograms of the world atlas because the scale of the maps is too small. It is necessary to unite diagrams of the same type to groups and to show only the distribution of these on the maps with diagrams of one or two stations as examples. The position of each station is shown on the maps by a number. The diagrams of these stations are listed under the same number on supplementary sheets.

The following ten principal climatic types are distinguished as indicated by roman numerals:

I Equatorial type, humid or with two rainy seasons.

II Tropical type, with summer rain.

III Sub-tropical type, hot and arid.

IV Mediterranean type, with arid summer and winter rains, frost rare.

V Warm temperate type, humid, frost rare.

VI Temperate type, with cold winter, humid.

VII Temperate arid type, with a cold season.

VIII Boreal type, with a long winter season.

IX Arctic type, cold, only a short warmer season.

$\mathrm{X}$ Mountain types, belonging to different climatic regions.

The subdivisions of these types are indicated on each map by arabic figures or letters. They are preliminary and only when all maps are ready will it 
be possible to give a detailed classification of all different climatic types based on climatic data only and not on vegetative regions. Only then shall we be able to carry out a true comparison between climate and vegetation.

In Eastern Europe such a comparison shows that the border lines of the vegetation regions (forest, forest steppe, steppe, semi desert) are much more complicated than the borders of the corresponding climatic regions. This can easily be understood, as the vegetation depends not only on climate but also on soils. In a region with loess soils, steppe invades the forest belt in tongue- or island-like extensions (Walter I957).

The borders between two vegetation regions are much sharper than those between two climatic types. In flat countries there is a steady transition from one climatic type to another. A cartogram with climatic diagrams shows this clearly. Border lines on ordinary climatic maps in a region of this type are, to a degree, misleading and arbitrary.

All diagrams of the world atlas (about I0,000) are drawn in the same manner, therefore it is easy to compare the climate of different stations. The months are printed for stations on the Northern Hemisphere, starting with January, those on the Southern Hemisphere starting with July, so the warm season always comprises the middle of the diagram. This is necessary to facilitate comparison. When confronted with the question where a climate, corresponding to the climate of the Central Anatolian steppe, might be found in other parts of the world by comparing different diagrams, it was easily possible to see that the climate of Ankara is similar to that of Salt Lake City (U.S.A.) and Kabul (Afghanistan). In fact these three places have a similar geomorphological situation and the vegetation of these regions is equally similar.

We hope that this atlas may prove useful in dealing with problems concerning ecology, plant geography, agriculture, forestry and many other fields of study. I wish to emphasise, that the figures in the diagrams are exactly those published by the meteorological stations. Therefore, if required, these data may be read from the diagrams. The diagrams comprise only the most important climatic factors. Minute details should be avoided, as the diagrams become overcrowded and consequently less clear. The diagram gives only a rough idea of a climatic type. It is impossible to do more, as even the most exact meteorological data do not correspond to the plant climate, for they are, (I) measured in a screen, which means protected from the radiation and (2) $2 \mathrm{~m}$ above ground. Moreover, only long-term means are published.

A normal climate, as given by the mean values, does not exist. There 
are periods every year either too cold or too warm, too dry or too humid. The extremes often are more important for the plants than the average conditions, and for agriculture or forestry purposes it is extremely important to know how often such extremes may occur. To get a better idea of the climatic conditions in a certain region with respect to its extremes, we use climatograms. Their construction is nearly the same as that of ordinary climatic diagrams, except for the curves. Instead of using the long-tern means, the values for single years (for a period at least of 20 years) are used instead. Such climatograms show at a glance, how often extreme years with strong deviations occur.

We hope the method of climatic diagrams described here will prove useful and find a wide application. The maps of our atlas need further improvements, as they are a first attempt.

\section{LITERATURE}

Publications in which the method of climatic diagrans was used.

Beydeman, I.N. \& KorCZAGyn, A.A.(1962) Report on the World Atlas of climatic diagrams and the Russian publications in which this method was used. Bot.Z.47, 288-290.

Borhidi, A.(196r) Klimadiagramme und klimazonale Karte Ungarn. Ann. Univ. Scient. Budapestinensis, Sect. Biol. 4, 2I-50.

Gaussen, H.(I955) Expression des milieux par des formules écologiques; leur représentation cartographique. Colloques Int. du Centre Nat. Rech. Scient. 59, 257-269.

Golubić, S.(1958) Beitrag zur Klimakenntnis des Jugoslavischen Küstenlandes. Geogr. Glasnik, 20, 139-148.

PANNIER, F.(I952) El climatogramma. Un aspecto neuva para el conocimiento del clima y de la distribucion de la vegetacion en Venezuela. Ergebn. dtsch. Limnol. Venezula-Exp. r, 57-66.

Paterson, S.S.(1959) Förslag till bioklimatisk regionindelning av Norden. Svensk Geogr. Arsbok, 35, 102-1 22.

Pisek, A.(1960) Immergrüne Pflanzen. Encyclopaedia of Plant Physiology, 5, 415 ff. Berlin.

WALter, H.(1957) Die Klima-Diagramme der Waldsteppen- und Steppengebiete in Osteuropa. Lautensach-Festschr., Stuttg. Geogr. Studien, 69, 253-262.

Walter, H.(1962) Die Vegetation der Erde, Bd. I, Jena.

WAiter, H. \& LerTH, H. (I960) Klimadiagramm-Weltatlas. Jena I960. 


\title{
POTENTIAL WATER DEFICIT AS A CLIMATIC DISCRIMINANT
}

\author{
F. H.W. GreeN \\ Nature Conservancy
}

THIS paper consists of two parts. In the first I will explain what is meant by 'Potential Water Deficit', and in the second I will suggest how useful the concept can be to ecologists as a climatic discriminant.

It may be stated simply that Potential Water Deficit or Potential Water Surplus (PWD and PWS, respectively, for short) is the difference between rainfall (and/or snowfall) and potential evaporation; it is a deficit or surplus of water according to which of these quantities is the greater. One need not at the moment say much about rainfail measurement beyond pointing out a few of the known difficulties in measurement. For instance, 'rainfall' is not always rainfall; it may be precipitation of water in other forms, e.g. snow, hail, or ice pellets, all of which it is normally attempted to measure in rain-gauges. Then there is so-called 'occult precipitation', which includes dewfall and condensation from fog. Again, what is measured in a standard rain-gauge may not be quite the same amount as in fact falls on the neighbouring ground. Those difficulties will be referred to again later. For the moment it may first be said that in fact, in this as in most countries, an attempt is made to measure rainfall under certain 'standard' conditions, which are inevitably arbitrary.

It needs now to be explained what is meant by potential evaporation(or evapo-transpiration). Broadly, it is the amount of water which would be evaporated if there were always water available to be evaporated. It thus may differ from actual evaporation which is dependent upon availability of water. Measurement of potential evaporation (or 'PE') presents difficulties, so that, since it is related, like air temperature, to incoming radiation (direct and indirect), it has commonly been computed, by various formulae, from other climatic elements which are widely measured. It is, however, possible to measure PE by means of irrigated lysimeters, provided various precautions are taken, and certain 'standard' conditions are accepted. Then, as with rainfall, comparison can, with caution, be made between values at different places.

The measurement of PE by lysimeter involves the remainder method, 
i.e. it is the difference between water going into the lysimeter-natural and added-and what percolates through. Expressed as an algebraic equation it is:

$$
\mathrm{PE}=R+A-N \pm S
$$

where $R$ is rainfall, $A$ is added water, $N$ is percolate, and $S$ is the difference in the amount of water stored in the lysimeter. There are various ways in which $S$ can be eliminated from the equation, and $A$ and $N$ can be measured quite accurately, so the main element of doubt is due to uncertainty that $R$ is measured correctly.

If, however, one considers the PWD or PWS, it is possible to eliminate $R$, since

$$
\begin{aligned}
& \mathrm{PWD}=\mathrm{PE}-R \\
& \mathrm{PWS}=R-\mathrm{PE}
\end{aligned}
$$

which equations are the same as

$$
\begin{aligned}
& \mathrm{PWD}=R+A-N-R \\
& \mathrm{PWS}=R-R-A+N
\end{aligned}
$$

these simplify to

$$
\begin{aligned}
& \mathrm{PWD}=A-N \\
& \mathrm{PWS}=N-A
\end{aligned}
$$

so long as $A$ is always kept high enough to ensure that $N$ does not sink to nil-i.e. there must be enough irrigation water to ensure that percolation is maintained, since otherwise it is not possible to allow for variations in storage.

PWS is potentially run-off, while PWD is an indication of water shortage, or alternatively, of drying power. It is not necessarily the same as the actual water deficit, because the potential evaporation may not be the same as the actual evaporation. The latter (AE) differs from PE by amounts which depend upon many factors, the nature of the soil, the vegetation cover, the land use and treatment, and other differences in the surface. But the PWD is an inescapable climatic factor, and so long as there is a potential water deficit, there must be an actual water deficit of some sort, unless water is supplied from elsewhere.

PWD and PWS can be assessed according to different unit lengths of time. If this time unit is one year, there will be either a single deficit or a single surplus. To quote a year's surplus would be quite misleading however. In the example shown in Table I, although an annual assessment gives a PWS of $10 \cdot 0$ in. an assessment made by calendar months shows this PWS to be made up of a winter PWS of I6. 0 in. minus a summer PWD of 
6.0 in. Even a month is too short a unit for considering a water budget, and, from the point of view of vegetation requirements, the unit of time should be short enough for the plants concerned not to suffer from water shortage. In an average soil (with average water retention properties) in a temperate climate, all but extremely shallow-rooted plants will be able to endure lack of rain for up to about five days. Table $\mathrm{I}$ thus gives assessments made, not

\section{TABLE I}

Potential water deficit and potential water surplus at Achnagoichan, 1959

$\begin{array}{lllllllllllll}\text { J } & \text { F } & M & \text { A } & M & \text { J } & \text { J } & \text { A } & \text { S } & \text { O } & \text { N } & \text { D } & \text { Year }\end{array}$

Calculated by units of one year:

PWD - $-\quad-\quad-\quad-\quad-\quad-\quad-\quad-0.0$

PWS - - - - - - - - - -

Calculated by units of one calendar month:

PWD - $\quad-\begin{array}{llllllllllll}- & - & 2.1 & 0.3 & 0.4 & 1.3 & 1.9 & - & - & - & 6.0\end{array}$

$\begin{array}{llllllllllllll}\text { PWS } & 2.7 & 0.8 & 0.6 & 1.2 & - & - & - & - & - & 3.5 & 3.9 & 3.3 & 16.0\end{array}$

Calculated by wet and dry periods of five days or more:

PWD - $-\begin{array}{llllllllllll} & 0.2 & 0.1 & 2.1 & 0.3 & \text { I.6 } & \text { I.3 } & \text { I.9 } & 0.5 & - & - & 8.0\end{array}$

$\begin{array}{llllllllllllllllllll}\text { PWS } & 2.7 & 0.8 & 0.8 & 1.3 & - & - & 1.2 & - & - & 4.0 & 3.9 & 3.3 & 18.0\end{array}$

(Values in inches.)

only by whole calendar months, but by calendar months divided into wet and dry spells, the dry spells being continuous periods of five days or more with no rainfall (and/or rainfall far less than the PE over the same period). Even this does not allow for isolated heavy thunderstorm downpours, which may cause flash floods because the rate of fall is greater than the rate of penetration into the soil.

It will be seen in the example that some calendar months can, in total, have both a surplus and a deficit. If the rainfall were distributed evenly throughout the month, there could be only one or the other. If the rainfall distribution is very uneven, there can be both, because, for instance, the surplus at one time will have disappeared as run-off before a dry period commences, and will not be available, necessarily, to make up for the deficit in that period.

Let us consider first what happens at a site where no period of PWD occurs. Rain is always falling at a greater rate than it can be removed, either by evaporation, run-off, or deep percolation, and this is virtually the case 
whatever the nature of the surface and subsoil (other than a sloping sheet of impervious concrete or 'tarmac', which could dry between showers). Thus no amount of artificial drainage could prevent waterlogging, and improving the land for arable agriculture is practically impossible. The natural vegetation cover is blanket bog ('climatic' bog) consisting of plants with very shallow roots, growing on top of the decayed remains of their predecessors. Lack of oxygenation of the waterlogged substratum prevents any development of living roots downwards. Only where slopes are too steep for the dead or living vegetation to be retained (or where, because of altitude, cold and wind enforce an upper limit) is there no bog. Here there is only bare rock, save for occasional very exceptional sites, where deeper rooted plants may temporarily obtain a footing in rock crevices. In the olden days, in the north-western Highlands and islands of Scotland, the inhabitants hit on one of the few possible methods of very slightly ameliorating the conditions-by the laborious construction each year of 'lazy-beds', deep ridges and furrows, which did permit of a certain amount of drainage, and so of oxygenation, in the upper parts of the ridges.

There does not at present exist a very satisfactory general map showing the distribution of peat deposits in Scotland, but Fig. I shows the distribution of 'improved land' (i.e. arable and ley), which is complementary to it. It will be seen that-excluding hill and mountain-it corresponds with the map (Fig. 2) showing the observed PWD in 1957-a year probably fairly close to the average. On the basis of the known distribution of 'climatic' peat, and of 'improved land', one can tentatively insert the average line of no significant PWD (less than $\frac{1}{2}-\mathrm{I}$ in. or $\mathrm{I} 3-25 \mathrm{~mm}$ calculated on a calendar month basis, in an average year) as shown on this map. Almost the only satisfactory arable land in the north-west is on the coastal 'machair'calcareous dune sand-forming a relatively fertile porous soil, where it can be saved from wind-blow. But it should be noted that, with evaporation augmented by strong winds, and slightly less summer rainfall than occurs a little way inland, there are probably 'outliers' of rather greater PWD here also.

Many places with small PWD will be in the same state as those with no PWD, because there is no practicability of artificial drainage. Almost all of north-western Scotland is in this position, the few areas of cropland being precisely at those places where the local physiography and geology specially favour drainage. Places with a larger PWD in an average year would, it is suggested, develop bog only where drainage is impeded, and if this impedance is removed, arable cultivation becomes possible. This is the case in most lowland areas in the east and south of Scotland, where it is on 


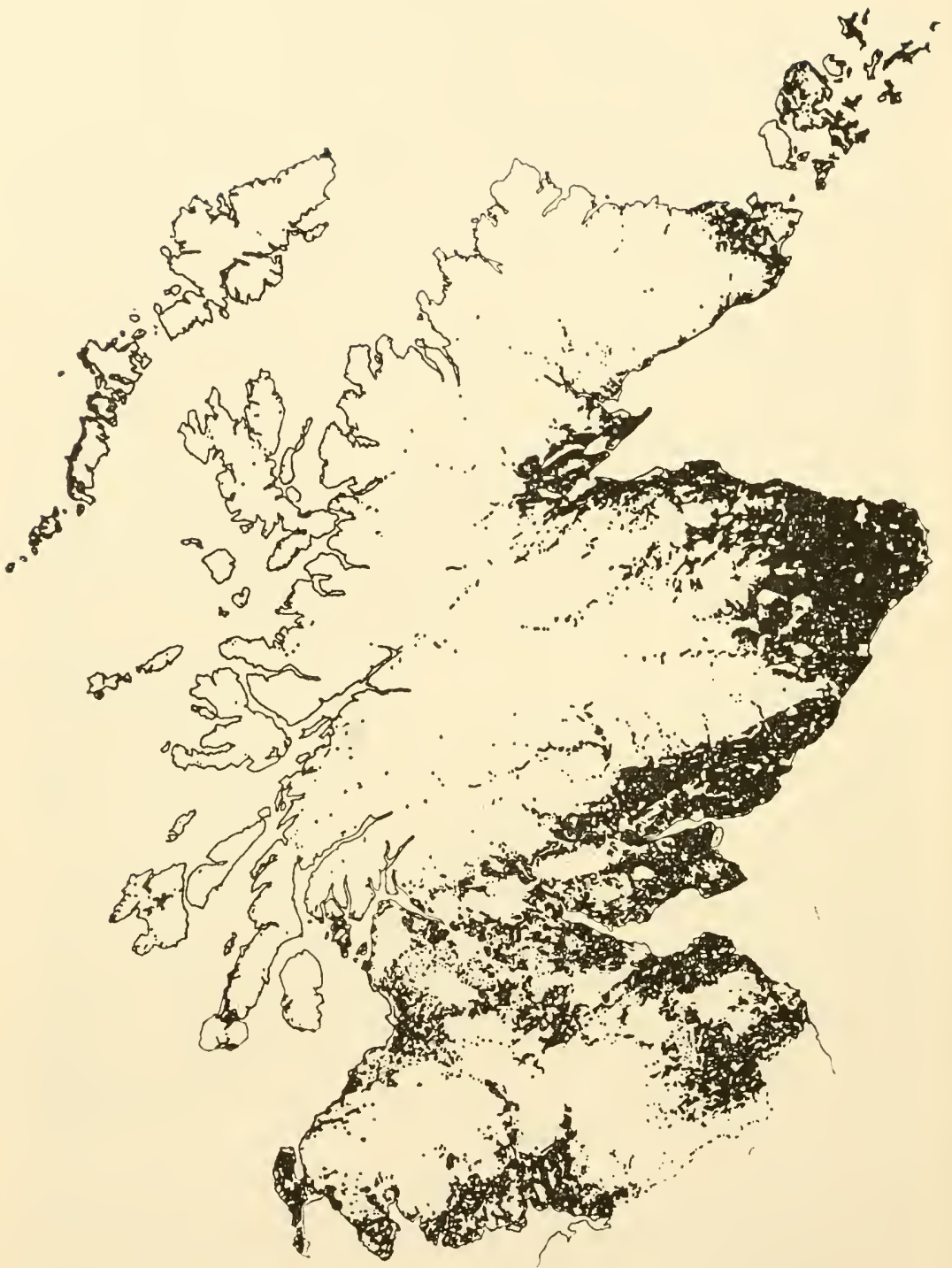

FIG. I. The distribution of arable land in Scotland. (From L. D. Stamp: The Land of Britain, Longmans, Green \& Co., London, 1948).

historical record that much of the now most fertile land was peaty until it was either drained or the peat taken away or both.

It is important to see where the threshold line, as here described, passes 


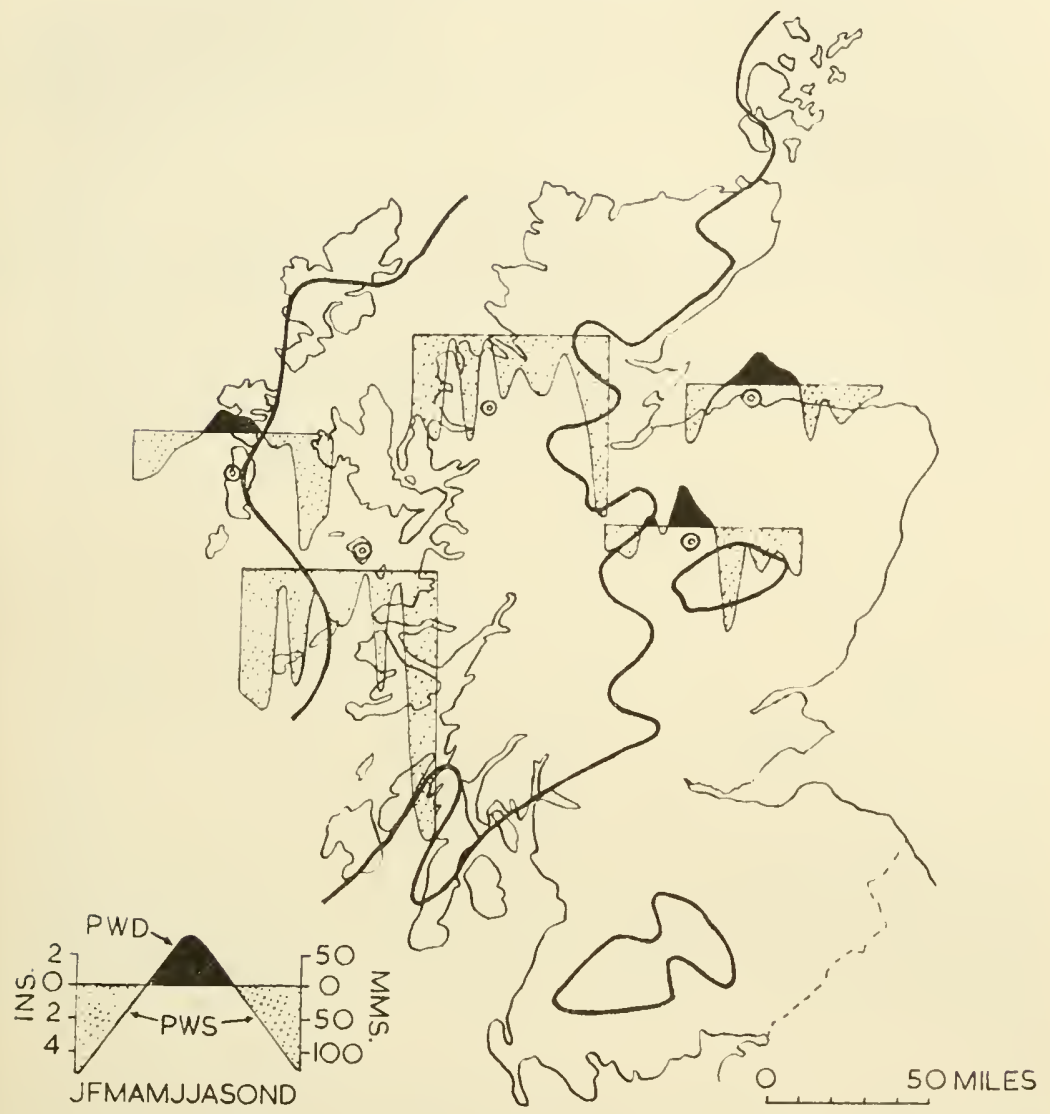

FIG. 2. The monthly distribution of potential water deficit and surplus at five stations in Scotland in 1960 . The black line indicates the generalised limit of areas with no potential water deficit.

across north-west Europe, outside Scotland. A map has been compiled on lines somewhat similar to those discussed in this paper, by Mohrmann (1958) and this shows that the areas of negligible PWD can be found in Ireland, Wales, north-west England, and in Norway, with an outlier in the Alps. But Mohrmann based his map on computed values of PE and he does not wnrk on PWD by wet and dry periods-i.e. he does not take into account the distribution of rainfall. If he had done so, it is unlikely that nearly so many areas would be included. Much of Wales, north-west England, and Norway 
would have been omitted, and almost certainly the Alpine and Alpine foreland areas. Why is this? The summer rainfall in the latter areas occurs mainly in heavy showers, with long dry periods in between; these allow for aeration of the soil.

Rainfall and PE have been measured in recent years at Cwm Dyli at the foot of Snowdon. Here the annual rainfall is of the order of I 50 in., and in all calendar months in 1960 , for instance, rainfall exceeded PE. Thus, if assessed by calendar months, Cwm Dyli had no PWD in that year. If however, the assessment is made by wet and dry periods, Cwm Dyli is seen to have had about 6 in. PWD in 1960. At Cwm Dyli there is good grassland; it has been possible to drain the soil and prevent it from being

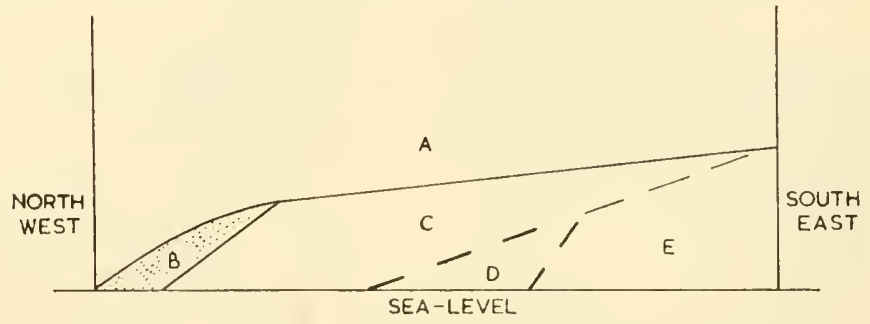

Fig. 3. Diagram illustrating the suggested altitudinal distribution of certain different 'water balance regions' in a section across Europe (not to scale). A is fell (Montane Zone), B is the extreme 'oceanic' type, with no significant potential water deficit, C is the main humid region of north-west Europe but with significant periods of potential water deficit each year, D is the Mediterranean type, with dry summers and wet winters, $\mathrm{E}$ is steppe. (See text.)

permanently waterlogged during the growing season. The climatic situation in summer in the pastures of Switzerland and Norway is comparable. It is different in the truly humid areas of north-western mainland of Scotland, which in this sense can be described as the most 'maritime' in Europe.

This brief paper has attempted to deal only with one threshold which can be studied, and defined, in this manner. It needs to be investigated whether light can be shed on other climatic limits. Figure 3 shows diagramatically the nature of the possible limits of the Mediterranean type of vegetation; the relevant numerical values of PWD and PWS, and their seasonal distribution, need to be determined. There is great scope similarly for investigating 'finer' limits, for natural plant communities, and individual cultivated crops, between these very broad divisions.

It may be useful to make reference here to some other physiological effects on plants-and animals-and of the lack of a period of PWD. As a first 
example, it has been shown by Alvin (I960) that moisture stress is an essential requirement for flowering of the coffee plant; it is no good irrigating a coffee crop unless it has been allowed to experience a period of water shortage. If there is continual water surplus, rank vegetative growth appears to be encouraged, but maturation is inhibited. It is but commonsense to expect that a crop which consists largely of water, such as a vegetable marrow, will not be able to develop unless there is, as in Britain in 1958 or 1960, a plentiful supply of water when the fruit is enlarging. But there could very well have been no flowering, and thus no fruit to enlarge at all, unless the period of plentiful water had been preceded by a period of water stress.

Turning from flora to fauna, it has been found that many invertebrates exhibit variations in movement, and in population density, according to whether or not there has been a moisture deficit in the soil or other habitat. Thus Pearce, working in the Moor House Nature Reserve in Westmorland, found that Enchytraeid worms move upwards in the soil under conditions of PWS and downwards in periods of PWD.

If one accepts that the climatic threshold described in this paper has a valid close correlation with the vegetational and agricultural features as suggested, one can speculate about secular changes. It would require only a very small change in 'total climate'-i.e. the results of secular changes in atmospheric circulation - to throw a place from one side of the threshold to another. An attempt has been made at an individual station in Scotland, to estimate monthly PWD in retrospect, back to the middle of last century. Since this had to be done by subtracting measured rainfall from $\mathrm{PE}$ computed by formula-both values being suspect and valid only relatively-one could not place very great confidence in the result. It is significant that no obvious general trend was discernible over this period (though quite incidentally it may be remarked that the individual years 1955 and I959 had the highest values of PWD in the whole I04 years). Indirect evidence exists however that significant changes in PWD could be found over the preceding cencenturies and these can be correlated with existing knowledge of the changes in vegetation and agricultural practices at places near the threshold.

Human interference has been referred to above, when it takes the form of deliberate improvement of drainage for agricultural purposes, but climatic bog can be affected by indirect improvement of drainage. Inducement of increased grazing by animals, and moor-burning for various purposes, will alter the surface sufficiently to intensify the natural effects of short periods of PWD. The combined effects of a slow natural secular 
increase in the annual PWD, combined with human-induced modification of the natural surface, can often be sufficient to start spectacular erosion of bog which had developed during a period when the annual PWD was insignificant in amount.

\section{REFERENCES}

Alvin, P. DE T. (1960) Moisture stress as a requirement for flowering coffee. Science, I32, No. 3423, 354.

Mohrmann, J.C.J. (1959) A tentative survey of the water deficiencies in Europe and the need of (supplemental) irrigation. Report of the Conference on Supplemental Irrigation, Copenhagen, 1958, 25-34. (Published by the Institute for Land and Water Management Research, P.O. Box 35, Wageningen, Netherlands.) 


\title{
THE ROLE OF EVAPORATION IN THE SURFACE ENERGY BALANCE
}

\author{
M.J. BLACKWELL \\ Meteorological Office, Agricultural Research Unit, School of \\ Agriculture, University of Cambridge
}

\section{INTR ODUCTION}

DURING the past fifteen years, a small research group of the Metcorological Office has been working in Cambridge on the development of methods for the evaluation of natural evaporation from land surfaces. For much of this time, the subject has been viewed as a meteorological problem in turbulent transfer and several observational programmes have been designed to test the physical basis of an aerodynamic equation first suggested by Thornthwaite and Holzman. Although the method is valid only for occasions when the lower layers of the atmosphere are in the near-adiabatic state, limited practical use can be made of the method if certain conditions are observed in the siting of apparatus.

Other theoretically inspired or empirically derived modifications of this equation have been shown to be capable of providing accurate results in conditions other than adiabatic, but further refinement entails more exacting observations requiring highly specialised techniques which tend to become impracticable for routine use. Nevertheless a fundamental insight into the nature of the physical mechanisms seems necessary if the more promising of the simpler field techniques are to be modified to yield acceptable results over a wide range of conditions.

In order to introduce an independent and continuous check on the degree of success achieved by the aerodynamic method, techniques have recently been developed for measuring the four components of the energy balance at the surface. To handle such a vast amount of data, modern methods of data-handling have been introduced. The main purpose of these is to measure gradients or profiles by digitisation on to counters, but there is an additional facility for computing the energy balance components directly by means of an analogue computer.

The combination of the aerodynamic approach and the surface energy balance control is beginning to enable us to assess the role of evaporation under a wide range of conditions. It is hoped that the shortcomings in the theories of turbulent transfer, which result from over-simplification of our 
working models of atmospheric turbulence, will soon be determined on a more quantitative basis.

\section{TURBULENT TRANSFER CONSIDERATIONS}

An attempt is made here to indicate the elements of atmospheric turbulence theory applicable to the particular problem of evaporation, and the limits of practical application of this theory. At the outset it should be made clear that there are two distinct concepts of the mechanism of atmospheric turbulent transport, one being that of continuous mixing by eddies and the other being the classical theory of transfer in terms of the product of a transfer coefficient and the gradient of the property concerned. Regarding the first concept, evaporation is derived from the simple equation:

$$
E=\overline{\rho w^{\prime} q^{\prime}}
$$

where $E$ is the eddy flux of vapour and $w^{\prime}$ and $q^{\prime}$ represent the fluctuations of vertical velocity and specific humidity. Its simplicity suggests that other methods are hardly necessary. Yet it is only in the last few years that instrumental techniques and data-processing equipment have begun to allow the potentialities of the method to be realised, e.g. by Swinbank (I955) and Taylor and Dyer (1958).

The second concept was followed by Pasquill (1949) in taking the laboratory established wind-profile law for aerodynamically rough surfaces:

$$
u_{z}=\frac{\mathrm{I}}{k} \sqrt{\left(\frac{\tau_{0}}{\rho}\right) \log _{e}\left(\frac{z}{z_{0}}\right)}
$$

where $k$ is von Karman's constant $(0 \cdot 4), \tau_{0}$ is the surface drag or shearing stress, and $z_{0}$ is a parameter based on the characteristic roughness length of the surface. This has been shown to apply in the atmosphere in conditions of neutral stability (i.e. when there is no gradient of potential temperature). It is convenient at this stage to introduce the stability parameter known as the Richardson number:

$$
R i=\frac{g}{T} \frac{\left(\frac{\partial T}{\partial z}+\Gamma\right)}{\left(\frac{\partial u}{\partial z}\right)^{2}}
$$

which takes values $R i<0$ for unstable, $R i=0$ for neutral and $R i>0$ for stable conditions. It is found that $u, \log z$ profiles are convex to the $u$-axis for $R i<0$ and concave for $R i>0$. 
Lastly, the definitions of the three coefficients of eddy transport are given:

eddy viscosity, $\quad K_{m}=\frac{\tau}{\rho \frac{\partial u}{\partial z}}$

where, for practical purposes, $\tau$ (the momentum flux) can be considered effectively constant $=\tau_{0}$

eddy diffusivity,

$$
K_{w}=-\frac{E}{\frac{\partial \chi}{\partial z}}
$$

where $\chi$ is absolute humidity and $E$ is the flux of vapour, also effectively equal to $E_{0}$ the evaporation at the surface.

eddy conductivity,

$$
K_{h}=-\frac{Q}{\rho c_{p}\left(\frac{\partial T}{\partial z}+\Gamma\right)}
$$

where $\Gamma$ is the dry adiabatic lapse rate and $Q$ is the flux of sensible heat.

The eddy transfer of momentum, water vapour and sensible heat involves three aspects of atmospheric diffusion. Considerable progress in the subject has been made by assuming the equality of at least two of the diffusivities, and sometimes of all three. Thus there is a distinction from the somewhat analogous case of molecular diffusion, from which the mixing length concept originally arose. Two main complications should be kept in mind. For $R i \gg 0$, eddy viscosity becomes comparable with molecular diffusion as fully turbulent flow degenerates into laminar flow. For $R i \ll 0$, free convection affects the transport mechanism and might be expected to introduce (or increase) differences between the diffusivities. Between these extremes, it can be assumed to a first approximation that the diffusivities are equal.

\section{ENERGY BALANCE CONSIDERATIONS}

With sufficient accuracy for nearly all practical purposes, the energy balance at the earth's surface may be expressed by the equation:

$$
R+\lambda E+S+Q=0
$$

where $R$ is the net flux of short-and long-wave radiation, $S$ is the flux of heat in the ground and $\lambda$ is the latent heat of evaporation.

In the last few years it has been possible to place more and more confi- 
dence in direct measurements of $R$, by means of ventilated net flux radiometers (e.g. as described by MacDowall, 1955). Previously, solarimeters were used to measure the short-wave components received and reflected back from the surface; grass minimum thermometers were used to estimate the radiative temperature of the surface, from which the upward long-wave component was calculated; and the downward atmospheric radiation was computed from radiation charts. The type of net flux radiometer referred to above permits measurements to be made under broken cloud but not in rain. Its accuracy can approach $\pm 5 \%$, or a little better with careful checks. Recently, a most promising radiometer, covered with thin hemispherical polythene shells, has been developed by Funk (1959). This removes the need for forced ventilation and is not affected by precipitation. Its accuracy is probably of the order of $\pm 2 \%$ and impressive measurements of radiative flux-divergence have already been made. Over periods of a day or more, the integrated radiation is as large as the total of the other three fluxes. It is therefore of paramount importance to measure it with an accuracy not worse than $\pm 2 \%$, if energy balance checks of other methods are to be fully effective. In recent work at Cambridge a significant, though apparently simple, step has been made in duplicating all the sensing instruments for the four components in the energy balance. In this way, consistency of calibrations, efficient working of the data-logging circuits and possible sampling differences between neighbouring sites can be monitored continuously. Sooner or later in this type of study, most workers are faced with the problem of how representative their measurements are in space and in time.

The second item in the balance concerns the flux of heat in the ground. Here we are faced with more serious problems of heterogeneity in soil density, specific heat, moisture and other physical parameters. As with the radiation measurements, it has been possible in the last few years to place more confidence in suitably calibrated soil flux-plates to record the variations of heat flux. This avoids the need to compute the flux from the equation:

$$
S=-K \rho \frac{\partial T}{\partial z}=k_{s} \frac{\partial T}{\partial z}
$$

where $K$ is the thermal diffusivity, and $k_{s}$ the thermal conductivity. However, although the laborious measurement of $\rho$ and $c$ from soil samples and the difficulty of measuring the temperature gradient near the surface are eliminated, certain precautions must be observed. The first of these is that two or more flux-plates should be used in series to obtain a representa- 
tive measurement. The plates should be near the surface to minimise storage errors arising from undetected changes in the surface layers, but deep enough to permit proper growth of grass or other cover. For many of the larger-rooted crops it is, of course, necessary to revert to temperature profiles, though soil flux-plates can still be used with advantage to measure the flux at a level below the roots. In addition warning should be given concerning the use of flux-plates near the surface in very dry conditions. Drying out or cracking of the surface layers is then liable to cause imperfect thermal contact with the flux-plate, and evaporation may occur at depths below that of the detecting instrument, giving false indications of the lack of an energy balance.

For specialised short-term applications, it may be desirable to correct for the storage term. This could be done quite accurately by invoking the well-known exponential decrease of the amplitude of the diurnal temperature variation with depth, and also the linear dependence of the phase lag of temperature with depth. By comparing graphically the results of two or three flux-plates buried at suitable intervals of depth, values of the flux at the surface could be derived by extrapolating first for zero phase lag and then adjusting the amplitude in accordance with the exponential law. Strictly, this assumes that the physical parameters for the soil are constant with depth, but only a second-order approximation is involved here. After initial trials have been carried out for a particular site and arrangement of instruments, it might be possible to allow for phase lag by altering the time scale, and for amplitude by incorporating a correction in the calibration constant.

The original method of calibration used was one described by Hatfield and Wilkins (1950) using layers of felt as the surrounding medium. To obtain more realistic conditions, the felt was replaced in turn by dry sand, oven dried soil and finally by slightly moist soil. Though $S$ is often as little as a tenth of $R$, and typically of the order of a fifth of $R$, it becomes of similar importance during the night when systematic errors must be avoided if insight is to be gained into the variation of $K_{h}$ under stable conditions. The typical order of accuracy of soil flux-plate calibrations has been about $\pm 20 \%$, due largely to variations in thermal conductivity of the soil compared with that of the flux-plate. To bring about a significant improvement it has been found necessary to calibrate in situ. For this, a calibrating box is placed over the site of the flux-plate, for various soil conditions, and a constant flux is directed downwards until a steady reading is obtained. This takes about two days to achieve and the apparatus is therefore made self-balancing. By suitably varying the heat flux, the phase lag and amplitude 
reduction factor can also be determined. Again it must be stated that these techniques are only suitable for level, bare or short grass surfaces, but these are nevertheless the natural surfaces which must be used first for fundamental investigations of high precision. When the theoretical, or soundly-based semi-empirical, advances are well established, then the simpler techniques which give satisfactory results for these surfaces can be extended to other crops. With the developments described above, it seems possible to obtain heat-flux measurements in soil to about $\pm s-10 \%$. This will give energy contributions of similar absolute accuracy to the $R$ terms.

We have now come to the main point of difficulty reached in all energy balance studies. From eq. 7, we have:

$$
\lambda E+Q=-(R+S)
$$

where the sign convention is that fluxes directed away from the surface are considered positive. The classical approach was that of Bowen (1926) who expressed eq. 9 as:

$$
-(R+S)=\lambda E(\mathrm{I}+\mathrm{Q} / \lambda E)
$$

where $Q / \lambda E$ is known as the Bowen ratio $B$. The direct measurement of $Q$ encounters difficulties similar to that for $E$, and the ratio $B$ has therefore received considerable study. To gain some insight into the behaviour of $B$, we can substitute from eqs. 5 and 6 :

$$
\lambda B=\frac{Q}{E}=\frac{K_{h} c_{p} \frac{\partial \theta}{\partial z}}{K_{w} \frac{\partial q}{\partial z}}
$$

where $\theta$, the potential temperature, is used instead of $T+\Gamma z$, and $\chi$ is replaced by $\rho q$.

Priestley (1959) has discussed the ratio $K_{h} / K_{w}$ for varying stability and various heights near the ground. Although this ratio varies considerably, for near neutral conditions and with approach to the surface, $K_{h} / K_{m}$ and hence $K_{h} / K_{w}$ (see section 4 ) is very close to unity. Within these limits then, we have:

$$
\lambda B=c_{p} \frac{\Delta \theta}{\Delta q}
$$

where the gradients have been replaced by finite differences. Moreover, for land surfaces in temperature climates, $B$ is sufficiently small to enable the evaporation to be determined with much greater accuracy than that of $B$ 
itself, since:

$$
E=-\frac{(R+S)}{\lambda} \cdot \frac{\mathrm{I}}{(\mathrm{I}+B)}
$$

Unfortunately, in arid regions where accurate knowledge of evaporation is vital, $B$ is no longer small and $K_{h} / K_{2 v}$ may vary widely from unity.

In several respects, therefore, we have come to regard the Bowen method as a rough check for $E$, but of less use for $Q$, e.g. in studies of eddy conductivity $K_{h}$. Considerable discussion has taken place in the literature, e.g. Rider and Robinson (I95I), on why the diffusivities for heat, vapour and momentum should not be identical when the profiles of the elements have the same form, as this implies that the ratios of the gradients, and hence of the diffusivities themselves, must be constant with height. It must be remembered however that, with the accuracy until recently possible in measurements of the elements, the test of the identity of the profile shapes is not very critical. Management of wet- and dry-bulb thermocouples has always been difficult, with corresponding scatter being caused in humidity profiles; recording of temperature is affected by radiation and emergentstem errors; while wind profiles measured with sensitive cup anemometers have recently been shown to be much affected by position errors (Rider, I960). There is also the problem of deciding, for a particular site, whether typical profiles have been established in the available distance upwind or within a given time of measurement. Until profiles can be obtained, as a routine, with an accuracy sufficient to determine their second derivatives, controversy about the ratios of the diffusivities is unlikely to be settled by this method and hopes must rest with the eddy fluctuations approach.

Although there is no simple method for measuring $Q$, a most promising direct check on $E$ has recently become available following the development of a very large soil-balance by Morris (1959). One of these has been used successfully at Cambridge at intervals during the 1960 season, both evaporation and dewfall being recorded satisfactorily. The soil container carries some $2000 \mathrm{Kg}$ of soil which is representative of the site and is covered with a crop of short grass. The latter is accurately coplanar with the natural surface, with as small an air gap as possible. The load is supported on a triangular structure which in turn is supported by three levers, one of which receives the load from the other two. In this way the total load can be balanced by a single load from a secondary lever. Having roughly balanced the weight of soil, changes of weight are balanced by the movement of travelling weights, driven by a synchronous motor which is controlled by a self-balancing optical system. 
In the Cambridge version, movement of the secondary lever interrupts the illumination of a photo-transistor which in turn operates the relay controlling the drive motor. This scheme was originally developed at N.I.A.E. and gives a saw-tooth type of record which can be read to about $\pm \mathrm{I}$ o g. As originally developed the soil-balance used a pen-recorder, with consequent loss of sensitivity through friction. To overcome this the pen and chart system can be removed and a remote-recording system instituted. A drive taken off one of the moving weight pulleys is used to turn a helical potentiometer which feeds a variable voltage to a recorder. The system has the advantage of requiring less frequent removal of the guard plants for chart changing.

For the derivation of $E$ and $Q$ by the acrodynamic approach (historically the first major problem of the group), wet-and dry-bulb fine wire thermocouples were finally adopted for measurement of temperature and humidity gradients or differences. These were chosen partly to facilitate future investigations in and above growing crops where forced ventilation would disturb the local regime, and partly to reduce radiation errors to a value which is not only very small but also constant for each level. One new disadvantage is the efficiency with which the thermocouples respond to rapid temperature fluctuations. For wind profiles, sensitive cup contact anemometers are used.

\section{THE AERODYNAMIC METHOD}

At this stage, we must return to the basic concepts of turbulent transfer theory already touched upon in section 2. It follows from eq. 2 and the definitions of $K_{m}$ and $K_{w}$ in eqs. 4 and $s$ that:

$$
E=\frac{k^{2}\left(u_{2}-u_{1}\right)\left(\chi_{1}-\chi_{2}\right)}{\left(\log _{e} \frac{z_{2}}{z_{1}}\right)^{2}}
$$

provided that $K_{w}=K_{m}$. This result was first applied by Thornthwaite and Holzman (I942). The analogous relation for Q:

$$
\mathrm{Q}=\frac{k^{2} \rho c_{p}\left(u_{2}-u_{1}\right)\left(T_{1}-T_{2}\right)}{\left(\log _{e} \frac{z_{2}}{z_{1}}\right)^{2}}
$$

depends on the assumption that $K_{h}=K_{m}$ but has not been tested as effectively.

For conditions when vigorous buoyancy forces are absent, the aero- 
dynamic method relies on the eddy viscosity being expressible in terms of relatively easily measured wind profiles. In the simplest case of near-neutral stability, we obtain from eqs. 2 and 4 that:

$$
K_{m}=k^{2} z^{2} \frac{\partial u}{\partial z}
$$

Thus from eq. 5, Pasquill (I949) was led to investigate the non-dimensional parameter:

$$
\frac{E}{z^{2} \frac{\partial u}{\partial z} \frac{\partial \chi}{\partial z}}=\frac{K_{w}}{z^{2} \frac{\partial u}{\partial z}}
$$

If $K_{m}=K_{w}$, then values of this parameter should equal $k^{2}(\bumpeq 0.17)$. By determining $E$ from small evaporimeters and careful weighing, it was shown that the near-neutral experimental results were grouped closely about $0 \cdot 17$. A direct verification of the identity $K_{w}=K_{m}$ was therefore provided for near-adiabatic conditions.

By measuring $\tau_{0}$ with drag plates, Rider (1954a) was further able to show that the non-dimensional parameter:

$$
\frac{\tau_{0}}{\rho z^{2}\left(\frac{\partial u}{\partial z}\right)^{2}}=\frac{K_{m}}{z^{2} \frac{\partial u}{\partial z}}
$$

had virtually identical values to those given by the parameter in eq. I 7 , not only in neutral conditions but over a wide range of stabilities. This makes the identity $K_{w}=K_{m}$ of general application.

BothRider (1954a) and Pasquill (1949) found that such parameters varied systematically with the departure of the wind profiles from the simple logarithmic form of eq. 2, or with the Richardson number Ri. In general, this stability dependence can be expressed:

$$
-\frac{E}{z^{2} \frac{\partial u}{\partial z} \frac{\partial \chi}{\partial z}}=\frac{\tau_{0}}{\rho z^{2}\left(\frac{\partial u}{\partial z}\right)^{2}}=k^{2} f(R i)
$$

The major problem now facing us is the specification of the function, $f(R i)$. First of all it must be remarked that wind profiles tend to approach the simple logarithmic form near the surface, and correspondingly that variations of stability or $R i$ become less for measurements made near the ground. This has dominated most practical applications of the method (e.g. Rider, 1954b, 1957) and it seems probable that fluxes based on the 
formula (eq. I4) can be derived with an accuracy of about $\pm 20 \%$ for typically wet seasons in this country, with a fairly small range of stability and for periods of a few hours.

To give a practical example of the advantage of taking measurements near the ground, Pasquill (I949) showed that the non-dimensional parameters of eq. I9, which we refer to as $k^{2} f(R i)$, would have a two-fold variation at a height of $37.5 \mathrm{~cm}$ for a corresponding ten-fold variation at I $50 \mathrm{~cm}$. The variation found at the lower level covered a wide range of natural conditions, from moderate stability to marked instability, and is merely another expression of the statement above that fluxes derived from the assumption that $f(R i)$ equals unity would normally be in error by up to $\pm 20 \%$, even with the most favourable experimental arrangements, for short-term rates of evaporation.

Returning to the definition of eddy viscosity, we must next re-examine the behaviour of $K_{m}$ with stability, and hence of $K_{w}$. It is clear that, to explain the stability dependence found:

$$
K_{m}=\left(K_{m}\right)_{\text {neutral }} \cdot f(R i)
$$

For unstable conditions, the most promising approach has been to follow Deacon (I949) who proposed that wind profiles could be well represented by relationships of the type:

$$
\frac{\partial u}{\partial z}=a z^{-} \beta \quad(a \text { and } \beta \text { being independent of } z)
$$

where $\beta$ is a slowly varying parameter, close to unity, taking values $\beta>\mathrm{I}$, I and $<_{\mathrm{I}}$ in unstable, neutral and stable conditions respectively. Noting the observed tendency of non-neutral wind profiles to approach the logarithmic form (as for neutral conditions-eq. 2) near the surface, Deacon assumed the boundary condition $\left(11=0\right.$ at $\left.z=z_{0}\right)$ to hold in the general case. Integrating eq. $2 \mathrm{I}$ and allowing for the profile tendency to approach the logarithmic form as $\beta$ approaches unity, he obtained the generalised wind profile:

$$
u_{z}=\frac{\mathrm{I}}{k(\mathrm{I}-\beta)} /\left(\frac{\tau_{0}}{\rho}\right)\left[\left(\frac{z}{z_{0}}\right)^{1-\beta}-\mathrm{I}\right]
$$

Since eq. $2 \mathrm{I}$ is not an exact relationship, values of $z_{0}$ derived from eq. 22 are found to vary markedly with stability. To overcome this difficulty, it is customary to determine $z_{0}$ separately from neutral wind profiles and to regard eq. 22 as determining $\beta$ for various conditions of stability. From the definition of $K_{m}$ and the generalised wind profile: 


$$
K_{m}=k^{2} z^{2} \frac{\partial u}{\partial z}\left(\frac{z}{z_{0}}\right)^{2 \beta-2}
$$

which implies, over the range of validity of eq. 22 , that

$$
f(R i)=\left(\frac{z}{z_{0}}\right)^{2 \beta-2}
$$

Because of the failure of eq. 22 in stable conditions, attributed mainly to the fact that $z_{0}$ is no longer constant in these conditions, eq. 24 cannot be applied for $R i>0$. In neutral and unstable conditions, however, there is excellent agreement between the parameters given in eq. I9 and $k^{2}\left(\frac{z}{z_{0}}\right)^{2 \beta-2}$

It is not intended to make more than a passing mention of the suggested forms for $f(R i)$ under stable conditions. The best known are due to Rossby and Montgomery (1935):

$$
f(R i)=\frac{\mathrm{I}}{(\mathrm{I}+\sigma R i)}
$$

and to Holzman (1943), who gave:

$$
f(R i)=\mathrm{I}-\sigma R i
$$

This latter relation has often been used as a basis for discussing experimental results, even for unstable conditions, for example, by Priestley (1959). Suggested values of $\sigma$ are given in the next section.

\section{PRACTICAL ASPECTS}

The first modification of the formulae given in the previous section arises when measurements are required over a crop which is tall compared with the heights of the apparatus above ground level. This may be allowed for by replacing $z$ by $(z-d)$, where $d$ is known as the zero-plane displacement. Rider (I954b) used the simple eq. I4, with this modification, throughout the growing season of a field of oats. For tall crops which bend appreciably with wind, $d$ can change with wind speed by a factor of two as well as varying progressively with crop height. It is determined by plotting $\|_{z}$ against $\log _{e}(z-d)$ for suitable values of $d$ until a linear relation is found. Daily evaporation from similar cropped surfaces can be obtained with an accuracy of about $15 \%$, there being a systematic tendency to underestimate the water loss. 
If, following Rider (I954b), an attempt is made to use the generalised wind-profile method of eq. 22 , it is found that the complex dependence of $d$ on crop height and wind speed makes it impossible to determine Deacon's stability parameter $\beta$ with the accuracy required to give $E$ from the modified aerodynamic equation:

$$
E=\frac{\rho k^{2}(\mathrm{I}-\beta)^{2}\left(q_{1}-q_{2}\right)\left(u_{2}-u_{1}\right) z_{0}^{2-2 \beta}}{\left[\left(z_{2}-d\right)^{1-\beta}-\left(z_{1}-d\right)^{1-\beta}\right]^{2}}
$$

The existence of errors in readings from the present type of anemometers must also be borne in mind. Even I \% errors can produce changes in $\beta$ of the order of $10 \%$ and there is no doubt that we must reject any further ideas of using this method over tall crops. Simultaneous measurements, with two sets of apparatus used at different heights, again confirm the value of making measurements at the lowest practicable height. It is unfortunate that this requirement causes almost insuperable difficulties in determining the zeroplane displacement and other parameters needed in the calculations.

In the present writer's opinion, one of the next steps must be to arrange for stability effects to be clearly recognisable so that the function $f(R i)$ can be investigated and suitably corrected for. In addition, in the simple aerodynamic formulae (eqs. I4 and I s) for $E$ and $Q$, and in the energy balance control checks (eq. I I), we may have to introduce simple idealised models for the variation of $K_{h} / K_{m}$ with the Richardson number. The fact that the use of formulae, valid only for neutral conditions, leads to results which have even some limited practical value, makes it seem worthwile to introduce an equally simple and idealised stability function $f(R i)$. A schematic diagram of the main results from three observational programmes, designed by members of the Cambridge group, is given in Fig. I, together with a line based on Deacon's eq. 24 and two Holzman-type lines based on the Cambridge data. The latter are:

$$
\begin{array}{ll}
f(R i)=\mathrm{I}-\mathrm{I} 5 / R i & (\text { for } R i<0) \\
f(R i)=\mathrm{I}-7 / R i & (\text { for } R i>0)
\end{array}
$$

and

These values of $\sigma$ are of a similar order to those found elsewhere. It is to be expected from recent work on free convection that a fairly sharp transition will occur between the regimes for forced and free convection.

It is perhaps surprising that Rider and Robinson's (I95I) method of extrapolating 'aerodynamic' fluxes to zero height, or to zero Richardson number, has received so little attention in later years. This method clearly needs careful investigation, but it is interesting that the experimental 
scatter of the results of the three programmes, shown in Fig. I, would be fitted to a first approximation by two straight lines, implying that the corresponding extrapolation of the fluxes would also be linear.

Rider (I957) made further measurements over bare soil and over three

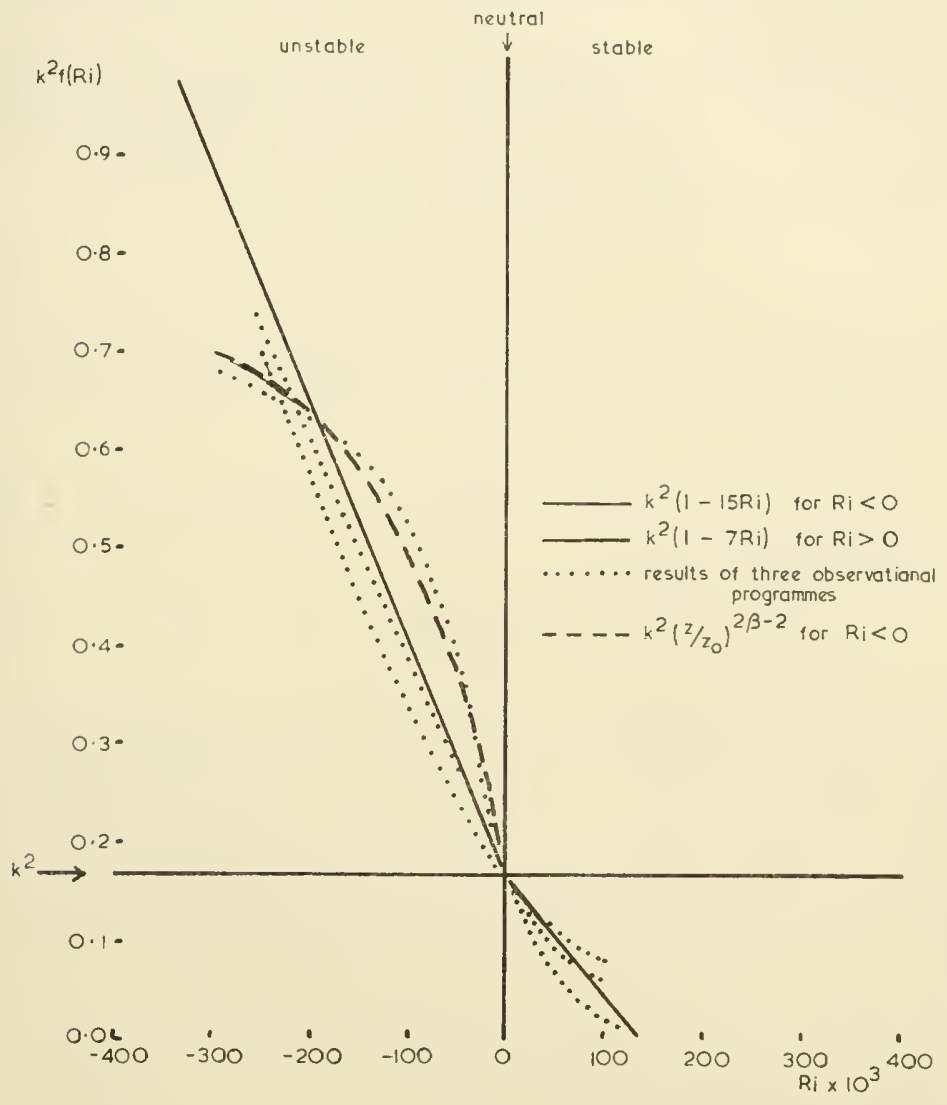

FIG. I. Showing the variation of eddy diffusivity with stability of the atmosphere, The simple aerodynamic formula gives $k^{2} f(R i)=$ const. (i.e. $0 \cdot 17$ ). Possible modifications are indicated by the straight lines $k^{2}(\mathrm{I}-\sigma R i)$.

different crops which were said to be transpiring at their potential rates, and concluded that the water losses could be significantly different for the three crops. It was found that the humidity gradients over neighbouring crops could vary over fairly wide limits. This work suggested re-cxamination of the assumption, that potential transpiration is the same for all green 
crops which completely cover the ground, made in applications of Penman's (1948) method for the calculation of irrigation needs. However, quite apart from the short term microclimatic variations, it seems highly probable that significant differences of surface roughness would also qualify the assumption. Equally, depending on the roughness of a crop, evapotranspiration can often exceed evaporation from a smooth surface of open water, a result which was not predicted by earlier workers in the subject.

One last method, suggested by Deacon and Swinbank (1956), might overcome some of the earlier difficulties arising from stability dependence. The surface drag coefficient $C_{n}$, defined by:

$$
\tau=\rho C_{n} u_{n}^{2}
$$

where $u_{n}$ is the wind speed at the height of measurement $z_{n}$, can be determined from wind profiles obtained in neutral conditions for a given site. Then, since $K_{w}=K_{m}$,

$$
\frac{E}{\tau}=-\frac{q_{2}-q_{1}}{u_{2}-u_{1}}
$$

and substituting from eq. 30 :

$$
E=\rho C_{n} u_{n}^{2} \cdot \frac{q_{1}-q_{2}}{u_{2}-u_{1}}
$$

For convenience, $z_{n}$ and $z_{1}$ can be made identical, and $z_{2}$ chosen to be high enough to obtain the required accuracy in the measurements. $C_{n}$ does vary slightly with stability, but much less so than the roughness parameter $z_{0}$. The essential feature of the method is that no assumptions are made concerning the logarithmic profile law, only that the profiles have the same form. Provided that $z_{n}$ can be made sufficiently low to be independent of stability effects, eq. 32 will be valid for all stabilities.

\section{DATA-PROCESSING}

In my introduction, it was pointed out that a programme involving a combination of the intricacies of the aerodynamic method with the continuous control of energy balance considerations would yield a vast amount of somewhat intractable data. The change to semi-automatic dataprocessing, however, is not one which many physicists take to lightly since in the first place some loss of accuracy is almost inevitable, and secondly there are recognised stages in most experimental investigations where discrimination, selection and rejection thought-processes are required. These processes require the integrated experience and insight of the 
physicist and must take place before the purely numerical processes are carried out by a suitable computer. As against this, it must be admitted that computing aids are needed to cope with the volume of material, that machines can be unbiased and objective in the processing of the data and can accept a flow of data more rapidly than the human observer is able to do.

The latter point was one of the historical reasons for the development of the apparatus to be described. At the end of section 3 it was mentioned that, since unaspirated fine wire thermocouples have been adopted as the sensing elements for temperature and humidity, their output is going to consist of rapidly fluctuating voltages, following natural eddy fluctuations in the frequency range o to $100 \mathrm{c} / \mathrm{s}$.

The obvious way to record such voltages would be to use suitably damped galvanometers and photographic recorders. Anyone who has attempted to analyse such records would be only too willing to take the next step, which is to use galvanometer-digitisers or galvanometeramplifiers. In the original apparatus described by House, Rider and Tugwell (1960), the former method was in fact used to produce pulses from a photocell which were proportional to some simple function of temperature. The pulses were applied to a pulse amplifier and could then operate electromagnetic counters directly. The electrical contacts of the Sheppard-type cup anemometers were used to energise quenched relays which operated the wind counters. The original system is still used for measuring the mean wet- and dry-bulb temperatures, but improved methods have since been adopted for the gradients themselves.

These are now detected and amplified by a highly specialised D.C. amplifier which determines the pulse rate of a blocking oscillator and so operates the wet- and dry-bulb temperature gradient counters. At convenient stages in these circuits, there are conventional analogue computing circuits which solve the psychrometric equation and also compute $E$ and $Q$, using the simple aerodynamic equation. The radiation and soil heat fluxes are recorded by a galvanometer- amplifier which also operates counters via the pulse-rate of a blocking oscillator. The counters are photographed at desired intervals. The programming of the whole apparatus is determined by a seconds-contact chronometer and uniselectors.

As previously mentioned, the sensing heads which are self-directing into wind have now been duplicated and readings of these are either computed once per minute to give $E$ and $Q$, or integrated to give mean profiles over desired periods, usually of an hour. In the present writer's opinion, caution is needed in interpreting the computed values. More or less instantaneous 
determinations of profiles or gradients will clearly be influenced by eddy patterns which may result from temporary horizontal inhomogeneity. In the mean profiles, for a suitable site with adequate fetch, these crosscorrelation terms effectively cancel out. Furthermore, the concept of eddy transfer coefficients is only valid, at best, for describing mean flow conditions. Although, therefore, the means of many computed values of $E$ and $Q$ are eventually compared with the values derived from the mean profiles, there is no a priori reason for expecting perfect agreement. It is also thought that the periods for which the profiles are obtained should be reduced to about I 5 minutes to eliminate diurnal effects, and errors caused by averaging non-linear quantities.

Preliminary results obtained over the last three seasons are still being evaluated but the following tentative trends can be seen. In the cool, wet season of 1958 , an energy balance appeared to be established over some 80 hours of data. During the hot, dry season of 1959, an energy balance was often not obtained during the $\mathrm{I} 8 \mathrm{o}$ hours of recording but this could not be expected with the much wider range of stability encountered, since the original equations are based on near-neutral stability conditions. The use of $f(R i)$ for these results is being investigated. Effects of storage in the surface layers of the soil were of significance for short periods in 1958. Cracked soil and evaporation in depth, mentioned in section 3, caused difficulties in 1959.

A very important point, arising from the 1958 results, was that in many circumstances the energy used in evaporating water is roughly equivalent to the net radiative input (House, Rider and Tugwell, I960). This was not substantiated by the 1959 work, and it appears that the whole question will require further investigation. It is too soon to give any definite results from the I960 data, but among the more novel aspects are the first available comparisons of $E$ (aerodynamic) v. $E$ (soil balance), both evaporation and dewfall being recorded satisfactorily. There are also a few soil flux measurements at different depths, from which the storage error can be determined by the method described in section 3 .

\section{CONCLUSIONS}

A rather over-simplified version of the two standard meteorological approaches to the measurement of evaporation, as followed at Cambridge between the years 1947-196I, has been given as an attempt by a physicist to describe the successes and limitations of current theories and methods, in the hope of giving workers in allied subjects an up-to-date survey of the present state of knowledge. 
A part from the special difficulties of working over tall, flexible crops, it is thought that acceptable results can now be obtained (albeit with highly complex apparatus) over 'ideal' sites in the absence of 'oasis' or advection situations. This can be done by using knowledge (which is already available) of the stability dependence of the aerodynamic parameters described above. With the energy balance checks and data-processing apparatus now available, it should soon be possible to provide a standard against which the more promising of the simpler field techniques can be compared.

\section{ACKNOWLEDGMENTS}

The writer has only recently taken over the work of the Meteorological Office Research Unit at Cambridge and is indebted to his immediate predecessor, Mr. J. B. Tyldesley, and to his colleague, Mr. C. P. Tugwell, for many stimulating discussions and for access to unpublished results on the 1959 and 1960 seasons' work. However, the responsibility for presentation and criticism is my own. This paper is published with the permission of the Director-General of the Meteorological Office.

\section{REFERENCES}

Bowen, I.S. (1926) The ratio of heat losses by conduction and by evaporation from any water surface. Phys. Rev. 27, 779-787.

Deacon, E.L. (1949) Vertical diffusion in the lowest layers of the atmosphere. Quart. J. R. met. Soc. 75, 89-103.

Deacon, E.L. \& SwinbanK, W.C. (1956) Comparison between momentum and water vapour transfer. UNESCO Canberra Sympos. Climnt. arid Zone, Pap. No. 2 , 38-40.

Funk, J.P. (1959) An improved polythene shielded net radiometer. J. Sci. Instrun. 36, $267-270$.

Hatfieid, H.S. \& Wilkins, F.J. (1950) A new heat-flow meter. J. Sci. Instrum. 27, I-3. Holzman, B. (1943) The influence of stability on evaporation: boundary-layer problems in the atmosphere and ocean. Amn. N.Y. Acnd. Sci. 44, I3-r8.

House, G.J., Rider, N.E. \& Tugwerr, C.P. (1960). A surface energy-balance computer. Quart.J. R. met. Soc. 86, 2 I 5-23I.

MacDowall, J. (1955) Total radiation fluxmeter. Met. Mag. 84, 65-7I.

Morris, L.G. (1959) A recording weighing machine for the measurement of evapotranspiration and dewfall. J. agric. engng. Res. 4, No. 2, 16I-173.

PASQUIIL, F. (1949) Eddy diffusion of water vapour and heat near the ground. Proc. Roy. Soc. A198, II6-I40.

Penman, H.L. (1948) Natural evaporation from open water, bare soil, and grass. Proc. Roy. Soc. AI93, 120-145.

Priestley, C.H.B. (1959) Turbulent Transfer in the Lower Atmosphere. University of Chicago Press. 
Rider, N.E. (1954a) Eddy diffusion of momentum, water vapour and heat near the ground. Plil. Trans. A246, 48 I-501.

Rider, N.E. (I954b) Evaporation from an oatfield. Quart. J. R. met. Soc. 80, I98-2I I.

Rider, N.E. (I957) Water losses from various land surfaces. Quart. J. R. met. Soc. 83, I 81-I93.

Rider, N.E. (1960) On the performance of sensitive cup anemometers. Met. Mag. 89, 209-2I5.

Rider, N.E. \& Robinson, G.D. (I95I) A study of the transfer of heat and water vapour above a surface of short grass. Qmart. J. R. met. Soc. 77, 375-40I.

Rossby, C. G. \& Montgomery, R.B. (1935) The layer of frictional influence in wind and ocean currents. Pap. phys. Oceallogr. 3, No. 3, I-IOI.

Swinbank, W.C. (I955) Eddy transports in the lower atmosphere. C.S.I.R.O. Div. Met. Phys. Tech. Pap. No. 2, I-30.

TAYlor, R.J. \& DYER, A.J. (I958) An instrument for measuring evaporation from natural sources. Nature, I81, 4.08-4.09.

Thornthwaite, C.W. \& Holzman, B. (1942) Measurement of evaporation from land and water surfaces. U.S. Dept. Agric., Tech. Bull. No. 817, I-I43. 


\title{
DEW: FACTS AND FALLACIES
}

\author{
J.L.MONTEITH \\ Rothamsted Experimental Station, Harpenden, Herts.
}

\section{INTRODUCTION}

When plant leaves cool at night below the dew-point of the surrounding air they become covered with moisture, either in a surface film, or more spectacularly in visible droplets of dew. "Every poet who has sung the beauties of Nature has added his tribute to the sparkling dew drop, and Ballantine in his widely known song has drawn a comforting lesson from the thought that 'ilka blade o' grass keps its ain drap o' dew' (Aitken, I 885). Lacking a sound physical basis, many ecological investigations of dew have strayed into descriptions which belong to poetry rather than to science, and in an extensive literature, fact and fallacy are often confused. Their distinction is attempted here by appeal to physical theories for the dependence of condensation on the properties of the atmosphere and of the soil.

\section{CONDENSATION RATE AND WEATHER}

Fluxes of water vapour at the earth's surface are governed by radiation, temperature, humidity and wind speed; and from analysis of the surface heat budget, all four variables may be combined to give a formula such as Penman's (1948) for evaporation and Hofmann's (1955) for dew. The Penman and Hofmann equations are formally similar, and the derivation which follows contains elements from both.

Condensation on an isolated horizontal surface such as a leaf or a dew gauge cannot begin until the surface is colder than the ambient air. If the condensation rate is $W\left(\mathrm{~g} \mathrm{~cm}^{-2} \mathrm{hr}^{-1}\right)$ the release of latent heat $\lambda W\left(\mathrm{cal} \mathrm{cm}^{-2}\right.$ $\mathrm{hr}^{-1}$ ) will be accompanied by a transfer of sensible heat $C$ from relatively warm air to cooler surface. With a surface at temperature $T_{s}\left({ }^{\circ} \mathrm{C}\right)$ surrounded by air at temperature $T_{A}$, this transfer rate can be written

$$
C=h\left(T_{A}-T_{\delta}\right)
$$

* Dewdrops have often been confused with guttation, water exuded from within the plant through leaf hydathodes. Distinguishing features were described by Long (1958) with photographic illustration. 
where $h$ is a transfer coefficient depending on wind speed and surface aerodynamic properties. Ignoring a small difference between the molecular diffusion coefficient for heat and water vapour, latent heat transfer may be written

$$
\lambda W=h\left(e_{A}-e_{s}\right) / \gamma
$$

where $e_{A}, e_{s}$ are vapour pressure in the air and at the surface $(\mathrm{mb})$, and where $\gamma\left(=0.66 \mathrm{mb} /{ }^{\circ} \mathrm{C}\right)$ is a constant required to make the equation dimensionally correct.

The heat balance of the leaf or gauge can be written

$$
R=\lambda W+C+M
$$

where $R$ is the net loss of heat by radiation and $M$ is the decrease of internal heat content (both in cal cm $\mathrm{cm}^{-2} \mathrm{hr}^{-1}$ ). Assuming that $M$ is negligible and that air in contact with the dewed surface is saturated, $T_{s}$ and $e_{s}$ can be eliminated from eqs. I, 2 and 3 to give

$$
\lambda W=\frac{\Delta R-h e_{A}^{\prime}(\mathrm{I}-r)}{\Delta+\gamma} .
$$

where $\quad r=$ relative humidity $(\leqslant \mathrm{I})$

$$
\begin{aligned}
\iota_{A}^{\prime} & =\text { saturation vapour pressure } \\
\Delta & =\partial e_{A}^{\prime} / \partial T
\end{aligned}
$$

This formula is independent of the source of dew, to be discussed in section 5. At sunset on a clear night, net radiation loss $R$ increases and saturation deficit $c_{A}^{\prime}(\mathrm{I}-r)$ decreases. Condensation begins whenever $R$ exceeds he $e_{A}^{\prime}(\mathrm{I}-r) / \Delta$ and continues throughout the night if the sky remains clear. If gathering cloud reduces $R$ below the value he ${ }_{A}^{\prime}(\mathrm{I}-r) / \Delta$, dew which has already formed will begin to evaporate.

For a simple estimate of radiative loss from an isolated horizontal leaf, assume that both upper and lower surfaces behave like black bodies at temperature $\mathrm{T}_{A}$ emitting radiation at a rate $\sigma \mathrm{T}_{A}^{4}$ from each surface; that radiation emitted from the ground beneath the leaf is $\sigma T_{A}^{4}$; and that downward radiation from the atmosphere is $L_{d}=\phi . \sigma T_{A}^{4}$, where $\phi$ is a function of vapour pressure. Net radiative loss is then

$$
R=2 \sigma T_{A}^{4}-\sigma T_{A}^{4}-\phi \sigma T_{A}^{4}=(\mathrm{I}-\phi) \sigma T_{A}^{4}
$$

In the British Isles

$$
\phi=0.53+0.065 \sqrt{ } e_{A} \quad \text { (Monteith, 196I) }
$$


and error in using this formula elsewhere will be unimportant in this analysis.

The maximum or 'potential' rate of dew formation, found by setting $r=\mathrm{I}$ in eq. 4 and $e_{A}=e_{A}^{\prime}$ in eq. 6 is

$$
W=\Delta R / \lambda(\Delta+\gamma)
$$

and is therefore proportional to radiative loss. Table I shows that potential condensation increases with temperature from 0 to $15^{\circ} \mathrm{C}$ (because $\Delta$ increases with temperature) but decreases at higher tempcratures (because radiation loss decreases with increasing vapour pressure). Over a wide temperature range, potential condensation lies within $\pm 10 \%$ of 0.067 $\mathrm{mm} / \mathrm{hr}$.

TABLE I

Variation of potential condensation with temperature

\begin{tabular}{lccccc}
\hline$T\left({ }^{\circ} \mathrm{C}\right)$ & 0 & 5 & I0 & Is & 20 \\
$R\left(\mathrm{cal} \mathrm{cm}^{-2} \mathrm{hr}^{-1}\right)$ & $8 \cdot 7$ & $8 \cdot 2$ & $7 \cdot 6$ & $6 \cdot 8$ & $5 \cdot 8$ \\
$\lambda W\left(\mathrm{cal} \mathrm{cm} \mathrm{hr}^{-1}\right)$ & $3 \cdot 6$ & $4 \cdot 0$ & $4 \cdot 3$ & $4 \cdot 3$ & $3 \cdot 9$ \\
$W\left(\mathrm{IO}^{-3} \mathrm{~mm} / \mathrm{hr}\right)$ & 62 & 69 & 73 & 73 & 68 \\
\hline
\end{tabular}

The dependence of transfer coefficient on wind speed is needed to find condensation when $r<\mathrm{I}$. From measurements on the evaporation from small pieces of filter paper, de Vries and Venema (1953) gave

$$
h=3 \cdot 9 V^{0.7} \mathrm{cal} \mathrm{cm}^{-2} \mathrm{hr}^{-1}{ }^{\circ} \mathrm{C}^{-1}
$$

where $V$ is wind speed in $\mathrm{m} / \mathrm{sec}$, and with this value in eq. 4 , condensation rates were calculated for varying wind speed and relative humidity (Fig. I).

Equation 4 sets an upper limit on leaf dew formation, unlikely to be achieved in practice, even on rare occasions when the atmosphere is saturated, because the approximate value of $R$ in eq. 5 is a deliberate overestimate. First, in the spectral region 3 to 25 microns, the emissivity of many leaves is 0.90 to 0.95 (Gates and Tantraporn, 1952) so the assumption of black body emissivity overestimates $R$ by 5 to $10 \%$. Second, because $T_{\delta}<T_{A}$, radiation emitted by the leaf will be less than $2 \sigma T_{\delta}{ }^{4}$ by an amount which can be estimated for two special cases:

Case I: isolated horizontal leaf exposed some distance above a crop canopy which has radiative temperature $T_{\delta}$

$$
\begin{aligned}
R & =2 \sigma T_{\delta}{ }^{4}-\sigma T_{8}{ }^{4}-L_{d} \\
& \simeq(\mathrm{I}-\phi) \sigma T_{A}{ }^{4}-4 \sigma T_{A}{ }^{3}\left(T_{A}-T_{\delta}\right)
\end{aligned}
$$


Case 2: leaf forming part of crop canopy with underlying leaves at temperature $T_{A}$

$$
\begin{aligned}
R & =2 \sigma T_{s}^{4}-\sigma T_{A}^{4}-L_{d} \\
& \simeq(\mathrm{I}-\phi) \sigma T_{A}^{4}-8 \sigma T_{A}^{3}\left(T_{A}-T_{s}\right)
\end{aligned}
$$

Writing formally

$$
R_{n}=R+n f\left(T_{A}-T_{s}\right): f={ }_{4} \sigma T_{A}^{3}
$$

eq. 4 becomes

$$
\lambda W=\frac{\Delta R-h e_{A}^{\prime}(\mathrm{I}-r)(\mathrm{I}+n f / h)}{\Delta+\gamma(\mathrm{I}+n f / h)}
$$

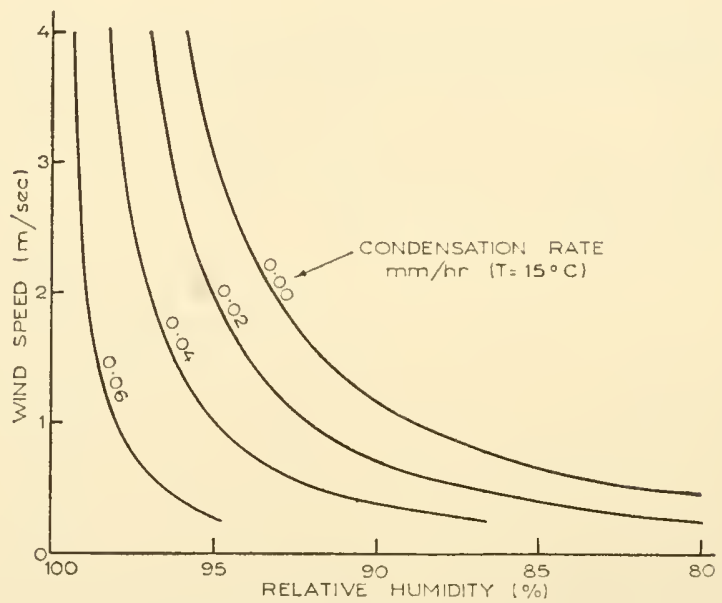

FIG. I. Condensation on horizontal leaf for given wind speed and relative humidity, calculated from eq. 4 .

The difference in $W$ calculated from eqs. 4 and 8 is approximately 0.002 $n / V \mathrm{~mm} / \mathrm{hr}$ for $T_{A}$ between Io and $20^{\circ} \mathrm{C}$ and $V$ between 0.5 and $4 \mathrm{~m} / \mathrm{sec}$. With these two sources of error, 'potential' condensation determined from the simple radiation balance of eq. 5 may exceed real condensation from a saturated air-stream by 10 to $20 \%$.

Anticipating discussion in section 4 , eq. 4 gives potential condensation on a closed crop canopy per unit area of underlying ground and can be used to distinguish field measurements which are physically reasonable from those which violate the conservation of energy. Monteith (1956) found that the rate of vapour transfer from the atmosphere to a short grass surface 
(dewfall) increased during the night as relative humidity rose slowly towards $100 \%$, and on one night reached an absolute maximum of 0.035 $\mathrm{mm} / \mathrm{hr}$ shortly before dawn. Allowing for simultaneous distillation of moisture from the soil to the grass (which could not be measured separately), total condensation may have reached $0.05 \mathrm{~mm} / \mathrm{hr}$, close to the theoretical limit. The maximum dewfall for a whole night was $0.13 \mathrm{~mm}$. Dewfall on agricultural crops was measured at Rothamsted from 1957 to I960 using a field balance designed by Morris (1959). The machine gives a continuous record of the change in weight of a block of soil $56 \times 56$ inches square and 24 inches deep, carrying the same crop as the field in which it is buried. Running at normal sensitivity, the scale is too coarse for condensation to be measured hourly, but Table 2 gives maximum nightly totals in millimetres with an accuracy of about \pm 0.02 .

TABLE 2

Maximum dewfall on crops at Rothamsted (mm/night)

$\begin{array}{lcc}\text { Spring wheat } & \text { 20 May, I957 } & 0.26 \\ \text { Sugar beet } & 8 \text { August, I958 } & 0.47 \\ \text { Grass }(60 \mathrm{~cm}) & \text { I August, 1960 } & 0.20\end{array}$

These figures, and many others in the literature, fall below the theoretical limit and are consistent with the predictions from Fig. I when relative humidity is a few per cent below saturation. On the other hand, House, Rider and Tugwell (1960), using a surface energy balance computer, observed a maximum dewfall rate of $0.097 \mathrm{~mm} / \mathrm{hr}$ over short grass. The contemporary radiation loss was $6 \mathrm{cal} \mathrm{cm}^{-2} \mathrm{hr}^{-1}$ and air temperature was $15^{\circ} \mathrm{C}$, giving a potential condensation rate of $0.065 \mathrm{~mm} / \mathrm{hr}$. The observed rate is energetically impossible.

Very high dewfall figures from two independent sets of observations in the United States are often quoted in the literature (e.g. by Went, I955). First, Thornthwaite and Holzman (I94I), using profiles of wind speed and vapour pressure measured to a height of $25 \mathrm{ft}$ over a meadow, calculated maximum dewfall totals of 0.8 to $\mathrm{I} \cdot 2 \mathrm{~mm} /$ night, barely possible energetically, and a ten-month total of $45 \mathrm{~mm}$ (compared with $300 \mathrm{~mm}$ evaporation). Subsequent experience showed that the Thornthwaite-Holzman formula is invalidated by vertical temperature gradients unless observations are made within a few feet of the ground. Applied to the mean gradient over $25 \mathrm{ft}$, the formula may seriously overestimate vapour transfer on a clear, calm night. 
Still higher values came from the lysimeters at Coshocton, Ohio (Harrold and Dreibelbis, 195 I). From 1944 to 1949, annual condensation recorded on various crops was 230 to $270 \mathrm{~mm}$, and daily records showed that the maximum condensation rate was about $0.5 \mathrm{~mm} / \mathrm{hr}$ (in the early evening) exceeding the theoretical maximum by an order of magnitude. These figures reveal a curious failure in lysimeter performance and it is surprising to find them seriously quoted as estimates of dew.

\section{DEW GAUGE MEASUREMENTS}

Many workers have attempted to 'measure' dew from the increase in weight of a 'dew gauge', often a plate of metal, glass or wood of arbitrary dimensions exposed during the night at an arbitrary height above the ground. Such measurements are open to dangerous misinterpretation, but useful observations are possible when the design and siting of a gauge are guided by physical principles rather than by whim or expediency. Similar condensation will form on a dew gauge and on adjacent (horizontal) leaves provided their thermal and aerodynamic properties are similar, and the following conditions should therefore be satisfied:

(a) the gauge should be a thin plate so that the area of vertical faces is much less than the area of horizontal faces. Equations $5,7 a$ and $7 b$ are then valid;

(b) emissivity should be close to unity. Polished metal surfaces are unsuitable except when their low emissivity is exploited deliberately (as in Hofmann's instrument);

(c) the heat capacity per unit surface area should be small enough to make $M \ll R$ over the shortest period of observation;

(d) the gauge should have approximately the same size and shape as adjacent leaves.

In saturated air, condition (d) can be relaxed because potential condensation is independent of wind speed and surface shape. Theoretically, potential condensation on a gauge satisfying conditions (a), (b) and (c) will be the same as potential condensation on a crop (per unit ground area) if the gauge is exposed close to the crop canopy but is unshaded by surrounding leaves. The gauge designed by Duvdevani (1947) was designed primarily for optical estimates of dew from the pattern of condensation, but it has also been used gravimetrically. (The optical method can be used by relatively unskilled observers with little auxilliary equipment, but has the serious disadvantage that the surface properties determining the dew pattern change after a few months' exposure.) This gauge is a block of painted wood 
which has an area of $5 \times 32 \mathrm{~cm}$ and a thickness of $2.5 \mathrm{~cm}$, dimensions which fail to satisfy condition (a). The emissivity of the paint is unknown but is unlikely to be less than 0.9 , satisfying condition (b). Assuming a specific heat of $0.4 \mathrm{cal} / \mathrm{g}$, heat capacity is $0.4 \mathrm{cal} / \mathrm{cm}^{2}$, satisfying condition (c) for periods exceeding a few hours. The relation between amounts of dew on a Duvdevani gauge and on underlying vegetation have not been studied systematically, but in a short series of observations by Angus (1958) the mean gauge deposit was $0.01 \mathrm{~mm} / \mathrm{hr}$ compared with $0.006 \mathrm{~mm} / \mathrm{hr}$ on short grass. As the filter-paper method used to absorb moisture from the grass inevitably underestimates condensation, this agreement is good. The duration of dew on a Duvdevani gauge and on crops was examined by Shaw (undatcd report) who found that the correlation coefficient $r^{2}$ was highest when the gauge was exposed at the same height as the crop canopy and when the canopy was completely closed. Over grass, $r^{2}=0.93$ with the gauge at the surface, decreasing to 0.80 at a height of $50 \mathrm{~cm}$ and to 0.74 at $100 \mathrm{~cm}$. With the gauge at the crop surface, $r^{2}=0.98$ for soybean and 0.96 for maize. These results suggest that observations of the duration of dew on a correctly exposed Duvdevani gauge, or on any simple surface satisfying the first three design criteria, may be useful in plant disease studies; but there is obviously no advantage in using such a gauge unless it is selfrecording.

Maximum dew deposits measured with various dew gauges were reviewed by Hofmann and by Jones (1956). Values in Table 3 support the conclusion from Table $\mathrm{I}$ that potential condensation is virtually independent of climate. The largest values are equivalent to about 7 hours maximum condensation from a saturated atmosphere but the rcal period of dew formation was probably ro to 12 hours with a correspondingly lower rate of condensation when the atmosphere was unsaturated.

TABLE 3

Maximum dew on artificial surfaces ( $\mathrm{mm} / \mathrm{night})$

\begin{tabular}{ll}
\hline Israel & 0.45 \\
Jamaica & 0.43 \\
England, south & 0.43 \\
Germany, Munich & 0.43 \\
Germany, Baltic Coast & 0.37 \\
Moravia & 0.25 \\
France, Montpellier & 0.22 \\
U.S.S.R., Moscow & 0.22 \\
Rumania & 0.17 \\
\hline
\end{tabular}


Empirical formulae for the dependence of gauge condensation on physical properties and exposure were presented by Suzuki (1944).

\section{DEW ON NON-HORIZONTAL SURFACES}

By definition, potential condensation on a surface is independent of aerodynamic properties and is proportional to radiative loss (eq. 4a). When the surface is horizontal this loss can be calculated from a simple empirical formula (eq. 6) and, in practice, the same formula is valid for a crop with horizontal dimensions much greater than the vertical irregularities of the canopy. The crop may then be treated as an infinite surface with total emission and absorption independent of surface contours. Isolated plants and trees have surfaces which are not horizontal and their radiative loss is found by integrating $R(\theta) \cos (\theta-\psi) \mathrm{d} \theta \mathrm{d} S$ where $R(\theta)$ is the net loss of radiation from a horizontal surface at zenith angle $\theta$, and $\mathrm{d} S$ is an clement of surface with zenith angle $\psi$. If this integral exceeds the radiative loss from a horizontal surface with the same projected area by a factor $p,(>I)$ potential condensation per unit projected area will be

$$
W=p \Delta R_{1} / \lambda(\Delta+\gamma)
$$

where $R_{1}$ is evaluated for a horizontal surface $(p=\mathrm{I})$. Theoretical values of $p$ will be given for a cylinder, cone, and hemisphere.

(I) Vertical cylinder.

According to Linke (quoted by Hofmann), $R(\theta)$ is proportional to $\cos ^{n} \theta$ and $n=0.4$ at $e_{A}=9 \mathrm{mb}$. For a vertical cylinder with height $x$ and diameter $d$, evaluation of the integral gives

$$
p=\mathrm{I}+\mathrm{I} \cdot 6 x / d
$$

The approximation that $R$ is independent of $\theta(n=0)$ gives

$$
p=\mathrm{I}+2 x / d
$$

The data in Table 4 arc from Hofmann's review of observations by Hiltner. Agreement is less close for other species.

(2) Cone with base on ground

A simple analytical solution for non-integral values of $n$ is unobtainable. With $n=0$, base diameter $d$ and slant height $l$

$$
p=0.5+1 / d
$$

and comparison of eqs. Io and I 1 shows that this expression will overestimate potential condensation. 
Regularly spaced heaps of stones cover several hillsides in the Negev region of Israel. It is generally agreed that they were built by Nabatean communities about the first and second centuries A.D., and that their purpose was agricultural; their Arabic name is teleilat el einab, 'the hillocks for grapevines' (Glueck, I959). Tadmor and others (I957) discounted a suggestion that the teleilat were built to collect dew, on the negative evidence that no plant material has yet been found within them. Assuming from present dimensions that the teleilat were originally conical with a diameter of $3 \mathrm{~m}$ and a height of about $\mathrm{I} \cdot 2 \mathrm{~m}$, then $p=\mathrm{I} \cdot \mathrm{I} 5$. The maximum yield from a saturated atmosphere at a temperature of $20^{\circ} \mathrm{C}$ would be about 0.5 litres per hour and, allowing for unsaturation in the early evening, condensation may have reached $2-3$ litres per night. If dewy nights were frequent this would be sufficient to maintain several small plants with their roots beneath the stones.

\section{TABLE 4}

Theoretical and measured values of $p$ for single plants of geranium and bean (after Hofmann)

\begin{tabular}{lcc}
\hline & Geranium & Bean \\
\hline$x \mathrm{~cm}$ & 25 & 125 \\
$d \mathrm{~cm}$ & 18 & 30 \\
$\begin{array}{l}p \text { from eq. Io } \\
p \text { from ratio of dew on plant } \\
\quad \text { to dew on gauge }\end{array}$ & 3.2 & $7 \cdot 2$ \\
& 4.1 & 6.6 \\
\hline
\end{tabular}

Gigantic stone piles on the hills above the port of Theodosia in the Crimea had roughly the same shape as the teleilat, but their height was Io $\mathrm{m}$ and their diameter 24 to $30 \mathrm{~m}$ (Hitier, 1925). Maximum yield, calculated from potential condensation and $p=\mathrm{I} \cdot \mathrm{I} S$, is about 300 litres per night. From the size of the aqueducts leading from the cairns to the famous fountains of Theodosia, Zibold estimated the yield from each to be 55,400 litres per day: dismissing dew as totally inadequate, the only alternative mechanism for moisture collection is the interception of fog and cloud droplets. On Table Mountain, the annual mean fog precipitation is 3.75 $\mathrm{mm} / \mathrm{hr}$ (Nagel, I956) and, assuming the same figure for Theodosia, each cairn could have produced about 12,000 litres per day in favourable weather.

At Montpellier in the south of France, L. Chaptal attempted to estimate the yield of the Theodosia cairns by building a miniature version in the 
form of a pyramid of calcareous stones with base $3 \times 3 \mathrm{~m}$ and height $2 \cdot 5 \mathrm{~m}$. During summer months, the amount of water collected daily was between I and 2.5 litres consistent with present calculations. At Dakar, attempts to exploit this simple method of obtaining water from the atmosphere appear to have been unsuccessful (Lejeune and Savornin, I958).

(3) Hemisphere with base on ground.

With $n=0, p=I \cdot 5$, independent of size.

Two fallacious conclusions have been drawn from the observation that dew on isolated plants (expressed on the basis of ground area) often exceeds condensation on a gauge. The first is that condensation on a field crop can be estimated by multiplying gauge condensation by a 'plant factor' equivalent to $p$ and determined from dew measurements on an isolated plant of the same species. For example, Ashbel (1949) applied Hilner's factor for beans $(p=6)$ to dew gauge measurements in the Negev, obtaining an annual dew total of $10-25 \mathrm{~cm}$. A more acceptable estimate for the region is $10-25 \mathrm{~mm}$ (Gilead and Rosenan, I954). Hofmann quotes similar examples and shows that in unsaturated air, $p$ may vary from zero to infinity depending on the variation of relative humidity with height near the ground. The variability of 'plant factors' when the atmosphere is unsaturated makes them worthless in ecological studies of dew.

The second fallacy is that the net water loss from isolated and heavily dewed plants is less than from plants of the same species in a closed community. Incoming radiation received by an isolated plant during the day always exceeds the radiation falling on a plane surface covering the same ground area, and when there is no physiological control, transpiration is greater than from the equivalent area of a closed canopy. Because potential evaporation is normally much greater than potential condensation, the net water loss from an isolated plant will then be greater, not less, than the loss from a closed canopy covering the same ground area.

The effect of plant spacing on dew may become important for xerophytic species when transpiration rates are comparable with potential condensation. Deacon and others (1958) suggested that the natural habit of desert species growing in isolated clumps may represent an optimum spacing for maximum dew, but there is no experimental evidence for this hypothesis.

\section{SOURCES OF DEW}

Controversy over the source of dew is more than two thousand years old, and in 1929 it reached the pages of Nature. Theories of rising and falling dew both received support, but Simpson (I929) stifled further correspon- 
dence with the categorical statement that: 'Dew is nowhere until it appears on the surface (of plant leaves): it therefore neither rises nor falls.' It was legitimate to adopt this standpoint in section 2 where the rate of dew formation was calculated without reference to initial sources of water vapour, but their differentiation is important ecologically.

The immediate source for condensation on plant leaves is water vapour in the surrounding air, but for continuous condensation throughout the night this vapour must be replaced from the free atmosphere, from the soil, or from both. Distinguishing terms are 'dewfall', for the downward flux of water vapour from the atmosphere; and 'distillation', for the transfer of water vapour from relatively warm soil to cooler leaves. Both dewfall and distillation are diffusion phenomena with fluxes which can be represented formally by the product of a vapour pressure gradient and a transfer coefficient $K_{W}\left(\mathrm{~cm}^{2} / \mathrm{sec}\right)$. For dewfall, $K_{W}$ is a coefficient of turbulent diffusion, determined by wind shear and atmospheric stability. Several metres above the ground on clear nights its order of magnitude is $\mathrm{IO}^{3}$. In contrast, characteristic values of $K_{W}$ for distillation on short grass are close to the value for molecular diffusion, $0.24 \mathrm{~cm}^{2} / \mathrm{sec}$ (Monteith, I956). Although respective transfer coefficients differ by four orders of magnitude, dewfall and distillation fluxes are often comparable, and their theoretical ratio may be estimated from the surface heat budget.

In Fig. 2, showing relevant fluxes, the wavy line represents a closed crop canopy at a lower temperature than the underlying soil. Sensible heat transfer $C$ is now split into two components, $C_{d}$ from the atmosphere, and $C_{u}$ from the soil. Similarly, the latent heat flux has components $\lambda W_{d}$ (dewfall) and $\lambda W_{u}$ (distillation). Corresponding temperature and vapour pressure profiles are shown in papers by Long (1958) and Penman and Long (1960). Within the soil, the main mechanism for heat transfer is conduction at a rate $G$, and latent heat transfer, normally a small fraction of $G$, will be neglected. When the moisture content of the soil is sufficiently high for the soil atmosphere to be assumed saturated (see Fig. 3), and when the free atmosphere is also saturated, the ratios $\lambda W_{d} / C_{d}$ and $\lambda W_{u} / C_{u}$ depend on temperature alone, and at surface temperature $T_{\delta}$

$$
\lambda W_{u} / C_{u}=\lambda W_{d} / C_{d}=\Delta\left(T_{\delta}\right) / \gamma
$$

The heat balance for the crop canopy is

$$
R=W_{d}+C_{d}+W_{u}+C_{u}
$$

and for the soil surface is

$$
G=W_{u}+C_{u}
$$


(Penman and Long showed that a crop may gain heat from the soil radiatively at a rate comparable with $C_{u}$ : here the term $R$ includes this exchange.) Combination of eqs. I3-I 5 then gives

$$
W_{d} / W_{u}=R / G-\mathrm{I}
$$

The theoretical limit $G=R$ is observed when the atmosphere is so calm and stable that atmospheric fluxes of heat and vapour are both negligible. Then $W_{d}=0 ; W_{u}=(\Delta R / \lambda(\Delta+\gamma))$. With increasing wind speed, turbulent transfer rates increase and soil heat flux decreases. Theoretically, when

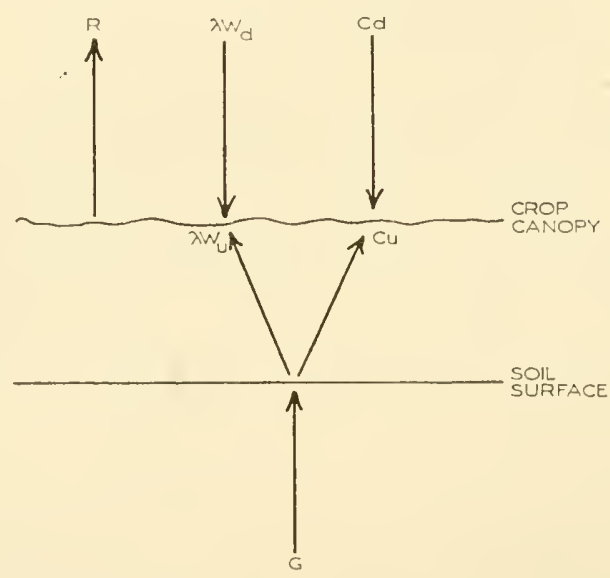

FIG. 2. Heat balance of crop canopy. For symbols, see text.

$G \rightarrow 0, W_{u \rightarrow 0}$ and $W_{d} \rightarrow(\Delta R / \lambda(\Delta+\gamma))$, but this condition is never met in nature.

When $W_{d}$ and $W_{u}$ are both finite, the ratio $R / G$ depends on the relative thermal properties of soil and atmosphere. Relevant parameters for the soil are volume heat capacity $\rho_{1} c_{1}\left(\mathrm{cal} / \mathrm{cm}^{3}\right)$ and thermal diffusivity $\kappa$ $\left(\mathrm{cm}^{2} / \mathrm{sec}\right)$; and for the air, volume heat capacity $\rho_{2} c_{2}$ and the turbulent heat transfer coefficient $\mathrm{K}_{H}\left(\mathrm{~cm}^{2} / \mathrm{sec}\right)$. Priestley (1959) showed that the assumption of constant $\kappa$ and $K_{H}$, though far from realistic, gives satisfactory heat flux ratios if their values are chosen 'some distance from the surface', and he derived an expression from which

$$
R / G=\frac{\rho_{1} c_{1} \sqrt{ }(\kappa)+\rho_{2} c_{2} \sqrt{ } K / H}{\rho_{1} c_{1} \sqrt{ } \kappa}
$$


Equation $\mathrm{I} 7$ is valid only when there are no latent heat fluxes, but a similar expression can be obtained for an isothermal saturated atmosphere, assuming equality of $K_{W}$ and $K_{H}$, and using eqs. 13 and 16 to give

$$
W_{d} / W_{u}=\frac{\rho_{2} c_{2} \sqrt{ }\left[K_{H}(\mathrm{I}+\Delta / \gamma)\right]}{\rho_{1} c_{1} \sqrt{ } \kappa}
$$

Frankenberger (1955) determined $K_{H}$ at $30 \mathrm{~m}$ for wind speed (at ro $\mathrm{m}$ ) in classes 0-I m/sec, etc., and from Priestley's tabulation of $\rho_{1} c_{1}$, a value of 0.04 c.g.s. units is appropriate for moist soils. Using these data, $R / G$ values calculated from eq. 17 are in good agreement with field measurements at Rothamsted (Monteith, 1958), and the same data were used to compute the values of $W_{d} / W_{u}$ in Table 5 .

\section{TABLE 5}

Variation of dewfall/distillation ratio with wind speed $V(\mathrm{~m} / \mathrm{sec}$ at $\mathrm{Io} \mathrm{m})$ : saturated air, temperature $10^{\circ} \mathrm{C}$ (eq. I7)

$\begin{array}{llllll}V & 0-\mathrm{I} & \mathrm{I}-2 & 2-3 & 3-4 & 4-5 \\ W_{d} / W_{u} & 0.20 & 0.50 & 0.79 & \mathrm{I} \cdot 3 & \mathrm{I} \cdot 5\end{array}$

The predicted variation of the dewfall/distillation ratio with wind speed has not been directly tested, but is consistent with measurements over very short grass referred to the wind speed at $2 \mathrm{~m}$ (Monteith, 1956). When the wind dropped to $0.5 \mathrm{~m} / \mathrm{sec}$ or less, dewfall was a negligible fraction of distillation. With wind about $2 \mathrm{~m} / \mathrm{sec}$, dewfall was maximum at about $0.03 \mathrm{~mm} / \mathrm{hr}$, and the value of $W_{d} / W_{u}$ estimated from radiation and temperature data was $\mathrm{I} \cdot 5$, consistent with a wind of $4-5 \mathrm{~m} / \mathrm{sec}$ at $10 \mathrm{~m}$.

Dewfall/distillation ratios will normally be much less than the theoretical value of eq. 8 because it is uncommon for the air above a crop to be saturated at night without fog. Both leaf temperature $T_{L}$ and the dew-point temperature $T_{D}$ of the surrounding air decrease from mid-afternoon onwards, whether dew is forming or not. When the wind is very light, $T_{L}$ falls more rapidly than $T_{D}$; and at sunset, or even before, condensation begins when $T_{L}=T_{D}$. The removal of water vapour as dew helps to keep the air slightly unsaturated (relative humidity $96-99 \%$ ) but, after further cooling of the air by radiation, saturation is reached and fog appears. With stronger wind, theoretically more favourable for dewfall, $T_{L}$ approaches $T_{D}$ more slowly and condensation may not begin until several hours after sunset. Radiative cooling of the air is negligible; relative humidity near the ground remains between 96 and $99 \%$, increasing slowly throughout the 
night; and the potential dewfall rate is never reached. In practice, the dewfall/distillation ratio does not increase systematically with increasing wind speed but reaches a maximum at some optimum value, about $2 \mathrm{~m} / \mathrm{sec}$ at $2 \mathrm{~m}$ over short grass. Gravimetric measurements of dew in south-east England and in Victoria, Australia (McIlroy, private communication) show that distillation is normally the dominant component of dew on agricultural crops.

Some workers expose dew gauges at different heights above the ground and infer the source of dew from its variation with height. This interpretation is invalid. The so-called 'dew gradient' depends on the vertical distribution of temperature, humidity, and wind speed, and is not uniquely related to the direction of vapour transfer.

The distinction between dewfall and distillation is relevant to studies of plant water balance. Dewfall on plant leaves is a real accretion of water in rainless weather, it is the only significant mechanism for transferring moisture from the atmosphere to the soil/plant system. Distillation is a redistribution of water within this sytem. Transpiration losses are negligible while dew is evaporating from plants, but the evaporation rate from wet leaves is normally somewhat greater than the corresponding rate of potential transpiration from dry leaves. Dervfall decreases the extraction of soil moisture by plant roots, whereas distillation increases soil moisture depletion by providing a short-cut for the transfer of water from the soil to the atmosphere.

\section{ABSORPTION OF WATER VAPOUR}

The uptake of water vapour by plants and by dry soil without the formation of visible water has been called 'hidden dew' and 'occult condensation', names which obscure an important thermodynamic difference between condensation on a plane surface and absorption by a hygroscopic medium. When water vapour condenses, latent heat is released and the condensation rate is limited by the rate at which this heat can be removed to prevent an increase of surface temperature. When water vapour is absorbed both latent heat and 'free energy' are released but the direction and rate of vapour transfer are determined by the potential gradient of free energy rather than by the availability of a heat sink. Absorption may be accompanied by a slight rise in temperature from the 'heat of wetting'. The fundamental unit for free energy is ergs/g but it is more convenient to use the equivalent gravitational potential $H$ expressed in metres. For water in the atmosphere, plant, or soil $H \leq$ o. 
The free energy of atmospheric water vapour $H_{A}$ is related to relative humidity and absolute temperature by the equation

$$
\begin{aligned}
H_{A} & =470 T(-\ln r) \\
& =-\mathrm{I} \cdot 38 \cdot 10^{4} \ln r \quad \text { at } T=293^{\circ} \mathrm{K}
\end{aligned}
$$

and Fig. 3 shows equivalent scales of $-H_{A}$ and $r$. In leaf cells (assumed completely vacuolated), the free energy deficit $\left(-H_{L}\right)$ is the difference between the osmotic potential energy of the vacuolar fluid and the elastic potential energy of the cell wall, a quantity known to physiologists as
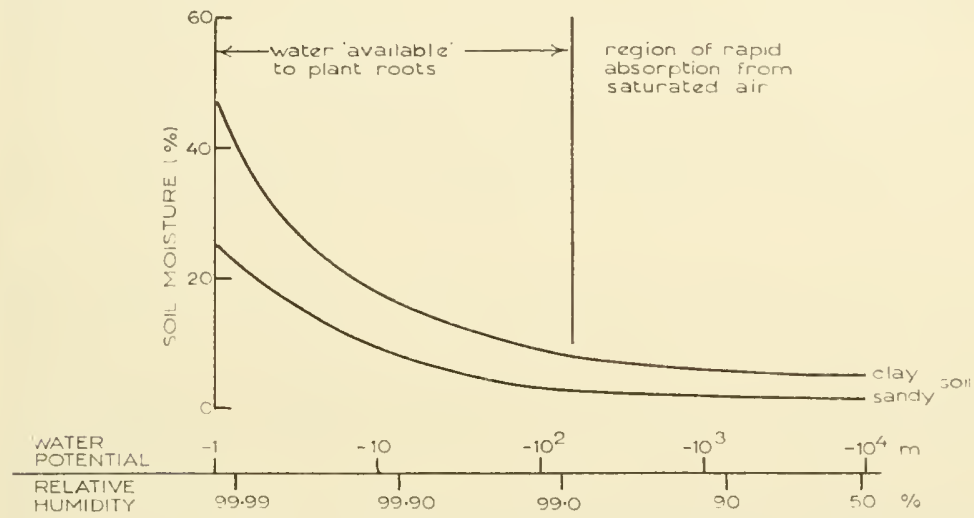

FIG. 3. Variation of water potential with soil moisture (per cent dry weight) for two idealised soils. The horizontal axis shows the relation between water potential and equilibrium relative humidity. The water potential of the clay soil at $8 \%$ moisture content is about - I00 $\mathrm{m}$ and absorption of atmospheric water vapour would occur only when relative humidity exceeded $99 \%$.

diffusion pressure deficit (DPD). The water deficit of plant leaves after a period of transpiration is normally met by the transfer of water from other parts of the plant and ultimately from the roots; but the direct uptake of atmospheric water vapour through the cuticle is possible when $H_{L}<H_{A}$. Leaves at the conventional 'I 5 atmosphere' wilting point $\left(H_{L}=-\right.$ I $\left.55 \mathrm{~m}\right)$ will absorb vapour from an atmosphere with relative humidity exceeding $98.8 \%$, and for a plant surviving at $H_{L}=-\mathrm{I} \mathrm{I} 20 \mathrm{~m}$ (Slatyer, I958) absorption is possible when the relative humidity is $92 \%$.

The free energy of soil moisture $H_{S}$ is determined by its salt concentration and by the radius of the largest water-occupied pores. At the soil surface, and in the neighbourhood of plant roots, $H_{S}$ decreases during the day as moisture content decreases. The condition for uptake of atmospheric water vapour during the night is $H_{S}<H_{A}$. 
Normal transfer of water through plants from the soil to the atmosphere requires

$$
H_{A}<H_{L}<H_{S}
$$

By imposing the reverse gradient

$$
H_{S}<H_{L}<H_{A}
$$

in the laboratory, Slatyer and others demonstrated the absorption of vapour by the leaf cuticle and the simultaneous transfer of water to the roots. Further transfer from roots to soil is theoretically possible but the experimental evidence is ambiguous. In Slatyer's experiments with one-year-old Pinus eclinata seedlings, water vapour was absorbed when the atmosphere was held saturated $(H=0)$ or with relative humidity $98.8 \%(H=-155 \mathrm{~m})$. With strict temperature control $\left( \pm 0.00 I^{\circ} \mathrm{C}\right)$ there was presumably no leafair temperature difference and therefore no condensation of liquid water on the plant leaves. In nature, plant leaves are usually cooler than the atmosphere by I or $2^{\circ} \mathrm{C}$ during the night, so condensation begins when the relative humidity rises to 96 or $98 \%$ (Fig. I). Unless $H$ is exceptionally low $(<-300 \mathrm{~m})$ condensation will precede and preclude cuticular absorption of vapour. The only species likely to benefit from vapour absorption are those which can survive extreme water stress. For example, Stone, Went and Young (1950) found that a Pinus coulteri seedling growing in soil unwatered for ten months could absorb vapour from air with relative humidity below $90 \%$, implying $H<-\mathrm{r} 400 \mathrm{~m}$.

Exposed to bright sunshine, surface soil may dry to very low values of $H$, say to $-10^{4} \mathrm{~m}$ in equilibrium with air at relative humidity $48 \%$, and subsequent absorption of vapour at night is common. In a study of vapour uptake by Indian soils, Ramdas and Katti (1936) found that the moisture content in the surface layer of a 'black cotton soil' increased from $2.6 \%$ dry weight in the afternoon to $7 \cdot 7 \%$ in the early morning. Damagnez (1958) measured absorption rates of $0.15 \mathrm{~mm} /$ night and showed that for given atmospheric conditions, uptake was greater at lower soil moisture contents. At Rothamsted, maximum absorption by fallow soil (a clay loam) was $0.6 \mathrm{~mm} /$ night, measured with the freld balance on May 6, 1957.

Most of the moisture absorbed by a dry soil is held at levels of free energy far below those available to plant roots (Fig. 3). Because this moisture cannot subsequently be absorbed by roots, it makes no direct contribution to plant water economy; but plant transpiration may be slightly reduced for a few hours after sunrise while absorbed moisture evaporates from the soil surface.

Confusion over the relationship between soil moisture and the relative 
humidity of the soil atmosphere has led some workers to study the condensation on artificial surfaces buried within the soil. Such observations are irrelevant to the water economy of plant roots.

\section{DEW AND PLANT GROWTH}

In purely physical aspects of dew formation, it is relatively simple to distinguish fact and fallacy. Stone's (1957a) review showed that the biological picture is less clear because there is so little relevant evidence from the field. Dew is known to promote the spread of plant discase by providing a suitable environment for plant pathogens (Duvdevani, r946); but when there is no potential disease, many farmers and gardeners believe that dew stimulates the healthy growth of plants in dry weather. Duvdevani (1957) clained that the yield of cucumbers exposed to dew was $50 \%$ greater than from undewed controls, but experimental details have yet to be published.

In countries where little rain falls during the growing season, there are two ways in which dew may contribute to plant water economy (Slatyer, 1960): the evaporation of dew from leaves nuay reduce transpiration in the early morning; and foliar absorption during the night may reduce local water deficits and accelerate growth. For purely physical reasons, the decrease in transpiration after dew is unlikely to benefit mesophytic plants because in cloudless summer weather the ratio of potential condensation to potential evaporation is (very roughly) $\mathrm{I}: 7$ in a humid climate and $\mathrm{I}: \mathrm{I}_{4}$ in an arid climate. Dewfall evaporates within a few hours of sunrise and plants with inadequate soil moisture reserves endure severe water stress for the hottest part of the day. The life of a plant not adapted to such stress may be prolonged for a few days while dew nights are frequent, but death is inevitable in the continued absence of rain. For desert plants, dewfall which cannot be absorbed is a luxury: none of the mechanisms by which xerophytes conserve moisture require the presence of liquid water on the external organs.

Data for dew absorption (Lehmann and Schanderl (1942); Arvidsson (I95I); Waisel (I958) and others) show wide differences between species, attributable to differences in cuticular permeability and in the free energy deficit of leaf cells. Distinguishing carefully between the nocturnal uptake of moisture from the soil and from the atmosphere, Waisel found that average saturation deficits* of Pinus halepensis and Olea europaea were

* Now using the term in its physiological sense: $100 \times$ (saturated leaf weight actual leaf weight)/saturated leaf weight. 


$\begin{array}{lr}\text { Evening: } & 19 \% \\ \text { Following morning: dewed } & 10 \% \\ & \text { undewed } \\ 17 \%\end{array}$

The measurements were made during September 1954 in Jerusalem after several months without rain. A further experiment showed that dew absorption increased the leaf water content of Ceratonia siliqua saplings exposed to drought by $10 \%$ during the night, whereas the increase for irrigated saplings was $7 \%$. These figures suggest that the absorption of dew by plants growing in dry soil may usefully supplement the absorption of soil moisture, but Waisel emphasised that dew absorption was never sufficient to restore full leaf water content. Stone (1957b) showed that when seedlings of Pinus and other forest species grew in soil with moisture at the wilting point, life could be prolonged for several weeks by spraying the foliage with artificial dew.

The effect of dew on photosynthesis has not yet been studied in the field but there is convincing laboratory evidence, recently reviewed by Stocker (I960), that when leaves subjected to severe water stress are subsequently wetted, the photosynthetic rate increases rapidly. As an example of recovery from sub-lethal stress, Montford and Hahn(I950) found that when leaves of Caltha palustris were dehydrated to $59 \%$ of their normal water content, photosynthesis increased within two hours of wetting to $40 \%$ of the value for controls. Synthesis of similar laboratory studies with field measurements of the Waisel type is needed to establish the significance of dew absorption for plant metabolism.

On the available evidence it is unlikely that dew is of great physiological importance, either in humid climates or in the desert. Where rainfall is marginal, there may be a few species which grow and reproduce more vigorously when their leaves are frequently wet at night. At least three plants of economic importance-cotton, pineapple and melon-are reported to yield well in climates where there is little rain but abundant dew, but a causal relation between dew and growth, exploitable in arid zone agriculture, has yet to be established.

\section{REFERENCES}

Artken, J.(1885) On dew. Trans. Roy. Soc. Edinb. 33, 134-186.

Angus, D.E.(1958) Measurements of dew. UNESCO Arid Zone Research, XI, 301-303. ARvidsson, I.(I95I) A ustrocknungs- und Dürreresistenzverhaltnisse einiger Repräsentanten öländischer Pflanzenvereine nebst Bemerkungen uber Wasserabsorption durch oberirdische Organe. Oikos, Suppl. I. 
Ashbel, D.(1949) Frequency and distribution of dew in Palestine. Geogr. Rev. 39 29I-297.

DAMAGNEZ, J. (I958) Les sources secondaires d'humidité. International Union of Geodesy and Geophysics. International Association of Scientific Hydrolog $\gamma$. General Assembly of Toronto, 2, 446-457.

Deacon, E. L., Priestley, C.H.B. \& Swinbank, W.C. (I958) Evaporation and the water balance. UNESCO Arid Zone Research, X, 9-34.

DEVRIES, D.A. \& VENEMA, H.J.(I953) Some considerations on the behaviour of the Piche evaporimeter. Vegetatio, Haag. V-VI, 225-234.

Duvdevani, S. (1946) The development of downy and powdery mildew of cucumber as related to dew and other environmental factors. Palestine J. Bot. hort. Sci. 5 , I27-ISI.

Duvdevani, S. (1947) An optical method of dew estimation. Quart. J. R. met. Soc. 73, 282-296.

Duvdevani, S.(1957) Dew research for arid agriculture. Discovery, 18, 330-334.

Frankenberger, E.(I955) Uber vertikale Temperatur-, Feutchte- und Windgradienten, den Vertikalaustauch und den Warmehaushalt. Ber. dtsch. Wetterd. Bd. 3, Nr. 20.

Gates, D. M. \& TANTraporn, W. (1952) The reflectivity of deciduous trees and herbaceous shrubs in the infrared to 25 microns. Science, II5, 613-616

Gilead, M. \& Rosenan, N.(1954) Ten years of dew observations in Israel. Israel Exploration Journal, 4, I20-123.

GlueCK, N.(I959) Rivers in the Desert. Weidenfeld and Nicolson, London.

Harrold, L.L. \& Dreibelbis, F.R.(I95I) Agricultural hydrology as evaluated by monolith lysimeters. Tech. Bull. U.S. Dep. Agric. No. Ioso.

Hintner, E.(1930) Der Tau und seine Bedeutung fur den Pflanzenbau. Wiss. Arch. Landw. A3, I-70.

Hitier, H.(I925) Condensateurs des vapeurs atmosphériques dans l'antiquité. C. $R$. Acad. Agric. Fr. II, 679-683.

Hofmann, G.(1955) Die Thermodynamik der Taubildung. Ber. dtsch. Wetterd. 3, Nr. 18.

House, G.J., RiDer, N.E. \& Tugwell, C. P.(I960) A surface energy balance computer. Quart.J. R. met. Soc. 86, $215-23$ I.

JoNes, R.L.(1956) Dew as a factor in plant water balance. N.Z. Dep. sci. indust. Res. inf. Ser. No. 12, 66-72.

Lehmann, P. \& Schanderl, H.(I942) Tau und Reif. Wiss. Abh. Reichsamt Wetterd. Bd. $9, \mathrm{Nr} .4$.

Lejeune, G. \& SAvornin, J.(1958) Recovering water-vapour from the atimosphere. Trans. International Conference on the Use of Solar Energy, 3, 138-141.

Long, I. F. (1958) Some observations on dew. Met. Mag. 87, I6I-I68.

Monteith, J.L.(I956) Dew. Quart.J. R. met. Soc. 83, 322-34I.

MonteItH, J.L.(1958) The heat balance of soil beneath crops. UNESCO Arid Zone Research, XI, 123-127.

MonterTH, J.L.(196I) An empirical method for estimating long-wave radiation exchanges in the British Isles. Quart. J. R. met. Soc. 87, I7I-I 79.

Montford, C. \& Hahn, H.(I950) Ätmung und Assimilation als dynamische Kennzeichen abgestufter Trockenresistenz bei Farnen und höheren Pflazen. Planta, 38, 503-515. 
MORRI, L. G. (1959) A recording weighing machine for the measurement of evapotranspiration and dewfall. J. agric. Engng. Res. 4, I6I-I73.

NAGEL, A.(1956) Fog precipitation on Table Mountain. Quart. J. R. met. Soc. 82, $452-460$.

Penman, H.L.(1948) Natural evaporation from open water, bare soil and grass. Proc. Roy. Soc. Al93, I20-I45.

Penman, H.L. \& Long, I.F.(I960) Weather in wheat. Quart. J. R. met. Soc. 86, I6-5o.

Priestley, C.H.B.(1959) Turbulent Transfer in the Earth's Atmosphere. Chicago University Press.

Ramdas, L.A. \& KatTI, M.S.(I936) Agricultural meteorology: Studies in soil moisture. Indian J. agric. Sci. 6, I $163-1200$.

SHaw, R.H.(undated) Observation of dew deposition on various types of cover. Iowa State College. Final report Contract AFI9(604)-589.

Simpson, G.C.(1929) Dew: does it rise or fall? Nature, 124, 578, 725.

SLATYER, R.O.(1958) Availability of water to plants. UNESCO Arid Zone Research, $\mathrm{XI}, \mathrm{I} 23-\mathrm{I} 27$.

Slatyer, R. O. (I960) Absorption of water by plants. Bot. Rev. 26, 331-392.

STOCKer, O.(1960) Physiological and morphological changes in plants due to water deficiency. UNESCO Arid Zone Research, XV, 63-I04.

StONE, E.C.(1957a) Dew as an ecological factor. I: A review of the literature. Ecology, $38,407-413$.

Stone, E. C. (1957b) Dew as an ecological factor. II: The effect of artificial dew on the survival of Pinus ponderosa and associated species. Ecology, 38, 4I4-422.

Stone, E.C., Went, F. W. \& Young, C.L.(I950) Water absorption from the atmosphere by plants growing in dry soil. Science, III, 546-548.

Suzuki, C.(I944) On the formation of dew (in Japanese). Agric. Met., Tokyo, 2, 23-4I. Tadmor, N.H., Evenari, M., Shanan, L. \& Hillel, D.(I957) The ancient desert agriculture of the Negev. I: Gravel mounds and strips near Shivta. Ktavim, 8, I27-15I.

Thornthwarte, C.W. \& Holzman, B.(1942) Measurement of evaporation from land and water surfaces. Tech. Bull. U.S. Dep. Agric. No. 8I7.

WAISEL, Y.(1958) Dew absorption by plants of arid zones. Bull. Res. Coun. Israel, $6 \mathrm{D}, \mathrm{I} 80-\mathrm{I} 86$.

WENT, F. W.(I95s) Fog, mist, dew and other sources of water. Water, U.S.D.A. Year Book of Agriculture. 


\title{
THE EFFECT OF DISSOLVED SALTS ON WATER MOVEMENT
}

\author{
D. A.ROSE \\ Rothamsted Experimental Station, Harpenden, Herts.
}

If plants are to survive drought they must have a source of water available near the roots, and to be of use the source must also be accessible. Because root extension is not unlimited, at some stage the water must move to the roots, and the flow will be governed by the product of a conductivity and a potential gradient (eq. 5). Full understanding of 'drought resistance' needs detailed study of both conductivity and potential, and in real soils there is great complexity arising from swelling and shrinking during wetting and drying. In the present note the complexity is avoided by concentrating on the behaviour of a rigid matrix.

\section{TOTAL POTENTIAL OF WATER IN A POROUS SYSTEM}

There are several possible components that can make up the total water potential in a porous system, but only two are important in the present context. First there is the matric potential, which the water possesses because it is held in a framework of fine pores, and arises from capillarity (dominant in wet media) and physical adsorption (dominant in nearly dry media). In the wetter media there is a curved meniscus separating water from air, the radius of curvature $(\mathrm{rm})$ being determined by the size of pore the meniscus occupies. Standard theory shows that the hydrostatic pressure in the water is less than that of the atmosphere by an amount $2 S / r$ in absolute units, where $S$ dyne $\mathrm{cm}^{-1}$ is the surface tension of water. This pressure deficit can be defined as the matric potential in a convenient practical unit, the height of water column $h \mathrm{~cm}$ required to product this deficit, when

$$
h=\frac{2 S}{\rho g r} \mathrm{~cm}
$$

where $\rho \mathrm{gm} \mathrm{cm}^{-3}$ is the density of water, and $\mathrm{g} \mathrm{cm} \mathrm{sec}^{-2}$ is the acceleration due to gravity. Note that the meniscus is a perfect semi-permeable membrane: water molecules can pass across it freely but solute molecules cannot. 
The second important component arises from the presence of such solutes and is an osmotic or solute potential that becomes important for water movement through semi-permeable membranes such as plant roots or a water surface from which there is evaporation. Over the meniscus of a salt solution the vapour pressure is less than it would be over a meniscus of pure water or over a plane surface of solution, and the decrease below what would exist over a plane pure surface is a measure of the total potential:

$$
\psi=\frac{R T}{g} \ln \frac{p}{p_{0}} \mathrm{~cm}
$$

where $\psi \mathrm{cm}$ is the total potential, $R \mathrm{erg} \mathrm{gm}^{-1}{ }^{\circ} \mathrm{C}^{-1}$ is the gas constant per gm of water vapour, $p$ is the vapour pressure over the meniscus, and $p_{0}$ is the value it would have over a plane surface of pure water at the same temperature $T^{\circ} \mathrm{K}$.

Note that $p / p_{0}$ is the equilibrium relative humidity, never greater than unity, and so $\psi$ is either negative or zero. Thus $\psi$ has the same sign as $h$, and may be split into components

$$
\psi=h+\pi \mathrm{cm}
$$

where $\pi$ represents the osmotic potential. It too is negative. The osmotic potential is proportional to the solute concentration $m$, so eq. 3 may be rewritten

$$
\psi=h+\lambda m \mathrm{~cm}
$$

where $\lambda=4 \cdot 73 \times \mathrm{IO}^{4}$ for $\mathrm{NaCl}$ when $m$ is measured in molal units. The partial specific Gibbs' free energy of the water is then $g \psi \mathrm{erg} \mathrm{gm}^{-1}$, while Schofield's $\mathrm{pF}=\log _{10}(-\psi)$.

The matric potential can be measured by tensiometer, suction plate, pressure plate, or pressure membrane devices: the total can be measured by freezing point determinations or by a variety of vapour pressure techniques such as that of Monteith and Owen (1958).

\section{MOVEMENT OF WATER}

If a gradient of potential exists, water movement can be expressed by the relation

$$
q=\frac{Q}{\rho A t}=-k \nabla \psi
$$

where $\mathrm{Q} / \mathrm{t} \mathrm{gm} \mathrm{sec}^{-1}$ cross an area $A \mathrm{~cm}^{2}$ normal to the direction of flow when moving under the total water potential gradient $\nabla \psi$. Equation 5 
defmes $k \mathrm{~cm} \mathrm{sec}^{-1}$, the capillary conductivity of the water in the medium. In soils free from solutes there is general agreement that both liquid and vapour move under a potential gradient $\nabla \psi=\nabla h$ because $\pi=0$, vapour movement having been treated theoretically by Philip (I955). When solutes are present, however, there are differences of opinion as to their effect on water movement.

Edlefsen and Anderson (1943, pp. 278-280) consider that an osmotic potential gradient along a soil column will lead to water movement before the solute concentration gradient has been brought to zero by ionic diffusion. In contrast, Richards and Weaver (1944) observe that, if a tensiometer is filled with distilled water and the manometer allowed to attain an equilibrium reading with the porous cup standing in distilled water, then almost no change in pressure (less than $0.003 \mathrm{~atm}$ ) is registered when saturated $\mathrm{NaCl}$ solution is substituted for the distilled water surrounding the cup. They state that in the absence of semi-permeable membranes moisture flow is produced primarily by gravity and gradients in soil-water tension, and not directly by solute concentration gradients'. Schofield (1952) also expressed the view that 'two distinct processes are involved in water movement, (a) bulk flow of the solution governed by its viscosity and one aspect of the geometry of the pore space, and (b) diffusion (of the water and solutes in opposite directions) governed by the diffusion coefficient and a different aspect of the geometry of the pore space'. Low (1955), from a thermodynamic treatment of the equilibrium and movement of soil water, predicted that osmotic potentials would act as negative hydraulic pressures in influencing water diffusion. His equation was tested on clay suspensions and shown to be valid, but the measured osmotic potentials were much lower than theoretically calculated values.

The following analysis assumes that vapour moves under the total water potential gradient $\nabla \psi$, but that liquid moves only under a matric potential gradient $\nabla h$.

\section{THEORY OF THE DIFFUSION CELL}

Consider the system $\mathrm{ABCDE}$ (Fig. Ia), consisting of a porous block BCD between air gaps $\mathrm{AB}, \mathrm{DE}$, with water potentials $\psi_{1}, \psi_{2}, \Psi, \psi_{3}, \psi_{4}$ imposed such that $\psi_{1}>\psi_{2}>\psi_{>} \psi_{3}>\psi_{4}$ and $\psi_{1}+\psi_{4}=\psi_{2}+\psi_{3}=2 \Psi$. In the steady state under these conditions the flux of water is uniform, either as vapour distilling across the air gaps $\mathrm{AB}$ and $\mathrm{DE}$ or as liquid diffusing through the porous sample $B C D$. In practice, $A$ and $E$ are pads of filter paper saturated with $\mathrm{NaCl}$ solutions of concentration $m_{A}$ and $m_{E}$ respectively, and BCD 
is a block of porous stone containing $\mathrm{NaCl}$ solution of concentration $m_{0}=\frac{1}{2}\left(m_{A}+m_{E}\right)$. At the outset the solute is redistributed in the sample, the concentration $m_{2}$ at $\mathrm{B}$ decreasing, and concentration $m_{3}$ at $\mathrm{D}$ increasing, until a steady-state solute profile is attained when the transfer of solute ions by mass flow of the water from $B$ to $D$ is balanced by a counterflow due

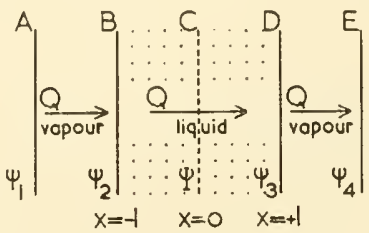

FIG. Ia. Theory of diffusion cell.

to ionic diffusion from $\mathrm{D}$ to $\mathrm{B}$. This is the case of water transfer through a semi-permeable membrane (the air-water interface). If it is assumed that:

(i) liquid movement occurs solely under the matric potential gradient,

(ii) there is equilibrium of the solute,

and (iii) steady state conditions obtain,

then, at any plane in the region $-l<x<+l$, the left-to-right transfer of solute is qm, and the right-to-left transfer is $D_{s}(\mathrm{~d} m / \mathrm{d} x)$ where

$q \mathrm{~cm} \mathrm{sec}{ }^{-1}$ is the velocity of liquid flow, governed by the matric potential gradient,

$m$ is the molal concentration of the solute at the plane, and $D_{s}$ is the coefficient of diffusion of the solute molecules through the pores of the medium. At equilibrium,

$$
q m=D_{s} \frac{\mathrm{d} m}{\mathrm{~d} x}
$$

or

$$
m=m_{0} \exp \left(\frac{q x}{D_{\delta}}\right)
$$

where $m_{0}$ is the concentration at $\mathrm{C}(x=0)$.

Hence, at $\mathrm{B}(x=-1)$,

$$
h_{2}=\psi_{2}-\lambda m_{2}=\psi_{2}-\lambda m_{0} \exp \left(-\frac{q l}{D_{s}}\right)
$$

and at $\mathrm{D}(x=+l)$,

$$
h_{3}=\psi_{3}-\lambda m_{3}=\psi_{3}-\lambda m_{0} \exp \left(+\frac{q l}{D_{\delta}}\right)
$$


The matric potential difference across the block is

$$
h_{3}-h_{2}=\left(\psi_{3}-\psi_{2}\right)-\lambda m_{0}\left\{\exp \left(+\frac{q l}{D_{8}}\right)-\exp \left(-\frac{q l}{D_{\delta}}\right)\right\}
$$

and, anticipating that $q / / D_{s}$ will be small, this reduces to

$$
h_{3}-h_{2}=\left(\psi_{3}-\psi_{2}\right)-2 \lambda m_{0} q l / D_{8}
$$

In the steady state

$$
q=k\left(h_{3}-h_{2}\right) / 2 l
$$

where $k \mathrm{~cm} \mathrm{sec}^{-1}$ is the true capillary conductivity of the porous system. In the experiment the total potential difference is measured, from which an apparent conductivity, $k^{\prime}$ is calculated

$$
q=k^{\prime}\left(\psi_{3}-\psi_{2}\right) / 2 l
$$

Combining equations 9, Io and I I

$$
\frac{\mathrm{I}}{k^{\prime}}=\frac{\mathrm{I}}{k^{\prime}}+\frac{\lambda m_{0}}{D_{8}}
$$

At a given moisture content-and so far there has been no assumption about the degree of saturation of the porous system-a plot of $I / k^{\prime}$ against $m_{0}$ should yield a line of slope $\lambda / D_{\delta}$, intercepting the axis at $\mathrm{I} / k$.

The most convenient check of the analysis is at saturation, when it is to be expected that the rate of diffusion of ions through the pore space, expressed as a fraction of the rate in free water $\left(D_{s} / D_{s_{0}}\right.$ say) will be the same as the corresponding ratio $\left(D / D_{0}\right)$ for gaseous diffusion through the same system when completely dry.

\section{EXPERIMENTAL}

Measurements were made in sealed brass diffusion cells, Fig. Ib. The porous sample BCD is held betwcen an evaporating source $A$ and a condensing sink E, separated from them by fixed air gaps maintained by spacing rings F of piano wire encased in polyvinylchloride insulation sleeving. The samples used were circular disks, $5 \mathrm{~cm}$ diameter, approximately I $\mathrm{cm}$ thick, of porous building stones, kindly supplied by the Building Research Station. The source and sink are pads of filter paper saturated with $\mathrm{NaCl}$ solutions at concentrations chosen to match the water potential in the sample so that equal fluxes of water vapour distil from the source to the upper surface of the sample and from the lower surface of the sample to the sink, the moisture 
content of the sample thus remaining constant. All measurements were made in a thermally insulated box in a constant-temperature room, and possible temperature gradients across a cell were minimised by maintaining metal-to-metal contact around a cell by inserting each into a G-clamp. Each experiment lasted for 24 hours during which temperatures were kept constant to within $0 . \mathrm{I}^{\circ} \mathrm{C}$ at $25^{\circ} \mathrm{C}$. Total vapour transfer was about $100 \mathrm{mg}$ day ${ }^{-1}$, i.e. $q$ is of the order of $5 \times 10^{-8} \mathrm{~cm} \mathrm{sec}^{-1}$.

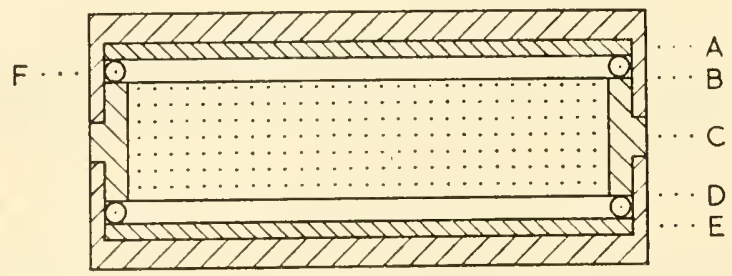

FIG. Ib. The diffusion cell.

Knowing the potentials $\psi_{1}$ and $\psi_{4}$ at the source and sink respectively, and measuring the mass of vapour transferred across each air gap, the potentials $\psi_{2}$ and $\psi_{3}$ can be inferred from the physical properties of water vapour and the dimensions of the diffusion cell. Hence the conductivity of the porous medium can be found.

Each experiment was conducted with five replicates of each of two stones, Portland limestone (a consolidated bed of oolitic aggregates), and Greenbrae sandstone (a consolidated bed of sand grains). Vapour transfer was measured with the pore space saturated with $\mathrm{NaCl}$ solutions of molal concentrations varying between 0.15 and 0.80 . On Fig. 2 are results of $\mathrm{I} / k^{\prime}$ plotted as a function of $m_{0}$. Clearly relations of the form of eq. I 2 hold, for which least-squares analysis gives:

$$
\begin{array}{ll}
\text { Portland } \quad \frac{\mathrm{I}}{k^{\prime}}=\left(3.53+7.50 \mathrm{~m}_{0}\right) \times 10^{10} \\
\text { Greenbrae } \frac{\mathrm{I}}{k^{\prime}}=\left(2.97+4.8 \mathrm{I} \mathrm{m}_{0}\right) \times 10^{10}
\end{array}
$$

From eq. I2, using the values of $\lambda=4.73 \times 10^{4}$, and $D_{s_{0}}=\mathrm{I}^{4} 47_{5} \times 10^{-5}$ $\mathrm{cm}^{2} \mathrm{sec}^{-1}$ given by Robinson and Stokes (1955, pp. 46I, 495) the diffusion ratios are

$$
\begin{array}{ll}
\text { Portland } & D_{s} / D_{s_{0}}=0.042_{7} \\
\text { Grecnbrae } & D_{s} / D_{s_{0}}=0.066_{7}
\end{array}
$$


Measurement of $D / D_{0}$ for the diffusion of hydrogen through the dry stones using the method of Currie (I960) gave

$$
\begin{array}{ll}
\text { Portland } & D / D_{0}=0.043_{0} \\
\text { Greenbrac } & D / D_{0}=0.066_{4}
\end{array}
$$

Although the almost exact agreement is probably fortuitous, it suggests that the analysis is correct, and the assumptions in it are acceptable. One of these, between eq. 8 and eq. 9, takes $q l / D_{s}$ as small. Its value for Portland stone is 0.045 , and the assumption is valid.

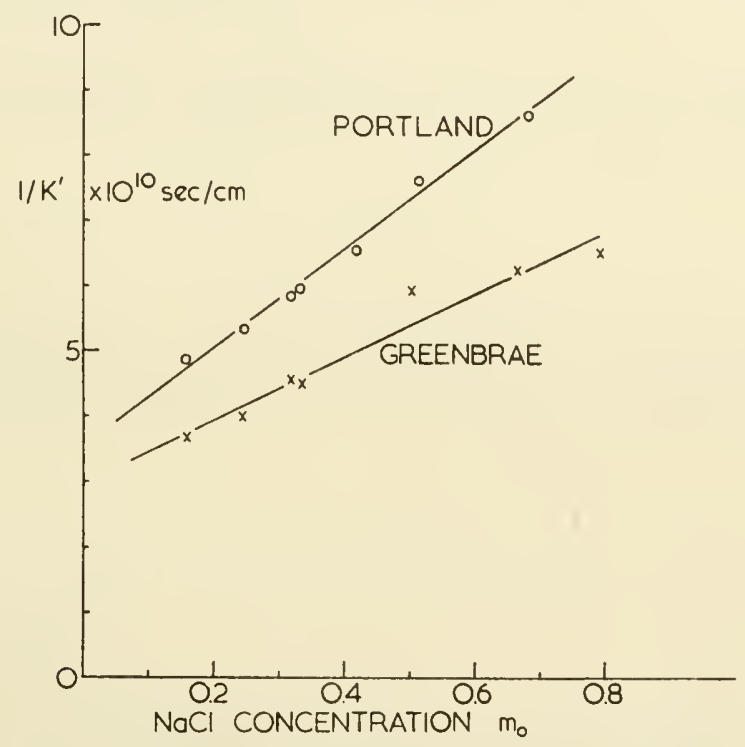

FIG. 2. The effect of dissolved salts on water movement.

\section{CONCLUSION}

In soil in which there is both a matric potential gradient and an osmotic potential gradient the bulk movement of water is controlled only by the former even though the latter may add greatly to the total potential gradient, or even impose an opposing gradient, which will happen when fertilisers are drilled in bands alongside the plants. There seems to be no serious risk that the very strong osmotic gradient set up by the fertiliser will successfully compete with the plant roots in drawing water out of the region between them. Water vapour will, it is true, move towards the 
fertiliser in the soil, but the predictions of Philip (1955), that vapour conductivity is several orders of magnitude lower than liquid conductivity in fairly moist soil, broadly confirmed by my current experimental work, show that this effect is likely to be small compared with liquid movement towards the roots.

In more general terms the presence of solutes causes an osmotic potential which tends to decrease the diffusion rate of water, this decrease being proportional to the solute concentration and inversely proportional to the diffusion coefficient of the solute molecules in the porous medium, thus confirming the views of Schofield (1952). Extension of this work to unsaturated media should provide information on the decrease of ionic diffusion as moisture content decreases, which should be of value in the study of movement of ions in the soil, the translocation of plant nutrients being an important example.

\section{ACKNOWLEDGMENTS}

The author gratefully acknowledges the award of a research scholarship from the Agricultural Research Council. He also thanks members of the Building Research Station for providing stone samples, and H. L. Penman for his help and encouragement.

\section{REFERENCES}

Currie, J. A. (1960) Gaseous diffusion in porous media, Parts I and 2. Brit.J. appl. Phys. II, 3 I $4-324$.

Edlefsen, N.E. \& ANDerson, A.B.C.(1943) Thermodynamics of soil moisture. Hilgardia, 15, 3 I-298.

Low, P.F. \& Deming, J.M.(I953) Movement and equilibrium of water in heterogeneous systems with special reference to soils. Soil Sci. 75, I87-202.

Low, P.F.(I955) Effect of osmotic pressure on diffusion rate of water. Soil Sci. 80, 95-IOO.

MonteITH, J.L. \& Owen, P.C.(1958) A thermocouple method for measuring relative humidity in the range $95-100 \%$. J. sci. Instrum. 35, 443-446.

Philip, J.R.(1955) The concept of diffusion applied to soil water. Proc. nat. Acad. Sci. India, 24A, 93-I04.

RichardS, L.A. \& WEAVER, L.R.(I944) Moisture retention by some irrigated soils as related to soil-moisture tension. J. agric. Res. 69, 2 I 5-235.

Robinson, R.A. \& Stokes, R.M.(I955) Electrolyte solutions. London: Butterworths Schofierd, R.K.(I952) Private communication to Low \& Deming (I953). 


\section{MODEL TESTS ON THE ECOLOGICAL EFFECT OF VAPOUR MOVEMENT AND CONDENSATION IN SOIL DUETO TEMPERATURE GRADIENTS}

\section{W.R.MÜLLER-STOLL \& G.LeRCH}

Botanisches Institut, Pädagog. Hochschule, Potsdam, E. Germany

\section{THE PROBLEM}

IT is well known that the surface of naked and sparsely overgrown soils is subject to extreme temperature fluctuations between day and night, in particular during bright weather.

Most of the solar energy directly reaching the earth is absorbed by the uppermost shallow layers of soil, and, therefore, the soil surface grows hotter than the adjoining parts of soil and air.

At night the inverse procedure prevails. A great deal of the accumulated heat is re-radiated leaving the ground surface much cooler than the regions above and below it. In this way a temperature gradient results between the soil surface and the adjoining layers of air and soil. This gradient is most distinct under a clear, cloudless sky when great differences in temperature commonly arise between the soil surface and just a few inches above or below it (see Geiger, I950).

Due to this temperature gradient water vapour moves from points of higher energy level to those of lower free energy, i.c. from warm moist parts into cold dry layers where condensation follows above ground, well known as dew.

This, too, happens underground. By day the deeper parts are cooler than the surface layers, and vapour moves downward. At night, on the contrary, vapour tends to move upward condensing to liquid water near the ground surface.

It has never been denied that water vapour docs move in such ways. There are very different opinions, however, on the question whether an ecological importance should be attributed to that vapour movement caused by temperature gradients, i.e. whether the water volume transported in this way might be sufficient to affect noticeably the water turnover of plants.

At present the majority of authors in soil science tend to deny this. Their reasoning was outlined and summarised recently by Veihmeyer, I956 (citing further literature), and formerly by Walter (I95I). In brief, these reasons are based upon two points: 
(I) When soil moisture has decreased below field capacity liquid water will be conducted through soil at only an extremely slow speed.

(2) If roots have dried out a certain soil volume available, the lost soil moisture will be replaced so slowly from the neighbouring parts of soil that usually the roots elongate much more rapidly, thus actively invading new water sources (Walter, I95 I Kausch, 1955; Veihmeyer, I956).

Apart from this group of contributors there are those who consider the vapour movement in soil under temperature gradients to be of practical importance to plants (Brawand \& Kohnke, 1952; Lebedeff, I927, I928; Smith, 1934, 1943); in particular Trénel (1949, 1950, 1954, 1955); Trénel et al. (1958). The main points of view of this group are as follows:

(I) Plants can be kept at full turgescence over several weeks, even months, getting the necessary moisture by no other means than a vapoursaturated atmosphere. Plants cultivated in this way may even grow, flower and bear fruit if provided with a suitable amount of minerals.

(2) If open Petri dishes or similar glass containers are mounted in horizontal tunnels driven at different levels into a soil profile, condensed water will accumulate in these dishes on warm days (Trénel, I954, measured about $30 \mathrm{~mm}$ per year).

Those experiments, however, did not deal directly with the problem of whether the plants are able to use the vapour condensation in soil, caused by temperature gradients.

On account of the methodological difficulties complicating experimental work in the field a series of model tests was performed to produce some contributions to this subject.

Work was done in 1957 in the Field Station of the Botanical Institute at Potsdam-Sanssouci, Germany. Technical performance was done by a student, Christa Giesche, using experience achieved in our laboratory from previous investigations made on similar subjects under direction of Dr. Lore Steubing.

\section{MATERIAL AND METHODS}

For the purposes of this subject an experimental set-up had to be developed allowing the changes of soil moisture to be traced during the test without disturbing the test plants. This was achieved in satisfactory manner by the following equipment (Fig. I):

Each apparatus consisted of two glass tubes, $4.5 \mathrm{~cm}$ wide and $10 \mathrm{~cm}$ long, one put upon the other after having been prepared before in different ways. 
The lower end of the basal tube was tightly closed by a rubber plug in order to prevent water from invading from outdoors. The lower end of the apical tube was closed by a piece of fine Perlon gauze.

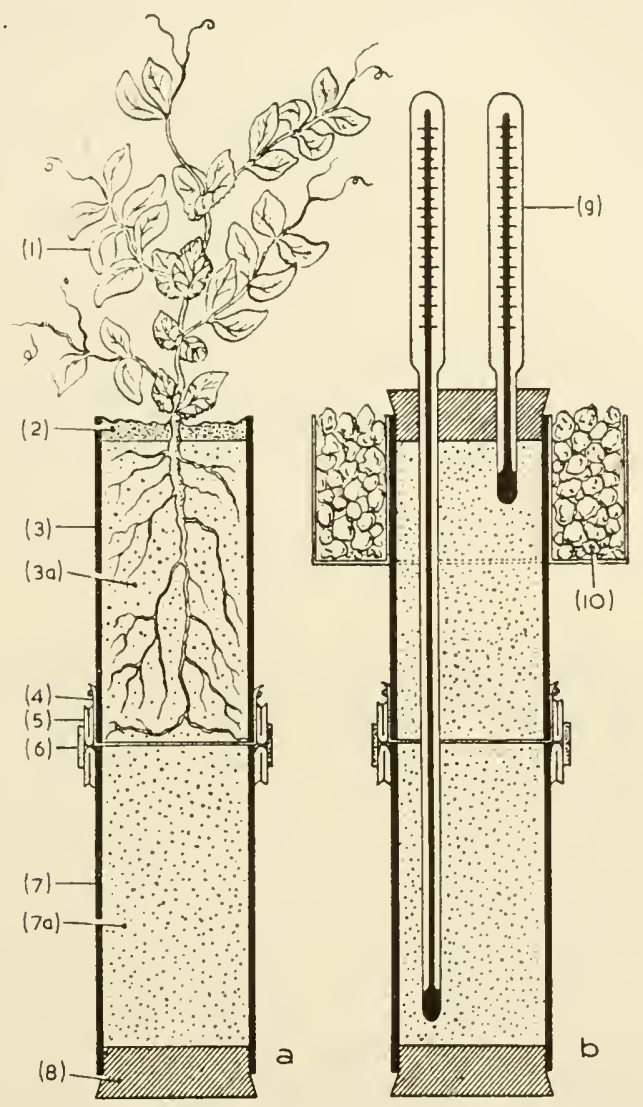

Fig. I. Test equipment, (a) with test plants, (b) without test plants, apical containers enclosed in ice jacket. Key: (I) Test plant, (2) Petroleum jelly-vaseline sealing, (3) Glass wall of the apical tube, (3a) A pical soil column (= 'top'), (4) Perlon diaphragm, (5) Folded rubber hose, (6) Strip of plaster, (7) Glass wall of the basal tube, (7a) Basal soil column (= 'base'), (8) Rubber plugs, (9) Thermometers, (I ) Hollow cylindrical ice containers.

Both containers were filled with fine soil (loamy sand) as firmly as possible. In the apical tubes seedlings of Pisum sativum ('Maiperle') were grown in the usual manner until their root systems had thoroughly permeated the small soil column available.

At the beginning of each test the soil surface in the apical tube was sealed 
by a layer of petroleum jelly-vaseline, and this container was then put with its bottom of Perlon gauze upon the open end of the basal tube filled to the brim with soil. In order to improve the sealing between the two tubes their adjoining ends were enclosed in a piece of folded rubber hose. In addition to it a strip of plaster, $2.5 \mathrm{~cm}$ wide, was fitted around the rubber cuffs and held both glass containers together during the test period.

Thus the soil columns of those two tubes were comnected forming a practically uninterrupted unit, merely separated by a Perlon diaphragm which prevented the roots in the upper container from invading into the basal soil column.

The two containers, however, could be separated at any time during the experiment and individually weighed, thus allowing the control of moisture movement in the upper and lower part of the test set-up.

As a rule, the temperature gradient was induced by a hot-water bath. The bottom of the basal tube was standing to about $4 \mathrm{~cm}$ depth in a hotwater basin the temperature of which was controlled by means of an electric heater combined with contact thermometer, relay and electric stirrer.

Two thermometers with a long and a short base were inserted into the test containers with their mercury bulbs resting in the apical tube about $2 \mathrm{~cm}$ and in the basal tube $18 \mathrm{~cm}$ below the common soil surface. Since the long thermometers piercing the diaphragn prevented the soil columns in their containers from being easily separated, the temperature gradient was checked in all cases by additional closed systems as shown in Fig. Ib. They were added to the test containers with rooted plants being thus subject to exactly the same temperature treatment.

In order to increase the temperature gradient or to cool down the contents of the tubes an ice jacket was applied to the containers. For these purposes a hollow cylindrical tin can was constructed the interior convex surface of which fitted tightly around the glass tubes. The can was filled with a mixture of ice and salt thus cooling the top of the apparatus as well as its bottom.

For technical reasons and in order to approach field conditions the artificial temperature gradient was run, as a rule, from 8.00 a.m. to 6.00 p.m. At night the temperature differences vanished gradually, and on the next morning the soil around the thermometer bulbs in both tubes showed the same temperature of about $2 I^{\circ} \mathrm{C}$.

Each experiment, including check tests, was repeated three times at least. Thus the data published in the following sections each represent an average value of four single observations. 
Experiments were performed during June and July, 1957, in a glasscovered green-house.

\section{EXPERIMENTAL EVIDENCE}

I. Model Tests on Vapour Movement in Naked Soil due to TemperaTURE GRADIENTS

A series of introducing tests was made without living plants in order to check the range of water transfer through the soil columns used for these experiments.

For the purposes of these tests both open ends of the test set were closed by rubber plugs; thermometers were inserted through the apical stopper (Fig. Ib). Experiments with these closed systems were run over I2 hours. Loss or gain of moisture in both glass containers of each set were registered by weighing every 30 minutes.

Results differ according to soil moisture gradients. Three typical variations will be described here, see Fig. 2.

\section{(a) Equal and Sufficient Moisture in both Containers}

The temperature of water bath was maintained constantly at $45^{\circ} \mathrm{C}$ from 30 minutes after the beginning of the test. The temperature of air varied due to insolation being increased by the accumulation of heat below the glass roof of the greenhouse.

Temperatures within the soil columns changed but slightly keeping in the basal tubes close to the water temperature, and about $10^{\circ} \mathrm{C}$ lower in the upper containers thus exceeding the air temperature by far, except in the forenoon.

Due to the lack of a uniform temperature in the atmosphere, the temperature gradient between the lower and the upper containers could not be kept exactly constant, but a difference of $10-12^{\circ} \mathrm{C}$ on average was maintained fairly steadily during the entire period of the experiments.

Within the apical soil columns moisture content increased in a nearly linear relation from I $1 \cdot 0$ up to $\mathrm{I} 2 \cdot 4 \%$. The corresponding loss of water could be measured from the basal tubes.

\section{(b) Different Soll Moisture in both Containers}

Fig. $2 \mathrm{~b}$ shows similar relations to Fig. $2 \mathrm{a}$, but resulted from a different initial situation. At the beginning of the test the apical tube held dry soil $(2.8 \%$ moisture content). From the moist soil ( $1 \mathrm{I} .0 \%$ water content) in the 
basal container however, that much water was transferred upward, due to the same temperature gradient $\left(\right.$ bout $10^{\circ} \mathrm{C}$ ), that soil moisture in the upper tube increased up to $4.2 \%$. Thus, after twelve hours the initial soil moisture in the upper containers had increased by approximately $50 \%$ compared with the initial status.

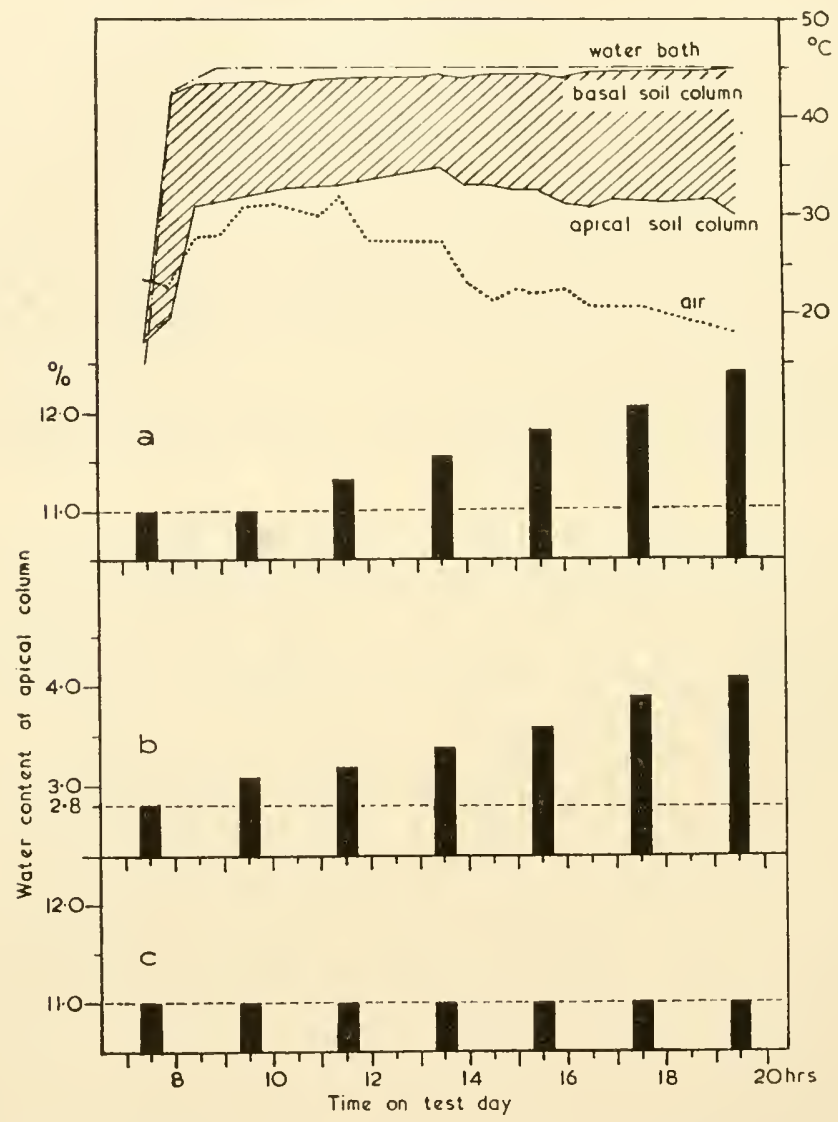

FIG. 2. Vapour condensation in bare soil due to temperature gradients. Initial water contents in apical and basal soils respectively (a) I I \%, II \%; (b) $2.8 \%$, II \% ; (c) $11 \%$, $2 \cdot 8 \%$.

Inverse experimental conditions-higher soil moisture ( $\mathrm{II} \cdot 0 \%$ ) in the apical tubes, dry soil $(2 \cdot 8 \%)$ below them-did not cause any change in the water content of the apical soil columns (Fig. 2c). 
These results, however, are not simply due to the inversion of the moisture gradient or to low moisture content in the basal containers, although this must be taken into consideration, too. In this case the temperature gradient proved to be too weak.

Temperature gradients of $30^{\circ} \mathrm{C}$ and more are well able to force water out of even such dry soils into colder parts, regardless of their water content. This was achieved in our experiments by refrigerating the apical tubes while the bottom of the apparatus was heated by hot water.

If the water bath was omitted, leaving the apical containers enclosed in their ice-wrap, a temperature gradient of about $10^{\circ} \mathrm{C}$ appeared, and this too was followed by the same results in moisture movement as described above.

By an inverse temperature gradient caused by cooling the lower tubes, the water vapour was caused to move downward, and the upper tubes lost water in favour of the lower ones.

\section{Model Tests on the Ecological Effect of Vapour Movement in Soll upon Plants due to Temperature Gradients}

The tests described in the preceding section were to provide information on the approximate range of vapour transfer in soil due to the temperature gradients. It should be tested now whether that vapour movement might be of practical use to the water relations of plants.

For the purposes of these tests the apical tubes containing pea-seedlings were used. After the soil surface had been sealed with petroleum jelly-vaseline, water could be lost from these containers only by transpiration of the test plants. This transpiration loss was registered by weighing the apical tubes at the end of each day. The actual loss of water by transpiration should be somewhat higher than the estimations made in this way, because these data are affected by the gain of substance due to daily photosynthesis and growth. The error, however, may be neglected since it does not alter the general results of the experiments.

In this series of tests temperature and temperature gradient as well as the soil moisture content had to be varied. The most typical variations will be described in the following:

\section{(a) Equal, Sufficiently Abundant Soil Moisture in Both Tubes}

This is the simplest case. The soil in both tubes held about $10 \%$ water. The bottom of the basal tube was heated again by the water bath; temperature gradient could be maintained at $10-15^{\circ} \mathrm{C}$ through every day. Within the 
control sets a natural temperature gradient of about $\mathrm{I}^{\circ} \mathrm{C}$ persisted between top and bottom of the soil column.

Results are very conspicuous, as shown in Fig. 3.

Temperature gradients, drawn in this and the following diagrams represent the average values of soil temperature reached about 30 minutes

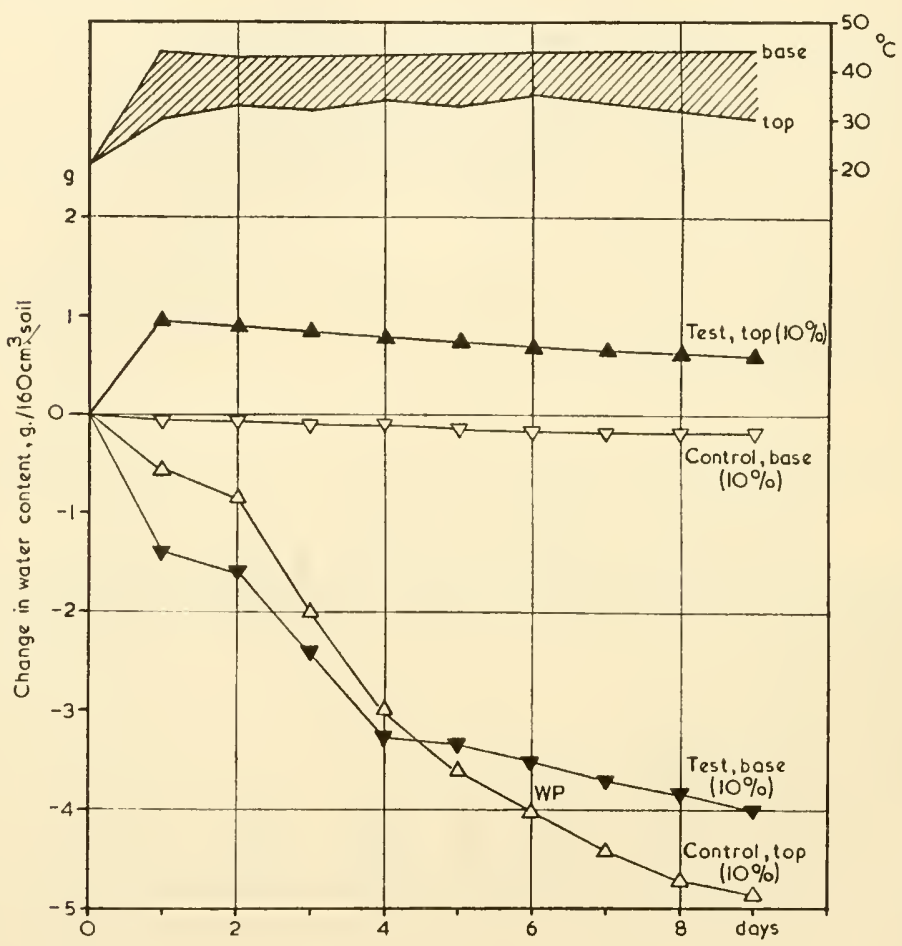

FrG. 3. Ecological effect of vapour movement and condensation due to a temperature gradient in a moist soil with a rooted plant (see Fig. I). Hatched area: temperature gradient within the test soil. Base $=$ basal soil column, top=apical soil column, W.P. = wilting point. Initial soil moisture, per cent, in brackets. Vapour tension of air: $45 \%$.

after the test had been started, and being maintained up to the end of each day. Night temperatures have not been regarded, because they do not affect the course of the experiments. Radiation like that in the field did not occur under the experimental conditions in the greenhouse.

The relations found in the control containers agreed with the results previously published by other authors (see Veihmeyer, 1956), in particular 
Kausch (1955). The basal soil columns hardly lost water, whereas the soil in the apical tubes was much desiccated by the plants, and on the sixth day permanent wilting percentage was reached.

Within the test sets, however, the soil of the lower tubes lost so much of its water content, due to the temperature gradient, that on the first day of the test the moisture in the upper container increased, and-in spite of transpiration from the plants-was kept nearly on the same level during the following days, decreasing but slightly. In this case the loss from transpiration was nearly completely reimbursed by the water supply from below.

\section{(b) Dry Soll in the Apical Tubes}

The apical containers were filled with soil that had been previously dried out to an approximate moisture content of $4 \%$. The basal tubes held soil of either the same low water content $(4 \%)$ or a moist packing of nearly i I \% water (Fig. 4).

The other environmental factors, in particular the temperature of air and water bath, were the same as in the preceding section.

The basal soil columns within the control sets did not lose water, as in the preceding cases, and the graphs of soil moisture loss in the apical tubes are similar to one another. The small difference in water loss may be attributed to slightly different transpiration from the control plants. All control plants wilted on the sixth day of the experiment.

The test plants in the sets containing dry soil in top and bottom behaved in the same way. The moderate temperature gradient of $10^{\circ} \mathrm{C}$ on average could not force sufficient water vapour from the lower containers which lost but very little of their moisture into the apical tubes. Test plants wilted there on the same day as did the controls after having exhausted their soil columms.

When sufficient water was available, however, within the lower soil columns, vapour could move upward in such quantities that in the upper containers the water loss from transpiration could be reduced considerably at the expense of a corresponding marked loss of moisture from the basal tubes. Consequently the test plants did not wilt in these cases.

\section{(c) Extreme Temperature Gradients $\left(30^{\circ} \mathrm{C}\right)$}

For these tests soil of the same moisture was used as described in section (b), but the temperature gradient was raised to the extreme limit of $30^{\circ} \mathrm{C}$, and even more, by an ice-wrapping applied to the top of the apical tubes while the bottom of the basal tubes stood in the hot-water bath. This time the control containers, too, were heated by the water bath, thus being subject 
to a moderate temperature gradient of about $8^{\circ} \mathrm{C}$. Therefore, the lower soil columns of the control sets also lost water in this case.

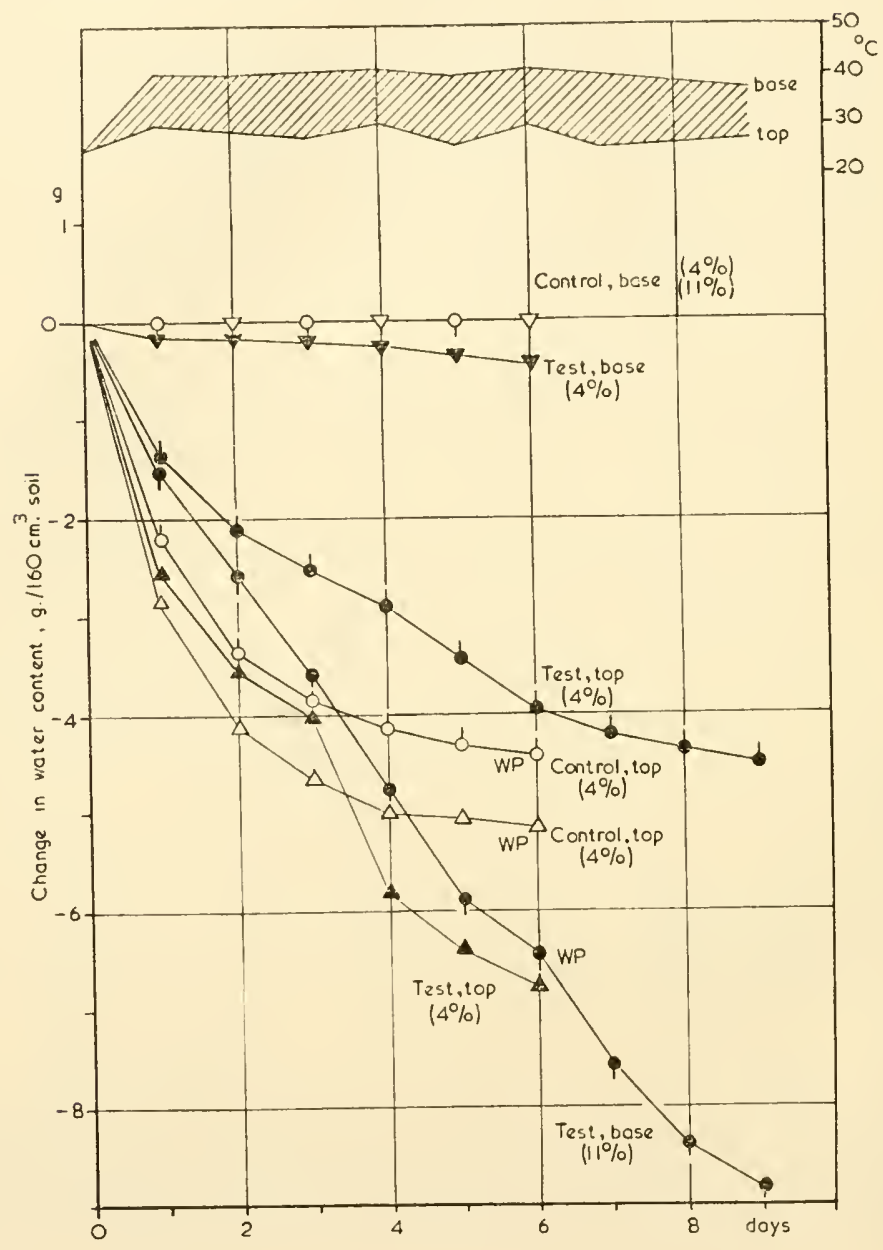

FIG. 4. Ecological effect of vapour movement due to a temperature gradient in soils, with rooted plants, of different moisture. For key, see Fig. 3. Vapour tension of air: $58 \%$.

From the dry basal soil less vapour moved upward than from the moist soil. The control plants above the dry basal soil thus wilted on the sixth day again, those with a moist soil in their basal tubes did so one day later (Fig. 5). 
The extremely strong temperature gradients, however, existing within the test sets were able to force so much water even out of the dry soil that

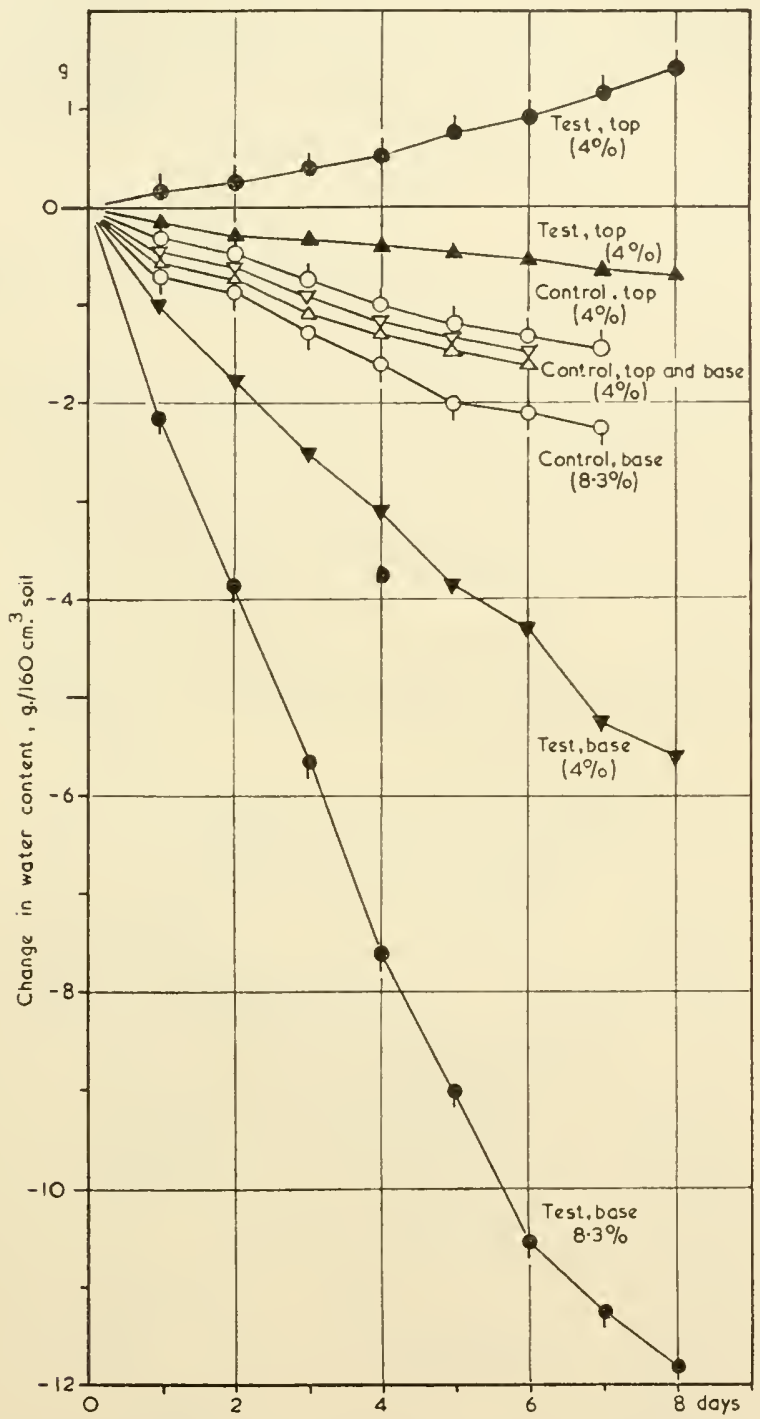

Fig. 5. Ecological effect of extreme temperature gradients on vapour movement and condensation in soil with rooted plants. For key, see Fig. 3. Temperatures: test, base $38.5^{\circ} \mathrm{C}$; test, top $4.5^{\circ} \mathrm{C}$; control, base $38.5^{\circ} \mathrm{C}$; control, top $30^{\circ} \mathrm{C}$. 
the relations, as shown by Fig. 4, were partly inverted here. From the dried-out basal soil, water could be moved upward to such an extent that soil moisture in the upper tubes decreased but very slightly. From the moist soil, finally, so great a quantity of water was transferred into the apical containers that soil moisture increased here continuously in spite of the transpiration from the test plants. When the experiment was stopped after 8 days no test plants showed any signs of wilting.

\section{(d) Low Temperature}

During the tests described so far, the temperature gradient was established by leaving the top of the test set-up in the temperature of the surrounding air $\left(20-30^{\circ} \mathrm{C}\right)$, and by heating the bottom of the lower tubes up to $45^{\circ} \mathrm{C}$. Thus the whole set-up was subject to relatively high temperatures, although the temperature gradient itself did not exceed $10-12{ }^{\circ} \mathrm{C}$. The same temperature difference, however, could be maintained by omitting the water bath and merely enclosing the top of the apical tubes in an ice jacket. Temperatures within the test set-up ranged then from $5^{\circ} \mathrm{C}$ at the top to $15^{\circ} \mathrm{C}$ at the bottom.

Figure 6 shows the results of these tests. In principle there is no change to the previous evidence. Vapour moved upward, condensed there, and was

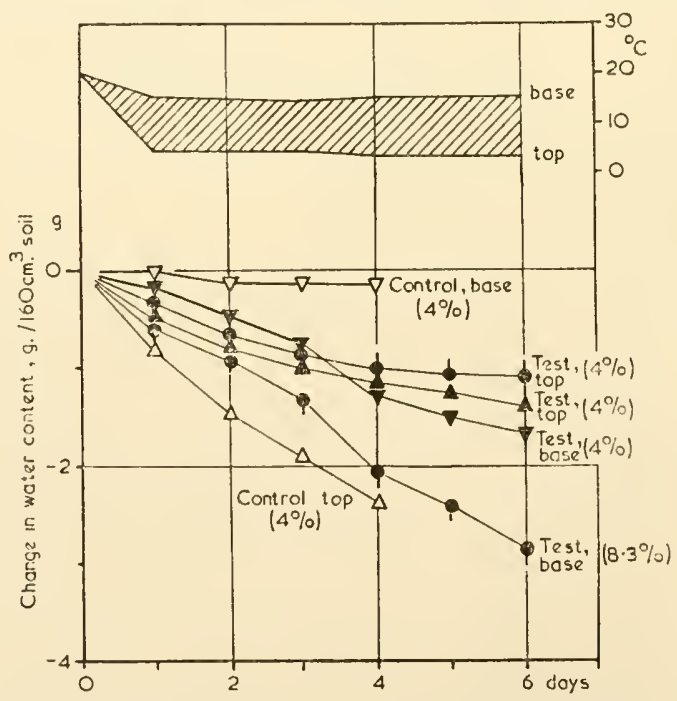

Fig. 6. Ecological effect of a moderate temperature gradient at low temperature on vapour movement and condensation in soil with a rooted plant. For key, see Fig. 3 . Vapour tension of air: $63 \cdot 3 \%$. 
used by the test plants which wilted 2 days later than the controls. From the desiccated soil less water could be extracted and transferred upward than from a moister soil.

The quantity of water, however, moved at these low temperatures was much smaller than under the influence of higher temperatures though the temperature gradient remained the same.

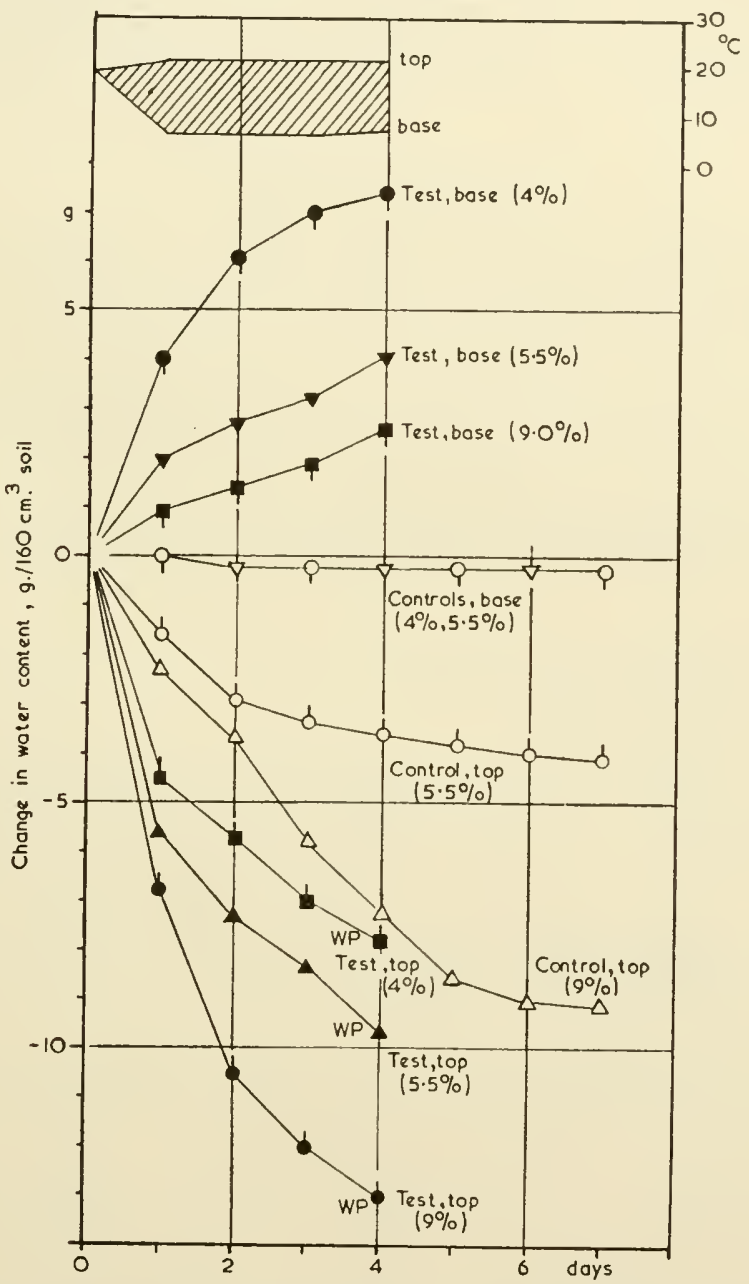

Fig. 7. Ecological effect of an inverse temperature gradient on the vapour movement and condensation in soils of different moisture, with rooted plants. For key, see Fig. 3. Vapour tension of air : $60 \%$. 


\section{(e) Inverse Temperature Gradient}

If the temperature gradient was inverted by cooling the basal tubes, water vapour moved downward, causing the relations shown by Fig. 7 .

This time the soil within the upper containers lost more water the higher the initial soil moisture content. Consequently water moved downward, and increased the weight of the basal tubes. Due to this additional loss of water from the upper tubes the test plants wilted on the fourth day of the experiment, whereas the control plants were kept fresh up to the end of the test, after 7 days.

\section{DISCUSSION}

The data of our model tests proved that under the experimental conditions chosen here the vapour movement and condensation in soil due to temperature gradients had practical importance to the plants.

As long as the basal soil columns were heated and thus the temperature gradient was maintained water vapour moved upward into the apical tubes, and the test plants grown here always wilted several days later than in the control containcrs with uniform temperature conditions, where the roots had nothing but the moisture of the apical tubes available.

The quantity of water moved in this way depends, at least, upon three variables:

(I) Range of temperature gradient.

(2) Temperature levels.

(3) Soil moisture content.

Apart from these, the duration of the temperature gradient and the specific texture of the soil concerned will doubtless affect the vapour movement, too.

The tests performed by relatively simple means do not yet allow a mathematical formulation of the influence of the variables, but a few relations stand out quite distinctly.

By the same temperature gradient considerably more water is extracted from a greater soil moisture, at best not much below field capacity (see Smith, 1934, r943), than from a lower moisture content. Likewise at high temperatures more water is translocated than at low temperatures.

Most effective is an increase of the temperature gradient itself. The extremely high gradient of $30^{\circ} \mathrm{C}$ was able to extract water even from a very dry underlying soil and to force it upward into moister layers of soil, a procedure that had been impossible under temperature gradients of merely $10^{\circ} \mathrm{C}$. 
Inverse temperature gradients achieved by cooling the basal tubes concluded the evidence. The upper soil columns now lost water, in a proportional ratio to their initial moisture content, to the lower containers, and the test plants wilted several days earlier than the control plants.

More difficult is the problem how far these model tests enable conclusions to be drawn about field conditions.

First of all the range of water volume moved by the temperature gradients will be considered. Leaving aside the extreme data there was an average quantity of $0.4-2 \cdot 0 \mathrm{~g}$ of water translocated per area of $15.3 \mathrm{~cm}^{2}$ every day. This would correspond to $0 \cdot 3-\mathrm{I} \cdot 3 \mathrm{~mm}$ precipitation per day. This evidence is confirmed by investigations of Trénel (1954, 1955) who measured a water gain of at least $40 \mathrm{~mm}$ per year due to condensation in the soil at I $5 \mathrm{~cm}$ depth near Berlin. Trénel presumed that there are approximately 50 days in the year having suitable temperature relations to make an extensive vapour condensation in soil possible. According to a personal communication by Prof. Dr. Trénel, investigations recently made under subtropical conditions in Vietnam, revealed a gain of $90 \mathrm{~mm}$ condensed water within one week at the same depth in the soil. In this case, however, vapour condensation from the atmosphere should be included.

The absolute levels of temperature used in our tests come near to field conditions.

The temperature gradient of $10^{\circ} \mathrm{C}$ along a distance of $16 \mathrm{~cm}$ is doubtless somewhat higher than the average field values in our Central European climate at the same depth of soil. In the loamy sand soil of our field station at Potsdam we found an average temperature gradient of $5-8^{\circ} \mathrm{C}$ between 2 and $20 \mathrm{~cm}$ depth on bright days in summer. Similar values are reported by the most authors (Kraus, I9I I ; Heilig, I930; Volk, I93 I ; Müller-Stoll, 1935; Walter, I95I; Geiger, I950).

There is considerable evidence, however, of higher temperature gradients even in Central Europe. Müller-Stoll (1935, p. I 86 f.) ascertained temperature gradients exceeding $18^{\circ} \mathrm{C}$ between $S$ and $15 \mathrm{~cm}$ depth in a silt loam soil of xerotherm grass slopes in the Kraichgau (S.W. Germany) on bright days. Under similar conditions Heilig (1930) found temperature gradients exceeding even $30^{\circ} \mathrm{C}$ between the ground surface and a depth of $20 \mathrm{~cm}$ in the Kaiserstuhl (S.W. Germany). Kraus (I9II, p. I32) measured temperature gradients up to $12{ }^{\circ} \mathrm{C}$ between 2 and $12 \mathrm{~cm}$ depth in a naked garden soil at Würzburg (Germany) during summer. Similar temperature differences may be read from the tables and graphs published by Geiger (1950).

The experimental conditions of our model tests thus come near to the 
temperature relations on dry locations, and even the extreme temperature gradients used in these tests do not appear too monstrous if temperatures of the ground surface are included in the considerations.

Similar temperature differences result within a short distance in the upper layers of soil due to nightly radiation, in particular under a clear sky, see Geiger, I950; Lebedeff (cited by Trénel, I949, p. I45); Walter, I95 I. Then water vapour moves upward from the warm deep layers of soil to its cooler surface.

The real distances through which soil moisture is moved in the freld due to temperature gradients may be estimated to be even much greater than the length of the small apparatus used in our tests. This means also a greater temperature gradient between the soil surface and the deeper layers of soil where considerable resources of water are available.

Of the two possible directions of water translocation in soil due to temperature gradients-by day downward from surface to depth, at night upward from depth to surface-the latter one must be given the greater practical importance. At night the ascending soil moisture may be able to increase the water content of the upper layers in soil. This procedure is supported by condensation of dew from the atmosphere.

In humid climates the temperature gradients in soil are much lower, of course, but under such conditions water movement in this way will not be of any practical importance, anyway, to the plants. High atmospheric precipitation combined with low evaporation rates involve a sufficient abundance of capillary water in the upper layers of soil, and roots are not dependent on the meagre quantities of vapour condensation. Thus, humid soil conditions, as a matter of course, should not be taken into the practical considerations of this problem at all (Trénel, I954, I955; Trénel et al., 1958).

Under dry conditions, however, if the capillary water resources have been used up to a great extent, the vapour movement and condensation due to the much stronger temperature gradients may certainly be of practical importance in the water supply of plants, provided that there is a distinct effective radiation surface, i.e. that the plant cover is not too dense and too high. Such conditions may be found even in Central Europe, i.e. on warm slopes of dry land weakly overgrown with natural sand or steppe plant communities.

By day the steady strong insolation must cause the soil moisture in the upper layers not only to evaporate into the dry air but also partly to move down into cooler layers of soil. At night it will return to the upper layers cooled down by nightly radiation and will be used there by the roots.

In this connection one more result of our tests should be interesting: when 
test plants and controls wilted (e.g. Fig. 4), the wilting percentage in the control soils was higher than in the test containers, i.e. the soil could be dried out much more within the test containers before the plants began to wilt. It may be supposed that the roots or root hairs of the test plants are points of condensation for the ascending water vapour, which in this way need not be bound to the soil colloids, but is at once made available to the plants. Trénel(1950) believes that vapour will be taken up 'in statu nascendi' of condensation by the roots.

Trénel (1949, 1950), citing papers of other authors, in particular Lebedeff (U.S.S.R.), Kekkonen (Finland), Beskow (Sweden), Chaptal (France)Literature, see Trénel, I949, summarised by Trénel et al., 1958-pointed out that vapour movement and condensation in soil may even affect the ground water level. Water is supposed to move from subsoil to topsoil in winter, in the opposite direction in summer. Keilhack (1912) considers vapour condensation in soil to be responsible for the fact that the ground water level may rise if gloomy weather with high air humidity has prevailed for a long period without precipitation. In the end, the drained water volume of a certain catchment area may be greater than the total amount of precipitation. In 1888 a total precipitation of $762,300 \mathrm{~m}^{3}$ was registered for the area of the Remscheid dam (Germany) compared with a total drain of $800,630 \mathrm{~m}^{3}$. It must be doubted that this surplus of nearly $40,000 \mathrm{~m}^{3}$ was only due to vapour condensation in soil, nevertheless this kind of water translocation seems to be of greater ecological importance than hitherto considered.

This opinion is supported by observations recently made at different field stations by the Melioration Department of the Agricultural Faculty, University of Rostock (E. Germany). Measurements conducted there over several years, on different soil types below different crops, showed that soil moisture was usually higher than expectations, calculated from the amount of precipitation.

Most importance, however, must be attributed to water movement due to temperature gradients in winter. The ice shield within the frozen soil surface is steadily increasing by condensation and freezing of water vapour ascending from deeper layers in the soil. The result is a considerably higher humidity in soil being available to the crops in spring.

From the results of our model tests it may be summarised that vapour movement and condensation in soil due to temperature gradients may be of considerable ecological importance under suitable conditions. A rough

* The authors are indebted to Prof. Dr. M. Olberts, Institut ür Meliorationswesen der Universität, Rostok, for kindly supplying this information. 
estimate shows that the experimental evidence may be generalised with some restrictions to field conditions, but before making final statements additional quantitative investigations must be performed in the field.

\section{REFERENCES}

Brawand, H. \& Konnke, H.(I952) Microclimate and water vapor exchange at the soil surface. Proc. Soil Sci. I6, I45-I48.

GeIGER, R.(I950) Das Klima der bodemnahen Luftschichten, 3. Aufl. Braunschweig.

Hentig, Hidde (I930) Untersuchungen iiber Klima Boden und Pflanzenleben des Zentralkaiserstuhls. Z. Bot. 24, 225-279.

KAUSCH, W. (1955) Saugkraft und Wassernachleitung im Boden als physiologische Faktoren, unter besonderer Berücksichtigung des Tensiometers. Planta (Berl.), 45, $217-263$.

Kenruck, K. (1912) Lehrbuch der Grundwasser- und Quellenkunde. Berlin.

Kraus, G. (I9I I) Boden und Klima auf kleinstem Raum. Jena.

LEBEDEFF, A.F. (1928) Die Bewegung des Wassers im Boden und im Untergrund. Z. Pflanzenernährung $u$. Düng., Teil A, I0, I-36.

LEBEDEFF, A.F. (1927) Methods of determining the maximum moisture holding capacity of soils. Proc. First int. Congr. Soil Sci. I, 55I-563.

MÜlLER-STOLI, W.R.(I935-36) Ökologische Untersuchungen an Xerothermpflanzen des Kraichgaus. Z. Bot. 29, 16I-253.

Smith, W.O. (1939) Thermal conductivities in moist soils. Soil Sci. Soc. Amer. Proc. $4,32-40$.

Sмгтн, W.O. (1943) Thermal transfer of moisture in soils. Trans. Amer. Geophysic. Union, 24, 5 I I-523.

TRÉNEL, M. (1949) Zur gutachtlichen Beurteilung des Einflusses der Grundwasserabsenkung auf den Ernteertrag im Löß. I. Mitteilung. Z. Pflanzenernähr., Dïng.u. Bodenkunde, 45, I33-I 47.

Trénel, M. (I950) Zur gutachtlichen Beurteilung des Einflusses der Grundwasser-absenkung auf den Ernteertrag im Löß. III: Mitteilung. Z. Pflaızenernähr., Düng. u. Bodenkunde, 49, 224-237.

Trénel, M. (1954) Über Kondensationsvorgänge im Boden. Sitzber. dtsch. Akad. Landwirtschaftswiss., Berlin, 3, Heft 6, I-30.

Trénel, M. (1955) Über Kondensationsvorgãnge im Boden. 2. Mitteilung: Zur pflanzenphysiologischen Bedeutung des dampfförmigen Wassers im Boden. Sitzber. dtsch. Akad. Landwirtschaftswiss., Berlin, 4, Heft 14, I-28.

TréneI, M., Weber, H. \& Lindner, H. (I958) Über die Kondensation des Wasserdampfes im Boden. C. R. et Rapp. Ass. Gen. de Toronto, 1957 (Gentbrugge 1958) 2, $517-522$.

Veinmeyer, F.J. (1956) Soil moisture. Encyclopedia of Plant Physiology, ed. by W. Ruhland, vol. III, I IO-I I 2. Berlin-Göttingen-Heidelberg.

Volk, O.H. (193I) Beiträge zur Ökologie der Sandvegetation der Oberrheinischen Tiefebene. Z. Bot. 24, 8I-I 85 .

Watter, H. (195I) Grundlagen der Pflanzenverbreitung. Standortslehre. (Einfïhrung in die Phytologie, Bd. III/1). Stuttgart. 
PHYSIOLOGICAL STUDIES OF WATER BALANCE AND MOVEMENT IN PLANTS 


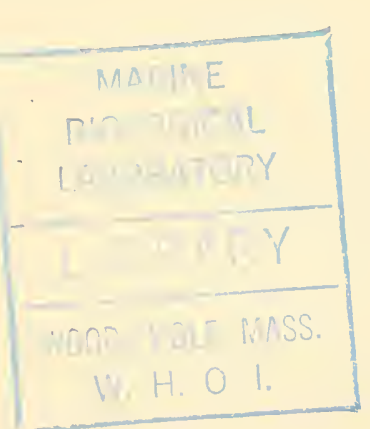




\section{THE PATHW AY OF WATER MOVEMENT ACROSS THE ROOT CORTEX AND LEAF MESOPHYLL OF TRANSPIRING PLANTS}

\section{P.E. WeAtherLey}

Botany Department, University of Aberdeen

\section{INTRODUCTION}

IN its passage from the soil to the atmosphere, water of the transpiration stream must traverse two cellular barriers: that between the soil and the xylem elements of the root, conveniently designated root cortex, and that between the xylem of the leaf vein and the transpiring cell, designated leaf mesophyll. Transpirational loss of water from the mesophyll cell causes a gradient of water potential through the leaf tissue in response to which water moves from the vein. This results in a reduction of hydrostatic pressure in the xylem in response to which water moves across the root cortex from the soil.

Of course such cellular barriers present an extremely complex pathway. The question before us in this paper is whether the water moves from vacuole to vacuole crossing the cell walls and membranes of each cell in turn or moves round the cells keeping within the cell walls (or perhaps in addition within the outer region of the cells as well) thus bypassing the vacuoles. We have in a sense two pathways in parallel. Water will move through both, but if there is a large difference in resistance between the two, water will move largely through the one with the lower resistance.

The older view was certainly that in the leaf, movement was from vacuole to vacuole and this seems to persist. Evidence that movement is in fact through the mesophyll cell walls was obtained by Strugger (1938-39) using fluorescent dyes although Hülsbruch (1956) has cast doubt on the validity of this evidence. Levitt (1956) on the basis of purely thoeretical considerations concludes that movement through the mesophyll cannot be diffusional and is prseumably mass flow in the cell walls. But there seems to be a dearth of positive experimental evidence one way or the other. In the first part of this paper a new experimental approach is described which strongly points to a superficial pathway round the mesophyll cells.

The root has been the subject of more extensive study but the position is more complex than that in the leaf and even less well understood. The complexity arises because the root is the seat of vigorous secretory processes 
and because the flux of water is very possibly different in the detopped plant from that in the intact transpiring plant. Sabinin (I925) showed that the exuding root behaved like an osmometer and the thorough study by Arisz et al. (I95I) confirmed and greatly extended this conclusion. This implies that the flux is through semi-permeable membranes. Yet De Lavison (I9I0) showed that some solutes could penetrate the cortex rapidly as far as the endodermis, indicating a rapid movement in the cell walls stopped by the casparian strips. Other solutes which could enter the cytoplasm could pass the endodermis. Later Scott \& Priestley (I928) emphasised the cndodermis as a barrier to free movement in the cell walls of the cortex and in more recent years the apparent free space concept is clearly in accord with rapid physical movement up to the endodermis (Bernstein and Nieman, 1960).

The osmotic barrier indicated by Arisz et al. would presumably therefore reside in the endodermis. Thus between the external medium and the xylem of the root there will be a catena of at least three links: (a) free diffusion or probably mass flow up to the endodermis, (b) osmosis across the endodermis and (c) probable mass flow beyond the endodermis. As is well known, the flux through such resistances in series will be largely controlled by the link with the highest resistance, provided its resistance is much higher than that of the other links. Osmosis across the endodermis is likely to be such a high resistance link, so that even if the pathway across the cortex and within the stele is by mass flow, the flux will be dominated by the endodermis, and the root after all will behave like an osmometer. But can we exclude the possibility under transpiring conditions, of a mass flow through the cytoplasm of the endodermal cells, through passage cells or even via the cell walls of the endodermis in regions of the root where the casparian strips are not suberised: In this event we are faced with the endodermal link itself presenting two pathways in parallel: one diffusional, the other permitting mass flow.

Theoretically it ought to be fairly easy to detect and even to measure the relative resistances of two such parallel pathways. Movement in response to an osmotic potential gradient should be less than that in response to an equal hydrostatic pressure gradient, since the latter would not only cause an osmotic flux equal to the former, but would also draw water through the mass flow pathway in addition. Such a difference in the case of a living cellular barrier was demonstrated by Kramer (1932) using a hollow petiole. The work described in the second part of this paper represents an attempt to apply this approach to the root system (Mees and Weatherley, I957). 


\section{MOVEMENT THROUGH THE MESOPHYLL}

This problem was approached by constructing a hypothetical model of the leaf cell. The behaviour of the model under certain experimental conditions was studied and experiments performed on the leaf to see whether it behaved in the way predicted by the model. If so, the model was considered to be a good representation of the leaf.

\section{i. First Hypothesis}

If water moves from vacuole to vacuole as represented in Fig. I A, loss of water by evaporation from cell $a$ will lead to a reduction in its water content and concomitant fall in its water potential. This depression of water potential* will lead to a diffusion of water from cell $b$ and in turn from cell $c$ and so from the xylem element. In this way a water deficit arises in cell $a$ depending on the rate of transpiration and the sum of the resistances imposed by cells $b, c$, the xylem elements and those resistances lying below (e.g. root resistance). Thus it is the depression of water potential in cell $a$ which is the operative force in moving the transpiration stream up to that point. Fig. IB represents a model of cell $a$. The apparatus is filled with water. $v$ represents the vacuole and the capillary tube $c$ the resistance in the transpiration stream lying below cell $a$. The bulb $b$ is porous and as evaporation takes place from it, water is drawn from the reservoir $w$ through the tube $c$ and since this imposes a resistance to flow a reduction of pressure in $v$ arises and mercury is drawn up the vertical tube. This reduction of pressure represents the depression of water potential in the cell. For a given rate of transpiration a certain reduction of pressure will be manifest as the mercury reaching a steady height $h$, and the volume of mercury occupying the length $h$ in the vertical tube will represent the water deficit in the cell.

If the tap $t$ is now closed, i.e. evaporation stopped suddenly, water will continue to move into the cell through $c$ whilst the mercury in the vertical tube falls, and finally $h$ will become zero $\nmid$ when uptake through $c$ will cease and the cell will have reached saturation. During this die-away in uptake the rate of uptake $f_{t}$ at any instant will be proportional to $h_{t}$ at that instant,

$$
f_{t}=\frac{h_{t}}{r}
$$

where $r$ is a constant proportional to the resistance of the tube $c$. Hence

$\star$ Depression of water potential = D.P.D. $=$ suction force.

$\dagger$ Differences in level between water and mercury reservoirs are ignored. 
the rate of uptake $f_{t}$ plotted against the height of the mercury $h_{t}$ will give a straight line as in Fig. IC. It can be shown that the die-away in uptake is logarithmic and may be represented by the equation:

$$
f_{t}=f_{0} \mathrm{e}^{-t / r^{\prime}}
$$

where $f_{0}$ is the steady rate of flow (evaporation) up to the instant of turning off the tap and $r^{\prime}$ a constant similar to $r$. Thus a plot of $f_{t}$ against time will give a logarithmic die-away curve as in Fig. ID and plotting the logarithms of $f_{t}$ against time will give a straight line (Fig. $\mathrm{rE}$ ). The constants in these
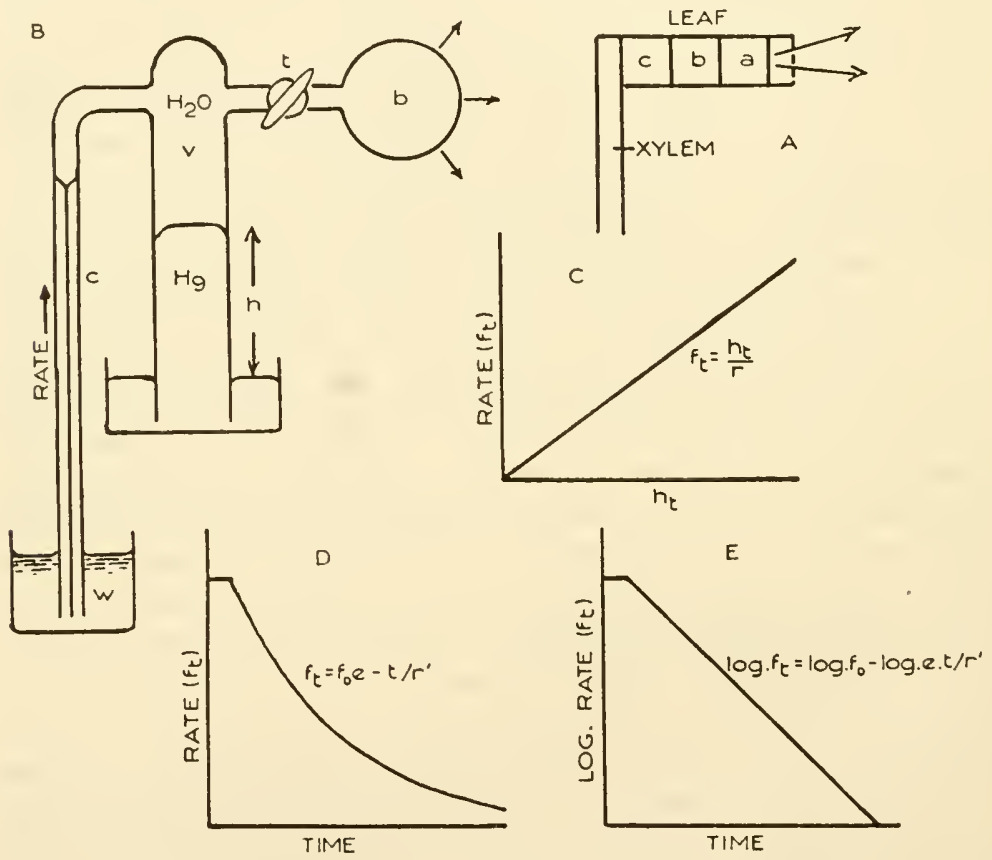

Fig. I. A: Diagrammatic representation of a train of mesophyll cells. B: Model of transpiring cell on the hypothesis that the water moves through the vacuoles. $v$, vacuole; $c$, capillary tube; $w$, reservoir of water; $t$, tap; $b$, porous bulb. C, D and E: Graphs showing the characteristics of the die-away curve of uptake by the vacuole when the tap $t$ is closed.

equations are characteristic for a piece of apparatus of given dimensions and all data, say, starting from different evaporation rates would fall on to the same curves. 

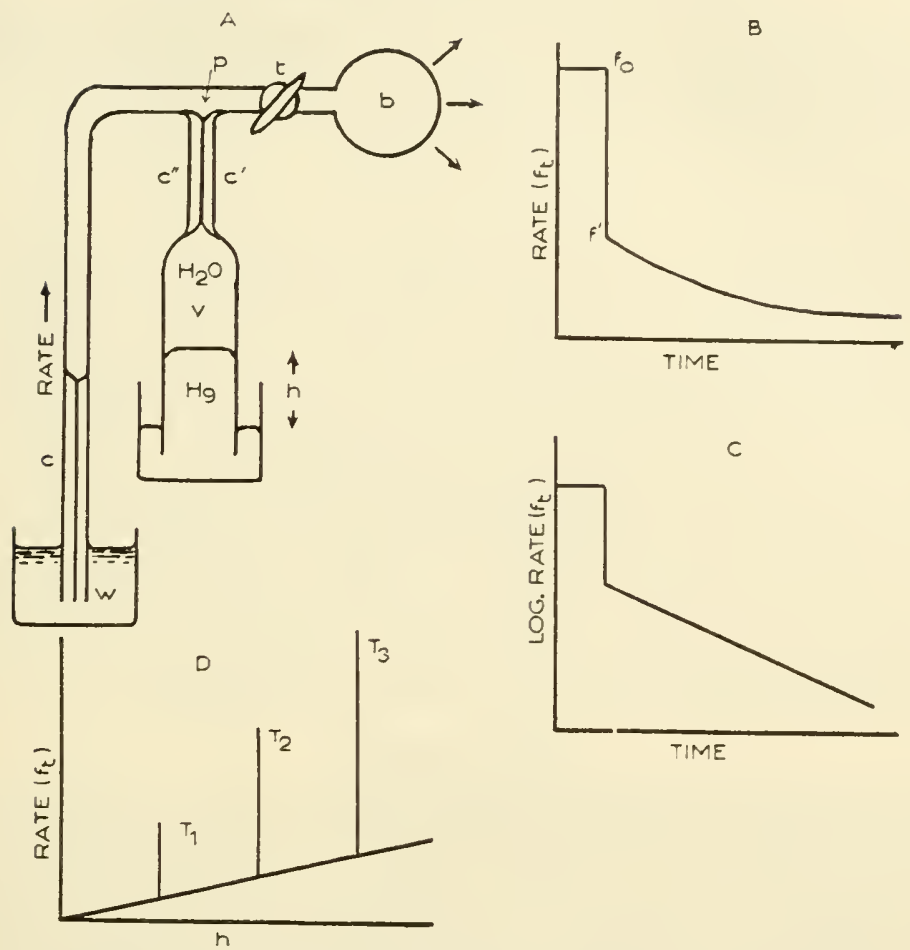

F1G. 2. A: Model of transpiring cell on the hypothesis that the water moves round the vacuoles. $c^{\prime \prime}$, capillary tube separating the vacuole from the transpiration pathway; other lettering as in Fig. IA. B, C and D: Graphs showing the characteristics of the die-away curve of uptake by the vacuole when the tap $t$ is closed. ( $T=$ transpiration rate.)

\section{SECOND Hypothesis}

If water passes round the outsides of the cells (through the cell walls) rather than from vacuole to vacuole the hypothetical model must be modified. The implication now, is that there is a resistance between the pathway and the vacuoles. Such an additional resistance is shown in Fig. $2 \mathrm{~A}$ in which the vacuole $v$ is separated from the main stream by a capillary $c^{\prime \prime}$ of resistance $r^{\prime \prime}$. With steady evaporation the mercury will rise as before and attain the same steady state position in relation to $f_{0}$ and $r$ as it will still measure the reduction of pressure $h$ at the point $p$. Closing the tap will, however, have an entirely different effect. During the period of steady transpiration water is dragged through the capillary tube $c$ alone, whereas 
after the tap has been closed and the mercury begins to fall, water must be dragged through both capillary tubes $c$ and $c^{\prime \prime}$. Thus the rate of uptake will instantaneously fall from that given by eq. $i$ to:

$$
f^{\prime}=\frac{h}{r+r^{\prime \prime}}
$$

After the instantaneous fall, $f$ will decline logarithmically according to eq. ii. Thus the curve of rate of uptake $\left(f_{t}\right)$ plotted against time will appear as in Fig. $2 \mathrm{~B}$ and the logarithmic plot as in Fig. $2 \mathrm{C}$. If the rate of uptake is plotted against the water deficit $h$ (Fig. 2D) instead of a straight line there will be an instantaneous fall from each transpiration rate $\left(T_{1}, T_{2}, T_{3}\right.$ etc.) on to the general straight line defined by eq. $\mathrm{i}$ though in this case the resistance is $\left(r+r^{\prime \prime}\right)$. It will be seen that these two hypothetical models predict that if transpiration could be stopped suddenly, the pattern of continued uptake of water in response to the water deficit in the mesophyll, would be entirely different according to whether the water of the transpiration stream moves round the cells or through them.

\section{Experimental}

Data were obtained using leaves of Pelargonium zonale, Populus candicans and Ribes sanguineum. In each experiment a detached leaf was fitted into a simple potometer as shown in Fig. 3. Uptake was measured by following the movement of a meniscus in the horizontal tube using a travelling vernier microscope. At first a steady measured rate of transpiration was maintained for one or two hours. Transpiration was then stopped suddenly by immersing the leaf in water or medicinal paraffin by raising a beaker from below and the die-away in uptake followed. Similar results were obtained using either water or medicinal paraffin. In the course of each experiment the total amount of water virtually to saturate the leaf was measured by the potometer and clearly this represented the initial water deficit in the leaf. Further, the water deficit at any time was measurable as the amount of water subsequently absorbed to attain full saturation. Typical results are shown in Fig. 4A, B and C. Clearly all these results fit the second hypothesis and not the first.

The experimental results do however differ from those predicted by the second hypothesis in that the drop in rate on stopping transpiration is not exactly vertical (Fig. ${ }_{4} \mathrm{~B}$ ). This is undoubtedly due to the pathway itself having a water deficit and taking up water to saturation. This uptake by the pathway appears to die-away logarithmically like that of the inner space of the cells but much more rapidly, indicating a low resistance between itself 
and the water supplied at the cut end of petiole. On this interpretation the initial steep fall in Fig. $4 \mathrm{~B}$ represents the die-away in uptake by the pathway (outer space of the cells, e.g. cell walls) and the subsequent slower fall represents the die-away in uptake by the inner space of the cells (vacuoles, etc.). Now if we assume that the pattern of uptake by the inner space of the cells was uniform throughout, its die-away curve during the first io

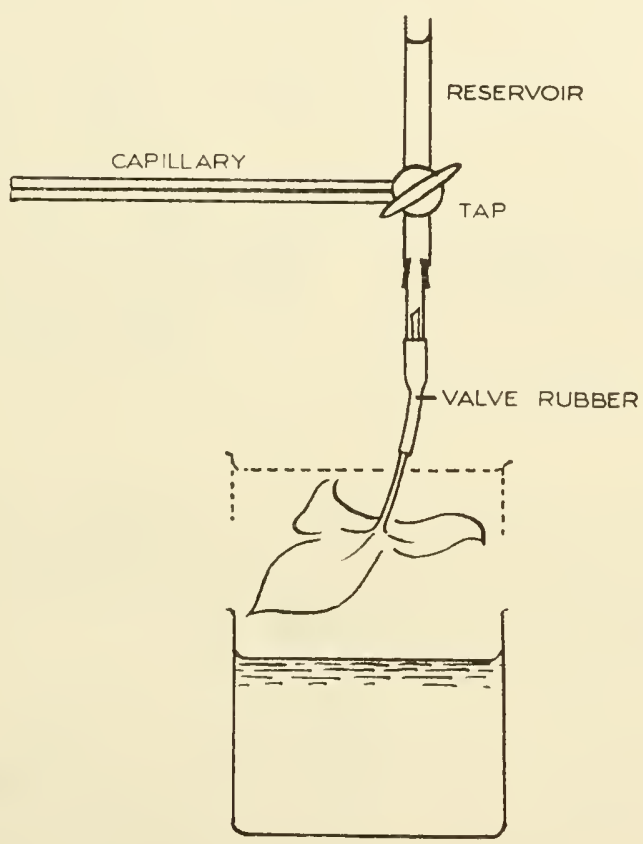

FIG. 3. Simple potometer showing method of attachment of leaf. Transpiration could be stopped suddenly by raising the beaker to submerge the leaf.

minutes will be represented by the line of extrapolation to $p$ and the line $p r$ represents the die-away in uptake by the inner space throughout the experiment. Thus the rates of uptake by the inner space alone during the first 20 minutes were obtained by taking antilogs of values lying along $p q$, and by subtracting these rates of uptake from the experimental values (total uptake) the rates of uptake by the pathway alone were obtained.

Integrated curves showing the progressive saturation of the two spaces in the leaf were obtained by summation of the rates derived in the above 

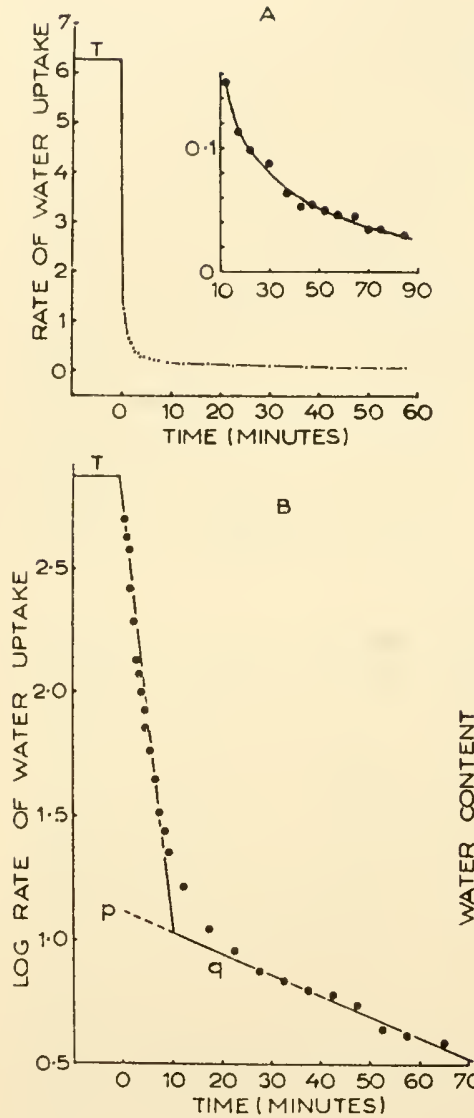
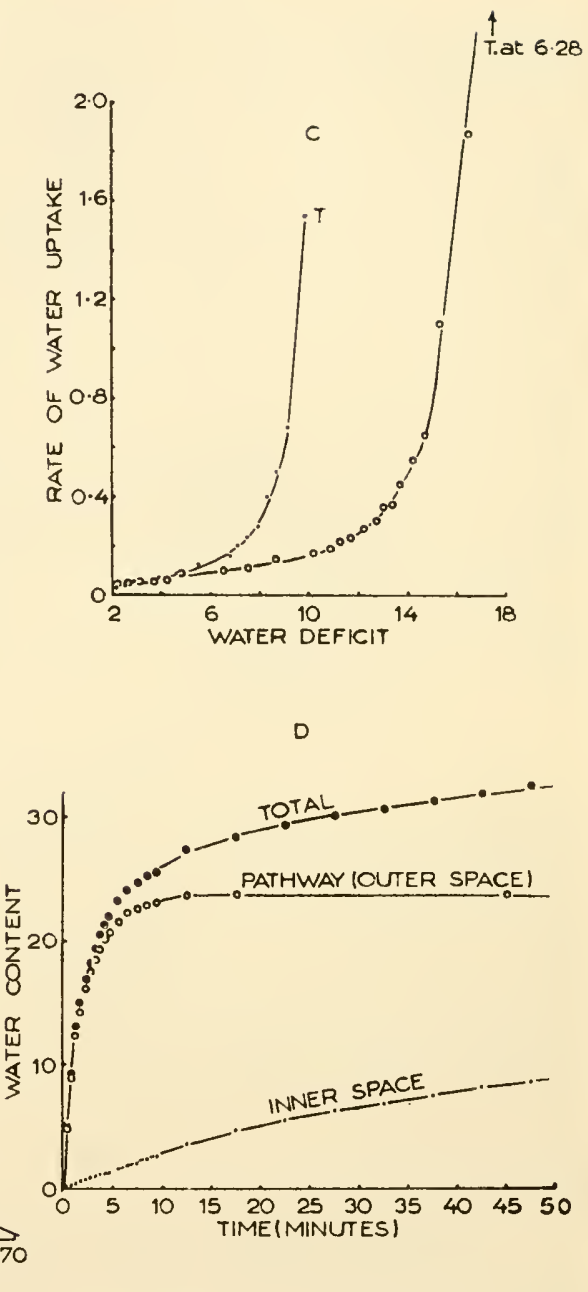

FIG. 4. A: Die-away curve of rate of continued uptake by a leaf on stopping transpiration. Inset: the same data from Io minutes onwards plotted on a different scale. The form of the whole curve is an almost instantaneous drop followed by a slower die-away. Cf. Figs. ID and $2 \mathrm{~B}$ (Ribes sanguineum). B: Logarithmic plot of the die-away curve. For $p q r$, see text. Cf. Figs. IE and ${ }_{2} \mathrm{C}$ (Pelargonium zonale). C: Relationship between rate of water uptake and leaf water deficit during the progressive saturation of a leaf on stopping transpiration. Data from a single leaf following two rates of transpiration. Cf. Figs. IC and $2 \mathrm{D}$ (Ribes sanguineum). D: Curves showing the progressive saturation of the inner and outer spaces of a leaf. The water contents were obtained by summating the rate data given in Fig. $4 \mathrm{~B}$. For further explanation see text. The rate of water uptake in all cases is expressed in arbitrary units based on the rate of travel of the water meniscus in the potometer tube. ( $\mathrm{T}=$ transpiration rate.) 
way and are shown in Fig. ${ }_{4} \mathrm{D}$. It will be seen that whilst the pathway became virtually saturated after 20 minutes, the inner space would have taken several hours. Evidently in detached leaves at least, rapid fluctuations in water content of the pathway would be accompanied by relatively slow changes in the inner space. But from the point of view of the present discussion perhaps more significant is the fact that the rate of uptake represented by $p$ (Fig. ${ }_{4} \mathrm{~B}$ ) is only $\frac{1}{5} \overline{9}$ of the transpiration rate $T$. In other words, in the case of this Pelargonium leaf water of the transpiration stream moved through the pathway about sixty times faster than water could pass into the inner space. A figure of about fifty times is obtained from Fig. 4A which refers to Populus candicans.

No great significance is claimed for the precise values of these ratios. They merely serve to show that water can move through the outer spaces much faster than into the inner space, and it should be emphasised here that the values for the latter are really summated values for all the individual cells each taking up water from its surrounding outer space. If on the other hand water were forced to move through a train of inner spaces in series, the total resistance would be correspondingly greater and the rate even less.

If the pathway is indeed located in the outer space of the cells, say the cell walls, and the offstream, inner space, is enclosed within a cytoplasmic membrane, not only will the rates of water movement into them be very different, but also they might well react differently to a change in temperature. Mass flow through the cell walls should be rather insensitive to temperature, whilst it is recognised that the permeability of cytoplasmic membranes is often much reduced by a lowering of temperature. To test this, transpiration was stopped suddenly as before except that in this case water at about $3^{\circ} \mathrm{C}$ was used for immersion. The results of such an experiment are shown in Fig. $5 \mathrm{~A}$ in which the logarithms of rate are plotted against time. It will be seen that the rate fell away logarithmically with no break until after 22 minutes, uptake had completely stopped. Thereafter no uptake was recorded for a period of 60 minutes when the cold water surrounding the leaf was replaced by water at $23^{\circ} \mathrm{C}$. As will be seen uptake was resumed at once and after attaining a maximum the rate declined logarithmically as in the previous experiments. Thus uptake into the pathway seemed to be little affected by temperature whereas uptake into the inner space was stopped completely by the low temperature. This is certainly consistent with the hypothesis that movement through the pathway is through cellulose cell walls whilst movement into the inner space of the cells is through cytoplasmic membranes. 

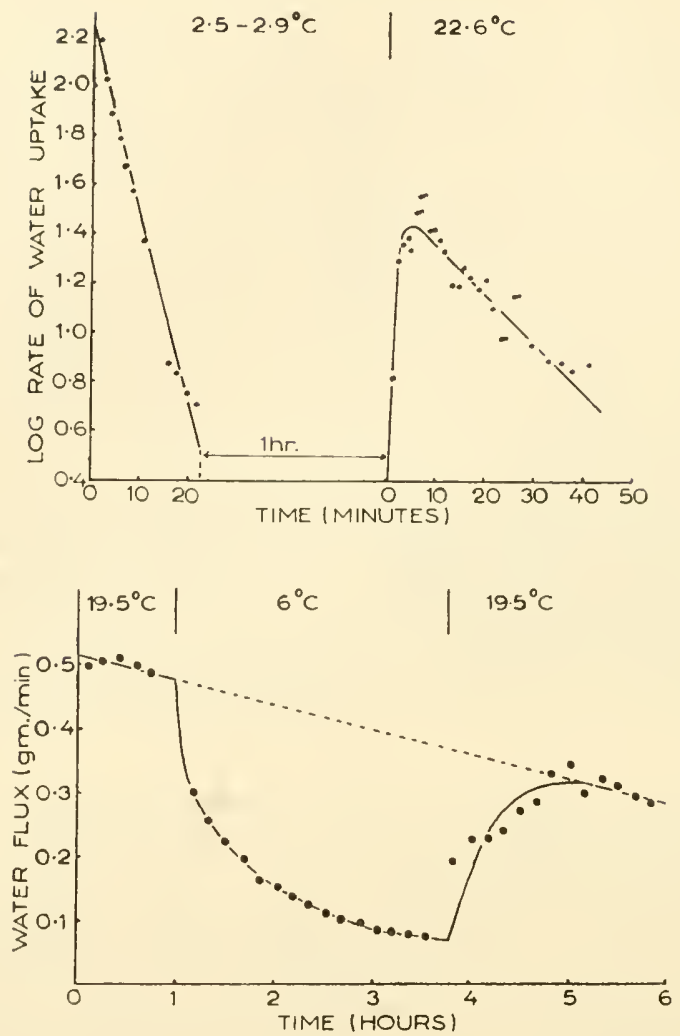

FIG. 5. A: The effect of temperature on uptake into the inner and outer spaces. Transpiration was stopped by immersion in water below $3^{\circ} \mathrm{C}$. The first phase of the die-away proceeded normally for 22 minutes (i.e. into the outer space). Thereafter there was no uptake for I hour. Only an immersion in water at $22.6^{\circ} \mathrm{C}$ was the second phase of uptake able to proceed (i.e. into the inner space). B: The effect of lowering the temperature on the flux of water through a tomato root system with the continuous application of a pressure difference of $2 \mathrm{~atm}$ across the cortex. (Redrawn from Jackson and Weatherley, 1962.)

\section{MOVEMENT ACROSS THE ROOT CORTEX}

Here, entirely different methods were used. In essence these were based on the following concept. If a permeable barrier permits only diffusional passage of water, then equivalent osmotic and pressure gradients will result in an equal flux of water. If on the other hand mass flow can occur 
in addition this will only come into opcration with a pressure gradient and will result in a greater flux in response to pressure than to an equivalent osmotic gradient. ${ }^{\star}$ It has been shown (Sabinin, 1925; Arisz et al., I95I) that root exudation conforms to the equation

$$
f=k_{0}\left(O_{s}-O_{m}\right)
$$

where $f$ equals the flux of water across the cortex, $\mathrm{O}_{s}$ the osmotic potential of the xylem sap and $\mathrm{O}_{m}$ the osmotic potential of the external medium. $k_{0}$ is a comstant, the osmotic permeability coefficient, reflecting the permeability of the root cells to the osmotic movement of water. If in addition there is a difference of hydrostatic pressure $P$ across the cortex:

$$
f=k_{0}\left(O_{s}-O_{m}\right)+k_{0} P
$$

Further, if there is a mass flow component of water movement across the cortex:

$$
f=k_{0}\left(O_{s}-O_{m}\right)+k_{0} P+k^{\prime} P
$$

where $k^{\prime}$ is a coefficient reflecting the reciprocal of the resistance of the cortex to viscous flow of water. Thus

$$
f=k_{0}\left(O_{s}-O_{m}\right)+\left(k_{0}+k^{\prime}\right) P
$$

For practical purposes it is convenient to lump $\left(k_{0}+k^{\prime}\right)$ as a single constant $k_{P}$ the pressure permeability coefficient. Evidently if there is no mass flow $\left(k^{\prime}=0\right)$ then $k_{P}=k_{0}$. Thus the problem resolved itself into measuring $k_{0}$ and $k_{P}$.

\section{EXPERIMENTAL}

Tomato plants grown in water culture were used. Detopped plants were placed in a pressure canister through the lid of which the cut stem protruded and in which the pressure on the medium surrounding the roots could be raised by compressed air The medium could be rapidly changed and thus the osmotic potential around the roots varied (Mees and Weatherley, 1957). In practice direct measurement of $k_{0}$ and $k_{P}$ from eqs. iv and $\mathrm{v}$ was not possible owing to changes in $k_{0}$ itself in response both to changes in the osmotic potential of the surrounding medium and to changes

* The view is held (see Pappenheimer, 1953) that osmosis itself involves mass flow. But if an osmotic flux through a semi-permeable membrane is regarded as a catena involving mass flow through the pores but with a diffusional link in the chain (at the orifice of each pore), then osmotic pressure and hydrostatic pressure will still have identical effects. 
in hydrostatic pressurc. The eventual technique for estimating the osmotic permeability coefficient was to measure the immediate change in flux caused by a change in the osmotic potential of the medium, the hydrostatic pressure remaining constant (Arisz's method). Thus

$$
\begin{aligned}
f_{1} & =k_{0}\left(O_{s}-O_{m_{1}}\right) \\
f_{2} & =k_{0}\left(O_{s}-O_{m_{2}}\right) \\
\therefore \quad f_{1}-f_{2} & =k_{0}\left(O_{m_{2}}-O_{m_{1}}\right)
\end{aligned}
$$

or

$$
k_{0}=\frac{\Delta f}{\Delta \mathrm{O}_{m}}
$$

where $f_{1}$ and $f_{2}$ are the water fluxes with external media of osmotic potential $\mathrm{O}_{m_{1}}$ and $\mathrm{O}_{m_{2}}$. In this method the duration of the measurements was kept very short so that the osmotic potential of the xylem sap $\left(O_{s}\right)$ had no chance to change appreciably. The pressure permeability coefficient was measured as the change in flux caused by a change in external pressure, the osmotic potential of the medium being kept constant. Thus from eq. $\mathrm{v}$

$$
\begin{aligned}
& f_{1}=k_{0}\left(O_{s}-O_{m}\right)+k_{P} P_{1} \\
& f_{2}=k_{0}\left(O_{s}-O_{m}\right)+k_{P} P_{2} \\
& \therefore \quad f_{1}-f_{2}=k_{P}\left(P_{1}-P_{2}\right) \\
& k_{P}=\frac{\Delta f}{\Delta P}
\end{aligned}
$$

where $f_{1}$ and $f_{2}$ are the water fluxes with applied pressures of $P_{1}$ and $P_{2}$. Under conditions of applied pressure the osmotic potential of the xylem sap $\left(O_{s}\right)$ was small so that any changes in $O_{s}$ conld be safely neglected. In effect the osmotic permeability coefficient was measured as the change in flux in response to unit change of osmotic potential of the external medium whilst the pressure permeability coefficient was measured as the change in flux in response to unit change of applied pressurc.

A comparison of measured values of the osmotic and pressure permeability coefficients is shown in Table $\mathrm{I}$. It will be seen that in every experiment $k_{P}$ was greater than $k_{0}$, the mean value of $k_{P} / k_{0}$ bcing about $\mathrm{I} \cdot 3$. This implies that with a pressure gradient of about 2 atm $\frac{3}{4}$ of the flux was osmotic and $\frac{1}{4}$ mass flow.

These two fluxes could also be differentiated by the use of cyanide. As shown in Table 2 , three hours after the addition of cyanide $k_{0}$ suffered an 
TABLE I

Comparison of permeability coefficients

\begin{tabular}{|c|c|c|c|c|c|}
\hline $\begin{array}{l}\text { Experiment } \\
\text { number }\end{array}$ & $\begin{array}{l}\text { Osmotic } \\
\text { potential } \\
\text { of the } \\
\text { mediunt } \\
\text { (atm) }\end{array}$ & $\begin{array}{l}\text { Pressure } \\
\text { (atm) }\end{array}$ & $\begin{array}{l}\text { Osmotic } \\
\text { permeability } \\
\text { coefficient, } \\
k_{0}\end{array}$ & $\begin{array}{l}\text { Pressure } \\
\text { permeability } \\
\text { coefficient, } \\
k_{P}\end{array}$ & $k_{P} / k^{0}$ \\
\hline I & $I \cdot 25$ & 2.03 & 4.35 & 5.9 & $I \cdot 36$ \\
\hline 2 & 0.6 & $2 \cdot 0 \mathrm{I}$ & $11 \cdot 9$ & 14.5 & $I \cdot 22$ \\
\hline 3 & 0.6 & $2 \cdot 18$ & 9.4 & I 3.9 & $I \cdot 48$ \\
\hline 4 & 0.6 & $2 \cdot$ I 8 & $8 \cdot 9$ & II $\cdot 6$ & $1 \cdot 30$ \\
\hline
\end{tabular}

(Data from Mees and Weatherley, 1957)

almost $90 \%$ inhibition whereas $\mathrm{kp}-\mathrm{k}_{0}$ only $20 \%$ in one experiment and about $60 \%$ in another.

One of the most striking features of these results was the demonstration of a several fold increase in $k_{0}$ following a rise in pressure of about $2 \mathrm{~atm}$. This constitutes a direct confirmation of the conclusions of Brewig (1936-39) and Brouwer (1953-54) who worked with whole transpiring plants. Significant though this may be in indicating that transpirational tensions reduce the resistance of roots to osmotic water flux, it hardly clarifies the complex picture of water movement through the root for the mechanism of this change in permeability is as yet unknown. In view of the insensitivity of the transpiration pathway in the leaf to low temperature it is noteworthy that flux through the root is not only sensitive to metabolic inhibitors as shown above but is also greatly reduced by lowering the temperature (see Fig. $5 \mathrm{~B}$ ). Evidently metabolic activity is necessary to 'keep

\section{TABle 2}

The effect of cyanide on the osmotic and pressure permeability coefficients

\begin{tabular}{|c|c|c|c|c|c|}
\hline & & $k_{0}$ & $k_{P}$ & $k_{P} / k_{0}$ & $k_{p}-k_{0}$ \\
\hline \multirow[t]{2}{*}{ Before addition of $\mathrm{KCN}$} & expt. I & $8 \cdot 26$ & II $\cdot 66$ & $I \cdot 4 I$ & $3 \cdot 40$ \\
\hline & expt. 2 & $5 \cdot 80$ & $8 \cdot 84$ & $I \cdot \leq 2$ & $3 \cdot 04$ \\
\hline \multirow{2}{*}{$\begin{array}{c}3 \mathrm{~h} \text { after addition of } \\
5 \times 10 \mathrm{~m}-\mathrm{KCN}\end{array}$} & expt. I & $\mathrm{I} \cdot \mathrm{OI}$ & $2 \cdot 23$ & $2 \cdot 2 \mathrm{I}$ & $I \cdot 22$ \\
\hline & expt. 2 & 0.70 & $3 \cdot 53$ & 4.97 & $2 \cdot 83$ \\
\hline \multirow[t]{2}{*}{ Inhibition ( $\%)$} & expt. I & $87 \cdot 75$ & - & - & $64 \cdot 1$ \\
\hline & expt. 2 & $87 \cdot 9$ & - & - & $20 \cdot 6$ \\
\hline
\end{tabular}


the door open' to the water flux in response to the purely physical force of a pressure difference.

\section{CONCLUSIONS}

An analysis of the die-a way curve of continued water uptake by a detached leaf when transpiration is suddenly stopped, can be understood in terms of a model which suggests that the water in the leaf consists of two phases: the pathway of transpiration itself and a second phase lying off-stream and separated from it by a barricr of relatively high resistance. Thus at the instant of stopping transpiration, water was found to pass into the second phase at only about $\frac{1}{50}$ of the rate of the transpirational uptake.

In view of the cell consisting broadly of regions of high permeability (e.g. cell walls) on the outside separated by barriers of low permeability in the cytoplasm from inner regions (c.g. vacuoles), it seems likely that the transpiration pathway is the 'outer space' of the cells and the off-stream phase is the 'inner space'. The experiments which have been described do not tell us precisely whether the outer space of the cells includes the cytoplasm or is the cell wall alone. The seeming lack of sensitivity of water uptake into the outer space to temperatures a little above freczing point suggests perhaps that the cytoplasm is not included. The cytoplasm might well be in a gel state at these low temperatures when uptake of water would be mainly diffusional and probably too slow for the observed rapid absorption. In this connection it is interesting that from their study of the water relations of leaf discs Carr and Gaff (196I) have concluded that the cell-wall water is a significant and important fraction of the leaf water content and indeed their evidence strongly suggests that the outer space referred to in this paper should be regarded as the cell wall. We have obtained no information on the relative volumes occupied by the inner and outer spaces; this is clearly essential for ascertaining their nature and will be the subject of further work.

The conclusion that the water deficit in a leaf can be partitioned into phases is perhaps a side-issue from the point of view of this discussion. Nevertheless it may have important physiological, ecological and even technical implications (Carr and Gaff, I96 I; Barrs and Weatherley, I962). For example the inner space, at least in detached leaves responds to changes of external water potential at only $\frac{1}{5} \delta$ of the rate of the outer space, and this could lead to the inner space being cushioned from external fluctuations as envisaged by Carr and Gaff. This aspect clearly deserves further intensive study. 
If water moves so readily through the mesophyll walls the same might well be expected of parenchymatous cells generally and the root cortex in particular. How then is this reconciled with at least $75 \%$ of the flux through the root being due to osmotic diffusion and its extreme sensitivity to cyanide and low temperatures: As was suggested in the introduction the answer probably lies in the root endodermis. Here, as is well known, flow through the walls is prevented by the casparian strips and the transpiration stream must be canalised through the cells. Thus the root behaves like an osmometer albeit one possessing a membrane endowed with solute secreting properties, sensitive to pressure gradients and needing constant metabolic activity to maintain its permeability to water.

As for the difference between $k_{0}$ and $k_{P}$ this may be regarded as due to mass flow through the passage cells in the endodermis or through regions in which the casparian strips are not suberised. In the case of culture-grown tomato plants these together seem to allow about $\frac{1}{4}$ of the flux through the root as mass flow with pressure differences of about $2 \mathrm{~atm}$. On this view and assuming movement in the xylem is by mass flow, transpirational fux is a purely mechanical flow between soil and air except at one point, the endodermis, which constitutes the only living barrier in the whole complex catena. Thus the flux from soil to air through the plant is a tensile stream everywhere save through the inner space of the endodermis where the water representing at least $\frac{3}{4}$ of the total flux is transitorily under pressure. The other cells of the root, cortex, stele and leaf, play little part as Dixon recognised (1938), but merely act like manometers attached to the main stream and adjusting their water content, perhaps somewhat tardily, to the tension therein. No doubt they are also in a state of dynamic equilibrium with the stream as regards ions and other solutes (Jackson and Weatherley, I96I). But through the endodermis alone are water and solutes dispensed through the living cells. As was recognised long ago, it is a knowledge of the physiology of this important tissue which may be crucial to our further understanding of water and ion movement in the higher plant.

\section{REFERENCES}

Arisz, W.H., Helder, R.J. \& NiE, R. van (I95I) Analysis of the exudation process in tomato plants. J. exp. Bot. 2, 257.

BARRS, H.D. \& WeAtherley, P. E. (I962) A re-examination of the relative turgidity technique for estin1ating water deficits in leaves. (In the press)

Bernstein, L. \& Nieman, R.H. (1960) Apparent free space of plant roots. Pl. Physiol. 35,589 .

Brewig, A. (1936) Beobachtungen über den Einflusz der Sproszaugung auf die Stoffdurchlässigkeit der Wurzel. Ber. dtsch. Bot. Ges. 54, 80. 
Brouwer, R. (1953) Water absorption by the roots of Vicia faba plants at various transpiration strengths. Proc. Kon. Ned. Akad. Wet. Series C56, 105, I29.

Brouwer, R. (1954) The regulating influence of transpiration and suction tension on the water and salt uptake by the roots of intact Vicia faba plants. Acta bot. Neerl. 3, 264.

CARR, D.J. \& GAFF, D.F. (I96I) The role of the cell wall water in the water relations of leaves. Unesco-Spain Symposium on plant-water relationships in arid and semiarid conditions. Paper 28.

De Lavison, J. De Rufz (I9Io) Du mode de pénétration de quelques sels dans la plante vivante. Revue gén. Bot. 22, 225.

Drxon, H. H. (I938) Transport of substances in plants. Proc. Roy. Soc. B I25, I.

HülsBruch, M. (1956) Water transport in parenchyma. Encyclopedia of Plant Physiology. Ed. W. Ruhland, vol. III, 522.

JACKSON, J.E. \& WEATHERLEY, P.E. (I962) The effect of hydrostatic pressure gradients on the movement of potassium across the root cortex. J. exp. Bot. I3, I28.

Kramer, P. J. (1932) The absorption of water by root systems of plants. Amer. J. Bot. I9, I48.

Levitt, J. (I956) The physical nature of transpirational pull. Pl. Physiol. 31, 248.

MeEs, G.C. \& Weatherley, P.E. (1957) The mechanism of water absorption by roots. I: Preliminary studies on the effects of hydrostatic pressure gradients. II: The role of hydrostatic pressure gradients across the cortex. Proc. Roy. Soc. BI 47, 367, 38I.

Pappenheimer, J.R.(1953) Passage of molecules through capillary walls. Physiol. Rev. 33, 387 .

SABININ, D. A. (I925) On the root system as an osmotic apparatus. Bull. Inst. Recherche biol. Univ. Perm. (Molotov) 4, Suppl. 2, 129.

Scott, L. I. \& Priestley, J. H. (1928) The root as an absorbing organ. I: A reconsideration of the entry of water and salts in the absorbing region. New Phytol. 27, I25.

STRUgGer, S. (1938-9) Die Lumineszenzmikroscopische Analyse des Transpirationsströmes in Parenchymen. Flora, Jena, 133, s6. 


\title{
WATER SATURATION DEFICIT AND ITS DEVELOPMENT IN YOUNG AND OLD LEAVES
}

\author{
JIŘÍ Č ATSKÝ \\ Institute of Biology, Czechoslovak Academy of Sciences, \\ Praha, Czechoslovakia
}

\section{INTRODUCTION}

THE origin and development of the water saturation deficit (WSD) in plants in situ represents a problem not yet satisfactorily explained from the point of view of ecology. The authors of the first studies on the water deficit of plants (Stocker, I928, I929a, b; Magyar, 1930; Schanderl, I930; Vassiljev, 193I, and a number of others) emphasised the importance of this then newly-defined value especially in ecological investigation, particularly in view of the fact that the values of the water deficit make it possible to compare the water balance of plants from different localities. The significance of the water deficit is, however, not restricted to this type of work. Its values gain in importance especially on detailed examination of wilting of plants and in studying the relationships of individual life processes in plants on the supply of plant tissues with water.

The present communication was conceived from this very point of view, its aim being to be extended by further studies of the dynamics of plant wilting. It attempts to correlate the existing rather varied and occasionally contradictory findings on the water deficit from the point of view of physiological ecology, to check the methods of its determination and to obtain fundamental data on the course of wilting of some model plants.

\section{LITERATURE}

The concept of water deficit as one of the most important indicators of plant water balance was introduced by Stocker (1928, I929a, b) on the basis of Iljin's studies (1923). His original method of estimation of WSD was used by a number of authors. Relatively very detailed data on the absolute value of the water deficit under normal and extreme conditions resulted from their work, together with data on its diurnal and seasonal changes, relationships with climatic factors, etc. As was mentioned in a previous paper (Čatský, 1959) the reliability of these data is unfortunately rather questionable on account of the considerable error which might be 
incurred on application of Stocker's method to not quite mature leaves. The uptake of water by a severed young leaf is not produced only by a momentary incomplete water saturation of the tissues but to a considerable extent also by their extension growth. The saturation to constant weight required by Stocker's method which is reportedly achieved in young leaves within several days actually marks the beginning of leaf dying. From this point of view it is possible to explain even some surprising data found in the literature concerning the dynamics of wilting of young and old leaves (e.g. Magyar, I930; Arvidsson, 195I) or the annual pattern of water deficit (e.g. Ackley, 1954).

The possibility of an error in estimating the water deficit in growing tissues was mentioned by Welten (1933) and by Müller-Stoll (1935) who, however, did not consider its value as significant and did not pay any attention to it. More recently the possibility was taken up by Weatherley (I950) and Yemm and Willis (1954). The last-named authors, therefore, when estimating the water deficit of detached whole leaves, determine the shape of the saturation curve and by means of graphical extrapolation subtract the amount of water required for growth. Rutter and Sands (1958) also call attention to the very slow uptake of water by the dwarf shoots of Pinus sylvestris after Io hours of saturation; they consider it as a consequence of osmotic changes within the tissue which contained abundant starch. It is very likely that this 'osmotic uptake' actually plays a role during saturation of detached leaves or leaf discs.

The importance of the WSD values as a reliable indicator of water balance was clearly demonstrated both by the author of the term and by a number of his followers. The weakest point of the investigation of WSD is now apparently the method of its estimation which, strangely enough, has remained practically unchanged since the time of the first of Stocker's papers. It was only Weatherley who (1947, I950, I95 I) used, for estimating the WSD, discs cut out from experimental leaves and floating on water. A similar method was used by Wormer (1956). Recently a method was suggested for estimating the WSD in discs saturated in a moist plate made of polyurethane foam (Čatský, I960). By using the discs it was possible to cut down the time required for attainment of full turgescence of the tissue and thus to decrease the effect of extension growth on the WSD value obtained. Even here, however, the possibility of a certain even if small error due to this growth persists.

More complete data on the dynamics of wilting of plants in situ are very rare in the literature. Important contributions to this problem are cited by Stocker (1929a), Magyar (1930), Arvidsson (I95I), Slavik (1955), Halevy 
(1960) and others. These authors call the attention to the high WSD of young leaves (as determined by Stocker's method) on plants under natural conditions. Rutter and Sands (1958) and Sands and Rutter (1958) bring out the close relationship between the WSD and transpiration and soil humidity. Both of their papers contain valuable data on the WSD values during different water content of the soil.

\section{MATERIAL AND METHODS}

About IOO-Iso-day-old plants of fodder cabbage (Brassica oleracea L., convar. acephala/DC./Alef., var. medullosa Thell. in Hegi) of the sort Markstammkohl, and of rape (Brassica napus L., var. oleifera DC.) of the sort Slapská, grown in pots in a greenhouse were used for the experiments. Plants of both species had between 6 and 9 leaves.

The water deficit was estimated by a method suggested earlier (Čatský, I960) modified for young leaves: a cork-borer was used to cut out discs of $8 \mathrm{~mm}$ in diameter from the leaves; the discs were then weighed, saturated in openings $(7.5 \mathrm{~mm}$ in diameter) in a moist plate of polyurethane foam. After 3 hours of saturation the discs were taken out, dried with filter paper, weighed and saturated again. After another 3 hours they were again dried, weighed and desiccated at $\operatorname{IO}^{\circ} \mathrm{C}$. The WSD was calculated by the following formula:

$$
\% \mathrm{WSD}=\frac{(2 x \text { weight after } 3 \mathrm{~h})-(\text { weight after } 6 \mathrm{~h})-\text { initial wt. }}{(2 x \text { weight after } 3 \mathrm{~h})-(\text { weight after } 6 \mathrm{~h})-\text { dry wt. }} \times 100
$$

The applicability of this modification was confirmed by experiments to be described in the experimental section.

Other details of method will be presented with the individual experiments.

\section{RESULTS}

\section{i. Saturation Curve of Whole Leaves}

The experiments carried out in this section were to investigate the course of water uptake by detached whole leaves during estimation of WSD according to Stocker; the results were to serve as a basis for the experiments to be described later concerning the experimental proof of 'growthWSD'. Six young and 6 old leaves were detached from well-watered plants in pots. The leaves were weighed and saturated in the dark through 
their petiole immersed in water in a water-saturated atmosphere. At given time intervals the leaves were dried with a filter paper and weighed. Water uptake was expressed as percent initial value after subtracting the dry weight. The result (Fig. I) clearly demonstrates the qualitative difference between the saturation curves of young and of old leaves.

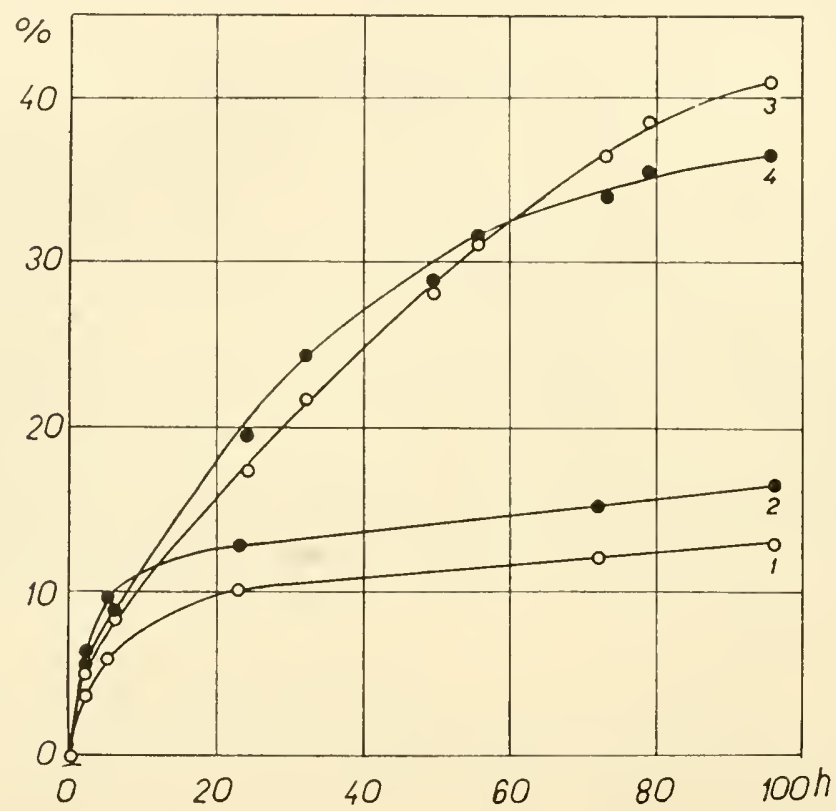

Fig. I. Sat uration of old $(\mathrm{I}, 2)$ and young $(3,4)$ leaves in estimating the water saturation deficit by Stocker's method. I, 3-rape; 2, 4-fodder cabbage. Abscissa: time of saturation in hours; ordinate: weight of water in per cent initial weight.

\section{Origin of 'Growth-WSD' in Leaf Tissue Discs}

Experiments shown in Fig. 2 were designed to demonstrate experimentally the origin of the 'growth-WSD' and its subsequent disappearance. Two equal sets of discs were cut out from young leaves of fodder cabbage and saturated in the polyurethane plate (see Methods). After 3 hours the discs were weighed; the control ones were saturated further and the experimental ones were placed on a nylon mesh in a Petri dish containing a water-saturated atmosphere and placed in darkness. After I hour, these experimental discs (in which a growth WSD and hence an actual WSD was presumed to 
be produced) were then saturated in the polyurethane plate. It follows from the results that the experimental discs reached the control curve, i.e. that growth persisted in spite of interrupted water supply and gave rise to a growth WSD (Fig. 2).

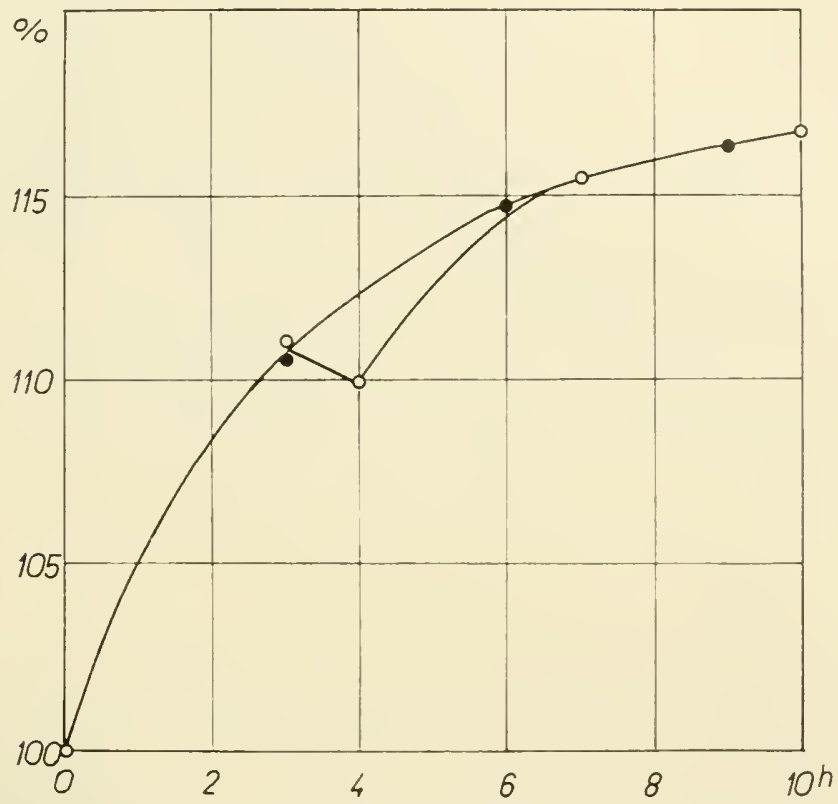

FIG. 2. Saturation of two sets of discs from young leaves in one of which water supply was cut off between the third and fourth hour. For details see the text.

3. Verification of the Applicability of the Method of WSD Estimation by Means of Extrapolation

It was the aim of the following experiments to test the applicability of extrapolation (Yemm and Willis, 1954) in estimating the WSD by the 'disc method'. Experimental leaves were saturated in the dark for 24 hours with their petioles immersed in water in a water-saturated atmosphere. After that, rectangles of leaf tissue without large nerves were cut out from them, well dried and left to wilt on a nylon mesh. After reaching a certain WSD, which was calculated from the observed loss in weight of the initially saturated rectangles, discs were cut out from the whole area of the sample and their WSD estimated after saturation in a polyurethane plate by extra- 


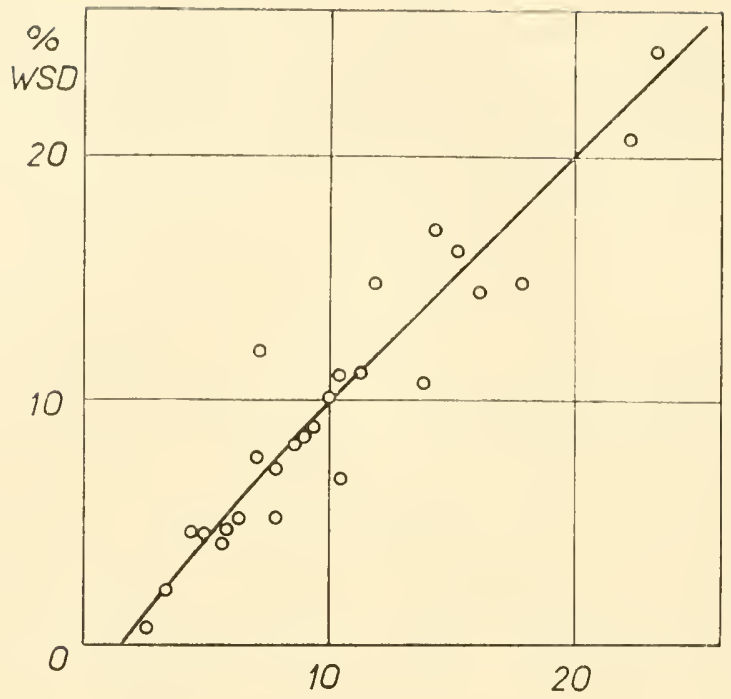

FIG. 3

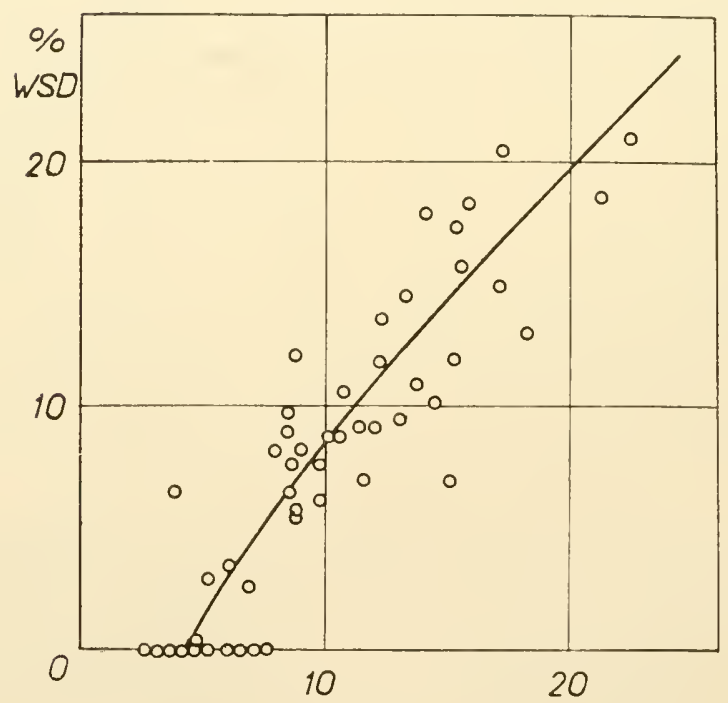

FIG. 4

Figs. 3 and 4. Verification of the water saturation deficit estimation by the disc method and extrapolation in old (Fig. 3) and young (Fig. 4) leaves. Abscissa: WSD values obtained by the disc method; ordinate: WSD values derived from wilting of saturated tissue (see the text). 
polation (for the formula, see Methods). It was found by this experiment (Figs. 3 and 4 ) that the extrapolation procedure is applicable even to young leaves as the error caused by extension growth is decreased to a very low value.

\section{Origin and Development of the WSD in Plants In Situ during}

\section{Decreasing Soil Moisture}

Experimental plants (a total of I 8 plants of fodder cabbage and 36 plants of rape) were divided into groups of six. These groups were then taken as single samples. Before the experiment the plants were well watered and left overnight in a water-saturated atmosphere. Then three discs were cut out from each leaf of the genetic spiral and their WSD determined jointly in corresponding leaves (i.e. I 8 discs from the first leaves, I 8 discs from the second leaves, etc.). The plants were then placed in a greenhouse at $18-23^{\circ} \mathrm{C}$ and at $65-75 \%$ relative humidity and were not watered. During wilting two more samples were removed for estimating the WSD. Figures 5 and 6 show the course of wilting of leaves of different age in average values.

\section{DISCUSSION}

The long-known observations and morphological descriptions of the course of wilting of plants find an experimental counterpart in the results of the above experiments. Let us consider first the methodological significance of the described experiments. Their results emphasise very clearly the necessity of careful interpretation of the results of Stocker's method as well as of critical interpretation of the general conclusions advanced in older papers about the water deficit. This is not to say, of course, that Stocker's method in its original form would be of no use or that it would yield nothing but erroneous results. The observed effect of extension growth on the WSD estimation cannot be neglected however, and particularly in cases where the water deficit of the whole plant is to be estimated. The original method of Stocker was intended even for estimations of this type and a number of authors have actually applied it. On account of the fact that young or at least partially growing leaves represent a considerable proportion of the leaf total in most plants, the utmost care should be exercised in such work. To my mind, this drawback of Stocker's method has probably given rise to the data on the high water deficit of young leaves (e.g. Magyar, I930; Arvidsson, I95I and others) and apparently to the data on higher WSD of plants during the spring months as compared with later seasons (e.g. Ackley, 1954). 


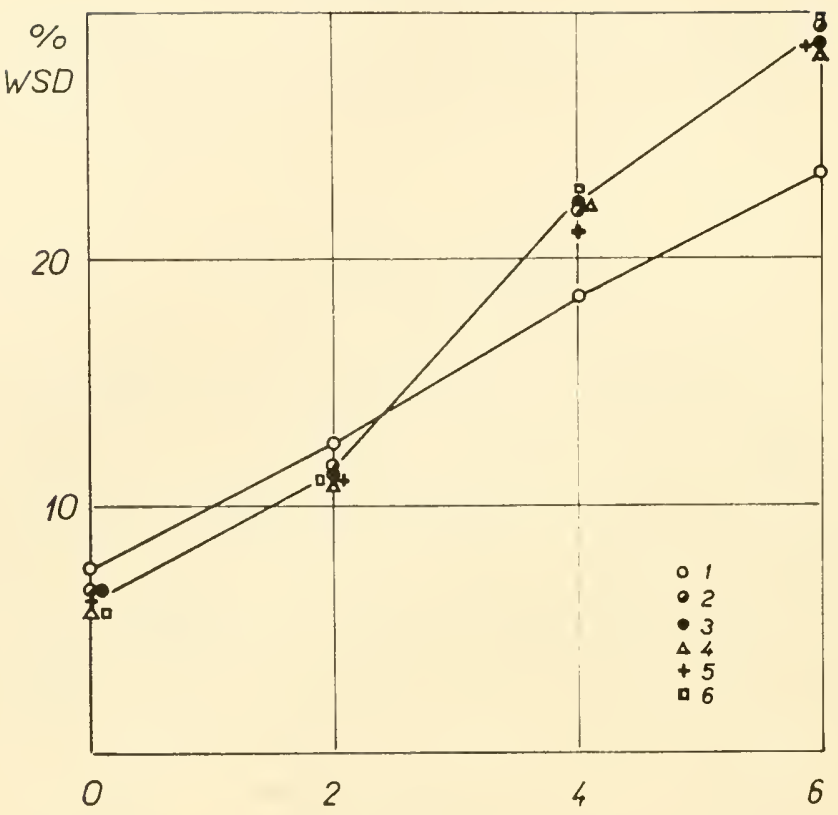

F1G. 5

FIGs. 5 and 6 . The course of wilting of a plant in situ during decreasing soil moisture; fodder cabbage (Fig. 5) and rape (Fig. 6). Abscissa: days from the beginning of experiment (= days of wilting); ordinate: percent water saturation deficit. The figures for individual curves indicate the position of the leaf on the genetic spiral beginning from the top (leaf no. I : area about $8 \mathrm{~cm}^{2}$ ).

The second methodological contribution of this paper consists in the method applied to the estimation of the actual water deficit employing discs of leaf tissue. The use of discs for the estimation of the WSD possesses a number of advantages over the estimation in whole plants: among others (technical ones, for instance) are the rapid saturation of the tissue (and thus a decrease of the extension growth effect) and further the possibility of taking representative samples without destroying leaves or whole plants. Only this method makes it possible to investigate directly the course of wilting. From the physiological point of view there are no serious objections to the use of leaf discs as is well seen in the successful work of Weatherley (1947, I950, I95I) concerning water deficit. A basis for the technical arrangement of the procedure was found in the paper by Bartos, Kubin and Šetlik (1960) and in the hitherto unpublished results of the same 


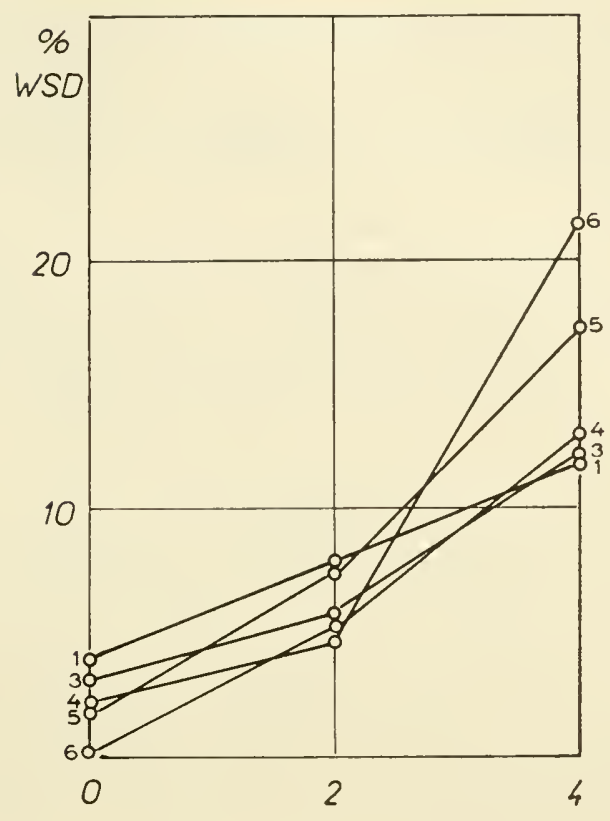

FIg. 6

authors. Bartoš et al. (1960) demonstrated that the intensity of photosynthesis (which certainly is a sensitive indicator of the physiological state of the tissue) is maintained on the same level for several hours (6 and morc) when leaf discs are exposed in a moist polyurethane plate. It thus appears probable that even water uptake leading to WSD saturation will be the same in the disc as in the whole leaf at least for a certain period of time. The saturation curve of young leaf discs has a roughly exponential shape (Fig. 2) which is in agreement with the literature (Oppenheimer, I954; Fritz, I956). In young leaves, the clear linear phase described by Yemm and Willis (I954) and amenable to extrapolation could not be found here. It does not appear probable that the extension growth in the disc would proceed at a completely identical rate for the whole duration of exposure, i.e. for 6 hours. In spite of this, the extrapolation suggested by Yemm and Willis (1954) and applied here might help to come closer to the true values of actual WSD; Fig. 4 provides some information about the accuracy of this type of estimation in young leaves. Young leaves display a greater dispersion of values than older leaves. It must be borne in mind, however, that the dispersion in both leaf groups is not due only to an error in 
estimation but largely also to the heterogeneity of the leaf-blade (Slavik, 1959). Another very important source of dispersion in young leaves lies in the anatomical structure of these leaves, particularly the high number of large nerves, which cannot be avoided in young leaves and which might considerably affect the values obtained.

So far attention was devoted solely to problems of method. Let us consider the results from a general point of view. As was said above, the uptake of water by a detached young leaf or tissue is caused by a tendency to saturate the actual water deficit and secondly by the requirement for water used for extension growth. On the basis of these findings it was possible to distinguish between the actual water deficit and the 'growth'WSD produced in the course of time. We are not dealing here purely with a problem of method; if the water deficit is considered as a dynamic feature expressed by water requirement then the growing tissues will really possess a sort of potential water deficit. The 'growth'-WSD thus cannot be separated from the actual WSD in any strict fashion even if their distinction is quite clear. This growth-WSD is shown very markedly in experiment no. 2 where, during a complete cut-off of water supply to a saturated tissue, this tissue produces a growth-WSD, which, of course, becomes at once an actual WSD. After restoring the water supply this actual WSD is saturated. A prerequisite of this compensation is the following: the true actual water deficit, i.e. the sum of the WSD caused by wilting (decrease in weight) which can be hardly avoided methodologically, and of the growth-WSD must not reach such level and must not act for such a long time as to cause inhibition of extension growth.

On the basis of these facts some measurements of the actual WSD were carried out on plants during decreasing soil moisture. It was the aim of these experiments to employ the proposed method for obtaining some fundamental data on the wilting of plants in situ, which could serve as a basis for more detailed investigation of the dynamics of wilting. The results support quite unequivocally the view about the preference of young leaves during wilting of the wholc plant. It was not possible, however, to demonstrate quite unambiguously the differences in the water deficit at the beginning of wilting, i.e. at WSD between 5 and $8 \%$. It appears that within this range young leaves possess actually a slightly higher deficit than mature leaves which may be expected in view of the greater transpiration intensity of young leaves (Slavik, 1956; Halevy, I956). It cannot be demonstrated quite conclusively, however, whether this, even if small difference, is not due to a very intense extension growth of the tissue at the beginning of estimation. With the possibility of the growth intensity being decreased 
between the third and sixth hour of estimation, this error cannot be eliminated by extrapolation. On the other hand, the very small differences in WSD values obtained by extrapolation in young and old leaves of fully turgescent plants oppose this possibility. The solution of this problem must be postponed to further work.

\section{ACKNOWLEDGMENTS}

It is my pleasure to thank Dr. B. Slavik for the interest he has taken in the work described and for many valuable discussions on the topic. My thanks are due to Mrs. Mandlová for skilled technical help.

\section{REFERENCES}

ACKLEY, W.M.B. (1954) Seasonal and diurnal changes in the water contents and water deficits of Bartlett pear leaves. Plant Physiol. 29, 445-448.

Arvidsson, I. (195I) Austrocknungs- und Dürreresistenzverhältnisse einiger Repräsentanten öländischer Pflanzenvereine nebst Bemerkungen über Wasserabsorption durch oberirdische Organe. Oikos, suppl. I, I-I 8 I.

BARtoš, J., Kubín, Š. \& ŠETLíx, I. (I960) Dry weight increase of leaf disks as a measure of photosynthesis. Biol. Plant. 2, 20I-2 I 5 .

ČATSKÝ, J. (1959) The role played by growth in the determination of water deficit in plants. Biol. Plant. I, 277-286.

C̆ATSK Ý, J. (1960) Determination of water deficit in disks cut out from leaf blades. Biol. Plant. 2, 76-78.

FrITZ, M. (I956) Über die Aufsättigung abgeschnittener Blätter bei Einstellen in Lösungen von Elektrolyten und Anelektrolyten. Protoplasma, 46, 198-209.

Halevy, A. (1956) Orange leaf transpiration under orchard conditions. V: The influence of leaf age and changing exposure to light on transpiration, on normal and dry summer days. Bull. Res. Counc. Israel, 5D, 165-175.

Halevy, A. (1960) Diurnal fluctuations in water balance factors of Gladiolus leaves. Bull. Res. Counc. Israel, 8D, 239-246.

ILjIN, W.S. (1923) Der Einfluss des Wassermangels auf die Kohlenstoffassimilation durch die Pflanzen. Flora, N.F. Ix6, 360-378.

Magyar, P. (1930) Növényökológiai vizsgálatok szíkes talajon. Pflanzenökologische Untersuchungen auf Szikböden. Erdészeti Kisérletek (Sopron) 32, 75-I I 8, 237-256.

MülleR-Stoll, W.R. (I935) Ökologische Untersuchungen an Xerothermpflanzen des Kraichgaus. Z. Bot. 29, I6I-253.

Oppenheimer, H.R. (1954) Critique experimentale de deux méthodes employées en vue d'établir le déficit de saturation hydrique (DSH) des feuilles. Rapp. Comm. $8^{\text {ime }}$ Congr. int. Bot. (Paris), Sec. I I-12, 2 I 8-220.

RutTer, A.J. \& SANDS, K. (1958) The relation of leaf water deficit to soil moisture tension in Pinus sylvestris L. I: The effect of soil moisture on diumal changes in water balance. New Phytol. 57, 50-65.

SANDS, K. \& RutTER, A.J. (1958) The relation of leaf water deficit to soil moisture tension in Pinus sylvestris L. II: The variation in the relation caused by developmental and environmental factors. New Phytol. 57, 387-399. 
SCHANDERL, H. (1930) Ökologische und physiologische Untersuchungen an der Wellen- und Muschelkalkflora des Maintales zwischen Würzburg und Gambach. Planta, ro, 756-8 ro.

SiAv'K, B. (I955) K dynamice vodního deficitu rostlin. (Über die Dynamik des Wasserdefizits der Pflanzen.) Preslia, 27, I24-I 53.

SLAvík, B. (1959) Water relations within the area of one leaf blade. Proc. 9th int. bot. Congr. (Montreal), 2, 367.

STOCKeR, O. (1928) Das Wasserhaushalt ägyptischer Wüsten- und Salzpflanzen. Bot. Abhandlungen (Jena), Hft. 13, 200.

STOCKER, O. (I929a) Vizsgálatok különbözö termöhelyen nött növények vízhiányának nagyságáról. Über die Höhe des Wasserdefizites bei Pflanzen verschiedener Standorte. Erdészeti Kisérletek (Sopron), 31, 63-76, I04-1 I4.

STOCKER, O. (1929b) Das Wasserdefizit von Gefässpflanzen in verschiedenen Klimazonen. Planta, 7, 382-387.

VassiIJev, 1.M. (I93I) Über den Wasserhaushalt von Pflanzen der Sandwüste im südöstlichen Kara-Kum. Planta 14, 225-309.

WEATHERLEY, P.E. (1947) Note on the diurnal fuctuations in water content in floating leaf discs. New Phytol. 46, 276-278.

Weatherley, P.E. (1950, I95I) Studies in the water relations of the cotton plant. I: The field measurement of water deficits in leaves. New Phytol. 49, 8I-97; II: Diurnal and seasonal variations in relative turgidity and environmental factors. New Phytol. 50, 36-51.

Welten, M. (1933) Physiologisch-ökologische Untersuchungen über den Wasserhaushalt der Pflanzen mit besonderer Berücksichtigung der Wasserabgabewiderstände. Planta 20, 45-165.

Wormer, Th.M. (1956) Mise au point d'une technique pour l'étude du bilan d'eau du palmier à huile (Elacis guineensis). C. R. Conf. franco-brit. sur le palmier à huile, I956, I8I-I90.

YEMM, E. W. \& WIILIS, A.J. (I954) Stomatal movements and changes of carbohydrate in leaves of Chrysanthemum maximum. New Phytol. 53, 373-396. 
WATER RELATIONS IN NATURAL CONDITIONS 



\title{
ON THE DISTRIBUTION OF THE PRECIPITATION IN A SPRUCESTAND
}

\author{
AN ATTEMPTED ANALYSIS
}

M. G. STÅLfELT

University of Stockholm, Sweden

AN attempt was made to analyse the water economy of a natural plant community. This was done by measuring the water supply to the root zone and the water uptake through overground organs, as well as by measuring the distribution of the precipitation by transpiration, interception and surface run-off.

For this purpose, I chose a plant community of simple composition, namely, a spruce wood, in which the tree layer consisted only of spruce (Picea excelsa Link.) and the remainder of the higher vegetation was chiefly in the form of mosses. The stand was about 40 years old, and was not completely closed. The trees covered about half the ground surface. The other half-that is, the gaps between the trees-was covered mainly by Hylocomium species. Mosses grew near the periphery of the surface under the tree canopy; otherwise, there was only a litter of needles, pieces of bark, twigs, remains of cones, etc.

The site was in southern Sweden (Scania). It is a low-hilled moraine, i.e., an unstratified, unsorted glacial deposit, of which about half consists of fens and bogs. The other half-the low hills-is covered by woods.

Transpiration was measured in II spruces; these are denoted in the following as the experimental trees. Three of them grew on the edge of a fen, with the water table about $0.2 \mathrm{~m}$ below the base of the tree stems. The remaining trees grew on the moraine hills, and had a distance to the water table ranging from 2 to $7 \mathrm{~m}$.

Precipitation was measured on the open ground, as well as below the crowns of the trees, and in the gaps between the trees. Triangular troughs, with a length equal to half the diameter of the crown, were placed under the crowns. Their opening measured $53-66 \mathrm{dm}^{2}$. The apex of the triangle lay close to the stem of the tree, and the base in the periphery of the crown. The triangular shape was chosen in view of the fact that the quantity of water penetrating the crown of a spruce differs in the peripheral and central parts of the ground covered by it. The quantity increases from the centre outwards, and is relatively great under the tips of the branches. 
Two such troughs were used for each of 5 of the experimental trees. One trough was empty, and the other contained a piece of the top portion of the soil. This was cut from the ground below the trough, and consisted of the organic layer of raw humus and litter lying on the mineral soil. The roots of the trees spread in the uppermost layer of the mineral soil, and penetrated to a varying depth, generally a maximum of $0.5 \mathrm{~m}$.

Interception in the crowns of the trees and in the top portion of the soil, as well as the quantity of water that penetrated the top portion of the soil and reached the root zone of the trees, were calculated from the values for precipitation on the open ground, in the empty trough, and in the trough containing the top portion of soil.

The gaps between the trees were usually small (a few or some tens of square metres), and were infiltrated by the roots of the trees. Consequently, the precipitation on these areas could be utilised by the trees. Rain gauges were also set up in the gaps; they were round and smaller than the troughs, having an opening of $375 \mathrm{~cm}^{2}$. In each of 4 gaps $\left(2,4,10\right.$ and $\left.74 \mathrm{~m}^{2}\right)$ two gauges were set up. One was empty, and the bottom of the other one was covered with a piece cut out of the top portion of the soil-in this case consisting of moss, with the litter present in it. The gaps were surrounded not only by the experimental trees, but by many other trees as well. The interception in the mossy layer was calculated from the values obtained for precipitation.

Calculations were also made of the rain-shielding effect of the surrounding trees-that is, of the screening effect on the precipitation (precipitation is less in the gaps than on open ground) -and of the quantity of water which penetrated the top portion of the soil, and reached the mineral soil, and thereby the root zone of the trees. The depth to which this water penetrated was determined, among other ways, by measuring the humidity of soil specimens taken at various times of the year.

Attempts were also made to measure the water uptake through needles and other overground organs. Weighing of whole plants allowed determination of their water deficit, as well as of the changes that took place after they had been immersed in water for some hours, or had stood in rain or fog. It could then be established that a not inconsiderable amount of water was absorbed by the overground organs, if they had previously had a water deficit. In the case of the experimental trees, the exact quantity could not, however, be determined.

The whole experimental period amounted to 4 years. The collected data on precipitation were divided into two periods, namely, the months of September-April and May-August. The object was to permit a comparison 
with the transpiration of the trees, which was measured during the 4 months of May-August. At the site in question, appreciable transpiration occurs only during this time.

During the 4 experimental years, the mean annual precipitation at this site was $793 \mathrm{~mm}$ of which $495 \mathrm{~mm}$ fell in September-April, and $298 \mathrm{~mm}$ in May-August. The distribution of these quantities on the canopy, the top portion of the soil and the root zone of the trees can be seen from Fig. I, showing the distribution on and below the tree canopies. Fig. 2 shows the distribution in the gaps between the trees.

The crowns of the trees are effective chicfly through their strong interception. This took about half of the precipitation, namely, I $70 \mathrm{~mm}(57 \%$ of $298 \mathrm{~mm})$ in May-August, and $257 \mathrm{~mm}(52 \%$ of $495 \mathrm{~mm})$ in SeptemberA pril. It must, however, be pointed out that the crowns of the experimental trees were well developed, and reached the ground or close to it. The surface covered by the individual crown was minimally $\mathrm{I} 4 \mathrm{~m}^{2}$ and maximally 56 . The quantity of needles belonging to each tree-which was measured and calculated at the end of the experimental period-ranged from 53 to $204 \mathrm{~kg}$.

Actually, the interception of the crowns is greater than that shown in Fig. I. To these figures should be added the precipitation screened off from the gaps by the crowns; it is denoted by the values $I$ and $L$ in Fig. 2.

The values given for interception are the total figures for several months. If the interception on individual occasions is compared, varying values are noted, since the quantity of intercepted water is determined by the precipitation per time unit, and by the duration of precipitation. The quantity of intercepted water may be slight-for example in a cloudburst. It may, on the contrary, be great-approaching $100 \%$-when the quantity of rain is small.

Interception in the top portion of the soil was also considerable. During the summer months, almost half the precipitation reaching the gaps was retained, and in September-April about one-fourth.

The annual precipitation reaching the root zone below the canopy was $262 \mathrm{~mm} ; 73 \mathrm{~mm}$ during the summer, and $\mathrm{I} 89 \mathrm{~mm}$ in September-April.

The water supply to the root zone in the gaps is somewhat greater. This is because the precipitation is greater in the gaps than below the canopy. Consequently, interception is greater in the gaps, and the water supply to the root zone also greater. Of the $793 \mathrm{~mm}$ annual precipitation, altogether $316 \mathrm{~mm}$ reached the root zone in the gaps; $100 \mathrm{~mm}$ in May-August, and $216 \mathrm{~mm}$ during the rest of the year.

The gaps occupied about the same area of ground as the part covered by the crowns of the trees. The water supply to the root zone can therefore be 
calculated as half the precipitation (measured in $\mathrm{mm}$ ) on these two surfaces. This gives $87 \mathrm{~mm}$ (half of $73+100 \mathrm{~mm}$ ) for May-August, and $202 \mathrm{~mm}$ (half of $189+216 \mathrm{~mm}$ ) for September-A pril, or totally $289 \mathrm{~mm}$.

The transpiration of the trees was determined by the 'momentan method' (Stocker, I929), i.e. by weighing severed leaves, shoots or parts of shoots.

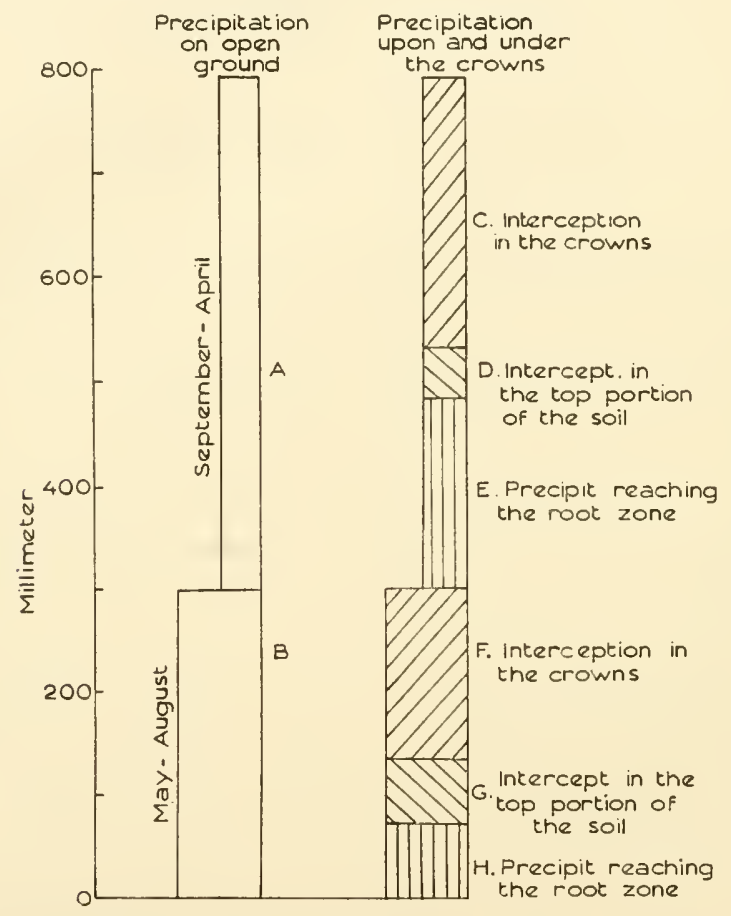

Fig. I. Precipitation on and below 5 spruce trees (mean value of 4 years). $A$ and $B$. Annual precipitation on open ground: $793 \mathrm{~mm} ; 495 \mathrm{~mm}$ in September-April $(A)$ and $298 \mathrm{~mm}$ in May-August $(B)$. C. Interception in the crowns during September-April: $260 \mathrm{~mm}(52.3 \%$ of $495 \mathrm{~mm})$. The interception in the crowns includes the (unknown) quantity of wind-driven precipitation collected, and thus screened-off from the gaps. $D$. Interception in the top portion of the soil (moss, litter and raw humus) in September-April: $46 \mathrm{~mm}(9 \cdot 3 \%$ of $495 \mathrm{~mm})$. E. Precipitation reaching the root zone of the trees in September-A pril: $189 \mathrm{~mm}(38.4 \%$ of $495 \mathrm{~mm})$. F. Interception in the crowns during May-August: $170 \mathrm{~mm}(57.2 \%$ of $298 \mathrm{~mm})$. The interception in the crowns includes the (unknown) quantity of wind-driven precipitation collected, and thus screened off from the gaps. $G$. Interception in the top portion of the soil (moss, litter and raw humus) in May-August: $55 \mathrm{~mm}$ ( $18.4 \%$ of $298 \mathrm{~mm}$ ). H. Precipitation reaching the root zone of the trees in May-August: $73 \mathrm{~mm}(24.4 \%$ of $298 \mathrm{~mm})$. 
The reliability of this method is dependent on whether or not the cut part of the plant does, in fact, give off the same quantity of water before and after cutting. No generally applicable answer can be given to this question, since the effect of cutting may vary in different species. Moreover, it may vary with such factors as the hydration and osmotic equipment of the plant,

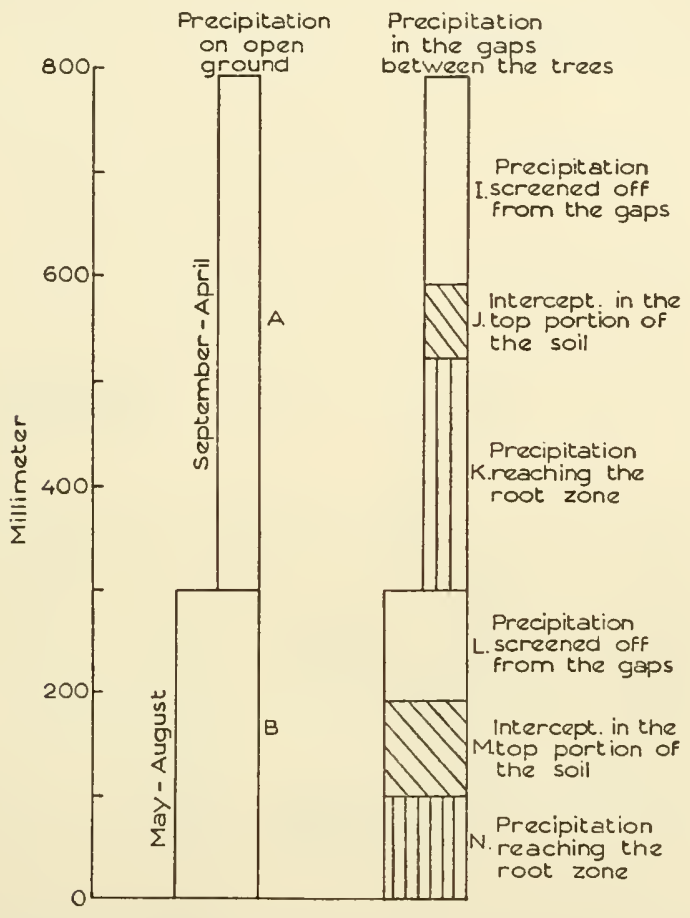

Fig. 2. Precipitation in the gaps between the trees (mean value of 4 years). $A$ and $B$. As in Fig. I. I. Wind-driven precipitation collected by the tree canopy, and thus screened off from the gaps: $205 \mathrm{~mm}(4 \mathrm{I} \cdot 5 \%$ of $495 \mathrm{~mm})$. J. Interception in the top portion of the soil: $74 \mathrm{~mm}$ ( $14.8 \%$ of $495 \mathrm{~mm}$ ). K. Precipitation reaching the root zone of the trees: $216 \mathrm{~mm}(43.7 \%$ of $495 \mathrm{~mm})$. $L$. Wind-driven precipitation collected by the tree canopy, and thus screened off from the gaps: $106 \mathrm{~mm}(35.6 \%$ of $298 \mathrm{~mm}) . M$. Interception in the top portion of the soil: $92 \mathrm{~mm}(30.9 \%$ of $298 \mathrm{~mm})$. N. Precipitation reaching the root zone of the trees: $100 \mathrm{~mm}(33.5 \%$ of $298 \mathrm{~mm})$.

its xeromorphy and rapidity of reaction. Examples have been given by Parker (1957) and by Eger (1958). Consequently, it is necessary in every individual case to test the agreement between the size of transpiration before and after cutting. 
Unfortunately, a control study of this kind often meets with great technical difficulties. This applies in particular when the plants consist of large trees, as in the present investigation. I therefore used young ( 5 - to 8-year-old) spruce plants for the control measurements, as described earlier (r944). Transpiration was then measured by weighing the plants, after the

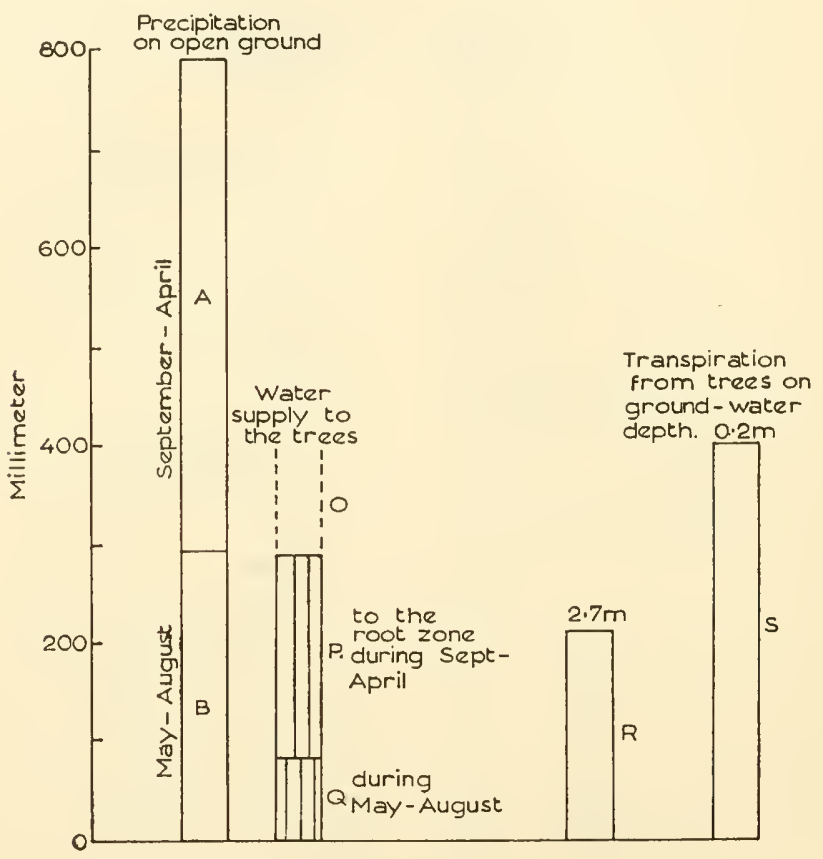

Fig. 3. Comparison between transpiration and water supply of the trees. $A$ and $B$. As in Fig. I. $O, P, Q$. Water supply to the trees from the soil below them and in the gaps, as well as from the water-absorption of the needles. O. Moisture supply from the ground-water and from the water-absorption of the needles. Quantity not definitely known. P. $202 \mathrm{~mm}$ ( $4 \mathrm{I} \%$ of $495 \mathrm{~mm}$ ). Mean value for 5 spruces, and for the root zone of the trees under the crowns and in the gaps. Q. $87 \mathrm{~mm}(29 \%$ of $298 \mathrm{~mm}$ ); otherwise as in $P . R$ and S. Transpiration. R. 2 II $\mathrm{mm}(7 \mathrm{I} \%$ of $298 \mathrm{~mm}$ ). Mean value for 8 trees ( 5 in $P$ and $Q$ and 3 other trees on the same site), with a ground-water depth of $2-7 \mathrm{~m}$. S. $378 \mathrm{~mm}$ ( $127 \%$ of $298 \mathrm{~mm}$ ). Mean value for 3 trees, with a ground-water depth of about $0.2 \mathrm{~m}$.

roots had been freed from soil by suspending them in water, and wrapped in aluminium foil. After several weighings, the stem was severed close to the root and weighing continued for the next 5 minutes. In some cases 
transpiration increased after cutting the stem, whereas in other cases it decreased. The number of decreases was, however, greater than the number of increases, and transpiration was about 10\% lower after cutting the sample than before it.

Allerup (1959), using 7- to Io-day-old wheat plants grown in water culture, found an increase in transpiration after cutting stem or root in air, immediately or shortly after this process. He assumed that the plants were well supplied with water, since they were taken from a water culture. It therefore appears, he says, 'reasonable to assume that in order to find an increase in transpiration upon cutting, it is necessary to ensure that transpiring parts of plants have ample available water reservoirs ...' (p. 9I2). For this reason, Allerup criticised my experiments with spruce (I944), and stated that my failure to find an increase in transpiration in all my experiments must probably be attributed to the fact that the plants used had different water reserves. He also suggested that the plants I used had injured roots, since they had been freed from soil by suspension directly before the experiment.

With respect to the question of whether or not the experimental plants should be water-saturated, it must be stressed that my control experiments were not only intended to test how the plants reacted when water-saturated, but also how plants with a varying water deficit reacted to cutting. My transpiration measurements on spruce were, in fact, made at different times of the day, and on days with varying weather-during both rainy and dry periods. Consequently, they were made on objects which almost invariably had a water deficit of varying degree. Normally, there is an initial water deficit in the morning-when transpiration starts-and it increases in the course of the day. Furthermore, the deficit is lowest immediately after a rainy period, and rises with increasing length of the subsequent dry period. It was in order to make the control measurements comparable with measurements of the transpiration of forest trees under normal conditionsthat is, with varying degrees of water deficit-that I used spruce plants that also had a varying water deficit.

I do, on the contrary, attach greater importance to Allerup's other criticism, namely, that possible injury to the roots may have influenced the reaction after cutting the stem. I therefore repeated these experiments, but using spruce plants that had been allowed to grow in a nutrient solution for some weeks beforehand. The plants were 2 years old, and were taken from a plant nursery.

After the roots had been freed from soil by suspension in water, the plants were placed in a nutrient solution for $6-8$ weeks before starting the experi- 
ment. Transpiration was then measured in the same way as earlier. Thus, the root system was wrapped in aluminium foil. The plants were then placed on a scale on which rapid readings could be made. They remained on the scales during the whole experimental period, during which they were exposed to illumination of about i $5,000 \mathrm{~m}$ candles. The weight was read off every 2 or 3 minutes. After IO-I 5 minutes, the stem was severed at the base, the plants were weighed at once, and then every other minute for 6 minutes. Before the experiment, the plants were allowed to transpire with or without a water supply for a varying period. This resulted in a water deficit ranging from o to $32 \%$.

In 28 such experiments, either an increase or a decrease in transpiration occurred during the first 6 minutes after cutting. In 12 of these cases an increase occurred, and in 16 cases a decrease. In another such experiment, the value remained unchanged. As in the earlier measurements (I944), the sum of the decrease in the individual experiments was about $10 \%$ greater than the sum of the increase.

The results are in agreement with the measurements made by Rutter (I959) on Pinus sylvestris. Rutter compared the transpiration of 3-year-old plants which could be weighed intact in pots, and of detached branches, in the 10 minutes following cutting. He found that the transpiration of the detached branches was about $12 \%$ less than that of undamaged plants. Similar results were obtained by Rawitscher (1955) in a study of Coffea arabica, and by Parker (1957), who investigated Pinus strobus L. in the same way. The latter author stated that transpiration of excised twigs or fascicles 'declined only slightly after severing in the subsequent 6 minutes'.

Consequently, the possible root damage that occurred in my earlier measurements (1944) cannot have had any appreciable effect on the results, as was claimed by Allerup (1959). The results do not, in any case, conflict with Allerup's experiments and conclusions. This is because the spruce plants used in my experiments lacked the ample water supply considered by him to be a prerequisite for an increase in transpiration after cutting. Thus, according to the control measurements, the mean values for transpiration given by the momentan method are not higher-but are rather lower-than the transpiration immediately before the organ is severed. This is provided that the measurements are limited to the minutes directly after cutting. It was for this reason that I chose the 'momentan method' for measuring the transpiration of the II experimental trees.

The needles from the last 5 years were used for the measurement. The samples were taken at various levels of the crown, up to $6 \mathrm{~m}$ above the ground, and from all sides of the trees. From 7-8 measurements were made 
each day. The daily transpiration was calculated from these values. The quantity of needles (in kilogrammes) per tree was also measured at the end of the experimental period. The number of experimental days was 42 , distributed over the months of May-August during 4 years. The days were chosen irrespective of the weather, except that measurcments were not made on days when it rained for more than 4 hours.

The total transpiration during the 4 months of May-August was calculated from the mean values of the daily measurements. For trees on dry sites it amounted to 2 II mm, and for trees on damp sites to $378 \mathrm{~mm}$, calculated as the precipitation on the root zone of the trees under the crowns and in the gaps.

Naturally, I am aware that the method has its deficiencies. The greatest error is probably that the transpiration measurements were made on samples taken only from the lower third of the crowns, and that the samples were allowed to transpire at a level of merely $\mathrm{I}-2 \mathrm{~m}$ above the ground. The trees were about $20 \mathrm{~m}$ high. At the natural site of the samples-higher up in the crowns of the trees-there are greater opportunities of evaporation. This applies particularly to the upper half of the crowns. This error can be expected to have a one-sided effect on the experiments, resulting in the values for transpiration being too low. Obviously, extrapolation of shortterm values to longer periods, such as days and months, is an additional source of error. Even so, I consider that the deficiencies and difficulties of the momentan method are less than those inherent in other methods for measuring the water consumption of plants under natural conditions.

A comparison between the water consumption of the trees and the supply of precipitation to the roots is shown in Fig. 3. It can be scen that the trees on a dry site ( $R$ in Fig. 3 ) utilise a quantity of water corresponding to the precipitation supplied to their roots during the summer and, in addition, a considerable part of the precipitation stored in the ground during the autumn and winter. On a damp site ( $S$ in Fig 3 )-where the roots of the trees reach the ground-water-the quantity of water consumed represents the entire annual precipitation in the root zone, as well as part of the ground-water. Thus, at damp sites, the trees have a draining effect on the soil.

How the water supply to the root zone influences the consumption of the trees can be seen from a comparison made between the trees on the two sites during a rainy and a dry period, respectively. It was found that the trees on the damp site transpired about as much $(0.73$ and $0.74 \mathrm{~kg}$ of water per $\mathrm{kg}$ of needles per day) during both periods. Their water consumption was thus practically independent of the current precipitation. The water consumption of the trees on the dry site was about as large $(0.69 \mathrm{~kg})$ during 
the rainy period. However, during the subsequent period of dry weather, the values fell to $0.57 \mathrm{~kg}$ even after a few days, so that the consumption became less than on the damp site. The difference between the values $R$ and $S$ in Fig. 3 is due to such differences in water supply.

The water consumption of trees on a dry site is thus dependent on the current precipitation, and is limited by it. Had more water been available, the consumption would have been greater, and probably as great as that of the trees on a damp site.

The total quantity of water reaching the root zone of the trees-that is, the sum of $P$ and $Q$ in Fig. 3-is $289 \mathrm{~mm}$, and the transpiration of the trees 2 I I mm. The difference, $78 \mathrm{~mm}$, consists of water that has evaporated, and possibly of the surface run-off on frozen ground as well. No excess water capable of sinking to the ground-water is, on the other hand, present on the dry site (distance from the water table $2-7$ metres). It was possible, by means of special measurements, to establish that the precipitation that had sunk through the moss and litter layer had remained chiefly in the $20-\mathrm{cm}$ thick uppermost layer of the mineral soil. The water that sinks deeper $(5 \%$ during the summer and $23 \%$ during the winter) reaches a maximal depth of $70-100 \mathrm{~cm}$, but can be carried further by diffusion, and penetrate to a depth of about $\mathrm{I} 50 \mathrm{~cm}$ in the morainic soil. The water is subsequently returned to the root zone, when the latter becomes dry.

According to these measurements, interception is the largest debit item in the water economy of woods. Partly on this account, the wood's need of precipitation is probably greater than that of other plant communities. An example has been given by Rutter (1959) who found the water consumption of an I 8-year-old Pinus sylvestris plantation to be I $5-36 \%$ greater than that of grass.

The many-layered structure characterising naturally-growing woods-as well as their large leaf surface per unit of ground surface-gives these plant communities a transpiration capacity that requires an ample water supply to be fulfilled. Since the supply is diminished to such a great degree by interception, it can be presumed that woods on the mainland have sufficient water only on such occasions when precipitation is so plentiful, and so frequent, that the soil is kept constantly damp. But if the precipitation amounts to only 600-1000 $\mathrm{mm}$ a year-as in most regions of Scandinaviaprecipitation-free periods of one or several weeks are common. Under such conditions, transpiration can take place without restriction only during a few days after plentiful rain. During the rest of the time, consumption is restricted by the lack of water, so that the transpiration regulators of the plants come into action. 
It has, in fact, been found that if the changes in the stomatal values are followed over a long period-in the spruce, for example-a large and persistent stomatal width is present only during the first few days after a downpour (Stallfelt, 1926, I929, p. 324). The width and duration of opening subsequently decrease, as the soil dries out. After some time, the stomata are found to be open only in the morning, and still later only during an hour or so directly after sunrise. Similar observations have been made by Pisek and Cartellieri (193 I, I939), Pisek and Tranquillini (I95I) and by Rutter and Sands (1958).

In the present investigation, water consumption was $167 \mathrm{~mm}$ more on the damp sites than on the dry ones. But during the rainy periods-when the soil was wet through-transpiration was about as large in both kinds of trees. It was not until the rain had ceased, and the ground had started to dry, that transpiration began to decrease in the trees on the dry sites, whereas it remained practically unchanged in those on the damp sites. On dry sites, consumption is limited by the water supply. The trees utilise the water supplied during the winter-or that stored in the soil from the winter months-and they would be able to consume more if the supply were greater.

\section{REFERENCES}

AlleruP, S. (1959) Transpiration and water movement in young wheat plants. Physiol. Plant. I2, 907.

Eger, G. (1958) Untersuchungen zur Methode der Transpirationsbestimmung durch kurzfristige Wägung abgeschnittener Pflanzenteile besonders an Wiesenpflanzen. Flora, 145, 374.

PARKER, J. (1957) The cut leaf method and estimations of diurnal trends in transpiration from different heights and sides of an oak and a pine. Bot. Gaz. I I9, 93.

Pisek, A. \& Cartellieri, E. (I93 I) Zur Kenntnis des Wasserhaushaltes der Pflanzen. I: Sonnenpflanzen. Jb. wiss. Bot. 75, I95.

Pisek, A. \& Cartellieri, E. (1939) Zur Kenntnis des Wasserhaushaltes der Pflanzen. IV : Bäume und Sträucher. Jb. wiss. Bot. 88, 22.

Pisek, A. \& Tranquillini, W. (I95I) Transpiration und Wasserhaushalt der Fichte (Picea excelsa) bei zunehmender Lufttrockenheit. Pliysiol. Plant. 4, I.

Rawitscher, F. (I955) Beobachtungen zur Methodik der Transpirationsmessungen bei Pflanzen. Ber. disch. bot. Ges. 68, 287 .

Rutter, A.J. (1959) Evaporation from a plantation of Pinus sylvestris in relation to meteorological and soil conditions. Int. Ass. Sci. Hydrol., Publ. 48. Ior.

RutTer, A.J. \& SandS, K. (I958) The relation of leaf water deficit to soil moisture tension in Pinus sylvestris L. Variation in the relation caused by developmental and environmental factors. New Phytol., 57, 387 .

STÅlfelt, M. G. (1926) Die Abhängigkeit der 'Stomatären Diffusionskapazität' von der Exposition der Objekte. K. Svenska Vet. Akad. Handl. Ser. 3, Band 2, Nr. 8. 
StÅlfelt, M.G. (I939) Die Abhängigkeit der Spaltöffnungsreaktionen von der Wasserbilanz. Planta, 8, 287.

STÅLfELT, M.G. (I944) Granens vattenförbrukning och dess inverkan på vattenomsättningen i marken. K. Lantbruksakad. Tidskr. 83, 3 .

Stocker, O. (1929) Eine Feldmethode zur Bestimmung der momenthanen Transpirations- und Evaporationsgrösse. Ber dtsch. bot. Ges. 47, I 26. 


\title{
MEASUREMENT AND SIGNIFICANCE OF THROUGHFALL IN FOREST STANDS
}

\author{
E.R.C.ReYNOLDS \& L.LEYTON
}

Department of Forestry, Oxford University

\section{INTRODUCTION}

MuCH work is currently in progress attempting to measure the water balance of vegetative covers, and very frequently, these investigations are made on a comparative basis to obtain information relevant to the problem of land use and water supply. However, to discriminate between vegetative types in this way, it is essential that the various parameters of the water balance should be measured by techniques which give data of adequate and measurable precision.

Some of these techniques have been examined in a woodland near Oxford. In a small plantation of I 7-year-old Picea abies (L.) Karst., a square plot (side I $40 \mathrm{ft}$ ) was marked out, and for sampling purposes, a one-foot grid superimposed; random positions within the stand were defined by coordinates drawn from tables of random numbers. The average distance of one tree from another was $4 \frac{1}{2} \mathrm{ft}$ and the mean tree height at the beginning of 1959 was $26 \mathrm{ft}$. Methods of estimating different phases of the water balance (gross precipitation, throughfall, evaporation from the woodland floor, the transpiration of the trees and the soil moisture) are being studied, but only work on the first two have advanced sufficiently to report in this paper.

\section{PATTERN OF THROUGHFALL}

Throughfall is defined as the precipitation which reaches the ground under the trees; included in this is stem flow, which is commonly measured separately.

A definite pattern of throughfall distribution was detected by using twenty gauges with small collecting areas (the British Meteorological Office standard 5 in. diameter rain gauge), distributed at random within the plot. This pattern can be represented by linear regressions of catch on distance from the stem, as shown in Table I. Evidently, the tree crowns were sufficiently close to each other to allow for such simple linear regressions despite the presence of a drip zone located near the edge of the crown where somewhat higher throughfall is found than under gaps in 
TABLE I

Throughfall distribution patterns under young Spruce, 1959 $Y=$ throughfall in inches, $x=$ distance from tree stem in inches

\begin{tabular}{|c|c|c|c|c|c|}
\hline \multirow[b]{2}{*}{ Period } & \multirow{2}{*}{$\begin{array}{l}\text { Inches } \\
\text { gross } \\
\text { rainfall }\end{array}$} & \multicolumn{2}{|c|}{ Stationary s-in. gauges } & \multicolumn{2}{|c|}{ Moved 5-in. gauges } \\
\hline & & Regression & $r$ & Regression & $r$ \\
\hline I $3.4-10.6$ & $2 \cdot 2 I$ & & & $Y=0.63+0.029$ & $0.65 t$ \\
\hline $10 \cdot 6-24 \cdot 7$ & $I \cdot 62$ & & & $Y=0.26+0.027$ & $0 \cdot 79^{\star}$ \\
\hline $24 \cdot 7-30 \cdot 7$ & I.07 & $Y=-0.03+0.028 x$ & $0.8 I^{\star}$ & $Y=0.22+0.017$ & $0.67 t$ \\
\hline $30 \cdot 7-14 \cdot 8$ & I. 68 & $Y=0.24+0.042 x$ & $0 \cdot 77^{\star}$ & $Y=0.12+0.048$ & $0.8 I^{\star}$ \\
\hline I $4 \cdot 8-22 \cdot$ IO & $I \cdot 29$ & $Y=0.20+0.025 x$ & $0.75^{\star}$ & $Y=0.53+0.013$ & 0.42 \\
\hline $22 \cdot$ IO -4 II & $\mathrm{I} \cdot 03$ & $Y=0.26+0.015 x$ & $0.64^{\star}$ & $Y=0.41+0.009$ & $0.50 \neq$ \\
\hline $4 \cdot I I-I S \cdot I I$ & $\mathrm{I} \cdot \mathrm{O} 2$ & $Y=0.2 \mathrm{I}+0.016 x$ & $0 \cdot 74^{\star}$ & $Y=0.36+0.010$ & $0.56 \div$ \\
\hline
\end{tabular}

24.7 -I 8.I I $6.09 \quad Y=0.87+0.13 x \quad 0.79^{\star}$

$\star$ Significant at $0 \cdot \mathrm{r} \%$ level, $\uparrow$ at $\mathrm{x} \%$ level and $\ddagger$ at $5 \%$ level. (Gauges not moved between 10.6 and 30.7 .)

the canopy (see Fig. 1). However, perhaps the most marked discontinuity in the pattern of throughfall occurs near the stem where water trickling down the trunk is concentrated over a small but ill-defined area around the base. Stem flow has been measured on twenty trees selected at random within the stand. If we express this part of the throughfall arbitrarily in terms of the projected area of the trunk at $4 \frac{1}{4} \mathrm{ft}$, i.c. 'breast height' (B.H.), the mean stem flow (Table 2) varied between four and twenty times the incident rainfall.

\section{IMPLICATIONS OF THROUGHFALLDISTRIBUTION}

During certain periods, the uneven distribution of throughfall below a forest stand will lead to an uneven distribution of soil moisture and this may have some important consequences; however, surprisingly few systematic investigations have been made into this phenomenon. Voigt (1960) investigated the effect under considerably larger trees of the species Tsuga canadensis and Pinus resinosa, using fibre-glass resistance units at four depths down to two feet, at each of five points along a radius of the tree crown. With Tsuga, stem flow increased soil moisture near the trunk, but only at shallow depths; with Pinus, although stem flow itself had no measurable effect, increasing throughfall with increasing distance from the tree was reflected in increasing soil moisture even down to a depth of two feet. 
TABLE 2

Stemflow in young spruce, 1959. (Means of 20 trees)

\begin{tabular}{|c|c|c|c|c|}
\hline Period & $\begin{array}{l}\text { Inches } \\
\text { gross } \\
\text { rainfall }\end{array}$ & $\begin{array}{l}\text { Volume } \\
\text { per trec } \\
\text { (cu. in.) }\end{array}$ & $\begin{array}{l}\text { Contribution } \\
\text { to total } \\
\text { throughfall } \\
\text { (in.) }\end{array}$ & $\begin{array}{l}\text { Stem flow } \\
\text { based on B. } \\
\text { area (in.) }\end{array}$ \\
\hline $10 \cdot 6-24 \cdot 7$ & $I \cdot 62$ & $8 \mathrm{I}$ & 0.02 & $7 \cdot 3$ \\
\hline $24 \cdot 7-30 \cdot 7$ & I.07 & 92 & 0.03 & $8 \cdot 2$ \\
\hline $30 \cdot 7-\mathrm{I} 4 \cdot 8$ & $I \cdot 68$ & 264 & 0.07 & $23 \cdot 6$ \\
\hline $\mathrm{I} 4 \cdot 8-22 \cdot 10$ & $I \cdot 29$ & 220 & 0.06 & I9.7 \\
\hline $22 \cdot \mathrm{IO}-4 \cdot \mathrm{II}$ & $\mathrm{I} \cdot \mathrm{O} 3$ & I93 & 0.05 & $17 \cdot 3$ \\
\hline $4 \cdot$ I I-I $8 \cdot$ I I & I $\cdot 02$ & 232 & $0 \cdot 06$ & $20 \cdot 7$ \\
\hline $24 \cdot 7-I 8 \cdot I I$ & 6.09 & IOOI & 0.27 & 89.5 \\
\hline
\end{tabular}

In the present investigation, we have installed resistance units and tensiometers along a random radius of each of six trees. The distances from the stem are respectively, $0 \%, 40 \%$ and $95 \%$ of the radius of the tree crown, as well as halfway across the adjacent opening in the canopy. The depths at each of these points are dependent on the depth to impermeable clay, but the shallowest is at one foot and there are three locations at greater depths. Preliminary results have indicated the presence of a soil moisture pattern corresponding with that of throughfall, which we hope to confirm with further measurements.

The uneven distribution of soil moisture would be expected to influence evaporation from the forest floor, and this should be borne in mind when measuring evaporation as a factor in the water balance. Drainage might also be affected; it is therefore neither sufficient to take samples for soil moisture measurement, nor to install soil moisture detcctors, without taking into account the possibility of local sinks. It would be interesting and important to know whether greater water abstraction by tree roots coincides with areas of the woodland floor receiving greater quantities of water. Under some conditions, leaching too might be expected to show a correspondingly uneven pattern, with consequent pedological implications. For example, Stewart (1960, unpublished) has reported an increasing depth of $\mathrm{A}_{2}$ horizon in a podzol below Scots Pine with increasing distance from the stem. Since the micro-environment of the forest floor is also affected by throughfall distribution patterns, this might underlie certain observed distributions of regeneration and of soil organisms. 

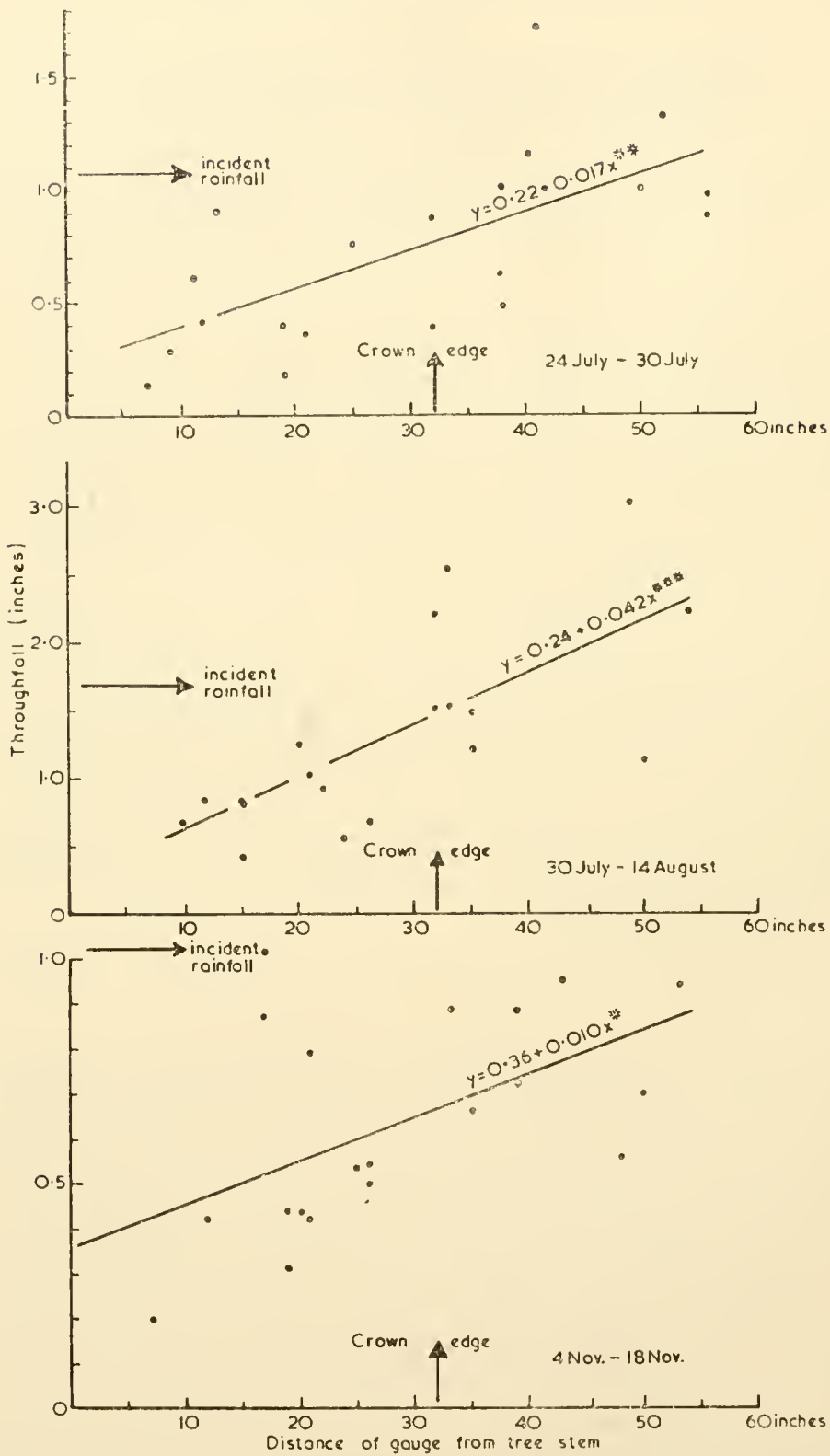

FIG. I. Relationship of 5 -in. gauge catch on position beneath trees for three periods, 1959. 
The importance of total throughfall in a stand is that it often represents all the water available for transpiration and drainage. Its accurate measurement is therefore of considerable hydrological significance. The presence of a pattern of throughfall distribution, however, introduces certain complications which have not always been appreciated by workers in this field.

\section{MEASURING TOTAL THROUGHFALL}

Because of the spatial variability of throughfall, a sampling technique must be selected which provides an estimate with an appropriate statistic of this variability; in the present case we will employ the standard error expressed as a percentage of the mean. One object of the present investigation was to compare the efficiencies of various measuring techniques.

Some difficulty has been experienced in the past in keeping the standard error of throughfall estimates, exclusive of stem flow, sufficiently low and yet maintain a manageable set up.

Wilm and Niederhof (194I) found that estimates based on stationary gauges in forest stands were subject to large standard errors. To improve the sampling procedure, Wilm (1943) employed a single 8-in. gauge in each experimental plot, moving it after every storm, to one of twelve random positions. However, this experimental design did not achieve the desired precision, and calculations suggested that the number of alternative positions in each plot should have been increased to forty.

In Yorkshire, Law (1957) adopted a somewhat similar approach, but used a rather restricted randomisation of ten 5 -in. gauges beneath a stand of Sitka spruce, moving each of these after approximately equal amounts of rain to one of thirty-six alternative positions. Over a period of a whole year, though not for shorter periods, he obtained a standard error of almost I $2 \%$ : for a strictly random (but less practicable) design, the corresponding figure was $6.4 \%$.

In the present investigation with twenty 5 -in. gauges sited at random in the plot, large standard errors were also found (simple S.E., Table 3).

An attempt has been made to increase the precision of the estimates from stationary gauges by taking into account the relation between catch and the distance from the stem, as presented in Table I. From the appropriate regression equation, the catch was calculated for the mean position under the canopy (estimated for a large number of random locations), and the standard error of this value determined, taking into account the variance of the estimate of mean position. Niederhof and Wilm (I943) used a somewhat similar approach but over a much greater range of canopy conditions. 
TABLE 3

Standard errors of Stationary s-in. gauges, 1959. (Expressed as \% mean)

\begin{tabular}{|c|c|c|c|}
\hline Period & $\begin{array}{l}\text { Simple } \\
\text { S.E. }\end{array}$ & $\begin{array}{l}\text { Regression } \\
\text { method }\end{array}$ & Stratification \\
\hline $24 \cdot 7-30 \cdot 7$ & $I 4^{\cdot} \mathrm{I}$ & $9 \cdot I$ & $9 \cdot 3$ \\
\hline $30 \cdot 7-14.8$ & II $\cdot 7$ & $8 \cdot I$ & $8 \cdot 4$ \\
\hline I $4 \cdot 8-22 \cdot 10$ & $I I \cdot I$ & $7 \cdot 8$ & $8 \cdot 5$ \\
\hline $22 \cdot 10-4 \cdot \mathrm{II}$ & $9 \cdot 0$ & $6 \cdot 5$ & $6 \cdot 8$ \\
\hline $4 \cdot \mathrm{II}-\mathrm{I} 8 \cdot \mathrm{II}$ & $9 \cdot 7$ & $6 \cdot 9$ & $7 \cdot 6$ \\
\hline $24 \cdot 7-I 8 \cdot I I$ & $10 \cdot 9$ & $7 \cdot 3$ & $7 \cdot 8$ \\
\hline
\end{tabular}

In the present investigation, there was some improvement in precision compared with that of the simple mean (Table 3).

As another approach (cf. Kittredge et al., 194I), the data were stratified into three zones corresponding to $<50,50-80$ and $>80 \%$ of the crown radius; the use of relative positions of the gauges under the crown allows for variations in crown size. The areas of these zones were readily calculated from a number of random locations. For each zone, the mean catch and its variance were calculated, and a value obtained for the stand as a whole by weighting the means according to the areas represented. The standard errors obtained (Table 3 ) were again about 0.7 times those associated with the simple mean of all the gauges, and so still rather large.

Besides these mathematical methods, the effect of moving another set of twenty 5 -in. gauges to new random positions after approximately each inch of incident precipitation was tested. As is evident from Table 4, over a period of four months involving five different gauge distribution patterns, the standard error of $5.7 \%$ indicated a definite improvement over the stationary gauges, although the variability within any individual distribution pattern was similarly high.

A more logical solution to the problem of measuring precipitation under trees would be to increase the gauge size so as to integrate the throughfall pattern over a larger area.

In Germany, Delfs (I955) reports the use of troughs $20 \mathrm{~cm}$ wide and $5 \mathrm{~m}$ long, but, in the absence of replicated measurements, no information is available as to the precision of the estimates, and it is impossible to decide therefore, whether or by how much troughs are superior to small gauges.

Troughs have also been tested in the present investigation; these had rectangular collecting areas, $3 \mathrm{ft} \times 2 \mathrm{ft}$, i.c. forty-four times that of the 5 -in. gauges. Twenty troughs were placed in the area with their centres at 


\section{TABLE 4}

Standard errors of moved gauges, troughs and stem gauges, I959.

(Expressed as \% mean)

\begin{tabular}{|c|c|c|c|}
\hline Period & $\begin{array}{l}\text { Moved } \\
\text { s-in. gauges }\end{array}$ & Troughs & $\begin{array}{l}\text { Stem } \\
\text { gauges }\end{array}$ \\
\hline $13.4-10.6$ & $10 \cdot 2$ & - & - \\
\hline $10 \cdot 6-24 \cdot 7$ & I I 9 & $5 \cdot 5$ & $24 \cdot 0$ \\
\hline $24 \cdot 7-30 \cdot 7$ & $12 \cdot 6$ & $6 \cdot 6$ & $20.5^{\circ}$ \\
\hline $30 \cdot 7-14 \cdot 8$ & $12 \cdot 8$ & $6 \cdot 6$ & I $6 \cdot 9$ \\
\hline $14 \cdot 8-22 \cdot 10$ & 10.6 & $6 \cdot 4$ & I $6 \cdot 7$ \\
\hline $22 \cdot 10-4 \cdot I I$ & $8 \cdot 4$ & $5 \cdot 0$ & I $8 \cdot 7$ \\
\hline $4 \cdot$ I I-I $8 \cdot$ I I & $8 \cdot 2$ & $4 \cdot 8$ & I $8 \cdot 2$ \\
\hline $24 \cdot 7-18 \cdot I I$ & $5 \cdot 7$ & $5 \cdot 6$ & 16.9 \\
\hline
\end{tabular}

(5-in. gauges not moved between 10.6 and 30.7.)

random locations. The results (Table 4 ) show that for long or short periods, the standard errors of the estimate ranged around $6 \%$. Over a four month period, there was little to choose between moved gauges and the troughs and, although with more frequent moving, 5 -in. gauges would be expected to give a still smaller standard error, the increase in labour should not be minimised.

The desired level of precision will be dependent of course, on the precision of the measurements of any other phases of the water balance with which throughfall is intended to be combined. Although much depends on local conditions and on the application of the data, for many purposes a standard error of about $5 \%$ of the mean would appear to be acceptable.

It must be emphasised that it is the reliability or precision of the estimates of total throughfall obtained by various methods which is being examined. The mean values given in Table 5 indicate differences of up to $5 \%$ between the various estimates.

It is necessary to point out that the trough size adopted was almost certainly not the most efficient for the pattern of throughfall which occurred in this plantation. This pattern is related to the spacing and habit of the trees, and the troughs were a little less than a quarter of the mean area occupied by a tree. The size of the troughs used was still small enough to reflect the relationship between catch and distance of the trough centre from the surrounding trees (see Fig. 2).

Although the results have not shown it, troughs are more susceptible 
TABLE 5

Comparison of mean catch by various methods, 1959. (Inches of water)

\begin{tabular}{|c|c|c|c|c|c|}
\hline \multirow[b]{2}{*}{ Period } & \multicolumn{3}{|c|}{ Stationary 5 -in. gauges } & \\
\hline & $\begin{array}{l}\text { Simple } \\
\text { Mean }\end{array}$ & Regression & Stratification & $\begin{array}{l}\text { Moved } \\
\text { s-in. gauges }\end{array}$ & Troughs \\
\hline I $3.4-10 \cdot 6$ & - & - & - & $I \cdot 36$ & - \\
\hline $10.6-24.7$ & - & - & 一 & $\mathrm{I} \cdot 09^{\star}$ & $\mathrm{I} \cdot 08$ \\
\hline $24 \cdot 7-30 \cdot 7$ & 0.70 & $0 \cdot 74$ & 0.74 & $0.73^{\star}$ & $0 \cdot 70$ \\
\hline $30 \cdot 7-14 \cdot 8$ & $I \cdot 35$ & $I \cdot 40$ & $I \cdot 4 I$ & I 19 & $I \cdot 3 I$ \\
\hline $14 \cdot 8-22 \cdot 10$ & 0.86 & 0.89 & 0.89 & 0.92 & 0.84 \\
\hline $22 \cdot 10-4 \cdot I I$ & 0.65 & 0.67 & 0.67 & 0.66 & 0.65 \\
\hline $4 \cdot$ I I-I $8 \cdot 1$ I & 0.64 & 0.66 & 0.66 & 0.64 & 0.68 \\
\hline $24 \cdot 7-\mathrm{I} 8 \cdot \mathrm{II}$ & $4 \cdot 20$ & $4 \cdot 36$ & $4 \cdot 37$ & $4 \cdot 14$ & $4 \cdot 19$ \\
\hline
\end{tabular}

( ${ }^{\star}$ Not moved between 10.6 and 30.7 .)

to bias than small gauges, simply due to the fact that they cannot be placed with their centres nearer a tree than a distance of half their width. Using a mathematical model approximating to the stand conditions, J.F. Scott (unpublished) has shown that with 5 -in. gauges, this bias may be in the region of $2 \%$, whereas troughs of the dimensions used could increase the estimate by as much as $19 \%$ over the true mean.

For more accurate measurements, annular gauges might well be installed to sample the throughfall in the area which is not adequately sampled by the troughs. There is no reason why such annular gauges should not be made to incorporate stem flow measurement.

Increasing the size of the collecting area through the use of troughs, considerably increases the work of measuring and recording the large volumes of water collected. An automatic measuring system has therefore been devised on the principle of the tipping bucket rain gauge. The movement of the bucket is made to actuate a counter directly, or electrically through a microswitch. The trough collection can then be readily measured at any interval appropriate to the investigation, with a reasonably low standard error, yet without any need to move the gauges or to record the collection at unnecessarily frequent intervals.

Stem flow was measured separately on twenty random trees using a plastic putty collar held in position by a copper band and receiving throughfall within one centimetre of the trunk at a height of $4 \frac{1}{4} \mathrm{ft}$. The percentage 

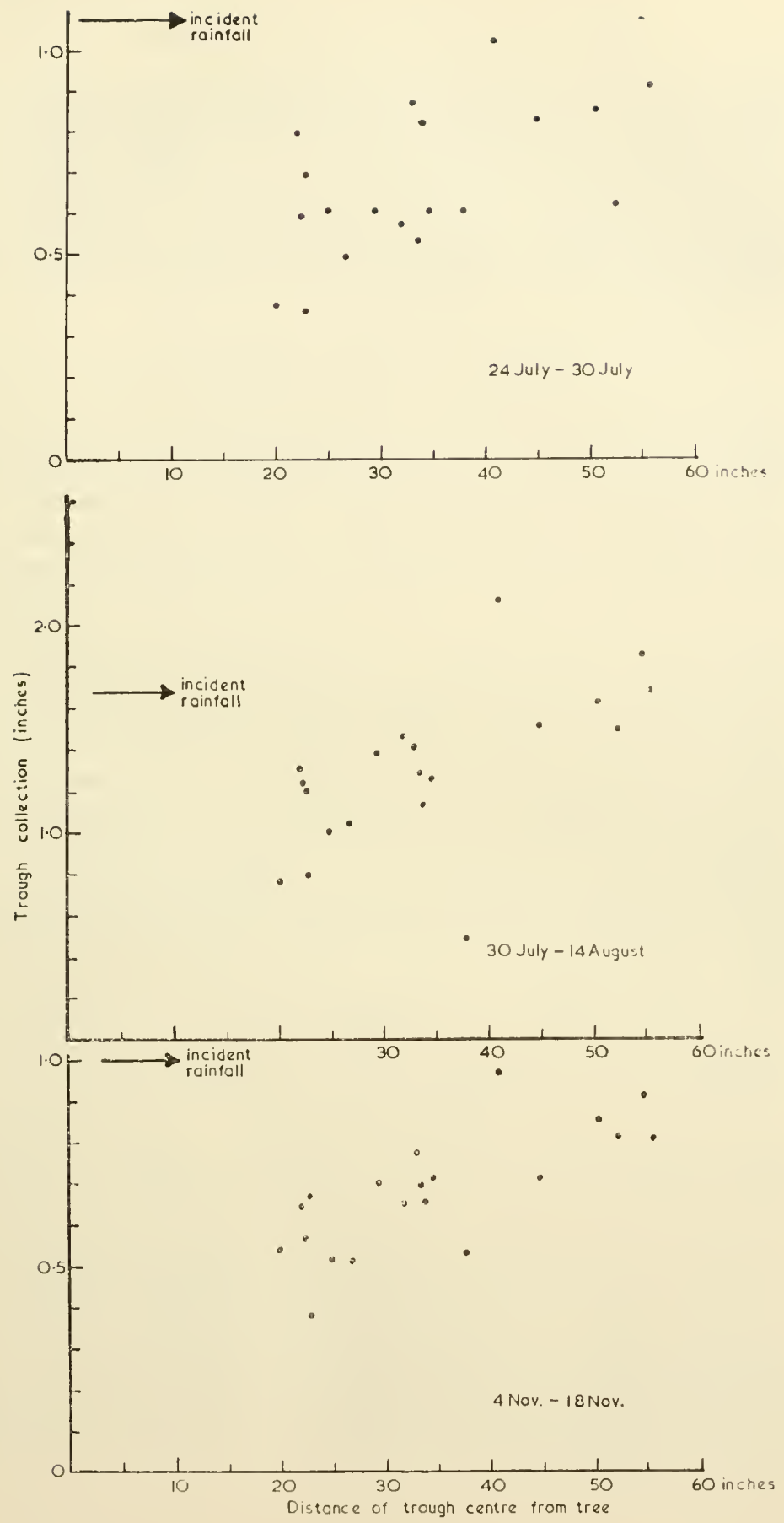

FIG. 2. Relationship of trough collection to position for three periods, I959. 
standard errors were very high (Table 4) but, since the amount collected formed only a small part of the total throughfall (Table 2, column 4), its contribution to the variability of the latter was negligible. If stemflow is investigated as a separate entity, because of its local significance, the regression techniques adopted by Wicht (194I), and by Wilm and Niederhof (194I), offer means of studying the causes of variation, which Voigt (1960) has examined experimentally.

\section{INCIDENT PRECIPITATION}

Commonly, throughfall estimates are deducted from the precipitation incident upon the canopy to determine interception, that is, the amount or proportion of the precipitation which fails to reach the ground. Measurement of incident precipitation, however, is beset with many complications. Usually, it has been measured in adjacent open ground, but this is not always available and the occasional attempts which have been made, using gauges mounted above the trees, have proved generally unsatisfactory. In neither case is it sufficient to append statistics of variability to the mean catch of such gauges; evidence must be presented to support the contention that the measurement is not subject to errors due to difference in location or, in the case of 'tree-top' gauges, to instrumental errors. Instrumental errors associated with rain gauges above trees are considered to be particularly great in areas where wind speeds are appreciable. Under his relatively exposed conditions, Law (1959, unpublished) suggests the addition of $15 \%$ to the catch of gauges elevated io $\mathrm{ft}$ above the tree canopy; this correction was based on the relationship of catches of gauges at different heights over short grass.

For critical investigations into the water balance, it is essential to have estimates of incident precipitation and of its spatial variability over the plantation.

In the present work, therefore, sixteen gauges of various types were installed above the tree crowns (cf. Plate I); these gauges were at random locations. The water was conducted down P.V.C. tubing to ground level and collected in enclosed bottles. Six unshielded 5-in. gauges were placed in the canopy itself, as low as possible to obtain shelter from the wind, yet not so low as to be affected by interception or splash. All other gauges were $38 \mathrm{ft}$ above the ground, Io $\mathrm{ft}$ above the mean tree height at the beginning of 1960 . Eight of these gauges were 5-in. gauges, two being surrounded by $60^{\circ} \mathrm{Nipher} \mathrm{shields} \mathrm{with} \mathrm{a} \mathrm{horizontal} \mathrm{wire} \mathrm{mesh} \mathrm{border,} \mathrm{and}$ six by Alter shields such as are used with the International Standard rain 
gauge. The two remaining gauges were designed by Prof. Thom at Oxford, and have an aerodynamic profile which was shown in wind-tunnel tests to give only a $6 \%$ increase in wind speed immediately above the collecting area; these gauges have two concentric compartments of equal area, to provide internal comparison. In one of the gauges, these chambers are each slightly smaller than the 5 -in. gauge, and in the other, rather larger; in both there is an outer guard chamber. In open ground 350 yds from the plot, a recording rain gauge and two 5 -in. gauges are exposed in the standard manner. As expected, there were differences in catch between gauges of the same type located in different places, and between the various types of gauge. Over several months, the gauges provided with Nipher shields agreed with the standard ground level gauges to within I $\%$, while the catches of the unshielded elevated gauges, the Alter gauges and the larger aerodynamic gauge were lower by about $2 \%$. It should be pointed out that the conditions in this plantation were far less exposed than in that of Law.

Data for selected storms occurring in autumn 1960, have been examined by multiple regression techniques. Up to half the variability between different types of gauge could be attributed to, or was associated with, variables which might be expected to affect evaporation from the gauge, or aerodynamic factors affecting gauge catch (wind velocity, temperature, etc. measured at the centre of the plot above the trees).

It is difficult, if not impossible, to distinguish between local variations of true rainfall and other local climatic variations which effect gauge efficiency. However, the regression approach shows some promise in assessing the capabilities and limitations of the various gauges which might be used to

\section{TABLe 6}

Stem flow, trough catch, incident precipitation and interception. (Inches)

\begin{tabular}{|c|c|c|c|c|c|}
\hline $\begin{array}{l}\text { Period } \\
\text { I959 }\end{array}$ & $\begin{array}{l}\text { Stem } \\
\text { flow }\end{array}$ & $\begin{array}{l}\text { Trough } \\
\text { catch }\end{array}$ & $\begin{array}{l}\text { Total } \\
\text { throughfall }\end{array}$ & \multicolumn{2}{|c|}{$\begin{array}{l}\text { Gross } \\
\text { precipitation Interception }\end{array}$} \\
\hline $10 \cdot 6-24 \cdot 7$ & $0.02 \pm 0.005$ & $\mathbf{I} \cdot 08 \pm 0.059$ & $I \cdot 10 \pm 0.060$ & $I \cdot 62$ & $0.5 I$ \\
\hline $24 \cdot 7-30 \cdot 7$ & $0.03 \pm 0.005$ & $0.70 \pm 0.046$ & $0.70 \pm 0.046$ & $I \cdot 07$ & 0.34 \\
\hline $30 \cdot 7-14.8$ & $0.07 \pm 0.012$ & $\mathrm{I} \cdot 3 \mathrm{I} \pm 0.086$ & $I \cdot 3 I \pm 0.086$ & $\mathrm{I} \cdot 68$ & $0.3 \mathrm{I}$ \\
\hline $14 \cdot 8-22 \cdot 10$ & $0.06 \pm 0.010$ & $0.84 \pm 0.054$ & $0.84 \pm 0.054$ & $I \cdot 29$ & $0 \cdot 39$ \\
\hline $22 \cdot$ IO 4 .I I & $0.05 \pm 0.010$ & $0.65 \pm 0.033$ & $0.65 \pm 0.034$ & $\mathrm{I} \cdot 03$ & 0.33 \\
\hline $4 \cdot$ I I-I $8 \cdot$ I I & $0.06 \pm 0.012$ & $0.68 \pm 0.033$ & $0.68 \pm 0.035$ & $\mathrm{I} \cdot \mathrm{O} 2$ & 0.27 \\
\hline $24 \cdot 7-$ I $8 \cdot$ II & $0.27 \pm 0.046$ & $4 \cdot 20 \pm 0.230$ & $4 \cdot 46 \pm 0.240$ & 6.09 & $\mathrm{I} \cdot 64$ \\
\hline
\end{tabular}


measure incident precipitation above trees. Further work along these lines may suggest the type of gauge subject to the smallest instrumental errors.

\section{INTERCEPTION}

When the water reaching the ground is subtracted from that incident upon the canopy, a figure for interception is obtained. Under our particular conditions, interception was generally about $30 \%$, though occasionally as low as $18 \%$ (see Table 6 ) and is of the same order as figures published elsewhere for forest canopies (e.g. Delfs, 1955). Wider recognition is now being given to the fact that interception losses rarely, if ever, should be interpreted independently of transpirational losses. It is probable that there is an inverse relationship between transpiration from the plant and simultaneous evaporation of intercepted water. Burgy and Pomeroy (1958) have shown that for grasses, evaporation of intercepted water proceeds to an equal amount, and instead of, the transpiration which would have taken place if the foliage had not been wetted. On the other hand, other evidence suggests that the intercepted water evaporates rather more rapidly than that which would have been lost by transpiration. Nevertheless, it is almost certain that transpiration is reduced while intercepted water is being evaporated, and this is supported by consideration of energy relations.

Graphs representing the relationship between incident rainfall and throughfall (cxcluding stem flow) as in Fig. $3 A$, have been extrapolated to determine incident precipitation at zero throughfall. This value has been termed 'canopy saturation', and under the present conditions, is in the region of a twentieth of an inch. Consideration of stem flow (cf. Fig. ${ }_{3} B$ ) indicates that appreciably more rain must fall in the summer months before water begins to trickle down the stems. However, the computation of 'canopy saturation' is very approximate, partly because of the high errors associated with extrapolation, and partly because the relationship necessarily departs from linearity with small storms, since the slightest showers must penetrate canopy gaps. Inclusion of records for small storms in computing the linear regression would therefore slew the line giving a smaller figure for 'canopy saturation'. Curves of this type have also been used to compute mean throughfall for the mean storm size (Wilm, 1943).

\section{CONCLUSION}

Though much useful information on the water cycle in a forest stand might be gained by studies on isolated phases, it is clear that their inter- 
[ facing p. 138 


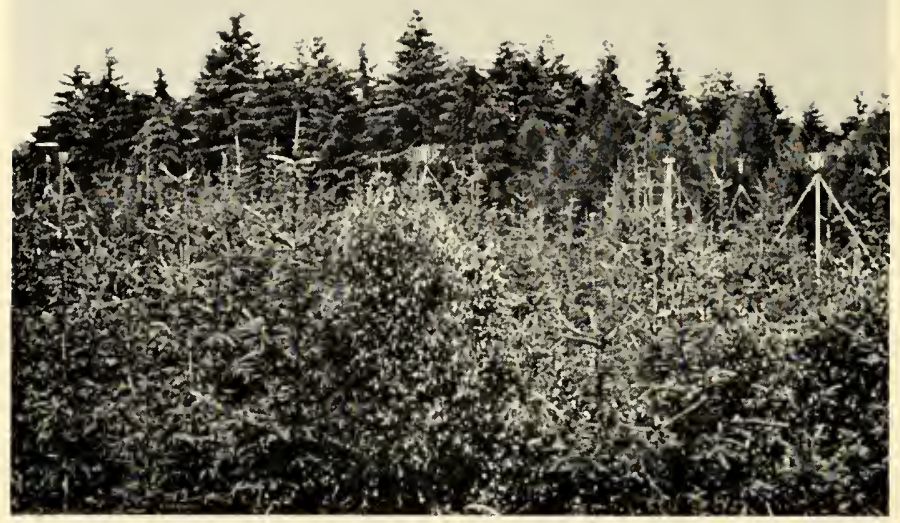

$A$. General view of the stand;

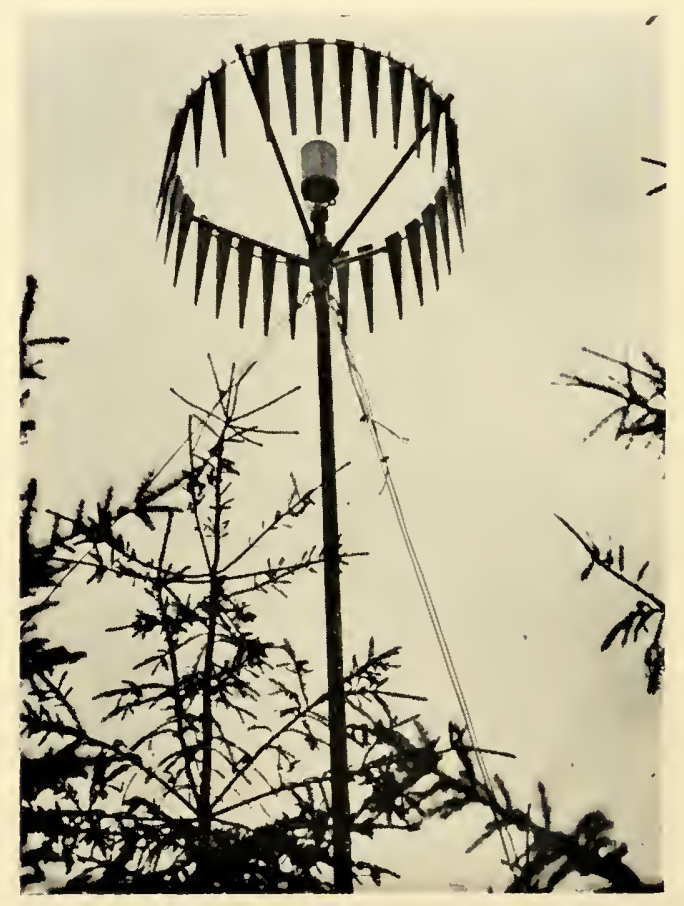

C. Alter shield; 


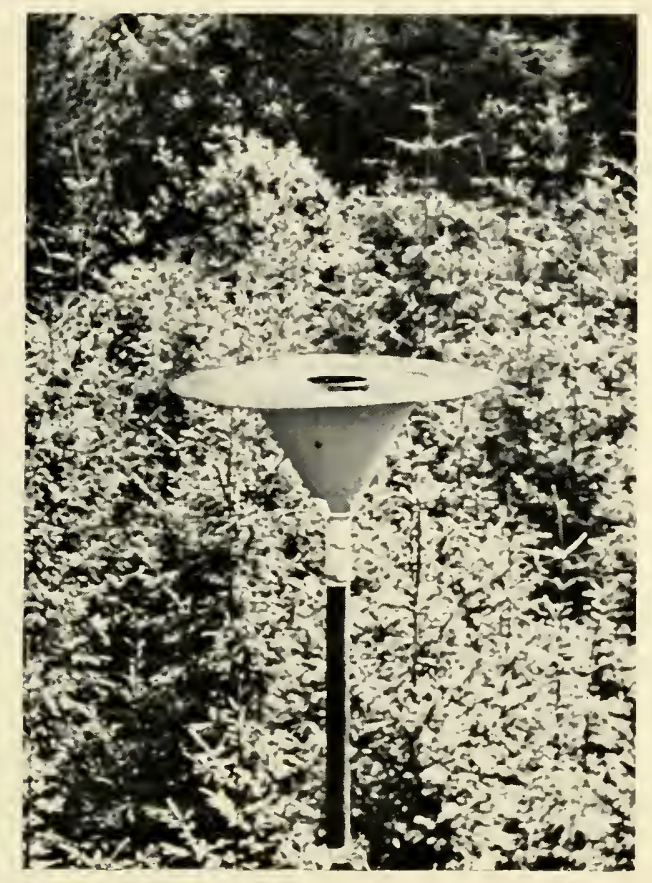

B. $60^{\circ}$ Nipher shield;

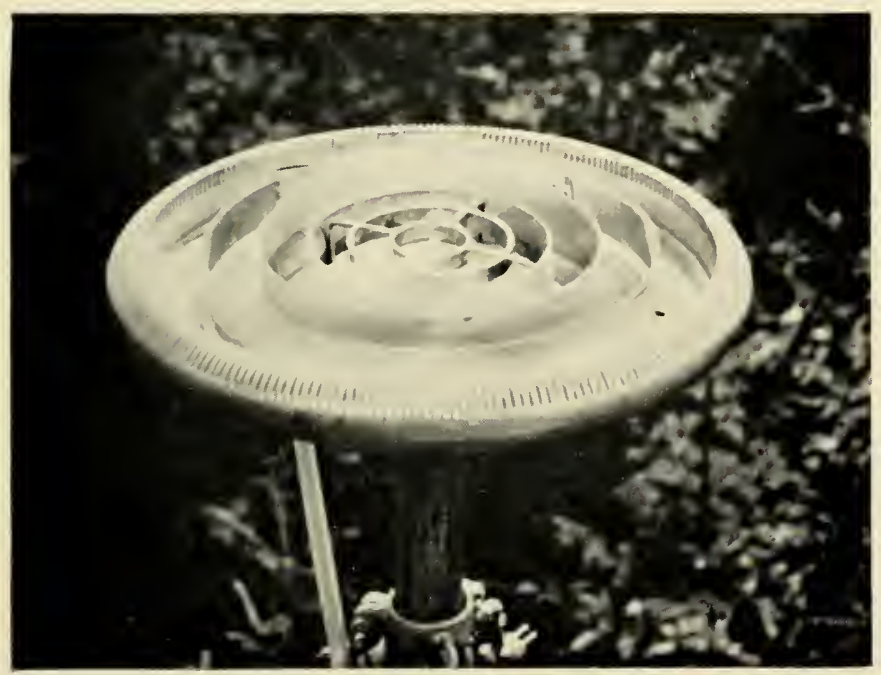

D. Prof. Thom's aerodynamic gauge.

itation incident on the canopy. 


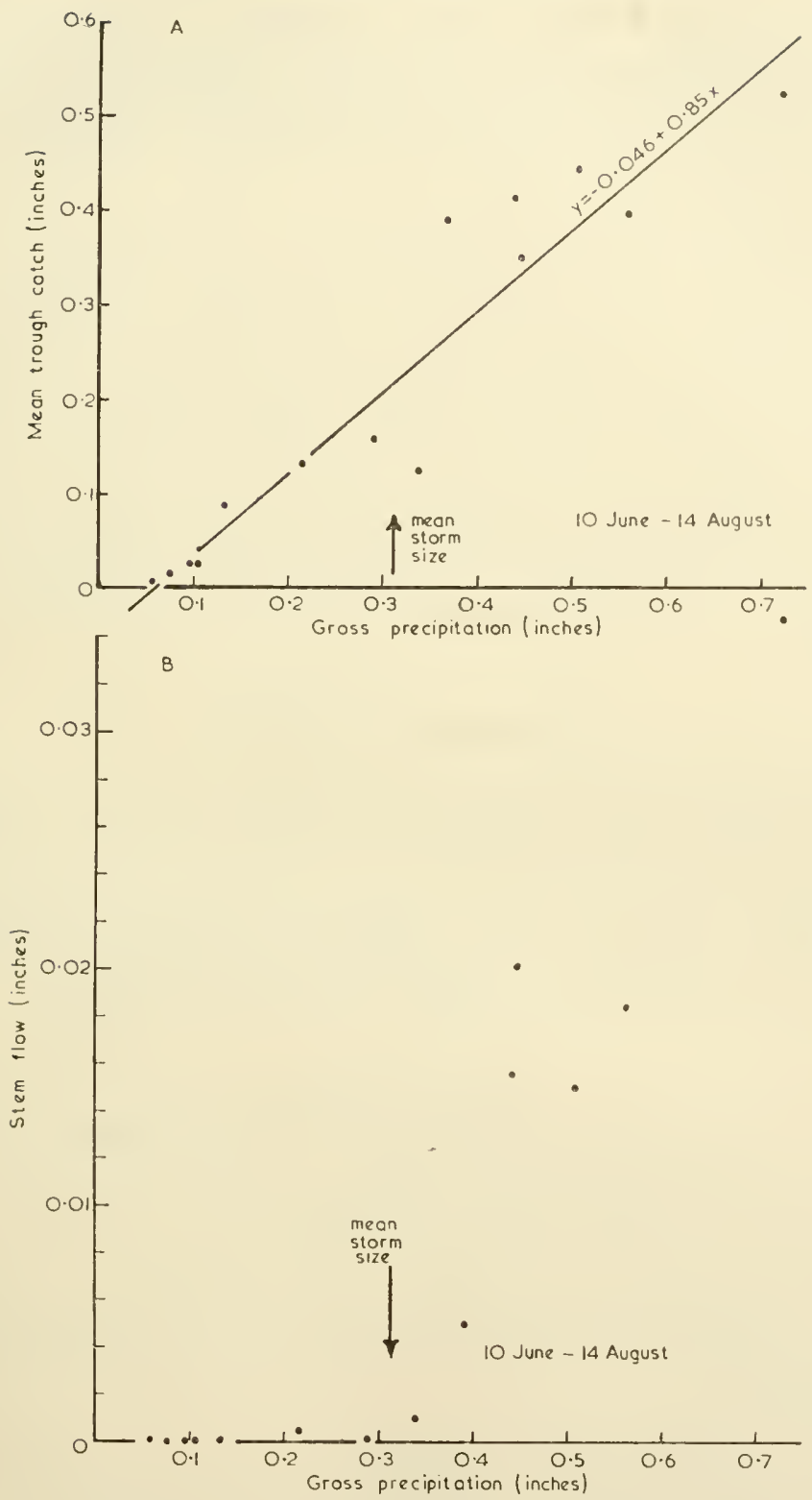

FIG. 3. Relationship between throughfall and storm size, I959. $A$ throughfall excluding stem flow; $B$ stem flow alone. 
pretation would be incomplete without reference to other phases of the cycle. For example, evaporation from a forest includes both transpiration and evaporation of intercepted water, and because these two phenomena are related, measurements of one or the other alone are of limited value; similarly, studies on soil moisture must also take into account the pattern of throughfall distribution.

In view of their importance, it has been the purpose of this communication to stress the need for techniques, which by virtue of their precision and practicability, can be incorporated into water balance studies. It has been shown that reasonably precise estimates of throughfall could be obtained by using troughs with relatively large collecting areas, but a suitable technique has still to be developed for the measurement of precipitation incident on the stand, since precipitation measurements made on nearby open ground are inadequate. Attention has been largely restricted to these two measurements, but investigations are continuing on the development of techniques to measure the other components of the water balance.

\section{ACKNOWLEDGMENTS}

Mr. J. F. Scott (Unit of Biometry, Oxford University) has given invaluable advice and help with the statistical aspects of this study. Dr. A. Carlisle (Nature Conservancy) was associated with the initial work. Mr. J. Kemp, through the co-operation of the Forestry Commission, has considerably assisted the investigation. We are pleased to acknowledge the financial support of the Department of Scientific and Industrial Research.

\section{REFERENCES}

Burgy, R.H. \& Pomeroy, C.R. (1958) Interception losses in grassy vegetation. Trans. Amer. Geophys. Un. 39, I095-I IоO.

Delfs, J. (1955) Die Niederschlagszurïckhaltung in Walde (Interception). Mitt. Arbeitskr. 'Wald und Wasser'. (Koblenz); 2, 7-54.

Kittredge, J., Loughead, H.J. \& MAZurak, A. (I94I) Interception and stem flow in a pine plantation. J. For. 39, 505-522.

LAw, F. (1957) Measurements of rainfall, interception and evaporation losses in a plantation of Sitka Spruce. Paper read to IIth Gen. Assem. (Toronto) Int. Ass. Hydrology.

Niederhof, C.H. \& Wilm, H.G. (1943) Effect of cutting mature Lodgepole Pine stands on rainfall interception. J. For. 4I, 57-61.

Voict, G. K. (1960) Distribution of rainfall under forest stands. For. Sci. 6, 2-Io.

Wicht, C.L. (194I) An approach to the study of rainfall interception by forest canopies. J. S. Afr. For. Ass. 6, 54-70. 
WILM, H.G. (1943) Determining net rainfall under a conifer forest. J. agric. Res. 67, 50I-5I2.

WILM, H. G. \& NiEDERHoF, C. H. (I94I) Interception of rainfall by mature Lodgepole Pine. Trans. Amer. Geophys. Un. 22, 660-665. 


\title{
THE BEHAVIOUR OF NOR WAY SPRUCE (PICEA ABIES (L.) KARST) IN CENTRAL JUTLAND, DENMARK, IN THE S UMMER OF I 955
}

\author{
E. B. OKSBJERG \\ Royal Forestry College, Stockholm
}

\section{THE WEATHER CONDITIONS}

THE summer of I9S5 was very hot and dry in large parts of northern Europe. Observations made at the meteorological station Loendal, in Central Jutland, are shown in Fig. I comprising temperatures at 2 p.m. and rainfall, computed as averages and sums respectively, for 5 -day periods.

Compared with 'normal figures' from climate tables, April, May and June of I95s were very cold, humid and windy and the cloudy weather reduced the occurrence of night frosts to five occasions. At Loendal station (a cupboard on poles $\mathrm{I} \cdot 5 \mathrm{~m}$ above soil surface) the five lowest minimum temperatures were between -0.2 and $-\mathrm{I} \cdot 8^{\circ} \mathrm{C}$. At an experimental field between Loendal and Salten mentioned below, the night temperatures measured on the soil surface were lower and frosts occurred more frequently (Oksbjerg, 1956).

\section{OBSERVATIONS ON GROWTH AND INJURY IN SPRUCE PLANTATIONS}

The extension growth of leader shoots of late- and early-flushing spruces during the sprouting period, shown in Fig. I, was observed in I95S in an experimental plantation 2 kilometres north of Loendal. The two plots were established in 1952 by separate planting of four-year-old spruce plants which in the spring of $195 \mathrm{I}$ in the nursery were marked out as extremely late- and extremely early-flushing individuals.

The flushing process of spruce is strongly influenced by temperature, and the belated sprouting appearing in Fig. I for both spruce types, about three weeks later than usual, is undoubtly due to the coldness.

Some scattered frost injury occurred in the early-flushing plot on the new shoots of the lowermost branches which, as is well known, flush before the leader.

In the years 1952, 1953 and 1954 the shoot growth of the two plots had been equal, and as the differences shown in Fig. I cannot be due to soil 


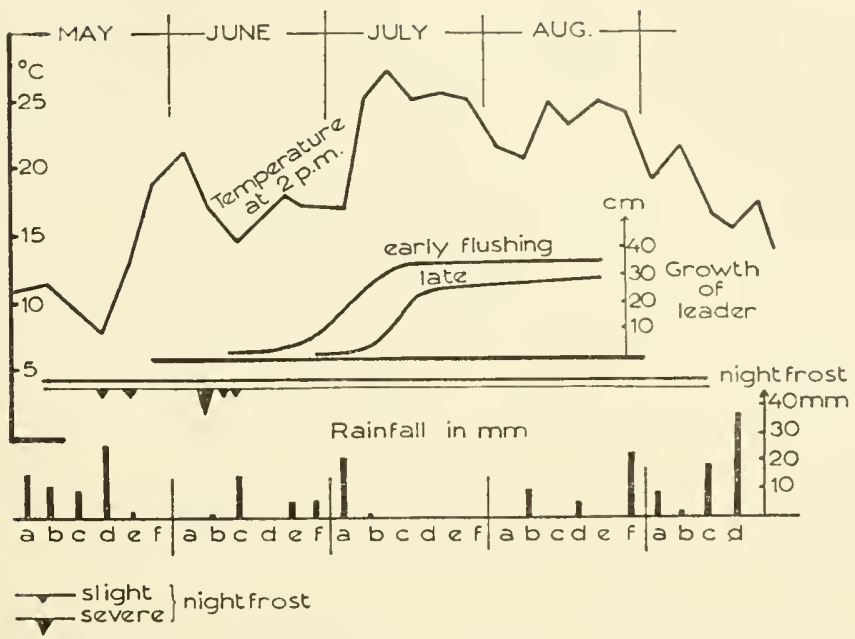

FIG. I. The march of air temperature (at 2.00 p.m.) and precipitation (averages and sums respectively for 5 -day periods) at Loendal, Central Jutland, together with the growth of leading shoots of Picea abies.

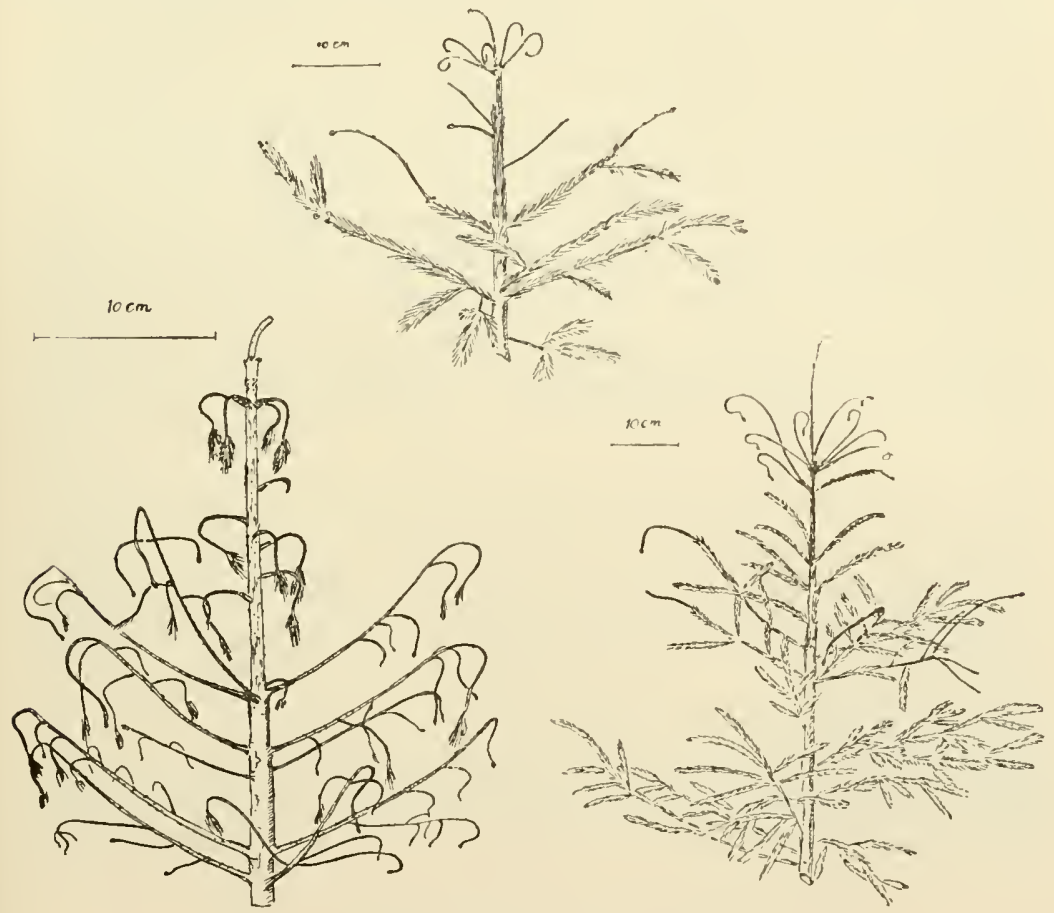

FIG. 2. Drought injury in late-flushing Picea abies. 
differences, the only cause appears to be that the weather of the summer of I955 has influenced the two flushing types in different ways. The check in leader growth of the late-flushing plot continued in the following years and significantly different figures for early compared with late-flushing spruces were for 1955, 33-26; for 1956, 19-9; and for $1957,21-9 \mathrm{~cm}$. Later the differences diminished and have now disappeared.

Some observations on visible damage proved that the late-flushing spruces had less resistance to drought. Of I 40 plants in every plot, IOO standing on bare soil (sand, light coloured) and 40 in grass vegetation (sand rich in humus), 2 and 37 respectively died in the late-flushing plot but in the carly-flushing plot only o and 2 . In addition, damage such as distortion of the shoots, death of the younger shoots or parts of them, needle loss, etc. predominantly occurred in late-flushing plants (see Fig. 2).

In the spring of 1956 it was evident that in Central Jutland only extremely late-flushing spruces flowered. That means that flowering is influenced not only by general temperature effects but also in some cases by a decided drought, and that the progeny of seed collected in 1956 do not represent the whole population of a locality, but only the late-flushing part of this.

In the summer of I95s the sprouting period of the late-flushing plants coincided with the culmination of high temperature and drought, whereas the early plants had finished growth and to some extent had lignified the shoots before the conditions became critical. The severe damage and the growth depression in the late-flushing plot could be presumed to be caused by high transpiration rates of the leafy, soft shoots having a very thin peridermis. An examination of the transpiration situation for one-year-old shoots and sprouting ones showed, however, that in most cases the older had highest values whether these were expressed on the basis of weight or of surface area, and whether of shoot or only of needles. When sprouting shoots are terminating their growth, transpiration seems to increase, probably in connection with the differentiation of stomata (Oksbjerg, I96I).

During drought periods the transpiration rate of sprouting shoots will be higher than or equal to that of one-year-old ones, probably because of the fact that the main part of transpiration during drought passes through the cuticule. In the last weeks of July, I955, I found that transpiration from one-year-old shoots had nearly stopped, whercas young shoots, checked in sprouting by the drought, continued to loose water.

Another part of the explanation of the pronounced difference in drought damage to late- and early-flushing spruces is differences in 'hydrature' in the sense of Walter (193I). The growth features and related metabolic 
processes presuppose a low osmotic pressure in the tissues. The high water content produces high transpiration rates even in the older shoots.

A third part of the explanation is the fact that the needles of older shoots, even those of the previous year are shed during a drought, whereas the needles of the ripened parts of the new shoot survive. The corresponding bark gives rise to a new bud formation.

Concurrently with the drought damage a depression in diameter growth in spruce took place. A comparison between late- and early-flushing individuals is very difficult because many late-flushing spruces-even trees under 20 years of age-flowered and fructified in 1956 and therefore suffered from an extraordinary loss of dry matter. I hope later to have an opportunity to elucidate these questions. In passing it can be mentioned that drought damage of the summer of 1947 affected the early-flushing spruces more than the late-flushing types (Oksbjerg, 1956, 1958).

One of the reasons for growth depressions, during and after drought periods, may be that drought can produce a colour change from dark to light green or to yellow occurring in connection with a decline in the $\mathrm{N}$-content of the needles, decreasing from about I. I 5 to $0.8 \%$ of dry weight.

Two years after the drought, in the summer of 1957 , attempts were made to measure the needle temperatures under different conditions, though periods of drought did not occur in this summer.

\section{OBSERVATIONS ON NEEDLE TEMPERATURES}

The apparatus used had ten thermocouples in the simple form of bare wire ends and one couple in contact with the reference temperature, an ice mixture in a thermos flask. The existing couples could be sharpened sufficiently, or new couples of thinner copper and constantan wires could be made, for an insertion in spruce needles. This operation was less difficult in needles on soft shoots but also possible in big needles on fully ripened shoots.

When the couple points were introduced in needles the electric wires were fixed to suitable twigs with clothes pegs. The readings were often irregular and only repeated readings which could be reproduced were recorded. The galvanometer deflections could be directly converted to degrees centigrade.

The results ought to be presented in a table with detailed information about weather conditions, supposed to be important for the course of the needle temperature, such as solar radiation, air temperature, precipitation and evaporation levels in the hours and days previous to the moment of 
observation. In order to save space I have tried to present the many scattered measurements by diagrams, from four days in succession, but am well aware of the fact that the observations were made under such different conditions that strictly speaking they are not comparable and, therefore, should not appear in the same diagram. In representing the observations the question of eventual differences in needle temperatures in older and in sprouting shoots is left out of account (see Fig. 3).

All measurements show that needle temperatures under the experimental conditions in question (moderate shelter in a 2-4 $\mathrm{m}$ high spruce plantation) are higher than air temperature from dawn to sunset whether in sunshine, cloudy weather or mist. No measurements are made when needles are wet from rain but a few minutes after the needles had dried up after a shower the needle temperature was again higher than air temperature. Immediately after sunset the needle temperature will be lower than air temperature when the sky is clear.

The difference in temperature is an important factor governing transpiration and is the reason for a slight transpiration which takes place when spruce plants (or probably all green plants :) are put into a transparent vessel saturated with water vapour (for example a glass flask the inside of which is covered by permanent wet filter paper), when the flask is illuminated only by diffuse daylight, not sunshine.

Unfortunately no opportunity occurred of measuring needle tempcratures during the drought of 1955 nor in the warm summer of 1959. The difference between needle temperature and air temperature is biggest in the early afternoon with high sun radiation intensity and decreasing transpiration (see Fig. 3 b) when the water content in the shoots is reduced. Lack of water naturally will increase the needle temperature while thermal loss to evaporation diminishes it.

The widest difference between needle temperature and air temperature appearing in Fig. 3 is about 5 centigrade and in no reliable observation during the summer of 1957 is this value exceeded. But in a dry and hot summer, no doubt needle temperatures of over 35 centigrade will occur. At such temperatures the respiration is very high and the balance of carbohydrates in the needles is certainly negative. Probably the loss of nitrogen in the needles is caused by proteolysis also causing decomposition of chlorophyll.

In many circumstances in a cold and wet August, or especially a dry and hot summer, the colour of the vegetation changes from dark to light green in connection with flowering and ripening of seed (e.g. in grasses). In many summers this may also occur as a result of a fall in available 


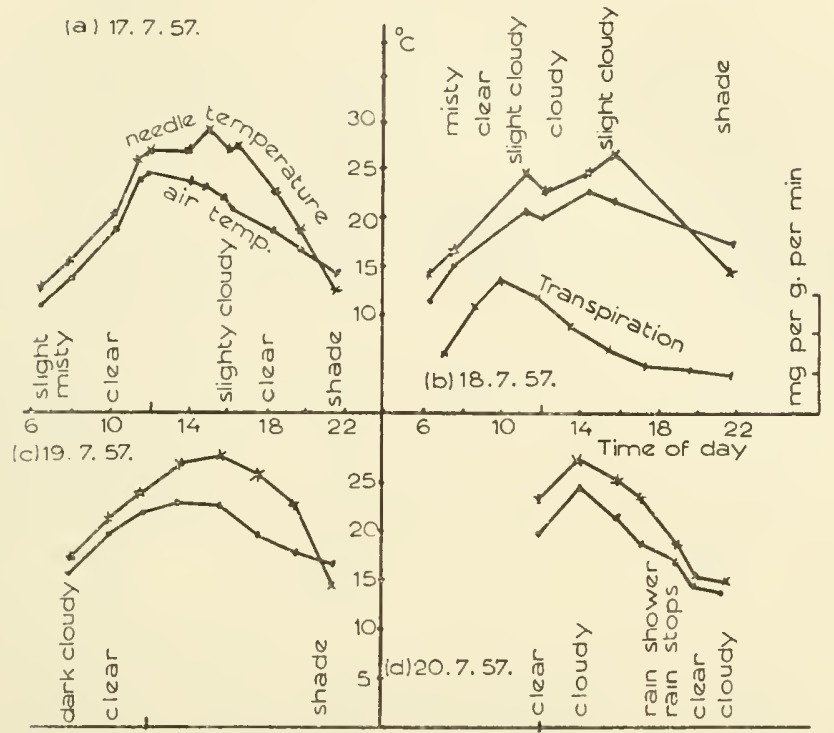

FIG. 3. A comparison of needle and air temperatures on four successive days in July 1957.

nutrients or, as we have seen, may be caused by heat. In all cases the colour change probably consists of a reduction of the chlorophyll concentration of leaf and needles.

It is possible to construct an equation relating thermal radiation and transmission to and from an area and the total evapotranspiration from the same area, an equation in the sense of Penman (1956). The equation can naturally only be formulated for a fully transpiring, green crop which covers the soil completely. Such endeavours can, no doubt, be of great use for certain regional estimations of ideal, maximal values of evapotranspirations, but they cannot teach anything about evapotranspiration from different vegetation types. The influence and extent of changes in colour or leaf area of the vegetation and the occurrence of imperfect transpiration (see the transpiration curve in Fig. 3b) can only be elucidated through detailed ecological field observations.

\section{SOIL MOISTURE}

Soil moisture was measured in an old-fashioned manner by digging out the soil samples, opening a new profile at every new examination. 
The water content in April after a winter rich in precipitation is taken to represent field capacity. Very infrequently the state of field capacity was established artificially. With the available facilities the estimation of permanent wilting point was undertaken by balancing the soil samples against sulphuric acid in closed jars, placed in a cool dark cellar.

The water capacity or the accessible water is a vague idea comprising among others a quantity which I have called the apparent water capacity, i.e. the difference between field capacity and wilting capacity in the soil space occupied by the root system. The investigation led to the advancing of another concept, the physiological water capacity, which means the difference between field and wilting capacity in the soil space from which the roots can take up all accessible water during a critical period of drought, i.e. the volumes of the soil where the density of roots is so high that complete utilisation occurs after a longer period of drought.

In some cases in the following account the water capacity of the raw humus layer (or better the spruce mor) is indicated in brackets after the figure of the total water capacity, for example in locality nr. I, Rosenholm: I 20 (45). This arises from the assumption that a part of the water content in this superficial layer is exposed to atmospheric influence and consequently open to direct evaporation, a water loss which does not benefit much the physiological processes of the stand.

Locality I, Rosenholm. A spruce stand planted more than a hundred years ago on drift sands formed as dikes alternating with strips bared to the hard pan. A larger sand drift is examined and the course of soil moisture is graphed in Fig. 4. In Table I some data of the profile are collected.

Excluding the horizons 5 and 6 which are nearly free of roots, the apparent water capacity of the given example is about I 5 ( $45 \mathrm{~mm}$ ) of rain. In Fig. 4 it appears that even during a drought of two months the accessible water is not exhausted in the three uppermost horizons. To avoid further indistinctness in Fig. 4, the curves of the horizons 4, 5 and 6 for the summer 1955 are not drawn. In these horizons the water content was reduced slightly but significantly, by $15-20 \%$ of the field capacity even though the root density is very low and very different. Roots occur most frequently in the horizon 4 , near the boundaries to horizon 3 and 5 .

The uptake of water from the soil seems to desiccate it only very moderately during a 'normal' summer as that of I953, considering the balance of the soil in Fig. 4. But even in a very dry period the accessible soil water is not completely evacuated from the horizons penetrated by roots. Judging from the conditions of 1955 the physiological water capacity of the profile in question is assessed to be about $60 \mathrm{~mm}$. 
TABLE I

The soil profile at Rosenholm

\begin{tabular}{|c|c|c|c|c|c|}
\hline Horizon & $\begin{array}{l}\text { Ignition } \\
\text { loss } \\
\text { (\% dry } \\
\text { weight) }\end{array}$ & $\begin{array}{l}\text { Field } \\
\text { capacity } \\
\text { (vol. \%) }\end{array}$ & $\begin{array}{l}\text { Wilting } \\
\text { capacity } \\
\text { (vol. \%) }\end{array}$ & $\begin{array}{l}\text { Depth } \\
\text { of the } \\
\text { horizons } \\
(\mathrm{cm})\end{array}$ & $\begin{array}{l}\text { Sample } \\
\text { depth } \\
\text { (cin) }\end{array}$ \\
\hline $\begin{array}{l}\text { I. Spruce mor } \\
\text { 2. Bleached sand or drift }\end{array}$ & $85-95$ & 55 & 9 & $0-10$ & $s$ \\
\hline $\begin{array}{l}\text { s.nd, humic } \\
\text { 3. Fossil humus, previous }\end{array}$ & $2 \frac{1}{2}-3 \frac{1}{2}$ & Is & 3 & $10-22$ & Is \\
\hline $\begin{array}{l}\text { surface with heather mor } \\
\text { 4. Usual bleached sand or }\end{array}$ & $4-7$ & 22 & 6 & $22-29$ & 25 \\
\hline drift sand, poor in humus & $I-2$ & 9 & 2 & $29-85$ & 45 \\
\hline s. Humic iron pan & $3-3 \frac{1}{2}$ & 29 & 8 & $85-98$ & 90 \\
\hline 6. Sub-soil, C-horizon & $\mathrm{I} \frac{1}{2}-2 \frac{1}{2}$ & 7 & 2 & $100-$ & IIS \\
\hline
\end{tabular}

The most humid 'pockets' in the profile in September 1955 were recorded in the bottom of the mor layer and in horizon 3 , the fossil humus. The water content in both these horizons is, to a certain extent, 'dead capital', probably due to a lack of living root tips which, by the way, were very actively formed just in these humid volumes in the month of September I955, when root formation otherwise was very sparse and slow.

Locality 2, Kompedal plantation, dpt. 408. A sixty-year-old spruce stand planted on previous field cultivated heath. The profile, therefore, is 'disturbed' and the numbering of the horizons will only apparently corres-

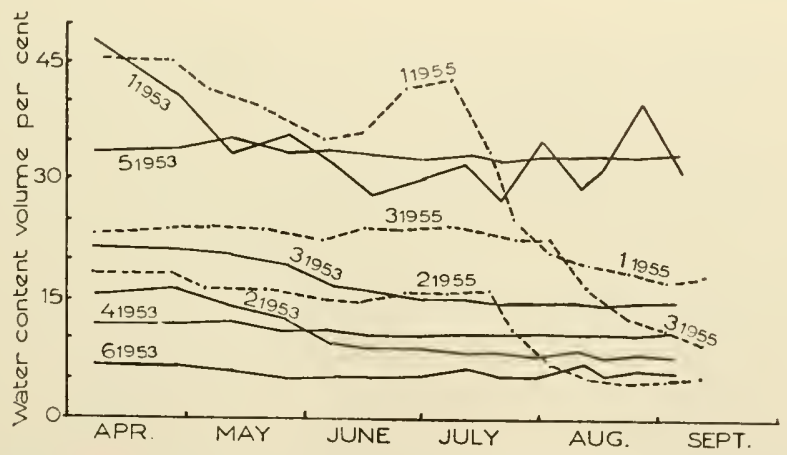

FIG. 4. The march of water content during the summers I953 and I955 in different horizons of the soil at Rosenholm. Numbers refer to horizons in Table I. 
TABLE 2

The soil profile in'Kompedal plantation

\begin{tabular}{lcccc} 
Horizon & $\begin{array}{l}\text { Ficld } \\
\text { capacity } \\
\text { (vol. \%) }\end{array}$ & $\begin{array}{c}\text { Wilting } \\
\text { capacity } \\
\text { (vol. \%) }\end{array}$ & Depth (cm) \\
\hline I. Spruce mor & & & $(\mathrm{I})$ & $(2)$ \\
2. Humic sand or gravel & 38 & 8 & $0-8$ & $0-6$ \\
4. Bleached sand & $\mathrm{I} 2$ & 3 & $8-\mathrm{I} 4$ & $6-26$ \\
5. Hard iron pan with liumus & 8 & 2 & $14-29$ & $26-30$ \\
6. Sub-soil & $\mathrm{I} 6-24$ & $3-6$ & $29-39$ & $30-42$ \\
& 9 & 2 & $39-$ & $42-$
\end{tabular}

pond with those of the above mentioned profile. A summary of the data from localities $I$ and 2 is given in Table 2 .

In this soil many roots occur down to $50 \mathrm{~cm}$ (the designation 'sub-soil' used in table 2 is therefore wrong as to definition, it only refers to colour). The apparent water capacity of the soil dealt with in Fig. 5 and Table 2 is about $70 \mathrm{~mm}$ of rain because the computation includes the pan and the uppermost Io $\mathrm{cm}$ of the sub-soil.

The march of water content in the horizons during the summers of 1953 and I955 was very similar to those of the locality Rosenholm, but in Kompedal the decline set in more simultaneously and more uniformly in the different horizons, probably because of the more shallow root system and therefore more equable temperature and root density in the soil of the root volume.

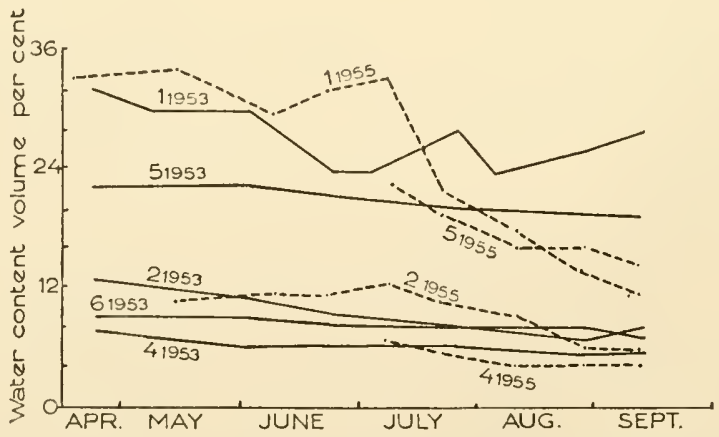

FIG. 5. The march of water content during the summers 1953 and I9s5 in different horizons of the soil at Kompedal. Numbers refer to horizons in Table 2. 
But here also much accessible water remains in the different horizons and the reason may also here be an insufficient number of root tips per unit of root volume. The physiological water capacity of the Kompedal profile is at most $40 \mathrm{~mm}$ of rain.

Locality 3 , the experimental plantation near Loendal mentioned in section 2. The soil was previously cultivated and no 'natural' profiles occur. Both in the grass-covered and in the bare, light-coloured sand, roots occurred down to a depth of 40-45 cm. On 22 July the whole rooted volume of the grassy soil was devoid of available water and by i September the bare soils had also reached the wilting capacity. In the spring of 1957 the field capacity was determined, and a definitive account is presented in Table 3 .

TABLE 3

Water-holding properties of soil near Loendal

$\overbrace{\begin{array}{c}\text { Calcu- } \\ \text { lated for } \\ 45 \mathrm{~cm} \\ \text { depth, } \\ \mathrm{mm}\end{array}}^{\text {Field capacity }} \overbrace{\begin{array}{c}\text { Calcu- } \\ \text { lated for } \\ 45 \mathrm{~cm} \\ \text { depth, } \\ \mathrm{mm}\end{array}}^{\text {Wilting capacity }} \overbrace{\begin{array}{c}\text { Calcu- } \\ \text { lated for } \\ 45 \mathrm{~cm} / \mathrm{l}\end{array}}^{\begin{array}{c}\text { depth, } \\ \mathrm{mm}\end{array}}$

Grass-covered soil with

high humus content

Bare soil poor in humus

$\begin{array}{rl}\text { I } 50 & 68 \\ 90 & 40\end{array}$

30
24

I 4

120

54

II $\quad 66 \quad 29$

As will be remembered the plants on bare soil survived whereas many of those on grass-covered soil died; in the late-flushing plot all the latter died. The cause may be a high consumption of water by grass and a very intense root penetration by spruce in the previous field-soil rich in humus.

Locality 4 , a very good forest soil on moraine. On a slight, north facing slope in Silkeborg Sønderskov, dpt. 232, Norway spruce 25 years ago succeeded beech. Samples were taken in September 1955 and three times during the summer of 1957 . The profile, which was rooted to $85 \mathrm{~cm}$, was presumed to be fairly represented by samples from three different depths, and a rough estimation showed that there was left more than $50 \mathrm{~mm}$ accessible water in September I955 before any important shower had fallen after the drought. Water content increased with depth, and in no 
place, not even in the uppermost layers, did it approximate to wilting capacity. In the summer of 1957 no substantial fluctuations occurred in the water content except for a slight and nearly uniform decrease in the uppermost $50 \mathrm{~cm}$. The field capacity of the profile to a depth of $85 \mathrm{~cm}$ is about $2 \mathrm{r} 5 \mathrm{~mm}$ and the wilting capacity $c a$. $100 \mathrm{~mm}$.

\section{CONCLUSION}

The investigations of soil moisture show that Norway spruce during severe drought does not exhaust the accessible soil water to the depth of the deepest roots, except in one example, in a former field soil. In older plantations, especially on podsolised soils the spruce roots become more and more superficially situated or concentrated in some 'rootfriendly' horizons.

But also young plantations show-e.g. in comparison with oak-a very ineffective water uptake which sometimes can be an advantage. As an example I shall mention two young stands, one of spruce and one of oak (Quercus robur (L.)), growing side by side in Silkeborg Forest district in Central Jutland. In the summer of I955 some of the spruce plants died about 20 July, and by 28 July $8 \%$ had died. After that none of the spruces died even though drought and heat continued. Until 28 July not a single oak had died-on the contrary they seemed to appreciate the heat-but in the first week of August the whole plantation of oak died. No examinations of soil humidity were undertaken in a quantitative sense but the soil under the oaks was considered to be completely desiccated whereas it was evident that some humidity was left in small pockets under the spruces. One got the impression that the spruces were already thirsting by the middle of July whereas the oaks had grown well until the last days of their life.

\section{REFERENCES}

OksBJERG, E.B. (1956) Sommervejret I955 pa en midtjydsk lokalitet og torkens virkning pa parceller med tidligt og sentudspringende rodgraner. (English summary-The weather of the summer I955 and the effect of the drought upon plots with early and late flushing Norway spruce.) Dansk Skovforenings Tidsskr. 4I, 273-302.

OKsBJerg, E. B. (1958) Udspring og torketalsomhed. (English summary-Flushing time and drought resistance.) Dansk Skovforenings Tidsskr. 43, 292-307.

OKsBJERG, E.B. (196I) Transpiration of growing shoots in Norway spruce (Picea abies) with some notes on drought phenomena. Svensk Bot. Tidsskr. 55, 397415 .

Penman, H.L. (1956) Estimating evaporation. Trans. Amer. Geophys. Union, 37, 43-50. Walter, H. (193I) Die Hydratur der Pflanze. Jena. 


\title{
CLIMATE AND WATER RELATIONS OF PLANTS IN THE SUB-ALPINE REGION
}

\author{
Walter Tranquillini \\ Forschungsstelle für Lawinenvorbeugung, Innsbruck, Austria
}

\section{INTRODUCTION}

THE water balance of a plant is favourable as long as its transpiration and water absorption are equal. If the water loss exceeds the absorption the balance becomes negative. Plants have several means of recovering a good balance or avoiding an increase of water deficit. They can

I. intensify the water absorption

(a) through extension of the root system by growth thus reaching parts of the soil still wet

(b) through increase of their suction forces by which they are able to take up soil water that is held more firmly;

2. reduce the water loss

(a) through reduction of the transpiring surface (shedding of leaves)

(b) through increase in diffusion resistance of leaves (closing of stomata, incipient drying of cell membranes).

Especially the last possibility is frequently used by plants because it is effective very quickly. An increase in transpiration resistance can be easily measured by checking the relation between transpiration and evaporation, the so-called 'relative transpiration' (Livingston, 1906). As long as the water balance is favourable transpiration is closely related to evaporation, and the relative transpiration remains constant. If the balance becomes negative the stomata begin to close. In such a case transpiration lags increasingly behind evaporation. The stomata will close completely, if a certain water deficit is reached. Now the transpiration resistance of the cuticle becomes effective. If cuticular transpiration still exceeds water absorption, the balance gets worse and worse. This will be recognised by a further decrease of the water content of a plant or by an increase of the osmotic values of the cell sap. Plants tolerate this dehydration only to a certain limit. If this limit is exceeded they suffer drought damage. The saturation deficit beginning to cause injuries is the 'sublethal deficit' (Oppenheimer, 1932; Pisek and Berger, 1938). Walter (195I) coined the term 'maximum osmotic value' for the osmotic value corresponding to this water deficit. 
Besides the above mentioned protections against a negative balance, the ability to endure extensive drought periods depends on several internal conditions prolonging the period in which the sub-lethal deficit will be reached. Such conditions are the following ones:

I. rate of cuticular transpiration

2. the remaining water storage from which plants recover their cuticular water loss after complete stomatal closure

3. the amount of sub-lethal deficit, i.e. the 'resistance to dehydration'.

Before describing the water relations of some characteristic plants of the sub-alpine region in the Tyrolean part of the Central Alps it is necessary to discuss the climatic features of this area. I have made use of the investigations of our extcnsive ecological research station situated at an altitude of $2000 \mathrm{~m}$ above sea level, just above the timber line near Obergurgl, the highest village of Austria. The station covers a part of the western slope of the Gurgler valley. The studies were made by a team of botanists and climatologists.

\section{CLIMATE AND WATER RELATIONS IN SUMMER}

From a physical point of view transpiration of plants depends on the vapour-pressurc gradient from the transpirating surface to the surrounding air. Therefore transpiration is the greater the less water vapour the air contains and the higher the temperature of the transpiring surface, which is almost saturated with water. All the other climatic factors affecting evaporation influence transpiration over this vapour-pressure gradient. Solar radiation raises the temperature of plants above the temperature of the air and increases thereby the gradient. The wind cools off the plants whercby transpiration is reduced; on the other hand, it removes the air rich in water vapour from the vicinity of leaves and replaces it with drier air thereby increasing the gradient again.

With rising altitude the vapour pressure of the air decreases so much that the air at an altitude of $2000 \mathrm{~m}$ contains on the average only one half of the amount of water vapour as at sea level. As Rathschüler (I949) has pointed out for the Salzburger Alps this difference in gradients is especially marked during the night, while there is no difference between the bottom of valley and higher stations in the daytime. Its importance for evaporation loses significance if the temperature differences at different altitudes are considered.

Figure I shows the annual trend of the air temperatures at Obergurgl in comparison with the values of a station at an altitude of $500 \mathrm{~m}$ in the 


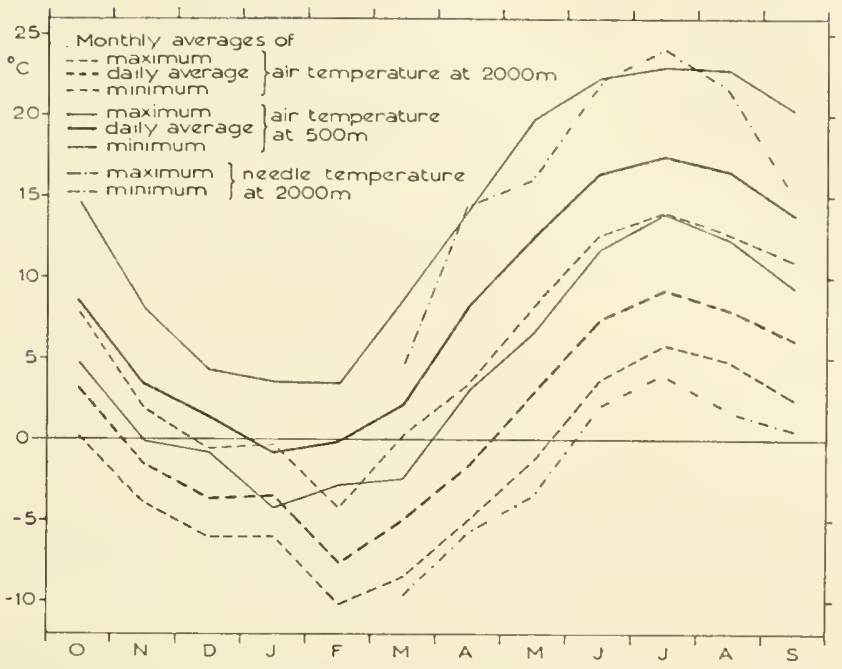

FIG. I. Annual trend (Oct. I954-Sept. 1955) of monthly maximum, minimum and daily averages of air temperature at different atlitudes (Obergurgl $2070 \mathrm{~m}$, Innsbruck $580 \mathrm{~m}$ ) and of temperatures of pine needles at Obergurgl.

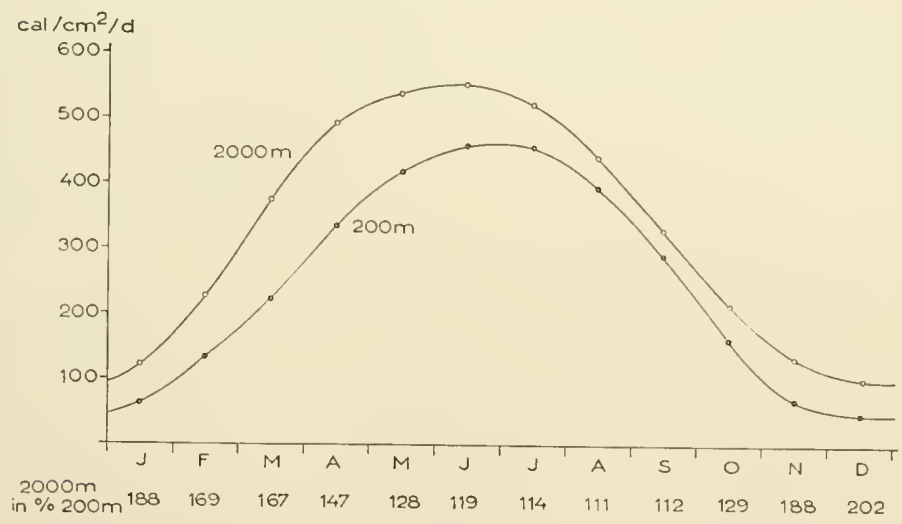

FIG. 2. Annual trend of monthly averages of solar radiation at different altitudes (Obergurgl $2070 \mathrm{~m}$, Wien $200 \mathrm{~m}$ ). (From Turner, I961a). 
vicinity. It will be recognised at once how much cooler it is in the higher region. Especially in summer during the growing season, the monthly average air temperatures at $2000 \mathrm{~m}$ are about $8-10^{\circ}$ lower than those of the valley station. The temperature ranges, limited by annual trend of maximum and minimum temperatures, do not overlap, i.e. the average monthly maximum temperatures at Obergurgl just reach the minimum temperatures at Innsbruck. In winter the differences are smaller because temperature inversions occur frequently then.

The average temperatures of leaves are similar to the air temperatures. We have measured the temperature of needles of young pine trees (Pinus cembra L.) at $2000 \mathrm{~m}$ for a whole year almost without interruption and found (Tranquillini and Turner, 196r) that the average monthly temperature deviates from the air temperature by only $2^{\circ} \mathrm{C}$ at the most. The average extremes though are twice as far apart as those of the air temperature; thus the average maxima of the needle temperature at $2000 \mathrm{~m}$ correspond approximately to those of the air temperature at $500 \mathrm{~m}$ (Fig. $\mathrm{r}$ ).

Since analogous measurements of plant temperature in lower regions have not been recorded, we have to observe how other factors important for the heat relations of plants change with increasing altitude, i.e. solar radiation and wind. Only then is it possible to estimate whether plants growing in higher altitude are heated above air temperature more highly than those in lower regions.

In Fig. 2 the annual trend of average monthly solar radiation measured at the research station near Obcrgurgl is compared with that found at an altitude of $200 \mathrm{~m}$ (Vienna) (Turner, I961a). Radiation at $2000 \mathrm{~m}$ is much more intensive than at lower altitudes. This depends less on the intensity of direct sun radiation than on the intensity of diffuse radiation under cloudy conditions because of the smaller thickness of the cloud layer at $2000 \mathrm{~m}$. Because the horizon in the mountain area is strongly masked by clevations, radiation in summer is only 10-20\% higher than that of lower regions. Radiation in winter will be referred to later.

Wind velocity also increases with higher altitudes especially if we leave the forest area which covers the lower parts of the slopes in the mountains. During a long time we have measured the average wind velocity $3 \mathrm{~m}$ above ground in different places along a line being a cross-section of the valley. Aulitzky (1958) has pointed out that the wind velocity next to the timberline is already $40 \%$, and at the tree-line only $200 \mathrm{~m}$ above the timber-line is $70 \%$ higher than on the bottom ( $1800 \mathrm{~m}$ above sea level) of the valley (Fig. 3).

This increase in wind velocity is probably not important for the water 

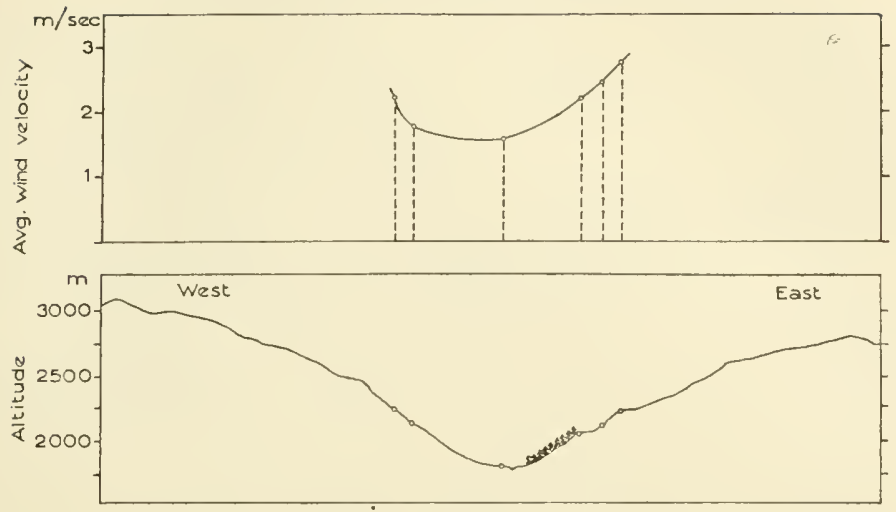

Fig. 3. Average wind velocity at several locations on the eastern and western slope of the Gurgler valley. Cross-section of the Gurgler valley. The points indicate the places where measurements were taken. (From Aulitzky, 1958.)

loss of the vegetation in summer because the effect of the wind on transpiration is only great at a very low velocity. It decreases rapidly with increasing wind velocity (Stålfelt, I932).

To summarise, during the summer at an altitude of $2000 \mathrm{~m}$ plants may not be subjected to much stronger evaporation than plants in lower regions. The lower water content of the air is more than compensated by lower air temperatures above which plants may be heated only a little more than those of lower regions.

This is confirmed by measurements of evaporation at several places of the station area (Prutzer, I96I) if we compare them with those values which Walter (I95I) has collected from different climatic regions. In late summer evaporation (measured with the Piche Evaporimeter) rose only a little over $\mathrm{I} \mathrm{ccm} / \mathrm{h}$ in our location in $2000 \mathrm{~m}$. It is therefore not higher than in lower regions of Central Europe.

If the other conditions are the same, water absorption of plants depends on the water storage in the soil which in turn depends on the amount of precipitation.

Precipitation increases rapidly with increasing altitude (Turner, I96Ib). This is especially true for the peripheral zones of the Alps (Fig. 4). Our research area, however, is sheltered from the wind bringing precipitation by mountain chains. Therefore it receives comparatively little precipitation; only $1000 \mathrm{~mm} /$ annum on the average. The maximum amount of precipitation falls in summer from July to August. The minimum occurs in March, i.e. before the growing season (Table I). 


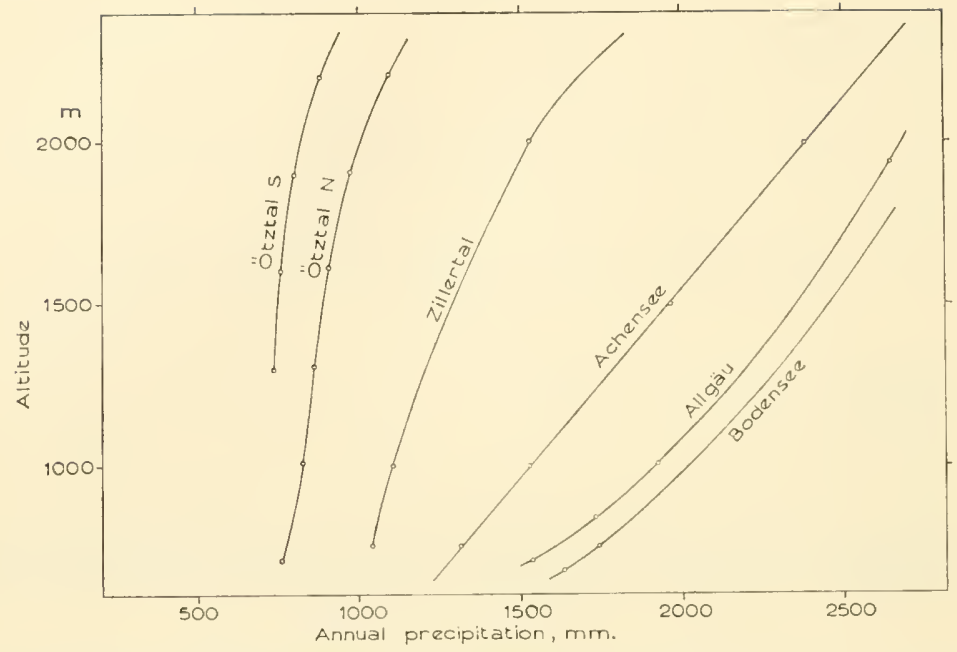

Fig. 4. Annual precipitation in $\mathrm{mm}$ at several locations in the eastern Alps at different altitudes. (From Turner, 196Ib).

\section{TABLE I}

Monthly, half-yearly and annual precipitation $(\mathrm{mm})$ at Obergurgl at the timber-line $(2070 \mathrm{~m})$. Mean from I9II-I950

I II III IV $\quad$ V VI VII VIII IX $\quad \mathrm{X} \quad \mathrm{XI}$ XII Win. $\quad$ Sum. Year $\begin{array}{lllllllllllllll}55 & 73 & 53 & 83 & 87 & 92 & \text { I05 } & 103 & 80 & 77 & 71 & 63 & 392 & \text { 55I } & 944\end{array}$

Therefore $60 \%$ of the annual precipitation falls in the summer half-year and only $40 \%$ in the winter half-year. Precipitation is evenly distributed throughout the summer; on the average there is precipitation every second day, and every fourth day brings precipitation exceeding $5 \mathrm{~mm}$. Periods without precipitation do not last long, in summer I4 days at the most, on the average 4 days; only outside the growing season are there longer periods without precipitation (up to 20 days) (Table 2).

\section{TABLE 2}

Maximum duration of dry periods in days at Obergurgl from 1954-1959

\begin{tabular}{lcrrrrrrrrrrr}
\hline & I & II & III & IV & V & VI & VII & VIII & IX & X & XI & XII \\
Mean & IO & 9 & 7 & 5 & 6 & 4 & 4 & 5 & 7 & I0 & I2 & I0 \\
Maximum & I3 & 20 & IO & 7 & I4 & 5 & 5 & 8 & II & 13 & I9 & I 8 \\
\hline
\end{tabular}


In the continental research area dew ( 63 days) and fog (I4 days) are not important for the water relations of plants.

The even distribution and quantity of precipitation in the summer keep the soil wet in the root zone of plants.

Because of the equal amount of evaporation and the higher precipitation in summer even continental high regions in the Eastern Alps (i.e. the area near Obergurgl) are more humid than lower ones.

Therefore it is not surprising that all field investigations of transpiration and water balance carried out in the sub-alpine and alpine region have demonstrated that water relations are only seldom stressed severely. This has been shown by the osmotic values of about ioo species of plant communities of this region round Innsbruck measured by Pisek, Sohm and Cartellieri (I935). The osmotic values do not exceed I8 atm; they only rise to $20 \mathrm{~atm}$ in the evergreen dwarf shrubs and conifers. Another reason for a favourable water balance is that most of the tested plants are very sensitive to the smallest water deficits and start reducing transpiration very quickly. This has been shown convincingly by Berger-Landefeldt (1936) and Cartellieri (I94I). Therefore even at the end of an extreme dry period in August extending over 3 weeks (which very seldom occurs in high regions) the osmotic values of some divarf shrubs grown on southern slopes did not exceed 25 atm; only Erica carnea reached 27 atm (Pisck and Cartellieri, 1934).

\section{CLIMATE AND WATERRELATIONS IN WINTER}

In winter the conditions are quite different. The decrease in temperature with increasing altitude causes a longer cold season at $2000 \mathrm{~m}$ and a shorter growing season than in lower regions (Fig. I).

About half the amount of precipitation falls as snow. The period with continuous snow-cover lasts 6 months on the average. If the ground is covered with forest the distribution of snow on the ground is even, because the forest raises and whirls the streamlines of the wind. Above the timber-line the wind acts down to the ground. It carries away the snow from all wind-cxposed elevations and accumulates it at wind-screened locations because the wind mainly comes from one direction only. Therefore in the sub-alpine and alpine region which are strongly undulated the snow cover may be quite different within the smallest distances. Especially windblown places like crests and ridges are covered with snow only a few weeks; they may be snowless at any time during the winter. On the other hand in wind-protected hollows of ground and troughs the snow stays for 
$7 \frac{1}{2}$ months; such places are constantly and reliably covered with deep snow.

The composition of the vegetation reacts very sharply to these variations in snow cover. This means that they are of great importance to the vegetation and they influence basically the water relations of plants in winter as we shall see later on.

The areas with no or only a thin snow-cover support only a certain community of Lichenes (Alectorietum), or the dwarf azalias (Loiseleurietum) rich in Lichenes; in troughs very long covered with snow there grows the alpine rose (Rhododendretum ferruginei) or some other community (in our station area, i.e. Festucetum Halleri). Between these extremes of location there are many transitions which are occupied by defined plant communities (Vaccinietum uliginosi and Vaccinietum myrtilli) (Fig. 5).

Corresponding to the different snow cover we can separate 3 types of wintering by evergreen plants:

I. plants growing in locations mostly without any snow protection

2. plants that grow in snow-covered places, but with parts projecting from the snow

3. plants which are completely covered by snow during the winter.

First we will consider the evaporation conditions to which plants or parts of plants protruding from the snow are exposed. The evaporation conditions firstly depend on the temperature of the plant. Therefore they depend on solar radiation.

In winter the snow-covered mountain slopes reflect so much radiation, that in this season a horizontal area gets a radiation twice as intensive as one in low regions. The curve of the annual trend of solar radiation is so asymmetrical that the intensity of solar radiation in April is as high as in

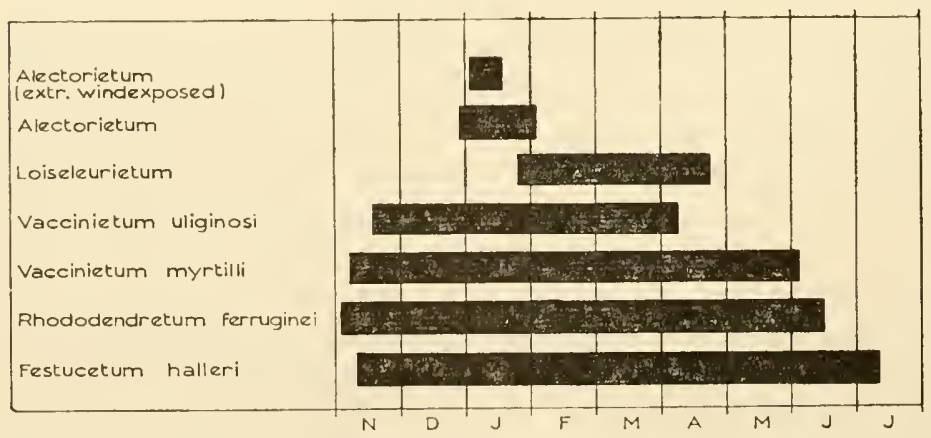

FIG. 5. Average duration of continuous snow cover $(>5 \mathrm{~cm}$ high) for several plant communities at our research station near Obergurgl. (From Turner, 196Ib.) 
July (Fig. 2). This higher intensity of radiation in high altitudes causes plants to be heated above the air temperature in winter much more than in lower regions. So we have found that the temperature of the needles of pine trees is surprisingly often above the freezing point; on $83 \%$ of all the days, during a research period from September to May, the temperature of the needles exceeded $0^{\circ} \mathrm{C}$ at least for a short time (Tranquillini, 1957). Especially at the end of winter when the snow had not yet melted and when radiation was very intensive there were high temperatures and high vapour pressure gradients from plants to the cold air poor in water vapour. By March the temperature of pine needles rose to $4.6^{\circ}$ on the average, in the extreme to $18.4^{\circ}$ at midday, in April to $14.4^{\circ}$ on the average, in the extreme to $29.7^{\circ}$; therefore sometimes the temperature is as high as in summer (Fig. I).

It is very important for the water relations of such parts of plants protruding from the snow and being occasionally heated very much, whether the water loss, which at times is as high as in summer, can be made good by water absorption from the soil. This question can be answered from records of soil temperature, carried out by Aulitzky (I96I) at a snowless and a snowy site at different depths of the soil at our station (Fig. 6). In the snow-covered place the temperature of the soil sinks below $0^{\circ}$ only in the upper $20 \mathrm{~cm}$ of soil but does not fall below $-\mathrm{I}^{\circ} \mathrm{C}$. This is the result of the good thermal insulation of the snow-cover. On the other hand the ground not covered by snow or with only a thin snow-cover freezes completely to a depth of more than I $\mathrm{m}$ at the beginning of December and thaws only near the surface at the end of April, and to a greater depth in the middle of May (Fig. 6).

Whether the plants can absorb water from the soil in winter depends upon the temperature at which the water freezes in the soil. This has been shown by measurements of the soil moisture by means of electrical resistance blocks. Water does not freeze at a certain temperature at once but successively. With decreasing temperature ice is formed in the larger pores first, later in the smaller and smallest ones. The water turning to ice last, is held so firmly in the soil that it cannot be absorbed by the plants, although it is not yet frozen. The water available for plants is frozen at $-\mathrm{I}^{\circ} \mathrm{C}$ (Larcher, 1957).

It can be concluded that plants in snowless locations certainly cannot absorb water from the soil during a period of 5 months; this is a long time during which they permanently lose water. At the end of the winter this water loss occasionally reaches an amount similar to that in the summer.

On the other hand the water absorption of plants that grow in snow- 
covered places and parts of which stick out of the snow is not interrupted as a rule. Of course the absorption of water is reduced at low temperatures. Döring (1935) has found that spruce trees absorb one third less water at $0^{\circ} \mathrm{C}$ than at $20^{\circ} \mathrm{C}$. The absorption is also reduced because the roots do not grow in winter, therefore the soil moisture near the roots is soon exhausted. From the parts of soil still wet water moves to the roots slowly. Abundant moistening of the root zone takes place at the time of snow melting, which occurs between February and March. Therefore those plants will suffer the greatest deficits until February.
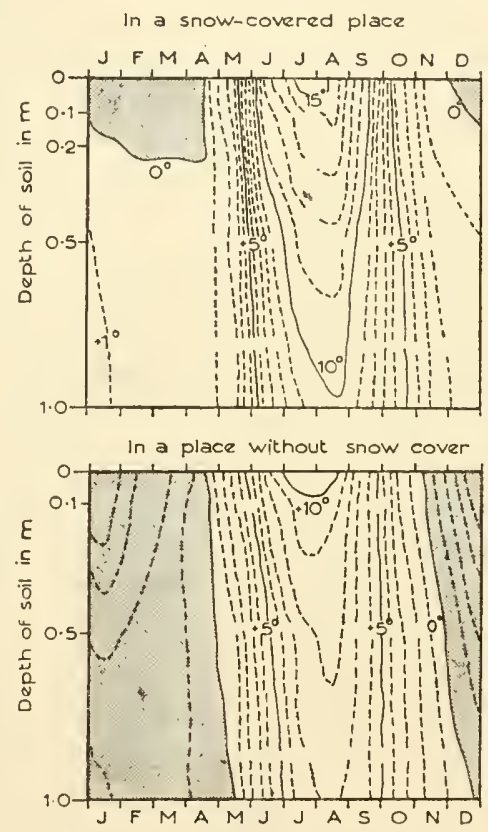

FIG. 6. Tautochrones of monthly averages of the soil temperature at different depths in the soil. The region where the tempcrature falls below $0^{\circ} \mathrm{C}$ is indicated by grey shading. (From Aulitzky, 196r.)

The Siberian pine tree (Pinus cembra) winters in three different ways in our station area. Above the timber-line young plants grow on windblown ridges which are without any snow during the winter; at the timber-line there are many young plants which are entirely covered with snow throughout the winter, and there are also taller plants and adult trees, which protrude 
partly out of the snow. Therefore it is possible to follow clearly the effect of the environmental conditions in winter on the water relations from the annual trend of the osmotic values and the water content of needles of this tree species (Fig. 7).

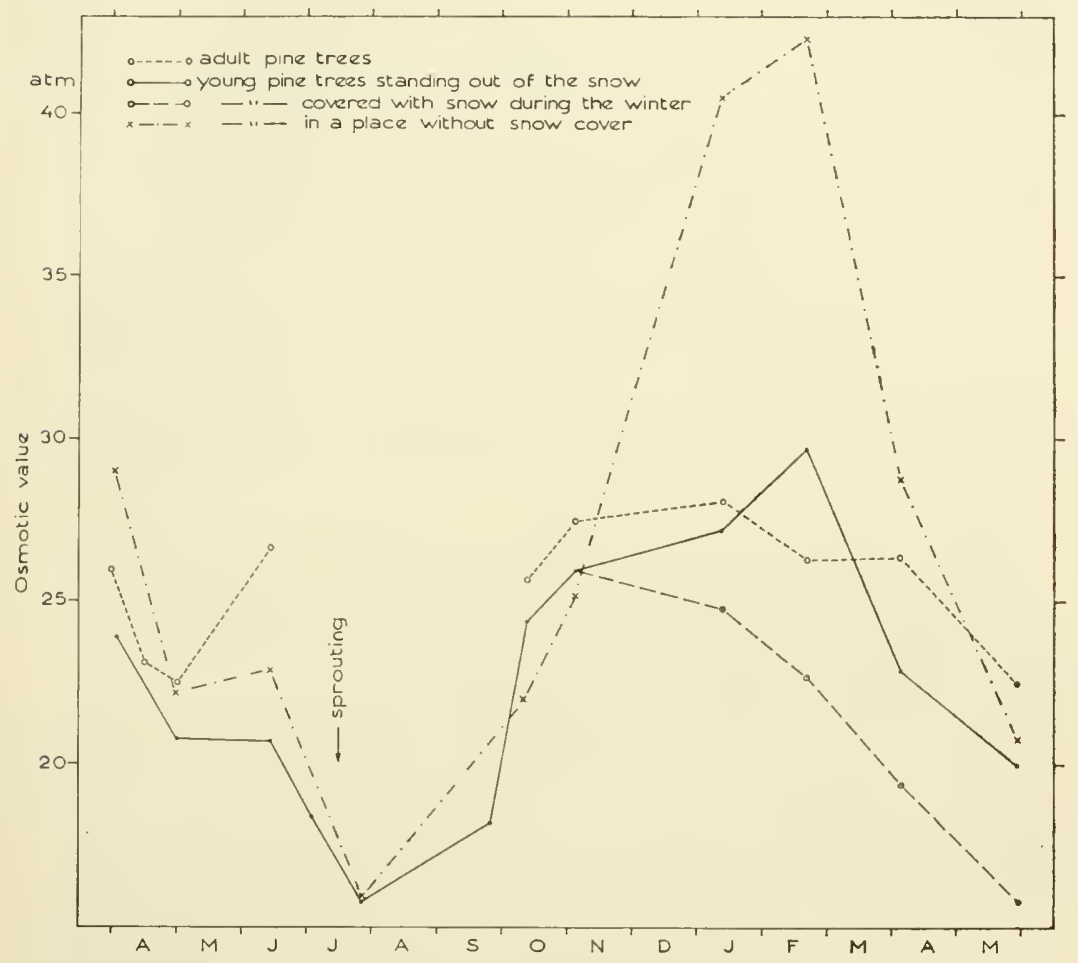

FIG. 7. Annual trend of osmotic values of the needles of some pine trees at several places at the research station near Obergurgl.

We will begin with young plants growing in a snow-covered location. The upper shoots of them stick out above the surface of the snow just a little. In this case the plants were about $\mathrm{I} m$ tall. In summer especially when the plants sprout, the osmotic values (o.v.) are low (I6-I 8 atm). At the end of September they increase strongly $(24.5 \mathrm{~atm})$ as a result of an active accumulation of the osmotically effective substances. This is the case in all evergreen plants at the beginning of the cold season. The further increase up to $30 \mathrm{~atm}$, however, is attributed to water loss. The water content decreases to $36 \%$ between October and February. That this 
decrease is not greater is due to the fact that water absorption is possible from the snow-covered soil at least at times.

The water balance of comparable plants which are completely covered with snow is different. Beginning at the time when they are snowed-up the water content of their needles rises slowly but steadily. Therefore the o.v. falls continuously under the snow. Plants do not lose water by transpiration because the air within the cavities of snow is saturated with water vapour. Hence they are able to balance slowly their water deficit existing at the beginning of the snow cover, first by absorption by the needles, later on by absorption from the soil. For this reason shortly before plants melt out of the snow their o.v. is as low as in the summer.

Adult trees also have a favourable water balance because they are able to compensate greatly the water loss of their crowns by absorption from the unfrozen soil. Their o.v. does not rise over 28 atm, and the water content of the needles decreases only by $13 \%$ of that at the beginning of November. That their needles dry up less than those of smaller plants on comparable places is due to the bigger water storage in their branches and stems.

In snowless locations above the timber-line young plants have the worst water balance. In winter they lose $52 \%$, that is somewhat more than one half of the water content in autumn. Their water content decreases to $78 \%$ of the dry weight, and their o.v. increases to $42 \mathrm{~atm}$.

We have to compare this dehydration with the annual trend of the resistance to dehydration, measured by Pisek and Larcher (1954), of several plants in the sub-alpine region, to decide whether the critical limit at which plants begin to suffer injuries was exceeded or not (Fig. 8).

From Fig. 8 can be seen that only in winter are plants dried severely and that this dehydration has its maximum between February and April.

We see also, that during this time the water content of needles of grown up pine trees remains well above the level of dehydration injury.

Larcher (1957) has collected all measurements of water content which Pisek and co-workers carried out near Innsbruck above the timber-line during several years from January to April. From this collection we can determine the mean and the maximum drought stress (Höfler, Migsch and Rottenburg, I94I; Larcher, 1960) (Table 3). This shows that this tree species is extremely adapted to drought.

Smaller pine trees are stressed much more because they have in their stems less water than taller trees.

In snowless sites in the zone between timber-line and tree-line the water content of pine plants decreases to the critical limit (Fig. 7). 


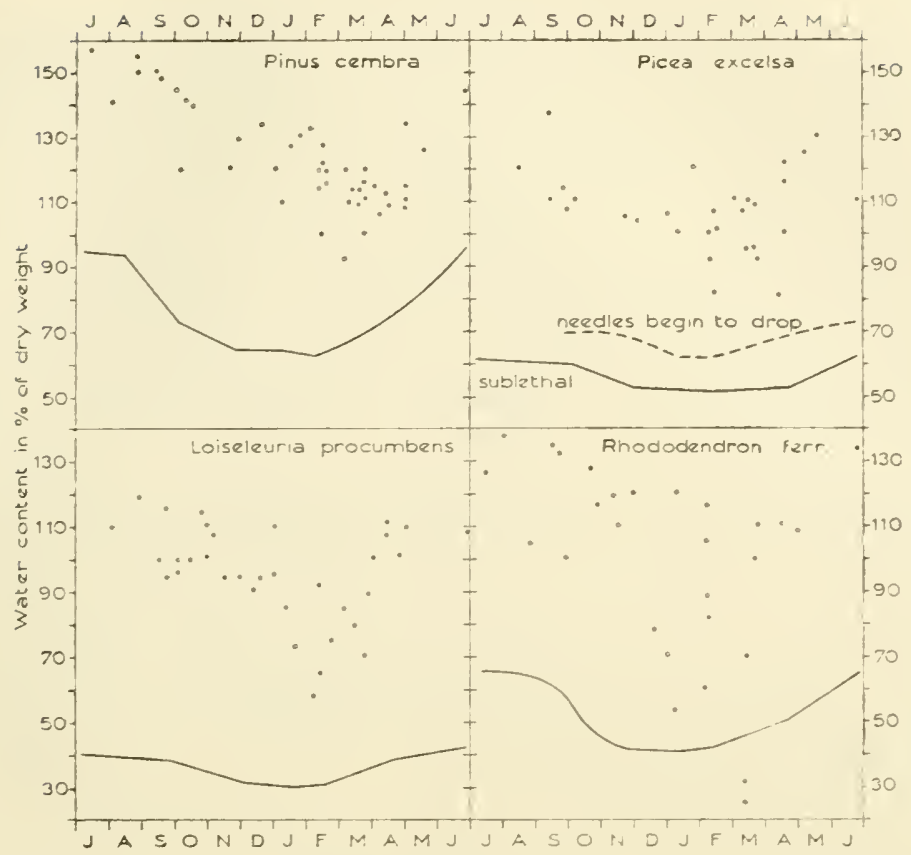

FIG. 8. Natural (circles) and sub-lethal water content (solid line) in percentage of dry weight of several sub-alpine plant species without snow cover at the Patscherkofel in winter. (From Larcher, 1957).

In winter the dehydration of needles of grown up spruce trees (Picea excelsa) approached the critical limit more than that of the adult pine trees especially if we take the beginning of the dropping of their needles as an injury.

\section{TABLE 3}

Injury delay of cut-off leaves and twigs exposed to the open air in February and March (Pisek and Berger, 1938) and drought stress (actual as per cent sub-lethal deficit) (Höfler, Migsch and Rottenburg, I941 ; Larcher, I960) in the natural habitat

\begin{tabular}{lccccc}
\hline & $\overbrace{\text { Leaves }}^{\text {Twjury delay (days) }}$ & & $\overbrace{\text { Mean }}^{\text {Maximum }}$ \\
Pinus cembra (adult trees) & 26 & 49 & 15 & 26 \\
(young plants) & - & - & 34 & 50 \\
Picea excelsa & 20 & 28 & 18 & 64 \\
Loiseleuria procumbens & I4 & 26 & 34 & $5 \mathrm{I}$ \\
Rhododendron ferrugineum & 5 & $2 \mathrm{I}$ & 42 & $>100$ \\
\hline
\end{tabular}


The water loss of leaves of the alpine rose (Rhododendron ferrugineum) clearly exceeds the critical limit at some measurements (Fig. 8). If we cut off twigs of this plant in winter and expose them to the open air in February and March they wilt after only $2 \mathrm{I}$ days (Table 3). Twigs of pine trees can endure the same conditions for 49 days. Therefore the alpine rose depends on the protection of a snow cover and grows only in such places which are covered with snow reliably and for a long period during the winter.

Among the tested plant species the trailing azalea (Loiseleuria procumbens) has an exceptional position. When a twig is cut off and is exposed to the air it starts wilting after nearly the same time as a twig of the alpine rose. This is due to the high cuticular transpiration and little water storage in the shoots (Table 3) but in its natural habitat it is not more stressed than are young pine trees (Fig. 8, Table 3). For this phenomenon the only explanation is that the azalea is well supplied with water in late winter, although it grows in snowless places (Fig. 5), where the soil is certainly frozen. On warm sunny days during this period there is a lot of water from melting snow, which cannot penetrate into the soil. Therefore it saturates the litter and mould layer. In this wet layer numerous adventitious roots are spread by which the plant can absorb this water.

\section{REFERENCES}

Aulrtzky, H. (1958) Waldbaulich-ökologische Fragen an der Waldgrenze. Cbl. ges. Forstwesen, 75, I8-33.

Aulitzky, H. (I96I) Die Bodentemperaturverhältnisse an einer zentral-alpinen Hanglage beiderseits der Waldgrenze. Arch. Met. Geophys. Bioklim. IoB, 445532.

Berger-Landefeldt, U. (1936) Der Wasserhaushalt der Alpenpflanzen. Bibl. bot. I I s. Cartellieri, E. (I94I) Über Transpiration und Kohlensäureassimilation an einem hochalpinen Standort. Sitzmingsber. Akad. Wiss. Wien, math.- naturw. Kl. Abt. I. I49, 95-I 43.

DöRING, B. (1935) Die Temperaturabhängigkeit der Wasseraufnahme und ihre ökologische Bedeutung. Z. Bot. 28, 305-383.

Höfler, K., Migsch, H. \& RotTenburG, W. (r94I) Über die Austrocknungsresistenz landwirtschaftiicher Kulturpflanzen. Forschungsdienst, I2, 50.

LARCHER, W. (1957) Frosttrocknis an der Waldgrenze und in der alpinen Zwergstrauchheide auf dem Patscherkofel bei Innsbruck. Veröff: Ferdinandeum Imusbruck, $37,49-8 \mathrm{I}$.

LARCHER, W. (1960) Transpiration and photosynthesis of detached leaves and shoots of Quercus pubescens and Quercur ilex during desiccation under standard conditions. Bull. Res. Counc. of Israel, 8D, 213-224.

Lrvingston, B.E. (1906) The relation of desert plants to soil moisture and to evaporation. Carnegie Inst. Publ. so. 
OpPENHEIMER, H.R. (I932) Zur Kenntnis der hochsommerlichen Wasserbilanz mediterraner Gehölze. Ber. dtsch. bot. Ges. 50A, I $85-245$.

PISEK, A. \& Berger, E. (I938) Kutikuläre Transpiration und Trockenresistenz isolierter Blätter und Sprosse. Planta, 28, I24-155.

Pisek, A. \& Cartellieri, E. (I934) Zur Kenntnis des Wasserhaushaltes der Pflanzen. III. Zwergsträucher. Jb. wiss. Bot. 79, I 3 I.

Pisek, A. \& LARcher, W. (I954) Zusammenhang zwischen Austrocknungsresistenz und Frosthärte bei Immergrünen. Protoplasma, (Wien), 44, 30.

Pisek, A., Sohm, H. \& Cartellieri, E. (1935) Untersuchungen über den osmotischen Wert und Wassergehalt von Pflanzen und Pflanzengesellschaften der alpinen Stufe. Beih. bot. Zbl. 52, 634-675.

Prutzer, E. (196I) Ökologische Untersuchungen in der subalpinen Stufe. Die Verdunstungsverhältnisse. Mitt. forstl. Bundesvers. anst. Mariabrun (Wien), 59, $23 I-256$.

RAthschüLER, E. (I949) Über die Änderung des Tagesganges der Luftfeuchtigkeit mit der Höhe im Gebirge. Arch. Met. Geophys. Bioklim. IB, I7-3I.

Stalfelt, M.G. (1932) Der Einfluss des Windes auf die kutikuläre und stomatäre Transpiration. Svensk bot. Tidskr. 26, 45 .

Tranquillini, W. (1957) Standortsklima, Wasserbilanz und $\mathrm{CO}_{2}$-Gaswechsel junger Zirben (Pinus cembra L.) an der alpinen Waldgrenze. Planta, 49, 6I 2-66I.

Tranquillini, W. \& Turner, H. (I96I) Ökologische Untersuchungen in der subalpinen Stufe. Pflanzentemperaturen. Mitt. forstl. Bundesvers. anst. Mariabrum (Wien), 59, I27-15I.

Turner, H. (I96I a) Jahresgang und bilogische Wirkungen der Sonnen- und Himmelsstrahlung an der Waldgrenze der Ötztaler Alpen. Wetter und Leben (Wien), r3, 93-II3.

Turner, H. (196Ib) Ökologische Untersuchungen in der subalpinen Stufe. Die Niederschlags- und Schneeverhältnisse. Mitt. forstl. Bundesvers. anst. Mariabrum (Wien), 59, 265-3is.

Walter, H. (I9SI) Standortslehre. Stuttgart: Eugen Ulmer. 


\title{
INVESTIGATIONS ON THE WATER RELATIONS OF SAND-DUNE PLANTS UNDER NATURAL CONDITIONS
}

\author{
A.J. Willis \& R. L. JefFeries \\ Department of Botany, University of Bristol
}

\section{INTRODUCTION}

Although many studies of the water relations of plants have been made, only a few of them relate to the behaviour of plants under the normal conditions of their habitat. The aim of the present investigation has been to gain information concerning the water balance of plants in their natural environment of sand dunes. In this habitat, conditions tend to be somewhat extreme, especially on the dunes themselves where rates of evaporation are often high, and the water supply limited during the summer. Furthermore, conditions are strongly contrasting within the dune system, as although in some parts insolation is considerable and the water content of the sand very low, elsewhere the sand may be water-saturated and some shelter afforded. These habitat differences are most marked during the summer, a time when any physiological differences between plants with regard to their water relations are likely to be clearest. The data reported here are of studies made in mid-June (1952-60) on a range of plants of the dune system of Braunton Burrows, North Devon.

Previous investigations have stressed the importance of the water factor in respect of plant distribution on the Burrows (Willis, Folkes, HopeSimpson and Yemm, I959), many species being restricted to low-lying 'slacks' where their roots are always within reach of the capillary fringe of the water table and others occurring characteristically on the drier dune slopes. An attempt was made to estimate to what extent plants of these various sites differed in respect of their water relations. Hygen (195 I, 1953) has attempted an ecological characterisation of plants in terms of their rates of stomatal and cuticular transpiration, and has shown the usefulness of transpiration decline curves in this connection. Somewhat similar studies have been made in the present investigation alongside assessments of stomatal behaviour and water deficits. In particular, the diurnal course of transpiration has been followed under natural conditions, measurements being also made of physical factors of the environment such as temperature, relative humidity and light intensity, as well as the rate of evaporation, at different times of the day and night. 
Despite the difficulties associated with field measurements and the interacting complex of changing factors, these exploratory studies were planned to provide some basic data concerning the diurnal changes of water deficit, transpiration rate and stomatal behaviour in a range of species, and thus clucidate characteristic differences in the water relations of plants of different sites.

\section{EXPERIMENTAL METHODS}

The choice of plants for the experiments was made so as to include some representatives of the vegetation of the dune slopes and of the 'slacks'. A plentiful supply of leaves of suitable size and shape for weighing was required and it was also desirable that the epidermis should strip readily for stomatal studies. The most extensive investigations were with Senecio jacobaea L., Cynoglossum officinale L. and Hydrocotyle vulgaris L. (all amphistomatous species); a number of other plants was also studied.

The various methods used to investigate features which affect the water balance of the plants are considered in turn.

\section{(a) Measurement of the Water Content of the Soll}

Soil samples were collected from freshly excavated holes, at various sites, in 2 in. $X_{\mathrm{I}}$ in. specimen tubes, sealed with waxed corks and tape. The samples were dried to constant weight at $80^{\circ} \mathrm{C}$, and the water content expressed as a percentage of the weight of the oven-dried soil.

\section{(b) Physical Factors of the Environment}

The chief physical features assessed were temperature, relative humidity, light intensity and the rate of evaporation; measurements were made at frequent intervals.

Air temperature was taken as the dry-bulb reading of a whirling psychrometer, which was swung rapidly at approximately $\mathrm{I} m$ above ground level for about 20 seconds. The relative humidity was estimated from the depression of the wet bulb.

Light intensity was measured by means of an EEL Lightmaster photometer, graduated in three ranges-0-I0, 0-I00 and 0-I000 ft candles (lumens/sq. ft). The sensitivity of the cell to different wavelengths is recorded by Ashton (1958). To extend the range of the photometer to approximately ro,000 ft candles, a clip-on neutral density filter was employed. Although light intensities are expressed in this study in terms of foot candles, it is clear that these units are arbitrary, and that the measure- 
ment of light intensity in absolute units in the field is of great complexity (Evans, 1956).

An indication of the rate of evaporation was obtained from the changes in weight of saturated filter paper suspended from a torsion balance on the dunes. Pieces of filter paper, usually of $12.65 \mathrm{sq} . \mathrm{cm}$ or $4 \mathrm{sq} . \mathrm{cm}$ area, were saturated with water, weighed initially and again at appropriate intervals (usually about I min) for some ro min. In the cxperiments reported here the rate of loss of water vapour was seen to be uniform over this period. Estimates made in this way at every hour were found to give a satisfactory indication of the diurnal changes in evaporation.

\section{(c) Estimation of Water Deficits}

The water deficits of leaves at different times of day were measured by the method described by Yemm and Willis (I954), which is similar in principle to that of Weatherley (1950). After an initial weighing of the leaf, immediately after excision, it was transferred to a saturated atmosphere, and its cut petiole allowed to stand in distilled water. The leaf was then weighed at appropriate intcrvals until it was fully turgid; the dry wcight of the leaf was finally determined. The water deficit is here expressed as the amount of water absorbed by the leaf to reach full turgidity, calculated as a percentage of the water content of the fully turgid leaf(Stocker, 1929). Under field conditions on very hot dry days difficulties were encountered in maintaining a saturated atmosphere, and it was found convenient, particularly when high deficits were involved, to allow the leaves to pick up water overnight, a final weighing being made early the next morning. However, many plants restored their deficit in less than 3 hours, the course of water uptake being as illustrated by Yemm and Willis (1954, Fig. 3).

\section{(d) Measurement of Transpiration Rates: Transpiration Decline Curves}

Transpiration rates were estimated from weight losses of detached leaves. The decline in transpiration of the cut leaves was determined from weighings at frequent intervals; in this way transpiration decline curves of the type described by Hygen (1951, 1953) were obtained. There were, however, several important differences from the procedure of Hygen; the leaves were not initially always completely turgid, nor wcre the stomata always open. Furthermore, the conditions under which the detcrminations were made were those of the variable environment.

The method adopted in this investigation was to cut a leaf of convenient size (100-500 $\mathrm{mg}$ ) from the plant in its natural habitat, weigh the leaf on a 
torsion balance as soon as possible after cutting (usually within I min), and make a series of subsequent weighings at known times. When there had been a heavy dew, the leaves used in transpiration studies in the early morning were blotted dry before the initial weighing. It was necessary to shield the balance from wind; for this a box was used with a perspex front, which was removed between readings. Trials showed that the results obtained when the leaves remained on the hook of the balance were usually fairly similar to those obtained when the leaves were removed between weighings and suspended in the open. Only on very hot days and under windy conditions were the differences considerable (most of the experiments of this study were carried out when there was little wind). By using a torsion balance with a scale of o-100 $\mathrm{mg}$, and by employing appropriate counterbalance weights, it was possible to weigh to an accuracy of $\mathrm{O} \cdot \mathrm{I} \mathrm{mg}$. The timing was accurate to one second.

The form of the transpiration decline curve of leaves investigated usually conformed to that described by Hygen (195I). At first there is a rapid, fairly uniform transpiration rate (the 'stomatal phase'), the decline following a rectilinear course; this is succeeded by a phase of decreasing transpiration rate (the 'closing phase'), which is followed by a final rectilinear portion of the decline curve (the 'cuticular phase') when the rate of loss of water vapour is low. In the experiments of Hygen the leaves were brought to a condition of full turgidity initially, the stomata being assumed fully open; by the end of the second ('closing') phase the stomata were regarded as completely shut. Although in many of the experiments of the present study carried out during the day the leaves were not fully turgid, and the stomata not fully open, decline curves showing initial and final portions approximating to straight lines were often obtained; however, the initial rectilinear portion was frequently short. On the other hand, the decline curves for leaves detached in the early morning or during the evening are not so readily interpreted in terms of three phases, as these are not sharply defined. Some examples of curves obtained at different times of day are given for leaves of Senecio jacobaea in Fig. I. The decline curve for the leaf detached at about I I a.m. indicates three phases, but these are less clear for the leaf detached in the evening, when the initial rectilinear phase is short. Very different is the curve for the leaf excised at about 6.30 a.m., as the transpiration rate is rather low initially and fairly uniform for a considerable time (a prolonged steady rate of transpiration of leaves excised in the early morning has been often observed in the present study). The major differences in the curves are clearly in part referable to different physical conditions at different times of day and in part to differences with respect 
to the behaviour of stomata. For example, stomatal closure from fairly wide apertures $(c .4 .5 \mu)$ probably occurred about one hour after excision of the leaf at I I a.m.; however, in the leaf detached in the early morning, although the stomata were initially of only moderate aperture $(c .3 \cdot 3 \mu)$, closure was delayed.

The rate of transpiration at the time of cutting was estimated by extrapolation of the decline curves to zero time. The validity of this estimate may be questioned in view of the quick changes in transpiration rate which may occur on cutting a leaf, in particular when the stomata are

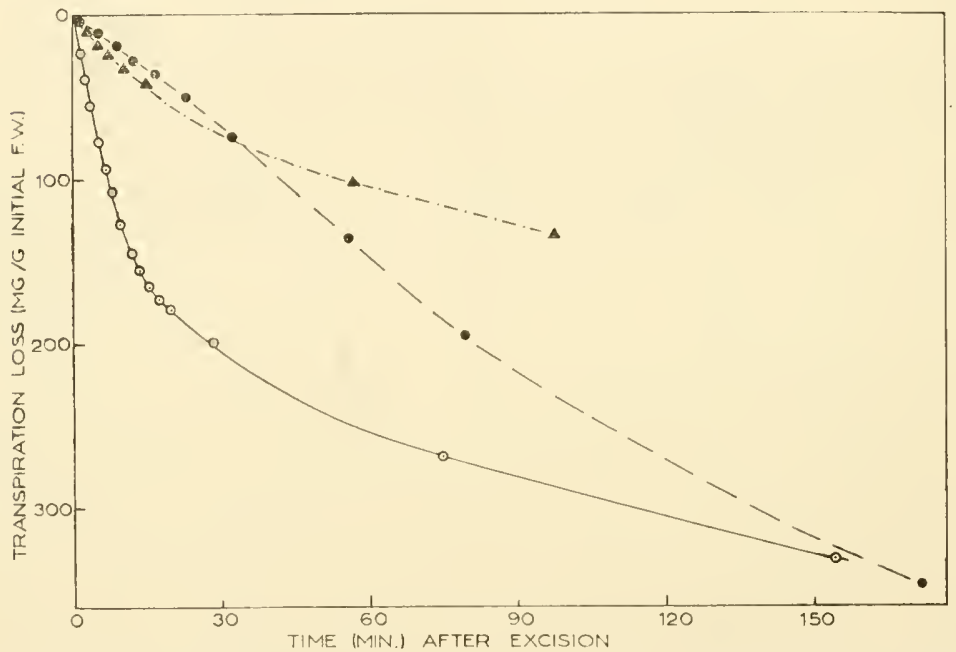

FIG. I. Transpiration decline curves for Senecio jacobaea. For simplicity in comparison, transpiration losses are calculated as $\mathrm{mg} / \mathrm{g}$ initial fresh weight of the excised leaves. A selection of the results for leaves cut at 6.27 a.m. $(---\bullet), 10.55$ a.m. $(\odot-\bigcirc)$ and 6.18 p.m. (

only partly open. Substantial increases in transpiration rate on leaf excision have been noted by many observers, including Andersson, Hertz and Rufelt (I954) and Parker (I957); similar observations have also been made under some conditions in this laboratory. Milthorpe and Spencer (1957) obtained evidence of increased transpiration rates and opening of stomata following the removal of the water supply of leaves, and further showed that data of Hygen (1953) are consistent with these findings. However, there is only little indication of appreciable increases in transpiration rate on leaf excision in the present field studies; in fact, the points of the majority 
of the decline curves appear to fall closely on a straight line for the first few minutes and to form the basis for a useful comparative estimate of transpiration rate. In practice, the estimate of the rate of transpiration at the time of excision is derived by extrapolation from the values for the first three minutes after cutting the leaf. Values based on a rather longer period give similar results; detailed examination of records for Hydrocotyle vulgaris showed that the estimates of rate based on the first four minutes after excision are not appreciably different from those based on the first three minutes. The estimates by Hygen (1951, 1953) of initial transpiration rate are based on semi-logarithmic plots of weight against time, but, as discussed by Williams and Amer (1957), it is not essential to take logarithms (or compute a 'reduced fresh weight'), there being a prolonged constant rate phase during which transpiration is independent of water content. Williams and Amer (1957) further point out that Hygen's 'standard product' may be calculated directly from the slopes of the first and second straight portions of a plot of instantancous weight of the leaf against time.

Transpiration rates are usually expressed on either an area or a weight basis. In the present investigations the most convenient basis of expression, in view of the methods used, is $\mathrm{mg}$ transpiration/g initial fresh weight/ minute, the initial fresh weight at the time of excision being estimated by extrapolation. It must, however, be noted that on some occasions the leaves were essentially fully turgid but at other times had an appreciable water deficit, which in extreme instances was of the order of $20 \%$. Nevertheless, comparison of results for Hydrocotyle vulgaris showed that the diurnal changes of transpiration rate expressed on a fresh weight basis followed a very similar course to that of rates expressed on the basis of dry weight of the leaves. In a few experiments leaf areas were determined, and the results can be expressed in terms of both weight and of area.

\section{(e) Investigation of Stomatal Behaviour}

Although estimations of stomatal changes have been attempted with various types of porometer at Braunton Burrows, the two most useful methods of investigating the behaviour of stomata under natural conditions were found to be the examination of strips of epidermis and the infiltration technique.

Epidermal strips, fixed by the method of Lloyd (1908), were examined in iodine-phenol-KI reagent (Heath, 1947) and the stomatal apertures measured as described by Yemm and Willis (1954). Although there is evidence that in Pelargonium (Heath, I950) the stomata may open during stripping and fixing, measurements made from epidermal strips do never- 
theless indicate trends of opening and closure of stomata (Heath, I959). Results obtained in the present study indicate that, for a range of plants of sand dunes, Lloyd's strips provide a useful, if not absolute, index of stomatal aperture. Several strips of the lower epidermis from at least two leaves were taken on sampling occasions; mean apertures are based on measurements of not less than 20 stomata (frequently more), at least two strips being examined. In view of the importance of starch/sugar changes in stomatal behaviour, at the same time as apertures were measured assessments were made of the amount of starch in the guard cells by the method of Yemm and Willis (1954), a scale of o-5 for starch content being used.

Infiltration methods integrate the effects of large numbers of stomata and give quick information of stomatal apertures. A variety of infiltrating liquids has been used by different workers (cf Heath, I959); in the present study a graded series of seven solutions involving petrol ether and alcohol was employed. The series was as follows: I, petrol ether; 2, 4 vols. petrol ether/I vol. absolute ethanol; 3, 2 vols. petrol ether/I vol. ethanol; 4, equal vols. petrol ether and ethanol; 5, I vol. petrol ether $/ 4$ vols. ethanol; 6 , abs. ethanol; 7, 95\% ethanol. Of these solutions, no. I is the most penetrating, and $95 \%$ ethanol the least, entering the leaf only when the stomata are very widely open. To aid the subjective assessment, by eye, of the degree of penetration, crystal violet (cf Williams, I949) was added to solutions 3-7 (c. $100 \mathrm{mg} / \mathrm{I} 50 \mathrm{ml}$ ), and waxoline blue to solutions I and 2. Estimations were made by immersing leaves in a shallow layer of the solutions, washing quickly in water and assessing the cxtent of infiltration. By use of a number of leaves it is possible to find the point in the series (the infiltration index) giving a mean value of $50 \%$ penetration of the leaves; trends of stomatal movement can be detected from changes in this index. Parallel studies by the epidermal strip and the infiltration methods gave results which were strongly correlated; for a particular species, a point on the infiltration scale can be expressed in terms of mean stomatal aperture. Some indication of the relation between aperture and infiltration is given for Senecio jacobaea in Fig. 2. However, in view of differences in the structure of stomata (e.g. the presence or absence of ridges or 'beaks' on the guard cells) in different species, it is necessary to determine for each species the mean stomatal aperture corresponding to a particular point on the infiltration scale. Although the infiltration technique provides a rapid indication of stomatal aperture, two main difficulties may be noted. The method is not suitable for use with thickly hairy leaves (e.g. Verbascum thapsus L., Cynoglossum officinale), as the infiltrating solutions may be trapped in the tomentum and hence the degree of penetration is not easily assessed. A second diffi- 
culty is that the volatile solutions may quickly change in composition by evaporation, especially during a hot dry day.

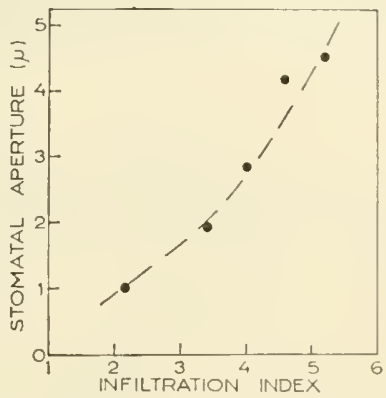

FIG. 2. The relation between infiltration index and mean stomatal aperture in Senecio jacobaea.

\section{(f) General Procedure}

As far as was practical, measurements of physical factors, of water deficits, transpiration rates and stomatal apertures of particular species were made at intervals of about one hour from dawn to sunset. These data were augmented by information from many shorter-term experiments. In any experiment, care was taken to ensure that the leaves taken for the various assessments were as far as possible comparable. The leaves used were fully expanded, but not senescent.

All times are given in G.M.T.

\section{EXPERIMENTAL RESULTS}

For convenience, data relating to the water content of the dune soils are given first, and then the results of investigations made on particular species.

\section{(a) The Water Content of the Soils}

Especially during the summer, there is a sharp contrast in the water content of the sand of the dune slopes and of the 'slacks'. Even in dry years the water content of the soil of the low-lying parts is high, whereas on the dunes themselves it is more variable, being very low in times of drought and moderate in wet periods.

It has already been shown (Willis et al., I959, Fig. I4) that in dry dune pasture the layers of the sand above the reach of the capillary rise may be of low water content in summer. In some years, however, moister conditions 
prevail; for example the data given in Table $\mathrm{I}$ indicate that in June 1956 the sand of the dune slopes had a water content of some $4-8 \%$ in the top $90 \mathrm{~cm}$. On the other hand it is clear that in June 1957 the surface layers of this site were very dry, plants rooted in the top $15 \mathrm{~cm}$ being extremely limited in their water supply.

\section{TABLE I}

The water content of the soils at Braunton Burrows. Water contents are expressed as percentages of the weight of oven-dried soil

\begin{tabular}{|c|c|c|c|}
\hline \multirow{2}{*}{$\begin{array}{l}\text { Depth } \\
\text { from } \\
\text { surface } \\
(\mathrm{cm})\end{array}$} & \multicolumn{2}{|c|}{$\begin{array}{c}\begin{array}{c}\text { Dry dune pasture } \\
\text { (dune slope) }\end{array} \\
\text { Plope }\end{array}$} & \multirow{2}{*}{$\begin{array}{c}\text { 'Slack' } \\
22.6 .56\end{array}$} \\
\hline & 22.6 .56 & 28.6 .57 & \\
\hline 3.75 & $4^{\cdot I}$ & $I \cdot 4$ & $9 \cdot 7$ \\
\hline $7 \cdot 5$ & $5 \cdot 7$ & $I \cdot 7$ & I $2 \cdot 9$ \\
\hline 15 & $6 \cdot 1$ & $2 \cdot 2$ & I9. 4 \\
\hline 30 & $7 \cdot 6$ & $4 \cdot 4$ & $2 I \cdot 2$ \\
\hline 60 & $4 \cdot 6$ & $4 \cdot 2$ & $2 I \cdot 7$ \\
\hline 90 & $6 \cdot 1$ & $4^{\circ} 0$ & $\begin{array}{c}26 \cdot 0 \\
\text { (saturated) }\end{array}$ \\
\hline
\end{tabular}

Plants of the 'slacks', being always near to the water table, have a much more constant and plentiful water supply. Only rarely does the water content of the soil fall appreciably below 10\% even at the surface, and for much of the year the soil is saturated throughout.

\section{(b) The Water Relations of Senecio jacobaea}

This study was carried out on plants in their second year of development growing on the dune slopes well above the level of the water table. Generally the 6th-8th expanded leaves (counting from the apex downwards) were used experimentally.

The results of a typical investigation are shown in Fig. 3 . The transpiration rate was very low at dawn, and rose during the morning to reach a peak value of almost $20 \mathrm{mg} / \mathrm{g}$ fresh $\mathrm{wt} / \mathrm{min}$ before midday. Subsequently the rate decreased fairly uniformly and by the end of the day was similar to that at dawn (c. $2 \mathrm{mg} / \mathrm{g} / \mathrm{min})$. The changes in stomatal apertures in general paralleled those of transpiration rate. The stomata opened quickly after $6 \mathrm{a} . \mathrm{m}$. and were of greatest mean aperture at about I I a.m. After this time there was a progressive closure. The water deficit of the plants was considerable $(c .8 \%)$ at dawn, and increased during the morning. There was, however, some restoration of the deficit in the early evening. 
The records of air temperature, relative humidity, light intensity and of observations on wind indicate that the greatest opening of the stomata and the highest rates of transpiration precede the peak evaporation rates by

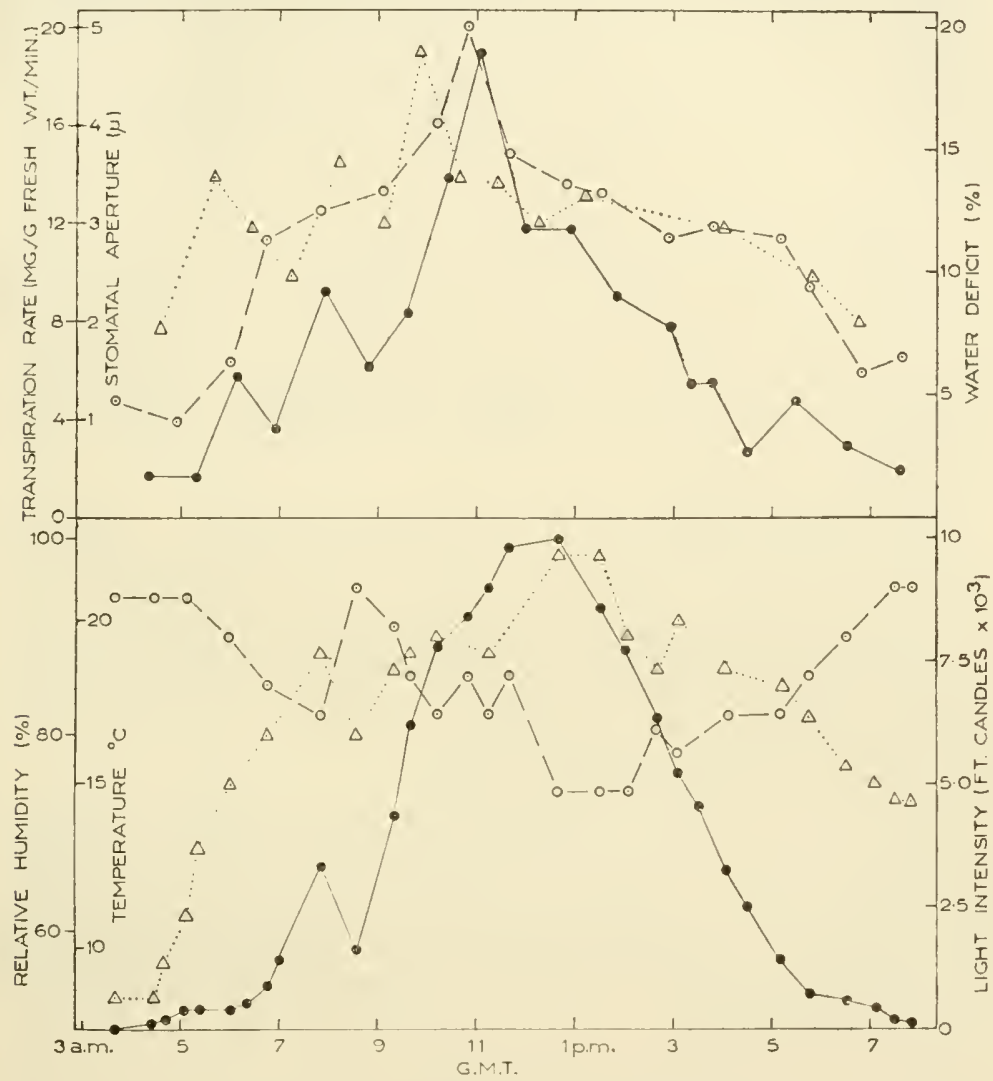

FIg. 3. The diurnal changes in transpiration rate, stomatal aperture and water deficit in Senecio jacobaea. Some of the results of an experiment of 16 June 1959 are plotted. The upper part of the figure shows transpiration rate $(-\bullet)$, mean stomatal aperture $(\odot---\odot)$ and water deficit $(\triangle \ldots . . \Delta)$. Changes in some of the chief physical factors are illustrated in the lower part of the figure: air temperature $(\triangle \cdots \cdots \Delta)$, relative humidity $(\odot--\odot)$, light intensity $(-\bullet)$

about 2 hours. The correspondence of the greatest transpiration rate with the maximum stomatal opening is striking; the decrease of transpiration rate at a time when environmental conditions are tending to increase evaporation is strongly suggestive of stomatal regulation. It may be noted 
that this record does not indicate any re-opening of the stomata after midday.

Similar results to those described have been obtained on a number of occasions. Usually the transpiration rate is highest just before midday and declines substantially in the afternoon. Less commonly a fairly high transpiration rate is maintained well into the afternoon; for example, on I 8 June I958, a rate of about I4 $\mathrm{mg} / \mathrm{g} / \mathrm{min}$ persisted for some 6 hours (from about Io a.m. to 4 p.m.), the stomata showing fairly constant apertures of about $4 \mu$ over this period.

Characteristically the stomata of $S$. jacobaea show pronounced diurnal changes; shut during the hours of darkness, they open early in the morning to a maximum before midday. They then tend to close with various degrees of rapidity. On one occasion there was some indication of midday closure of stomata, followed by slight re-opening later in the afternoon, as reported for various plants by Loftficld (I92I) and Sayre (1926), but usually no re-opening is observed.

Water deficits greater than $20 \%$ have been found several times, and during the day in the summer are usually well in excess of $10 \%$. Often the deficit developed during the day is still quite large on the following morning, especially at times when the water content of the sand is low. Despite the fact that the water deficit of the leaves may be $8-10 \%$ at dawn, the stomata usually show a strong opening reaction and closure often does not begin until the deficit reaches about $15 \%$.

Attempts have been made to estimate the rate of 'cuticular' transpiration from decline curves; under field conditions the final portion of the curves is not strictly rectilinear and the assessments are to some extent arbitrary. The results indicate a rather low value of $0.6-0.8 \mathrm{mg} / \mathrm{g} / \mathrm{min}$ under conditions of high evaporation. These values are of the order of $5-8 \%$ of the total transpiration losses.

\section{(c) Observations on Cynoglossum officinale}

The water relations of this plant show a general similarity to those of Senecio jacobaea, with which it is often associated on the dry dune slopes at Braunton Burrows. Leaves from first year rosettes were used experimentally.

A representative set of data is given in Fig. 4. The transpiration record indicates a gradually rising rate to a maximum value at about Io a.m., soon followed by a rather sharp decline. On the other hand, the rate of evaporation reached a high value by Io a.m. but remained high for some hours. It is clear that the peak transpiration rate precedes the maximum light intensity, maximum temperature and lowest relative humidity. In this experi- 
ment no large changes in stomatal apertures were observed; however, it is of note that the widest apertures correspond with the greatest transpiration rate, and the stomata are partly closed during the early morning and the late afternoon when rates of loss of water vapour are low. The water deficit is seen to be low at dawn, but to develop rapidly to a value of about

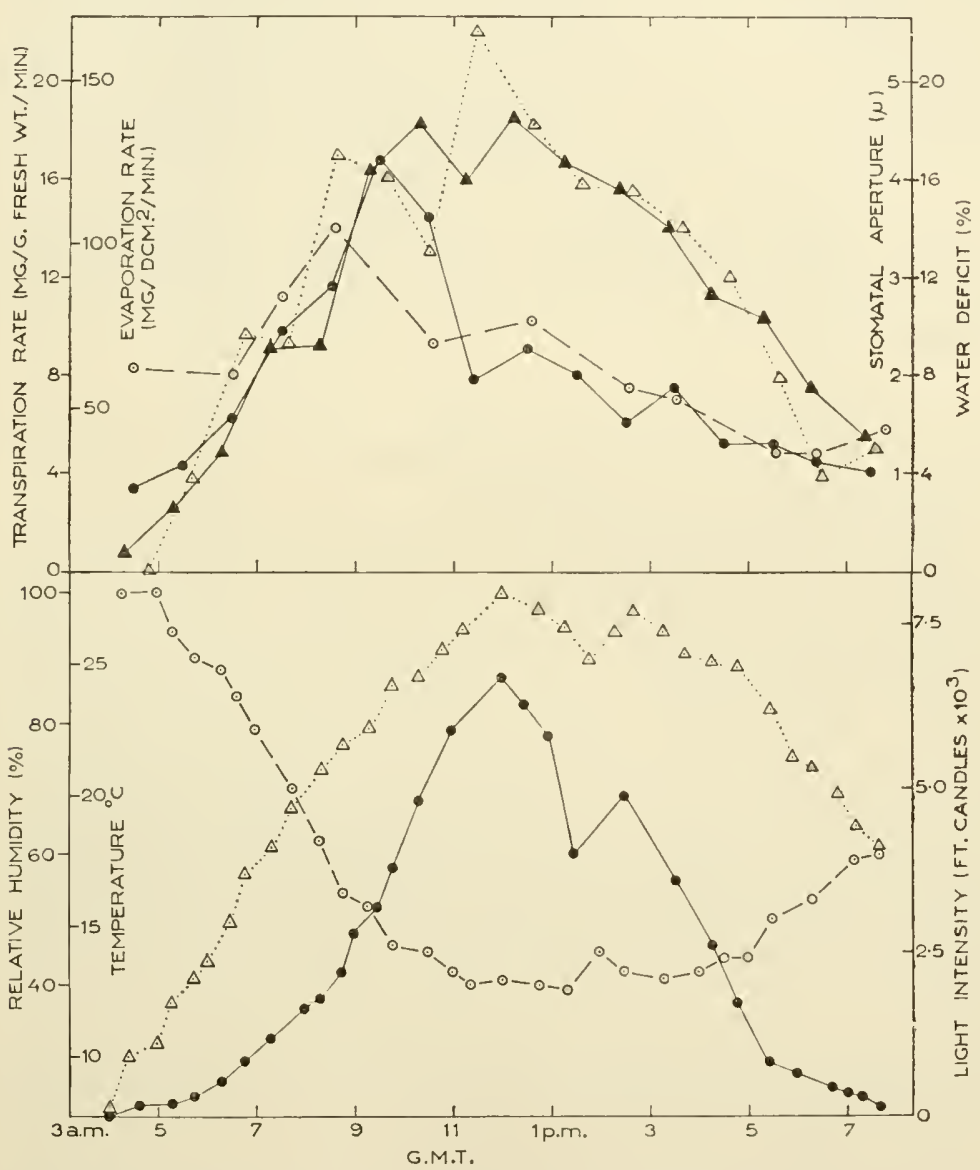

FIG. 4. The diurnal changes in transpiration rate, stomatal aperture and water deficit in Cynoglossum officinale. A selection of the results obtained on 2 I June I960 is plotted. The upper part of the figure shows transpiration rate (- ) evaporation rate $(\Delta \longrightarrow \Delta)$, mean stomatal aperture $(\odot---\odot)$ and water deficit $(\Delta \ldots . . \Delta)$. Below are given data for air temperature $(\Delta \ldots . . \Delta)$, relative humidity $(\odot---\odot)$ and light intensity (-๑). 
$20 \%$ by midday. The deficit was subsequently reduced, a feature doubtless related to the closing of the stomata and a reduced transpiration rate.

As discussed with reference to Senecio jacobaea, there is seen to be here also evidence of stomatal regulation of transpiration; the daily course of transpiration appears to be rather similar in these plants. Rates of 'cuticular' transpiration are also of about the same magnitude $(0.7-0.9 \mathrm{mg} / \mathrm{g} / \mathrm{min}$ under conditions of high evaporation). Some difference may be shown with respect to the water deficits of leaves; usually the deficits are more readily restored overnight in Cynoglossum officinale than in Senecio jacobaea. This feature may be related to differences in habit and root systems of the plants used experimentally; in the erect second-year plants of Senecio the root and conducting systems may be inadequate to supply the water required by the numerous leaves, whereas the first-year plants of Cynoglossum have fewer leaves in a basal rosette, and an extensive tap-root (cf Salisbury, 1952).

\section{(d) Investigations on Hydrocotyle vulgaris}

Well-developed leaves of this plant collected from vigorous populations in the 'slacks' were used experimentally.

Some of the observations made on I 8 June I958, and on I6 June 1959, are shown in Fig. 5. Transpiration rates rise from low values in the early morning to fairly high rates by about $8 \mathrm{a} . \mathrm{m}$. These rates remain high for $5-7$ hours, and then decline to low values in the early evening. The daily course of transpiration of $H$. vulgaris is similar to that of evaporation. The stomata are almost closed at night, opening during the morning; they stay widely open for some hours and then close. A general parallelism may be noted between the size of the stomatal aperture and transpiration rate; on 16 June 1959 the stomata closed appreciably after I p.m. and there was a decline in transpiration rate at about this time. On the other hand, on I8 June I958, the stomata did not close so quickly (at 2 p.m. the mean aperture was $3.6 \mu$ ) and the transpiration rate was maintained at a high value for longer. The record of water deficit indicates that the leaves are turgid in the early morning, but by midday may develop a deficit of $12 \%$ or more. This deficit is, however, to a large extent restored even by dusk.

General confirmation of these findings is given by a number of other experiments. The results of one of them (on 2I June 1960) are shown in Fig. 6. In this investigation the stomata opened in the morning and were of high aperture for much of the day. Typical trends in the starch content of the guard cells were observed; starch decreased during the phase of stomatal opening, was present in only small amounts when the stomata 
were wide open and increased when the stomata were closing, there being a negative correlation between starch content and pore width (cf Yemm and Willis, 1954); similar observations were made on Senecio jacobaea and Cynoglossum officinale. The changes in transpiration rate are clearly similar to those of the evaporation rate, the relative transpiration (transpiration rate/evaporation rate calculated on an area basis) being fairly constant, and

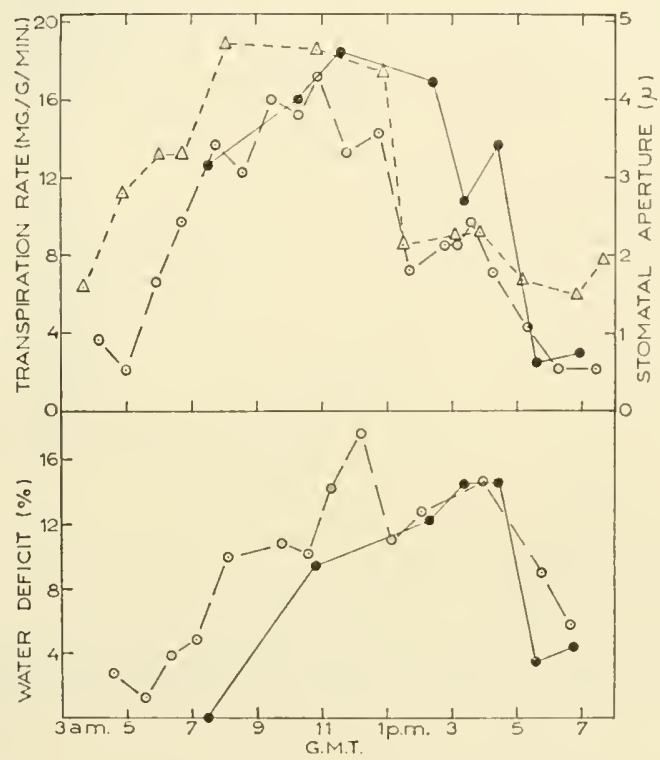

FIG. 5. Diurnal changes in transpiration rate, stomatal aperture and water deficit in Hydrocotyle vulgaris. Results obtained on I8 June 1958 (solid circles) and on I6 June I959 (open circles) are shown. Values for stomatal aperture are given for I6 June I959 only ( $\Delta---\Delta)$; records of temperature, relative humidity and light intensity for this date are plotted in Fig. 3 .

declining only a little towards the end of the day. In another experiment, extending from Io a.m. to 5 p.m. on Is June I959, there was also a marked parallelism of the course of transpiration and of evaporation, the relative transpiration varying only slightly; it tended to fall from an initial value of $60 \%$ to $50 \%$ by the end of the investigation.

Some estimates of 'cuticular' transpiration gave values as high as $I \cdot 8$ $\mathrm{mg} / \mathrm{g} / \mathrm{min}$ (about $10 \%$ of the total transpiration) under conditions of high evaporation. 


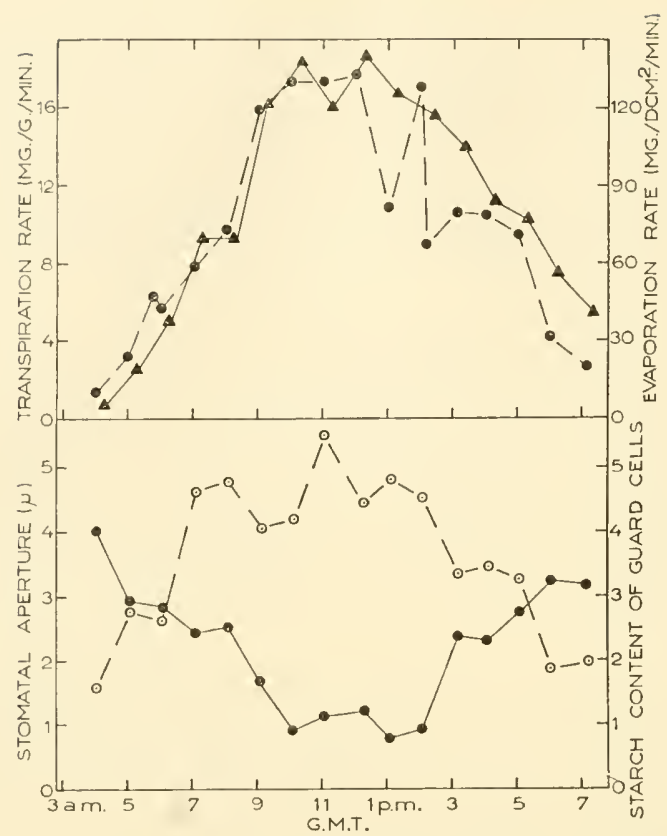

FIG. 6. Transpiration rate and stomatal behaviour of Hydrocotyle vulgaris in relation to evaporation rate. The experiment was carried out on 2 I June 1960. Upper part of figure: transpiration rate $(--\bullet)$, evaporation rate $(\mathbf{\Delta}-\mathbf{\Delta})$; lower part of figure: mean stomatal aperture $\left(\bigcirc_{---}\right)$), starch content of guard cells $(-\bullet)$. Records of temperature, relative humidity and light intensity for this date are shown in Fig. 4.

\section{(c) Studies on Other Plants}

The chief results of investigations on the water relations of various other sand-dune plants are outlined below.

Plants of the 'slacks' generally have little or no water deficit. Even on hot days in summer, deficits exceeding $10 \%$ are unusual for the majority of the species. For example, low deficits are normally found in the leaves of plants of such different growth form as Epipactis palustris (L.) Crantz, Scirpus holoschoenus L. and Salix atrocinerea Brot. On the other hand, some plants characteristic of low-lying habitats on the dunes such as Orchis praetermissa Druce and Filipendula ulmaria (L.) Maxim. have been known on some occasions to develop deficits of the order of $10 \%$ and $15 \%$ respectively.

On the dry dune slopes considerable water deficits are by no means uncommon; under extreme conditions leaves may wilt on the plants here. 
Deficits of some $10 \%$ or more have been recorded in, for example, Lycopsis arvensis L., Potentilla anserina L. and Ammophila arenaria (L.) Link. On the other hand the leaves of Carex arenaria L. from dune slopes do not usually show very high deficits; an average figure for midday in June is $5 \%$.

Transpiration rates greater than $12 \mathrm{mg} / \mathrm{g} / \mathrm{min}$ have been observed in Potentilla anserina and Filipendula ulmaria, with 'cuticular' rates of about $10 \%$ of these values. Losses from, for example, Viola hirta L. and Carex arenaria (midday values of $c .5 \mathrm{mg} / \mathrm{g} / \mathrm{min}$ ) are, however, somewhat lower; several experiments indicate that in C. arenaria 'cuticular' transpiration may be more than $10 \%$ of the total. Low transpiration rates have also been found in

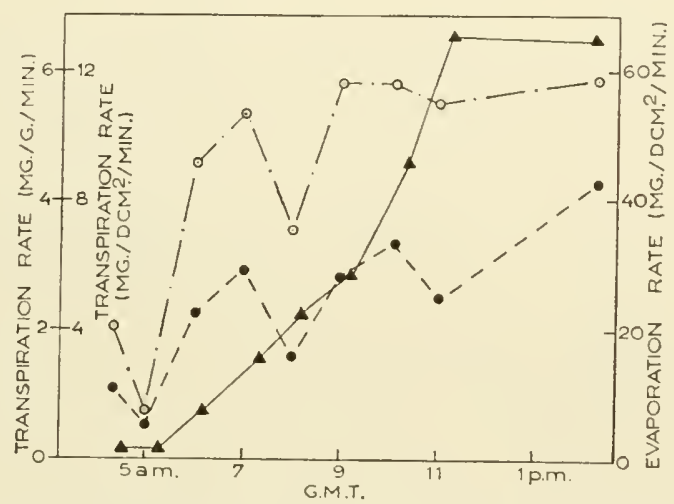

FIG. 7. Changes in transpiration rate of Ammophila arenaria. Transpiration rates are plotted on a weight $(---\bullet)$ and an area basis $(\bigcirc-\cdot-\cdot \bigcirc)$; rates of evaporation are also shown ( $\mathbf{\Delta} \boldsymbol{\Delta})$. The results were obtained on 24 June 1960.

Salix atrocinerea $(3-7 \mathrm{mg} / \mathrm{g} / \mathrm{min}$ during the middle of the day). In Ammoplita arenaria rates of transpiration expressed on a weight basis are low, as shown in Fig. 7. The leaves of marram have a high proportion of dry weight to fresh weight; however, the trends of transpiration are similar when the rates are expressed on an area basis. In this experiment inrolling of the leaf was noticeable from 9 a.m. onwards; it is of interest in this connection that although rates of evaporation increased substantially after 9 a.m. there was no corresponding increase in transpiration rate (see Fig. 7).

\section{DISCUSSION}

In spite of the difficulties involved in weighing leaves under the natural conditions of plant habitats, and in calculating transpiration rates from 
decline curves, the results of the present study appear to give a fairly good indication of the daily march of transpiration in a number of sand-dune plants. However, a full analysis and interpretation of the course of transpiration is difficult in view of the many varying physical factors involved and of changes in certain features (especially stomatal apertures and leaf water content) of the plants themselves. When rates of transpiration are compared it must be realised that here the rates are expressed on a weight and not an area basis; as discussed by Kramer (1959), the relative rates of different species may be quite different when expressed on a different basis. However, many of the plants of this investigation have somewhat similar surface/weight ratios.

Under conditions of high evaporation in summer, plants of the dune slopes and of the low-lying 'slacks' often show high transpiration rates (I $5-20 \mathrm{mg} / \mathrm{g} / \mathrm{min}$ ). In Senecio jacobaea, for example, the water content of the leaf may be completely replaced in 45 minutes. These rates are considerably greater than the maximum rates obtained by Hygen (1953) under standard conditions, but fairly similar to those found by Bosian (1933-34) whose methods of investigation were in many respects like those employed in the present study, transpiration being estimated from quick weighings of cut shoots. For example, Bosian (1933-34) records rates of about Is $\mathrm{mg} / \mathrm{g} / \mathrm{hr}$ or more for the 'xerothermic' species Artemisia campestris, Teucrium chamaedrys and Helianthemum chamaecistus in summer (late May) on the Kaiserstuhl near Freiburg. However, the highest rates of transpiration recorded on Braunton Burrows are considerably lower than some of the highest reported, under summer conditions, by Evenari and Richter (1937) for plants in the Wilderness of Judaea, and by Oppenheimer (I95I) for plants of other hot, semi-arid countries.

It seems likely that the transpiration rates reported in the present study may provide a better indication of the rates of the plants of the dune slopes with regard to their own microclimate than of the plants of the 'slacks'. This is because the detached leaves of Senecio jacobaea are, between weighings, supported on the balance in conditions similar to those normally experienced by the leaves on the plants, whereas the low-growing leaves of Hydrocotyle vulgaris are removed from their microclimate of rather moist, still air of the floor of 'slacks' to somewhat drier conditions for weighing. The rates given for H. vulgaris may, therefore, tend to be too high. These difficulties do not, however, obscure the important differences in the course of transpiration of the plants of the dune slopes and of the 'slacks'. As shown for Senecio jacobaea and Cynoglossum officinale, the transpiration rate reaches a peak in the morning, and although the rate of 
evaporation may increase later in the day there is no corresponding increase in transpiration but usually a decline. This behaviour seems to be representative of many of the plants of the dry slopes. On the other hand, in plants of the 'slacks' such as Hydrocotyle vilgaris, there is frequently a fairly high correlation of transpiration rate and evaporation rate throughout the day, relative transpiration being rather high and varying only little. A similar contrast in the daily course of transpiration, related to differences of water supply, was noted by Bosian (1933-34).

In stomatal behaviour, most of the sand-dune plants investigated seem to fall into the alfalfa type recognised by Loftfield (I92I), the stomata opening during the morning and closing at night. Under conditions of high evaporation, and of water stress, early closure may, however, set in, as observed for example in Senecio jacobaea and Cynoglossum officinale. Midday closure of stomata has often been attributed to water stress (Loftfield, I921; Sayre, 1926), although Nutman (1937) has given evidence that in Coffea arabica (a plant of shade) this closure is related to high light intensity. More recently Heath and his collaborators (cf Heath, I959) have interpreted midday closure in onion as a high temperature effect, operating through an increase in carbon dioxide in the intercellular spaces of the leaf. In the present studies midday closure has often been found to precede the highest temperatures and light intensities, and most frequently is correlated with a high water deficit. Although no decisive information has been gained, it seemis probable that the early stomatal closure of the plants of the dune slopes is largely attributable to water stress; usually there is no re-opening of the stomata of these plants until the following day although during the afternoon light intensity and temperature normally decrease. It is of interest that on a few occasions at about or just after midday considerable variability in stomatal behaviour from leaf to leaf has been observed; at this time the stomata may well be in a very sensitive state, the delicate balance of turgor between the guard cells and other cells of the leaf being easily disturbed.

In many of the records there is a general parallelism of transpiration rate and size of stomatal aperture. This is suggestive that transpiration rates are influenced by the extent of stomatal opening over a wide range, as indicated by the experimental studies of Milthorpe and Spencer (I957). Stalffelt(I932) also showed that under conditions of high evaporation, especially in moving air, stomata influence transpiration rate up to the widest apertures obtained. Stomatal regulation of transpiration losses seen in the present studies in plants of the dry dune slopes is doubtless of considerable ecological significance. The diminished rate of transpiration after midday, associated with a 
reduction of pore size, is a feature characteristic of these but not of 'slack' plants, in which the transpiration losses and the stomatal apertures are more uniform for much of the day. Survival of plants on the dune slopes may in part depend on efficient regulation of transpiration under desiccating conditions, especially in plants where losses may potentially be very considerable. In some plants, for example Carex arenaria, on the other hand losses may never be very great, whatever the conditions of evaporation. Sometimes special features, such as the inrolling of the leaves of marram, may to some extent regulate transpiration losses.

In plants of the dune slopes complete stomatal closure leads to considerably diminished transpiration losses. Estimates of 'cuticular' transpiration during conditions of fairly rapid evaporation usually range between $0.6-0.9 \mathrm{mg} / \mathrm{g} / \mathrm{min}$ for plants such as Senecio jacobaea and Cynoglossum officinale. These represent rates of less than $10 \%$ of the total transpiration. Similar reductions of transpiration losses by stomatal closure were recorded by Hygen (1953) for plants of dry situations in Central Norway. On the other hand, he showed that for mesophytic species 'cuticular' losses were in general between $10-20 \%$ of the total; corresponding values were observed in the present study for a number of plants of the 'slacks'.

Ecological characterisation of plants by means of transpiration rates derived from decline curves has been attempted by Hygen (I95I, I953), who indicated that the 'standard product' $\left(E_{s} . E_{c}\right.$, where $E_{s}$ is the transpiration rate under standard conditions in watcr-saturated leaves with stomata open, and $E_{c}$ with stomata closed) may be used as an index of xerophytism. He demonstrated the usefulness of this parameter with studies on species of Vaccinium, the xerophytic $V$. vitis-idaea having the lowest values. In the present investigations, calculation of the 'standard product' under comparable conditions of high evaporation for Senecio jacobaea and Cynoglossum officinale gave values of about $\mathrm{I}_{4}$ in both of these plants, whereas for Hydrocotyle vulgaris it was almost double this (about 27). If (as other observations of the present study suggest) the results for these species may be taken as representative, values of the 'standard product' appear to be a useful means of characterising the plants of the dry dune pasture and of the 'slacks' in terms of their transpiration rates, the more xerophytic nature of the plants of the dry dune slopes being indicated on a quantitative basis.

As might be expected, water deficits in plants of the dry dunes are often large, and although this deficit is frequently to some extent reduced overnight, full turgidity may not be regained by the next morning. In a period of drought, there may be, as discussed by Slatyer (1957), a progressive increase from day to day in total soil moisture stress, and an associated 
increased water deficit. Under conditions when the sand is of low moisture content, deficits of more than $20 \%$ have been observed during the day in some plants, with values of the order of $10 \%$ at sunrise. The studies of Rutter and Sands (1958) and of Sands and Rutter (1958) with Pinus sylvestris are of interest in this connection, as they give evidence that when deficits of $17 \%$ or more develop in this plant the soil moisture has probably been reduced to the permanent wilting point. Species differ in their capacity to obtain water from the soil, but near wilting conditions are clearly often experienced by plants on the dry dunes. On the other hand, in the 'slacks' the plants are rarely under prolonged water stress and deficits developed during the day are quickly restored at night.

Although the leaves of plants of the dry dunes may have considerable water deficits at dawn, the stomata nevertheless usually open widely during the morning, as the experiments on Senecio jacobaca indicate. Stalfelt (1929, 1932, 1955) has, however, shown that in Vicia faba and Betula pubescens 'hydroactive closure' of stomata begins at deficits as low as 3 and $4 \%$ respectively. Similar findings on some other plants (many of them shade forms) have been reported by Pisek and Winkler (1953), but these workers (see also Pisek and Berger, I938) have further demonstrated that in sunexposed herbs 'hydroactive closure' does not usually start, under natural conditions, until deficits reach some $10 \%$ or more, particularly when light intensities are high. The present investigation shows that plants of the dry dunes fall into the latter category, the success of these plants in a dry environment doubtless being in part due to this feature of stomatal behaviour.

The results of the present study indicate some of the important differences in the water relations of plants of the dune slopes and of the 'slacks'. In their differing microclimates and under the different conditions of water availability, the plants show contrasted behaviour with respect to transpiration rates, stomatal changes and the development of water deficits. Ecological differences and the distinctive distribution of these plants may well in part have a physiological basis in terms of water relations; characteristically, plants of the dune slopes have an efficient means of regulation of transpiration, whereas this is not essential and may be lacking in plants of the 'slacks'.

\section{ACKNOWLEDGMENTS}

We are indebted to past and present members of the Department of Botany, University of Bristol, for assistance with field work and to Professor E. W. Yemm for helpful discussion. 


\section{REFERENCES}

Andersson, N.E., Hertz, C.H. \& Rufelt, H. (1954) A new fast recording hygrometer for plant transpiration measurements. Physiol. Plant. 7, 753-767.

Ashton, P.S. (1958) Light intensity measurements in rain forests near Santarem, Brazil. J. Ecol. 46, 65-70.

Bosian, G. (1933-34) Assimilations- und Transpirationsbestimmungen an Pflanzen des Zentralkaiserstuhls. Z. Bot. 26, 209-284.

Evans, G.C. (1956) An area survey method of investigating the distribution of light intensity in woodlands, with particular reference to sunflecks. J. Ecol. 44, 391-428.

Evenari, M. \& Richter, R. (1937) Physiological-ecological investigations in the Wilderness of Judaea. J. Limi. Soc. (Bot.) 5I, 333-38I.

HeAth, O.V.S. (1947) Role of starch in light-induced stomatal movement, and a new reagent for staining stomatal starch. Nature, Lond. 159, 647-648.

HeAth, O.V.S. (I950) Studies in stomatal behaviour. V: The role of carbon dioxide in the light response of stomata. J. exp. Bot. I, 29-62.

HeAt11, O.V.S. (1959) The water relations of stomatal cells and the mechanisms of stomatal movement. Chap. 3 in Plant Pliysiology Vol. II, ed. F. C. Steward. Academic Press, New York \& London.

Hygen, G. (r95I) Studies in plant transpiration. I. Physiol. Plant. 4, 57-1 83.

Hygen, G. (1953) Studies in plant transpiration. II. Pliysiol. Plant. 6, Io6-I33.

Kramer, P. J. (1959) Transpiration and the water economy of plants. Chap. 7 in Plant Physiology Vol. II, ed. F. C. Steward. Academic Press, New York \& London.

Lloyd, F.E. (1908) The physiology of stomata. Publ. Carneg. Instni. 82, I-I 42.

Loftfield, J. V.G. (1921) The behavior of stomata. Publ. Carneg. Instn. 314, I-IO4.

Milthorpe, F.L. \& Spencer, E.J. (1957) Experimental studies of the factors controlling transpiration. III : The interrelations between transpiration rate, stomatal movement, and leaf water-content. J. exp. Bot. 8, 4I 3-437.

Nutman, F.J. (1937) Studies on the physiology of Coffea arabica. II: Stomatal movements in relation to photosynthesis under natural conditions. Ann. Bot., Lond., N.S. I, $68 \mathrm{I}-693$.

OPPENHEIMER, H.R. (I95I) Summer drought and water balance of plants growing in the Near East. J. Ecol. 39, 356-362.

PARKER, J. (1957) The cut-leaf method and estimations of diurnal trends in transpiration from different heights and sides of an oak and a pine. Bot. Gaz. I19, 93-IOI.

PISEK, A. \& Berger, E. (1938) Kutikuläre Transpiration und Trockenresistenz isolierter Blätter und Sprosse. Planta, 28, 124-155.

PiseK, A. \& Winkler, E. (I953) Die Schliessbewegung der Stomata bei ökologisch verschiedenen Pflanzentypen in Abhängigkeit vom Wassersättigungszustand der Blätter und vom Licht. Planta 42, 253-278.

RutTer, A.J. \& SANDS, K. (1958) The relation of leaf water deficit to soil moisture teusion in Pints sylvestris L. I: The effect of soil moisture on diurnal changes in water balance. Nev! Phytol. 57, 50-65.

Salisbury, E.J. (1952) Downs and Dunes: their Plant Life and its Enviromment. Bell, London.

SANDS, K. \& RutTer, A.J. (1958) The relation of leaf water deficit to soil moisture tension in Pinus syluestris L. II : Variation in the relation caused by developmental and environmental factors. New Pllyfol. 57, 387-399. 
SAYre, J. D. (1926) Physiology of stomata of Rumex patientia. Ohio J. Sci. 26, 233-266. SLATYER, R.O. (I957) The significance of the permanent wilting percentage in studies of plant and soil water relations. Bot. Rev. 23, 585-636.

StÅlfElt, M.G. (1929) Die Abhängigkeit der Spaltöffnungsreaktionen von der Wasserbilanz. Planta, 8, 287-340.

Stalfelt, M.G. (1932) Der stomatäre Regulator in der pflanzlichen Transpiration. Planta, 17, 22-85.

Stalfeit, M.G. (1955) The stomata as a hydrophotic regulator of the water deficit of the plant. Phiysiol. Plant. 8, 572-593.

Stocker, O. (1929) Das Wasserdefizit von Gefässpflanzen in verschiedenen Klimazonen. Planta, 7, 382-387.

WeAtherley, P.E. (1950) Studies in the water relations of the cotton plant. I: The field measurement of water deficits in leaves. New Phytol. 49, 8I-97.

Williams, W.T. (1949) Studies in stomatal behaviour. III: The sensitivity of stomata to mechanical shock. Anr. Bot., Lond., N.S. 13, 309-327.

Williams, W.T. \& Amer, F.A. (1957) Transpiration from wilting leaves. J. exp. Bot. 8, I-I9.

Willis, A.J., Folkes, B.F., Hope-Simpson, J.F. \& Yемm, E.W. (I959) Braunton Burrows: the dune system and its vegetation. Part II. J. Ecol. 47, 249-288.

Yemm, E.W. \& Willis, A. J. (1954) Stomatal movements and changes of carbohydrate in leaves of Chrysanthemum maximum. New Phytol. 53, 373-396. 


\title{
WATER RELATIONS OF SOME PSAMMOPHYTES WITH RESPECT TO THEIR DISTRIBUTION
}

\author{
Milena RychnovsKá \& Jan KvěT \\ Geobotanical Laboratory of The Czechoslovak Academy of Sciences \\ Brno, Czechoslovakia
}

\section{INTR ODUCTION}

THE psammophytes in Czechoslovakia are grouped in characteristic plant communities on sandy soil. Although various plants in these communities require the same substratum, they belong to widely different areas of distribution. A small strip of land having uniform edaphic and climatic conditions may thus contain both continental and oceanic species, in addition to those commonly found in the Northern Hemisphere (i.e. holarctic plants). For some species Czechoslovakia forms part of the boundary of their areas of distribution. The sandy region of Southern Moravia was thus a highly suitable place for the physiological analysis of some characteristic plants. Such analysis could lead to the causal explanation of their distribution in Central Europe. Water relations of the psammophytes and their habitats, besides their common specific adaptation to sandy soils, were considered, after numerous observations, comparisons and experiments, to be an important factor in the distribution of these plants in Czechoslovakia. Having all these facts in mind, we performed a ficld experiment in which we measured the daily variations in transpiration of three characteristic psammophytes. A group of plants was artificially supplied with water and a control group was observed under natural conditions.

\section{METHODS AND MATERIALS}

During three characteristic days in the middle of the growing season ( $1-3$ June, 1960) we observed the transpiration of the following plants:

Corynephorus canescens (L.) P. Beauv.

Festuca dominii Kraj. (Festuca ovina subsp. enovina var. vaginata Hack. p. p.)

Helichrysum arenarium Moench.

They were growing on sand dunes near the railway station of StrážnicePřivoz in Southern Moravia. The tufts selected for experiment were approximately of the same age. Some of them were artificially supplied 
with water, up to $8-10 \%$ of soil moisture, while others were observed on arid substratum, with $2-4 \%$ of humidity. Every 60 minutes transpiration measurements were carricd out by a rapid weighing followed by a 3 minutes exposure in the original stand and another weighing. Light showers of rain occurred between the 4 Ist and 45 th hour of the experiment. During this period the plants, after being picked up, were cursorily dried with blotting paper and exposed, for 3 minutes, in their original stand under a small cover of plastic foil. Weighing was performed on a torsion balance, the scale of which was divided into sections of I mg. Each sample consisted of a bunch of leaves collected from the same tuft. When the whole tuft had been used up, samples were taken from the neighbouring tuft. The change of tuft is always noted in the appended figures. The base of the bunch of leaves was tied up with a narrow strip of Cellux plastic band, which greatly facilitated further operations with the grass. Each sample of Helichrysum arenarium consisted of one terminal portion of the stem bearing several leaves. Variations in the temperature of air and of soil at a depth of $5 \mathrm{~cm}$, and air humidity and evaporation from the disc of the Piche evaporimeter $(5.2 \mathrm{~cm}$ in diameter, $5 \mathrm{~cm}$ above ground) were measured every hour. At 4-hour intervals a soil sample from the root system of each plant under study was taken with a narrow probe trowel and its moisture, expressed as percentage of dry weight, was determined. When the field experiment had been concluded, the plant samples were oven-dried at $105^{\circ} \mathrm{C}$ and their water content was established. Transpiration was expressed in milligrams water loss per I $g$ of the water content in I minute. The water content was expressed as percentage of fresh weight.

\section{RESULTS}

Variations in the rate of transpiration and the water content in the tissues of the plants, microclimatic data and soil moisture data, during the period of 50 hours, are expressed by graphic methods in the appended figures. Variations in the values measured, irrespective of the changes due to accidental and unknown factors, were illustrated by a curve plotted from moving averages of five successive measurements.

As shown in Fig. I, climatic conditions during the so hours of the experiment varied considerably. The weather in the afternoon of the first day, during the following night and the whole of the second day was of an anticyclonic type, with a high maximum temperature of $32.4^{\circ} \mathrm{C}$ during the daylight hours and with relatively low night temperature of $10.3^{\circ} \mathrm{C}$. During the second night, however, the sky became overcast with clouds 
and the thermometer stood rather high at $\mathrm{I}_{4}{ }^{\circ} \mathrm{C}$. A drizzle began at about 6 o'clock in the morning of the third day and developed to a mild shower lasting up to 9 o'clock. The air humidity at the beginning of the second night was also higher than that of the first. The variations in soil temperature are also in harmony with this pattern, although the extreme values of soil temperature were recorded I-2 hours later than those of air. Evaporation values obtained from the Piche evaporimeter present only a crude picture of the pattern of atmospheric conditions by which the evaporation rate is influenced. This rate is higher on the first day than on the

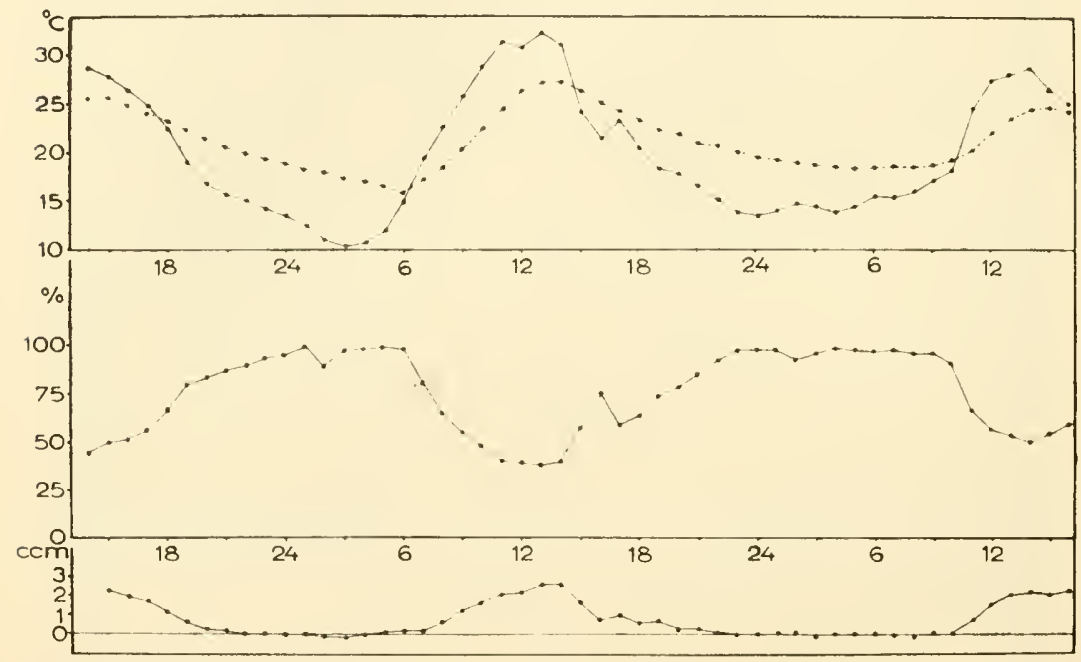

FIG. I. Microclinatic data in the period between I June to 3 June, 1960. Upper graph: Variations in temperature of air $5 \mathrm{~cm}$ above ground (full line) and of soil at the depth of $5 \mathrm{~cm}$ (dotted line). Middle graph: Variations in relative air humidity. Lower graph: Water evaporation from the disc of Piche evaporimeter $\left(\mathrm{cm}^{3}\right)$. The fifty hours of experiment are marked on the $x$-axis.

second and its values are on the whole inverse to those obtained from the psychrometer.

The daily variations in transpiration among the control group of Festuca dominii (Fig. 2) were in almost perfect harmony with the physical conditions of evaporation. The noon maximum of the second day was higher than that of the third day, and the night transpiration of the first night was higher than that of the following night, in full accordance with lower air humidity at the beginning of the night. Except for a depression in the first 
5 hours of the experiment, no fundamental change in the pattern of the curve took place after the plants were supplied with water.

The daily variations in transpiration among the control group of Corynephorus canescens (Fig. 3) differ from both the microclimatic factors and the curve of Festuca dominii in the position of the second-day noon maximum, which is shifted to the morning hours and followed by a depression of transpiration. The curve of the third day, however, does not show any depression, and the transpiration values are even somewhat

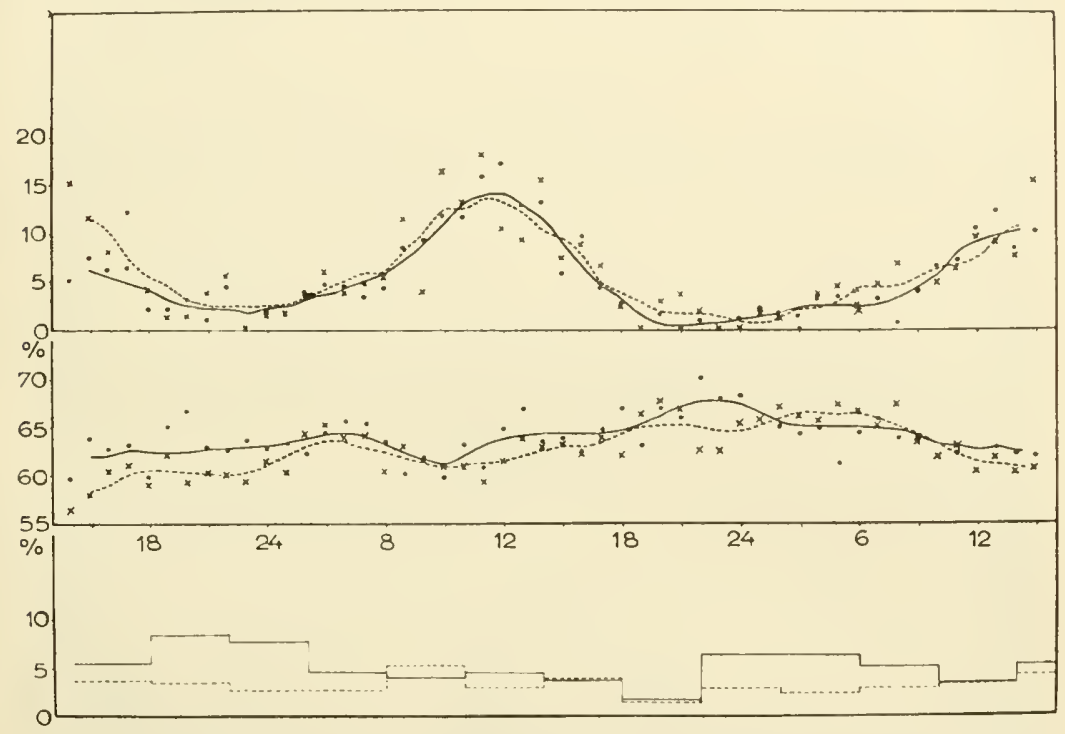

FIG. 2. Water relations of Festuca dominii during the three days of experiment. Upper graph: Daily variations of transpiration. Water loss is expressed in parts per thousand, i.e. in $\mathrm{mg}$ per I $\mathrm{g}$ of water content of the leaves during I min. Middle graph: Water content of the leaves (as percentage of fresh weight). Lower graph: Water content of the rhizosphere of grass tufts (as percentage of dry weight). The so hours of experiment are marked on the $x$-axis. The full line and dots belong to plants supplied with water. The dotted line and crosses belong to the control group (observed under natural conditions).

higher than those of the preceding day. The night minima do not fall to zero and are approximately equal. The pattern of the curve is, however, somewhat different for plants supplied with water. The noon maximum of the second day is higher, shifting towards the midday hours, and markedly exceeds the noon transpiration of the third day. Compared with that of the control group, the morning increase in the third-day rate of 


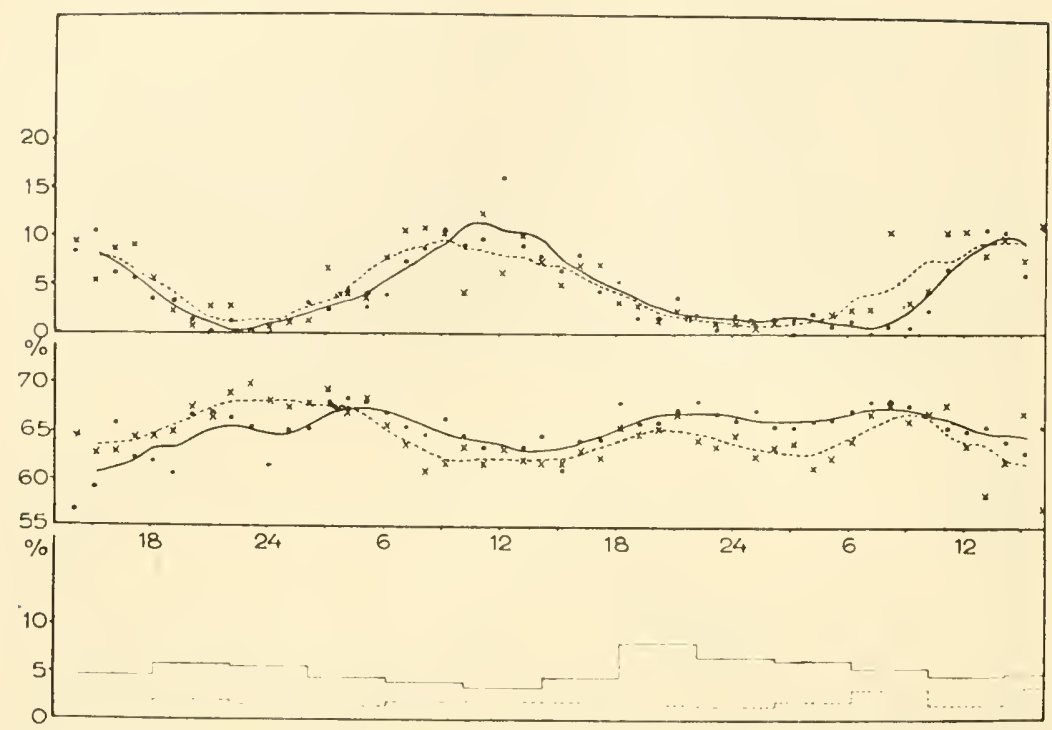

FIG. 3. Water relations of Corynephorus canescens during the three days of experiment. Explanation as for Fig. 2.

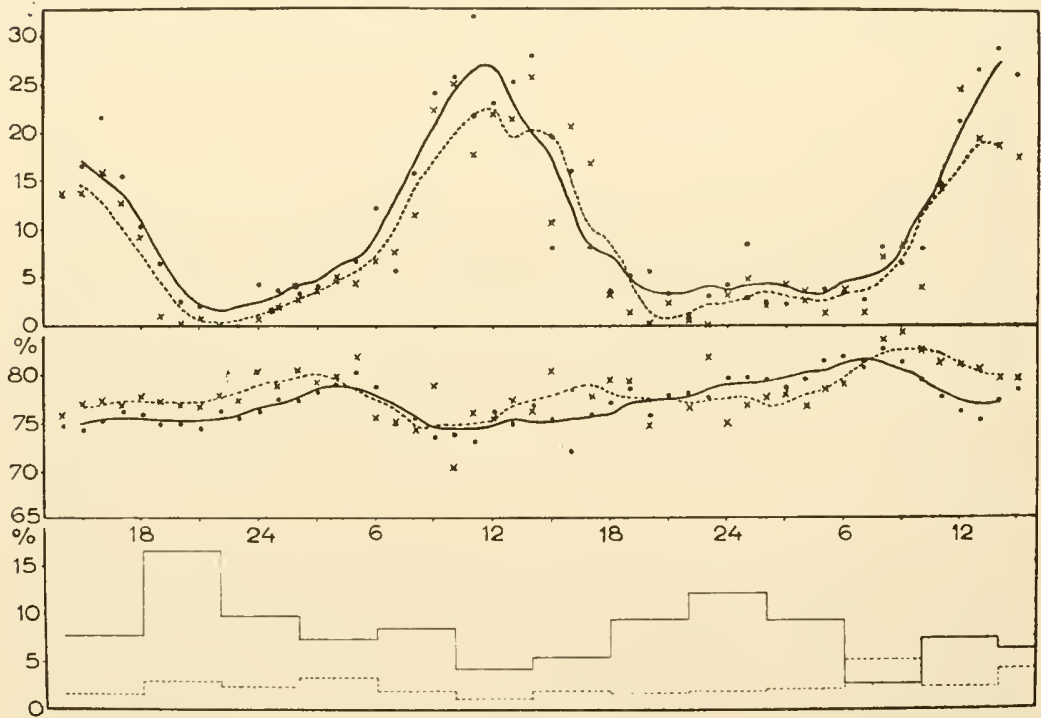

FIG. 4. Water relations of Helichrysum arenarium during the three days of experiment. Explanation as for Fig. 2. 
transpiration is several hours late. The rate of transpiration during the second night somewhat exceeds that of the first night.

The curve of the third plant under study-Helichrysum arenarimm (Fig. 4)reveals two distinct maxima during the daylight hours and a depression at noon. The rate of transpiration fell to zero during the first night while in the second night noticeable evaporation of water was observed. The intensity of transpiration among plants supplied with water was enhanced, but the pattern of the curve is similar.

\section{DISCUSSION}

A comparison between the two transpiration curves of Festuca dominii and the climatic factors points to the unmistakable fact that this plant has lost its ability actively to control its transpiration. As reflected in the morphological and physiological properties of the plant, its water turnover is adapted to permanent water deficiency. The rate of transpiration is limited, that is to say, under favourable conditions it reaches definite maximum values and is not able to surpass them. The transpiration curve runs parallel to that of evaporation. This is exemplified by the two curves in Fig. 2, showing the same pattern of transpiration, whether the plants were supplied with water or not. No increase in the rate of transpiration was observed after the plants were supplied with water. The rate of transpiration during the night was also in agreement with the physical conditions, especially with air humidity, during our experiment. Dry periods more pronounced than those recorded during our experiment would probably result in perceptibly reduced loss of water. Corynephorus canescens, on the other hand, is far more active in controlling its rate of transpiration. Although its transpiratory system does not provide for extensive variations, a depression in the rate of transpiration takes place during hot midday hours of a dry 'continental' day, when the plant suffers from water deficiency. No depression, however, occurs during a wet 'oceanic' day. If the rhizosphere of the plant holds enough water a definite increase in the rate of transpiration takes place and no noon depression can be observed. During the night hours, the water loss of plants growing on a dry substratum is probably limited to cuticular transpiration; if, however, the plant is supplied with a sufficient amount of water, the vital factor of transpiration, which depends on temperature and not on relative air humidity, plays a more active role than the physical factor. The second night was warmer than the first, and thus the rate of transpiration of the plant was somewhat higher. 
Helichrysum arenarium proved to be the most adaptable plant of the three. As shown by the noon depression, the plant regulates its water turnover by stomatal action. Its night transpiration falls to zero, which is apparently due to the closing of the stomata. When the plant is supplied with water, its rate of transpiration is enhanced and the noon depression is not so clearly pronounced. The rate of transpiration during the night is probably also controlled by vital (rather than physical) factors. The plant, enveloped in a warm environment both above and below ground, loses water by evaporation, even if the atmosphere is saturated with water vapour to a high degree. We did not take note of the state of the stomata during our experiment. The stomata of xerophilous grasses are mostly found on the upper, i.e. inner, side of the tube-shaped leaves, and thus are difficult to observe by ordinary methods. This observation was not considered necessary for our study of the character of transpiration.

All these facts are in agreement with phytogeographical conditions which have impressed their mark on the plants during their development. Festuca dominii, a 'continental' plant, one of the group of xerophytic Festucae inhabiting the deserts and semi-deserts of Central Asia, has become adapted to permanent drought. As permanent closing of the stomata would make photosynthesis impossible, the plant appears to restrict loss of water by substantially diminishing the rate of transpiration while its stomata remain half open. Its rate of transpiration is thus low and depends on physical factors. Stocker, (1956), reports similar conditions among desert plants. As the transpiratory system of Festuca dominii adapted to arid situations does not provide for an enhanced rate of transpiration, no increase in the rate of transpiration occurs after supplying the plant with water. Water-retention of the soil under the dense tufts of Festuca dominii is also perceptibly higher than under those of Corynephorus canescens, which points to the highly economical water turnover of the former plant in dry periods. I have reported in another paper(Rychnovská, 196I) that supplying an experimental tuft with water does not enhance the rate of sugar production. That again fully conforms with our hypothesis. Although the abovementioned water relations are highly beneficial in arid situations, they constitute an obstacle for the vital activities of the plant in more favourable circumstances. Thus we cannot be surprised that-as the continental climate gives way to the climate of the oceanic type in Central Europe and competition with plants of more pronounced vital activities becomes more intensified-Festuca dominii appears more sporadically. Its area of distribution does not extend further westward into regions characterised by still fewer climatic extremities. 
Corynephorns canescens, on the other hand, is an 'atlantic' plant adapted to the water conditions of maritime dunes. Long periods of drought are quite unknown there, and thus no adaptation to permanent drought could develop among the plants in that area. Although the anatomy of Corynephorus canescens has adapted itself to sandy soils, the plant has not lost its ability actively to regulate its water turnover. In the more arid conditions of Central Europe it usually restricts its water output, as shown by the depression in the midday and afternoon hours. This controlling of the loss of water is probably due to the closing of the stomata. If it is so, it must result in reduced gas exchange and dimnished rate of photosynthesis. That would constitute a serious drawback for the plant during prolonged periods of drought, since it would reduce its vital activity, and the plant would not be able to survive in competition with others. Indeed its area of distribution in Central and Eastern Europe does not extend further into the interior of the continent. The daily variations in transpiration of plants supplied with water, without any noon depression, and the enhanced rate of transpiration of the control samples during a rainy day conclusively indicate that, only when sufficiently supplied with water, Corynephorus canescens is able to retain its full vital activity. Direct evidence for the diminished rate of photosynthesis of plants growing on dry soils and for the enhanced rate of sugar production, after the plants were supplied with water, was submitted in another paper(Rychnovská, 196I).

From the phytogeographical point of view, Helichrysum arenarium occupied an intermediate position between the two above-mentioned species. It is a continental boreomeridional European plant whose area of distribution extends westward up to Belgium and the Netherlands and northward to Denmark and the southern part of Sweden (Meusel, I943). It is highly probable that the water relations of this plant are adaptive to a considerable degree. As shown by its transpiration curve, the intensity of transpiration is relatively high and actively controlled. During the hot midday hours the rate of transpiration is temporarily diminished, but in the early afternoon it again reaches a high level. As the stomata were apparently closed during the first night, the rate of transpiration fell to zero in both groups. The second night, characterised by higher temperature, provided better conditions for active transpiration, although the atmosphere was saturated with water vapour to a considerable degree. The rate of transpiration of the samples supplied with water is higher than that of the control group, even though the noon depression is also present. The plant is able to endure prolonged periods of drought, because its rate of photosynthesis is comparatively low and not immediately affected by 
variations of humidity (Rychnovská, I96I). The water turnover is intensified when the soil contains a sufficient amount of water. An interesting fact should, however, be noted in this connection. If the plant is supplied with a large amount of water, the water content of its tissues is smaller than that in the control group of plants. The question here is, whether the regulating mechanism does not partially fail in plants adapted to dry habitats when supplied with an excessive amount of water and whether a paradoxical situation of disproportionate water loss does not arise in this case. All this will have to be verified by further research.

The present paper lends further support to the idea that many phytogeographical problems can be solved on the basis of physiological and ecological analysis, and that, although the ecological factors are of only local applicability and complex in character and although the plant species have a wide range of adaptability (Meusel, 1943), it is possible to ascertain the causal fundamentals responsible for the distribution of the various species of plants. On the other hand, it would be a mistake to limit the explanation of the causes of plant distribution to one factor only; it is necessary to investigate the selected species of plants in relation to all the important factors (Boysen-Jensen, 1949). In our case, however, the other factors have already been analysed and the results reported in another paper of mine already quoted. We may thus be allowed to conclude that, with respect to specific edaphic conditions, it is the water relations of these three plants, those water relations which resulted from the plants' adaptation to the climatic conditions in the centre of their area of distribution and which became established during the phylogenesis of these plants, that on the boundary of their area of distribution constitute the decisive phytogeographical factor.

\section{REFERENCES}

Boysen-Jensen, P. (1949) Causal Plant Geography. Kgl. Danske Videriskabernes Selskab, Biologiske Neddelelser, B. XXI, Nr. 3. Kobenhavn.

Meusen, H. (1943) Vergleichende Arealkunde. Berlin.

Rychnovsk Á-Soudková, M. (1961) Corynephoruscanescens (L.) P. Beauv. Physiologischökologische Studie einer Pflanzenart. Rozpravy ČSAV. 71. Praha.

Stocker, O. (1956) Die Abhängigheit der Transpiration von den Umweltfaktoren. Handbuch der Pflanzenphysiologie, Bd. III. Berlin. 


\title{
THE WATER SUPPLY OF DESERT PLANTS
}

\author{
H. WAlteR
}

Botanisches Institut, Stuttgart-Hohenheim, W. Germany

By deserts we mean arid regions with a very low and unreliable rainfall. It is generally supposed that perennial plants in such regions suffer from a lack of water and need special physiological adaptations such as a physiological drought resistance, low transpiration rate, high osmotic pressure, etc. Often it is difficult to understand how perennial plants can thrive in a desert with perhaps only $25 \mathrm{~mm}$ of rainfall per year, e.g. around Cairo. But rainfall as such is not the appropriate measure to estimate the water supply of desert plants, which is considerably better than it appears if we consider only the rainfall data. Rainfall in mm means the amount in litres per square metre, therefore it is also necessary to compare it with the transpiring surface of the plants per square metre. To understand properly the water economy of desert plants, we must keep two facts in mind:

(I) The density of the vegetation decreases in arid countries with the decreasing rainfall.

(2) In extremely dry countries with a very low vegetative cover density, the amount of run-off increases and the water is unevenly distributed in the soil after a rain. The major portion of the soil remains dry (the water runs off and does not penetrate into the soil) and on a small part of the area (depressions, runnels, wadis) the water accumulates and penetrates quite deep into the soil.

Let us consider more thoroughly the first factor. Exact measurements of the density of plant cover were made in South-West Africa. In this region the rainfall is nearly nil on the coast and gradually increases from WSW. to ENE. from o to $500 \mathrm{~mm}$. The temperature conditions remain more or less constant over the entire region (Fig. I).

For comparative purposes, it is necessary to utilise similar types of vegetation for which we choose ungrazed grassland. Following the period of the summer rains, it was relatively easy to determine the production of dry matter per hectare by weight. The results showed that the dry matter production increased proportionally with the rainfall (Fig. 2). For every $100 \mathrm{~mm}$ of rainfall per year, the dry weight of grass was $1000 \mathrm{~kg} / \mathrm{ha}$ 
or $100 \mathrm{~g} / \mathrm{m}^{2}$. If we compare the same vegetative types, we can assume that the transpiring surface is more or less proportional to the dry weight. That means: The transpiring surface decreases in proportion to the rainfall, that is, the

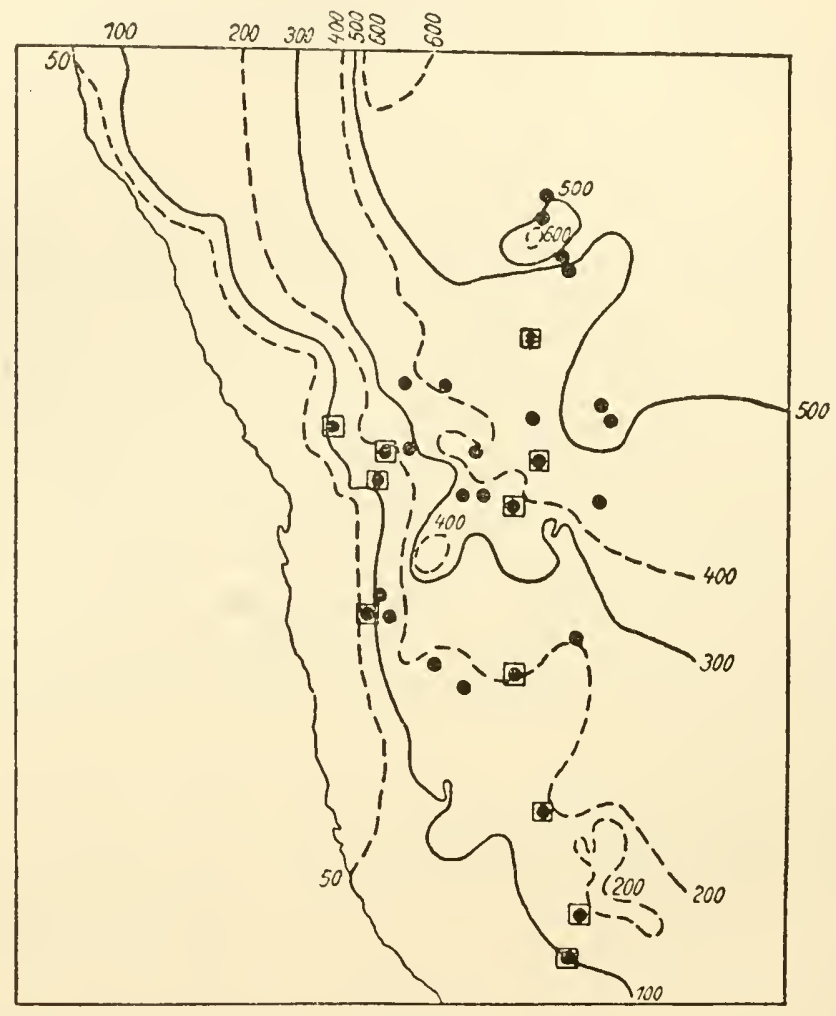

FIG. I. Rainfall map of South-West Africa in $\mathrm{mm}$.

$\square$ Sites of samples for determination of the dry weight production in grassland.

- Samples for determination of the nutrition value of grassland plants (from $\mathrm{H}$. Walter, 1954).

water supply of a unit of transpiring surface is the same under arid or humid conditions up to a rainfall of $500 \mathrm{~mm}$.

This statement was checked in south-west Australia in the Eucalyptusforest region with a rainfall from $500 \mathrm{~mm}$ up to $500 \mathrm{~mm}$ (Tables I and 2) (Walter, 1962): 
TABLE I

Virgin Eucalyptus forest

\begin{tabular}{|c|c|c|c|c|c|}
\hline \multicolumn{2}{|c|}{ Rainfall } & \multicolumn{2}{|c|}{ Amount of litter } & \multicolumn{2}{|c|}{ Leaf litter surface } \\
\hline $\mathrm{mm}$ & Relative & $\mathrm{kg} / \mathrm{ha}$ & Relative & $\mathrm{m}^{2} / \mathrm{m}^{2}$ & Relative \\
\hline 1530 & 100 & 2400 & 100 & $I \cdot 14$ & 100 \\
\hline 810 & 53 & 1280 & 53 & 0.57 & so \\
\hline 750 & 49 & I 500 & 62 & 0.66 & 58 \\
\hline
\end{tabular}

TABLE 2

Young growth of Eucalyptus forests

\begin{tabular}{|c|c|c|c|c|c|}
\hline \multicolumn{2}{|c|}{ Rainfall } & \multicolumn{2}{|c|}{ Amount of litter } & \multicolumn{2}{|c|}{ Leaf litter surface } \\
\hline $\mathrm{mm}$ & Relative & $\mathrm{kg} / \mathrm{ha}$ & Relative & $\mathrm{m}^{2} / \mathrm{m}^{2}$ & Relative \\
\hline 1330 & 100 & 2740 & 100 & $x \cdot 30$ & 100 \\
\hline I 290 & 97 & 2040 & 75 & $I \cdot 05$ & $8 \mathrm{I}$ \\
\hline 560 & 42 & 1290 & 47 & 0.39 & 30 \\
\hline
\end{tabular}

The data were kindly provided by Mr. Loneragan of the Forest Department. The measurements were made in the Eucalyptus astringens, E. redunca, $E$. marginata and $E$. diversicolor forest zones. In this winter rain region, the same rules seem to hold: The amount of the surface of the transpiring leaves (equal to the average leaf litter) decreases proportionally with the rainfall, therefore the water supply does not change essentially. There are some deviations from the given proportions, but this can be expected from a relatively short average of $3-6$ years.

The decrease in rainfall and consequent reduction in plant cover density in arid regions creates a greater distance between individual plants and causes the water penetration into the soil to become shallower. Therefore the root systems of plants in arid regions are shallower but the root itself has a greater horizontal growth.

The shoot/root growth ratio also decreases with the rainfall. Some physiological experiments allow the supposition, that the growth of the shoot is more reduced than the growth of the roots, as the water supply of the plants becomes more critical. Let us consider the growth of pea seedlings in sugar solutions of different concentrations and in an atmosphere with a relative humidity equal to the corresponding sugar solution. The osmotic 
pressure of the cell-sap and therefore also the hydrature of the protoplasm, is in this case nearly equal to the osmotic pressure of the sugar solution. The results show that with increasing osmotic pressure from o to $30 \mathrm{~atm}$ (i.e. decreasing hydrature from $100-98 \%$ ), the growth of the shoot decreases rapidly reaching zcro at about 20 at11, but on the contrary to this, the growth of the root first increases three times, reaching a maximum at 7 $\operatorname{atm}(=99.5 \% h y)$ and only then decreases. It was still measurable however, at $30 \mathrm{~atm}$ (Fig. 3). Kausch (1955) mentioned that the same is true if the

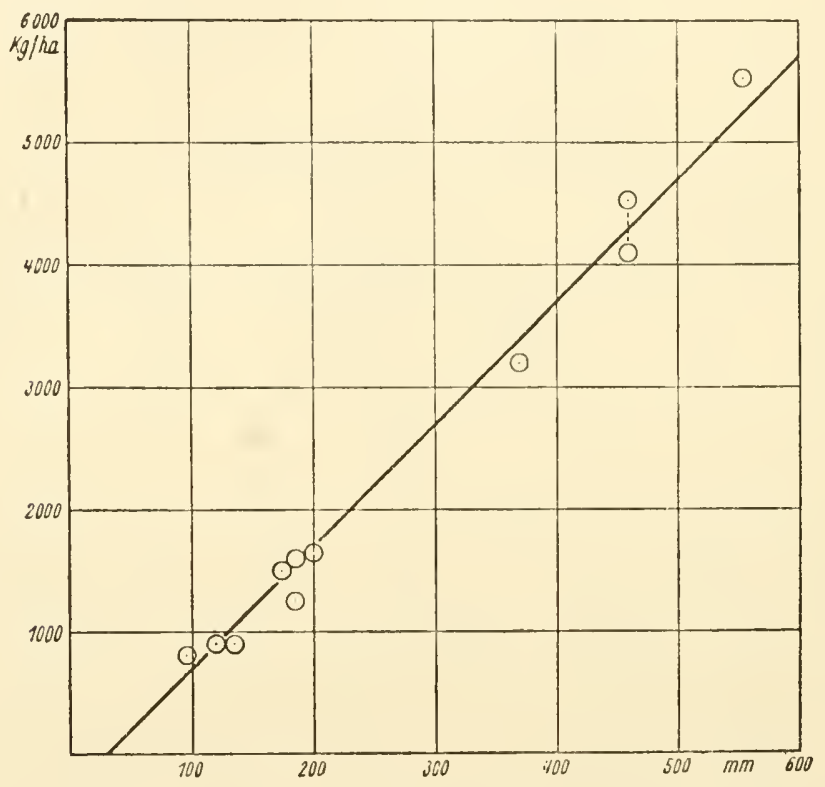

FIG. 2. The productivity of grassland $(\mathrm{kg} / \mathrm{ha})$ in relation to the mean yearly rainfall in $\mathrm{mm}$ (from $\mathrm{H}$. Walter, 1954).

soil moisture decreases. The behaviour of side roots is different and similar to that of the shoot.

Under humid conditions the osmotic pressure is low, therefore we have to expect a vigorous shoot and side root growth, but slow growth of the main root. With increasing aridity the osmotic pressure increases, the growth of the shoot is retarded, also that of side roots, but elongation of main root is increased. This is in accordance with the facts observed in the freld: the shoot/root ratio of plants in arid regions decreases with the rainfall. Simonis (1936) grew Trifolium incarnatum in moist soil $(80 \%$ of 


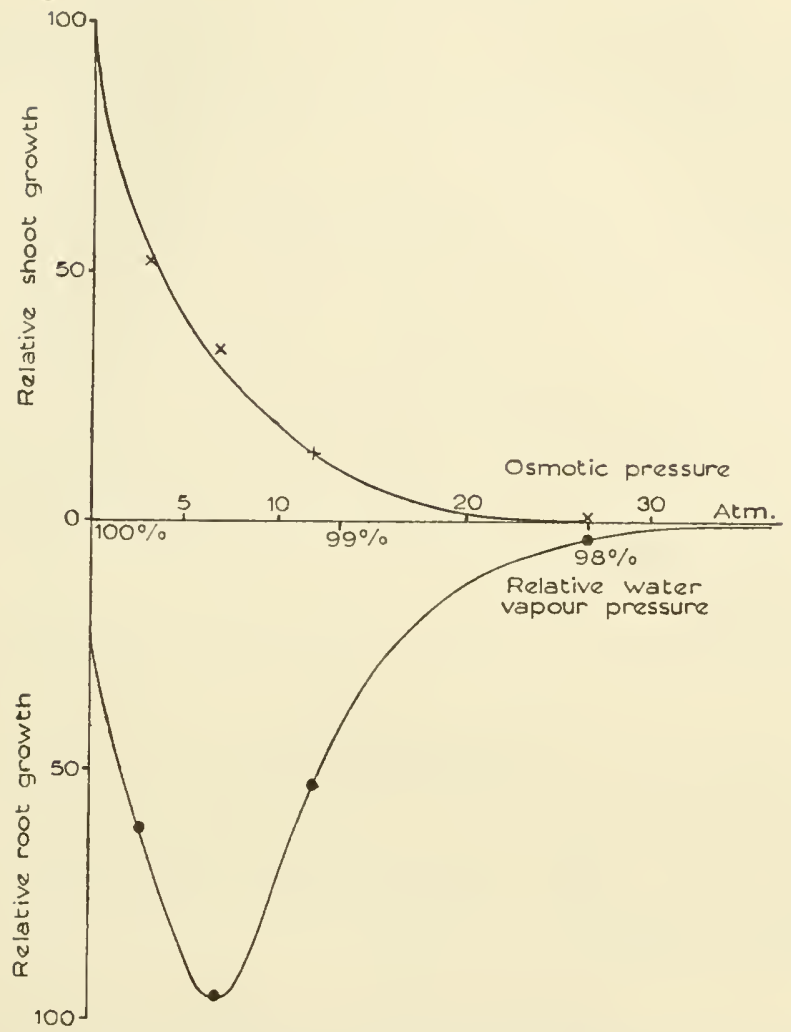

Fig. 3. Growth of shoots and roots (pea seedlings) in relation to the osmotic pressure or relative water vapour pressure (from $\mathrm{H}$. Walter).

the water capacity) and in dry soil ( $40 \%$ of the water capacity). During the first week the total increase in dry weight of the plants was the same in both cases ( $16 \mathrm{~g}$ ), although the ratio of the shoots to the roots decreased appreciably in the dry soil (Table 3 ).

TABLE 3

Trifolium incarnatum. Percentage of total dry weight of plants in moist and dry soil

\begin{tabular}{llll}
\hline Plants in & I. Shoots & 2. Roots & Ratio I:2 \\
\hline Moist soil & $66.0 \%$ & $34.0 \%$ & I.94 \\
Dry soil & $4 \mathrm{I} \cdot 4 \%$ & $58.6 \%$ & 0.71 \\
\hline
\end{tabular}


In this case the decreasing shoot/root ratio is attributed to a functional adaptation. Due to the severe competition in arid regions, we find only species with a fast-growing, genetically fixed root system.

In an area where the rainfall becomes less than $100 \mathrm{~mm}$, the second factor, the run-off, is more important. This is primarily due to the low density of the vegetation, and consequently even in ncarly flat deserts the run-off is extremely high. The water penetrates into the soil more readily in sandy runnels or depressions moistening the soil to a greater depth. Following the rain the upper layer of the soil dries out, although in the deeper layers the moisture may be conserved for years.

The type of vegetation also changes under these conditions, The "diffuse type', that is a vegetation more or less evenly distributed, gives way to a 'restricted type', a vegetation confined only to rather restricted areas (depressions, runnels, wadis). In this type of arca, the water supply is usually adequate.

If the run-off in a region with $25 \mathrm{~mm}$ precipitation is $80 \%$, and the area in which the water accumulates constitutes $4 \%$ of the total area, that area will receive an amount of water corresponding to a rainfall of approximately $500 \mathrm{~mm}$. This is an appreciable amount of moisture in an arid region.

The root systems of plants in this type of situation are quite decp and correspond to the decper water penetration. Recently Kausch (I960) investigated the root systems of desert plants around Cairo and rccorded the following root penetration depths:

$\begin{array}{ll}\text { Pituranthus tortuosus } & 5.00 \mathrm{~m} \\ \text { Moltkin callosa } & 4.00 \mathrm{~m} \\ \text { Farsetia aegyptiaca } & 3.30 \mathrm{~m} \\ \text { Zilla spinosa } & 2.80 \mathrm{~m} \\ \text { Convolvulus lanatus } & 2.50 \mathrm{~m} \\ \text { Euphorbia cormuta } & 2.30 \mathrm{~m} \\ \text { Centaurea aegyptiaca } & 2.10 \mathrm{~m} \\ \text { Fagonia arabica } & \mathrm{I} \cdot 20 \mathrm{~m}\end{array}$

These observations show that the water supply of the plants even under extreme arid conditions is quite adequate. Therefore it is not surprising that the osmotic pressure of the cell-sap of desert plants is not much higher than of plants in humid regions and also the transpiration per unit leaf surface may be quite high.

The problem of halophytes is a special one. For them, the water economy is usually not of primary importance but rather the salt economy.

The adaptation of the perennial desert plants seems to be chiefly a 
morphological one rather than a physiological one. The chief adaptation is the reduction of the transpiring surface, the better development of the main root system, and the ability to reduce water loss during prolonged drought periods to nearly nil.

A special group are the succulents in the arid parts of North and South America and of South Africa. In the Sahara and in the arid parts of Asia they do not play a role and in the arid parts of Australia they are absent.* Most of the succulents prefer an arid climate with two rainy seasons in order to replenish their water storage tissues.

During the dry seasons the succulents can remain without water uptake. Therefore their root system is weakly developed and shallow. The water economy of succulent plants is quite different from that of other xerophytes and is not considered here.

The annual or ephemeral plants and also the geophytes in arid countries grow during the short periods when water is in abundance. Their water supply is guaranteed and therefore does not present any problems for them.

\section{REFERENCES}

KaUSCH, W. (I955) Saugkraft und Wassemachleitung im Boden als physiologische Faktoren. Planta, 45, 217-263.

KAUSCH, W. (I960) Unesco Document NS-9I4-58.

SimoNIS, W.(I936) Untersuchungen über die Abhängigkeit des osmotischen Wertes vom Bodenwassergehalt bei Pflanzen verschiedener ökologischer Gruppen. Jb. wiss. Bot. 83, 191-239.

Walter, H. (1924) Plasmaquellung und Wachstum. Z. Bot. 16, 353-417.

WaLTer, H. (1954) Grundlagen der Weidewirtschaft in Südwestafrika. E. Ulmer, Stuttgart. Walter, H. (1960) Standortslehre (Einf. in die Pliytologie, Bd. III, I) 2. Aufl., p. 265 ff. E. Ulmer, Stuttgart.

WALTER, H.(I962) Die Vegetation der Erde, Bd. I.

Walter, H. (1962) Grundlagen des Pflanzenlebens(Einfiihrung in die Phytologie, Bd. I) 4. Aufl., p. 344 ff. E. Ulmer, Stuttgart.

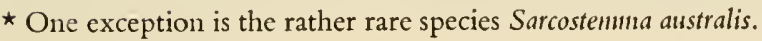




\title{
SEASONAL DIMORPHISM OF DESERT AND \\ MEDITERRANEAN CHAMAEPHYTES AND ITS SIGNIFICANCE AS A FACTOR IN THEIR WATER ECONOMY
}

\author{
G. ORSHAN \\ The Hebrew University, Jerusalem
}

\section{INTRODUCTION}

Although chamaephytes as a life form characterise high latitudes and high altitudes where temperature is the limiting factor, they also play an important role in steppes and deserts(Raunkiaer, I934; Cain, I950). In the Middle East they are the leading species of both desert and certain Mediterranean plant communities.

Seasonal dimorphism is a most common feature among the chamaephytes and is generally associated with a seasonal reduction in their transpiring body. Most of them show a certain amount of growth and development throughout the year, in spite of the dry and hot summer, but this growth yields different kinds of leaves and branches in different seasons which are in turn periodically shed. At present we know very little about the mechanisms through which environment affects the growth and form of chamaephytes on the one hand, and the ways through which their particular form and growth types serve as an adaptation to the environment on the other. It seems that even the problems have not yet been properly defined.

The present paper deals with aspects of the seasonal dimorphism of chamaephytes. Their phenology and growth habit will be described, and its effect on the extent of the seasonal reduction in their body accounted for. In addition, data will be presented showing the annual march of their transpiration rate. An attempt will then be made to correlate these aspects and to find out what their relative importance is in the water balance of the chamaephytes.

During the last few decades, the transpiration rates of a considerable number of chamaephytes has been measured in Isreal, in their natural habitat, by the cut leaf quick-weighing method (Evenari andRichter, 1937; Orshansky, 1952, 1954; Shmueli, 1948; Zohary and Fahn, 1952; Zohary and Orshan, 1954, 1956; Zohary, 1955). Recently the annual march of the weight of the transpiring body of some chamaephytes was determined 
quantitatively under natural conditions (Zohary and Orshan, I954; Orshansky, I952; Orshan and Zand, I96I). Ten species have been selected for the present discussion for which information both about the transpiration rates and about the extent of the seasonal reduction in the plant body is available and in addition the life cycles of which are known. Six of them are dominants of desert plant associations while four are leading species of Mediterranean plant communities.

The measurements were carried out in several stands in two different localities, a desert one nearRevivim in the Northern Negev, where annual rainfall averages $80 \mathrm{~mm}$, and a Mediterranean one in the vicinity of Jerusalem where annual rainfall averages $550 \mathrm{~mm}$. The climate in both localities is typical Mediterranean. The rainy season lasts from September to May while the summer is hot and rainless.

The desert plants which were selected for presentation are: Artemisia herba alba Asso., and Noea mucronata (Forsk.) Asch. et Schw. which are leading species of the Artemisietum herbae albae, one of the most widespread Irano-Turanian plant associations in the Middle East (Zohary and Feinbrunn, I95I); Haloxylon articulatum (Cav.) Bge. the leading species of the Haloxylonetum articulatae plant association dominating the pluviatile loess plains in the Northern Negev (Zohary and Feinbrunn, I95I); Anabasis articulata (Forsk.) Moq., the leading species of the Anabasidetum articulatae plant association dominating the small, shallow, and dry water courses cutting the plantless Hamada plains of the Southern Negev (Zohary, 1953); and Zygopliyllum dumosum Boiss., the leading species of the Zygophylletum dumosi which is the plant community occupying the most extreme habitat within the Saharo-Sindian territory in Israel (Zohary and Orshan, I954).

The following are the Mediterranean plants presented: Poterium spinosum L., the leading species of the widespread Poterietum spinosi dwarf shrub plant community which is one of the first stages in the succession from abandoned frelds; Cistus salvifolius L., one of the leading species of the Grigue succeeding in many places the Poterietum in the succession; Thymus capitatus (L.) Lk. et Hoffm. which dominates the Thymetum capitati occupying stands with shallow soil layers both on limestone and on a sandstone locally called 'Kurkar', and Teucrium polium L. which is an important component of several dwarf shrub communities (Zohary, 1955).

In addition, data are presented of Artemisia monosperma Del. which is a dominant of the Artemisietum monospermae, the most important plant community of the sand dunes of the Northern Negev (Zohary and Feinbrunn, 195I). 
THE LIFE CYCLE OF SELECTED CHAMAEPHYTES Practically all chamaephytes in Israel are seasonally dimorphic but the seasonal dimorphism is not always achieved in the same way. Two types of branches may be distinguished in most of them, i.e. dolichoblasts and brachyblasts, but these terms may be misleading as the same branch may start growing as a brachyblast, remain short for a considerable time and later start elongating and turn into a dolichoblast. The clongation generally takes place in spring which is the main growing season when both temperature and water supply are optimal. Such a brachyblast may be called a temporary brachyblast. In other plants the dolichoblasts and the brachyblasts are not merely different stages of development of the same branch but are developed from different buds and a brachyblast never turns into a dolichoblast. This type of brachyblast may be called a permanent brachyblast. Moreover, the brachyblasts may also be classified according to their degree of elongation, absolute brachyblasts which do not elongate at all and resemble small rosettes, and partial brachyblasts which show a certain although limited degree of elongation.

The dolichoblasts and brachyblasts are generally associated with two leaf types, i.e. larger and more differentiated winter and spring leaves, and smaller summer leaves. The seasonal dimorphism is attained by the shedding and growth of the different types of branches and leaves at different seasons.

A few types of chamaephytes differing in their types of branches and the sequence of their development will now be discussed.

(a) Thymus capitatus. The dolichoblasts start elongating in January from temporary absolute brachyblasts developed in the preceding spring. In February they attain a length of $I-2 \mathrm{~cm}$. During March and April, their growth rate increases and branching takes place in their upper portions. At the apex of these branches the inflorescences are developed during June and July and the plant sets fruit in September. These dolichoblasts bear larger leaves which are gradually shed in an acropetal direction, from the middle of May until August. From the buds at the axils of these leaves brachyblasts bearing small scale-like summer leaves are developed. They remain short during the whole summer and only some of them, mainly those on the lower portion of the dolichoblasts, start to elongate in winter turning into the dolichoblasts of the next season. The others which do not elongate, subsequently die and fall off. The upper portions of the dolichoblast die back and are also shed (Fig. I).

(b) Teucrium polium. The life cycle of this plant resembles that of Thymus but its brachyblasts are partial brachyblasts elongating slowly during the 


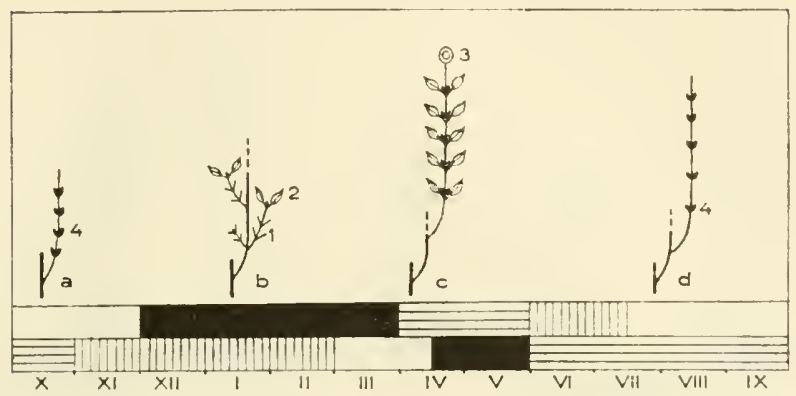

FIG. I. Life cycle of Thymus capitatus.

(a) The lower part of a dolichoblast developed during the previous spring bearing small absolute brachyblasts (4).

(b) One of the brachyblasts of the same branch which has started elongating. (I) Summer leaves, (2) winter leaves.

(c) The same elongating brachyblast reaching its maximal height. (3) The inflorescence.

(d) The same branch; the winter leaves already shed and the new brachyblasts developed at their axils (4) which form the whole green cover of the plant.

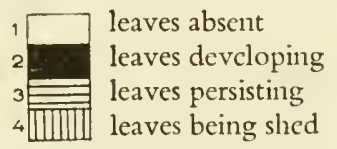

Upper row-winter leaves

Lower row-summer leaves

whole summer. The plant flowers in June and sets fruit in August (Fig. 2).

(c) Poterium spinosum. While the inflorescences of Thymus and Teucrium are developed on the dolichoblasts those of Poterium are developed on the brachyblasts which are absolute and permanent. The dolichoblasts generally are developed from renewal buds and start growing late in February. Their growth rate is very rapid during March and April and they may attain their maximal height at the beginning of May. Branching takes place on their upper portion and the apices of the small branches taper into spines. The larger spring leaves of these dolichoblasts are gradually shed in an acropetal direction from the middle of May to the end of July. In the axils of these leaves small brachyblasts are formed druing April. They look like half open buds and bear small summer leaves. During the summer the older leaves of these brachyblasts are also gradually shed while new ones develop at their apices. This process goes on during the autumn but the new leaves which are formed from October onwards are larger and resemble the 


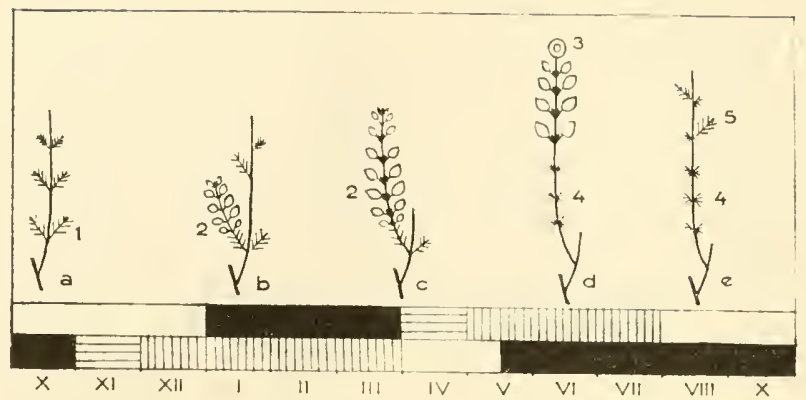

FIG. 2. Life cycle of Teucrium polium.

(a) The lower part of a dolichoblast developed during the previous spring bearing small partial brachyblasts (I).

(b \& c) One of the brachyblasts of the same branch turning into a new dolichoblast bearing winter leaves (2).

(d) The same dolichoblast reaching its maximal height. The older winter leaves have already been shed and new brachyblasts (4) have developed in their axils. (3) The inflorescence.

(e) All the winter leaves already shed. The upper brachyblasts slowly elongating ( 5 ).

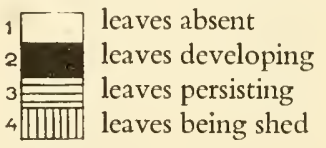

Upper row-winter leaves

Lower row-summer leaves

leaves of the dolichoblasts, and the brachyblasts then look like small open rosettes. Meanwhile practically all the summer leaves are shed. In February, the inflorescences are developed at the apices of these brachyblasts. By that time the new dolichoblasts start developing either from renewal buds formed on older branches or as axillary buds on the brachyblasts. The autumn leaves of the brachyblasts are gradually shed in March and the beginning of April. The upper portions of the dolichoblasts die back during the end of their first summer (Fig. 3).

(d) Artemisia herba alba. The dolichoblasts start elongating in the autumn (October to December) from temporary brachyblasts or from renewal buds. Their growth rate is slow in the early winter but increases rapidly towards the spring. During A pril and May these stems branch once or twice in their upper part and the inflorescence develop at their tops in September and October. The plant sets fruit druing November and December.

There is a gradual change in leaf size and form from the base to the tops 


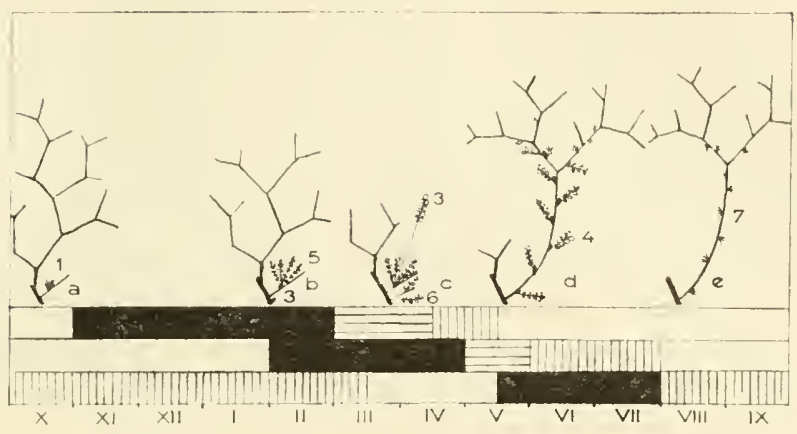

FIG. 3. Life cycle of Poterium spinosum.

(a) A small absolute brachyblast (I) on the lower part of a dolichoblast developed during the previous spring.

(b) New winter leaves are formed on the same brachyblast which resembles a small rosette (s). The renewal buds (3) appear on older branches.

(c) The inflorescence (3) appears at the apex of the brachyblast. The young dolichoblasts (6) emerge from the renewal buds.

(d) The new dolichoblasts bearing spring leaves (4) reach their maximal height. The autumn and winter leaves already shed.

(e) The spring leaves of the same dolichoblasts already shed. New brachyblasts (7) bearing summer leaves developed in their axils.

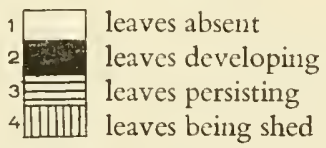

Upper row-autumn and winter leaves

Middle row-spring leaves

Lower row-summer leaves

of these dolichoblasts. The lower leaves are larger with many lobes while the upper ones are bractlike, simple and linear. Leaf shedding starts in April from the lower parts of the dolichoblasts and goes on gradually during the late summer in an acropetal direction until the autumn when practically no leaves remain on the stems except from a few flower bracts.

During the late summer the axillary buds at the lower part of the dolichoblasts start developing into tiny rosette-like brachyblasts. Although no elongation takes place they do not stop growing, new leaves are formed at their apex and the older ones dry out and are gradually shed. In the autumn, part of them starts elongating, yielding the new dolichoblasts, while the others dry out and drop. The upper portion of the dolichoblasts die back almost to their base during their second winter. 
(e) Artemisia monosperma. The life cycle of this plant is similar to that of A. herba alba with one difference, that dolichoblasts develop not only from the base of older dolichoblasts, but also from their upper portions.

(f) Noea mucronata. The dolichoblasts start growing from renewal buds in November. Their growth reaches its maximum rate in spring. These branches bear larger linear leaves which are gradually shed in an acropetal direction from the middle of May to the beginning of July. Meanwhile (from the middle of May to August) thorny brachyblasts develop bearing scale-like smaller summer leaves from the axillary buds at the upper part of these dolichoblasts. The flowers appear on the brachyblasts by September and the plant sets fruit during October and November.

During the winter and the next summer the upper portions of the dolichoblasts as well as all the brachyblasts die back while the renewal buds appear in the autumn on their lower portion or on older stems.

(g) Zygophyllum dumosum. This plant differs from those already described in that there is no summer growing season and the two types of branches develop and grow almost simultaneously. All the leaves are of the same type.

The renewal buds are developed on the lower parts of the dolichoblasts immediately after the first effective rains. The brachyblasts develop almost immediately from the axils of the leaves of the dolichoblasts. The flowers which appear a short time after the onset of growth are born on the dolichoblasts. The plant sets its fruit early in summer.

Surface reduction takes place mainly through the shedding of the double laminae which starts at about May and goes on gradually through the early summer. During the late summer the succulent petioles alone form the only leaf cover of the plant. They are also gradually shed with the increase of water shortage.

(h) Anabasis articulata. This plant is an articulate stem succulent bearing no leaves. Its dolichoblasts develop in winter after the first rains from renewal buds situated at the lower part of the plant. They reach their maximal length (which is generally about $10-20 \mathrm{~cm}$ ) in March. From March to May lateral brachyblasts distinguished from the dolichoblasts by their shorter internodes develop on them and later in October bear the flowers. The plant sets fruit in November and December.

Instead of leaf shedding, which is typical of the non-articulate chaemaphytes, the green cortex of Anabasis starts dying back, becoming ycllow in an acropetal direction from May onwards. Cracks appear in it on stems older than one year and later it is shed.

Apart from the drying and shedding of the green cortex, the transpiring 
body of Anabasis is markedly reduced by the shedding of the brachyblasts and the upper portion of the dolichoblasts.

(i) Haloxylon articulatum. This plant has a life cycle very similar to that of Anabasis.

\section{EXTENT OF SEASONAL BODY REDUCTION}

Measurements of the extent of seasonal body reduction were carried out in desert and Mediterranean plants through two successive years, 1957 and

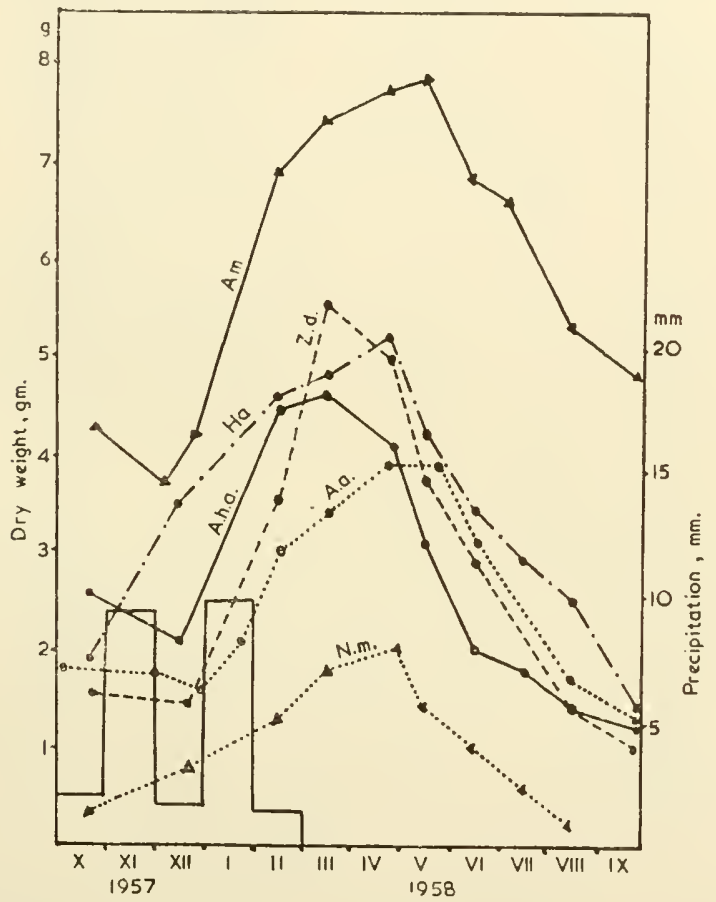

FIG. 4. Annual march of dry weight (grams) of the transpiring body of desert plants.

A.m.-Artemisia monosperma

A.ha.-Artemisia herba alba

A.a.-Anabasis articulata
H.a.-Haloxylon articulatum

N.m.- Noea mucronata

Z.d.-Zygophyllum dımosum

I958, differing in their annual rainfall. The values for Revivim were 177.5 $\mathrm{mm}$ for the winter of $1956-57$ and only $32 \cdot 4 \mathrm{~mm}$ for the winter of $1957-58$. The corresponding values for Jerusalem were $62 \mathrm{I} \mathrm{mm}$ and $384 \mathrm{~mm}$ respectively. 
Between 100 and I 50 plants belonging to each species, as equal as possible in size, were selected in their natural habitats and marked when the measurements were started. A sample of 5 plants was randomly removed from the plot every month. All the green parts, whether they were leaves,

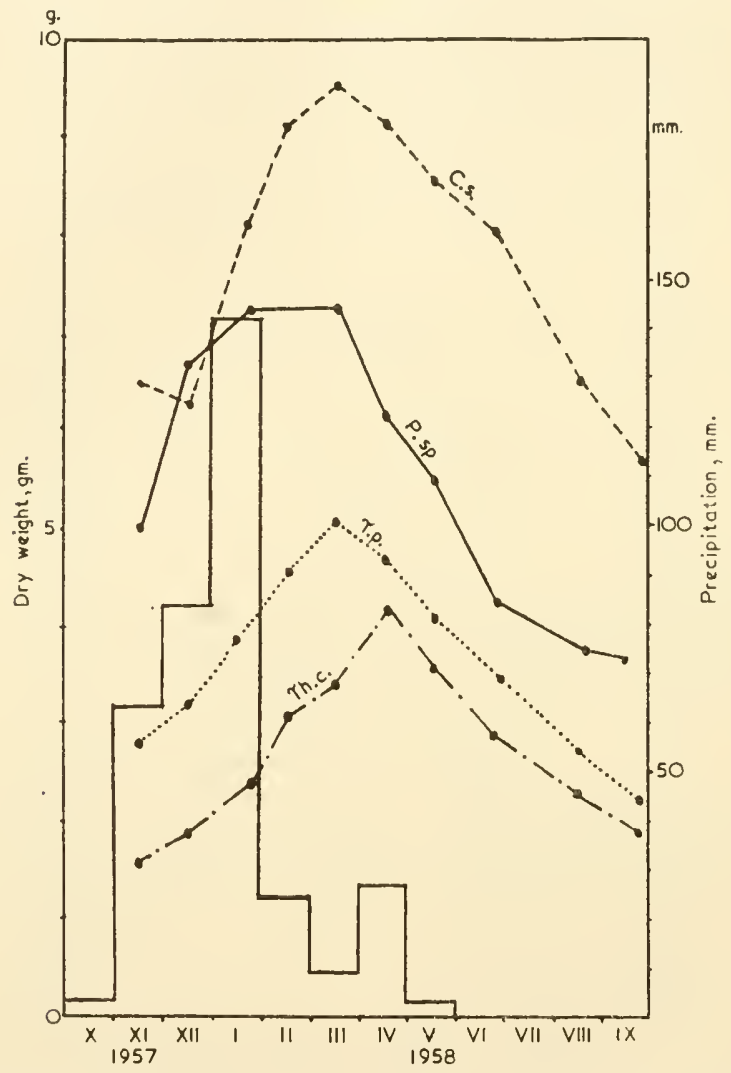

FIG. 5. Annual march of dry weight (grams) of the transpiring body of Mediterranean plants.

\section{C.s.-Cistus salvifolitis \\ P.sp.-Poterium spinosim}

Th.c.- Thymus capitatus

T.p.- Tetucrium polium

stems or both, werecollected from each plant separately and their dry weight determined in the laboratory.

The annual march of the dry weight of the transpiring body is presented in Figs. 4 and 5. From these figures, it is evident that all the plants examined markedly reduce their transpiring body during the summer. The maximum 
values are attained in March and April at the end of the season of extensive growth and the minimum values for most of the plants are reached in the autumn and early winter when a great part of the older summer leaves have been shed and the new growth of the autumn and winter branches and leaves after the first rains have only just started.

\section{TABLE I}

Relative seasonal body reduction of desert and Mediterranean chamaephytes

\begin{tabular}{lcc}
\hline Mediterranean plants & I957 & I958 \\
Poterium spinosum & $5 \mathrm{I}$ & 52 \\
Cistus salvifolius & 39 & 47 \\
Teucriunt polium & 55 & 63 \\
Thymus capitatus & 64 & 74 \\
Desert sand dune plant & & \\
Artemisia monosperma & 57 & 54 \\
Desert plants & & \\
Artemisia herba alba & 72 & 91 \\
Zygophyllum dumosum & 84 & 96 \\
Noea mucronata & $9 \mathrm{I}$ & 90 \\
Anabasis articulata & 73 & 77 \\
Haloxylon articulatum & 72 & 85 \\
\hline
\end{tabular}

The values for the relative seasonal body reduction, i.e. the decrease in weight of the transpiring body during the summer expressed as a percentage of the weight in spring, are presented in Table I. This shows that the values for the desert plants are higher than those for the Mediterranean ones, while Artemisia monosperma, which is a desert sand dune dominant, is intermediate between them. Table I also shows that no marked differences between the values for 1957 and 1958 could be found although the values for 1958 tend to be somewhat higher. On the other hand the amount of new growth for the desert plants in 1957 was higher than that in 1958, as seen from Table 2 , in which the values for the weight of the transpiring body of the plants in the spring of 1958 are expressed as a percentage of the corresponding values for 1957 . No clear-cut differences were found between the amounts of new growth of the Mediterranean plants in the two years.

\section{TRANSPIRATION RATES}

The transpiration rates of the chamaephytes were measured during I9so and I95I in the field by the cut leaf quick-weighing method. Because the 
TABLE 2

Dry weight of the transpiring body in the spring of 1958 expressed as a percentage of the weight in the spring of 1957

Mediterranean plants

Poterium spinosum

Teucrium polium

Thymus capitatus

Cistus salvifolius

85

96

107

98

Desert sand dune plant

Artemisia monosperma

Desert plants

Artemisia herba alba

Zygophyllum dumosum

Noea mucronata

Anabasis articulata

Haloxylon articulatum

\section{$6 \mathrm{I}$}

72

47

7 I

76

plants examined were either microphyllous or articulate, small branchlets were weighed instead of single leaves. From each plant a branchlet was cut from the southern side of the plant at a defmite height with a razor blade, tied with a silver wire, weighed and hung back on the plant for three minutes at approximately the place from which it was detached and weighed again. Two branchlets were weighed every hour and the transpiration rates calculated on a basis of fresh weight. The measurements were started at about sunrise and continued until sunset. The average values for each day were calculated from all the measurements carried out during the day. The annual march of the transpiration rates is presented in Figs. 6 and 7 .

The most striking fact emerging from these figures is that the curves for practically all the plants run more or less parallel. The maximal values occur during April and May when there is still a considerable amount of available water in the upper soil layers and the saturation deficit of the atmosphere is high. The decrease in the transpiration rates during the summer months may be attributed to the decrease in the amount of available water in the soil and the increase of soil water tension. The low values for the transpiration rates during the winter are caused by the low saturation deficit of the atmosphere. Another striking fact is the marked difference between the values for the Mediterranean and desert plants. The transpiration rates for the former are far higher than those for the latter.

When the relative seasonal reductions in transpiration rates, i.e. the drop in the transpiration rates during the summer expressed as a percentage 


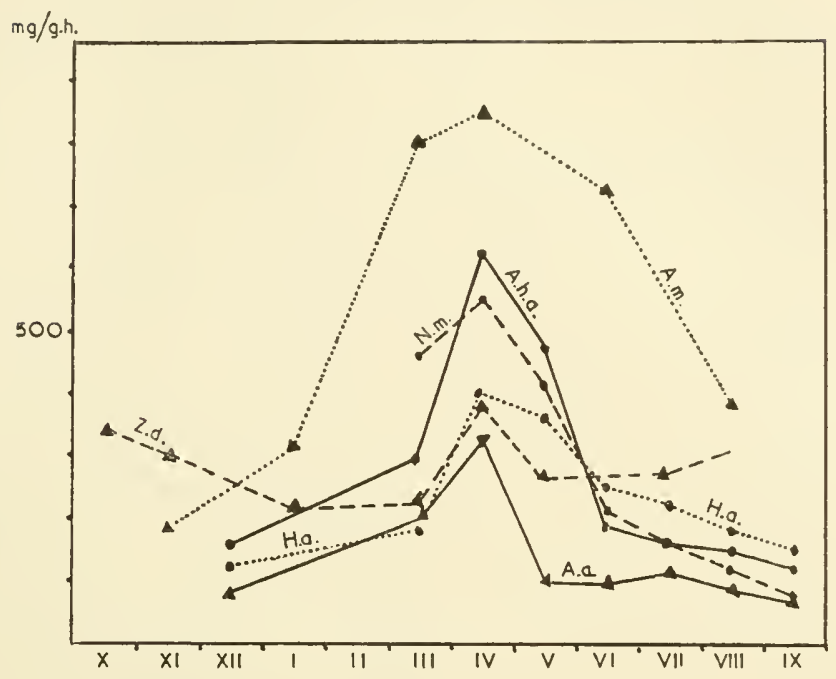

FIG. 6. Annual march of transpiration rates in $\mathrm{mg}$. per gram fresh weight per hour of desert plants.
A.m.-Artemisia monosperma
H.a.-Haloxylon articulatum
A.ha. - Artemisia herba alba
N.m. - Noea mucronata
A.a.-Anabasis articulata
Z.d.-Zygophyllum dumosum

of the values in spring, are calculated (Table 3 ), it is evident that there is no clear-cut difference between the desert and Mediterranean plants. Apart from Zygophyllum dumosum which is a leaf succulent the values are higher than $50 \%$ and for most plants range from 60 to $75 \%$.

\section{TABLE 3}

Relative seasonal reduction in the transpiration of desert and Mediterranean plants

\begin{tabular}{ll} 
Mediterranean plants & \\
Poterium spinosum & 62 \\
Cistus salvifolius & 76 \\
Teucrinm polium & 50 \\
Thymus capitatus & 72 \\
Desert sand dune plant & \\
Artemisia monosperma & 55 \\
Desert plants & \\
Artemisia herba alba & 73 \\
Zygophyllum dumosum & 86 \\
Noea mucronata & 78 \\
Anabasis articulata & 68 \\
Haloxylon articulatum & 27 \\
\hline
\end{tabular}




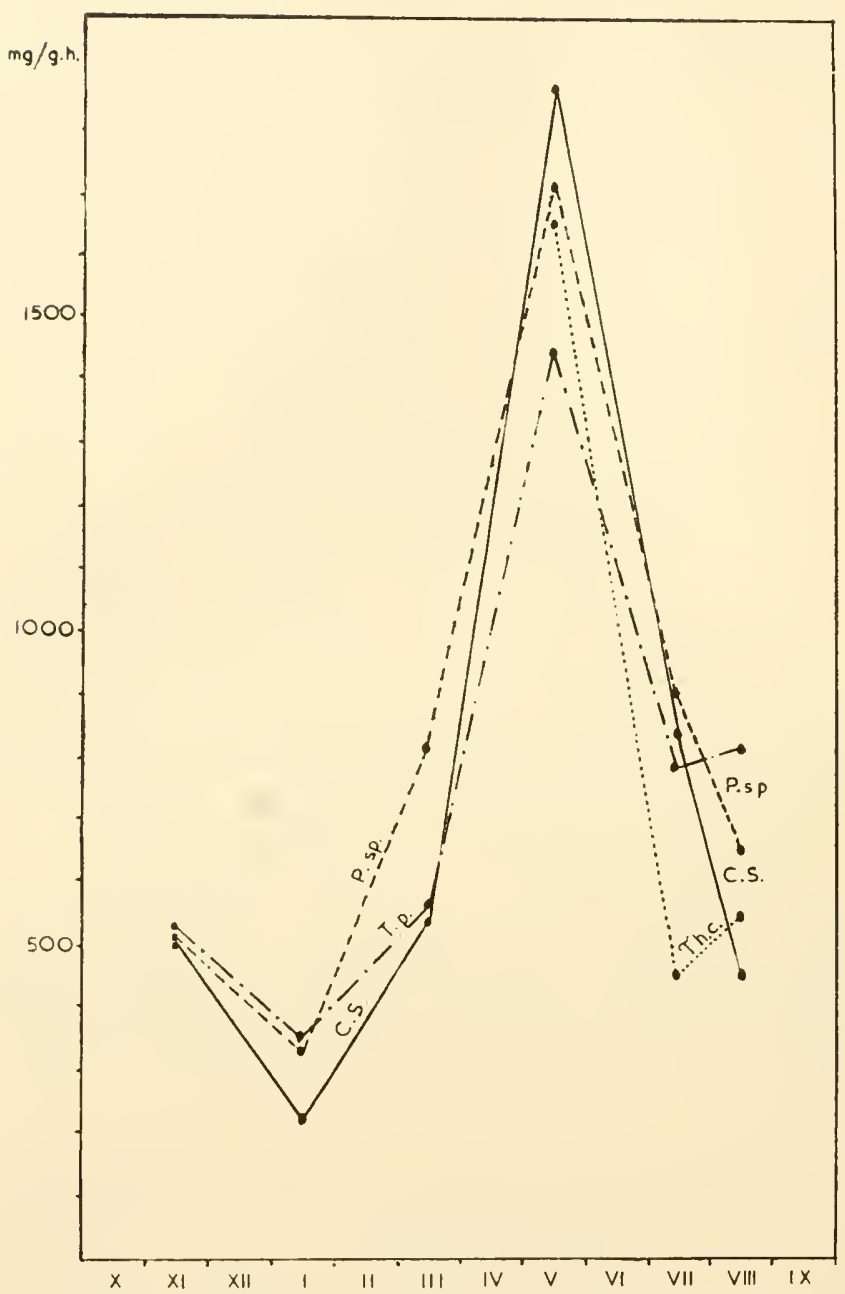

FIG. 7. Annual march of transpiration rates in $\mathrm{mg}$. per gram fresh weight per hour of Mediterranean plants.
C.s. - Cistus salvifolius
Th.c. - Thymus capitatus
P.sp.-Poterium spinosum
T.p.- Teucrium polium

\section{DISCUSSION}

The data presented above clearly demonstrate that the seasonal dimorphism of the chamaephytes examined markedly contributes through surface 
reduction to the regulation of their total water output during the prolonged dry summer of the Mediterranean climate.

As seen from Table I the relative seasonal body reduction of the desert plants examined was far higher than that of the Mediterranean ones. The question which may arise is whether this difference is due to the effect of the environment or to some internal characteristics in which the two groups of plant differ from each other.

The fact that the relative seasonal body reduction of the same species was of similar magnitude for the two successive years examined, in spite of the striking differences in the total rainfall between them, and that no marked differences could be found in this respect between desert and Mediterranean plants, supports the postulate that the differences in the relative seasonal body reduction between the Mediterranean and desert plants is in some respects, at least, due to certain inherent characters.

Although no great differences between the values of the relative seasonal body reduction for the years 1957 and 1958 could be found, the absolute values of the seasonal body reduction in 1957 , which was a better year, were much higher than those in 1958 for the desert plants, but not for the Mediterranean ones. These higher values were due to more extensive growth in the spring of 1957 , as seen from Table 3, affecting mainly the number of dolichoblasts developed and their length. The fact that in the Judaean hills no such differences between 1957 and 1958 were observed, suggests that annual rainfall in the Judacan hills during the winter of 1957-58 was not a limiting factor for growth of the Mediterranean plants.

The question which one may put forward is whether the amount of rainfall limiting spring growth is different for desert and Mediterranean plants.

If one considers the phenomenon of seasonal body reduction as partial drought evasion (Orshan and Zand, I96I), one must admit that the plasticity of the plant with regard to the extent of spring growth is more extensive than that of the part of this growth which is being shed during the summer. The absolute volume of the plant body which is shed during the summer seems therefore to be more or less predetermined in the spring.

The partial drought evasion of the desert chamaephytes, however, goes one step further than that of the Mediterranean by some kind of radial subdivision of the plant when only a sector of it remains alive while the rest dies back to the roots. During the next rainy season, the sector which did remain alive grows into a whole plant (Ginsburg, 1961).

This radial subdivision is achieved through different anatomical mechanisms in various desert chamaephytes and there are some hints of its 
existence in a few Mediterranean ones at least. In the Mediterranean territory, however, partial death correlated with radial splitting of the plant is not common.

Although the cut leaf quick-weighing method has many defects it still seems to be the only practical method yet devised to measure transpiration rates of intact plants in the fields. An analysis made on transpiration rate values of a few desert plants showed that the coefficients of variance for the daily averages were about $10 \%$ and when parallel measurements were made on 2 plants in the same stand the values were of the same order of magnitude (Orshan, I961; Zohary and Orshan, 1954).

These data support, although do not prove, the assumption that the curves in Figs. 6 and 7 represent actual transpiration rates and that both the desert and Mediterranean chamaephytes markedly reduce their transpiration rates during the summer. The fact that no clear-cut reduction in the transpiration-rate values was found for cvergreen Mediterranean trees and shrubs while a marked reduction in the values for the deciduous ones was observed(Poljakoff, I945; Oppenheimer, I953) is supporting evidence.

The means by which the reduction in transpiration rate during the summer is brought about is not clearly understood. One has to bear in mind that in the chamaephytes different leaves or stems make up the transpiring body of the plant in different seasons. When the transpiration rates of different leaf types were measured on the same plant in a few chamaephytes during periods when both could be found intact, no significant differences were found between the daily averages, although differences in the daily march of the curves were prominent (Orshansky, I952). This fact suggests that, while transpiration by different leaf types of the same plant may be affected in different ways by the same factor, it is doubtful whether these differences are sufficient to account for the striking reduction in the transpiration rate of the chamaephytes during the summer. It seems more probable that this reduction is simply caused by the decreasing availability of water in the soil.

Although it is not intended to enter in this paper into a full discussion of the nature of the differences in the transpiration rates between the Mediterranean and desert plants the much higher values of the former are worthwhile noting. Zohary (1959) has already pointed out that our results do not agree with the views of Maximov (I929) and others that higher transpiration rates are characteristic of desert plants. The fact that most of the plants measured by us are either stem succulents or bear more or less succulent leaves may account in part for this disagreement.

The absence of differences between the relative seasonal reduction in the 
transpiration rate of desert and Mediterranean plants may also partially be accounted for by the high degree of succulence of the former.

A comparison between Tables I and 3 shows that the relative decrease in the transpiration rate during summer and the decrease in the transpiring body, are of the same order of magnitude, the two processes playing a more or less equal role in regulating the water output by the plant. When the relative reduction in the total water output is computed, the values obtained range between 90 and $98 \%$. These high values probably account for the fact that chamaephytes play an important role in arid vegetation. As partial drought-evading plants they are intermediate between the drought-evading therophytes, cryptophytes and hemicryptophytes on the one hand, and the drought resisting phanerophytes on the other. Among the perennial plants persisting throughout the year they are distinguished by combining the powers to reduce their transpiring body and their transpiration rate. In this respect they differ from the phanerophytes, whether deciduous or evergreen, except perhaps a few plants like Anagyris foetida L. and Lycium spp.

\section{REFERENCES}

Cain, S. A. (1950) Life forms and phytoclimates. Bot. Rev. I6, I-32.

Evenari, M. (1960) Plant physiology and arid zone research. The Problems of the Arid Zone, Proc. Paris Symp., UNESCO, Arid Zone Res., I8.

Evenari, M. \& Richter, R. (1937) Physiological and ecological investigations in the wilderness of Judaea. J. Liml. Soc. Lond, 5I, 333-8I.

Ginsburg, Ch. (196I) Splitting in Desert Chamaephytes. Its Anatony and Ecology. (MS.)

Maximov, N. A. (1929) The Plant in Relation to Water. London.

Oppenheimer, H.R. (1953) An experimental study on ecological relationships and water expenses of Mediterranean forest vegetation. Palest. J. Bot. Rehovot, 8, IO3-124.

Oppenheimer, H. R. (1959) Adaptation to drought: Xerophytism. Plant Water Relationships in Arid and Semi-arid Conditions, Reviews of Research, UNESCO, Arid Zone Res. I5, 105-38.

OrShan, G. (1954) Surface reduction and its significance as a hydro-ecological factor. J. Ecol. 42, 442-444.

Orshan, G. (1961). A Note on the Ecological Significance of the Cut Leaf Method for Measuring Transpiration. (MS.)

Orshan, G. \& ZAND, G. (196I) Extent of Seasonal Reduction in the Transpiring Body under Mediterranean and Desert Conditions. (MS.)

Orshansky, G. (1952) Effect of morphological and physiological factors on the water economy of plants. Ph.D. Thesis, Hebrew University, Jerusalem.

PolJakoff, A. (I945) Ecological investigations in Palestine. I: The water balance of some Mediterranean trees. Palest. J. Bot. Jerusalemi, 3, I $38-1$ I 50.

Raunkiaer, C. (1934) Life Forms of Plants and Statistical Plant Geography. Oxford, Clarendon Press. 
Shmueli, E. (1948) The water balance of some plants of the Dead Sea salines. Palest. J. Bot. Jerusalem, 3, II 7-I 43 .

Zohary, D. (1953) Ecological studies in the vegetation of the Near Eastern deserts. III: Vegetation map of the central and southern Negev. Palest. J. Bot. Jerusalem, 6, 27-36.

Zohary, M. (1952) Ecological studies in the vegetation of the Near Eastern deserts. IV: Hydro-economical types. Symposium on the Biology and Productivity of Hot and Cold Deserts. London, 56-57.

Zohary, M. (1955) Geobotany (Hebrew) 'Sifriath Poalim' Merhavia.

Zohary, M. (1959) On hydroecological relations of the Near Eastern desert vegetation. Plant Water Relationships in Arid and Semi-arid Conditions, Proc. Madrid Symp., UNESCO, Arid Zone Res., 16, 199-212.

Zohary, M. \& FAHN, A. (I952) Ecological studies on East Mediterrancan dune plants. Bul. Res. Council Israel, $\mathbf{1}, 38-53$.

Zohary, M. \& Feinbrunn, N. (195I). Outline of the Vegetation of the Northern Negev. Palest. J. Bot.Jerusalem, 5, 96-1 I4.

Zohary, M. \& Orshan, G. (1954) Ecological studies in the vegetation of the Near Eastern deserts. V: The zygophylletum dumosi and its hydroecology in the Negev of Israel. Vegetatio, 5-6, 34I-350.

Zohary, M. \& Orshan, G. (1956) Ecological studies in the vegetation of the Near Eastern deserts. II: Wadi Araba. Vegetatio, 8, I 5-37. 
RELATION OF GROWTH AND DISTRIBUTION TOWATER 


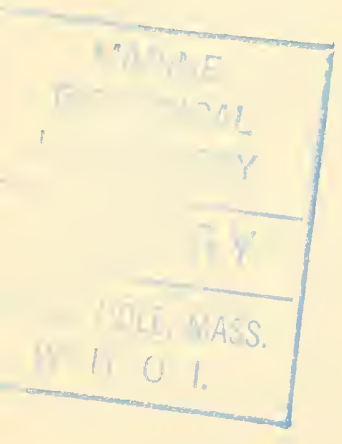




\title{
ON THE PROBLEM OF THE RELATIONSHIP BET WEEN HYDRATION OF LEAF TISSUE AND INTENSITY OF PHOTOSYNTHESIS AND RESPIRATION
}

\author{
Bohdan Slavík \\ Institute of Biology, Czechoslovak Academy of Sciences, \\ Praha, Czechoslovakia
}

\section{INTRODUCTION}

A considerable number of papers has been devoted to the relationship between the intensity of photosynthesis and hydration of photosynthesising tissues. Papers will not be mentioned in the sequel which do not take into consideration the intensity of carbon dioxide assimilation but rather the final yield (of the more recent ones, e.g. Baumann, 1957; Kreeb, 1958).

Concerning the lower poikilohydric plants (algae, bryophytes, lichens) there exists a fundamental unity of view that hydration directly affects the intensity of $\mathrm{CO}_{2}$ assimilation (Brilliant, 1924; Mayer and Plantefol, 1926; Stocker, 1927; Walter, 1928, 1929; Smyth, 1934; Stocker and Holdheide, 1937; Stälfelt, 1937, I938; Danilov, 1938; Kaltwasser, 1939; Ellée, 1939; Romose, 1940; Ried, 1953; Ensgraber, 1954 and others).

On the other hand, papers where this relationship is considered in higher dry-land homoiohydric (hydrostable) plants without interaction of the stomata, have not reached a common basis so far. For instance, Pisek and Winkler (I95S) did not find in their results any experimental support for the view that photosynthesis should decrease on water loss in any other way than by virtue of stomatal closure. A similar standpoint is maintained by Larcher (1960). An elimination of the influence of the hydroactivity of stomata is rather difficult from the experimental point of view. Iljin (r923) worked with plants with closed stomata and he still found a relationship to exist between water content and intensity of photosynthesis, different in different taxons. Brilliant (1924, 1925, a review of 1949) and Chrelashvili (1940) carried out experiments on small segments of leaf tissue after having ascertained that the state of the stomata did not limit the saturation of the tissues with $\mathrm{CO}_{2}$ which took place through the planes of section. In addition to a dependence of the intensity of photosynthesis on water content in the tissue they demonstrated the existence in higher plants of an optimal water deficit at which the intensity of photosynthesis was in some cases higher 
than at complete water saturation. Stocker $(1954,1956)$, who was concerned with higher plants, entertained no doubt about the intensity of photosynthesis being dependent directly on the chemical potential of water in the assimilating tissue. A similar view is held by Alexeev and his school (1952, 1954) who found very significant correlations between the intensity of photosynthesis and various indicators of the water relations of the tissue, particularly between the colloid-bound water and the osmotic pressure of the cell sap.

The papers mentioned represent but a few examples of the fundamental viewpoints extant rather than an exhaustive review of all papers where the problem in question is touched upon. Such review of papers prior to the early forties may be found in the monograph by Brilliant (I949), another is given by Stålfelt (1960).

The present communication should contribute to the problem from an entirely new and different point of view.

In keeping with the physiological gradients in plant organs (Prat, 1948, I95 I) it was shown earlier (Slavik, I959a, I959b) that sugar-beet and tobacco possessed a definite distribution pattern of values of the osmotic pressure of the cell sap over the leaf-blade which did not change even during a complete saturation of the leaf-blade with water, i.e. at a zero diffusion pressure deficit of tissues in situ, and which was thus associated with an identical gradient of the turgor pressure. This osmotic pressure gradient remained relatively unchanged both during active (supplementary saturation) and passive (wilting) water balance. I am of the opinion that such a natural and constant difference in the cell sap osmotic pressure under normal conditions in a steady state of individually identical material (one and the same leafblade) is very suitable for studying the relationship between hydration and the photosynthetic or respiratory activity.

The present paper thus attempts to compare the differences in the intensity of photosynthesis and respiration at the base and at the apex of the leaf-blade, i.e. in those leaf-blade sections between which the greatest natural and permanent differences in the osmotic pressure of the cell sap are known to exist (for details see Slavik, I959a).

\section{MATERIAL AND METHODS}

About 120-I50-day-old tobacco plants (Nicotiana Sanderae hort.) in the vegetative state with a leaf rosette of 10 to 12 leaves, grown in pots, were used for the experiments.

For the purpose of measuring the intensity of photosynthesis the plants 
were kept for 24 hours in a saturated atmosphere and then placed in a small air-conditioned chamber of the following inner dimensions: $35 \mathrm{~cm} \times 35 \mathrm{~cm}$ $\times 40 \mathrm{~cm}$. The chamber was flushed with temperature- and humidityconditioned air with the normal concentration of carbon dioxide (i.e. about $\left.0.55 \mathrm{mg} \mathrm{CO}_{2} / \mathrm{r} 000 \mathrm{ml}\right)$. The air in the chamber had a temperature of $25+0.2^{\circ} \mathrm{C}$, relative humidity of $80 \pm 3 \%$. The plant in the chamber was illuminated from above with five incandescent bulbs, Tungsraphot B 500 W, and with four Philora 75 W Phillips, through a continuous-flow water filter $8 \mathrm{~cm}$ in height, the total constant intensity being 40,000 lux (with stabilised mains voltage). For the experiments mature leaves of the central insertion level were used in situ (on the plant), the apex and the base of the leaf being covered bilaterally with leaf chambers provided with plexite windows (photograph in Čatský, I960) which enclosed an area of $12 \mathrm{~cm}^{2}$. Experimental air was drawn through these horizontally placed leaf chambers by means of membrane pumps at the constant rate of $101 / \mathrm{hr}$, passing then into an infrared $\mathrm{CO}_{2}$-analyser (Infralyt, Dessau, Germany). This analyser with a selective condenser detector was set up in a differential circuit so that it measured directly the difference in concentration between the experimental and control air. The measuring tube of the analyser was alternately connected with the basal and apical leaf chamber placed on the same leaf. Control air was passed through the reference tube. A so $\mu \mathrm{A}$ recorder registered values which, during constant flow of experimental air, were directly proportional to the intensity of photosynthesis of the part of the leaf-blade enclosed in the leaf chamber. Sufficient rate of air flow with a very small leaf-chamber volume ensured that no excessive heating of the leaves occurred and that even at the highest intensitics of photosynthesis the concentration of carbon dioxide never dropped by more than $20 \%$. A second control infrared analyser measured the concentration of $\mathrm{CO}_{2}$ in the control air. For details see Slavik and Čatský (I96I). The values of intensity of photosynthesis were expressed as $\mathrm{mg}$ $\mathrm{CO}_{2} / \mathrm{dm}^{2} / \mathrm{hr}$.

When the intensity of respiration was measured higher accuracy was achieved by using the conventional manometric estimation according to Warburg. Each manometric flask contained 6 leaf discs of $15 \mathrm{~mm}$ in diameter cut out either from the apical or from the basal part of the leaf-blade (circles in Fig. I). Experimental leaves were chosen on the basis of criteria common to analogous experimental plants as used for estimation of photosynthesis and were also saturated with water prior to the experiment.

The side-arm of the flask contained I $\mathrm{ml} /$ water which ensured minimum transpiration loss from the leaf tissue discs during measurement. The esti- 
mation was carried out at $25^{\circ} \mathrm{C}$. It was ascertained before the experiment that different size of the discs and thus a different ratio of the total intact area to the cut plane area had but a negligible effect on the relative values of respiratory intensity. These values are expressed in $\mu 1 . \mathrm{CO}_{2} / \mathrm{mg}$. dry weight/hr.

Parallel material was used for determining the number and size of stomata by direct microscopy. The density of stomata was expressed as number per I $\mathrm{mm}^{2}$ leaf area, the size as the length of the pore in $\mu$. Under the theoretical assumption that the stomata are of the same shape all over the leaf-blade, i.e. that the index of length to maximum width of the pore is the same, the pore area is proportional to the square of its length. The product of the density and square of pore length (together with the sum of these values for the lower and upper part of the leaf-blade) is given as the relative index of the area of pores.

I am indebted to Mrs. Krejcarová for her skilled technical assistance.

\section{RESULTS}

Gradients of the osmotic pressure of the cell sap of a single material were the following: during average osmotic pressure of the cell sap in the leaf-blade apex amounting to $12 \cdot 9+0.3 \mathrm{~atm}$. the average osmotic pressure at the base was $10 \cdot 6 \pm 0 \cdot 32$ atm, i.e. lower by 18 per cent. The difference of $2 \cdot 3$ $\pm 0.20 \mathrm{~atm}$ is very significant statistically (see Table I).

\section{TABLE $\mathbf{I}$}

Review of results

\begin{tabular}{lcccc}
\hline & OP & PR & R & ST \\
\cline { 2 - 5 } $\begin{array}{l}\text { Leaf-blade apex } \\
\text { Leaf-blade base }\end{array}$ & $12.9 \pm 0.3$ & $10.8 \pm 1.3$ & $2.4 \pm 0.06$ & 135.0 \\
\hline $\begin{array}{l}\text { Average difference } \\
\begin{array}{l}\text { Difference base-apex in } \\
\text { percentage }\end{array}\end{array}$ & $-2.3 \pm 0.2$ & $+2.1 \pm 0.4$ & $+0.3 \pm 0.07$ & +4.3 \\
\hline
\end{tabular}

$\mathrm{OP}$-osmotic pressure in atm.

$\mathrm{PR}$ - phosynthetic rate in $\mathrm{mg}$. $\mathrm{CO}_{2}$ per $\mathrm{dm}^{2}$ per hour.

$\mathrm{R}$-rate of respiration $\mathrm{Qo}_{2}$ in $\mu$ l. $\mathrm{CO}_{2}$ per dry weight per hour.

ST-relative index of total pore area (see text and Table 2). 
The photosynthesis rate was measured in 28 leaves, i.e. in a total of 28 pairs of apical and basal parts of the leaf-blade. The leaf chambers were placed as shown in Fig. I by the rectangles. At the beginning of each experiment the stomata were opened photoactively (previous saturation with water took place in the dark) so that after 20 or 30 min the intensity of photosynthesis reached mostly a steady value which was maintained for at least one hour but usually for several hours. The plants were well watered and the conditioned air passing through the leaf chamber had a high humidity so that the water saturation deficit formed was reflected in a

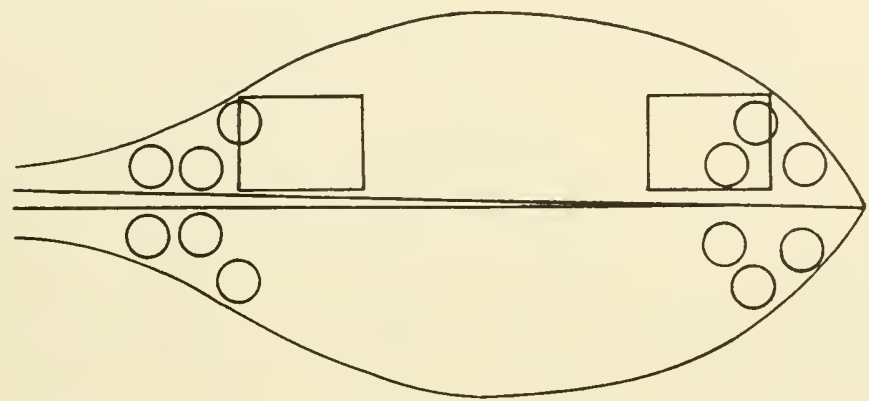

FIG. I. Localisation of the chambers in photosynthesis determinations (rectangles) and of the disks cut out for respiration measurements (circles).

decrease of the apparent photosynthesis only after several hours' exposure. The water saturation deficit values at which a marked drop in photosynthesis could be observed on long exposure varied about the value of Io per cent. For our results, values of photosynthesis were chosen from the initial, completely steady measuring intervals. An important fact should be mentioned here, however, namely that the basal part of the leaf revealed in a separate experimental series a quite regularly higher water saturation deficit than the apical parts. Thus the possible differences in the water deficit could affect the difference in photosynthesis in the reverse direction only, i.e. they could decrease the intensity of photosynthesis in the basal part, thus diminishing (and in no case increasing) the observed difference in the intensity of photosynthesis between the base and the apex.

The results showed that under the given experimental conditions the intensity of photosynthesis referred to area was on the average 20.2 per cent higher in the basal part of tobacco leaves than in the apical one. The observed average difference $d=2 \cdot \mathrm{I} \pm 0.4 \mathrm{mg} \mathrm{CO} / \mathrm{dm}^{2} \mathrm{hr}$ (the average 
intensity at the leaf base being $\mathrm{I} 2 \cdot 0 \mathrm{mg} \mathrm{CO} / \mathrm{Cm}^{2} \mathrm{hr}$ ) is statistically very significant $(P \doteq 0 \cdot 000000 \mathrm{I})$. (See Table I.)

If the differences in the intensity of photosynthesis are to be compared with the different tissue hydration expressed as osmotic pressure of the cell sap, i.e. if the differences are to be compared with the plasma factors of photosynthesis it must be known to what extent our results could be influenced by a different factor, viz. by the stomata, possible differences in their density, size and state. The results of these estimations are shown in Table 2.

\section{TABLE 2}

Number and size of stomata and relative index of pore area

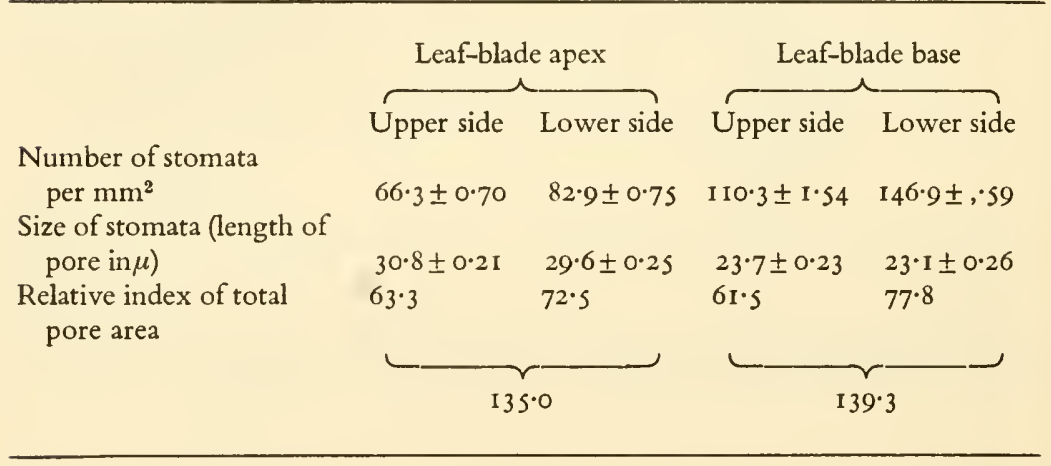

While the number of stomata on the upper and lower side of the leafblade is significantly greater at the base, the length of the pores is statistically greater in the stomata from the apical part. In order to calculate the relative index of the true pore area a simplifying assumption must be employed, namely that all stomata have the same relative shape or in other words, the same ratio of length to width of pore at the given extent of opening all over the leaf-blade area. As the pore area is proportional to the square of its length, the product of the number and square of pore length may be taken as the relative index of pore area. Indexes derived in such way (as shown in Table I) indicate that the total area of pores at the base and at the apex differs by 2.5 per cent only, in spite of the above contradictory differences in number and size.

Statistical significance of this difference was not tested on account of the very laborious calculation of the index separately for each field of vision. But even if the difference is statistically significant it is insufficient in 
comparison with the observed differences in the intensity of photosynthesis to explain them.

As concerns the opening width of the stomata, it should be mentioned at this point that in the present paper the intensities of photosynthesis are compared during the steady initial phase of measurement when no decrease takes place which could be ascribed to hydroactive closing of the stomata. As was mentioned above, any possible (but not observed here) hydroactive closing of the stomata would be reflected first at the base where regularly higher water saturation deficits were observed. This closing would thus act against the observed difference in the intensity of photosynthesis.

Still greater, statistically significant differences were observed in the respiration intensity. Average differences in the intensity of $\mathrm{CO}_{2}$ production in the dark amounted to $0.3 \mathrm{I} \pm 0.07 \mu \mathrm{g} \mathrm{CO} / \mathrm{mg}$ dry weight and were statistically very significant $(P \doteq 0.0000 \mathrm{I})$. The average intensity of respiration of the discs cut out from the apical part of the leaf-blade was in the same experiment $2.38 \mu \mathrm{g} / \mathrm{mg}$ dry weight, while of those from the base it was on the average 13 per cent higher (number of sample pairs $n=82$ ) (see Table I). In the course of estimation in the Warburg apparatus the discs acquired within 90 min an average of $s-8$ per cent water saturation deficit. 'There were no significant differences between the water deficit of the discs from the apical and basal part of the leaf-blade.

In common with the intensity of photosynthesis the respiration intensity of assimilatory tissues of the leaf-blade was significantly higher in the basal part than in the apical one.

\section{DISCUSSION AND CONCLUSIONS}

Intensity of photosynthesis referred to leaf area was about $22 \%$ higher at the base of tobacco leaf-blades than at their apical part. This statistically very significant difference could be associated by about I/9 only with the greater area of stomatal pores at the leaf base where the density of stomata is significantly higher but their area significantly smaller, so that the calculated relative index is 2.5 per cent greater at the base than at the apex. Different opening width of the stomata affect the results only by decreasing the observed difference (see Results). The stomata played no role whatever in the measurement of respiration, when they were photoactively closed. Respiration intensity referred to dry weight was 13 per cent higher at the base than in the apical part of the leaf-blade. This difference is also statistically very significant. It may be concluded that the observed statistically very significant differences between the rate of photosynthesis and respira- 
tion of assimilatory tissues at the base and near the apex were not due to a stomatal factor, i.e. neither to their different size and number nor to their state. It should be noted here that in the experiments the effect of possible differences in the permeability of the cuticle or of the whole epidermis for $\mathrm{CO}_{2}$ and the effect of the inner structure were not eliminated. In experiments on photosynthesis the effect of possibly different chlorophyll content could also play a role.

The osmotic pressure of the cell sap was 18 per cent lower in the basal part than in the apical one and this difference was also statistically very significant.

If the differences observed are correlated with differences in hydration of the tissue expressed by differnt osmotic pressure of the cell sap it is with the awareness of the possibility of an actual effect of the state of hydration as well as of its structural consequences formed during leaf ontogeny. In other words, the stable differences in hydration of leaf tissue cells as known from the differences in the osmotic pressure of the cell sap represent both an actual and an ontogenetic factor which has affected both the anatomical and plasmatic structure of leaf tissue cells. These structures influence then the intensity of functions, in our case of $\mathrm{CO}_{2}$ assimilation and respiration.

A distinction between the actual effect of hydration and the ontogenetic effect on structure and thus on function is difficult to make especially, if the question of reversibility of these changes is considered. Many changes in the photosynthetic activity due to dehydration are completely reversible but not all of them (Stocker and Holdheide, I937; Kaltwasser, I939; Brilliant, 1949; Ried, I953; Stocker, I954; Ensgraber, I954; Stålfelt, I 960 and others). The additive irreversible changes become structurally permanent. Therefore, even those structural changes, the effect of which could not be eliminated during the experiments described here and which could not be distinguished from the actual effect of hydration are in fact the consequences of dehydration. They can thus be causally connected with hydration, particularly in such cases where the observed differences in hydration at different parts of the leaf-blade are permanent as is the case in our experiments.

The observed relative differences in osmotic pressure of the cell sap are practically independent of the tissue diffusion pressure deficit (Slavik 1959a). They persist even during complete water saturation, during complete turgescence. The same relative differences may thus be ascribed to the maximum cell turgor. These relative differences in the turgor pressure are undoubtedly connected with relatively permanent structural differences.

To my mind, the observed differences in the intensity of photosynthesis 
and respiration are causally connected with permanent differences in hydration of cells of the assimilatory tissue of different parts of the leafblade. A quantitative comparison of relationships between the above values of photosynthesis and respiration rates is quite complicated. It must be borne in mind, however, that the localisation of sites for which the intensity of photosynthesis and respiration was determined was somewhat different from methodological reasons (see Fig. I).

\section{REFERENCES}

AleXferv, A.M. (1952) Zavisimost fotosinteza ot vodnogo rezhima rastenyi. .Izv Akad. Nauk. SSSR, IOS-I I 3.

Alexeev, A.M. (1954) Zavisimost fotosinteza ot sostoyaniya vody v listye. Utch. Zap. Kazanskogo gos. Univ. I14, I67-178.

Bauman, L. (1957) Über die Beziehungen zwischen Hydratur und Ertrag. Ber. dtsch. bot. Ges. 70, 67-78.

Brinliant, V. (1924) La teneur en eau dans les feuilles et l'énergie assimilatrice. C. $R$. Acad. Sci. Paris, 178, 21 22-2124.

BrILLANT, V.A. (I925) Zavisimost energii fotosinteza ot soderzhaniya vody v listyakh. Izv. Gl. bot. Sada, 24, I-I 2 .

Brimlant, V.A. (1949) Fotosintez kak process zhiznedeyatelnosti rasteniya. Moskva.

ČATSKÝ, J. (1960) Zur Frage der pH- Bestimmung bei colorimetrischen Assimilationsmessungen. Planta, 55, $38 \mathrm{I}-389$.

Chrelashvili, M.N. (I94I) Vliyaniye soderzhaniya vody i nakopleniya assimilyatov $\mathrm{v}$ liste na energiyu fotosinteza i dykhaniya. Trudy BIN-Exper. bot., 5, Ior-I 37.

DANIIOv, A.N. (I938) Zavisimost fotosinteza ot vodnogo rezhima v raznikh usloviyakh osveshcheniya. Trudy BIN-Exper. bot. 3, I-74.

ElıÉE, O. (1939) Über die Kohlensäureassimilation von Flechten. Beitr. Biol. Pfl. 26, 250-288.

EnsGraber, A. (1954) Über den Einfluss der Austrocknung auf die Assimilation und Atmung von Moosen und Flechten. Flora, I4I, 432-475.

IIjIN, W.S. (I923) Der Einfluss des Wassermangels auf die Kohlenstoffassimilation durch die Pflanzen. Flora, II6, 359-378.

Kaltwasser, J. (1938) Assimilation und Atmund von Submersen als Ausdruck ihrer Entquellungsresistenz. Protoplasma, 29, 498-535.

KreEB, K. (1958) Die Bedentung der Hydratur für die Kontrolle der Wasserversongung bei Kulturpflanzen. Habil. Stuttgart-Hohenheim.

LARCHER, W. (1960) Transpiration and photosynthesis of detached leaves and shoots of Quercus pubescens and Quercus ilex during desiccation. Bull. Res. Counc., Israel, 8, 213-224.

Mayer, A. \& Plantefol, L. (1926) Teneur en eau des plantes et assimilation chlorophyllienne. Etude de l'assimilation des mousses revivescentes. Ann. physiol. et physichoch. biol., 2, 564-605.

PISEK, A. \& WinKıER, E. (I956) Wassersättigungsdefizit, Spaltenbewegung und Photosynthese. Protoplasma, 66, 597-6I I.

Prat, H. (I948, I95 I) Histophysiological gradients and plant organogenesis. I: Bot. Rev. 14, 603-643; II: Bot. Rev. 17, 693-746. 
Ried, A. (1953) Photosynthese und Atmung bei xerostabilen und xerostabilen Krustenflechten in der Nachwirkung vorausgegangener Entquellung. Planta, 4r, 436-438. Romose, V. (I940) Ökologische Untersuchungen über Honlolothecimm sericeum, seine Wachstmsperioden und seine Stoffproduction. Dansk. bot. Ark. 10, I-134.

Slavík, B. (I959a) Gradients of osmotic pressure of cell sap in the area of one leaf blade. Biol. Plant., I, 39-47.

Slavík, B. (1959b) Water relations within the area of one leaf blade. Proc. gth int. bot. Congr. (Montreal), 2, 367.

SiAvík, B. \& ČATSKÝ, J. (1963) Differentially measuring infrared analyser with an air-conditioned exposure chamber for photo-synthetic rate measurements. Biol, Plant., 5, in press.

Sмyтн, E. (1934) A contribution to the physiology and ecology of Peltigera canina and P. polydactyla. Amn. Bot., 48, 78 I-818.

Stålfelt, M. G. (1937) Der Gasaustausch der Moose. Plaita, 27, 30-60.

Stålfelt, M. G. (1938) Der Gasaustasch der Flechten. Planta, 29, I I-3 I.

StÅlfelt, M.G. (1960) Wassergehalt und Plasmazustand. Hb. d. Pflanzenphysiol. (Ruhland) Vol. 5, Teil 2, 174-179, Springen-Berlin, Göttingen, Heidelberg.

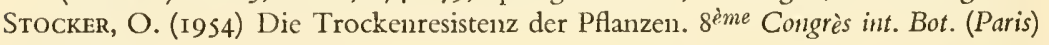
223-232.

Stocker, O. (1956) Wassermangel und Zellaktivität. Hb.d. Pflanzenpnysiol. (Ruhland), 2, 639-654, Springen.

StOcker, O. (1927) Physiologische und ökologische Untersuchungen an Laub- und Strauchflechten. Flora, 2I, 339-4I5.

StOcKer, O. \& HoldheIDE, W. (1927) Die Assimilation Helgoländer Gezeitenalgen während der Ebbzeit. Ztschr. Bot. 32, I-59.

Walter, H. (1928) Die Bedeutung des Wassersättigungszustandes auf die $\mathrm{CO}_{2}$ Assimilation der Pflanze. Vorläuf. Mitt. Ber. dtscl. bot. Ges. 46, 530-539.

Walter, H. (1929) Plasmaquellung und Assimilation. Protoplasma, 6, i I3-I 56. 


\title{
THE EFFECTS OF EXPOSURE ON GROWTH
}

\section{AND DEVELOPMENT}

\author{
F. H. Whitehead \\ Imperial College, London
}

THE importance of wind as a factor in plant growth has long been recognized. In the field of agriculture and forestry many empirical studies have been carried out mainly associated with the design and location of 'wind breaks'. Far less attention has been focused on the experimental investigation of effects that exposure to wind during growth may have on the development and physiology of plants.

At the beginning of the investigations presented here it was not even clear to what extent wind effects could determine survival or death of plants or communities. As a preliminary to laboratory investigations field studies were carried out on M. Maiella in the Central Apennines of Italy. This mountain has a fairly flat altopiano near the snow line covered with limestone rock detritus and with typical 'alpine desert' vegetation. It is particularly exposed to strong winds and the various community types, often in close juxtaposition, appeared to be associated with the degree of shelter from wind afforded by the rock fragments (Whitehead, I95I). The aerodynamic parameter $Z_{0}$ was found to be the best measure of the degree of shelter from wind afforded by the surface irregularities. In these alpine communities where the vegetation is sparse and the main drag on the air stream is caused by the rock fragments themselves this parameter is not open to the objections which can be made against its use in relation to most vegetation types. The average values of $Z_{0}$ were determined in the field for four of the community types described in Whitehead (I95I). Four of these communities, A, E, G, and $\mathrm{H}$, representing a gradation of exposure from most exposed to least exposed were studied in detail. It was found that there was a clear relationship between $Z_{0}$ and average plant height; average inflorescence height and annual yield (Fig. Ia and b). The larger the value of $Z_{0}$ and thus the greater degree of shelter the taller were the plants and the greater the annual yield.

The degree of shelter, expressed as $Z_{0}$ also appeared to be related to both the number of species and the diversity of growth forms in a community (Fig. Ic). The smallest number of species and least diversity of 


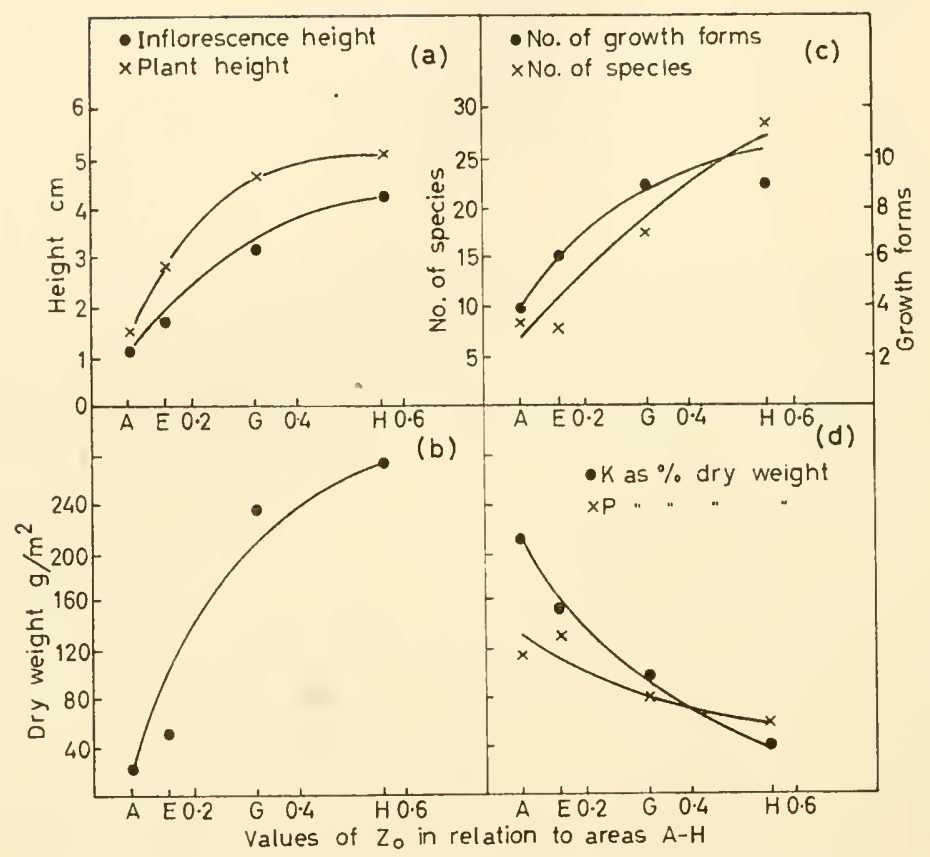

FiG. I. Relationship of average wind speed $(\mathrm{Zo})$ on mountain top to (a) heights of inflorescences and plants (b) annual yield of dry matter (c) number of growth forms and species and (d) uptake of potassium and phosphorus.

growth form is found in area $A$ and these progressively increase until in the most sheltered area $H$ the largest number of species and the greatest diversity of growth form is found.

These data show a relationship between the degree of shelter and the characteristics of the communities. If this relationship were causal then alteration to the degree of shelter in a given area should result in changes in the community characteristics. This simple experiment was carried out in the field by erecting low stone walls around mapped and recorded quadrats in the most exposed areas. After a period of time changes did occur in the vegetation of the kind which had been predicted and are 
described fully in Whitehead (1959). The experiment was set up to test, at the same time, the alternative hypothesis that the observed effects were due to shading. This alternate hypothesis was shown to be untenable.

The growth form of a plant is of great importance in relation to wind effects. A rough classification of such form is considered in Whitehead (I957). In this paper only the exposure sensitive class will be considered. These are plants which show a marked dwarfing when grown in conditions of continuous exposure to wind. In addition to the reduction of height which is not accompanied by a reduction of the number of internodes, there are also extensive anatomical changes. All these changes are such that it can be said that the plant shows increased xeromorphic characters the higher the wind speed under which it is grown. Observations made on plants grown in wind tunnels showed considerable similarity to plants of the same species (Senecio nebrodensis) from areas of increasing exposure in M. Maiella.

In earlier experiments (Whitehead, 1957) it was found that leaf saturation deficits of plants exposed to wind for a time increased despite the fact that the roots were in soil maintained at field capacity. Recovery took place during a subsequent period without wind. Other species of Senecio not found in nature in such exposed conditions, e.g. Senecio elegans appeared to accumulate so large a leaf saturation deficit that under the conditions of the experiment permanent wilting could be expected after a few days.

Resulting from the experiments, however, it became clear that any genotype has some power of reacting to the environment in such a way that the changes in development can be considered advantageous to survival under those conditions. Accordingly experiments were carried out to investigate the extent of change which could be produced by species not adapted to the severe conditions of the mountains. The species chosen were Zea mais and Helianthus anmuns. The plants of Zea were grown in a wind tunnel and their anatomy and morphology compared to control plants not subjected to wind. The results are given in full in Whitehead and Luti, 1962. It was found that the plants exposed to wind were much more xeromorphic in all characters examined. The degree of difference between the treated and control plants was large being of the order of three to six times greater in the treated plants than the controls.

In further experiments using Helianthus anmuus a growth analysis of both treated and control plants was made (Whitehead, I962). These showed that the plants exposed to wind were shorter and had smaller leaves than the controls. This dwarfing effect increased with the wind speed under which the plants developed. 
A similar increase in xeromorphy was observed. Examination of the relative proportion of root to shoot dry weights showed that over most of the range of the experiments there was a greater proportion of root to shoot with increase of wind speed despite the smaller total dry weight (Fig. 2). At wind speeds approaching $40 \mathrm{~m}$.p.h. the plants failed to survive

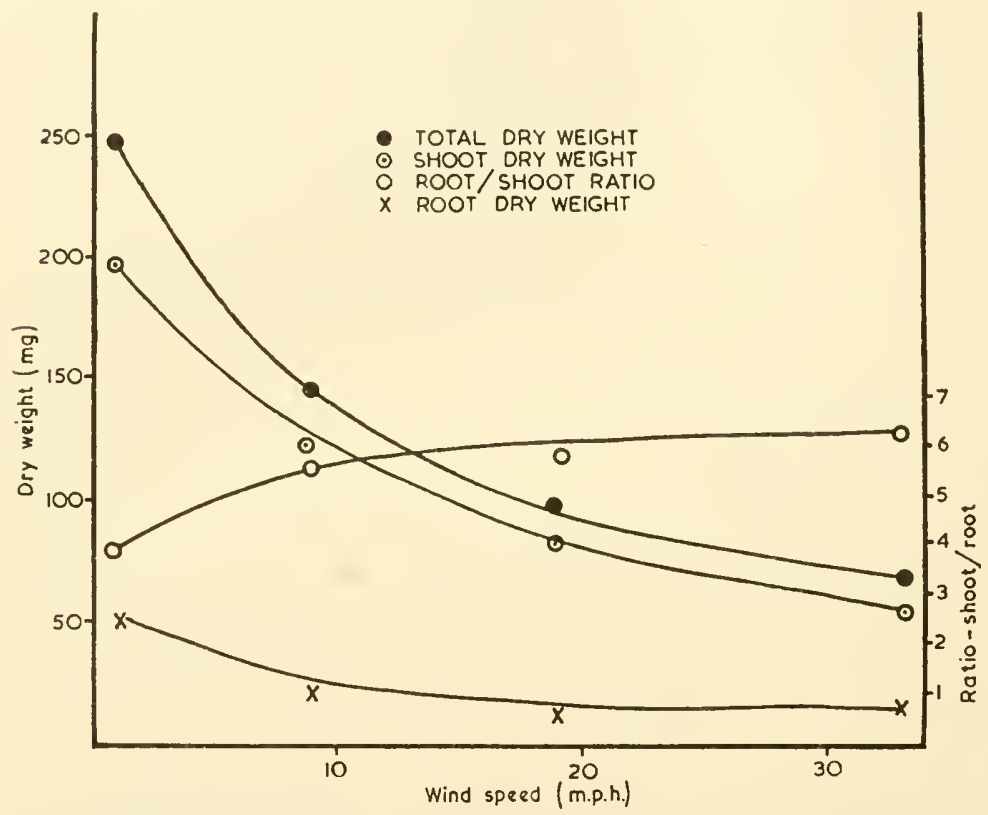

FIG. 2. Graph showing alterations of dry weight accumulation over 30 days in Helianthus annuus grown at four different wind speeds.

the full time of the experiment and these plants did not show an increase in root proportionally to shoot, indicating they were unable to produce phenotypic change with potential advantage beyond a certain critical level of conditions. Fig. 3 shows average internode length and average leaf areas of Helianthus annums grown at four wind speeds. These two characters show a marked decrease in value with increase of wind speed. Fig. 4 shows data of the plant height and leaf area for the mountain species Senecio nebrodensis grown for the same length of time and at a range of wind speeds. It can be seen that the 'critical level' beyond which compensation does not occur is much higher together with the fact that the degree of response to any one wind treatment is greater. It would appear that the degree of response and tolerance in mountain species is greater than 
species of less exposed habitats and this attribute must be of great importance in selection and survival.

Figure 3 also shows the gain in dry weight per unit of leaf area per unit time. There is very little difference at the four wind speeds indicating that the dry weight gain has been proportional to the leaf area attained. The actual photosynthetic activity of individual cells appears to have been little affected. The effect of the wind therefore appears to be on the processes

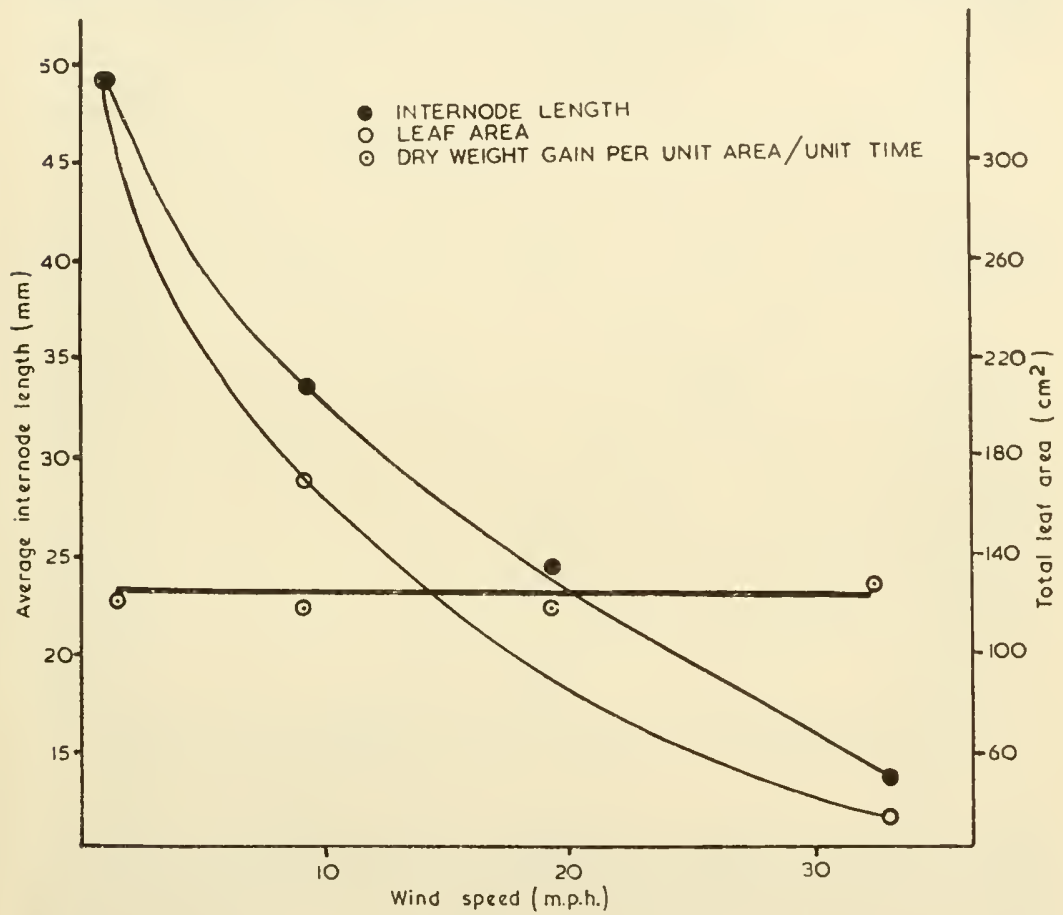

Fig. 3. Average leaf areas and internode length of Helianthus annuus plant grown at I mile/h, 9 mile/h, I9 mile/h and $33 \mathrm{mile} / \mathrm{h}$ together with the dry weight increment per unit area per unit time.

controlling differentiation and the development of leaf area rather than on the photosynthetic apparatus itself.

The increase in xeromorphy of the treated plants would appear to be advantageous in reducing water loss from the treated plants. Fig. 5 shows the results of an experiment designed to test this hypothesis. Plants of Helianthus annuus were grown for thirty days at four different wind speeds, the soil being maintained constantly at field capacity. The soil and roots 
were then sealed off and all plants were exposed to a 33 m.p.h. wind. The plants were weighed before and after the experiment and the leaf areas measured. The loss per unit area per unit time decreases with the increase of wind speed under which the plant developed. But the leaf area also decreases in a similar way so that the net water loss per plant is greatly reduced with the increase of severity of the conditions under which the plant developed. This demonstrates that the anatomical and morphological changes are advantageous in respect of water relations.

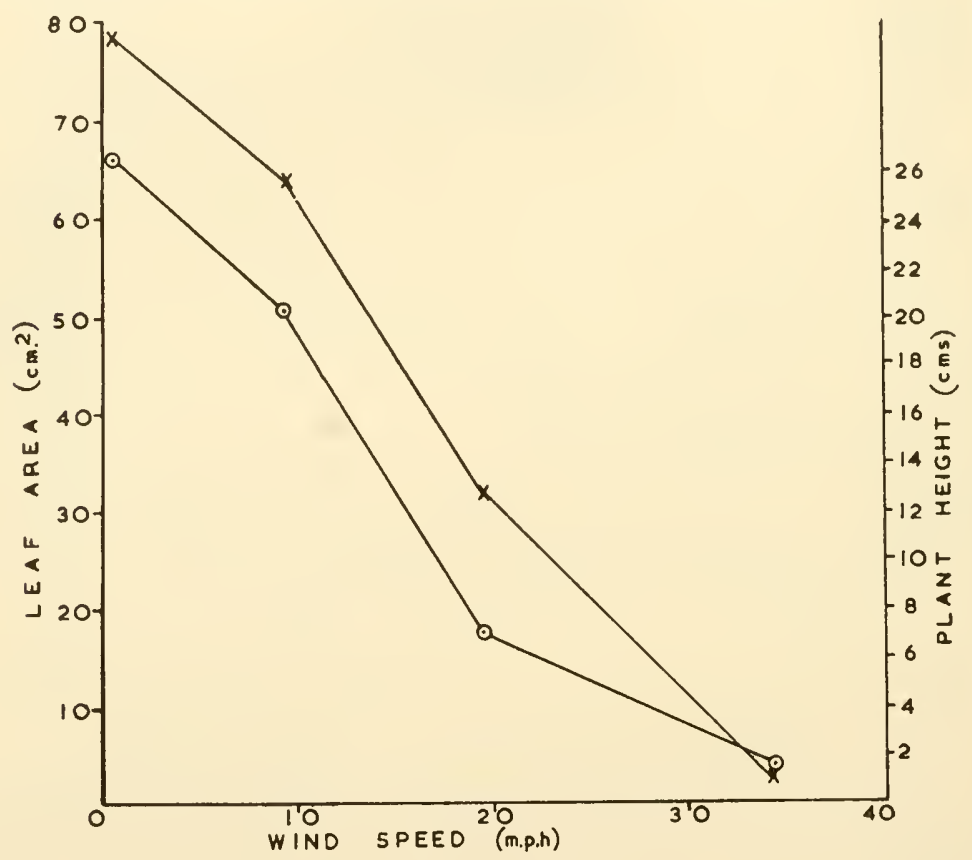

FIG. 4. Plant heights and leaf areas of Scnccio nebrodcusis grown at four wind speeds.

Two other factors in nature are associated with exposure to wind, namely precipitation and the soil moisture regime. Both these factors will affect the water balance of the plant and the question of how far the effect of wind operates through them requires consideration. The measurements already described indicate relationship of leaf water saturation deficits to the anatomical and morphological changes. If this relationship is causal then similar changes should result from alteration in leaf saturation deficits however produced. Water balance is, of course, the resultant between two 
processes, uptake and loss. Leaf saturation deficits can be produced by an adverse soil moisture regime. Experiments were therefore carried out in which plants of Helianthus anmuus were grown at a range of soil moisture conditions from field capacity to one sixteenth field capacity (Whitehead,

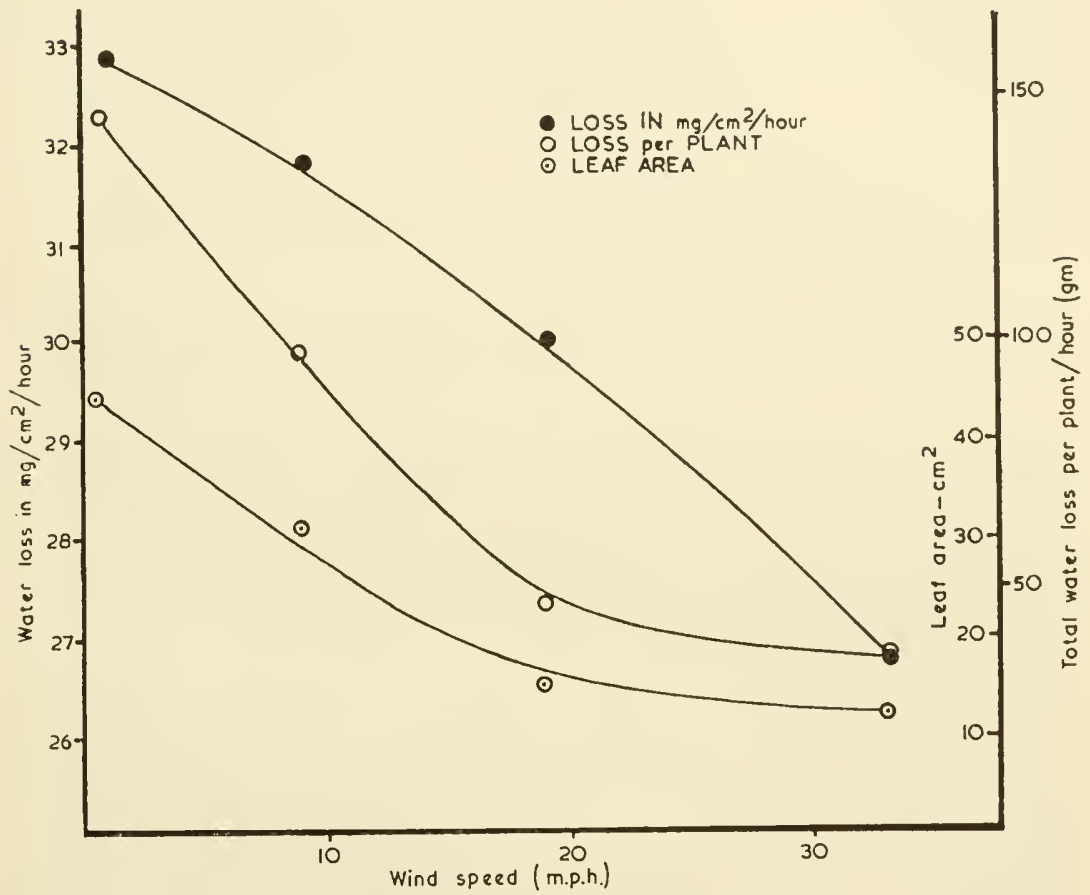

Fig. 5. Water loss of plants of Helianthus annuus in 6 hours. These four sets of plants were grown for 30 days at I mile $/ \mathrm{h}, 9 \mathrm{mile} / \mathrm{h}$, 19 mile $/ \mathrm{h}$ and $33 \mathrm{mile} / \mathrm{h}$ respectively. After bringing their substrate up to field capacity they were exposed to a $33 \mathrm{mile} / \mathrm{h}$ wind for 6 hours. The total loss per plant is shown in relation to leaf area per plant and its loss per unit area in unit time.

1962). The results of these experiments are shown in Fig. 6. It can be seen that anatomical and morphological changes essentially similar to those produced by exposure to wind resulted from these treatments. Again the main effect appeared to have been on the processes of differentiation except that at the most adverse regime some interference with the actual photosynthetic apparatus appears to have occurred.

The other factor associated with wind effect, i.e. precipitation, would be expected to offset the effect of wind in lowering the water balance of the 


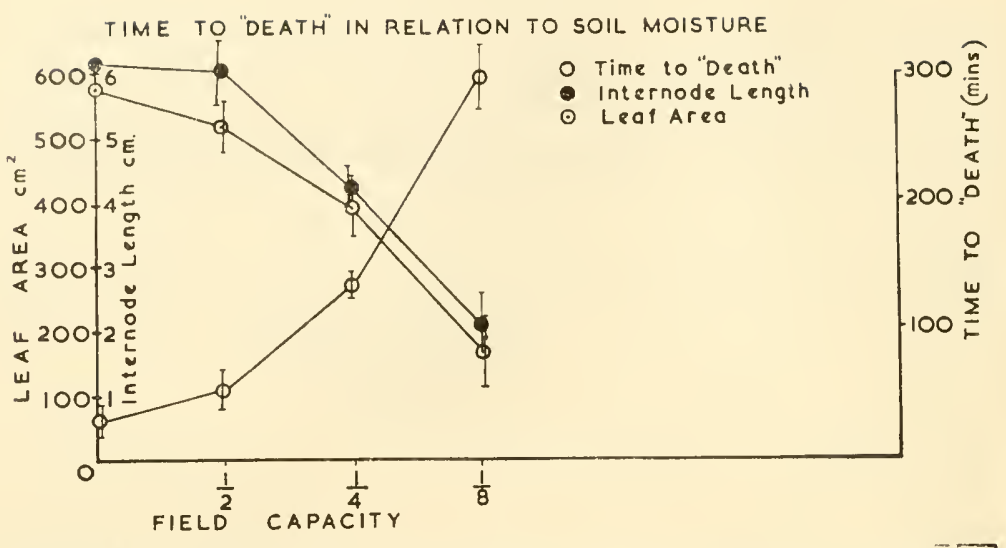

Fig. 6. Leaf areas and internode lengths of plants grown at four soil moisture levels and the time taken for 'death' of these plants to occur in a $40 \mathrm{mile} / \mathrm{h}$ wind.

plant since loss from the leaves would tend to be reduced if they are covered with a film of water. The validity of this hypothesis was demonstrated by growing plants of Helianthus annums in the wind tumnel, one set of which were kept sprayed with distilled water. The results are shown in Fig. 7 (Whitehead, 1962). It can be seen that the extent of modification in the sprayed plants is less than that of the controls.

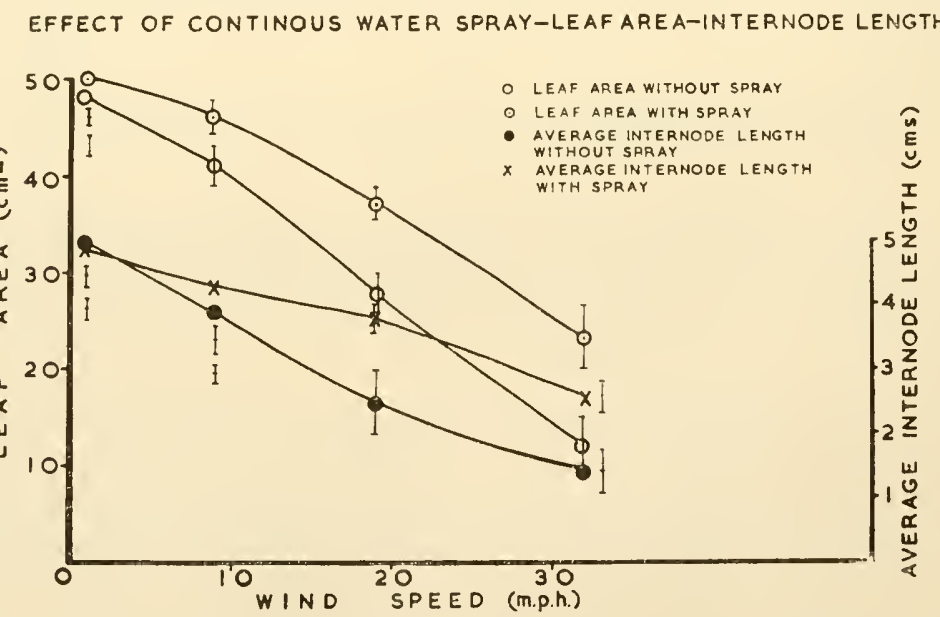

FiG. 7. Leaf areas and average internode lengths of plants grown, with and without a continuous water spray, for 35 days at mid speeds of I, 9,19 and $33 \mathrm{mile} / \mathrm{h}$ winds. 
The foregoing experiment suggests that the anatomical and morphological changes result from interference with processes controlling differentiation. Since growth substances are often involved in such processes the experiments were repeated, treating one set of plants with various growth substances. With $\beta$ indole-acetic acid, over a wide range of concentration, no differences were observed (Whitehead (I963)) between treated and untreated plants. With gibberellic acid however highly significant differences were observed. Both in wind treated and soil moisture regime experiments gibberellic acid tended to reverse the effect of these factors so that less anatomical and morphological change was seen in the treated plants. It is interesting to note that the full range of treatment of wind or soil moisture restriction could not be used because the gibberellic acid treated plants failed to survive above a relatively low limit of severity of conditions. This is a further demonstration that the changes have survival value.

A further test of the survival value of these changes was made in the following experiment (Whitehead (in the Press)). Plants of Helianthus annums grown under a range of wind conditions were exposed to an excessively high wind speed (6o m.p.h.). The time was noted that this wind took to so desiccate the plants that permanent wilting and 'death' occurred. The results are shown in Fig. 8 . It can be seen that the more severe the conditions under which the plants developed the longer they were able to survive. The plants treated with gibberellic acid were relatively soon killed, whilst the untreated plants survived much longer.

These experiments can be summed up as demonstrating that the main effect of wind is to reduce the water balance of the plant even if the roots are in optimum condition for water uptake. The reduction of water balance in the shoot whether due to excessive loss or to limited uptake appears to upset the processes of differentiation and only in extreme cases is the photosynthetic apparatus itself affected. This modification of differentiation is unaffected by $\beta$ indole-acetic acid but is counteracted to a large extent by gibberellic acid. The anatomical and morphological changes which result tend to produce a phenotype better adapted to growth under xerophytic conditions. The plants are dwarfed but the number of internodes is not affected; the leaf area is smaller and the leaves themselves have lower transpiration rates per unit area/unit time; the smaller amounts of assimilates are differently employed in that there is a large increase of root relative to shoot; the internal anatomy of the leaves is also affected being more xeromorphic and with increase in the number of palisade layers and reduction of inter-cellular spaces; the xylem and 


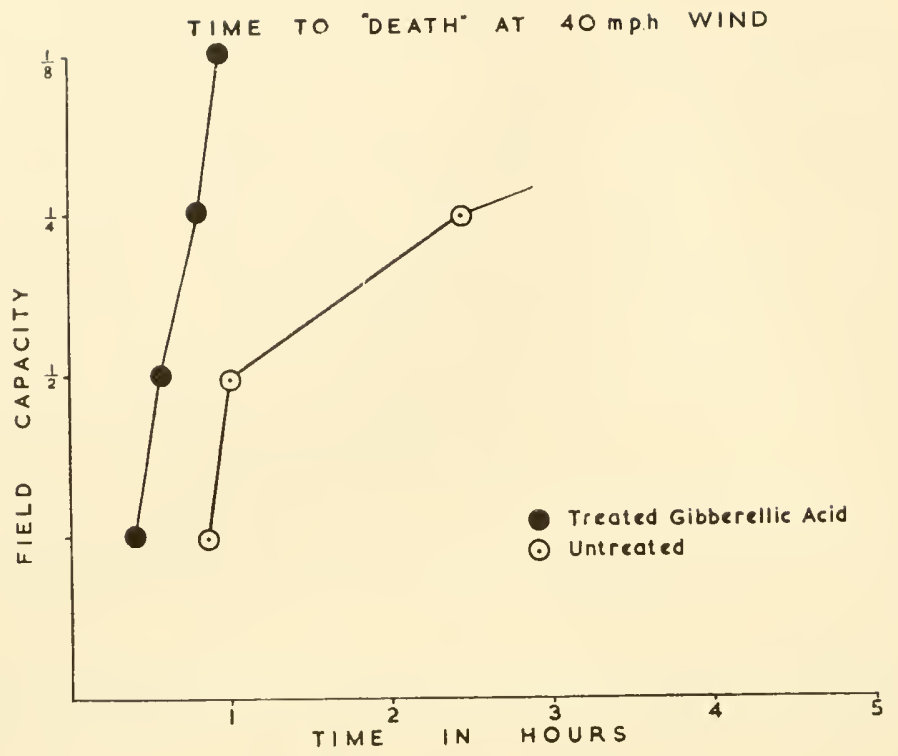

Fig. 8. Time to 'death' of plants grown at four levels of soil moisture. One set treated with giberellic acid and one set untreated.

phloem are more strongly developed together with the amount of fibres in the bundles.

The genetic basis of this phenotypic plasticity, adaptative in nature, must be of importance in species whose habitat involves exposure to wind or drought. It is suggested that there has been positive selection during evolution for genotypes having large potentialities for phenotypic plasticity of this kind. This is not the only solution that evolution has produced, c.f. the many genotypes of Cerastium (Whitehead, 1959), but that it is successful may be assumed from the occurrence of many highly plastic species in montane regions.

My thanks are due to the Royal Society for a grant for the construction of one of the wind tunnels used in this experiment.

\section{REFERENCES}

Whitehead, F. H. (1957) Wind as a factor in plant growth. In Control of the Plant Environment. Ed. J. P. Hudson. London.

WhiteheAD, F. H. (1959) Vegetational changes in response to alterations of surface roughness on M. Maiella, Italy.J. Ecol. 47, 603-606. 
Whitehead, F. H. (I9SI) The ecology of the Altipiano, Monte Maiella, Italy. J. Ecol. 39, 330-355.

WhiteHEAD, F. H. (1962) Experimental Studies of the effect of wind on plant growth and anatomy II. Helianthus annuus. New Phytol. 61, 59-62.

WHITEHEAD, F. H. (1963a) Experimental studies of the effect of wind on plant growth and anatomy. III. New Phytol. 62, 80-85,

WhITEHEAD, F. H. (1963 b) Experimental studies of the effect of wind on plant growth and Anatomy IV. New Phytol. 62, 86-90.

WhiteHEAd, F. H. \& Luti, R. (I962) Experimental studies of the effect of wind on plant growth. I. Zea mays. New Phytol. 6r, 56. 


\title{
GROWTH AND WATER USE OF VEGETABLES IN A GREENHOUSE
}

\author{
J.F. BIERHUIZEN \\ Instituut voor Cultuurtechnick in Waterhuishouding, \\ Wageningen, Netherlands
}

\section{INTRODUCTION}

INSIDE a greenhouse, temperature is higher and radiation lower than under field conditions. Radiation therefore, shifts to a stronger and temperature to a less limiting value for growth. For that reason yield response will be less influenced by a variation of temperature. However, since both climatic factors are intimately correlated with each other, it is difficult to distinguish the effect of each of them on growth. In spring and autumn, vegetables are cultivated under more or less the same light intensities. In the autumn with a same light intensity, however, temperature is higher than in spring, which is due to the phase lag between light and temperature. Yield of vegetables in spring as well as in the autumn have been compared, giving a relation between yield, heat sum and total radiation. Such a relation is valid only if soil conditions are not limiting growth.

De Wit (1958) observed that in a humid climate the ratio dry weight yield/total water use, is more or less independent of soil factors, unless extreme soil conditions are present. Moreover, his results obtained in experiments with containers could be compared with those obtained in the field.

From radiation and temperature data then a prognosis can be made on the length of a growth period necessary for a certain yield in different seasons. At the same time, it will be possible to calculate total water use via the relation between the latter and total yield. From these data, values for water use per day can be given for vegetables grown in various seasons which might be of use for irrigation purposes. An example with lettuce planted at different dates will be given.

\section{MATERIAL AND METHODS}

The experiments were performed in a greenhouse in the period from 1954 to I960. The plants were cultivated in containers with a surface area of $0.2 \mathrm{~m}^{2}$ and a height and diameter of 70 and $50 \mathrm{~cm}$ respectively. Each con- 


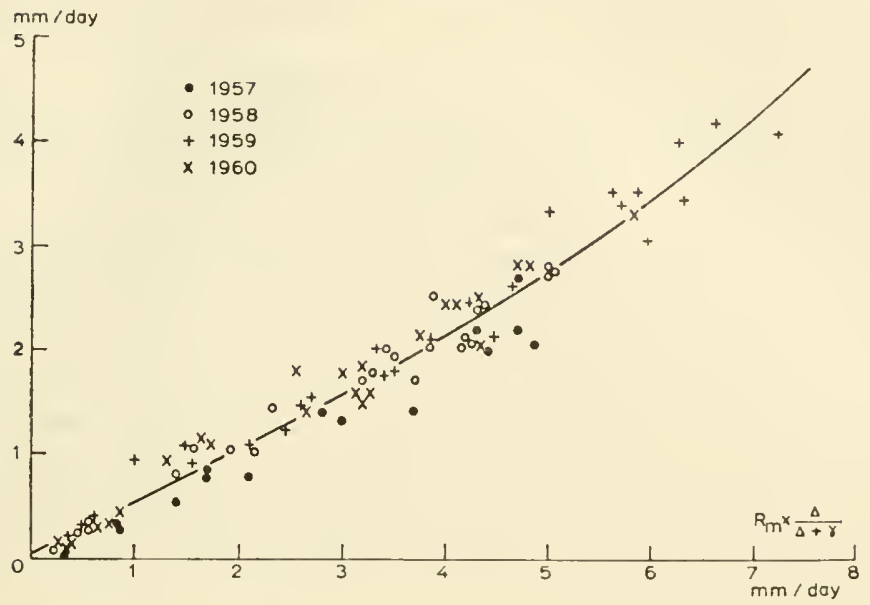

FIG, Ia. Relation between pan-evaporation in $\mathrm{mm}$ per day and measured incoming radiation $\left(R_{m}\right)$ in cal $\mathrm{cm} \sim^{2}$ per day. Average values of Io-day periods.

tainer was filled with a layer of gravel $(5 \mathrm{~cm})$, coarse sand $(5 \mathrm{~cm})$ and 50 to $60 \mathrm{~cm}$ of a light clay-loam or sandy soil.

During the experimental period, various data on temperature, relative humidity and pan-evaporation were measured. The daily radiation was

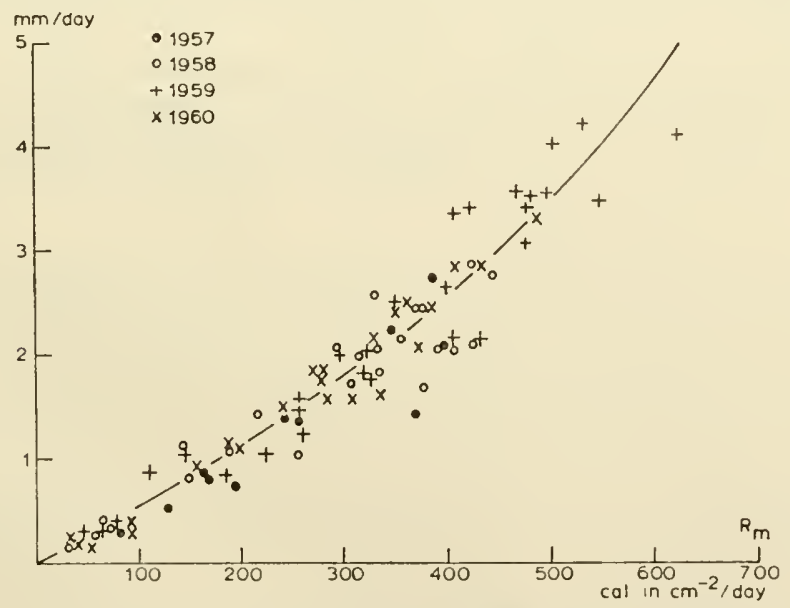

Fig. Ib. As Fig. Ia, but $R_{m}$ in $\mathrm{mm}$ and multiplied by $(\Delta / \Delta+\gamma)$ (where $\Delta$ is the slope of temperature-maximal vapour pressure curve and $\gamma$ is the psychrometer constant). 
obtained from the Physical Laboratory at Wageningen, situated within 2 miles from the greenhouse.

From a physical point of view, it would be expected that pan-evaporation and radiation are related to each other. In Fig. Ia, daily values calculated from periods of Io days are represented. A curvilinear relation was obtained in this way. According to Makkink (1957) a linear relation occurs, plotting pan-evaporation against $R_{m} \cdot(\Delta / \Delta+\gamma)$ (where $R_{m}$ is radiation in $\mathrm{mm}$ per day, $\Delta$ is the slope of temperature-maximal vapour pressure curve, and $\gamma$ the psychrometer constant, for which 0.49 was taken). For further details, the reader is referred to Makkink (1957) and to Rijtema (1958). It is obvious from Fig. Ib that although the curve straightened, it still remains curvilinear. This apparent contradiction might be ascribed to the fact, that extremely high values of pan-evaporaton and those below 0.5 $\mathrm{mm}$ per day, do not occur in Makkink's figures probably because average monthly values were taken.

\section{EFFECTS OF TOTAL RADIATION AND HEAT SUM ON GROWTH}

For every growth period the total radiation and the heat sum were calculated. The latter was computed by substracting the minimum temperature for growth $\left(4^{\circ} \mathrm{C}\right)$ from the average daily temperature and integrating all those values over the whole growth period.

In Fig. 2 the total radiation is plotted against the heat sum. It is obvious, that with longer growth periods both values increase. In the autumn, however, the heat sum is much higher than in spring for the same total radiation. This fact, as mentioned in the introduction, is due to a phase lag of temperature behind radiation.

If temperature were the most important factor for growth, one would expect for both seasons a similar relation with heat sum, and two distinct ones for total radiation, according to Fig. 2, or vice versa if radiation were the most important factor. In Fig. 3 dry-and fresh-weight yield of various vegetables has been plotted against heat sum and total radiation. Autumn yields are underlined. It is evident that, plotting against the heat sum two different lines for weight can be distinguished, the one for spring with a steeper slope than that for autumn. The differences between seasons nearly disappear when using total radiation. This result indicates that radiation is the most important factor for growth in a greenhouse.

Supposing that the effects of radiation and temperature are linear and 


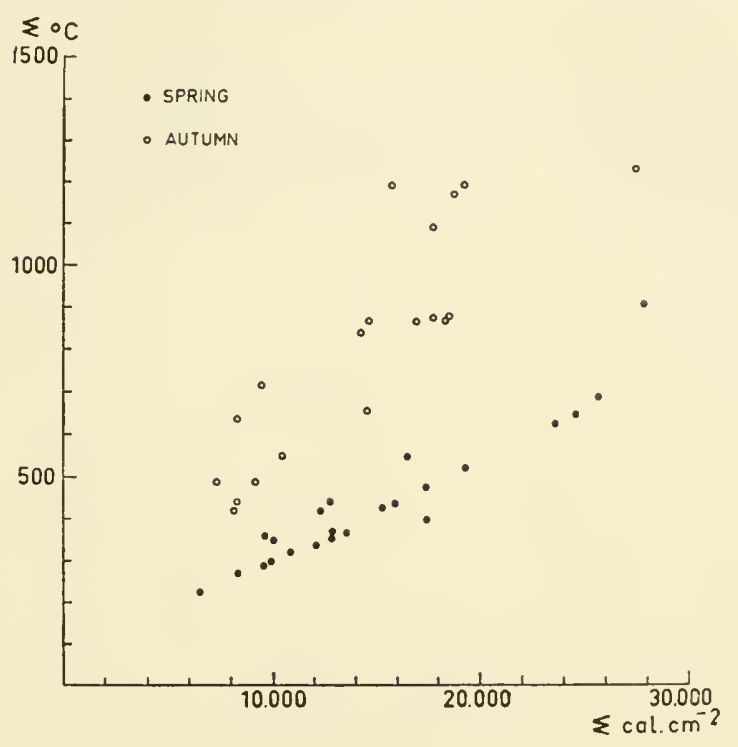

FIG. 2. The relation between radiation- and heat-sum for different growth periods in (spring $\left(^{\circ}\right)$ and autumn (o).

additive to one another, the following relation can be obtained from a statistical analysis:

$$
\begin{aligned}
& \left.z_{f}=\begin{array}{rr}
0.0903 x+0.26 y- & 32 \mathrm{I} \\
\pm 0.0072 \pm 0.13 & \pm \mathrm{IOI}
\end{array}\right\} r_{x y}=0.92
\end{aligned}
$$

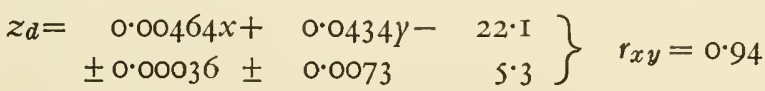

where $z_{f}$ and $z_{d}$ are respectively fresh- and dry-weight yeild and $x$ and $y$, total radiation and heat sum. The effect of heat sum $(0.26$ and 0.0434 with fresh-and dry-weight respectively) seems to be higher than that of total radiation $(0.0903$ and 0.00464 respectively). The real value of the latter, under our circumstances, is I 5 to 30 times that of the former (vide Fig. 3), so the effect of radiation is many times larger than that of the heat sum.

In the application of heat sum and radiation it is supposed that the effect on growth is linear and that minimum and optimum for growth are not surpassed. Moreover, that there is no influence of day-length, whereas the effect of day and night temperature is assumed to be the same. Though these suppositions are not exactly true, a fairly linear relationship was 
obtained, which is at least partly due to the fact, that favourable and unfavourable conditions balance each other over the growth period.

Photosynthesis experiments carried out by Böhnig and Burnside (1956) and by Gaastra (1959), seem to indicate that the ratio photosynthesis/ radiation in the range of light limitation is approximately the same for
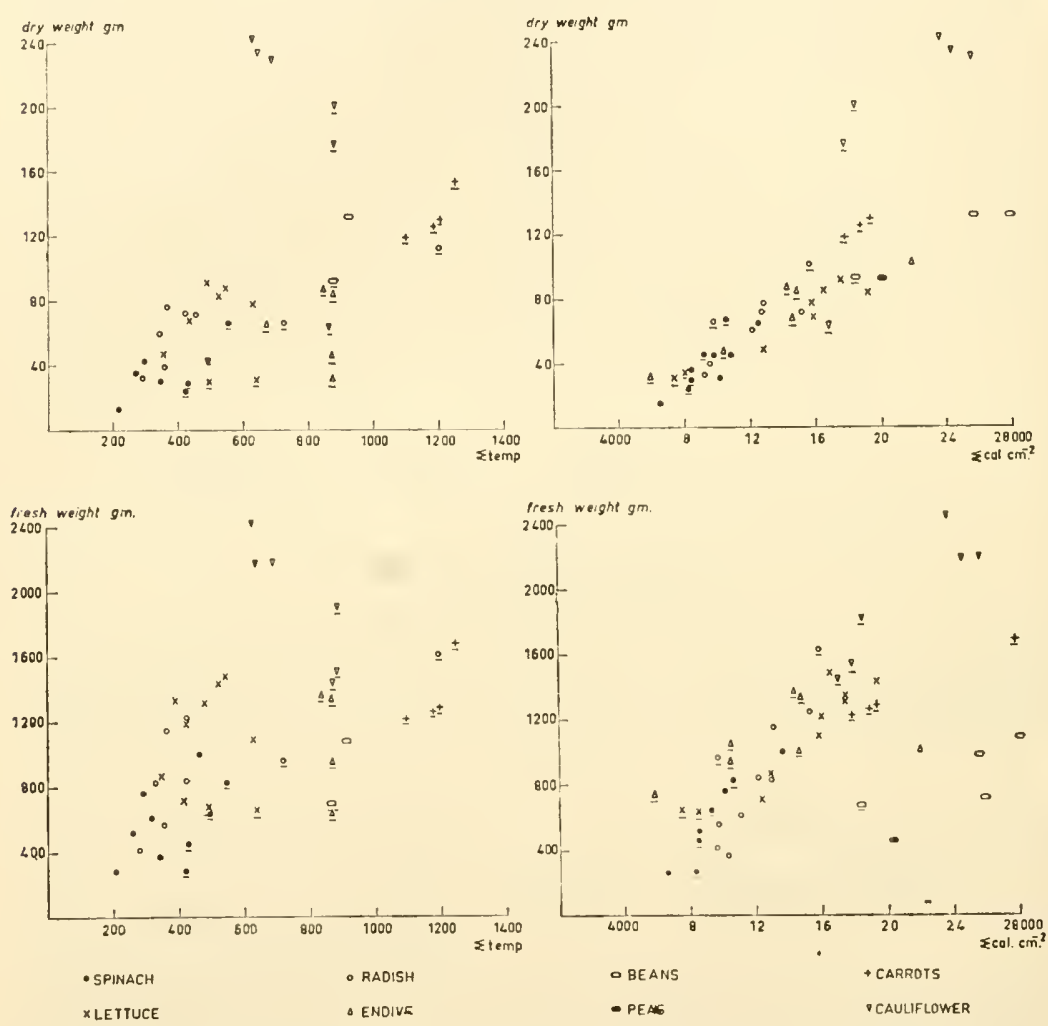

FIG. 3. The effect of heat- and radiation-sum on dry- and fresh-weight yield per container of various vegetables. The data obtained in autumn are underlined.

various crops. This fact would favour the result that the dry-weight yield of various crops are comparable with each other in accordance with the total radiation received (Fig. 3). Calculations made on energy conversion of radiation into dry weight seem to indicate that various crops show nearly the same conversion values (Wassink, 1948). Further experimental details and discussions concerning heat sum, total radiation and its practical application have been given elsewhere (Bierhuizen, 1960). 

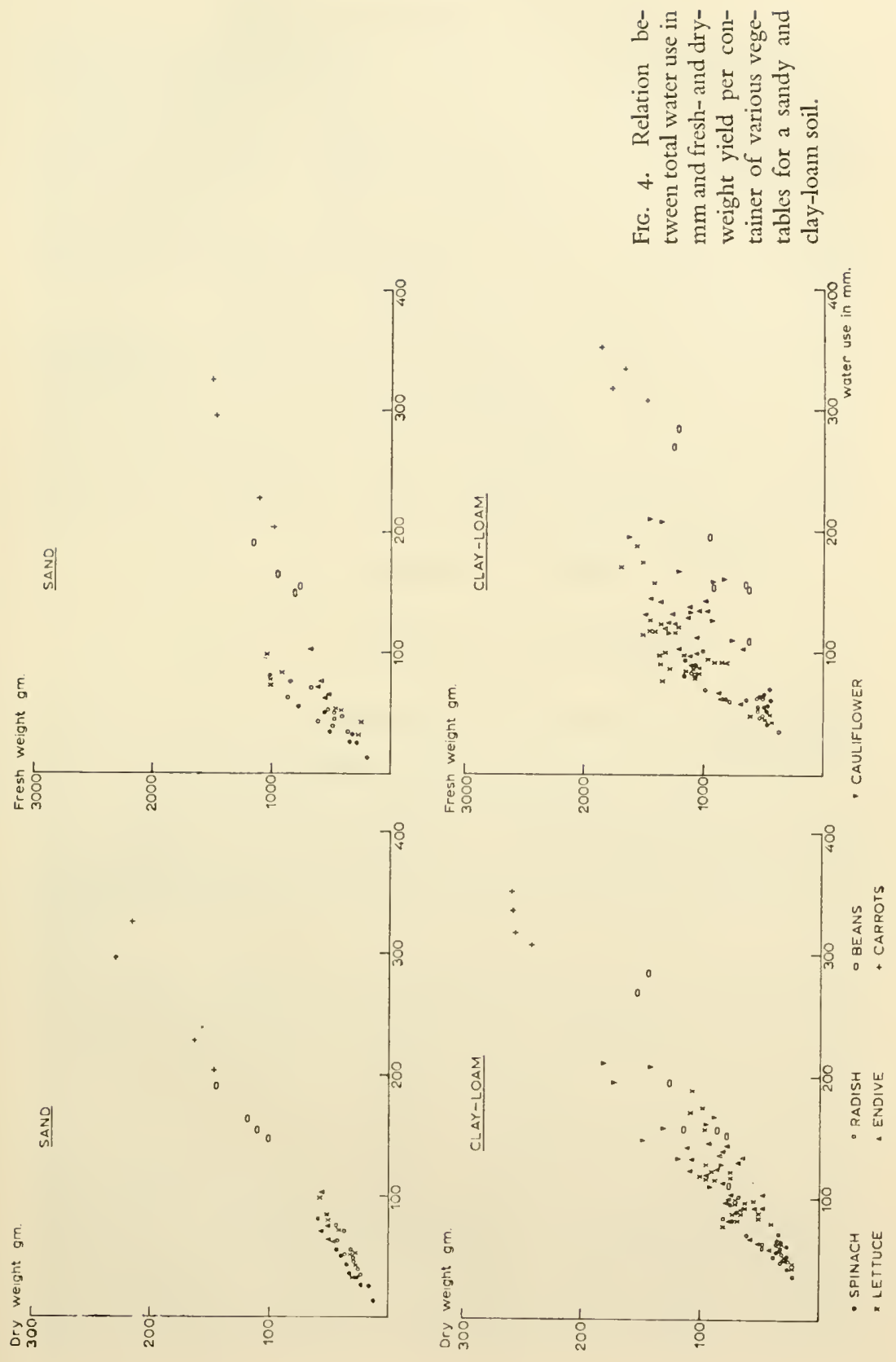


\section{WATER USE AND GROWTH}

The experiments discussed above were carried out under conditions in which the containers were frequently irrigated in such a way that the soil moisture content varied between $\mathrm{pF} 2.0$ and $\mathrm{pF} 2.4$. In another series of experiments a constant water-level was applied by means of sub-irrigation with a Mariotte flask. Four ground-water tables of 25, 35, 45 and $55 \mathrm{~cm}$ respectively, were used for each treatment with four replicates. From the Mariotte flask the daily water use could easily be measured. The experiments were performed in a clay-loam and in a sandy soil.

In Fig. 4, dry- and fresh-weight yield are plotted against total water use for both soil types. For dry weight a linear relation occurs, according the formula $y=m x$, (where $y$ is dry-weight yield and $x$ total water use). The tangent $m$ is approximately the same for the various vegetables treated in these experiments, and for both soil types. It is obvious that water use versus fresh weight shows a larger variation. This might be explained by the fact, that for $y=m x$, one could write:

$$
\text { fresh weight times dry weight percent }=100 m x
$$

or

$$
\frac{\text { fresh weight }}{x} \text { times dry weight percent }=\text { Ioom }
$$

which relation is a hyperbolic, as is shown in Fig. 5. It is clear that the ratio ( $\left.\frac{\text { fresh weight }}{x}\right)$ is low for vegetables with a high dry-wcight percentage such as beans and carrots, and high for a low dry-weight percentage such as lettuce and spinach have. Moreover, a small variation in dry-weight percentage at a low value, results in a large variation in the ratio $\left(\frac{\text { fresh weight }}{x}\right)$ The fresh-weight yield varies considerably without a large change in total water use $(x)$. In an experiment with lettuce, for instance, and harvesting under wet soil conditions, the fresh-weight yield and dry-weight percentage was $656 \mathrm{gm}$ and $4.5 \%$ respectively, under dry conditions it was $366 \mathrm{gm}$ and $5.5 \%$. In a similar dry treatment, but irrigated the day prior to harvest, it was $546 \mathrm{gm}$ and $4.5 \%$ (Bierhuizen and De Vos, I958). It was evident that with the large change in fresh-weight and dry-weight percentage, total dry matter and water use did not change to a large cxtent.

A statistical analysis revealed that the various ground-water tables gave no significant difference in dry- and fresh-weight yield. Total water use increased, however, almost linearly with a ground-water table at depths of 55 to 45,35 and to $25 \mathrm{~cm}$, respectively. This might be due to an increase 


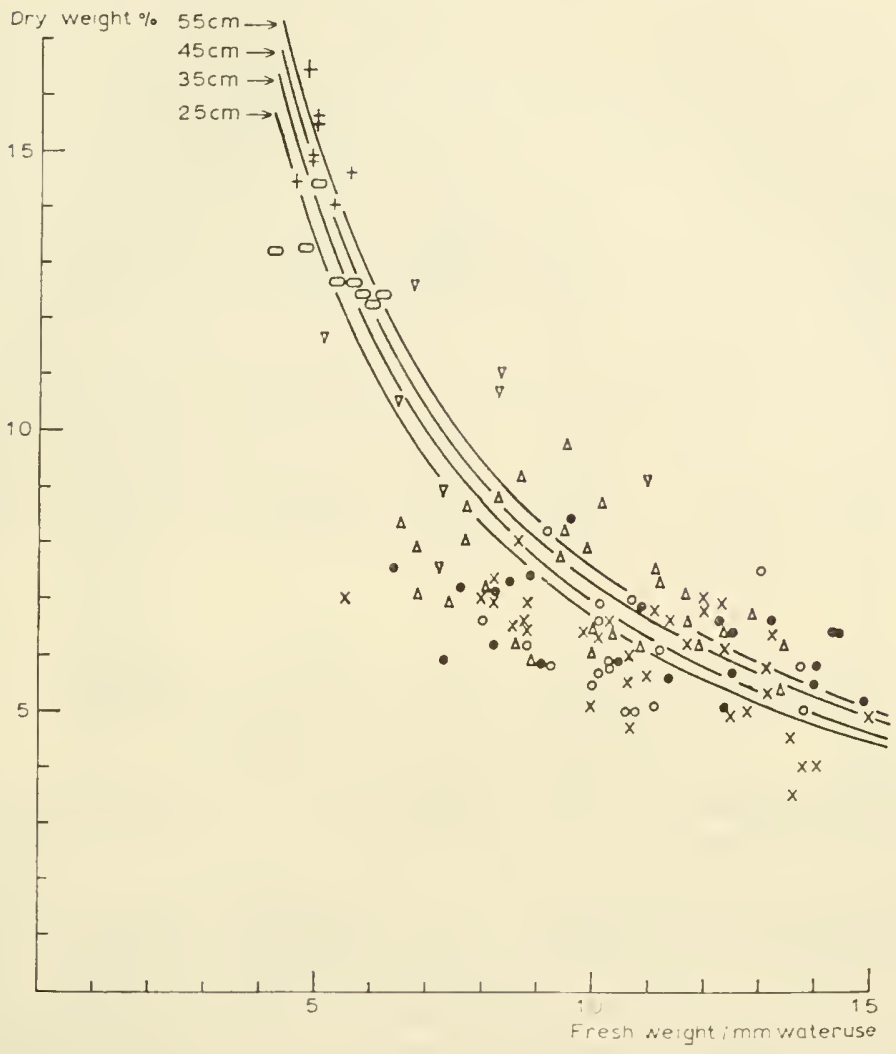

FIG. 5. Relation between dry-weight percentage and the ratio fresh-weight/total water use. The curves are valid for the indicated depths of the ground-water table. For key see Fig. 3 .

in direct evaporation from the soil. From the relation $y=m x$ between dry-weight yield $(y)$ and total water use $(x)$, the tangent is

$$
\begin{aligned}
& m=0.00306 z+0.594 \\
& \pm 0.00099 \pm 0.039
\end{aligned}
$$

where $z$ is the depth of the ground-water level.

Some remarks might be made when comparing yield and water use in the greenhouse with that under field conditions. From a physical point of view, evaporation has been studied in many ways on a basis of energy balance, in which net-radiation equals sensible and latent heat. Because 
of the rather low energy consumption in growth compared with the other terms in the heat balance, the energy consumption is not included in such calculations. In photosynthesis experiments with algae and leaves of higher plants, conversion yields between 10 and $20 \%$ are obtained between $\mathrm{CO}_{2-}$ consumption and absorbed visible radiation. In the field, energy conversion of growth is only I to $2 \%$ (Wassink, I948). In our greenhouse experiments a value of $3.3 \%$ was calculated (Bierhuizen, 1960). The I.5 times larger value in the greenhouse, still does not effect the individual terms of the energy balance to a large extent. It is possible, therefore, that total water use per $\mathrm{kg}$ dry matter produced, is I. 5 times less in the greenhouse. In our case, for $y=0.7 \mathrm{I} x, \mathrm{IOO} \mathrm{mm}$ water use produces $7 \mathrm{I} \mathrm{gm}$ per $0.2 \mathrm{~m}^{2}$ or $36 \mathrm{~kg}$ dry matter per $100 \mathrm{~m}^{2}$. The same amount of grass yicld would necessitate I $70 \mathrm{~mm}$ of water (Visser, I959), which is approximately I.5 times more than in the greenhouse.

\section{GROWTH AND WATER USE OF LETTUCE}

\section{IN DIFFERENT SEASONS}

From the results discussed in the preceding sections, the length of growing period and the total water use necessary for a given yicld in different seasons can be predicted. In Table I calculations are given for lettuce planted at different dates (column I). It was assumed that harvest took place with a head-weight of I $50 \mathrm{gm}$. In our case 4 heads per container yielded, therefore, $600 \mathrm{gm}$. From daily radiation (De Vries, 1955) and temperature data in the greenhouse (ranging between $5^{\circ}$ and $23^{\circ} \mathrm{C}$ for winter and summer) the date of harvest (column 2) was calculated, using formula $\mathrm{I}$. Radiation data alone can be used without a large error, in order to facilitate the calculations. In that case the total radiation is approximately $10,000 \mathrm{cal}$ $\mathrm{cm}^{-2}$ (Fig. 3). The harvest dates, calculated in this way, are confirmed by those in horticultural practice. Total water use (column 4) could be read from Fig. 4. The average daily radiation for each growth period could be calculated and is approximately 10,000 $\mathrm{cal} \mathrm{cm}^{-2}$ divided by the number of days of growth. From this value, pan-evaporation in $\mathrm{mm}$ per day (column 6) could be read from Fig. I. The ratio water-use pan-evaporation approximates closely unity and tends to decrease in the summer months and to rise in winter. The variation in this ratio agrees with that obtained in waterbalance studies in the freld (Bloemen, 1960). The steeper decrease in summer in Bloemen's results, might be due to the fact that deeper groundwater levels existed. 


\section{TABLE I}

Growth and Water use of Lettuce to a head-weight of $150 \mathrm{gm}$ in different seasons

(I)

Date of Date of planting harvest
(3)

Growth Total period in days
(4) water use in $\mathrm{mm}$
(5)

Water

use in $\mathrm{mm}$ per day
(6)

(7)

\begin{tabular}{|c|c|c|c|c|c|c|}
\hline & & in days & $\begin{array}{l}\text { use in } \\
\mathrm{mm}\end{array}$ & $\begin{array}{l}\text { in mm } \\
\text { per day }\end{array}$ & $\begin{array}{l}\text { tion } \\
\text { in } \mathrm{mm} \\
\text { per day }\end{array}$ & $\begin{array}{l}\text { pan- } \\
\text { evapora- } \\
\text { tion }\end{array}$ \\
\hline Jan. I & March 29 & 89 & s5 & 0.56 & 0.50 & $I \cdot 12$ \\
\hline Feb. I & April 4 & 64 & ss & 0.78 & 0.75 & $\mathrm{I} \cdot \mathrm{O} 4$ \\
\hline March I & April is & 46 & 55 & I $\cdot 09$ & $I \cdot 20$ & 0.91 \\
\hline April I & May 3 & 33 & 55 & $I \cdot 52$ & $I \cdot 75$ & $0 . \$ 7$ \\
\hline May I & May 26 & 26 & 55 & $1 \cdot 92$ & $2 \cdot 35$ & 0.82 \\
\hline June I & June 23 & 23 & 55 & $2 \cdot 17$ & $2 \cdot 70$ & $0.8 \mathrm{I}$ \\
\hline July I & July 24 & 24 & 55 & $2 \cdot 08$ & $2 \cdot 35$ & 0.88 \\
\hline Aug. I & Aug. 29 & 29 & 55 & $I \cdot 73$ & $1 \cdot 80$ & 0.96 \\
\hline Sept. I & Oct. I 3 & 43 & 55 & $I \cdot I 6$ & $I \cdot 20$ & 0.97 \\
\hline Oct. I & Feb. 6 & $9 \delta$ & 55 & $0.5 I$ & 0.40 & $I \cdot 27$ \\
\hline Nov. I & March I 5 & I 36 & 55 & 0.37 & 0.35 & $I \cdot 06$ \\
\hline Dec. I & March 24 & IIs & 55 & 0.44 & 0.40 & I'IO \\
\hline $\begin{array}{l}\text { Calcu- } \\
\text { lated } \\
\text { from }\end{array}$ & formula I & $\begin{array}{l}\text { columns } \\
2 \text { and I }\end{array}$ & fig. 4 & $\begin{array}{c}\text { columns } \\
3 \text { and } 4\end{array}$ & fig. I & $\begin{array}{c}\text { columns } \\
5 \text { and } 6\end{array}$ \\
\hline
\end{tabular}

Although for practical irrigation purposes other water losses than those calculated in Table I, column 5, may be of greater importance, the calculations made in Table I make it possible to give some indications of the irrigation frequency to be used for a particular crop in different seasons. Assuming a root depth of $50 \mathrm{~cm}$ and an available quantity of water between field capacity $\left(\mathrm{pF}_{2} \cdot 0\right)$ and wilting point $\left(\mathrm{pF}_{4} \cdot 2\right)$ of $12 \%$ by volume, the total amount of available water is $5 \times 12=60 \mathrm{~mm}$. If one fourth or $15 \mathrm{~mm}$ can be used without decreasing fresh weight and quality of vegetables, the irrigation frequency in different months can be given, using values of pan or water use per day (columns 6 and 5 respectively).

\section{SUMMARY AND CONCLUSIONS}

Some relations between yield, water use, temperature and radiation in a greenhouse were given and discussed in this paper. It appears that radiation 
is far more important for growth in greenhouses than temperature. There is a linear relation between total water use $(x)$ and dry weight yield $(y)$ of the form $y=m x$, the constant $m$ being dependent upon the depth of the water table. Using radiation and temperature data, a prediction of a certain yield or length of growth period can be made. It is possible, using total radiation and heat sum, to compare yield in various greenhouses in order to study the effect of glass-cover, soil type and other factors on growth.

The above mentioned restilts were obtained under optimal soil moisture conditions. At present a study is in progress on the relation between yield and water use, total radiation and heat sum, under various sub-optimal soil moisture conditions.

\section{REFERENCES}

Bierhuizen, J.F. (1960) De relatie tussen temperatuur en licht en de opbrengst van verschillende tuinbouwgewassen in kassen. (The relation between temperature, light and yield of various vegetables in a greenhouse. Dutch with an English summary.) Med. Dir. Tuinbonw, 23 (I2), 822-83I

Bierhuizen, J.F. \& Vos, N.M. DE (1958) The effect of soil moisture on the growth and yield of vegetable crops. Report Conference on Suppl. Irrigation, Comnission VI, Int. Soc. Soil Sci., Copenhagen, 83-92. Tecm. Bull. II, 1959. Inst. for Land and Water Management Research, Wageningen.

Bloemen, G. W. (1960) Het onderzoek naar de waterbalans van landbouwgronden (Investigations on the water balance of agricultural soils, Dutch.) Med. Cultuurtechn. Vereniging, $4(\mathrm{I}), 3-25$.

Böhnig, R.H. \& Burnside, C.A. (1956) The effect of light intensity on apparent photosynthesis in leaves of sun- and shade-plants. Am.J. Bot. 43, 557-561.

DE Vries, P.A. (1955) Solar radiation at Wageningen. Med. Landbouwhogescliool, Wageningen, $55(6), 227-304$.

DE W1T, C.T. (1958) Transpiration and crop yields. Versl. Landbouwk. Onderz. 64 (6), I-88. Med. 59, Instituut voor Biologisch en Scheikundig Onderzoek van Landbouwgewassen.

GaAstra, P. (1959) Photosynthesis of crop plants as influenced by light, carbon dioxide, temperature and stomatal diffusion resistance. Med. Landbouwhogeschool, Wageningen, 59 ( 13$), \mathrm{I}-68$.

Makкink, G.F. (1957) Ekzameno de la formulo de Penman. Neth. J. Agr. Sci. 5, 290-305.

Rujtema, P.E. (1958) Calculation methods of potential evaporation. Report Conference on Suppl. Irrigation, Conmission VI, Int. Soc. Soil Sci., Copenhagen, 15-24. Techn. Bull. 7, 1959. Inst. for Land and Water Management Research, Wageningen.

Visser, W.C. (1959) Crop growth and availability of moisture. Teclm. Bull. 6. Inst. for Land and Water Management Research, Wageningen.

Wassink, E.C. (1948) De lichtfaktor in de fotosynthese en zijn relatie tot andere milieufaktoren. (The factor light in photosynthesis and its relation to other growth factors, in Dutch.) Med. Dir. Tuinbouw', II, 503-5I4. 


\title{
PHOTOSYNTHESIS AND GROWTH OF A FIVE- YEAR-OLD STAND OF POPLAR TREES IN RELATION TO WATER ECONOMY OF THE SITE
}

\author{
H.POLSTER \\ Institute of Forest Science, Tharandt, E. Germany
}

IT is generally known from studies of forest yield that the water supply of trees in the stand profoundly affects growth and yield. The growth increment in times of drought is more or less impaired according to soil conditions and site climate. There are many references to this subject in forest literature. Among others is Weck (1948) who found out that the height increment of spruces (Picea abies) and pines (Pinus sylvestris) may decrease to a third of the normal value (average of ten years or longer), as a consequence of dry periods. Besides a very close correlation was to be seen between growth capacity and rainfall over longer periods. While these correlations are quite clear there is very little known about the correlation of water supply and photosynthetic efficiency of trees in forest stands. The first ecological investigations referring to this originate from Pisek and Tranquillini (195I, 1954), who determined the carbon dioxide exchange (assimilation, respiration) as well as the transpiration of $20-\mathrm{m}$ high spruces and beeches in forest stands. They found that the assimilation in the crowns of their rather free-standing trees depended on the climate of the standespecially on light, temperature and air humidity-as well as on the water situation. The better the internal water balance of the tree, the less restricted was assimilation intensity in periods of strong insolation or low air humidity. Generally the trees' assimilation and transpiration reacted very sensitively to disturbances of their water economy, although the top crowns maintained their metabolic activity longer than the rest of the tree.

Together with my assistant, Dr. Neuwirth, I investigated for the first time in 1957 the photosynthesis and growth of trees in relation to water economy in a dense though rather small and relatively young tree stand. For that purpose we used a planting of five-year-old black poplars, about $7 \mathrm{~m}$ high. In Fig. I can be seen a schematic diagram of the stand. The stand area was 0.0075 ha and the trees were planted on a grid system with 6 trees in the N.S. lines and I 6 in the E.W. lines. For assimilation measurements we used the infrared absorption recorder 'URAS'. As in previous studies the single leaves to be investigated were enclosed in containers made of a very 
thin foil ('Klarzell'). The soil moisture was determined by means of the thermal conductivity method of De Vries (1952) with special measuring aggregates, constructed by Neuwirth. The water available for plants was calculated from the observations in per cent of the available water maximum. Soil suction forces were measured by means of plaster blocks.

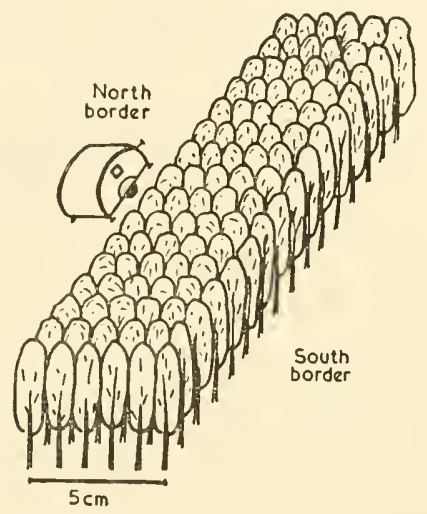

FIG. I. Schematic diagram of the test stand.

During the vegetation period and especially in the course of the drought period in the end of June and beginning of July, the measurements of soil moisture and suction forces showed great differences between the northern and southern border of the stand, and this appeared to affect the photosynthetic efficiency of the trees. As can be seen in Fig. 2, the southern border was always much drier than the northern one, though the borders of the stand were only $5 \mathrm{~m}$ apart. During the drought period the northern border dried temporarily to $30 \mathrm{~cm}$ depth, whereas the southern border dried to a depth of $60 \mathrm{~cm}$ and more. Before and after the drought period more than $50 \%$ of the north border's moisture content was available for plants, whereas already by May the south border was nearly dry in its upper layers. The heavy rainfall in the second half of July succeeded only in soaking the southern border soil for about a fortnight, while the soil of the northern border remained effectively water-saturated until the end of September.

By means of six figures I want to show you now the influence of these differences in soil moisture, surprisingly high for such a small stand, on the photosynthesis of the trees.

Under normal conditions of soil moisture, it was to be expected for a stand of light-demanding poplars, that the trees at the south border which 

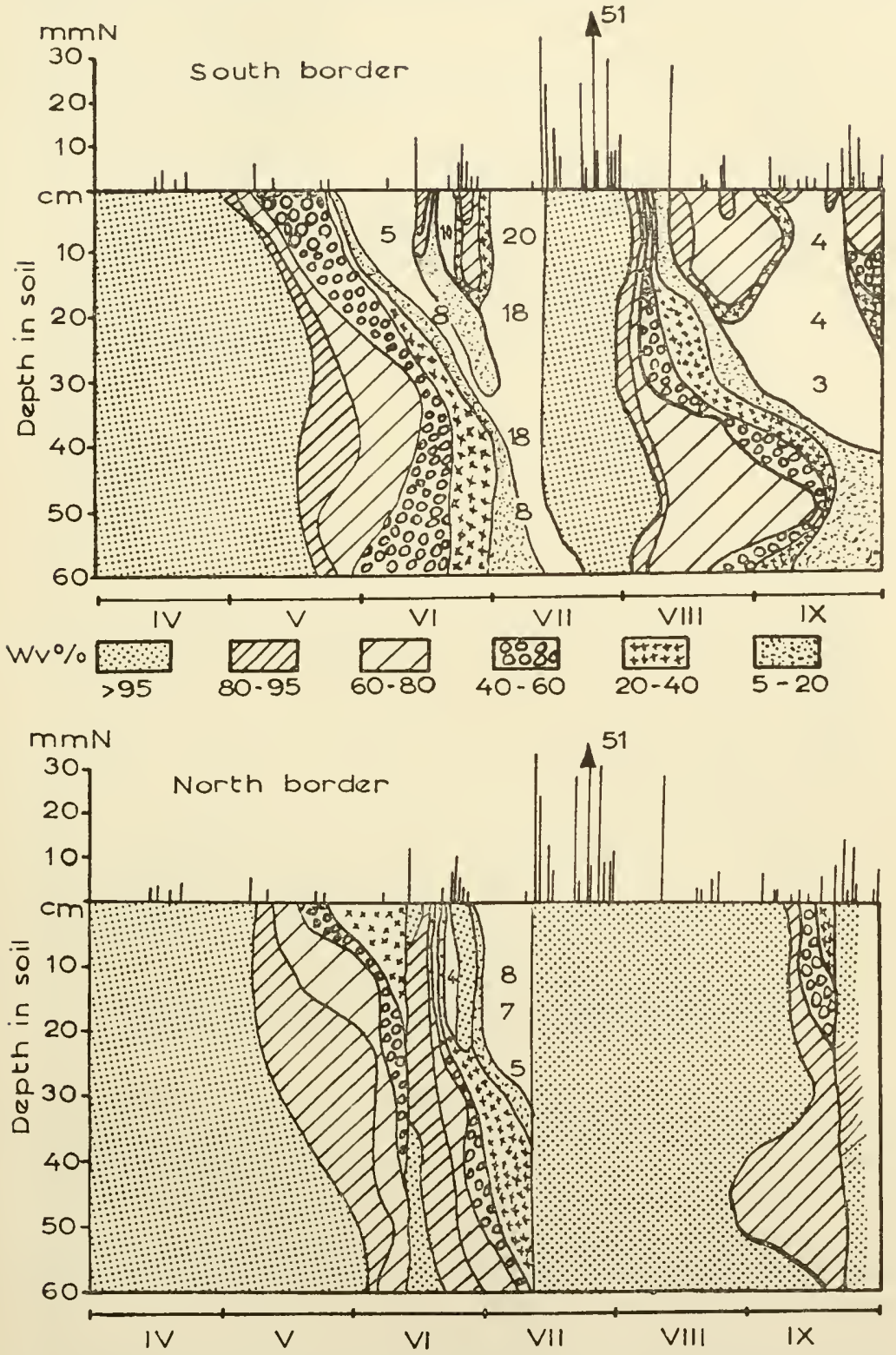

Frg. 2. Soil moisture, percentage available maximum, and soil suction, atm., at the borders of the stand. Values of soil suction are given as isolated numbers on the diagram. 


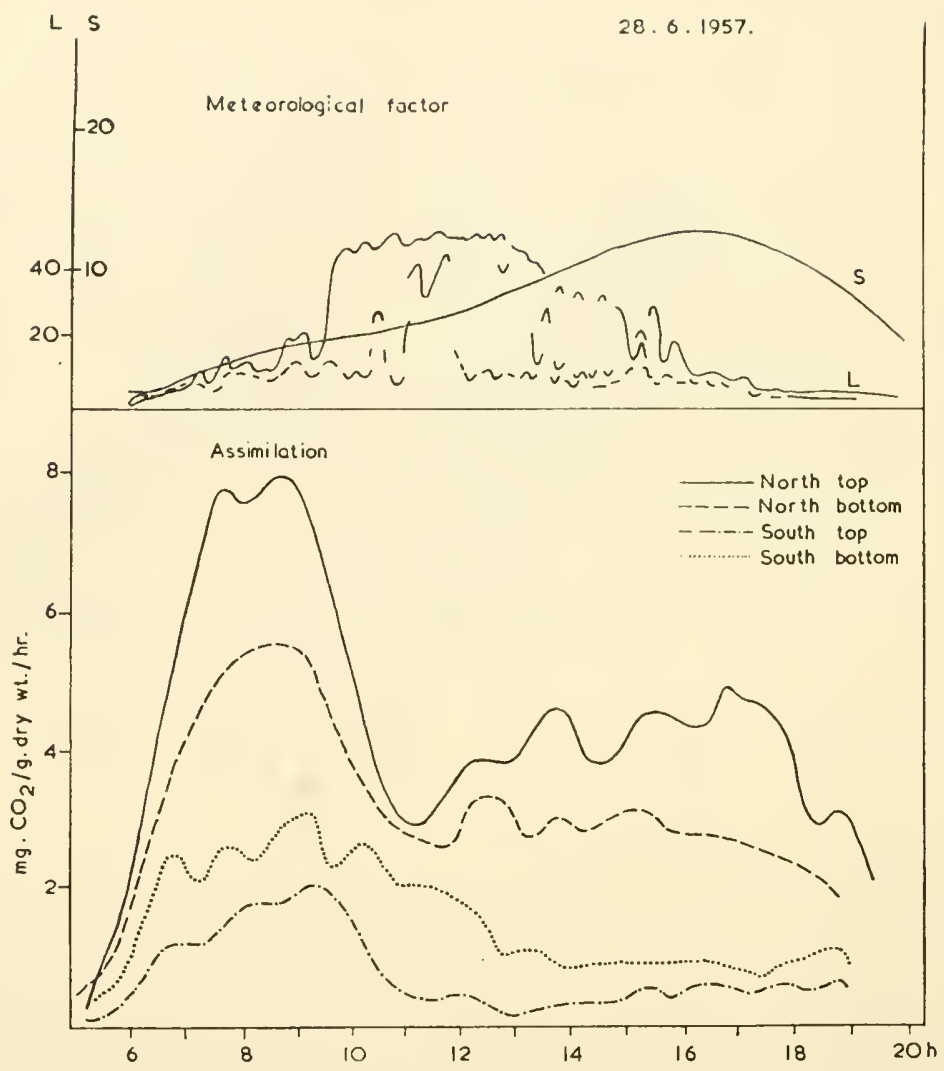

FIG. 3. Assimilation in different crown regions at the borders of the stand. $\mathrm{L}=$ light intensity in I000 lux; $\mathrm{S}=$ water vapour pressure, $\mathrm{mm}$ mercury.

were more exposed to light than the others, would show a stronger assimilation than those of the north border. As a matter of fact, the following figure proves the contrary for the dry period in summer (Fig. 3). The tree of the northern border, better supplied with water, shows a much more active assimilation in its top and also in its crown base than that of the southern border. Moreover the difference between the crown tops which are almost equally illuminated, is greater than that of the crown bases, which means that compared to the water factor the light factor plays only a subordinate role in the intensity of photosynthesis of the poplars during dry periods. 
10. 7.57.

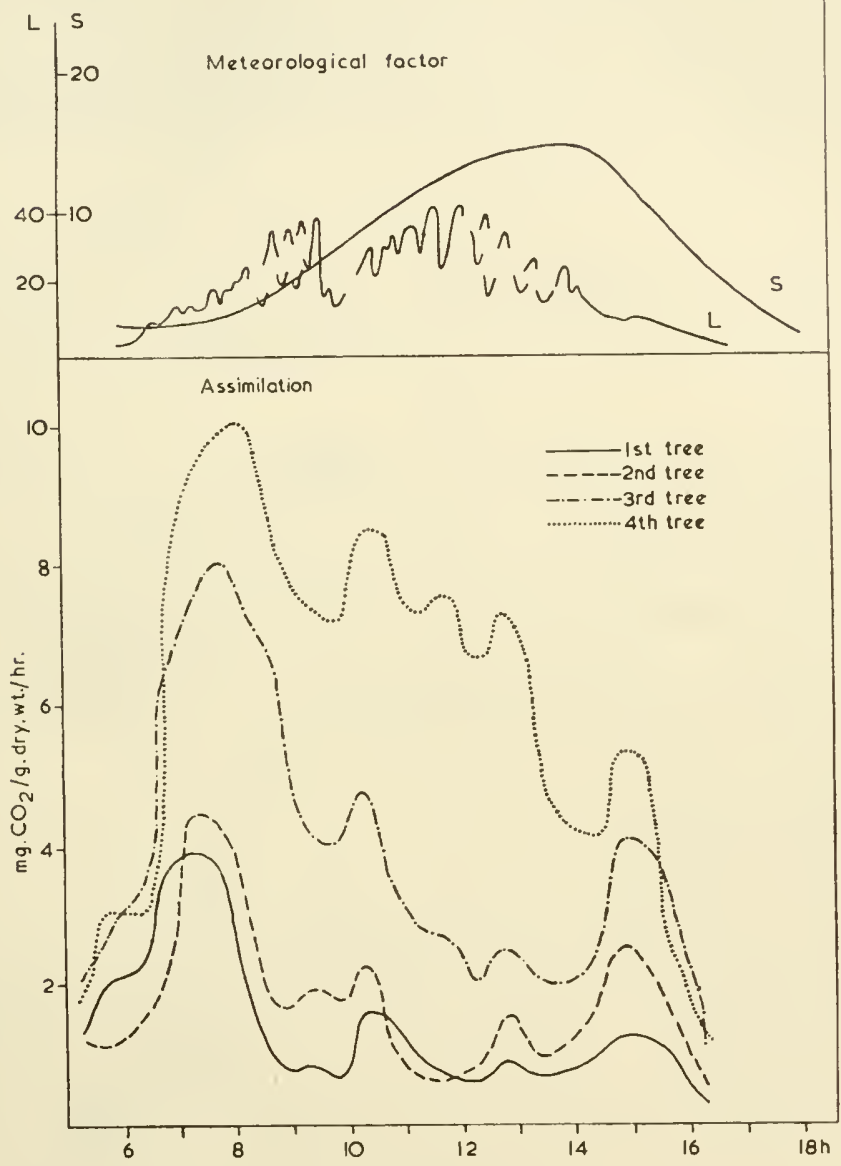

Fig. 4. Assimilation in crown tops across the stand. $\mathrm{L}$ and $\mathrm{S}$ as in Fig. 3.

If one considers not only the border trees but also the trees standing between the northern and southern border (Fig. 4), one will find a correlative ascent of the assimilation intensity corresponding to the soil moisture from the southern border across the middle of the stand to the northern border. As the curves show, tree No. 2, standing very close to the southern border, is still completely under the influence of the southern border's dryness; tree No. 3 in the middle of the stand, reaches almost the assimilation efficiency of the northern border tree in the morning, but at midday it 
still suffers a similar assimilation depression to its southern neighbours. The ratio of photosynthesis intensity of the south border tree compared to that of the north border tree was on that day approximately $1: 4$. As the measurements were made again with leaves of equally illuminated crown

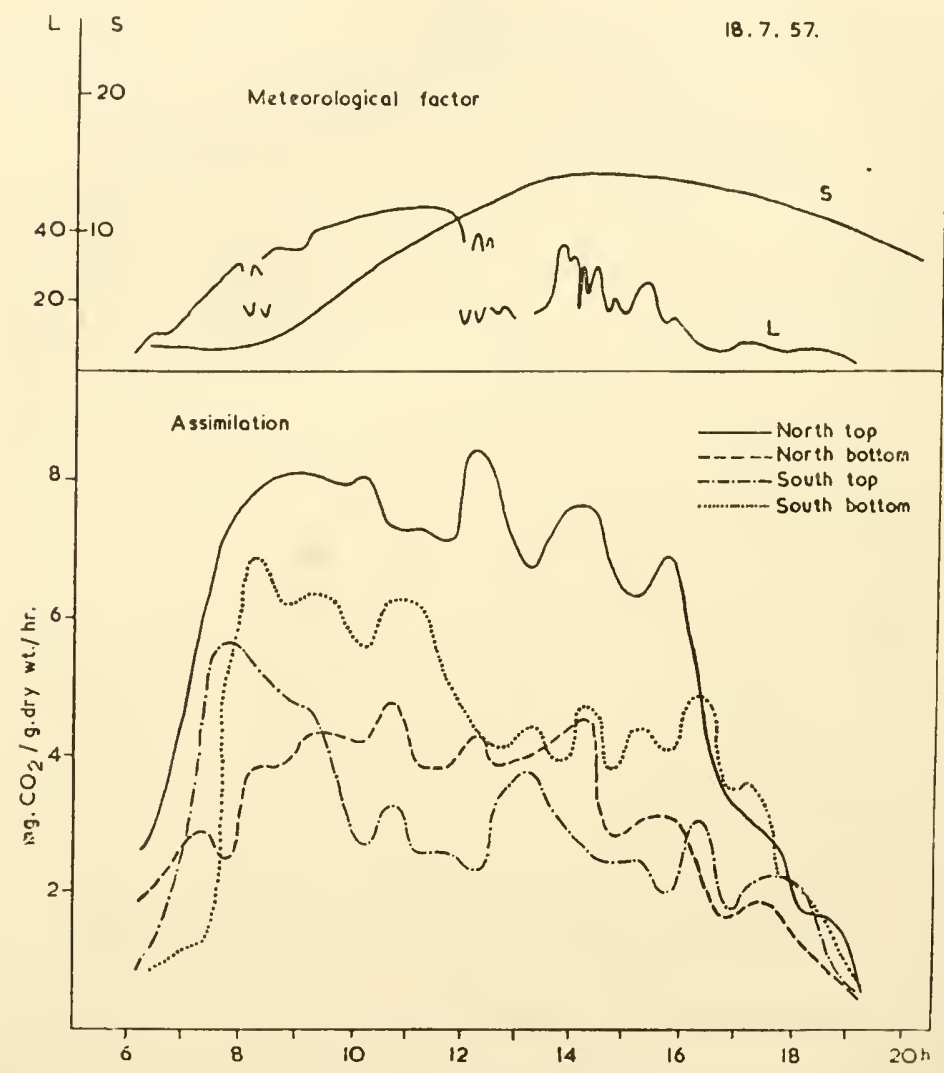

FIG. 5. Assimilation in different crown regions at the borders of the stand with sufficient water supply. $L$ and $S$ as in Fig. 3.

tops, it is evident that the water content of the soil is the limiting factor of assimilation. The assimilation activity of the crowns increases with the distance of the trees from the drier southern border and in parallel to the increasing soil moisture of the site.

If the water content of the soil has such an important influence-on the 
assimilation activity of the trees, that it can become the decisive factor of production in dry periods, it must also be shown how the limiting effect was again suspended, when the soil was naturally or artificially resaturated. Eight days after the drought period the soil of the southern border was water-saturated to a depth of at least $60 \mathrm{~cm}$ but the total assimilation activity was not yet restored (Fig. 5). It can be seen that the tops of the northern border still show the highest assimilation intensity. But they are closely followed by the southern border base, then comes the northern border base and finally the tops of the southern border. It is quite evident that when the investigations were carried out the leaves of the tree on the southern border had reached full turgidity only in the base foliage but not yet in the top foliage.

In the course of the drought period, we interfered with the soil drying process of some trees of the southern border by artificial irrigation. The result of this measure is to be seen in Fig. 6 . This time we measured the assimilation intensity of the mean crown region. From June 29 to July 3 the progressive soil drought affected photosynthesis in such a manner-upper figure-that the incipient ascent in the morning-as a consequence of a modest resaturation of the foliage during the night-was soon reversed. Before the watering on June 29 the treated tree at the southern border showed the same course of the assimilation curve, with a morning rise after 6 o'clock, a steep fall after 9 o'clock and a continuous depression until sunset. An intense soaking with roo l. per square metre had already led to a restitution of half of the assimilation activity by the next day, and to a total one on the following day: the curve of July 7 holds the level reached at 7 o'clock in the morning-notwithstanding a little decrease-until about 3 o'clock in the afternoon, whereupon stomatal closing and a fall in assimilation occurred as a consequence of the great air dryness (maximum saturation deficit ' $\mathrm{S}$ '). It is quite evident that in $\mathrm{CO}_{2}$-absorption the light factor does not play an essential role here either.

As is known, too great or too small a quantity of light may limit the activity of photosynthesis, when there is a sufficient water supply. Measurements with a poplar of our stand in the course of a cloudy day with light fluctuations between 2000 and 12,000 lux have resulted in an almost synchronous course of light intensity and assimilation (Fig. 7). The results may be re-arranged to reveal an almost linear relation between assimilation and light intensity, as shown in the lower half of the figure. The limiting effect of high radiation was revealed by measurement in the Hungarian Alcali Steppe with single trees of the common oak and the so-called 'Zerreiche' (Quercus cerris). I may insert here two figures and two illustra- 

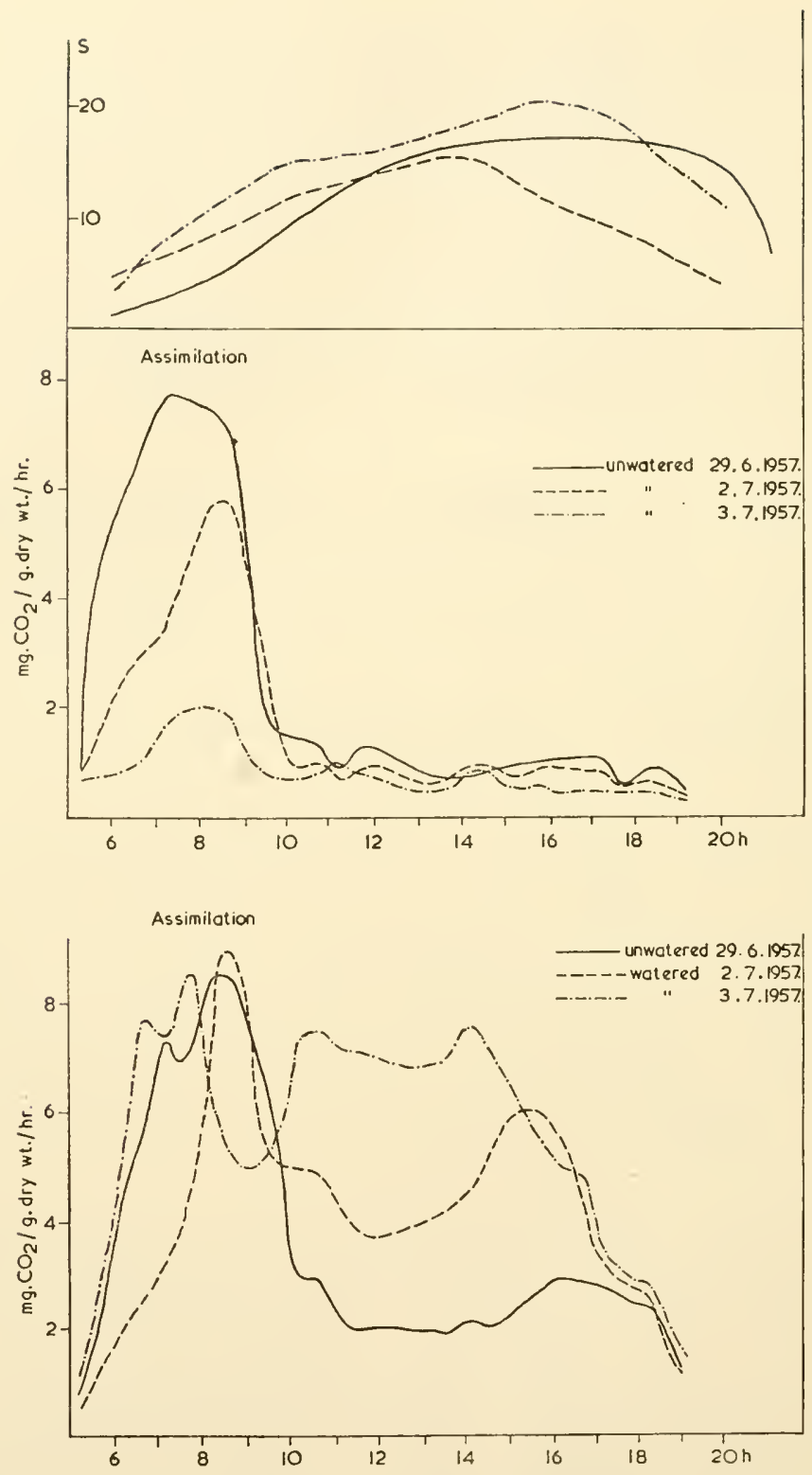

FIG. 6. Assimilation in crown tops of the south border on different days, in dry soil and after watering. $\mathrm{S}$ as in Fig. 3 . 
tions. These trees are outposts of a natural remnant forest of the HortobagyPußta near Ujszentmargita with a tree and bush vegetation of Quercus robur, Quercus cerris, Acer tataricum, Fraxinus excelsior, Pyrus communis and Prunus spinosa. The investigations were carried out on sunny days in August at maximum temperatures of more than $30^{\circ} \mathrm{C}$ and relative air humidities of less than $4.0 \%$. Besides the carbon dioxide assimilation, transpiration was
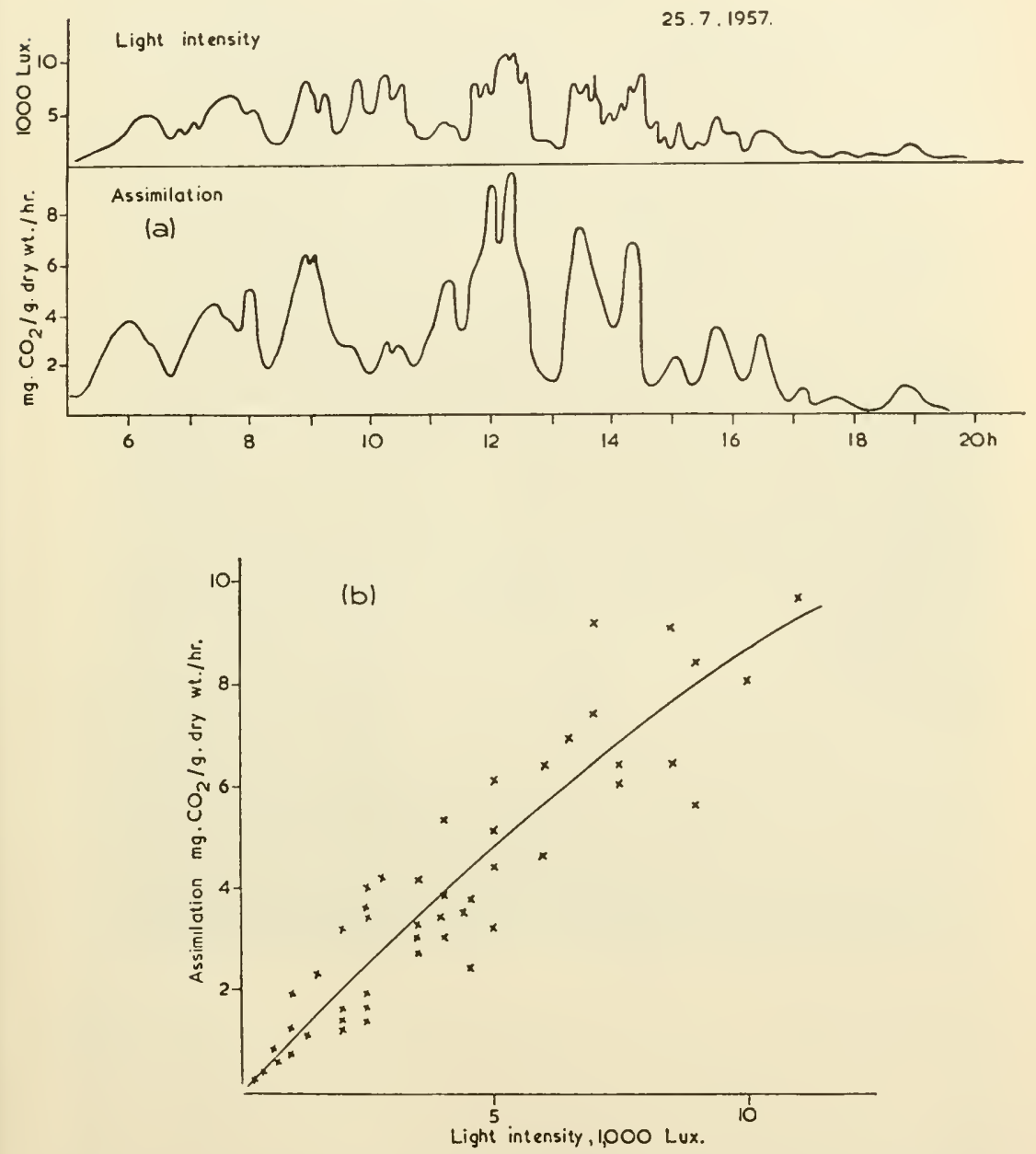

FIG. 7. Assimilation in the minimum region of light: (a) daily march, (b) dependence on light. 
also measured by URAS instruments. During the test days evaporation on the open steppe reached maxima of more than $\mathrm{I} \cdot 2 \mathrm{cc}$. $\mathrm{H}_{2} \mathrm{O}$ per hour. As the accompanying photographs will show, the crown formations of the two oak species are fundamentally different. As an 'out-post' of the steppe, Quercus robur has formed a globose crown (Fig. 8), whereas Quercus cerris has a thin-foliaged, largely extended one (Fig. 9).

With both species we investigated comparatively the gaseous exchange of the foliage of the southern crown side, of the crown's interior, and of the northern crown side. Consider first the daily course of the thin-foliaged Quercus cerris (Fig. Io). While in the forenoon the southern crown side is most active in both assimilation and transpiration, it is quite the reverse in the afternoon: at highest insolation and evaporation the leaves of the crown interior assimilate and transpire more intensively than those of the southern crown side. The excessive insolation together with the high temperature lead to stomatal closing and rapidly falling assimilation, as is shown by the transpiration and assimilation curves of the southern crown side. The highest assimilation rate is found in the crown interior in the afternoon, whereas in northern, shaded, side of the crown, photosynthesis remains at a low level during the whole day. On the other hand the thickfoliaged common oak (Quercus robur, Fig. I I) behaves quite differently in these extreme site conditions. The crown interior of that species is much too shaded for a great activity of gaseous exchange to be possible. But it is not the southern crown side either which shows the strongest assimilation, but the northern crown side, which is protected from insolation. As the columns show, neither Quercus robur nor Quercus cerris-in 'outpost position' and under conditions of summer climate in the Hungarian steppe-reach their highest assimilation rates at the southern crown side, where there is maximum exposure to light, but always in that part of the crown which possesses the best metabolic activity in moderate shade. Because of the low light required for maximum assimilation, this occurs in Quercus robur on the northern crown side which hardly receives any direct sunlight during the whole day, whereas, with Quercus cerris, it is the interior of the crown which profits in the light shade of its own foliage from intense side insolation in the morning and in the afternoon.

To return to the five-year-old black poplar stand, we determined the daily amount of assimilation in the base and top regions comparatively for the stand borders and the stand interior, during the drought period and after rain (Table I). The weak efficiency of photosynthesis of the southern border trees and the high efficiency of the northern border ones is readily recognised. After rainfall assimilation is generally higher but still the 


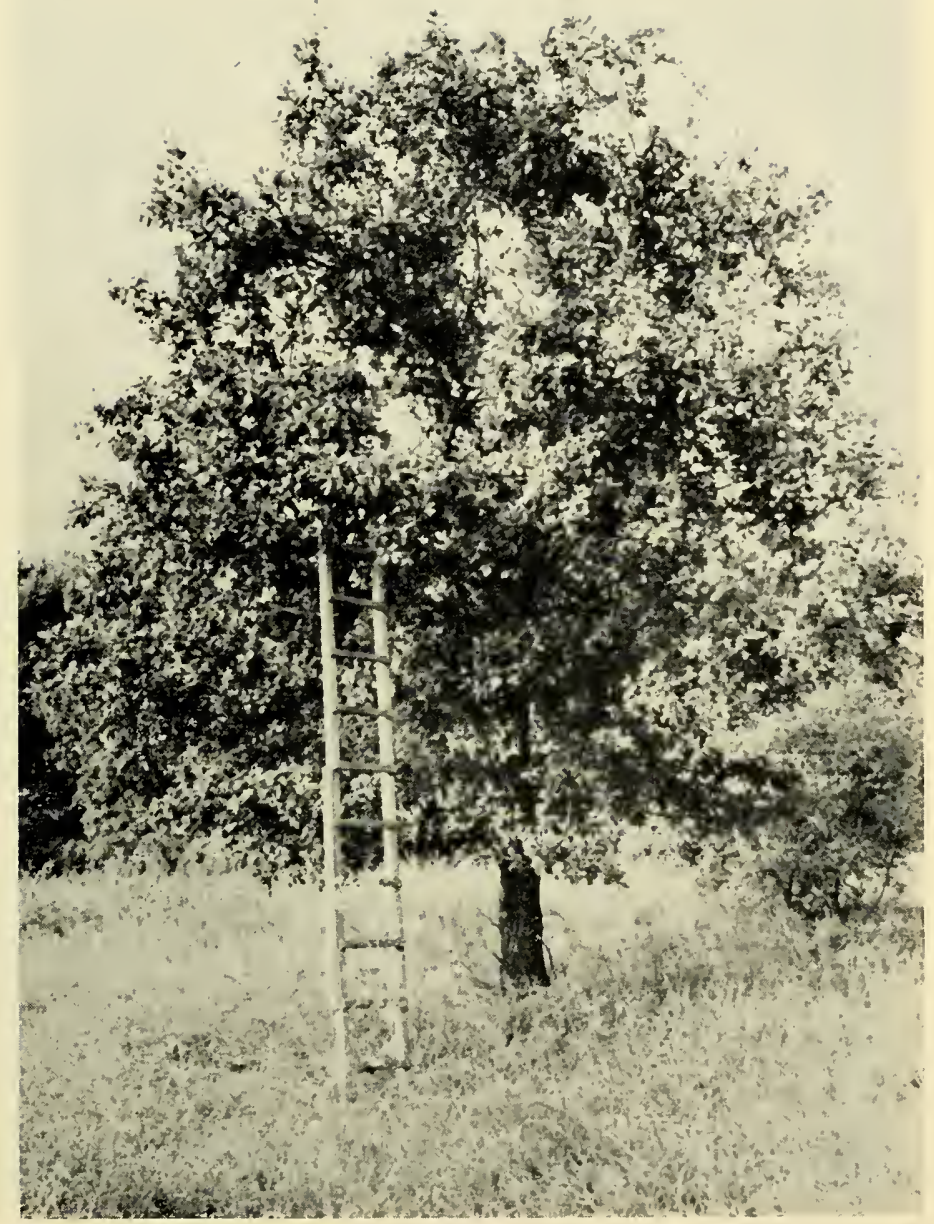

FIG. 8. Common oak (Quercus robur) with dense crown in outpost position of the forest steppe. 


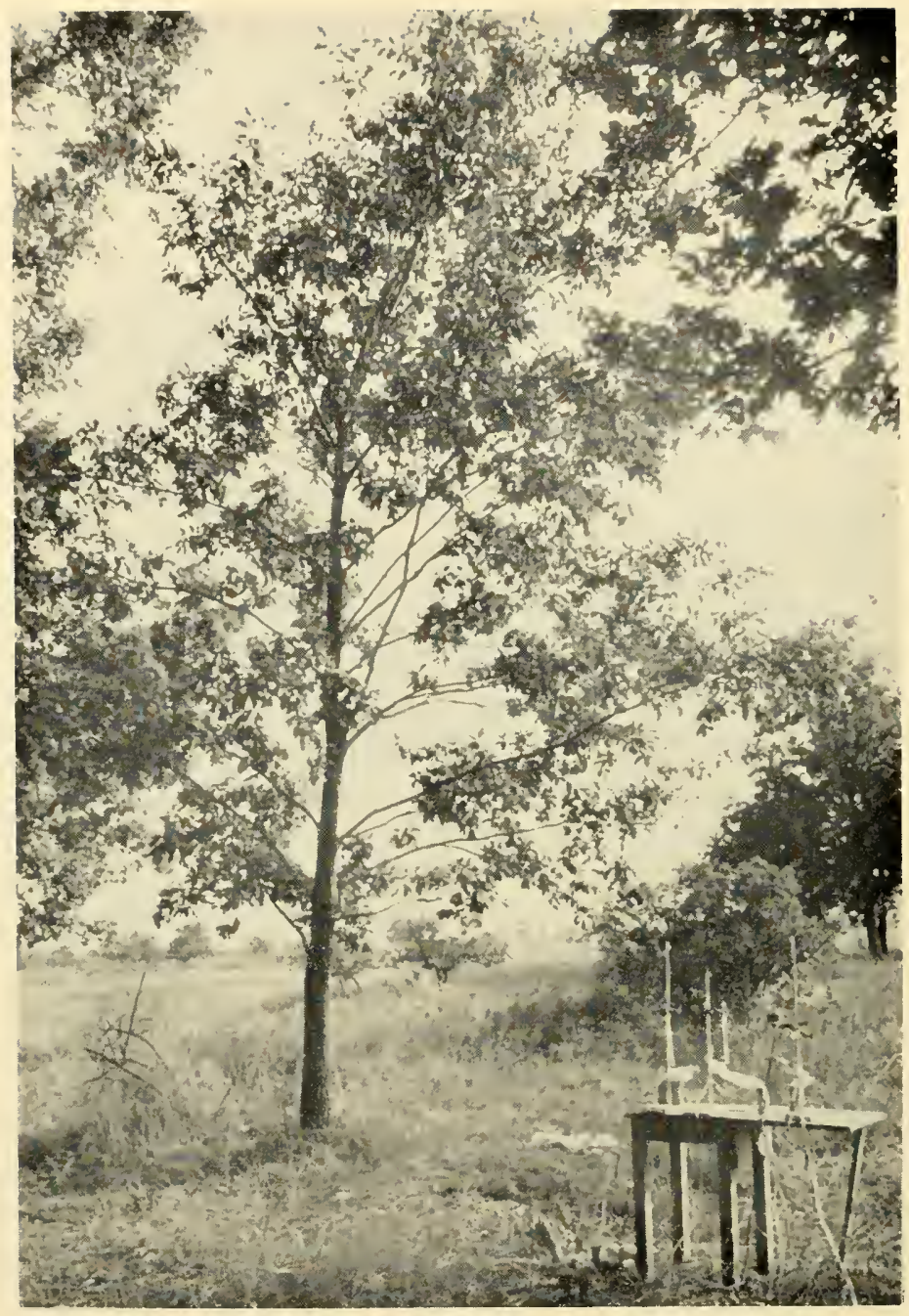

Fig. 9. Quercus cerris with thin-foliaged crown, filled with light, in outpost position of the forest steppe. 


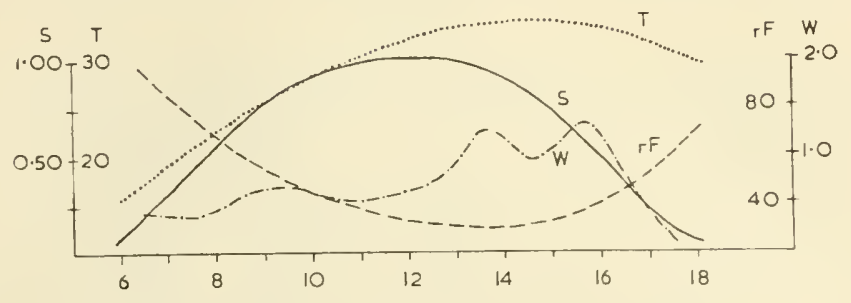

Bg $\bigcirc 00000000000$

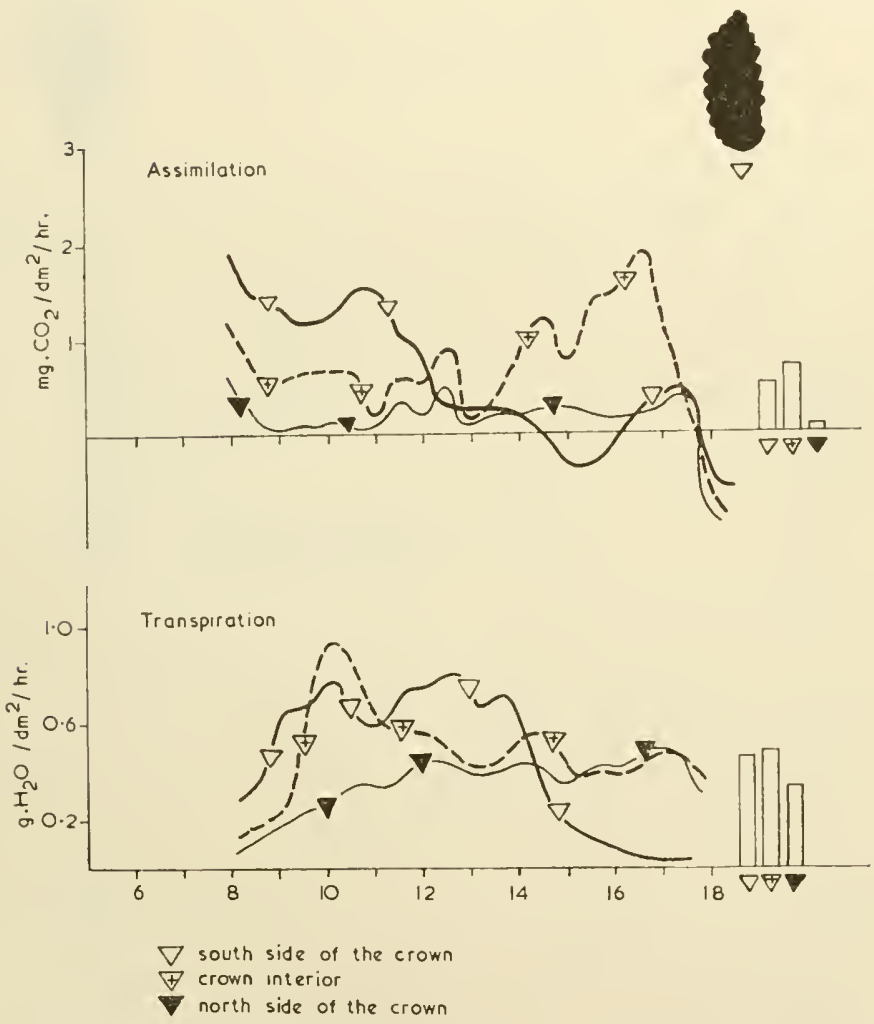

FIG. Io. Assimilation and transpiration of Quercus cerris in different regions of the crown, $24 / 8 / 59$; outpost of the forest steppe. $\mathrm{S}=$ total radiation, $\mathrm{cal} . / \mathrm{cm}^{2} / \mathrm{min} ; \mathrm{T}=$ air temp, ${ }^{\circ} \mathrm{C} ; \mathrm{rF}=$ relative humidity of air, percent; $\mathrm{W}=$ wind velocity, $\mathrm{m} / \mathrm{sec} ; \mathrm{Bg}=$ cloud cover (Bedeckungsgrad). 


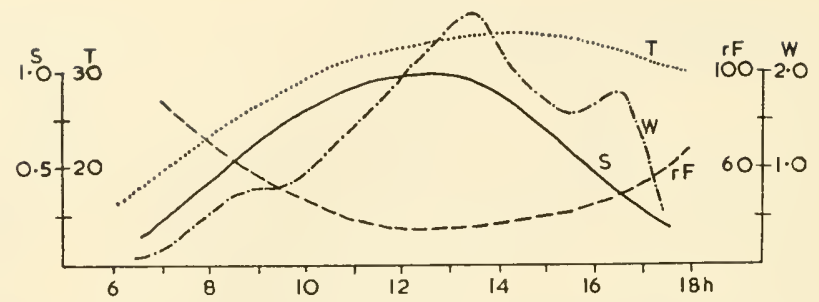

Bg 0000000000000
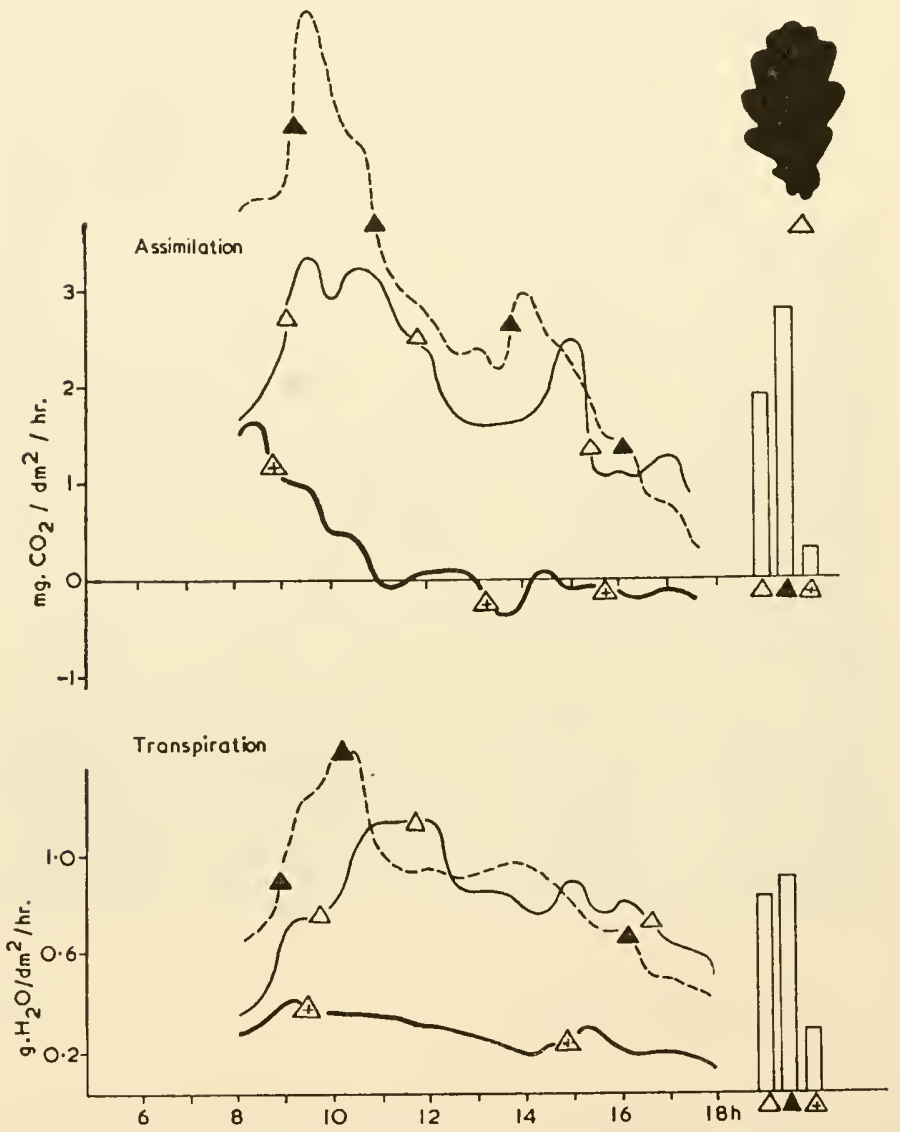

$\triangle$ south side of the crown

$\triangle$ crown interior

A north side of the crown

FIG. II. Assimilation and transpiration of Quercus robur in different regions of the crown, 24/8/59; outpost position of the forest steppe. Key as for Fig. Io. 
PHOTOSYNTHESIS AND GROWTH OF POPLAR TREES 269

TABLE I

Daily assimilation across the stand, $\mathrm{mg} \mathrm{CO}_{2} / \mathrm{g} / \mathrm{day}$

\begin{tabular}{|c|c|c|c|c|c|}
\hline Day & $\begin{array}{l}\text { South } \\
\text { border }\end{array}$ & 2nd tree & 3 rd tree & $4^{\text {th }}$ tree & $\begin{array}{l}\text { North } \\
\text { border }\end{array}$ \\
\hline $2 I \cdot 6$ & $54^{\circ} 9^{\star}$ & $48 \cdot 7^{\star}$ & 一 & $30 \cdot 0^{\star}$ & $36 \cdot I^{\star}$ \\
\hline $26 \cdot 6$ & $23 \cdot I$ & $42 \cdot 5^{\star}$ & 一 & $8 \cdot 3^{\star}$ & $56 \cdot 3]$ during the \\
\hline $9 \cdot 7$ & $27 \cdot 5$ & $28 \cdot I$ & $56 \cdot I$ & 一 & $63 \cdot 8\}$ drough period \\
\hline $10 \cdot 7$ & $26 \cdot 5$ & $23 \cdot 4$ & $59 \cdot I$ & - & $79 \cdot 8$ arougn period \\
\hline $13 \cdot 7$ & $4^{r} \cdot 9$ & $64 \cdot 0$ & - & - & $103 \cdot 37$ \\
\hline I5.7 & $53 \cdot I$ & $82 \cdot 0$ & - & 一 & $95.8\}$ after rain \\
\hline $16 \cdot 7$ & $43 \cdot 2$ & $7 I \cdot I$ & $82 \cdot 2$ & - & $87 \cdot 2$ \\
\hline
\end{tabular}

* In crown base; other figures in crown top.

highest rate is in the northern border top. The top foliage of the stand interior assimilates better, the closer the trees stand to the moister north border. However, if one considers the assinilation of the base foliage, one finds a reverse arrangement, though much diminished, from the southern border across the stand interior to the northern border. This is not at all surprising, as here the light factor dominates over the water factor. For one thing the base foliage is always better supplied with water than the top foliage, which leads to some diminution of the difference, and for anotherand this is the decisive fact-the light reaching the base foliage of the stand interior lies distinctly in the minimum range.

As has already been mentioned the assimilation measurements were carried out during and shortly after an extreme period of drought. Two days after the beginning of the heavy rainfall in July the soil of the whole stand area was totally saturated to a depth of $50 \mathrm{~cm}$ and in spite of that, still one week after the beginning of the rainfall, the tops of the northern border trees assimilated twice as strongly as those of the southern border ones. As the loamy-sand soil of the site dried up rather quickly-in the humusbearing upper layer a field-capacity with a water-content of $15 \%$ by weight was measured, whereas in the layers of more than $25 \mathrm{~cm}$ soil depth the percentage was only $7-8 \%$-the southern border of the stand was for the greater part of the year drier than the northern one, which affected not only the metabolism but also the vigour of growth. This is quite obvious in the concluding table (Table 2). Not only in stem height but also in stem diameter (measured one metre high) the trees of the north border are superior to those of the south border. But while the trees increase continuously in their stem height from the south border to the north border, the stem 
diameter of the stand interior decreases quite obviously when compared with the border trees: a fact which is well known from forest practice, especially when there is a greater stand density. However, we are interested above all in the correlation between water supply, assimilation efficiency and growth capacity, which is to be seen most distinctly with the border trees, and about that the reported facts informed us thoroughly.

For a final observation I want to deal briefly with a problem which is of the greatest importance for assimilation and transpiration physiologists. I think that it emerges clearly from my results that the assimilation values found for leaves or needles in any one crown region, are never representative for the whole tree, and certainly are not so when the measurements

\section{TABLE 2}

Stem height and diameter across the stand

\begin{tabular}{lcccccc}
\hline & $\begin{array}{c}\text { South } \\
\text { border }\end{array}$ & 2nd row & 3rd row & 4 th row & 5th row & $\begin{array}{c}\text { North } \\
\text { border }\end{array}$ \\
\hline $\begin{array}{c}\text { Stem diameter } \\
\text { (cm in I m height) }\end{array}$ & 5.2 & 4.8 & 4.2 & 4.3 & 5.4 & 6.4 \\
Stem height (m) & 5.09 & 5.32 & 5.2 I & 5.52 & 6.03 & 6.15 \\
\hline
\end{tabular}

maximum deviation: $0.49 \mathrm{~m}$ stem height.

average deviation: $\pm 0.33 \mathrm{~m}$ stem height.

have been made under extreme conditions of climate and site. The simple transference of such values to the tree through multiplication by the total quantity of foliage is in any case faulty, if not false. Also the determination of the difference of the carbon dioxide content in the air above the stand and in the crown space, as performed by Huber and his collaborators, is not reliable enough for a clear conception of the dry-matter production of forest stands. If we wish to obtain an approximately true picture of the dynamics of dry-matter production of trees and do not wish to renounce determinations of assimilation as a physiological guide to the productivity of adult trees, then-and this is how I estimate the present situation of experimental forest ecology - there remains only a comparative determination of the assimilation efficiencies of the leaves in the different crown regions.

This is the course we are following. 
PHOTOSYNTHESES AND GROWTH OF POPLAR TREES 27I REFERENCES

DE VRIES, D. A. (1952) A monostationary method for determining thermal conductivity of soil in situ. Soil Science, 73, 83 .

Pisek, A. \& Tranquiluin, W. (I95I) Transpiration und Wasserhaushalt der Fichte (Picea excelsa) bei zunehmender Luft- und Boden- trockenheit. Physiol. Plant. 4, I. Pisek, A. \& Tranquilinn, W. (1954) Assimilation und Kohlenstoff haushalt in der Krone von Fichten- (Picea excelsa Link) und Rotbuchenstämmen (Fagus silvatica L.). Flora, I4I, 237.

WeCK, J. (1948) Forstliche Zuwachs- und Ertragskunde. Radebeul and Berlin. 


\title{
HYDRATURE AND PLANT PRODUCTION
}

\author{
K. KREEB \\ Botanisches Institut, Stuttgart-Hohenheim, West Germany
}

\section{MEANING OF HYDRATURE}

THE term 'hydrature' * was introduced in I93 I by Walter (I93 Ia). By it he meant the availability of water to plants. In respect to the water economy the important thing is not the quantity of water but its chemical potential. This point has been explained further by Walter in 1955 in a paper written in English. As an example we can state: If we irrigate pot cultures with I 1. of water or with I 1. of a I $\mathrm{mol} \mathrm{NaCl}$ solution, an appreciable difference exists, even if we use same amounts of water in both cases.

The word hydrature can be used for any system containing water, for instance solutions, soil, humidity of the air, or imbibed materials. Here mainly the hydrature of plants will be considered, because any change in the water factor outside a plant will be reflected in its hydrature. On the other hand, we are able to check the water condition at a certain location by measuring a plant's hydrature. In that case the plant itself is used as an indicator.

Generally hydrature $(h y)$ can be measured and expressed by the 'relative humidity'. We say (see Walter, I950, page 66):

$$
h y=\frac{p}{p_{0}} \cdot 100=\text { percentage relative humidity }
$$

( $p=$ actual water vapour pressure, $p_{0}=$ saturation water vapour pressure at

* 'Hydrature' as a term should not be used interchangeably with 'hydration' as the terms do not have identical meanings. The word hydrature can be compared with 'temperature', which means the condition not the quantity of heat. Accordingly, hydrature does not depend on the quantity but on the condition of available water. 'Hydration is a chemical and physical term and means the state of being supplied with water. It is the English verb "hydrate" meaning "to add water to", converted to a noun by adding the common suffix "ion". Hydrature is the Greek noun "hydro" (water) plus the Latin termination "ura" or "atura", much used to denote condition of or effect of, as in juncture, aperture, temperature etc. . . Accordingly there is a clear parallelism in the words "hydrature" and "temperature", particularly as employed in physiology. Temperature is measured in degrees, hydrature in osmotic pressures, ... but hydration by a water content determination, hence it is entirely different' (written notice from Prof. J. C. Russel, Lincoln, U.S.A.). 
a certain temperature). From hy we can compute the osmotic value ${ }^{\star}(\mathrm{W})$ :

$$
W=-\frac{\mathrm{IO0O} \cdot R T s}{M} \ln \frac{p}{p_{0}}
$$

( $R=$ gas constant, $T=$ absolute temperature, $s=$ specific weight of water at $20^{\circ} \mathrm{C}=0.9982, M=$ molecular weight of water= I8.) After introducing the constants we have:

$$
W=-\mathrm{I} 334 \ln \cdot \frac{p}{p_{0}}=-307 \mathrm{I} \log \frac{p}{p_{0}}
$$

Because of this relation between the osmotic value of a solution and its relative humidity (one may imagine that in closed containers there always exists equilibrium between the osmotic value of the solution and the relative humidity in the air space above it) we can use either the relative humidity or the osmotic value to indicate hydrature.

For the determination of hydrature in plants we generally use the osmotic value of the cell sap. From the equation: $S=W-P$ it may be concluded that the suction tension $(S)$ might be the better expression for the hydrature of plants (see Renner, I933a and b; Huber, 1932; Fukuda, 1935; Stocker, I954). But it can be answered that the suction tension represents only the hydrature outside a cell, which must be considered as responsible for the change of water from cell to cell. The osmotic value represents the hydra-

* In order to avoid confusion we shall list here abbreviations used regarding osmotic terms:

$$
\begin{array}{ll}
\text { DPD (diffusion pressure deficit) } & =S \text { (suction tension) } \\
\text { OP (osmotic pressure) } & =W \text { (osmotic value) } \\
\text { TP (turgor pressure) } & =P \text { (turgor pressure) }
\end{array}
$$

Of the expressions mentioned above, the most erroneous is 'osmotic pressure,' as in reality we are unable to measure such a pressure in solutions. The 'real' osmotic pressure (in German 'osmotischer Druck') which actually exists, develops as hydrostatic pressure in an osmometer for instance. Its equivalent in the cell is the turgor pressure. Both the actual osmotic pressure and the turgor pressure act as back pressure which determines together with the osmotic value the resulting suction tension in an osmotic system. In order to distinguish exactly between the meanings of the equivocal term 'osmotic pressure' (in the sense of osmotic value and actual osmotic pressure $=$ hydrostatic pressure) we suggest using principally the term 'osmotic value' (meaning the chemical potential) instead of osmotic pressure. And because it is physically more useful to compare only measurable quantities (diffusion pressure cannot be directly determined, see Walter, 1955), it should be obviously better to write the osmotic equation not as: $\mathrm{DPD}=[\mathrm{OP}-\mathrm{TP}]$, but in the manner:

$$
S=W-P
$$

In this paper we shall use only these abbreviations and terms. 
ture inside a cell. It is in equilibrium with the hydrature of the protoplasm (its imbibition) where life processes such as growth, respiration and photosynthesis are located. Because it depends on the factors mentioned and upon how much a plant produces, we are practically compelled to understand by the hydrature of plants generally that hydrature inside cells, which can be expressed as the osmotic value of the sap.

Recently Kreeb (I960b, I96Ib, see also Kreeb and Önal, 196I) measured the suction tension using the gravimetric method (Slatyer, 1958) which has been improved and checked with solutions of known osmotic values. Thereby it was found in laboratory experiments that in the case of evergreen Mediterranean plants the suction tension may rise more than $60 \mathrm{~atm}$ above the osmotic value of the sap in still-living plants. That means a 'negative turgor pressure' of the cells. Ecologically it does not play a very important role (see Kreeb, I96Ib). However in some cases it does exist under natural conditions. In connection with this we have to ask if the hydrature of living plants can be affected by a negative turgor pressure. It is difficult to understand, how this could come about, as it represents only a cohesion tension, which probably does not change the imbibition state of the cytoplasm as in the case of changes in the osmotic value of the sap. For that reason the osmotic value has to be considered as the main factor determining the hydrature of plants.

\section{METHODS}

I. Sampling. Because of daily changes in the osmotic value of plants, sampling should always be done at precisely the same time of the day. We prefer I 2-2 a.m., in order to get extreme values. Insertion, age and general condition of leaves should be considered, because it is very important to have a uniform material which is easily comparable. The proper approach appears to be to collect an average sample at a certain place, using at least 20 leaves, leaflets or leaf parts, each having the size of about $10 \mathrm{~cm}^{2}$. This reduces the error of parallel measurements normally to less than I atm.

2. Extraction of cell sap. After samples have been collected in glass containers, sealed with rubber corks, they have to be kept in aluminium boxes. One should ensure that the cover of the aluminium box presses the cork well onto the glass container, and therefore prevents water losses by evaporation. After destroying the semipermeability of the cytoplasm by boiling the samples ( $15-20$ min in the water bath), sap can be obtained using a hydraulic press. The press-set, after Walter, was described in 1928. By adding a piece of thymol to the solutions they can be stored for several 
weeks in the refrigerator without danger of chemical changes due to bacteria or fungi.

3. Determinations of the osmotic values of the sap can be accomplished by the 'cryoscopic method'. Thereby the freezing point has to be determined. Because this apparatus is generally known we refer to the comprehensive literature given by Walter (r93 Ib) and Kreeb (I96Ia). Recently Kreeb (I957), see also Slavík (I952) used a cryoscope without air space around the sap container and an automatic stirring mechanism. These changes of the apparatus have the advantage of less variation between various determinations. Modern cryoscopes are fitted with a freezing apparatus and thermostat.*

4. Calculation of the osmotic pressure can be done by the formula: $W=\mathrm{I} 2.06 \Delta(\Delta=$ freezing point depression). Tables for direct readings are available (Walter, I93 Ib; Walter and Thren, I934).

\section{OSMOTIC VALUE OF PLANTS AND YIELD}

Initial observations regarding the relation between growth and osmotic values (hydrature) were reported by Walter (193 Ia). He found that the curves of osmotic values from plants grown at different locations (Solamm elaeagnifolium) show a good relation to the height of the shoot. Later Stieglitz (1936) worked with winter wheat and tested the production in two different years: In 1934, which was a relatively dry year, osmotic values were high, up to $25 \mathrm{~atm}$, and the yicld was only approximately $50 \%$ (grain) of the amount in 1933 (year with normal weather). With straw the difference was even greater.

Lobov (I95I) reports field experiments, whereby various plots, planted with cabbage, potatoes and tomatoes have been irrigated only after a maximum osmotic value of 8, IO and 12 atm respectively (Table I) had been exceeded. Generally it was found thereby, that with the rise in osmotic values the yield does decrease. This is not entirely true for tomatocs, as he reported no significant diminution in the yield between 8 and Io atm.

Yet it may be asked whether the result would not be different, if not only fruits, but the total production had been measured. This assumption can be made from the fact that tomatoes show a decrease in the production of fruits under extremely moist conditions. This does not dispute the general relationship between yield and osmotic values, but it should be considered because not all factors which affect yield show an influence on the osmotic

* The cryoscope of Drucker-Burian-Kreeb: designed and manufactured by W. Schulze, Heppenheim a.d.B., Schunkengasse Nr. 7, West-Germany. 
TABLE I

Maximum osmotic values, number of irrigations and yield of cabbage, potatoes and tomatoes. After Lobov, I95I

\begin{tabular}{|c|c|c|c|c|c|}
\hline \multirow{3}{*}{$\underset{\mathrm{W}}{\text { Maximum }}$} & \multirow{3}{*}{$\begin{array}{l}\text { Number of } \\
\text { irrigations at } \\
4 \text { replications }\end{array}$} & \multicolumn{4}{|c|}{ Yield in $100 \mathrm{~kg} / \mathrm{IO}, 000 \mathrm{~m}^{2}$} \\
\hline & & \multicolumn{2}{|c|}{ Cabbage } & \multirow[b]{2}{*}{ Potatoes } & \multirow[b]{2}{*}{ Tomatoes } \\
\hline & & Var. I & Var. 2 & & \\
\hline 8 & $5,3,5,5$ & 463 & 500 & 217 & 530 \\
\hline Io & $3,2,4,3$ & 4 I 8 & 400 & I 83 & 540 \\
\hline 12 & $\mathrm{I}, \mathrm{I}, \mathrm{I}, \mathrm{I}$ & 217 & 263 & I 52 & 420 \\
\hline
\end{tabular}

value itself. Hydrature of plants seems to be a very important condition for plant production especially in arid countries and dry years, if not the most important one, besides other factors such as nutrition, temperature, light, diseases, etc.

Bauman (1955) in Canada worked with irrigation experiments using alfalfa, wheat, barley, oats, sugar beet and potatoes. He found that time of irrigation can be better determined by hydrature of plants than by soil moisture measurement (Bouyoucos-block, tensiometer). Yield and average osmotic value showed a close relationship (Table 2 ). Generally it can be

\section{TABLE 2}

Average osmotic value in atm $(W)$ and yield of various crops (after Bauman, from Walter, 1956; see also Walter, I96I)

\begin{tabular}{|c|c|c|c|c|c|c|c|}
\hline \multirow[t]{2}{*}{ Alfalfa, Ist cut } & $W$ & $10 \cdot 6$ & II $\cdot S$ & II $\cdot 9$ & I 4.7 & $17 \cdot 2$ & $19 \cdot 8$ \\
\hline & $\mathrm{t} / \mathrm{acr}$ & $10 \cdot 9$ & $8 \cdot 6$ & $9 \cdot 7$ & $7 \cdot 4$ & $5 \cdot 2$ & $3 \cdot 6$ \\
\hline \multirow[t]{2}{*}{ Alfalfa, 2nd cut } & $W$ & $10 \cdot 3$ & $10 \cdot 4$ & 10.9 & I3 1 & $14 \cdot 1$ & $30 \cdot 3$ \\
\hline & $\mathrm{t} / \mathrm{acr}$ & $9 \cdot 7$ & $9 \cdot 2$ & $7 \cdot 6$ & $6 \cdot 2$ & $5 \cdot 7$ & 0.34 \\
\hline \multirow[t]{2}{*}{ Thather wheat } & $W$ & 10.5 & $10 \cdot 7$ & II $\cdot 7$ & II $\cdot 9$ & $12 \cdot 3$ & $12 \cdot 8$ \\
\hline & bsh/acr & $37 \cdot 0$ & $36 \cdot 2$ & $35 \cdot 0$ & $3 \mathrm{I} \cdot 3$ & $27 \cdot 9$ & $27 \cdot 2$ \\
\hline \multirow[t]{2}{*}{ Lemlu wheat } & $W^{\prime}$ & 10.4 & II $\cdot O$ & $I I \cdot I$ & II $\cdot 3$ & II 4 & $12 \cdot 2$ \\
\hline & $\mathrm{bsh} / \mathrm{acr}$ & $47 \cdot 7$ & $45 \cdot 5$ & 33.4 & $3 \mathrm{I} \cdot 2$ & $35 \cdot 9$ & $3 \mathrm{I} \cdot 2$ \\
\hline \multirow[t]{2}{*}{ Montcalm barley } & $W^{\prime}$ & $10 \cdot 3$ & $10 \cdot 7$ & $\mathrm{II} \cdot 8$ & $12 \cdot 0$ & $12 \cdot 6$ & $14 \cdot 6$ \\
\hline & $\mathrm{bsh} / \mathrm{acr}$ & $48 \cdot 3$ & $46 \cdot 2$ & $40 \cdot 2$ & $40 \cdot 7$ & $35^{\circ} 9$ & $30 \cdot 7$ \\
\hline \multirow[t]{2}{*}{ Eagle oats } & $W$ & $9 \cdot 4$ & IO I I & 10.4 & $10 \cdot 6$ & II $\cdot O$ & $\mathrm{I} 4 \cdot 4$ \\
\hline & $\mathrm{bsh} / \mathrm{acr}$ & $95 \cdot 2$ & $77 \cdot 9$ & $67 \cdot 7$ & $7 \mathrm{I} \cdot \mathrm{I}$ & $66 \cdot 5$ & $62 \cdot 8$ \\
\hline \multirow[t]{2}{*}{ Sugar beet } & $W$ & I $2 \cdot I$ & $12 \cdot 6$ & I $3 \cdot 2$ & $13 \cdot 6$ & $13 \cdot 6$ & 22.4 \\
\hline & $\mathrm{t} / \mathrm{acr}$ & $15 \cdot 9$ & $15 \cdot 0$ & I $2 \cdot 7$ & I 3.4 & I $2 \cdot 8$ & $5 \cdot 3$ \\
\hline \multirow[t]{2}{*}{ Potatoes } & $W$ & $8 \cdot 6$ & $8 \cdot 7$ & $8 \cdot 9$ & $9 \cdot 4$ & $9 \cdot 4$ & 10.5 \\
\hline & $\mathrm{bsh} / \mathrm{acr}$ & $363 \cdot 0$ & $276 \cdot 0$ & $294^{\circ} 0$ & $238 \cdot 0$ & $202 \cdot 0$ & $70 \cdot 0$ \\
\hline
\end{tabular}


said that decreasing hydrature means diminution of yield, that is: the higher the average osmotic value the lower the yield.

Sprinkling experiments carried out by the author in Abu Ghraib, Iraq (1956-58) produced identical results (Kreeb, I957, I961a). It was also found that the curve of decreasing yield with increasing average osmotic values shows the form of an $e$-function (see Figs. I and 2). This means, that the

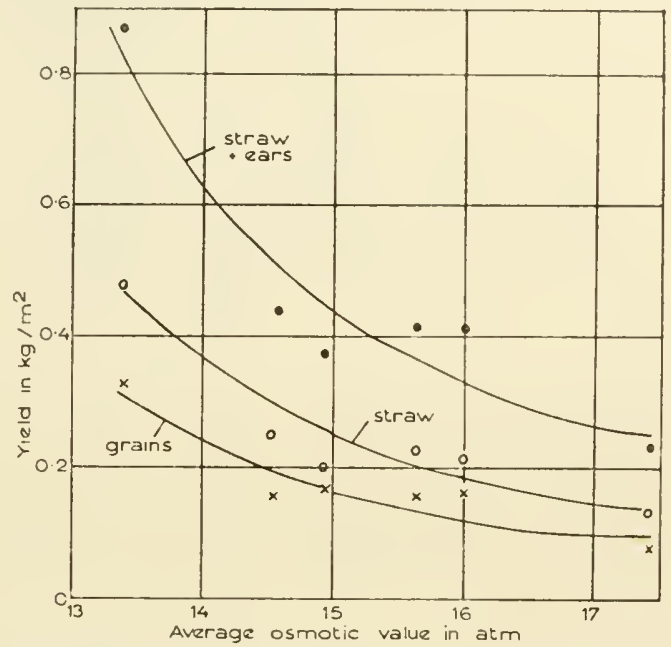

Fig. I. Curve of decreasing yield with increasing average osmotic values in barley (Trabot). After Kreeb, I957.

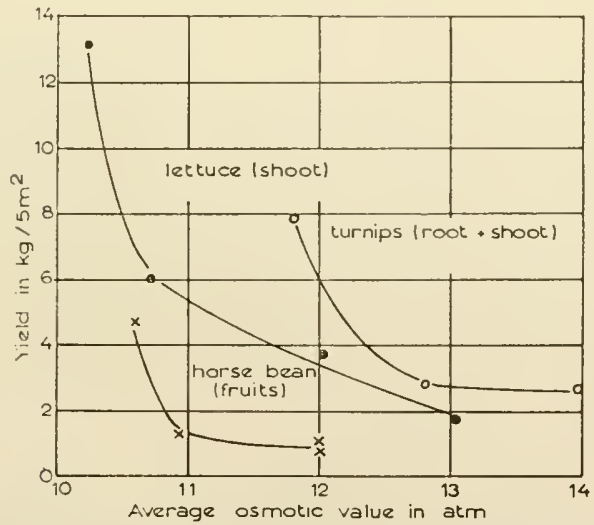

FIG. 2. Curves of decreasing yield with increasing average osmotic values in lettuce, turnips and horse beans. After Kreeb, 1958. 
first increase of the osmotic value above the optimulm (=owest value found under best water conditions and at a certain location and species) lowers the production of plant matcrial (vegetative and generative parts) relatively more than at higher osmotic value levels.

Also most of the yield data given by Bauman (1955) follow the same principle after being plotted against average osmotic values (Fig. 3). They are calculated as mean between numerous measurements during the

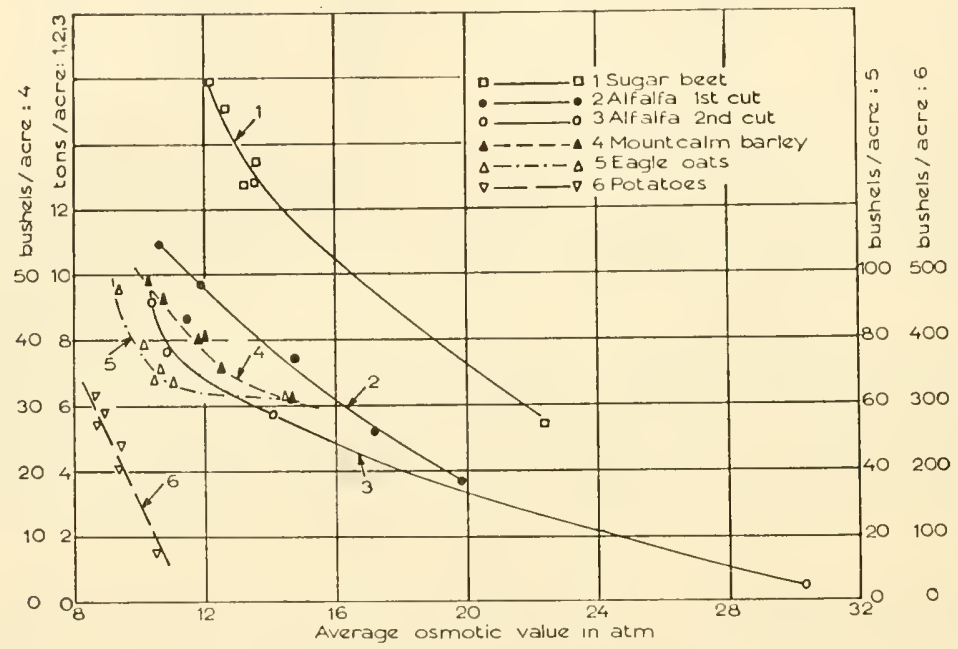

FiG. 3. Curves of decreasing yield with increasing average osmotic values in various crops. After Bauman, I955.

vegetative period. The yearly curves of the osmotic values are clearly related to the intensity of irrigation (Fig. 4): i.e. the decreasing water availability causes an increase in the osmotic value. At the termination of the experiment we found the highest osmotic value (more than $25 \mathrm{~atm}$ ) at the plots $\left(\mathrm{S}_{4}\right)$ with smallest amounts of irrigation water $(76.5 \mathrm{~mm})$. Plot S I with 'optimum hydrature conditions' (288 mm irrigation water) showed contemporarily a value between I4-I6 atm, and the plots S 2 (I27.7 mm) and $\mathrm{S}_{3}(84.2 \mathrm{~mm})$ more than 16 atm and approximately 19 atm respectively at the same time.

It was interesting to observe in this experiment that the decrease of the yield at lower hydrature conditions depends on the diminution of the number of grains more than on size of the caryopsis. The seeds ripen fully even under very poor water conditions which means that the reproduction 


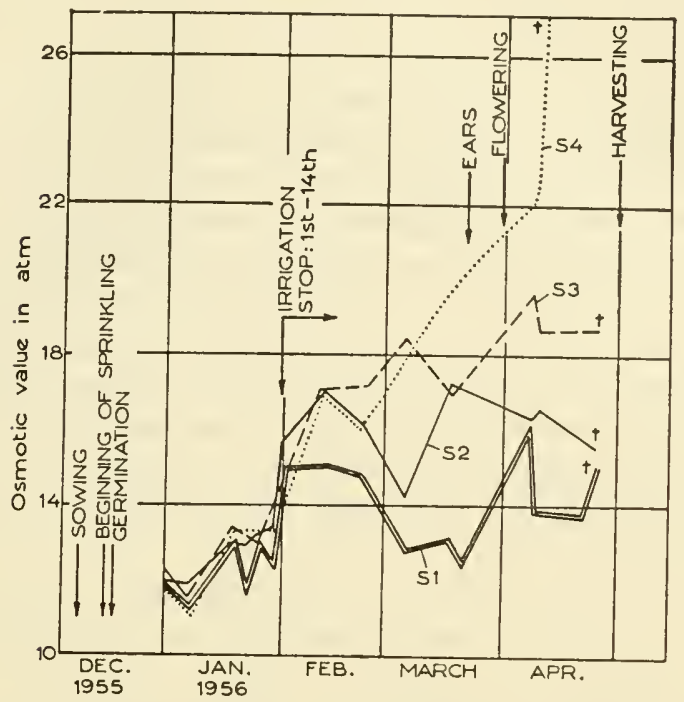

Fig. 4. Yearly curves of hydrature (osmotic values) of barley (Trabot) with different water supply: Curve $S_{I}=288 \mathrm{~mm} ; S_{2}=127 \cdot 7 \mathrm{~mm} ; S_{3}=84.2 \mathrm{~mm} ; S_{4}=76.5 \mathrm{~mm}$. After Kreeb, I957.

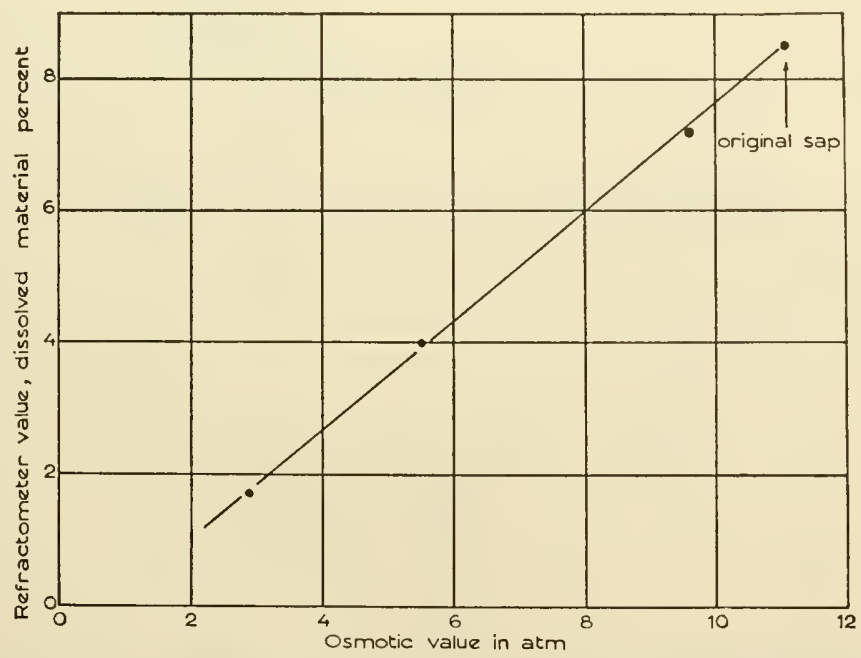

FIG. 5. Correlation between the osmotic value and refractometer value (percent dissolved material) of alfalfa sap, diluted with water. 
of plants will be possible as long as plants are able to grow and to complete their life cycle.

As a field method for determination of plant hydrature, Kreeb (1957, I96Ia) suggested measurement of the refractive index rather than the osmotic value of the sap. This can be simply done by a hand sugarrefractometer, giving direct readings of dissolved material, per cent, in the field. As long as changes in the cell concentration due only to water occur, and not due to salts dissolved (= active change of hydrature) a proportional relationship exists between the osmotic value and the refractive index. This can be seen from the data given in Fig. 5 . In this case we used sap of alfalfa which had been diluted with pure water to different levels of concentration. From each of the prepared solutions we determined the osmotic value and the refractive index. The correlation diagram shows very clearly the relation between the values.

If we do not find a correlation between refractometer readings and the osmotic value in yearly curves, we may then assume that changes in the

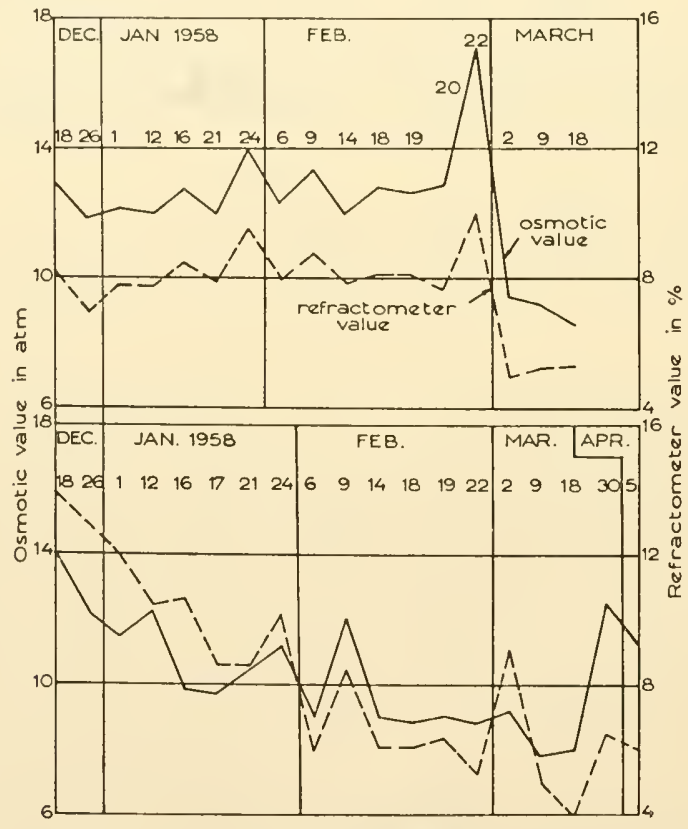

FIG. 6. Yearly curves of hydrature (osmotic valucs) compared with refractometer values in turnips (above) and lettuce (below). Plots with optimum water conditions. After Kreeb, I961. 
amounts of dissolved materials occurred (see Fig. 6, lettuce). In this case the refractometer values are only relatively valid. In order to avoid an incorrect interpretation we use principally the refractometer method as a relative method, i.e.: with this apparatus we only try to indicate a qualitative change of plant hydrature. Yet, for many investigations and practical purposes this is sufficient, because as soon as the refractive index rises we do know that plant hydrature changes to less than optimum conditions. Plants should be irrigated in that case.

The practical value of the refractometer method was tested and proved with an alfalfa experiment in Abu Ghraib, Iraq in the summer of I957, after natural rainfall was over and when temperatures went up to about $50^{\circ} \mathrm{C}$. Four treatments (2-4 replications) were watered after the refractive index at the plots showed a value just higher than the optimum (=lowest value possible), or higher than optimum $+2 \%$, optimum $+4 \%$ and optimum $+6 \%$ respectively. Because refractometer readings require a minimum of time, it was possible to measure the hydrature of plants every two days. The curves during that period (refractometer readings in dissolved materials, per cent) can be seen in Fig. 7. All are clearly related to the water supply, as also the curve of decreasing yield is to the average refractometer readings for the various plots.

Also here (Fig. 8) we find the above mentioned characteristic: the decrease in the yield is more evident initially than at higher levels of refractometer reading.

Successful application of checking hydrature by the method of refractometer determinations have been recently reported by Russian scientists (Babuschkin, I959; Belik, I960) for irrigation purposes.

If factors outside the plant as suction tension or soil moisture stress are employed for checking plant production instead of the osmotic value of the cell sap, it can be found that even then the curve of decreasing yield shows the above mentioned characteristic: it is like an $e$-function in shape. For instance, Wadleigh and Ayres (1945) got a similar result with bean plants. Recent data reported by Sands andRutter (1959) show that height of shoots, length of needles, and dry weight of young Pinus sylvestris plants produce similar curves (Fig. 9) when plotted against increasing suction tension in soil. In addition to this even the curve of decreasing net assimilation rate, representing the real production process, follows the shape of an $e$-function.

Of course the decrease of yield with decreasing hydrature is appreciably different in various crops. Those species which are relatively hygrophytic, or even mesophytes, show a rapidly declining yield curve. In plants which 


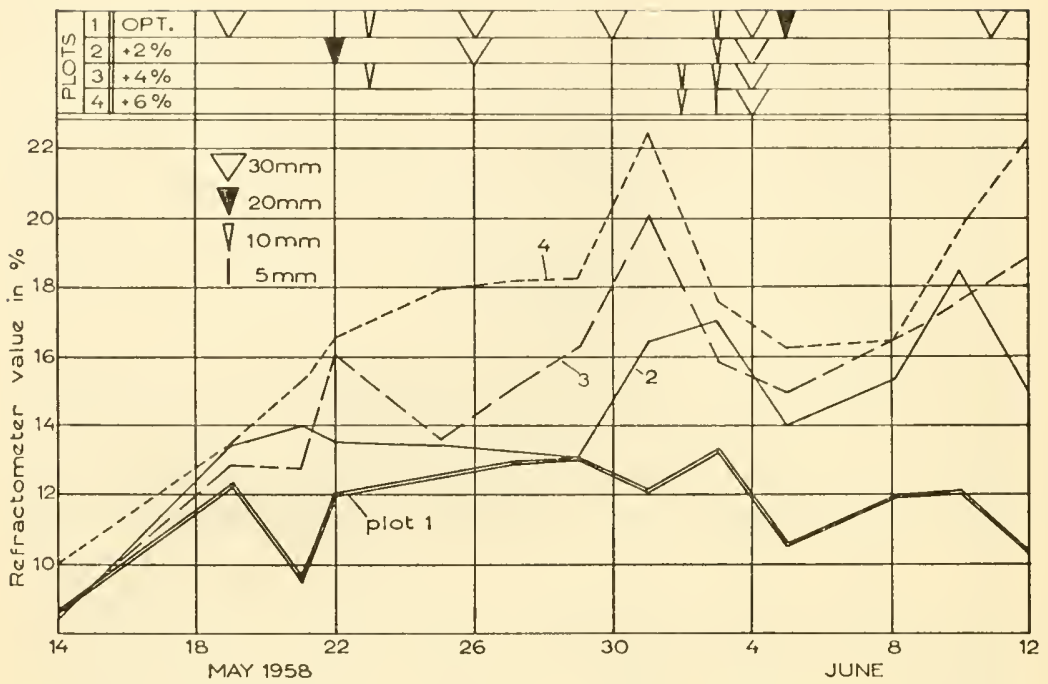

FIG. 7. Yearly curves of hydrature (refractometer values) in alfalfa plots with different irrigations. After Kreeb, I96I.

are able to endure drought to a certain exterit we find a less rapid diminution of the production. This can be seen from the following table (3).

Much affected by lack of water are horse beans, turnips, potatoes and lettuce. Their yield decreases by approximately $30-50 \%$, if the average

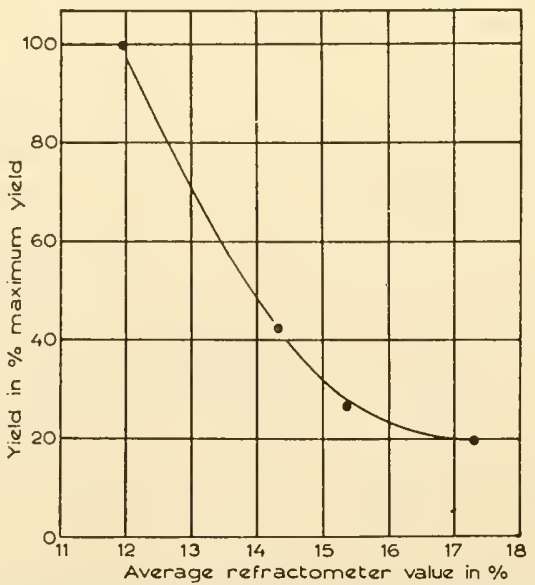

FIG. 8. Curve of decreasing yield with increasing average refractometer value. After Kreeb, 1961. 


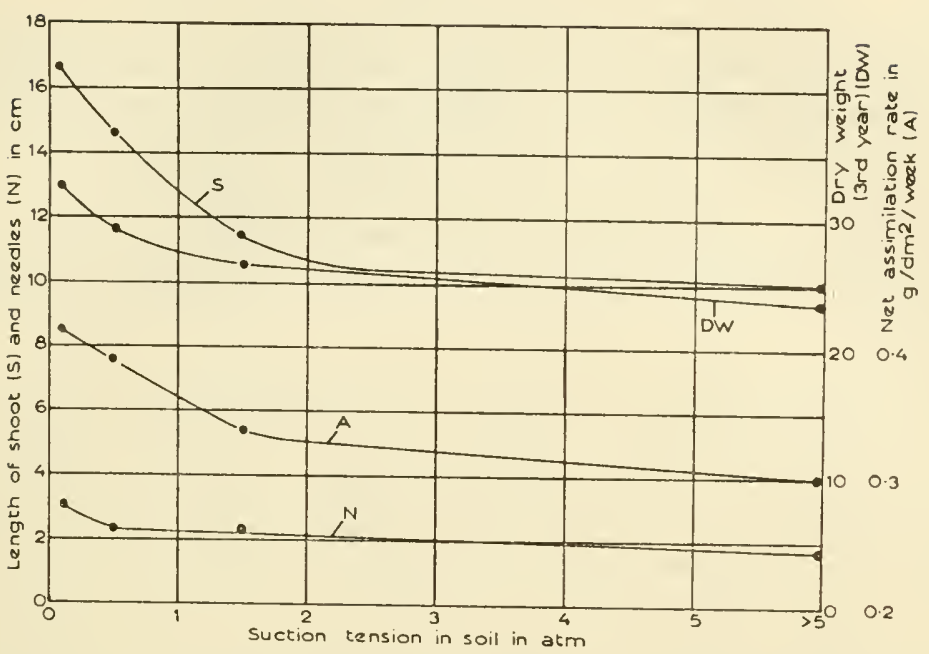

Fig. 9. Curves showing the relation between length of shoot and needles, dry weight, net assimilation rate and increasing suction tension in the soil. After Sands and Rutter, I959.

osmotic value rises by I atm. More resistant are barley, sugar beet, and alfalfa. The accuracy of the given figures is not too great, as some of the experiments have been made without replication. But it is conspicuous, that in the case of barley, the data of Bauman (Canada) and Kreeb (Iraq) are

\section{TABLE 3}

Diminution of yield of various crops per increase of the average osmotic value $(W)$ by I atm in percent maximum yield

\begin{tabular}{|c|c|c|c|c|}
\hline Author & Species & $\begin{array}{r}\text { lowes } \\
\text { W at } \\
\text { ex }\end{array}$ & $\begin{array}{l}\text { ghest } \\
\text { erned } \\
\text { it }\end{array}$ & $\begin{array}{l}\text { Diminution } \\
\text { of yield } \\
\text { per I atm }\end{array}$ \\
\hline Bauman & alfalfa & $10 \cdot 0$ & 30.0 & $4.8 \%$ \\
\hline Bauman & sugar bect & $12 \cdot 3$ & $22 \cdot 4$ & $6.8 \%$ \\
\hline Bauman & barley & $10 \cdot 3$ & $14 \cdot 4$ & $10 \%$ \\
\hline Kreeb & barley & 13.4 & $17 \cdot 4$ & $13 \%$ \\
\hline Bauman & oats & $9 \cdot 4$ & II $\cdot O$ & $17 \%$ \\
\hline Kreeb & lettuce & $10 \cdot 2$ & $13 \cdot 1$ & $32 \%$ \\
\hline Bauman & potatoes & $8 \cdot 4$ & 10.5 & $39 \%$ \\
\hline Kreeb & turnips & II $\cdot 8$ & 13.5 & $39 \%$ \\
\hline Kreeb & horse beans & $10 \cdot 5$ & $12 \cdot 0$ & $52 \%$ \\
\hline
\end{tabular}


in very close agreement. The tendency concerning the water requirement of the above mentioned crops is in line with general observations in the field. It may be of interest to note the fact that the ability to resist drought is in agreement with the salt tolerance of the plants listed in Table 3.

The effect of salts in saline soils upon plants is mainly an osmotic one (Kreeb, 1959, 1960a), therefore we have finally to discuss how the yield of crops will be changed if the hydrature of the soil decreases due to salt. Relatively few data are available from field experiments under natural conditions.

It is impossible to review here the comprehensive literature regarding pot and solution cultures showing the effect of different salt levels on growth and plant production. The following table (4) may give a general survey regarding the decrease in harvested plant materials with decrease of soil hydrature. The intensity of the effect differs with vegetative and reproductive plant parts and with different varieties of the same crop. In addition to this a toxic effect, which will not be considered here, is found when different kinds of salts arc used in the experiments (see experiment with wheat by Webster and Viswanath in Table 4). Because the plants were harvested 25 days after sowing, these figures may be regarded as only correct to a certain extent. For practical purposes it is important to know the final effect on harvested products.

Some interesting results were reported in mimeographs distributed by the Development Board, Baghdad (1958), showing results found by Dutch scientists: It can be seen with barley (Fig. Io) that increasing conductivity of solutions prepared from saturated soil (meaning decrcasing hydrature) causes diminution of production (grains). It appears that again the first

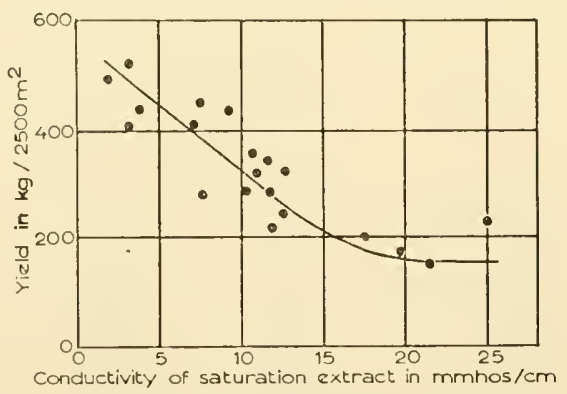

FIG. Io. Curve of decreasing yield of barley (Murakish) with decreasing hydrature in soil, expressed as conductivity of saturation extract. After Development Board Baghdad 1958. 
decline of the production curve is greater than later on. The same has been found with green gram (Fig. II). We may learn from this, that the direct lack of water or lowered water availability due to salt depends on the same basic fact: that is decrease of hydrature.

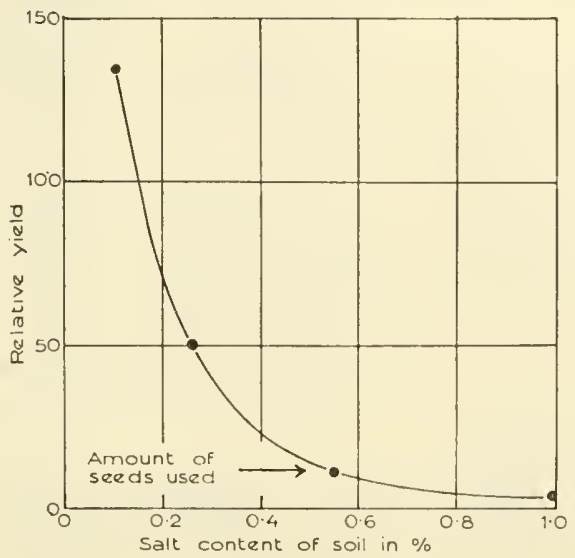

FIG. 11. Curve of decreasing yield with increased salt content of the soil for green gram. After Development Board Baghdad, 1958.

Certainly exceptions may occur, particularly if other factors are changed. This can be illustrated by the following example (Fig. I2). If we increase the salt content of the soil and at the same time also nutrients (nitrate) of the soil, then no decrease in yicld is found in case of barley because the fertilis-

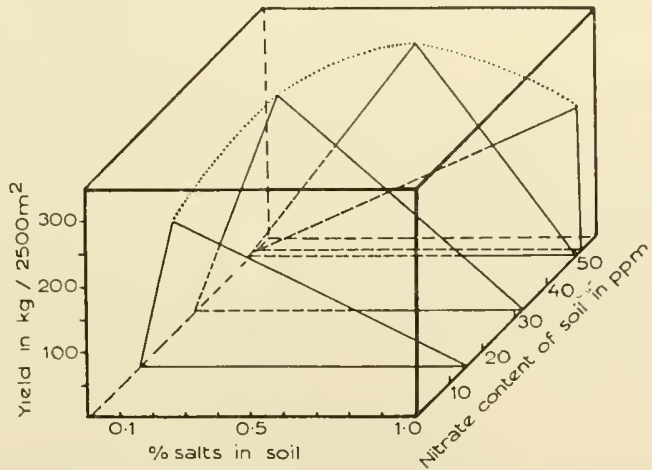

FIG. 12. Yicld curve of barley (Murakish) in relation to salt content in soil and nitrate present. After Development Board Baghdad, 1958. 
TABLE 4

Diminution of yield, in percent, of control plants at various species by increased salt content

\begin{tabular}{|c|c|c|c|c|}
\hline \multirow[b]{2}{*}{ Species } & \multirow[b]{2}{*}{ Author } & \multirow{2}{*}{$\begin{array}{l}\text { Salt content } \\
\text { control } \\
\rightarrow \text { experiment }\end{array}$} & \multicolumn{2}{|c|}{ Decrease in yield } \\
\hline & & & $\begin{array}{l}\text { Vegetative } \\
\text { parts }\end{array}$ & $\begin{array}{l}\text { Generative } \\
\text { parts }\end{array}$ \\
\hline Wheat & $\begin{array}{l}\text { Hayward and } \\
\text { Uhvits* }\end{array}$ & $0 \rightarrow 4$ at & $25 \%$ & $25 \%$ \\
\hline Wheat & $\begin{array}{l}\text { Webster and } \\
\text { Viswanath } \\
\text { I92 I }\end{array}$ & $\begin{array}{l}0 \rightarrow 0.4 \% \mathrm{NaCl} \\
0 \rightarrow 0.4 \% \mathrm{CaCl}_{2} \\
0 \rightarrow 0.4 \% \mathrm{MgCl}_{2} \\
0 \rightarrow 0.4 \% \mathrm{Na}_{2} \mathrm{So}_{4} \\
0 \rightarrow 0.4 \% \mathrm{MgSo}_{4} \\
\text { (pot cultures) }\end{array}$ & $\left.\begin{array}{l}92.7 \% \\
74.0 \% \\
55.0 \% \\
27.0 \% \\
17.0 \%\end{array}\right\}$ & $\begin{array}{l}25 \text { days } \\
\text { after } \\
\text { sowing }\end{array}$ \\
\hline $\begin{array}{l}\text { Barley ( } 8 \\
\text { varieties) }\end{array}$ & $\begin{array}{l}\text { Ayers and } \\
\text { Wadleigh }\end{array}$ & $0 \rightarrow 0.9 \%$ & $25 \%$ & $0 \%$ \\
\hline Barley & $\begin{array}{l}\text { Dev. Board } \\
\text { Baghdad, I958 }\end{array}$ & $\begin{array}{l}2 \rightarrow \text { I } 8 \mathrm{mhos} / \mathrm{cm} \\
\text { (saline land) }\end{array}$ & $\begin{array}{l}63 \% \text { of } \\
\text { total yield }\end{array}$ & - \\
\hline Tomatocs & Eaton, 1942 & $2 \cdot s \rightarrow 6$ at & $73 \%$ & $96 \%$ \\
\hline Beans & $\begin{array}{l}\text { Gauch and } \\
\text { Wadleigh, I } 945\end{array}$ & $0.5 \rightarrow 4.5$ at & $\begin{array}{c}63 \% \text { of } \\
\text { total yield }\end{array}$ & - \\
\hline $\begin{array}{l}\text { Phaseolus } \\
\text { mungo }\end{array}$ & $\begin{array}{l}\text { Dev. Board } \\
\text { Baghdad, I958 }\end{array}$ & $\begin{array}{l}\mathrm{O} \cdot \mathrm{I} \rightarrow \mathrm{I} \% \\
\text { (saline land) }\end{array}$ & - & $98 \%$ \\
\hline Grape fruit & $\begin{array}{l}\text { Hayward, Cooil } \\
\text { and Brown^ }\end{array}$ & $0.5 \rightarrow 3.5$ at & $45 \%$ & - \\
\hline $\begin{array}{l}\text { Alfalfa } \\
\text { var. a } \\
\text { var. b } \\
\text { var. c } \\
\text { var. } d\end{array}$ & $\begin{array}{l}\text { Cooil and } \\
\text { Brown }\end{array}$ & $0.5 \rightarrow 6.5$ at & $\begin{array}{l}23 \% \\
28 \% \\
62 \% \\
64 \%\end{array}$ & - \\
\hline
\end{tabular}

* After Hayward and Wadleigh (1949)

ing effect overcomes the salt effect. Above $0.5 \%$ salt in the soil however, more fertiliser can no longer balance the salt effect, and the yield curve declines. If the same experiment were carried out with non-salt-tolerant crops (for instance potatoes) a typical $e$-function-shaped curve might be obtained.

\section{REFERENCES}

Babuschkin, L.N. (1959) Diagnosen des Wasserbedarfs von Gemïsepflanzen auf Grund der Saftkonzentration. Fiziol. Rastenij 6, 480-483, Russian. 
Bauman, L. (1955) Determination of the right time for irrigation. Phases, Periods and Scales of Plant Hydrature. Author's mimeography.

Bauman, L. (1957) Über die Beziehungen zwischen Hydratur und Ertrag. Ber. dtsch. bot. Ges. 70, 67-78.

Belik, V.F. (1960) Die Bestimmung des Wasserbedarfs von Tomatenpflanzen durch Messung der Saugspannung und der Zellsaftkonzentration der Blätter. Fiziol. Rastenij, 7, 95-97, Russian.

Development BoARd Baghdad (1958) Dujailah Drainage Experiments Rep. Nr. 5 . EAton, F.M. (1942) Toxicity and accumulation of chloride and sulfate. J. agric. Res. 64, 357-399.

FukudA, Y. (1935) Über die Hydratur der Pflanzen und eine empirische Formel der Verdunstung unt Transpiration. G. Fischer, Jena.

Gauch, H.G. \& W Adleigh, C.H. (I945) Effect of high concentrations of sodium, calcium, chloride, and sulfates on ionic absorption by bean plants. Soil Sci. 59, I 39-I 53 .

Hayward, H.E. \& Wadieigh, C.H. (I949) Plant growth on saline and alkali soils. Advanc. Agronony, I, I-38.

Huber, B. (1932) Besprechnungen Walter, H.: Die Hydratur der Pflanzen. Bot. 25, 63I-635.

KreEB, K. (I957) Hydratur und Ertrag, Ber. dtsch. bot. Ges. 70, I2I-I 36.

KreEB, K. (1959) Die Bodenversalzung als störender Faktor bei Feldversuchen, Wachstum und Ertrag. Ber. dtsch. bot. Ges. 72, I23-I 37.

Kreeb, K. (I960a) Salzschädigung bei Kulturpflanzen. Pflanzenkr. Z. (Pflanzenpathologie) und Pflanzenschutz, 67, 375-399.

Kreeb, K. (I96ob) Über die gravimetrische Methode zur Bestimmung der Saugspannung und das Problem des negativen Turgors. Planta, 55, 274-282.

Kreeb, K. (I961a) Die Bedeutung der Hydratur für die Kontrolle der Wasserversorgung bei Kulturpflanzen. Beitr. Biol. Pflanzen, 36, 57-89.

Kreeb, K. (I96Ib) Zur Frage des negativen Turgors bei mediterranen Hartlaubpflanzen unter natürlichen Bedingungen. Planta 56, 479-489.

Kreeb, K. \& ÖNAL, M. (I96I) II. Mitteilung. Die Berücksichtung von Atmungsverlusten während der Messungen. Planta 56, 403-4I 5 .

Loвov, M.F. (I95I) Die Beziehungen zwischen dem Wachstum und der Zellsaftkonz. der Pflanzen. Bot. Z. (Russian) 36, 2 I-28.

Renner, O. (I933a) Wasserzustand und Saugkraft. I: Erwiderung an H. Walter. II: Berichtigung. Planta, 19, (1933b) 644-647.

RenNer, O. (I933b) Zur Kenntnis des Wasserhaushaltes javan. Kleinepiphyten. Mit einem Anhang zu den osmot. Zustandsgrößen. Planta, I8, 2 I 5-287.

SandS, K. \& Rutter, A.J. (I959) Studies in the growth of young plants of Pinus sylvestris L. II: The relation of growth to soil moisture tension. Ann. Bot. 23, 269-284.

SLATYER, R.O. (1958) The measurement of DPD in plants by a method of vapor equilibration. Aust. biol. Sci. 2, 349-365.

Stavík, B. (1952) Der osmot. Wert der Holzpflanzen als Zeiger für ihre Standortseignung. Tschechosl. Biologija, I, Nr. 2, Russian.

Stieglitz, H. (1936) Beiträge zur Zellsaftschemie des Winterweizens. Z. Pflanzenern., Dïngung und Bodenk., 43, I 52-170.

Stocker, O. (I954) Der Wasser- und Assimilathaushalt südalger. Wüstenpfl. Ein 
Beitrag zum Xerophyten- und Halophytenproblem. Ber. dtsch. bot. Ges. 67, 288-298.

Wadleigh, C.H. \& Ayres, A.D. (I945) Growth and biochemical composition of bean plants as conditioned by soil moisture tension and salt concentration. Plant Phys. 20, I06-132.

Walter, H. (I928) Über die Preßsaftgewinnung für die kryoskop. Mess. des osmot. Wertes bei Pflanzen. Ber. dtsch. bot. Ges. 46, 539 .

WALter, H. (I931a) Die Hydratur der Pflanze. G. Fischer, Jena.

W Alter, H. (I93 I b) Die kyroskop. Best. des osmot. Wertes bei Pflanzen. Abderhalden. Handb. d. biol. Arbcitsmethoden, Abteil., XI, 4, 353-37I.

Walter, H. (I950) Grundlagen des Pflanzenlebens. E. Ulmer, Stuttgart.

Walter, H. (1955) The water economy and the hydrature of plants. Ann. Rev. Plant Plysiol. 6, 239-252.

Walter, H. (I96I) Die Hydratur der Pflanze als Indikator ihres Wasserhaushalts. Handbuch der Pflanzenemälirung; in press.

Walter, H. \& Thren, R. (I934) Die Berechnung d. osmot. Wertes auf Grund von kryosk. Messung. und der Vergleich mit Saugkraftbest. Jb. Wiss. Bot. 80, 20-35. Webster, I.F. \& Viswanath, B. (I92I) Further studies of alkali soils in Iraq. Memoir Nr. 5, Dep. of Agriculture (Baghdad). 


\title{
A COMPARISON BETWEEN THE WATER RELATIONS OF SPECIES WITH CONTRASTING TYPES OF GEOGRAPHICAL DISTRIBUTION IN THE BRITISH ISLES
}

\author{
Margaret S. Jarvis \\ Department of Botany, University of Sheffield $\star$
}

\section{INTRODUCTION}

IN the Sheffield region, where the experiments to be described were conducted, many species of plants attain the north-western or south-eastern limit of their range in Great Britain. The distribution of species such as Prunus padus L. and Saxifraga hypnoides L. corresponds with the predominantly upland part of Great Britain to the north-west; that of species such as Thelycrania sanguinea (L.) Fourr. (Cormus sanguinea (L.)) and Filipendula vulgaris Moench. with the more lowland part to the south-east. Hence there are correlations between the patterns of distribution of the species and various features of climate such as annual rainfall, amount of sunshine and average maximum or minimum temperatures. Similarly, the distribution of such species on slopes of various aspects in the Derbyshire dales can be correlated with features of the microclimate. Species at the south-eastern limit of their range tend to exhibit preference for slopes of northerly aspect, and, conversely, species at the north-western limit of their range are restricted to, or most abundant on, the south-facing slopes.

Measurements made with plaster-of-Paris electrical resistance blocks in the summer of 1959 confirmed that on such south-facing slopes the soil dried out more rapidly and to higher soil moisture tensions than the soil on north-facing slopes. For example, after a fortnight without rain in August, 1959, the soil moisture tension at $4 \mathrm{~cm}$ depth was $20 \mathrm{~atm}$ on a slope of south aspect and from $I \cdot I$ to $2 \cdot 9$ atm on the opposite slope of northern aspect.

An investigation of the response of plants of these species to increases in soil moisture tension and to low atmospheric humidity was made experimentally in the course of an attempt to elucidate the factors which were limiting distribution. Two herbaceous species, S. hypnoides and F. vulgaris, and two woody species. P. padus and T. sanguinea were used.

* Now at The Institute of Physiological Botany of the University of Uppsala, Uppsala, Sweden. 


\section{THE RELATION OF GROWTH TO SOIL MOISTURE REGIME}

Method. In this series of experiments the plants were grown at three controlled soil moisture regimes. In the first the soil was kept watered so that measurable soil moisture tensions did not develop; in the second and third the soil was allowed to dry out to pre-determined levels of soil moisture tension (SMT) before watering took place. Results, from field experiments particularly, on the relation of growth of plants to soil moisture conditions, have often been confused by the difficulties involved in obtaining an integrated value of the soil moisture tension in the soil actually exploited by the root system, and also by differences in the rate of extension of the root system into regions of moister soil. In order to control these factors it was considered essential that the plants used in these experiments should be grown in containers, so that there would be uniform exploitation of the whole enclosed volume of soil by the root systems and consequent even drying-out. The containers were circular polythene bowls, $30 \mathrm{~cm}$ diameter, $13 \mathrm{~cm}$ deep. The same type of soil was used in all these experiments, and in all other experiments described in this paper. This was a limestone soil, from Haydale, Derbyshire, on which all the species grew well, so that nutrient and aeration factors were unlikely to be limiting.

The soil moisture tension was measured daily, using Bouyoucos plasterof-Paris electrical resistance blocks. These had been placed in the centre of the volume of soil in each container at the time of planting. The blocks were calibrated in a modified form of a Richards' pressure membrane apparatus (Richards, I94I). The structure and manufacture of the blocks and the apparatus used for calibration have been described in detail by Jarvis, M.S. (1960).

The experiments were carried out in the summer of 1959 in an unheated, well-ventilated glasshousc. The position of the containers was altered daily to minimise the effect of gradients of temperature and light. Measurements were made at the beginning of the experiment and at intervals, for ten to twelve weeks. Total leaf area was used as the most suitable estimate of growth which could be made on species of different growth forms without destroying the plants. The length of each leaf of Filipendula vulgaris, and the length and breadth of each leaf of Thelycrania sanguinea and Prunus padus were measured and the leaf areas were calculated from relationships established from samples of leaves taken at the end of the experiment. The projected area of each plant of Saxifraga lypnoides was measured. The num- 
ber of plants per container was 7 for F. vulgaris; 36 for S. hypnoides; 4 for $T$. sanguinea; and 4 for $P$. padus. The containers were not replicated. Results. Results for the four species are presented in Tables I(a)-(d).

Considering first the herbaceous species, it is apparent that growth of S. hypnoides was significantly reduced in moisture regime I as compared with $\mathrm{O}$; and also in II as compared with I. In contrast, the differences in growth of F. vulgaris in the same moisture regimes were not significant. The significance of the differences between treatments was decreased by the presence of one or two exceptionally small plants in each container. For all species, to ensure that the soil would be fully exploited by roots, it was necessary to have the plants rather close together; and it is possible that inter-plant competition caused an increase in the between-plant variation within each treatment. Notwithstanding, it is apparent that the growth rate of $S$. hypnoides was depressed to a larger extent in moisture regimes I and

\section{TABLE I}

Growth of four species in a limestone soil under three soil moisture regimes: $\mathrm{O}$, soil which was watered sufficiently often to prevent the development of measurable soil moisture tension (SMT) (i.e., $0 . \mathrm{I}$ to $0.2 \mathrm{~atm}$ ); I, soil watered after drying-out to I atm SMT; II, soil watered after drying-out to $2 \mathrm{~atm} \mathrm{SMT.} \mathrm{LSD} \mathrm{=} \mathrm{least} \mathrm{significant} \mathrm{difference}$

(a) Filipendula vulgaris

$$
(' P '=0.05) \cdot \text { n.s. }=\text { not significant }
$$

\begin{tabular}{|c|c|c|c|}
\hline \multirow{2}{*}{$\begin{array}{l}\text { Time } \\
\text { (days) }\end{array}$} & \multicolumn{3}{|c|}{ Mean leaf area per plant $\left(\mathrm{cm}^{2}\right)$} \\
\hline & $\mathrm{O}$ & I & II \\
\hline 0 & 3.5 & 4.0 & 5.0 \\
\hline $3 \mathrm{I}$ & $19^{\circ} \mathrm{O}$ & 14.5 & I $5{ }^{\circ} 0$ \\
\hline SI & $38 \cdot 0$ & $29 \cdot 5$ & 25.0 \\
\hline 85 & $S I^{\circ} \circ$ & $54^{\circ} \mathrm{O}$ & $45^{\circ} 0$ \\
\hline
\end{tabular}

Differences between treatments not significant.

(b) Saxifraga hypnoides

\begin{tabular}{ccccc} 
Time & \multicolumn{4}{c}{ Mean plant area $\left(\mathrm{cm}^{2}\right)$} \\
\cline { 2 - 5 } (days) & $\mathrm{O}$ & $\mathrm{I}$ & $\mathrm{II}$ & LSD \\
IS & $\mathrm{I} \cdot 6$ & $\mathrm{I} \cdot \mathrm{S}$ & $\mathrm{I} \cdot \mathrm{S}$ & $\mathrm{n} . \mathrm{S}$. \\
SO & $3 \cdot 2$ & $\mathrm{I} \cdot 6$ & $\mathrm{I} \cdot \mathrm{I}$ & $\mathrm{O} \cdot 5$ \\
73 & $4 \cdot 0$ & $2 \cdot 3$ & $\mathrm{I} \cdot 3$ & $\mathrm{I} \cdot 0$ \\
93 & $5 \cdot 0$ & $2 \cdot 8$ & $\mathrm{I} \cdot \mathrm{T}$ & $\mathrm{I} \cdot 0$
\end{tabular}


(c) Thelycrania sanguinea

\begin{tabular}{|c|c|c|c|c|c|c|c|}
\hline \multirow{2}{*}{$\begin{array}{l}\text { Time } \\
\text { (days) }\end{array}$} & \multicolumn{4}{|c|}{ Mean leaf area per plant $\left(\mathrm{cm}^{2}\right)$} & \multicolumn{3}{|c|}{ Mean leaf number per plant } \\
\hline & $\mathrm{O}$ & I & II & $\stackrel{\mathrm{LSD}}{\overbrace{}^{2}}$ & $\mathrm{O}$ & I & II \\
\hline 12 & $69 \cdot 0$ & $56 \cdot 5$ & $40 \cdot 0$ & & $4 \mathrm{I}$ & 40 & 23 \\
\hline 60 & $260 \cdot 0$ & $57 \cdot 5$ & $21 \cdot 5$ & I 37 & 80 & 32 & IO \\
\hline 84 & $568 \cdot 0$ & I I $8 \cdot 0$ & $43^{\circ} 0$ & 74 & I 12 & so & 22 \\
\hline
\end{tabular}

(d) Prunus padus

\begin{tabular}{|c|c|c|c|c|c|c|c|}
\hline \multirow[b]{2}{*}{$\begin{array}{l}\text { Time } \\
\text { (days) }\end{array}$} & \multicolumn{4}{|c|}{ Mean leaf area per plant $\left(\mathrm{cm}^{2}\right)$} & \multicolumn{3}{|c|}{ Mean leaf number per plant } \\
\hline & $\mathrm{O}$ & I & II & LSD & $\mathrm{O}$ & I & II \\
\hline o & $50 \cdot 0$ & $42 \cdot 0$ & $52 \cdot 0$ & n.s. & $13 \cdot 5$ & $12 \cdot 0$ & $13 \cdot 5$ \\
\hline 92 & $87 \cdot 5$ & $55 \cdot 5$ & $57 \cdot 5$ & n.s. & $15 \cdot 0$ & $10 \cdot 0$ & I I $\cdot 5$ \\
\hline
\end{tabular}

II relative to the control (moisture regime O) than was that of $F$. vulgaris. For T. sanguinea there were significant differences in total leaf area per plant between treatments $O$ and I after 60 days; and between treatments $\mathrm{O}$ and I, and I and II after 84 days: for $P$. padus the differences between treatments in total leaf area per plant were not significant after 92 days. For each of these woody species, one of the most striking effects of increased SMT was the abscission of some of the mature leaves, so that, during the whole or part of the period of the experiment there was a net reduction in leaf number for plants in treatments I and II but a net gain in treatment $O$. The changes in total leaf area per plant throughout the experiment, therefore, represent the difference between the increase in leaf area resulting from production and expansion of new leaves and the decrease resulting from the abscission of mature leaves. There was no such loss of leaves from plants of treatment $\mathrm{O}$ for either species. The production and expansion of new leaves at the shoot apices of $T$. sanguinea was continuous throughout the experimental period, provided that soil moisture tension was not limiting. However, in $P$. padus leaf production was not continuous but occurred in flushes, as is common for many tree species. In a second experiment, with first-year seedlings of $P$. padus, there was no further expansion or production of leaves during three months of the three moisture regime treatments. In treatments I and II all leaves abscissed; in treatment $\mathrm{O}$ all leaves remained apparently healthy. (In the following spring the plants from the three treatments grew vigorously, in soil kept watered.) 
It was not feasible to measure SMT in the containers more than once daily. The watering-to-drying cycles of treatments I and II were therefore not necessarily to exactly I or 2 atm, unless the SMT had reached these levels precisely at the time of measurement. Since the rate of drying-out of the soil depended both on environmental conditions and on the transpiring surface of the plants in the container, it is apparent that the length of the watering-to-drying cycles could neither be regular through the cxperimental period for one species, nor precisely comparable between species. It was therefore necessary to use some method of summing SMT in order that comparisons between species might be made. Graphs of SMT against time were constructed for each contaimer and accumulated SMT up to a level of I atm was measured, using a planimeter. This arbitrary level was chosen on the assumption that I atm would be approximately the SMT at which a considerable reduction in growth rate would occur. (This assumption, and the choice of the levels of I and 2 atm at which the soil was watered in treatments I and II, were based on the results obtained for Pimis sylvestris by Sands andRutter (1959) and other results in the literature, quoted by these authors.) The accumulated SMT, in 'atmosphere-days' was finally expressed as a percentage of the total number of the days in the period, so that, for example, a resulting figure of $25 \%$ would represent the situation where the SMT was I atm or more on a quarter of the days of the period or $0.5 \mathrm{~atm}$ for half the days of the period. The obvious disadvantage of this method of summing SMT lies in the premise that these two situations will have the same effect on growth. The relation between accumulated SMT and increase in total leaf area per plant throughout the experimental period (increase in mean plant area, for $S$. hyproides) as a percentage of that for plants growing in soil at field capacity, is shown in Fig. I. Tentative deductions can be made from these curves. For T. sangninea and S. Iypnoides growth is reduced to $50 \%$ of that in saturated soil by a soil moisture regime in which the SMT is at less than 0.5 atm for $50 \%$ of the period; and this indicates, therefore, that leaf area increase is reduced to a negligible amount by a soil moisture tension of $0.5 \mathrm{~atm}$ or less. Extrapolation of the curve for F. vulgaris indicates that leaf area increase would be reduced to $50 \%$ of that in saturated soil by a soil moisture regime in which the SMT is at a level of I atm or more for $50 \%$ of the time; hence the growth of this species is considerably less sensitive to increases of SMT than that of S. liypnoides or T. sanguinea. P. padus appearsintermediate in response, but the high betweenplant variation and the low rate of leaf area increase rendered the differences between treatments not significant, so that deductions based on the curve for this species are of doubtful validity. 


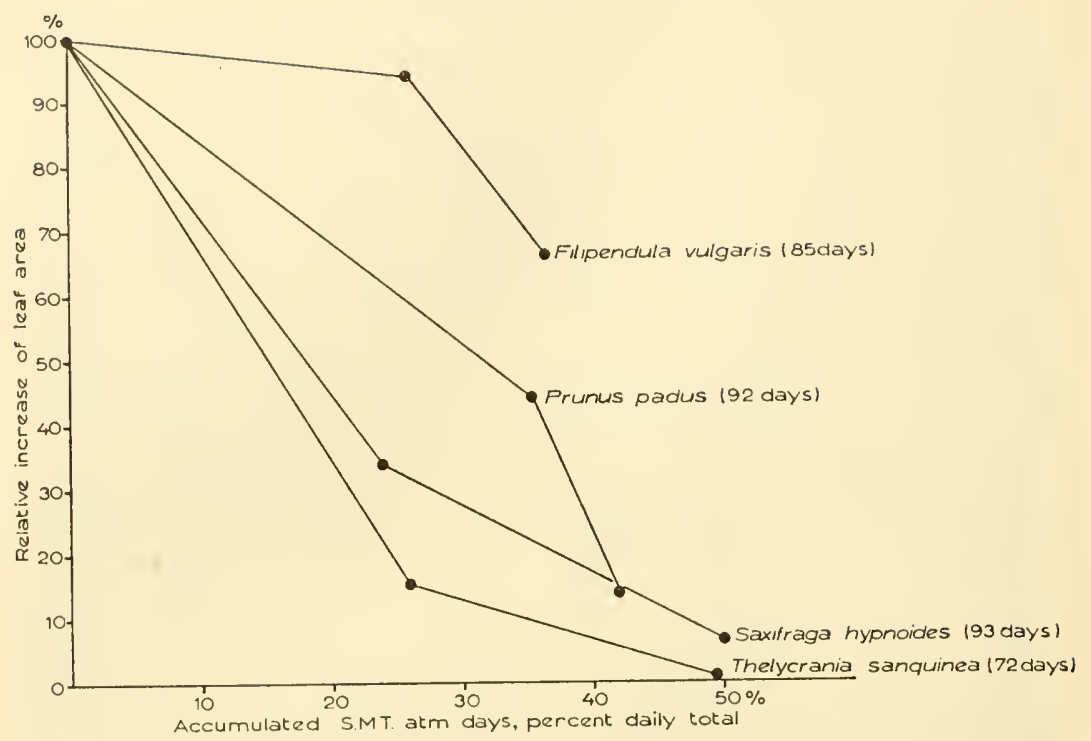

FIG. I. The relationship between leaf area increase and accumulated soil moisture tension for four specics grown in three soil moisture regimes. Increase in leaf area as percentage of that for plants on soil at field capacity. For explanation accumulated

SMT, see text.

\section{THE EFFECT OF SOIL MOISTURE TENSION ON GROWTH RATE}

These deductions as to the approximate level of SMT at which growth is reduced were tested in a further series of experiments. The response of each species to changes in SMT within a watering-to-drying-out cycle was investigated, in order to determine, as accurately as possible,

(a) the lowest SMT which causes a reduction in growth rate,

(b) the lowest SMT which causes a cessation of measurable growth.

Method. The rate of increase of SMT was sufficiently rapid to necessitate daily measurements of SMT and of growth, made at the same time each day. Therefore a quick and sensitive method of detecting changes in growth rate of each species was essential. Daily measurement of total leaf length was found to be a practicable procedure; and for plants of all the species the rate of increase in total leaf length with time was constant, in soil where measurable SMTs did not develop. Hence, deviations from this 
rate were easily detectable, as changes in the slope of curves of total leaf length against time.

All experiments were carried out in a heated glasshouse $\left(60-70^{\circ} \mathrm{F}\right)$, with supplementary lighting with fluorescent tubes, during the winter of 1959 to 1960 . Plaster-of-Paris resistance blocks were placed in the soil at the time of planting, and the experiments were commenced only after the roots had grown through the whole soil volume. The blocks used were individually calibrated to ensure the maximum possible accuracy in conversion of block readings to atmospheres SMT. Two blocks were used in each container.

The measuring technique varied according to the species; either the total leaf length of the plant, or of certain shoots, or the length of individual leaves, constituted the basic unit measured. Leaves which had ceased to elongate at the beginning of the experiment were not measured since it was required only to detect changes in the rate of increase of total leaf length and not to obtain absolute values for total leaf length.

Each container was subjected to several watering-to-drying-out cycles. All the curves for each species were examined and the SMT corresponding with the first decrease in slope of the curve (i.e., the lowest SMT causing a decrease in the rate of increase in total leaf length) was determined, subjectively, for each cycle. Similarly the SMT above which there was no detectable increase in total leaf length was determined.

Results. Figs. 2-5, inclusive, show examples of the curves obtained.

There were marked differences in response between $S$. hypnoides and $F$. vulgaris. The growth rate of the former was depressed by the smallest SMTs measurable with the plaster-of-Paris blocks, i.e. by approximately 0.2 to $0.3 \mathrm{~atm}$. There was no detectable increase in total leaf length after drying-out of the soil to a SMT of, at the most, 0.5 atm. In contrast, no depression of growth rate of leaves of $F$. vulgaris was caused by SMTs below 0.7 or $0.8 \mathrm{~atm}$. Cessation of elongation occurred at $\mathrm{I} \cdot 0 \mathrm{~atm}$ for about two thirds of the leaves; and at $\mathrm{I} .5$ or $2.0 \mathrm{~atm}$ for the remainder. There was apparently no differential effect of age of the leaf on the response of leaf elongation rate to increase in SMT.

For P. padus the lowest SMT which resulted in a reduction in growth rate was about $0.3 \mathrm{~atm}$ : the corresponding value for $T$. sanguinea was $0.7 \mathrm{~atm}$. This is a difference similar to that established for S. hypnoides and F. vulgaris. There was a large variation between shoots in the SMT at which there was apparent cessation of growth, especially for $P$. padus; and this masked any 
difference which might have existed between the species with respect to this particular response.

Thus the results from these experiments supplement the conclusions drawn from the results of the soil moisture regime experiments. The northern species, S. hypnoides and P. padus, were more sensitive to the effect of increase in SMT in depressing their rate of growth than were the southern species, F. vulgaris and T. sanguinea.

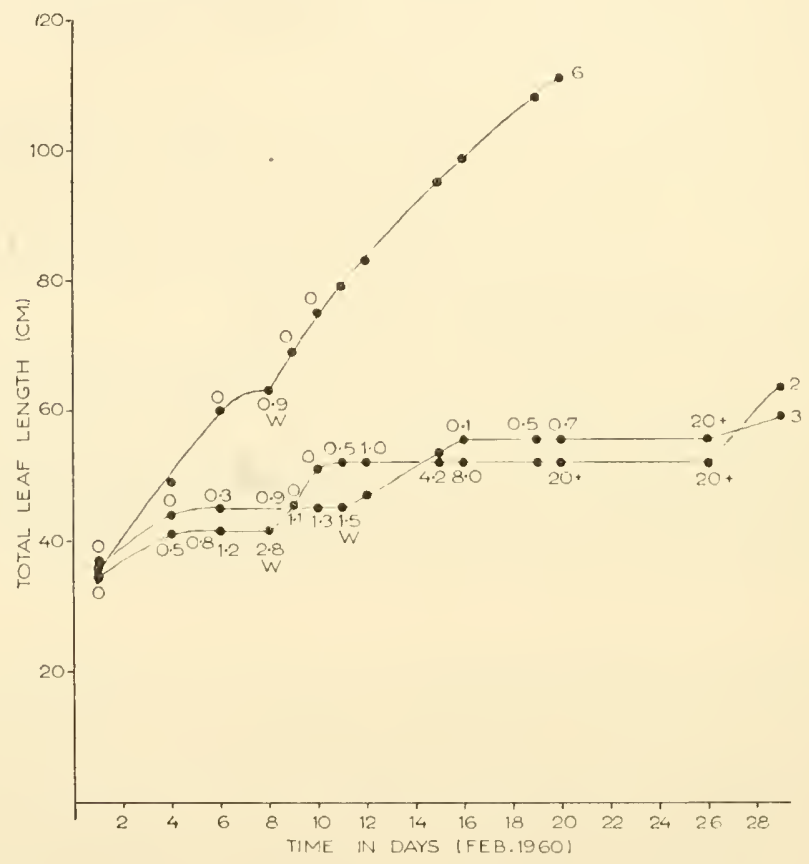

FIG. 2. Saxifraga hypnoides. The effect of soil moisture tension on the rate of increase of total leaf length. ( $1-29$ February 1960.) For details see text. Container numbers are at the ends of the curves. Soil water tensions (atm) are shown beside each point. The soil was watered thoroughly at points marked W. Plants in container 6 were not subjected to drying-out after day 8.

THE RELATION BETWEEN SOIL MOISTURE, LEAF WATER DEFICIT AND TRANSPIRATION RATE

Differences, in response to changing SMT, in the leaf growth of different species may arise in several ways; firstly, through different degrees of 
tolerance to the same loss of turgidity in the leaf; secondly, through differences in the maintenance of leaf turgor attributable to differences in the ability to take up water from soil of increasing SMT; and thirdly, through differences in maintenance of leaf turgor attributable to differences in the ability to restrict water loss from the leaves, for example, by stomatal closure and a subsequent low rate of cuticular transpiration. This third

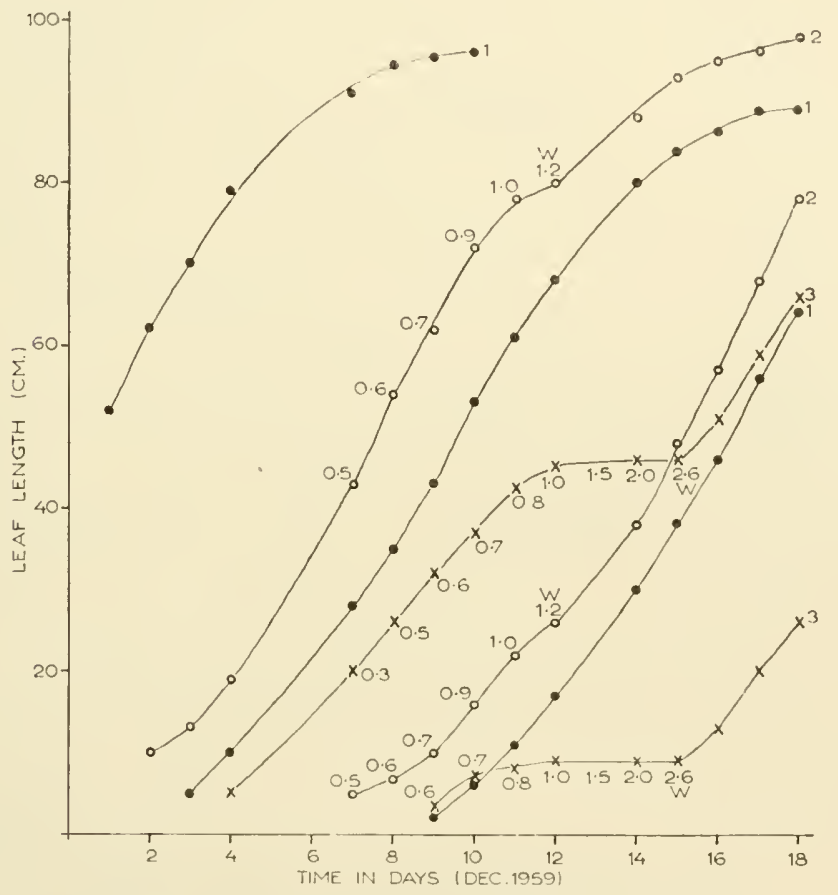

Frg. 3. Filipendula vulgaris. The effect of soil moisture tension on leaf elongation. (I - I 8 December 1959.) Each curve represents a single leaf. Container numbers are at the ends of the curves. Plants in container I were not subjected to drying-out. Soil moisture tensions (atm) for containers 2 and 3 are shown beside corresponding points on the curves. W: see Fig. 2.

possibility may result in maintenance of leaf turgor only at the expense of maintenance of the photosynthetic rate.

The relation between leaf water content and SMT was compared for the four species with the object of determining whether the greater effect of increasing SMT on the growth rate of Saxifraga lypuoides and Primus padus, as compared with Filipendula vulgaris and Tlelycrania sanguinea, was 
correlated with a lesser ability to maintain leaf water content under these conditions. Measurements of transpiration rate were concurrently made, in an attempt to distinguish maintenance of leaf turgor by increased water uptake from that by decreased water loss.

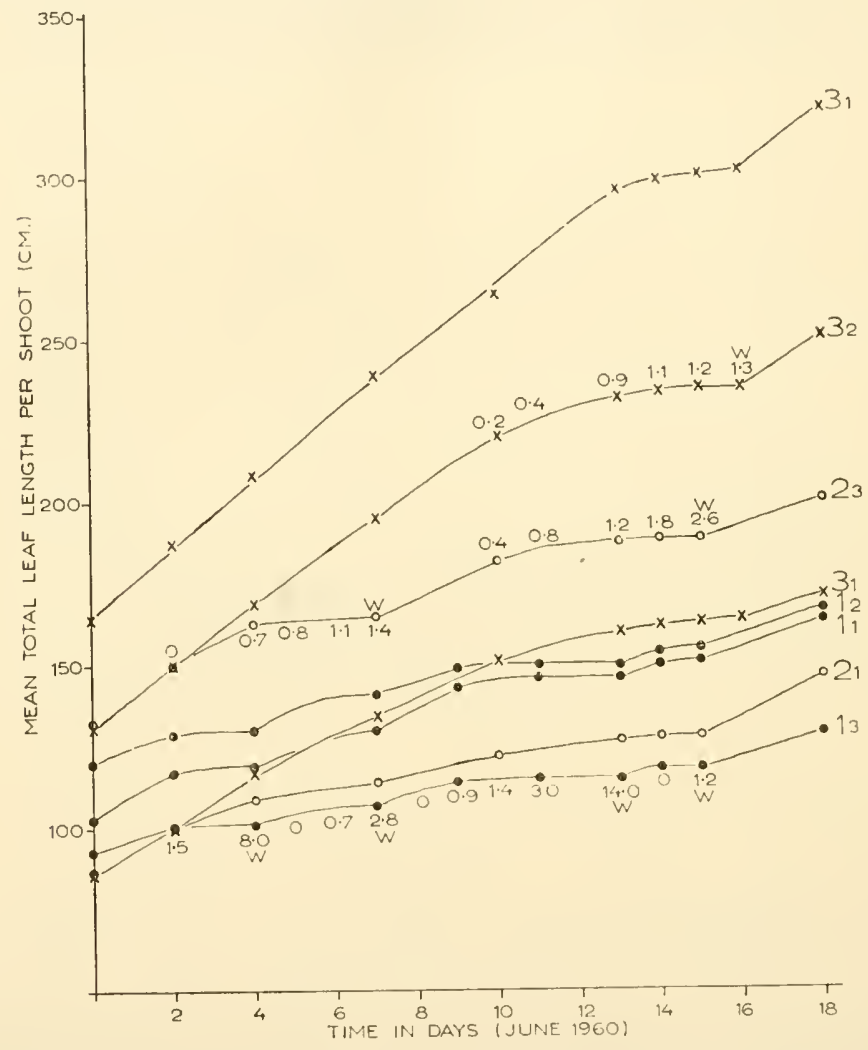

FIG. 4. Thelycrania sanguinea. The effect of soil moisture tension on the rate of increase of total leaf length. (I-I8 June 1960 .) The container number $(\mathrm{I}, 2$ or 3 ) and the number of the plant in the container ( 1,2 or 3 ) are at the ends of the curves. Soil moisture tensions for container $\mathrm{I}$ are shown beside corresponding points of curve $\mathrm{I}_{3}$; similarly for container 2 , by $2_{3}$; and for container 3 , by $3_{2}$. W: see Fig. 2 .

Methods (a) Leaf water content. This was expressed in terms of leaf water deficit (LWD), defined as the percentage reduction in leaf water content below that at full turgor; a concept introduced by Stocker (1929) and since widely used. The leaves were cut from the plant and weighed im- 
mediately on a torsion balance. They were then placed in a corked tube with the cut surface of the petiole in water. After 24 hours in the dark, at $15^{\circ} \mathrm{C}$, the leaves were blotted, re-weighed and dried in an oven. Preliminary tests, conducted to determine the effect of age and position of the leaf on

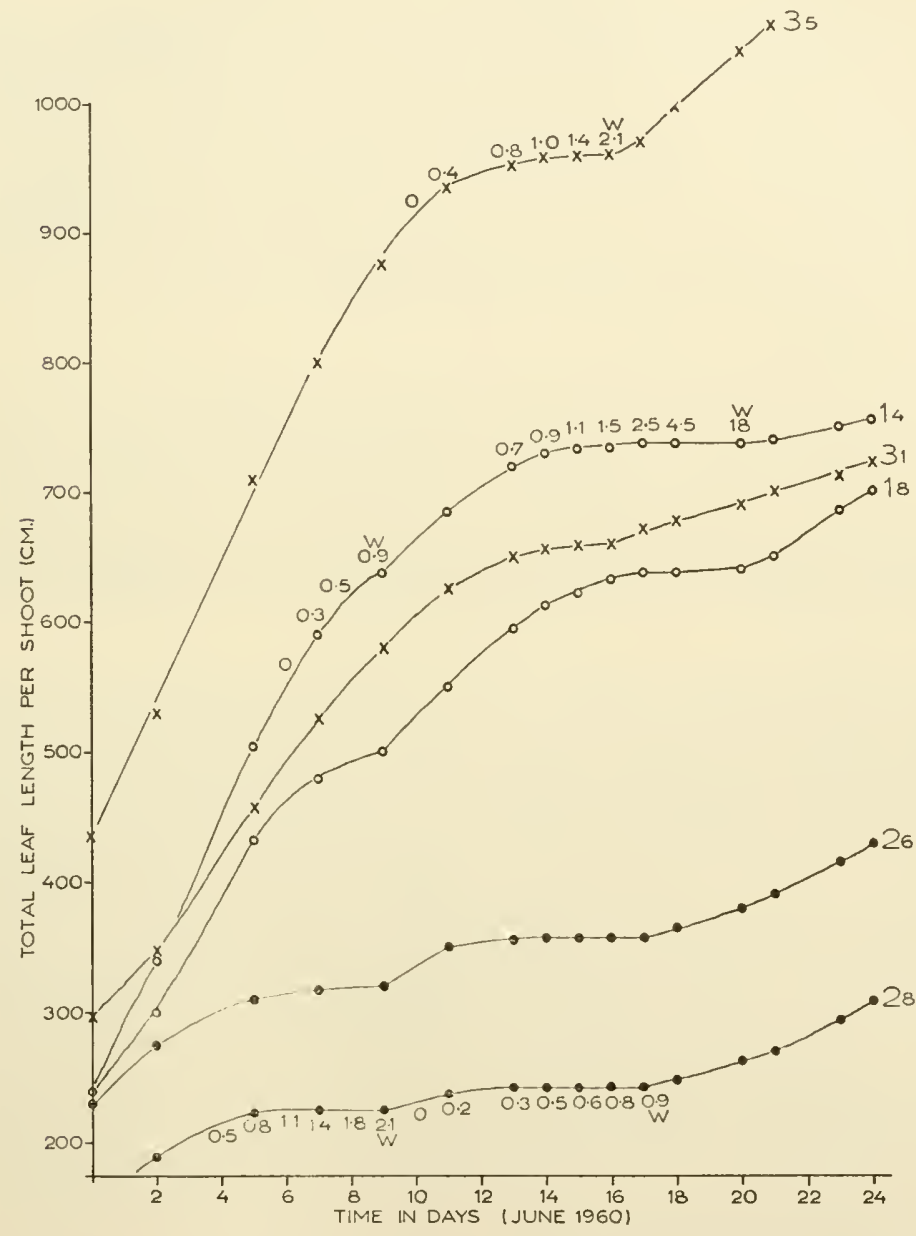

FIG. 5. Prunus padus. The effect of soil moisture tension on the rate of increase of total leaf length. (I-24 June I960.) The container number ( $I, 2$ or 3 ) and the number of the shoot are at the end of the curve. Soil moisture tensions (atm) for container $\mathrm{I}$ are shown beside corresponding points of curve $\mathrm{I}_{4}$; similarly for container 2 , by $2_{8}$; and for container 3 , by $3_{5}$. W: see Fig. 2. 
the LWD developed, showed, for P. padus, T. sanguinea and F. vulgaris, that there was little variation between values obtained for all mature leaves, i.e. leaves which were completely, or almost completely, expanded and which were not obviously senescent. The youngest leaves had apparently higher LWDs than the mature leaves, cf. Čatsky (I959).

(b) Transpiration rate. Transpiration rate was measured by determining the loss in weight of detached leaves during a standard time after cutting, this being the most practicable method available. Preliminary tests showed, for $P$. padus and T. sanguinea, that there was a constant rate of loss from 0.5 to $6.0 \mathrm{~min}$ after cutting, followed by a slight fall-off. The method was therefore considered satisfactory for these species. The experimental procedure adopted was to determine the loss in weight from $\frac{1}{2}$ to $4 \frac{1}{2}$ min after cutting. The transpiration rate was expressed as $\mathrm{mg}$ loss per $100 \mathrm{mg}$ (at $\frac{1}{2}$ min) per min.

Measurements of LWD and of transpiration rate (TR) were made on the plants used for the experiments on the effect of SMT on growth rate, described above; and on P. padus and T. sanguinea planted alternately within the same container, to ensure that SMT was identical for the two species. All experiments were conducted in a glasshouse, on days which were cloudy throughout, so that fluctuations in environmental conditions were relatively small.

Results. The results for $P$. padus and T. sanguinea are presented in Tables 2(a) and (b); and in Fig. 6. On July I 5, for soil with a SMT of below $0.2 \mathrm{~atm}$, there were no significant changes in LWD through the day for either species, and the differences between the LWDs of the species were not significant at any time of day (Tables $2(\mathrm{a})$ and (b)). No direct comparisons between the species for soil of higher SMT can be made, since the SMTs obtaining were not identical. There is, however, no evidence of a major difference in the LWDs developed at SMTs from 3 to 8 atm. For plants in soil at '20 atm' SMT it appears that the LWDs for leaves of T. sanguinea are larger than for $P$. padus. However, since these values of '20 atm' corresponded with the maximum reading of the electrical resistance blocks, such values may represent any value of SMT from 20 atm upwards. Hence, the soil in which the $T$. sanguinea plants were growing may have been at a higher SMT than that for $P$. padus.

In the experiment of 24 August 1960 (Fig. 6), designed to eliminate these difficulties, the LWDs of both species were smaller than for the previous experiments. With one exception, there was no overall increase in LWD through the day, from 7 a.m. to 7 p.m., so that water loss did not exceed 


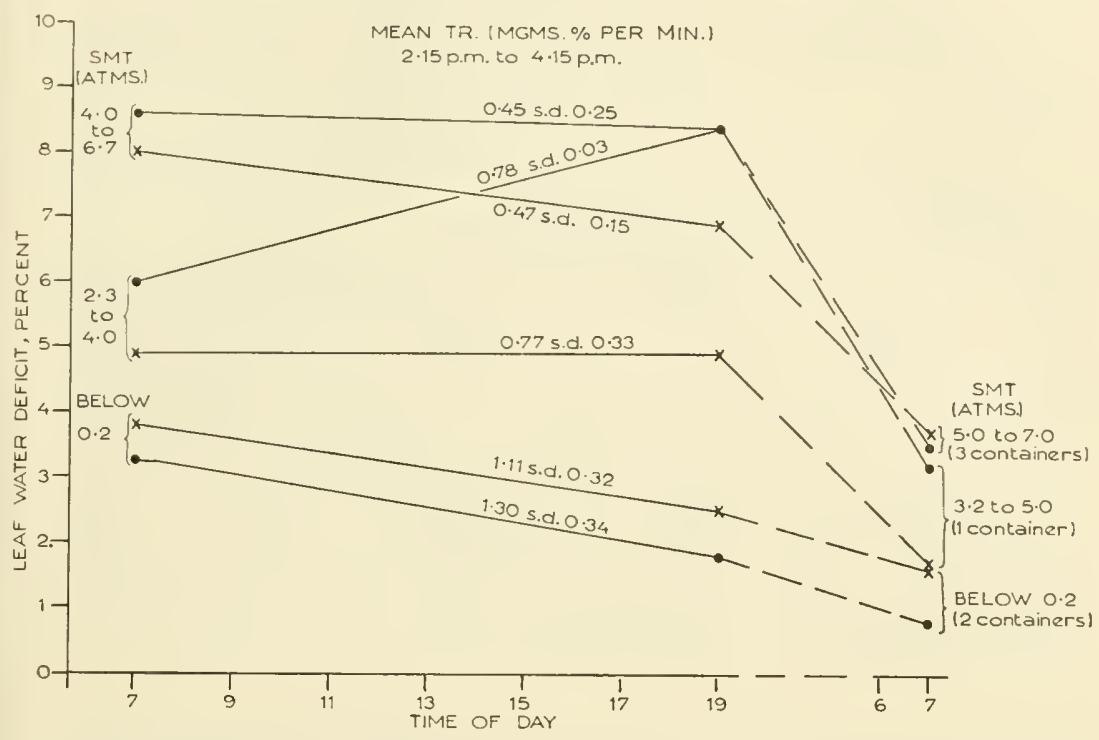

FIG. 6. The effect of soil moisture tension (SMT) on leaf water deficit and transpiration rate. (24 August 1960.)

- Thelycrania sanguinea

$\times$ Prunus padus

The two species were planted alternately in the containers. Values are means for at least ro leaves. Three containers had SMTs within the highest range of SMT (4.0 to $6.7 \mathrm{~atm}$ at the beginning of the experiment); one at the middle range $(2.3$ to $4.0 \mathrm{~atm})$; two at the lowest range (below $0.2 \mathrm{~atm}$ throughout the experiment). Readings of SMT were taken from four plaster-of-Paris blocks per container.

water uptake, even for plants in soil at more than $5.0 \mathrm{~atm}$ SMT. Values at 7 a.m. were smaller on 25 th than on the previous day, although SMT had increased slightly. The removal of two samples of leaves appreciably reduced the leaf area of each plant. Hence if equilibrium between plant and soil moisture was not achieved during the night, for plants with a normal number of leaves, then a reduction in leaf area might result in smaller early morning LWDs, which more closely approached the equilibrium value. It is difficult to explain the generally small values of LWD which prevailed, since environmental conditions were not very different from those during the previous experiments, and the transpiration rates were not very much lower than before. At 7 a.m., on both 24 and 25 August, there were no significant differences between LWDs of the two species. At 7 p.m., in the intermediate SMT condition, the mean LWD for T. sanguinea 
was just significantly larger than for $P$. padus (' $P$ ' $=0.05)$. In higher or lower SMTs the differences between species, in LWD at 7 p.m., were not significant.

There was no significant difference between the transpiration rates of the two species, in any of the treatments.

Table 2(c) shows results for S. hypnoides.

The $7 \mathrm{a} . \mathrm{m}$. value was significantly larger for the plants in soil at $20 \mathrm{~atm}$ SMT than for those in soil from 0.0 to $5.3 \mathrm{~atm}$ SMT, between which there were no significant differences. At $7 \mathrm{a} . \mathrm{m}$. on the same day, mean LWD for leaves of F. vulgaris, SMT $20 \mathrm{~atm}$, was $26 . \mathrm{I} \%$; for SMT $2.5 \mathrm{~atm}$, II $2 \%$; and for SMT less than $0.2 \mathrm{~atm}, 5 \cdot 9 \%$. The differences between these values were significant (for ' $P$ ' $=0.05$, least significant difference $=2 \cdot 1 \%$ ). It was not possible to compare transpiration rates of these two species, since reliable estimates of transpiration rate for $S$. hypnoides were not available. Results obtained by measuring the loss of water from detached shoots were too variable.

Discussion. For all four specics, increased SMT was associated with increased LWDs; and for P. padus and T. sanguinea, also with decreased transpiration rate. Such phenomena have been described for many species (e.g., Rutter and Sands, 1958, for Pinus sylvestris; Slatyer, I955, for cotton peanuts and sorghum). Despite the scantiness of the data, sufficient evidence was obtained to show that the major differences between the two tree species, in response of growth rate to increases in SMT, cannot be explained in terms of differences in the relation between LWD or transpiration rate and increase in SMT. For plants of these two species, there were no major differences observed between LWDs or transpiration rates prevailing, at SMTs from 0.0 to $20 \mathrm{~atm}$, and in moderate evaporating conditions.

Such data as were obtained for F. vulgaris and S. hypnoides indicate that the same conclusion may also be valid for these herbaceous species. Mean LWD values for S. hypnoides at SMTs of less than 0.2 atm and of $2.8 \mathrm{~atm}$, though not significantly different, were comparable in magnitude to those for F. vulgaris.

\section{DROUGHT RESISTANCE, AS DETERMINED USING CONTROLLED RELATIVE HUMIDITIES}

Resistance to reductions in growth rate resulting from low SMTs, considered previously, may be completely independent of resistance to injury 


\section{TABLE 2}

The relation between leaf water deficit (percent), transpiration rate ( $\mathrm{mg}$ per $100 \mathrm{mg}$ per min) and soil moisture tension (atm)

(a) Prunus padus (1 5.7.60)

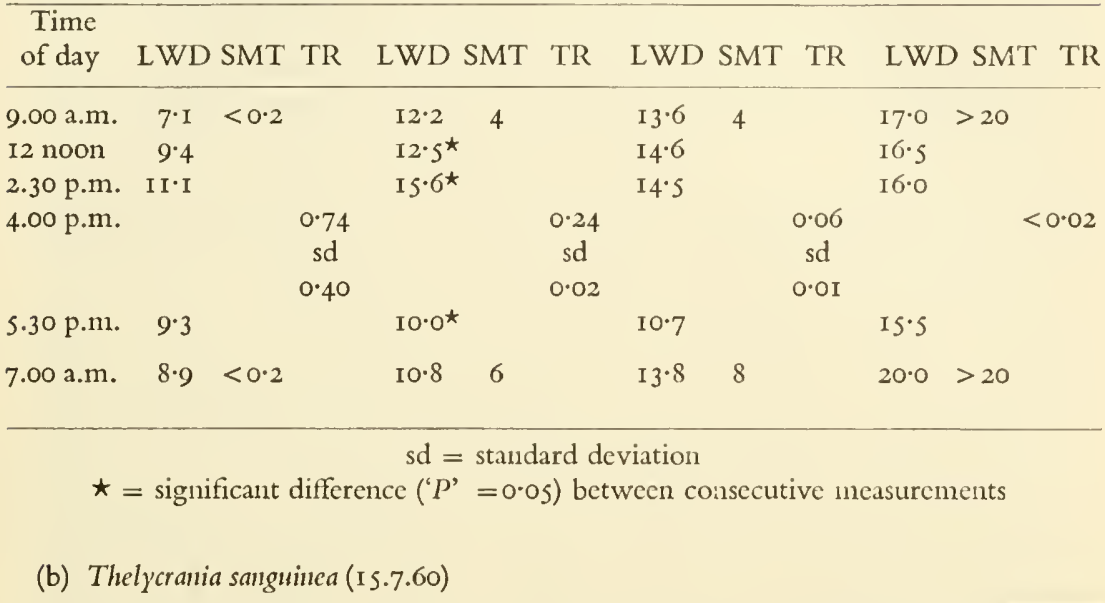

Time of day LWD SMT TR LWD SMT TR LWD SMT TR

\begin{tabular}{|c|c|c|c|c|c|c|c|c|c|}
\hline $9.00 \mathrm{a} . \mathrm{m}$. & $9 \cdot 0$ & $<0.2$ & & 13.0 & $2 \cdot 5$ & & $28 \cdot 0$ & $>20$ & \\
\hline I I.30 a.m. & $10 \cdot 0$ & & & $14 \cdot 0$ & & & $3 I \cdot O$ & & \\
\hline 2.00 p.m. & 10.5 & & & $16 \cdot 0$ & & & $28 \cdot 0$ & & \\
\hline 4.00 p.m. & & & I. SO & & & 0.34 & & & 0.02 \\
\hline s.30 p.m. & $8 \cdot 5$ & & & 13.5 & & & $27 \cdot 0$ & & \\
\hline $7.00 \mathrm{a} . \mathrm{m}$ & $7 \cdot 5$ & $<0.2$ & & $10 \cdot 0$ & 3.5 & & $29^{\circ} 0$ & $>20$ & \\
\hline
\end{tabular}

(c) Saxifraga hypuoides (4.4.60)

Time of day

LWD

\begin{tabular}{rrrrrrr} 
I0.30 a.m. & \multicolumn{1}{c}{ 6 } & 5 & 5 & 4 & I4 & I6 \\
I.00 p.m. & 7 & 5 & 5 & 2 & 8 & 20 \\
3.30 p.m. & 7 & 9 & II & 8 & 7 & 13 \\
5.00 p.m. & 8 & IO & 8 & I 3 & I3 & I7 \\
7.00 a.m. & 9 & I2 & 8 & I2 & I I & 22 \\
SMT & $<0.2$ & I.O & I.I & 2.8 & 5.3 & 20
\end{tabular}


in conditions of more severe drought. A method, of the type suggested by Levitt (1958), was designed to compare the resistance of the species to the development of critical LWDs, in atmospheres of a range of controlled relative humidities, at a standard temperature. (Critical LWD is the maximum LWD from which recovery of turgidity can be made.) Detached shoots of the species were subjected to the standard drying conditions for a standard time. Half the shoots had the cut ends in water, so that water uptake was not restricted: the other half were not supplied with water. Thus the drought resistance of the species can be compared, in conditions representing both situations where soil water is freely available and is unavailable. The critical LWDs, and the relative humidities which induced their development, were determined for the four species.

Methods. The drought chambers consisted of polythene bowls, $30 \mathrm{~cm}$ square and $\mathrm{I} 2 \mathrm{~cm}$ deep, covered with glass sheets. Twenty glass tubes were stuck, at evenly spaced intervals, on to the bottom of each chamber. Up to half of these were filled with water. The tops of all were sealed with 'parafilm'. The relative humidity (RH) was controlled by one litre of an appropriate sulphuric acid-water mixture. The change in this solution during an experiment was never greater than that equivalent to a $\mathrm{I} \%$ increase in RH. The experiments were carried out in growth chambers at $25^{\circ} \mathrm{C}$, with a standard light source.

Twenty leafy shoots were used in each chamber; half with their stems in water: half without water and with the cut ends of the stems Vaselined. The stems were pushed through the 'parafilm' seals into the glass tubes. The 'parafilm' prevented direct evaporation from the water into the drought chamber; and also supported the stems in positions arranged to give even distribution of the leaves within the chambers.

The shoots were subjected to the controlled RHs for 20 hours; I 2 hours in the dark, followed by 8 hours in the light. The dark period was designed to allow RH equilibration throughout the chamber, while water loss was restricted by stomatal closure. During the drought period the chambers were rocked gently from time to time to ensure change of the acid-water surface and to promote circulation of the air in the chamber. At the end of the period the acid-water mixtures were siphoned off and replaced with water. Samples of leaves were taken for LWD determinations. The bases of all the shoots were re-cut and replaced in the tubes, which had all been filled with water. The chambers were placed in the dark for 24 hours, after which period recovery of the leaves was estimated. Recovery of turgidity could be assessed subjectively, or objectively by comparing the ratio of saturated weight (i.c., the weight of the leaves after 24 hours in the dark, 
in an atmosphere of $100 \% \mathrm{RH}$, with the petioles in water) to dry weight. The value of this ratio was significantly lower for leaves permanently injured by the droughting treatment than for normal leaves and leaves which recovered.

Results. (1) Prunus padus and Thelycrania sanguinea. Five experiments were conducted; two with each of the species separately, and the fifth with shoots of the two species arranged alternately in the same drought chambers. It was thought likely that the apparent differences in response of leaves of a single species on successive occasions might be attributable to differences in environmental conditions, such as would arise if there were incomplete control of RH. Experiments using more than one species per chamber ensured that the results would be comparable.

In no experiment was there drought injury to leaves on shoots whose cut ends were in water. After the drought period, at all RHs, mean LWD for such leaves was less than $5 \%$. Results for shoots to which water was unavailable, are presented in Tables 3 and 4 .

Table 3 shows the difference in the ability of the two species to recover from the droughting treatments. The $\mathrm{RH}$ which could be tolerated was

\section{TABLE 3}

The recovery (as a percentage of the total number of leaves) of leaves on detached shoots of Prumus padus and Thelycrania sanguinea after subjection to atmospheres of various relative humidity, at $25^{\circ} \mathrm{C}$, for a 12 -hour period in the dark followed by an 8-hour period under a standard light source of $400 \mathrm{ft}$ candles; water was not supplied

\begin{tabular}{|c|c|c|c|c|c|c|}
\hline \multirow{3}{*}{$\mathrm{RH}$} & \multicolumn{6}{|c|}{ Recovery (as percentage of the total number of leaves) } \\
\hline & \multicolumn{3}{|c|}{ T. sanguinea } & \multicolumn{3}{|c|}{ P. padus } \\
\hline & 6.10 .59 & 22.6 .60 & I 3.7 .60 & I4.9.59 & 10.5 .60 & I 3.7 .60 \\
\hline 100 & 100 & IOO & 100 & & IOO & 100 \\
\hline 95 & & & 100 & & & IOO \\
\hline 87 & 100 & & IOO & & & 100 \\
\hline 76 & 66 & IOO & 100 & 30 & IOO & 66 \\
\hline 67 & & & 40 & & & 0 \\
\hline 59 & o & 0 & & & & \\
\hline 56 & & & & 0 & 0 & \\
\hline SI & & & 0 & & & o \\
\hline below so & 0 & 0 & 0 & 0 & o & 0 \\
\hline
\end{tabular}


TABLE 4

The mean leaf water deficits (LWD) developed by leaves on detached shoots of Prunus padis and Thelycrania sanguinea after droughting. Same experiments as Table 3. LWDs for leaves which did not regain turgor when left overnight in a saturated atmosphere with their petioles in water, after the droughting treatment, were calculated by using a value for the saturated weight obtained from the ratio of mean saturated weight to dry weight for those leaves, in the same experiment, which recovered. The value for critical LWD (the largest LWD from which turgidity can be regained) is between the largest LWD from which recovery occurred and the smallest from which recovery did not occur

\begin{tabular}{|c|c|c|c|c|c|c|}
\hline \multirow{3}{*}{ RH } & \multicolumn{6}{|c|}{ Mean LWD developed (with standard deviations) } \\
\hline & \multicolumn{3}{|c|}{ T. sanguinea } & \multicolumn{3}{|c|}{ P. padus } \\
\hline & 6.10 .59 & 22.6 .60 & I 3.7 .60 & I 4.9.59 & I0.5.60 & 13.7 .60 \\
\hline IOO & 36 & I3 & 24 & & I7 & I6 \\
\hline 95 & & & 24 & & & 20 \\
\hline 87 & 38 & & 40 & & & 24 \\
\hline 78 & $6 \mathrm{I}$ & 46 & 44 & 45 & 35 & 35 \\
\hline 67 & & & 60 & & & 48 \\
\hline 59 & 87 & 79 & & & & \\
\hline 56 & & & & 52 & 66 & \\
\hline $5 \mathrm{I}$ & & & 67 & 54 & & 62 \\
\hline 48 & 84 & 85 & & & & \\
\hline 43 & & & & 77 & 77 & \\
\hline 35 & & & & 68 & & \\
\hline \multirow[t]{3}{*}{25} & 94 & 89 & & 80 & & \\
\hline & & & Critical lea & vater def & & \\
\hline & $58-77$ & $57-70$ & $53-54$ & $<36$ & $43-5 I$ & 29 \\
\hline
\end{tabular}

slightly lower for T. sanguintea than for P. padus. This conclusion is based on the results of the experiment where shoots of the species were droughted together. All the leaves of $T$. sanguinea, compared with $66 \%$ of leaves of P. padus, recovered from the effect of $78 \% \mathrm{RH}$; and $40 \%$ of the leaves of $T$. sanguinea recovered from the effect of $67 \% \mathrm{RH}$, while no $P$. padus leaves did so. However, this difference is of the same magnitude as that obtaining between leaves of the same species collected from different localities, or of different ages, e.g., only $30 \%$ of leaves of $P$. padus collected from a Norfolk fen (experiment of I4.9.59) recovered from the effect of $78 \% \mathrm{RH}$, compared with $100 \%$ of leaves collected in Sheffield (experiment of I0.5.60) and $66 \%$ for the same tree, two months later (experiment of $\mathrm{r}_{4.7 .60)}$. 
Both, mean LWDs developed as a response to the treatment, and critical LWDs, were generally larger for $T$. sanguinea than for $P$. padus (Table 4). There was some variation between the successive experiments, notably for $P$. padus from the same tree. In May and July LWDs developed were similar on the two occasions but the critical LWD was $29 \%$ for the older leaves and between $43 \%$ and $51 \%$ for the younger leaves collected in May. Hence there was a higher percentage recovery in May, as mentioned above, indicating that drought resistance may change through the season.

Thus, although the critical LWD and the LWD developed at any RH was larger for T. sanguinea than for $P$. padus, there was insufficient evidence to demonstrate any appreciable difference in drought resistance, as measured by the ability of leaves to recover turgidity.

(2) The herbaceous species. For shoots whose stems were in water the LWDs developed were not related to the $\mathrm{RH}$ prevailing during the droughting treatment.

In four experiments with Saxifraga hypnoides from different localities there was $100 \%$ recovery by the shoots whose stems were not in water, after all RH treatments, down to $25 \% \mathrm{RH}$. Comparing results for samples from different localities, it is apparent that at the lower RHs larger LWDs were developed by plants from Cressbrook Dale, Derbyshire (24.9.59) than by plants collected from the Winnats, Derbyshire, both three weeks later (I 4.10.59) and in the following year (3.8.60) (Table 5). The reason for

\section{TABLE 5}

The mean leaf water deficit of Saxifraga hypuoides after droughting. Conditions as for Table 3

\begin{tabular}{rcccc}
\hline RH & 8.9 .59 & 24.9 .59 & I4.10.59 & 3.8 .60 \\
\hline I00 & & & 16 & 10 \\
86 & & & & 22 \\
77 & & 28 & 31 & 27 \\
67 & Not & & & 28 \\
61 & determined & 33 & 34 & \\
54 & & 42 & & 34 \\
48 & & 52 & 38 & \\
41 & & 50 & 36 & \\
25 & & 63 & 32 & 35 \\
\end{tabular}

N.B. In all four experiments, after all RH treatments, there was $100 \%$ recovery of turgidity by the shoots. 
this marked difference was not investigated; it might be attributable either to genetical differences or to differences in the preceding environmental conditions. Results for Filipendula vulgaris and Pimpinella saxifraga were in striking contrast (Table 6).

No leaves from $F$. villgaris recovered from any treatment except that of I00 $\% \mathrm{RH}$ : for $P$. saxifraga there was only $50 \%$ recovery from $86 \%$ and $78 \%$ RHs, and no recovery from lower RHs. In comparison with the other species tested, the LWDs developed, and the critical LWDs, in these species were remarkably large. Hence, in this respect, they may be regarded as being very much more drought sensitive than S. hypnoides.

\section{TABLE 6}

The mean leaf water deficit (LWD) developed and the percentage recovery of leaves of Saxifraga hypnoides, Filipendula vulgaris and Pimpinella saxifraga subjected to droughting conditions. Droughting conditions as for Table 3. LWDs of leaves which did not recover were calculated as for the tree species (Table 4). Date of experiment 3.8.60

\begin{tabular}{|c|c|c|c|c|c|c|}
\hline \multirow[b]{2}{*}{$\mathrm{RH}$} & \multicolumn{2}{|c|}{ S. hypnoides } & \multicolumn{2}{|c|}{ F. vulgaris } & \multicolumn{2}{|c|}{ P. saxifraga } \\
\hline & $\begin{array}{c}\text { Mean LWD } \\
\text { developed }\end{array}$ & $\begin{array}{c}\text { Recovery } \\
(\%)\end{array}$ & $\begin{array}{c}\text { Mean LWD } \\
\text { developed }\end{array}$ & $\begin{array}{c}\text { Recovery } \\
(\%)\end{array}$ & $\begin{array}{c}\text { Mean LWD } \\
\text { developed }\end{array}$ & $\begin{array}{c}\text { Recovery } \\
(\%)\end{array}$ \\
\hline 100 & IO & 100 & 43 & IOO & 30 & 100 \\
\hline 86 & 22 & 100 & 85 & 0 & 67 & 50 \\
\hline 78 & 27 & IOO & 89 & 0 & 77 & so \\
\hline 67 & 28 & 100 & 92 & 0 & 89 & o \\
\hline 53 & 34 & 100 & 95 & 0 & 93 & o \\
\hline 25 & 35 & 100 & $\stackrel{94}{\text { Critical LW] }}$ & $\mathrm{D}$ & 95 & o \\
\hline & $>47 \%$ & & $53-7$ & $8 \%$ & $64-75$ & $5 \%$ \\
\hline
\end{tabular}

\section{DISCUSSION}

The results presented above demonstrate physiological differences between the species in response to conditions of increasing water stress. Growth of Saxifraga hypnoides was depressed, in comparison with growth in soil at field capacity, more than that of Filipendula vulgaris, by soil moisture regimes where the soil was allowed to dry to I or $2 \mathrm{~atm}$ SMT before rewatering. Confirmation of this difference was obtained from the experiments investigating the effect of increasing SMT within a watering-todrying-out cycle. Similar differences, though not so large, were apparent 
between Prumus padus and Thelycrania sanguinea. Results of the soil moisture regime experiments were inconclusive for these two species because of the slow rate of increase of leaf area and the high between-plant variation for $P$. padus. In day-by-day correlation of growth with increase in SMT, reduction of growth of $P$. padus occurred at a lower SMT than that of $T$. sanguinea. It was not possible to make a distinction between the two in the SMT at which there was cessation of leaf elongation, because of the large variation between shoots in this respect, particularly for $P$. padus. There was no growth of either species at SMTs above 2-3 atm at the most. There was cessation of measurable growth of $S$. hypnoides at about 0.5 atm SMT and of F. vulgaris at $2.0 \mathrm{~atm}$ or below. In contrast, Wadleigh and Gauch (1948), studying the effect of increasing total soil moisture stress on the daily elongation of cotton leaves, during several irrigation cycles, found that elongation ceased at a narrow range of stress values, close to I $5 \mathrm{~atm}$. Slatyer (1957) found for privet and cotton that growth and elongation continued up to the point where DPD at dawn (27 and 34 atm, respectively) corresponded with zero turgor pressure in the leaves, i.e., at the permanent wilting point for the species. In the experiments described above, measurable leaf elongation of the four species ceased at SMTs considerably lower than those which caused wilting of the leaves at dawn. This point was not precisely determined but it certainly did not occur at SMTs lower than io atm.

It must be noted that these low values represent only the soil moisture tension (SMT) component of the total soil moisture stress (TSMS); and that the osmotic component cannot justifiably be neglected since it may be of comparable magnitude. Slatyer (I957) illustrated the relationship of both SMT and TSMS to soil water content for a 'sandy clay loam' soil, to which a complete fertiliser mixture had been added. For SMT values from o to 2 atm corresponding TSMS values were 2 to 3 atm higher. Russell (I950) quotes values of 0.2 to I atm for the osmotic pressure of the soil solution from field capacity to the wilting point, for "normal leached agricultural soils'. The values for SMT presented throughout this paper, may therefore be up to about $2 \mathrm{~atm}$ lower than the corresponding TSMS, but probably not more than I atm. This difference in magnitude of the absolute values does not, of course, affect the comparisons made between the species, since the same soil was used throughout.

There was apparently no difference between the relation of SMT and LWD, or of SMT and TR for P. padus and T. sanguinea; or of SMT and LWD for S. lypuoides and F. vulgaris. The marked difference in sensitivity of growth rate to increasing SMT can possibly be explained not in terms 
of a difference in ability to control water loss by stomatal closure, or in ability to take up water from soil of increasing SMT, but as a difference in sensitivity of the metabolism of the cells of the leaf to increasing LWD.

The results of the experiments in which detached shoots of the species were subjected to atmospheres of controlled relative humidity (RH) for a standard time under standard conditions, are particularly interesting, in that they emphasise the possibility of independence of different aspects of drought resistance. For the species used in the present investigation, the resistance of the leaves to desiccation at low RHs and with soil water unavailable was independent of the resistance of the plant to reduction of growth rate as a result of increasing SMT and concomitantly increasing LWD. The growth rate of $F$. vulgaris and Pimpinclla saxifraga was much less sensitive to the effect of increasing SMT than was that of S. hypnoides; yet the resistance of the leaves to desiccation was very much lower. Similarly for the tree species; the growth rate of $T$. sanguinea was less affected by increases of SMT than was that of $P$. padus; but there was no clear difference between the species in resistance of the leaves to desiccation.

This type of experiment demonstrates the differential ability of plants of the species tested to prevent water loss to a lethal level by stomatal closure and by low rates of cuticular transpiration. The threshold RH that causes injury can be determined, but, unless sufficient time is allowed for equilibrium to be reached, and this was not so in the present experiment, such values may correspond not only with drought tolerance but also with drought avoidance of the leaf tissues. The results of such experiments can probably justifiably be applied to field conditions where soil water availability is negligible. Thus, where soil water is unavailable both to $S$. hypuoides and to $F$. vulgaris in the field, and similar atmospheric conditions prevail, plants of the former species will survive for a longer period. However such a comparison does not take into account the size and extent of the root system or the capacity of the roots to grow into region of soil of lower. SMT; i.e., the capacity of the plant to avoid the condition where soil water is unavailable to it. Such factors may be of overriding importance where the drought resistance of a species in the field is concerned. The root system of $F$. vulgaris is more extensive than that of $S$. hypnoides, for plants growing on the slopes of the Derbyshire dales.

It is therefore difficult to apply to field conditions the results of experiments revealing physiological differences between species in their response to soil or atmospheric drought.

It is possible that the reduction in growth rate of $S$. hypnoides which ensues in response to slight drying-out of the soil may be an important 
factor controlling the distribution of the species. The competitive ability of plants of this species must be severely limited in habitats where the soil is not continuously moist. However, other factors, such as the effect of high soil temperature on vegetative growth or of SMT and temperature on flower initiation and seed production may play an equally important role (Jarvis, M.S., 1960).

Similarly for Primus padus it is possible that spread of the species southwards, or on to south-facing slopes at the south-eastern limit of its range, may be limited by soil moisture factors. Under identical conditions of soil moisture availability vegetative growth of the southern species, Thelycrania sanguinea, would certainly be faster.

All such conclusions must be extremely tentative. The limitation of distribution of a species, in the comparatively simple case where only climatic factors are of importance, may be caused by any one, or any combination of factors acting at any one, or any combination of stages in the life cycle The most important effect may be a continuous reduction of the competitive ability of the species throughout the life cycle; or an occasional catastrophic effect at the seedling stage or the flower or fruit production stage, for example.

\section{ACKNOWLEDGMENTS}

It is a pleasure to express my thanks to Dr. C. D. Pigott for his interest and supervision during the course of this work; to Professor A.R. Clapham, F.R.S., for the facilities of his department; and to the Department of Scientific and Industrial Research whose award of a Research Studentship made the work possible.

\section{REFERENCES}

ČATSKÝ, J. (1959) The role played by growth in the determination of water deficit in plants. Biologia Plantarum (Pralla) I, 277-286.

JARvis, M.S. (I960) The influence of climatic factors on the distribution of some Derbyshire plants. Ph.D. Thesis, Sheffield.

Jarvis, P.G. (I960) The growth and regeneration of Quercus petraea in the Sheffield region. Ph.D. Thesis. Sheffield.

LevitT, J. (1958) Frost, drought and heat resistance. Protoplasmatologia, Band VIII.

Richards, L. A. (I94I) A pressure membrane apparatus for extraction of soil solutions. Soil Sci. 5I, 377-386.

Russell, Sir J. E. (1950) Soil Conditions and Plant Growth. Eighth edition, London. RutTer, A.J. \& SANDS, K. (I958) The relation of leaf water deficit to soil moisture tension in Pinus sylvestris L. New Phytol. 57, 50-65. 
SAnDS, K. \& Rutter, A.J. (1959) Studies in the growth of young plants of Pinus sylvestris L. II: The relation of growth to soil moisture tension. Ann. Bot., London, N.S., 23, 269-284.

SLATYER, R. O. (I955) Studies of the water relations of crop plants grown under natural rainfall in northern Australia. Aust.J. agric. Res. 6, 365-377.

SLATYER, R.O. (1957) The influence of progressive increases in total soil moisture stress on transpiration, growth and internal water relationships of plants. Aust. J. biol. Sci. 10, 320-336.

StockFr, O. (1929) Das Wasserdeficit von Gefasspflanzen in verschiedenen Klimazonen. Planta, 7, 382-387.

Wadleigh, C.H. \& GAUCH, H.G. (1948) Rate of leaf elongation as affected by the intensity of the total soil moisture stress. Plant Physiol. 23, 485-495. 


\title{
THE EFFECT OF SOIL TYPE ON THE RELATION BETWEEN SOIL WATER REGIME AND GROWTH OF SEEDLINGS OF QUERCUS PETRAEA (MATT.)
}

\section{LIEBL.}

\author{
P.G. Jarvis \\ Department of Botany, The University of Sheffield $\star$
}

\section{INTRODUCTION}

A LARGE amount of literature now exists on the relation between soil water regime and the growth of many different plants (for reviews, see Stanhill, 1957; Veihmeyer, 1956). In many of these experiments, comparisons have been made between the responses of different species and types of plants to well-defined soil water regimes. However, most of the critical experiments have been carried out on one, or more rarely two, different soil types. The experiment described here demonstrates the need for a preliminary investigation to determine the comparative suitability of a range of soils for the growth of each species to be investigated, before an attempt can be made to compare the physiological responses of different species to defined soil water regimes.

As part of an investigation into the growth response of seedlings of Quercus petraea to certain factors of possible ecological importance, an experiment was carried out in which seedlings were grown under three different defined soil water regimes on five soils of different character. Since the response to similar soil water regimes was very different on the different soil types, as much information as is available is given for each soil used.

\section{METHOD}

The soils were collected (in April, I959) directly into the large polythene bowls $(35 \mathrm{~cm}$ mean diam. $\times$ I $5 \mathrm{~cm}$ deep) in which the plants were grown. Eight acorns were planted per bowl and the seedlings were subsequently thinned to leave 6 or 7 of similar size. The acorns were all obtained from one parent tree and were selected to be of uniform size. The bowls were regularly watered so that no soil moisture tensions (SMTs) occurred until the seedlings had all developed one whorl of leaves. The cotyledons were

* Now at: Institute of Physiological Botany of The University of Uppsala, Uppsala, Sweden. 
removed at this stage in order to accelerate any effects which the different soils might have on seedling performance.

Shortly after planting, plaster resistance blocks (modified Bouyoucos type; Jarvis, P.G., 1960) were inscrted with the long axis vertical, so as to have as much soil $(c .4 \mathrm{~cm})$ above as beneath them.

Three different soil-water regimes were practised on each soil. In one (treatment $\mathrm{I}$ ) the bowls were watered 2 or 3 times a week, depending on the weather, and (with the exception of one occasion) no measurable SMTs (i.e. no SMTs above $0.2 \mathrm{~atm}$ ) were allowed to develop. In the other

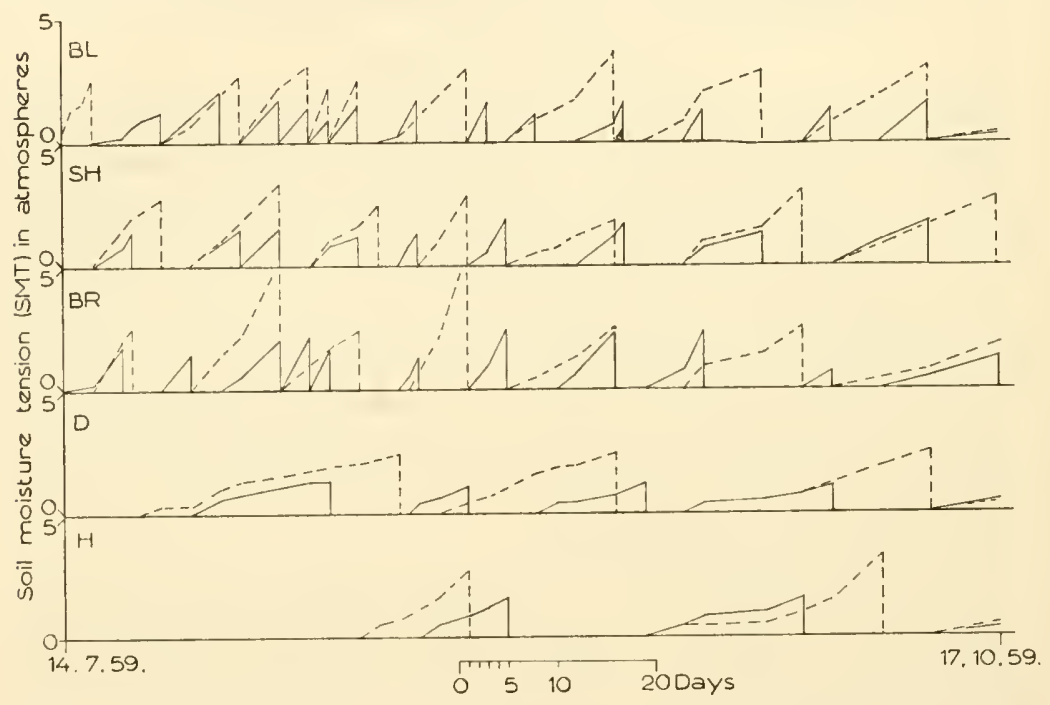

FIG. I. The soil moisture tensions (SMTs) in atmospheres which were allowed to develop in the five soils during the course of the experiment. The broken line represents moisture treatment 3; the solid line, treatment 2; and the blacked in area, treatment I. Vertical lines indicate watering.

two treatments (treatments 2 and 3 ) watering took place, as closely as could be arranged, when SMTs had reached $1 \cdot 2$ and $2 \cdot 5$ atm respectively. The actual range of SMTs over which watering took place can be seen in Fig. I. Watering was with deionised water (Elgastat) which was always added until the soil was thoroughly saturated throughout.

The experiment was conducted in a cold fully-ventilated glasshouse. The leaves were removed from the plants on 17 October 1959, to prevent an unnaturally long growing season, and the plants were subsequently harvested. 


\section{TABLE I}

Field characteristics of five soils

\begin{tabular}{|c|c|c|c|c|c|c|}
\hline Code & Cover & Soil type & Horizon & Colour & $\mathrm{pH}$ & $\begin{array}{l}\text { Apparent } \\
\text { density } \\
\mathrm{gm} / \mathrm{cc}\end{array}$ \\
\hline $\mathrm{BL}$ & D. flexuosa & $\begin{array}{l}\text { Iron-humus } \\
\text { podsol }\end{array}$ & $A_{2}, 10-25 \mathrm{~cm}$ & Grey & $3 \cdot 2$ & $2 \cdot I$ \\
\hline SH & $\begin{array}{l}\text { H. nollis } \\
\text { Endymiont }\end{array}$ & $\begin{array}{l}\text { Oligotrophic } \\
\text { brown earth }\end{array}$ & $(B), 5-25 \mathrm{~cm}$ & Brown & $4 \cdot I$ & $I \cdot 3$ \\
\hline $\mathrm{BR}$ & D. flexiosa & $\begin{array}{l}\text { Podsolised } \\
\text { brown earth }\end{array}$ & $(B), 5-25 \mathrm{~cm}$ & $\begin{array}{l}\text { Red- } \\
\text { brown }\end{array}$ & $3 \cdot 6$ & $I \cdot 7$ \\
\hline $\mathrm{D}$ & D. flexuosa & $\begin{array}{l}\text { Podsolised } \\
\text { brown earth }\end{array}$ & $A_{0}, 0-8 \mathrm{~cm}$ & Black & $2 \cdot 9$ & 0.38 \\
\hline $\mathrm{H}$ & $\begin{array}{l}\text { Oak leaf } \\
\text { litter }\end{array}$ & $\begin{array}{l}\text { Podsolised } \\
\text { brown earth }\end{array}$ & $A_{0}, 0-12 \mathrm{~cm}$ & $\begin{array}{l}\text { Black- } \\
\text { brown }\end{array}$ & $3 \cdot 0$ & 0.35 \\
\hline
\end{tabular}

$\mathrm{D}=$ Deschampsia $\mathrm{H}=$ Holcus

TABLE 2

Characteristics of the soils (treatment I) at the end of the experiment

\begin{tabular}{|c|c|c|c|c|c|}
\hline \multirow[b]{2}{*}{ Soil } & \multirow{2}{*}{$\begin{array}{l}\text { Apparent } \\
\text { density }\end{array}$} & \multirow[b]{2}{*}{$\begin{array}{l}\text { Humus } \\
\mathrm{g} / \mathrm{roO} \mathrm{cc}\end{array}$} & \multicolumn{2}{|c|}{$\begin{array}{l}\text { Exchangeable ions } \\
\mathrm{mg} / \mathrm{IOO} \mathrm{cc}\end{array}$} & \multirow[b]{2}{*}{ ODR } \\
\hline & & & $\mathrm{Ca}$ & $\bar{K}$ & \\
\hline BL & $\mathrm{I} \cdot 8$ & $6 \cdot 8$ & 0.38 & $0 \cdot 12$ & 13.5 \\
\hline $\mathrm{SH}$ & $I \cdot 3$ & I 3.4 & 0.84 & 0.17 & I I 5 \\
\hline BR & $I \cdot 9$ & I $3 \cdot 9$ & 0.42 & $\mathrm{O} \cdot \mathrm{I}_{4}$ & $10 \cdot 0$ \\
\hline $\mathrm{D}$ & 0.36 & $33 \cdot 2$ & I $\cdot 84$ & 0.24 & $20 \cdot 0$ \\
\hline $\mathrm{H}$ & 0.34 & $33 \cdot 6$ & $1 \cdot 69$ & 0.26 & $16 \cdot 5$ \\
\hline
\end{tabular}

N.B. $\mathrm{pH}$ determined with glass electrode; soil: water = I: I by volume. 'Humus' determined from 'loss on ignition' at $550^{\circ} \mathrm{C}$. Apparent density determined from volume displacement of toluene (after $c$. Io sec) by natural clods, followed by filtering and dry weight determination of the clods. Exchangeable $\mathrm{Ca}$ and $\mathrm{K}$ extracted by shaking with 2 successive quantities of $0.5 \mathrm{~N} \mathrm{NH}_{4} \mathrm{NO}_{3}$; estimation by 'Versenate' titration and flame-photometer respectively. Oxygen diffusion rate (ODR) determined with platinum electrode (Poel, 1960$)$; in $\mathrm{g} \times 10^{-8}$ of oxygen per sq. $\mathrm{cm}$ per $\min$.

For complete descriptions of the methods, see Jarvis, P. G., I960. 


\section{SOIL CHARACTERISTICS}

All the soils were obtained from a fragment of sessile oakwood (Padley wood, Grindleford) on the Millstone grit to the west of Sheffield (Pigott, I956).

With the exception of soil SH, the soils were obtained from over the gritstone; $\mathrm{SH}$ was from a nearby area of shales, with which the grit is inter-bedded. The soil in the SH area was a good brown earth with active litter incorporation. It had a high clay content as compared with the

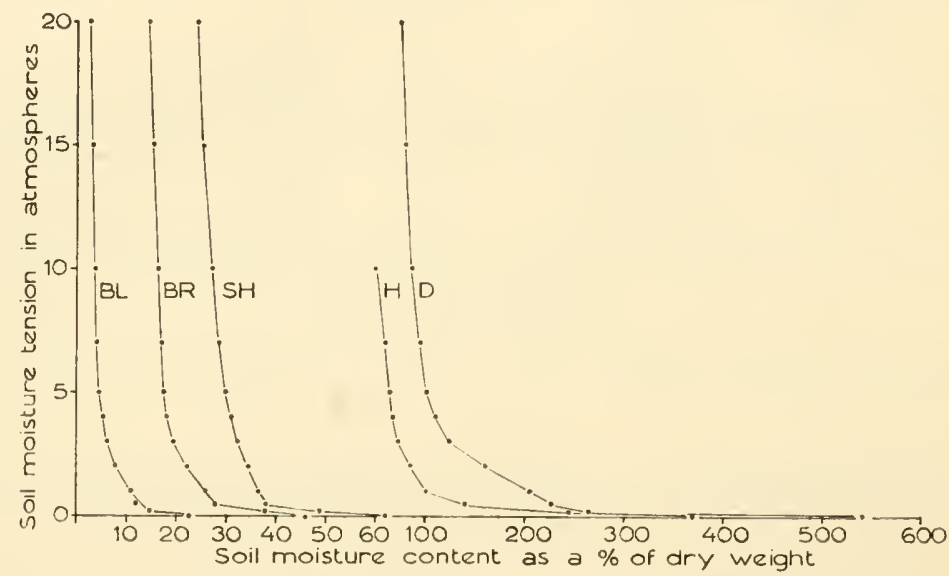

FIG. 2. The relation between soil moisture tension (in atmospheres) and soil moisture content (as percentage of dry weight), for the five soils. Soils D and H are plotted on the larger scale for moisture content. Values determined in an experiment in which seedlings of sessile oak, growing on the soils in sealed cans containing plaster resistance blocks for SMT determinations, dried out the soil (Jarvis, P.G., I960).

sandy gritstone soils. It also supported a richer flora and better growth of oak trees.

The relation between soil water content and soil moisture tension for the five soils is shown in Fig. 2. Large differences exist in the absolute amounts of water removed from the different soils for equal changes in SMT. If the soil water content is recalculated on a volume basis, these differences remain large (Table 3).

\section{RESULTS}

Representative seedlings from each treatment are shown in Plate I. On all the soils, except BL, the roots were found to occur throughout the whole 


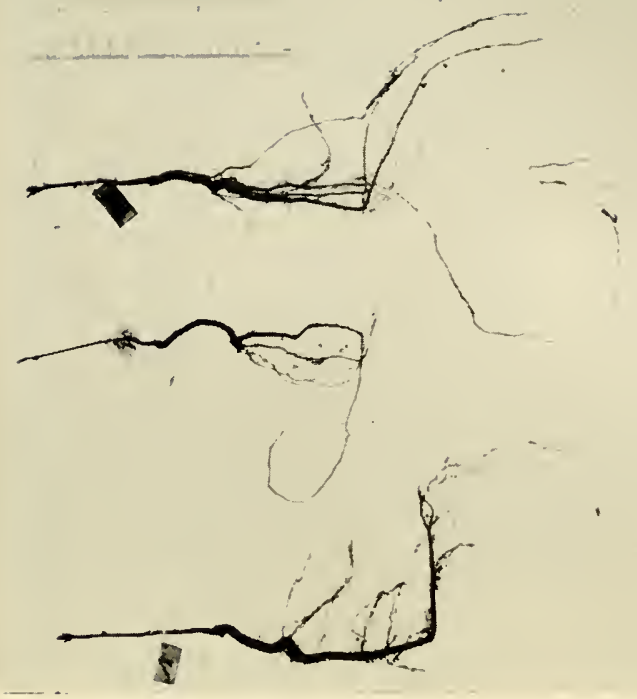

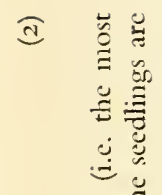

$-\frac{\mathscr{S}}{5}$

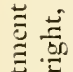

氖

氙芯

उ $\Xi 0$

可䜤

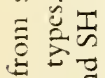

$\pm \pm 0$

कิ $\overline{0}$

$\Xi \cong$

总密

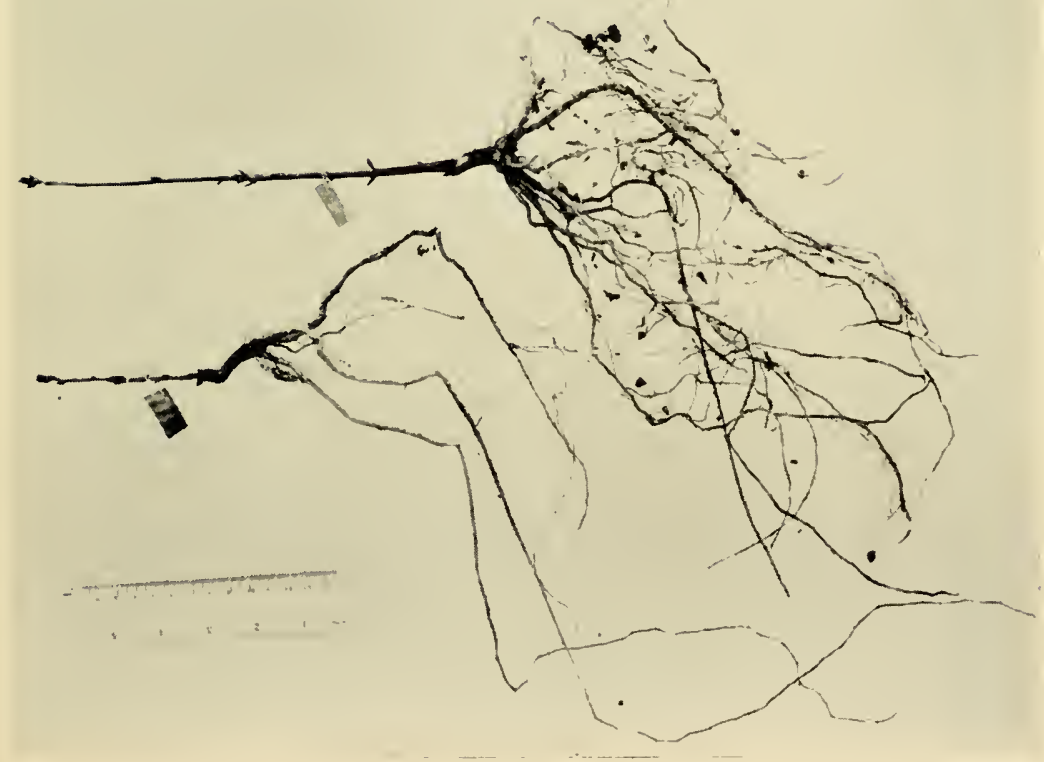

ह

ڤ造

$\div$ 훙

$\approx \widehat{\Theta} I$

를류

承

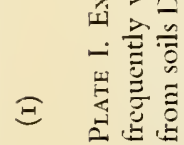



TABLE 3

The changes in moisture content of the five soils, for changes in SMT from o-s atmospheres, expressed on a weight and on a volume basis

\begin{tabular}{|c|c|c|}
\hline \multirow[t]{2}{*}{ Soil } & \multicolumn{2}{|c|}{$\begin{array}{c}\text { Changes in moisture } \\
\text { content }\end{array}$} \\
\hline & $\mathrm{g} / 100 \mathrm{~g}$ & $\mathrm{~g} / \mathrm{I} O 0 \mathrm{cc}$ \\
\hline $\mathrm{BL}$ & I 8 & $35 \cdot I$ \\
\hline $\mathrm{SH}$ & 32 & $4 \mathrm{I} \cdot 6$ \\
\hline BR & 28.5 & $5 \mathrm{I} \cdot 3$ \\
\hline $\mathrm{D}$ & 267 & $98 \cdot 8$ \\
\hline $\mathrm{H}$ & 475 & I 64.0 \\
\hline
\end{tabular}

soil volume. On BL about $\frac{1}{3}$ to $\frac{1}{2}$ of the root system was found at the soilcontainer junction, and much of the soil was unexploited.

Relative growth rate (RGR) is calculated from the formula of Fisher (I92I):

$$
\mathrm{RGR}=\frac{\log _{e} W_{2}-\log _{e} W_{1}}{t_{2}-t_{1}}
$$

where $t_{2}-t_{1}$ is the length of the growing period in weeks, taken here to be the time between appearance of the first whorl of leaves and harvest, i.e. I6 weeks. $W_{2}$ is the mean dry weight per plant at harvest. $W_{1}$ equals $(A-C)$, where $A$ is the mean dry weight at planting of cotyledon pairs, and $C$ is the mean dry weight per treatment of cotyledon pairs removed at the one whorl stage.

The results are presented in Table 4, where other indices of performance are also explained. 'Significant' assimilation is of ecological significance, since it does not include the leaf weight, which is not carried forward to the next growing season.

The significance of the differences between values for certain of the indices given in Table 4 was estimated from analyses of variance. The results are presented in Table 5 . Similar analyses could not be applied to the values for all the indices used because, for some of them, much larger variances occurred in the treatments supporting good growth.

There is considerable evidence that the growth of many plants is severely reduced by SMTs between 0.5 and I.O atm (for examples see Sands and Rutter, I959), and studies within single drying-out cycles have shown that for some plants growth ceases completely at SMTs of less than I atm 


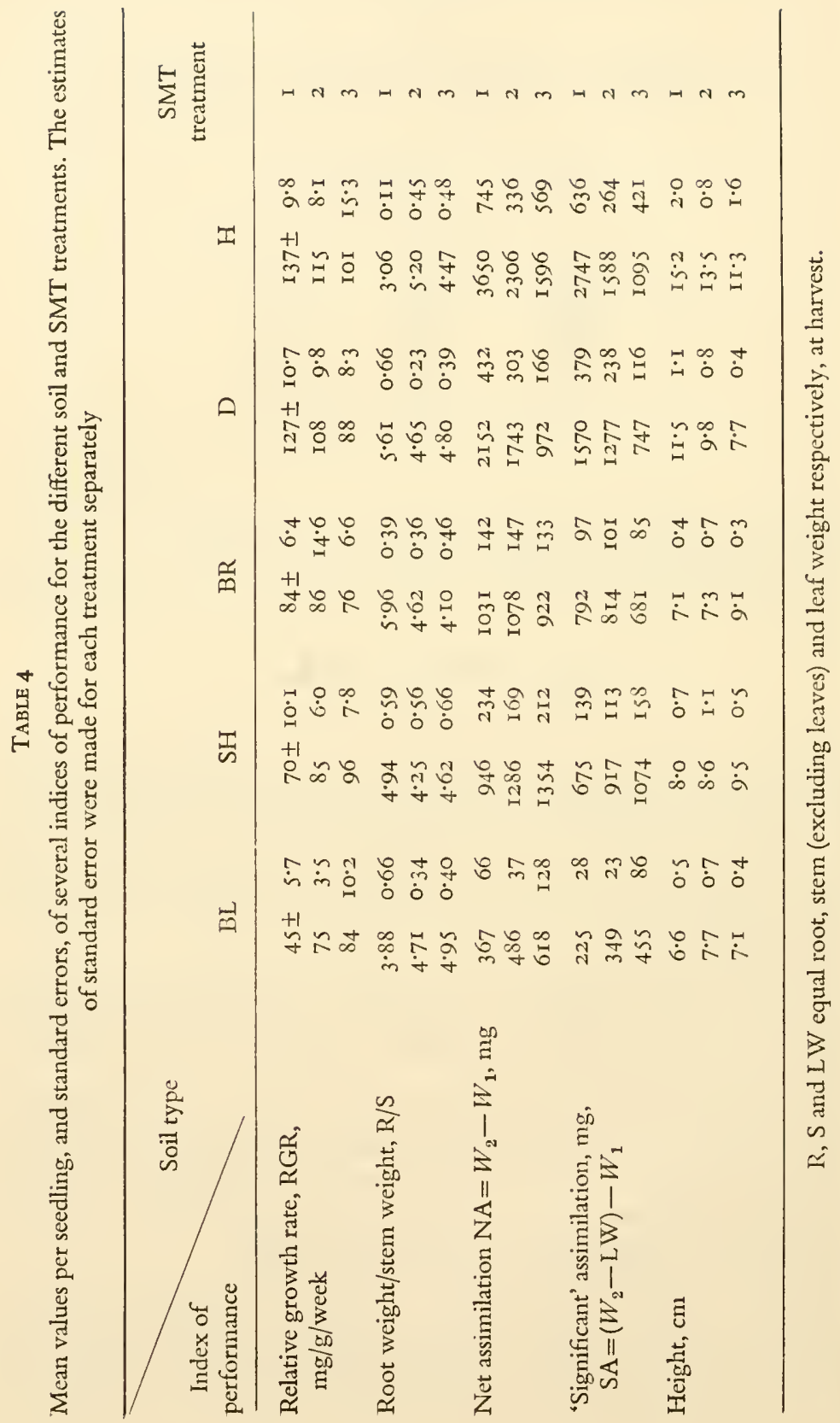


TABIE 5

Least significant differences (LSD) and standard errors (s.e.), determined from analyses of variance of the experiment as a whole, for certain of the indices of performances presented in Table 4 .

\begin{tabular}{|c|c|c|c|c|}
\hline & & LSD & & \\
\hline & $' P$ ' $=0.05$ & $0.0 \mathrm{I}$ & 0.001 & s.e. \\
\hline RGR & 22 & 29 & 37 & $7 \cdot 5$ \\
\hline $\mathrm{R} / \mathrm{S}$ & $I \cdot 3 I$ & $I \cdot 7 I$ & $2 \cdot 19$ & 0.47 \\
\hline Height & $2 \cdot 8$ & $3 \cdot 7$ & $4 \cdot 7$ & $I \cdot O$ \\
\hline
\end{tabular}

(Jarvis, M.S., 1963). In order to obtain estimates of the amounts of effective SMT experienced by the seedlings, the areas beneath the drying-out curves in Fig. I were summed up to a SMT of 0.5 atm. It was assumed that any short-term drying-out of the soil, which occurred above the SMT at which growth ceased, would have no additional effects. Some evidence for this, for other species, is provided by Jarvis, M.S. (1963). The total number of 'atmosphere-days', experienced by the plants in the different treatments, up to 0.5 atm SMT, are given in Table 6.

\section{TABLE 6}

The amount of drying-out, represented as number and percentage atmosphere-days

(for explanation, see text) occurring in the various soils and treatments

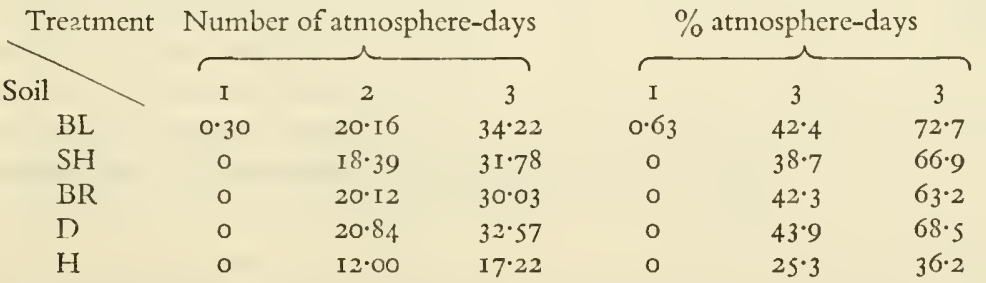

The second part of the table contains, for each treatment, the number of 'atmosphere-days' expressed as a percentage of the total theoretical number of 'atmosphere-days' possible if the SMTs had remained at 0.5 atm throughout.

The relation between RGR and 'percentage atmosphere-days' is presented graphically in Fig. 3 . 


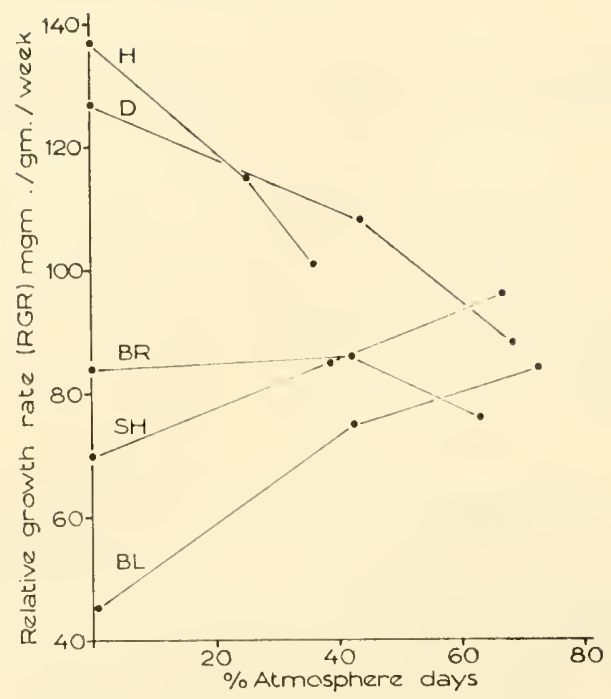

Fig. 3. The effect of the five soils on the relation between the average relative growth rate (of seedlings of sessile oak over a I6-week growing season) and the amount of drying-out of the soil (summed as percentage atmosphere days, up to a SMT of 0.5 atm) which was allowed to develop.

\section{DISCUSSION}

Large differences occur between the maximum RGRs of seedlings on the different soils. Since only five soils are involved, it is not possible to make any far-reaching correlations between plant performance and a particular soil character. However, it may be noted that better growth is associated with the following soil characters: higher humus content, higher base status, higher oxygen diffusion rate, lower apparent density, and greater moisture content ( $\mathrm{gm} / 100 \mathrm{cc}$ of soil) held between $0-5$ atm SMT, i.e. larger pore volume.

The response to the different soil water regimes is very different on the different soil types. Only on leaf litter $(\mathrm{H})$ and Deschampsia humus (D), the soils which supported the highest RGRs, are there marked decreases in $\mathrm{RGR}$ in response to the drying-out treatments. On both the soil from the bleached horizon $(\mathrm{BL})$, and the clayey soil from the shale band $(\mathrm{SH})$, the RGRs show significant positive increases with drying-out. The brown earth soil (BR) shows no significant response in RGR; it is possible, for this soil, that the optimum soil-moisture regime lies between treatments I and 2 . 
This is also a possibility for $\mathrm{D}$, since other experiments have shown that it is an unsuitable growing medium when saturated. The ecological implications of the growth attained on Deschampsia humus in this experiment are particularly meaningless, since, in all three treatments, appreciable surface drying and shrinkage occurred. The good growth of the seedlings probably resulted from the extensive mineralisation (Birch, I958). As fat as could be ascertained the other humus and soils were not appreciably altered.

Sands and Rutter (1959) have pointed out the difficulties involved in attempting to apply growth analysis methods to experiments of this sort, in which a variable number of drying cycles may be included in one sampling period. These difficulties are especially serious when soils with different rates of drying-out are to be compared. However, by making several assumptions and taking the growing season as the unit of time, it is possible to calculate approximate figures for net assimilation rate (NAR) (Table 7). These figures can be used to show that some of the differences in RGR result from the effect of water-regime and soil type on NAR.

\section{TABLE 7}

Approximate mean values of NAR $\left(\mathrm{g} / \mathrm{m}^{2} /\right.$ week $)$ for a I6-week period in summer 1959

\begin{tabular}{llllll}
$\begin{array}{l}\text { SMT } \\
\text { treatment }\end{array}$ & BL & SH & BR & D & H \\
\cline { 1 - 2 } I & $16 \cdot 6$ & $2 I^{*} 9^{\star}$ & $27 \cdot \mathrm{I}$ & $23 \cdot 2^{\star}$ & $25 \cdot 8$ \\
2 & $22 \cdot 2$ & $23^{\circ} 6$ & $25 \cdot 6$ & $23 \cdot 5$ & $20 \cdot 2$ \\
3 & $23 \cdot 8$ & $30 \cdot 4$ & $24 \cdot 0$ & $27 \cdot \mathrm{I}$ & $20 \cdot 0$
\end{tabular}

* Some leaves lost as the result of infection by oak mildew, i.e. figures probably too high. The values are based on the following assumptions: $\frac{2}{3}$ leaf area at harvest $=$ mean leaf area; leaf area/leaf wt. ratio is a constant.

There are several established examples of excessive irrigation causing reduced growth (Bergman, 1959), but in almost all experiments of this type maximum growth has occurred in the most frequently watered treatment (Stanhill, 1957). An exception to this is an experiment by Kenworthy (1949) with young apple trees. Maximum growth occurred when the plants were watered at $c .0 \cdot I$ atm SMT. A 9\% reduction in rate of growth occurred when the plants were watered at either 0.05 or $0.24 \mathrm{~atm}$ SMT. Similarly, in heavy soils maximum rates of photosynthesis have been found to occur at SMTs just above field capacity (Schneider and 
Childers, I94I, with apple; Negisi and Satoo, I954, with Pinus densiflora). These results are, however, rather less striking than those described here.

Considering performance on the five soils in this experiment, it can be seen that seedlings respond similarly, and in an inverse direction to that usually reported, on soils BL and SH. On both these soils RGR and NAR (and on $\mathrm{BL}, \mathrm{R} / \mathrm{S}$ also) increase with increasing drying-out, demonstrating the greater suitability for growth on the drier soil. Scedling performance on soil $\mathrm{H}$ is of the expected pattern, i.e. RGR and NAR decrease with increasing drying-out, but the figures for $\mathrm{R} / \mathrm{S}$ ratio are irregular. It is possible that a 'small amount' of drying-out (treatment 2) stimulated root production at the expense of the shoot. Performance on BR also varies in the expected direction, but the differences are mostly small and not significant: NAR, RGR and R/S tend to decrease with increasing drying-out. Performance on $D$ is remarkable in that $R G R$ decreases and NAR increases with increasing drying-out. This difference may be related to the occurrence of mineralisation, or to some other factor such as the stability of toxic substances in the different moisture treatments.

Part of the differences in growth, between the different soils, in response to the water regimes may result from apparently similar water regimes causing different degrees of water stress in the different soils. This could be caused by differences in the osmotic pressure of the soil solution, and in the permeability of the soil.

The osmotic component of moisture stress will raise the total soil moisture stress above the SMT by a characteristic amount for each soil. Such an effect would tend to accentuate responses, of the type occurring on $\mathrm{H}$, to water stress in nutrient-rich soils, but could not account for the pattern of response on soils $\mathrm{BL}, \mathrm{SH}$ and $\mathrm{BR}$, which are anyway low in nutrients.

The method used for measuring SMT did not measure tensions developing at the root surface. When plants are transpiring rapidly, these tensions may be greatly in excess of those in the soil short distances away. The magnitude of this difference in tension will partly depend on the rate of movement of water to the root, i.e. on the permeability of the soil (Slatyer, I960). Hence, similar SMTs measured in soils of different permeabilities do not necessarily indicate that the plants are experiencing similar moisture stress. However, the greatest difference between actual stress and measured strcss should occur in the least permeable soils, and hence this effect cannot be responsible for the pattern of response on soils $\mathrm{BL}, \mathrm{SH}$ and $\mathrm{BR}$.

Since, on soils $B L$ and $S H, R G R, N A R$ and $R / S$ (on $B L$ ) increase with increasing drying-out of the soil, it seems probable that the conditions of aeration in these soils are limiting growth. Inverse relations between soil 
water content and oxygen content are well established (Furr and Aldrich, I943; Boynton and Reuther, I939; Vine, Thompson and Hardy, 1942). Boynton and Reuther were able to relate the performance of apple trees to the influence of pore size on aeration; and Taylor (I949) showed that oxygen diffusion in soil is greatly influenced by the degree of compaction and water content of the soil, through their effects on the available airfilled pore space. No estimates of pore size were made for these soils, but the estimates of apparent density, oxygen diffusion rate and water availability provide some relevant information about their physical properties.

The apparent densities of the soils $\mathrm{BL}$ and $\mathrm{BR}$ are close to or above the upper limit of I·9, above which Veihmeyer and Hendrickson (I946, I948) state that, for most soils, no roots of any description are found. Mechanical impedence apparently restricted root growth on BL, since, for all treatments on this soil, only a part of the soil volume was exploited. However, the $\mathrm{R} / \mathrm{S}$ ratio increases with increasing amounts of drying-out, indicating the interaction with aeration. It would also be expected, as noted by Veihmeyer and Hendrickson, that the lower apparent density of the finertextured soil SH would have as great an inhibiting effect as the higher apparent densities in the coarser-textured soils.

It can be seen from Fig. 2 and Table 3 that the three soils BL, SH and BR differ greatly from the humus soils in the amounts of water held between $O \cdot I$ and I 5 atm SMT. Hence, small reductions in water content will produce large increases in SMT and consequent reductions in growth(Richards and Wadleigh, I952). However, the very small amounts of water held in these soils may be taken to indicate very small pore volumes and hence deficient aeration in the moist soils. Improvements in aeration as a result of dryingout are apparently more important than the removal of water or increases in SMT. This would be expected if the conditions of aeration were restricting water or nutrient uptake.

The oxygen diffusion rates (Table 2) were obtained in connection with another experiment and are for soils at 'field-capacity' only. They demonstrate general differences between the soil types, but emphasise that, although it is possible to interpret the results for any one soil in terms of aeration and SMT, the differences in growth between soils result from interactions of physical and nutritional factors.

It can be concluded from the results on leaf litter that, when growth is good and not severely restricted by other soil factors, assimilation by seedlings is considerably reduced by low SMTs. RGR is reduced by half by a SMT of $0.5 \mathrm{~atm}$ acting for $62 \%$ of the growing period (assuming proportionality of effect). 
There are inherent difficulties in attempting to use data from experiments of this type in field situations (Sands and Rutter, I959). The conditions of root growth in a restricted exploited soil volume and the technique of watering the whole soil mass back to saturation are essentially artificial.

During germination, seedlings of oak produce a very long tap-root from their acorn reserves. Hence, they are largely insulated from the effects of drying-out of the upper part of the soil profile by shallow-rooted herbaceous plants. However, as a result of the intensive exploitation of the rooting volume in an established wood, SMTs, which arise from the drying action of tree roots, are usually uniformly distributed, at least in the upper parts of the profile (Boggess, I956; Jarvis, P.G., I960). Such conditions are not unlike those in a container.

In sessile oakwoods in the region west of Sheffield, SMTs develop only in exceptionally dry summers, e.g. 1959. Reductions in growth as a result of increases in SMT are likely to be of greater importance in less moist areas, such as the New Forest. This experiment does, however, demonstrate the probable normal occurrence of unsuitable conditions for root growth in certain oakwood soils.

\section{ACKNOWLEDGMENTS}

This experiment was carried out as part of an investigation into the factors influencing the growth and regeneration of sessile oak in the Sheffield region. I should like to thank Dr. C.D. Pigott for his interest and supervision, and Professor A.R. Clapham, F.R.S., for the facilities of his department during the course of this work. I am also grateful to the Department of Scientific and Industrial Research for a Research Studentship which made this work possible.

\section{REFERENCES}

Bergman, H.F. (1959) Oxygen deficiency as a cause of disease in plants. Bot. Rev. 25, 4I7-485.

BirCH, H.F. (1958) The effect of soil drying on humus decomposition and nitrogen availability. Plant and Soil, 10, 9-31.

BogGESS, W.R. (1956) Weekly diameter growth of shortleaf pine and white oak as related to soil moisture. Soc. Amer. Foresters Proc. 83-89.

Boynton, D. \& Reuther, W. (1939) Seasonal variation of oxygen and carbon dioxide in three different orchard soils during 1938 and its possible significance. Amer. Soc. liort. Sci. Proc. 36, I-6.

Fisher, R. A. (192 I) Some remarks on the methods formulated in a recent article on 'The Quantitative Analysis of Plant Growth'. Amm. appl. Biol. 7, 367. 
FurR, J.R. \& Aldrich, W.W. (1943) Oxygen and carbon dioxide changes in the soil atmosphere of an irrigated date garden on calcareous very fine sand loam soil. Amer. Soc. hort. Sci. Proc. 42, 46-52.

JARvis, M.S. (1963) A comparison between the water relations of species with contrasting types of geographical distribution in the British Isles. The Water Relations of Plants Symposimm No 3 of The British Ecological Society.

Jarvis, P. G. (1960) The growth and regeneration of Quercus petraea (Matt) Liebl. in the Sheffield region. Ph.D. Thesis, Sheffield.

Kenworthy, A. L. (1949) Soil moisture and growth of apple trees. Amer. Soc. hort. Sci. Proc. 54, 29-39.

Negisi, K. \& SAtoo, T. (1954) The effect of drying of soil on apparent photosynthesis, transpiration, carbohydrate reserves and growth of seedlings of Akamatu (Pinus densiflora Sieb. et Zucc.). Japan. For. Soc. J. 36, 66-7I.

Pigotт, C.D. (I956) Vegetation, in Sheffield and its Region. Sheffield.

POEL, L. W. (1960) The estimation of oxygen diffusion rates in soils. J. Ecol.48, 165-I75.

Richards, L.A. \& WAdLEIGH, C.H. (1952) Soil water and plant growth; in B. T. Shaw (ed.), Soil Pliysical Conditions and Plant Growth, Agronomy II, New York.

SANDS, K. \& RutTer, A.J. (1959) Studies in the growth of young plants of Pinus sylvestris L. II: The relation of growth to soil-moisture tension. Ann. Bot., Lond. N.S. 23, 269-284.

SCHNeIder, G.W. \& Childers, N.F. (I94I) Influence of soil moisture on photosynthesis, respiration and transpiration of apple leaves. Plant Physiol. 16, 565-583.

Statyer, R.O. (I960) Absorption of water by plants. Bot. Rev. 26, 33I-392.

StANHIIL, G. (I957) The effect of differences in soil moisture status on plant growth: a review and evaluation. Soil Sci. 84, 205-2I4.

TAYLOR, S. A. (1949) Oxygen diffusion in porus media as affected by compaction and moisture content. Soil Sci. Soc. Amer. Proc. 14, 55-61.

VeIHMEYER, F.J. (1956) Soil moisture, in W. Ruhland (ed.), Encyclopedia of Plant Physiology, 3, 64-I23, Springer-Verlag, Berliu.

Veihmeyer, F.J. \& Hendrickson, A.H. (1946) Soil density as a factor in determining the permanent wilting percentage. Soil Sci. 62, 45I-456.

VeIhmeYer, F.J. \& Hendrickson, A.H. (I948) Soil density and root penetration. Soil Sci. 65, 487-493.

Vine, H., Thompson, H. A. \& HARdy, F. (1942) Studies on aeration of cacao soils in Trinidad. II: Soil-air composition in certain cacao soil-types in Trinidad. Trop. Agric. 19, 21 5-223. 


\title{
FORMULAE FOR THE ECOLOGICAL REACTION OF CROP YIELDS
}

\author{
W.C. VISSER \\ Instituut voor Cultuurtechniek en Waterhuishouding, \\ Wageningen, Netherlands
}

MANY investigations dealing with the influence of growth factors on crop yield will profit from the description of the result by a growth function.

The flexibility of freehand curves through scatter diagrams or of polynomials, fitted through the data, may be narrowed down by taking into account the mathematical properties of a growth formula. If the yield has to be described as the result of a complex system of productivity parameters, the description will never be very exact without the help of a formula. The modern technique of processing observations with electronic calculating machines requires a functional expression. A growth function based on biologically acceptable principles may be valuable, particularly if the growth factor has to be described by a complicated system of plant, soil and moisture parameters as is the case with moisture.

In the past, growth functions have attracted much attention, but interest has decreased in later years. This may be due to insufficient integration of mathematical reasoning and plant physiological insight. An extension of already known formulae seems possible to make up for imperfections.

Growth functions are often considered to be entirely empirical and of no fundamental value. As will be shown, the best known formulae, of entirely different origin, have so much in common that one will have to consider whether the assumptions behind these formulae have not a value exceeding the qualification 'empirical'.

Whatever the situation may be, it will be valuable to have a model available describing in principle the activity of a growth factor with respect to the maximum yield and the interaction between a number of growth factors.

\section{THE GROWTH FUNCTION}

The oldest formula, but still the best known, is that of Mitscherlich. The most important of his ideas was, that the increase in yield per unit increase in growth factor shotld bear an explicable plant physiological relation with 
the ecological properties and that the activity constants in the formulae should not be influenced by any other magnitude than the nature of the productivity factor. It was not considered to be necessary that in the growth function itself the plant physiological basis should be easily recognisable. It has not been possible to prove these theorics. This raises the questions whether the formula was not right or whether it was not applied in the right way.

The fundamental equation will have to express as general statement, that the differential equation can only be a function of the yield and of the growth factor. This may be described by

$$
\frac{\mathrm{d} q}{\mathrm{~d} x}=f(q, x)
$$

Three formulae will be discussed as examples of this general formula.

\section{The Mitscherlich Equation}

In the Mitscherlich equation the differential quotient was supposed to be only dependent on the yield. The following equations resulted:

differential equation

$\frac{\mathrm{d} x}{\mathrm{~d} q}=\frac{c}{A-q}(\mathrm{r} . \mathrm{I})$

growth function

$q=A\left(\mathrm{I}-\mathrm{e}^{-(x+b) / c}\right)(\mathrm{I} .2)$ typical form

$\log \frac{A-q}{A}=-\frac{x}{c}(1 \cdot 3)$

Multifactorial equation

Ist solution

$$
q=A\left(\mathrm{I}-\mathrm{e}^{-\left(x-b_{1}\right) / c_{1}}\right)\left(\mathrm{I}-\mathrm{c}^{-\left(y-b_{2}\right) / c_{2}}\right)\left(\mathrm{I}-\mathrm{c}^{-\left(z-b_{3}\right) / c_{3}}\right) \ldots
$$

2nd solution

$$
q=A\left(\mathrm{I}-\mathrm{e}^{-\left(x-b_{1}\right) / c_{1}-\left(y-b_{2}\right) c_{2}-\left(z-b_{3}\right) c_{3}} \ldots\right)
$$

The solutions of eqs. I.4 and I.S are represented in Figs. I and 2.

\section{Discussion}

In I.I the increase in yield is a function of the deficit with respect to the highest attainable yield $A$. The maximum increase for $q=0$ is equal to $A / c$. It seems questionable that the yicld increase for $q=0$ should be a function of the maximal yield $A$. The equation I.3 shows that the logarithm of the yield deficit in parts of the maximal yield is a linear function of the level of the growth factor. This is an important property for graphical treatment. 


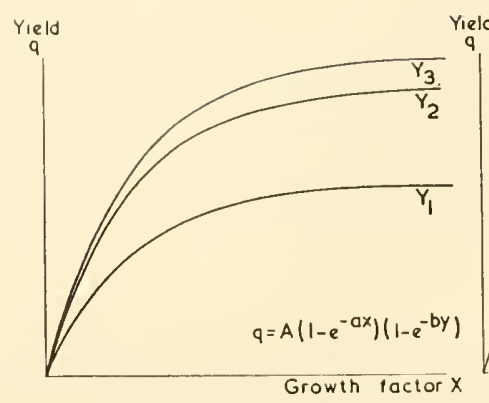

I

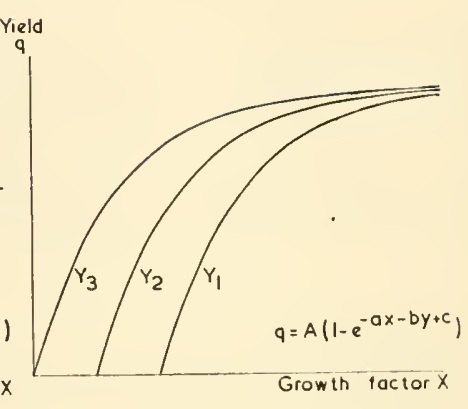

2

FIG. I. Shape of the growth curves according to the law of diminishing returns, or Mitscherlich equation, for two growth factors $x$ and $y$. Exponential approach to asymptote. All curves have same shape if expressed in percentage of maximum yield. FIG. 2. Second solution of the differential equations of the Mitscherlich assumption. Yield equation for substituting, or antagonistic, factors. All curves have same shape but are shifted to the left.

In formula I.4 the logarithm of the yield is an additive function of the influence of any separate growth factor. In formula I.S the same is true for the yield deficit.

The curves in Fig. I depicting formula I.4 may be derived from each other by vertical change of scale. The curves in Fig. 2, depicting formula I.5, may be derived by horizontal translation of any of these curves.

\section{The Projective Yield Function}

The projective function is often considered as an empirical formula. It may be proved, however, that the formula is based on the assumption that the yield increase is directly related to the yield deficit and inversely related to the level of fertility.

The following equations result:

differential equation growth function

$\frac{\mathrm{d} x}{\mathrm{~d} q}=\frac{x+B}{A-q}(2 . \mathrm{I})$ typical form

$\frac{A}{A-q}=\frac{x}{B-c}+\frac{B}{B-c}(2.3)$

\section{Multifactorial equation}

Ist solution

$$
q=A \frac{x-c_{1}}{x+B_{1}} \cdot \frac{y-c_{2}}{y+B_{2}} \cdot \frac{z-c_{3}}{z+B_{3}} \ldots
$$


2nd solution

$$
q=A\left\{I-\frac{1}{\left(x+B_{1}\right)\left(y+B_{2}\right)\left(z+B_{3}\right) \ldots}\right\}
$$

The eqs. 2.4 and 2.5 are depicted in the Figs. 3 and 4 .

\section{Discussion}

In formula 2. I the yield increase is supposed to increase in relation to the yield deficit and inversely with the level of fertility. The growth equation is a projective function and the inverse value of the yield deficit bears a linear relation with the growth factor as given in 2.3. In the multifactorial formula the logarithm of the yield or the yield deficit is, as in the Mitscherlich equation, the sum of the logarithms of the influences of every growth factor separately as appears from the first and the second solution. This property is important for a graphical analysis of the effect of a number of growth factors on the yield.

The curves in Figs. 3 and 4 offer a picture of the relations given by the

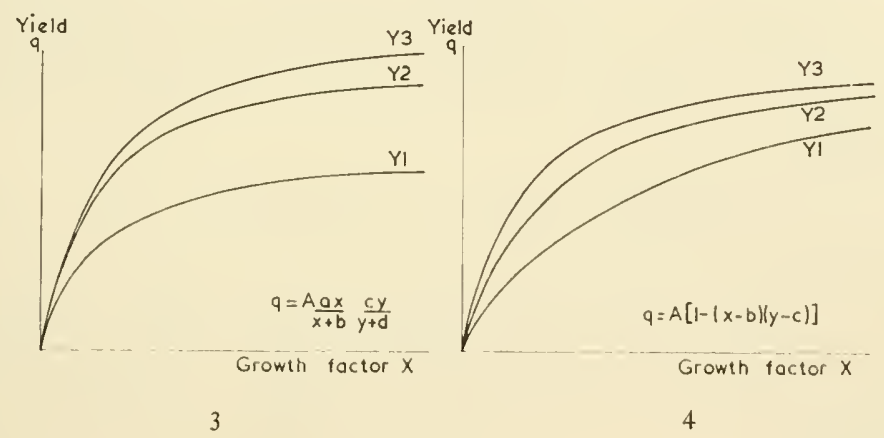

FIG. 3. Shape of growth curves for projective law of plant growth. The curves are somewhat steeper for low yields and give a somewhat more gradual increase in yield at high fertility levels than the exponential curves of Fig. I. The part valid for practical yield levels may approach the exponential curves very closely. The yields in per cent of the maximum give the same curves for different values of the $y$-factor.

Fig. 4. Second solution of the differential equation to be compared with the curves in Fig. 3. The curves may be derived from one single curve by expanding it in a vertical and horizontal way by means of two multiplication factors. Shape of growth relation often found in field experiments.

formulae 2.4 and 2.5. The curves in Fig. 3 may be derived from each other by changing the vertical scale, the curves in Fig. 4 by changing the horizontal scale. If instead of the horizontal scale of $x$, the curves are plotted 
against $\log x$, than the curves are transformed into the type of curve of the Mitscherlich equation.

\section{The Equation for Limiting Factors}

The productivity equations just discussed are not able to reproduce the consequences of the assumption that the growth factor is taken up by the plant in a fixed ratio to the amount of yield produced. If more of the growth factor is present than the plant needs for the production of its substance a part of the amount of nutritive material will not be taken up, or will be used for luxury consumption. The functions discussed before, deal mainly with this improper use of the nutritive material. The following assumption takes also into account the fixed relation between the yield and the amount of nutritive material that is necessary for plant growth.

The formulae are the following:

differential equation $\frac{\mathrm{d} x}{\mathrm{~d} q}=\frac{x-B}{A-q}+\frac{\mathrm{I}}{a}(3 . \mathrm{I} a) \quad$ or $\frac{\mathrm{d} x}{\mathrm{~d} q}=\frac{a x-q}{A-q}+\frac{\mathrm{I}}{a^{\prime}}(3 . \mathrm{x} b) \quad \begin{gathered}\text { growth function } \\ (a x-q)(A-q)=D\end{gathered}$

Multifactorial equation

Ist solution

$$
(a x-q)(b y-q)(c z-q) \ldots(A-q)=D
$$

2nd solution

$$
\{(a x-B)+(b y-C)+(c z-E)+\ldots\}(A-q)=D
$$

The eqs. 3.4 and 3.5 are represented in Figs. 5 and 6.

\section{Discussion}

The yield increase is assumed to be constant and equal to $\mathrm{r} / \mathrm{a}$, provided that no other factor is limiting growth, nor should the growth be inhibited by the limit of expansion $A$ of the plant. The differential equation may assume two shapes, which may be derived from each other. Formula 3.I $a$ is a direct and logical expansion of the formulac I.I and 2.I. For $x$ and $q$ zero the yield increase in the formula $3 . x b$ is not dependent on the optimum yield $A$. This seems more acceptable than the resulting value for the formulae I.I, 2.I and 3.I $a$ where the differential quotient for the minimum yield depends on the optimal yield.

In the multifactorial eq. 3.4 a new property is met. If only a few factors are taken up the equation takes for each factor separately a shape which 
differs from the solution in which a larger number of factors are given a place. For two growth factors the formula is of the third power and for every growth factor added the power increases by one unit. In the formulae I.I and 2.I the expression for a factor is not changed if other factors are taken up or left out. The formula implies that to solve an ecological problem, every factor should be accounted for, and the result obtained with a

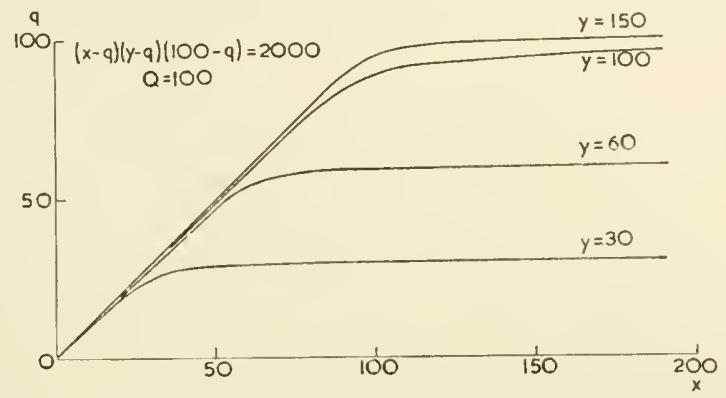

FIG. 5. Shape of the growth curves according to the law of limiting factors. The approach to the asymptotes is closer if more growth factors are taken into account. The curves are all of a different shape with a bend sharper, the higher the maximum yield.

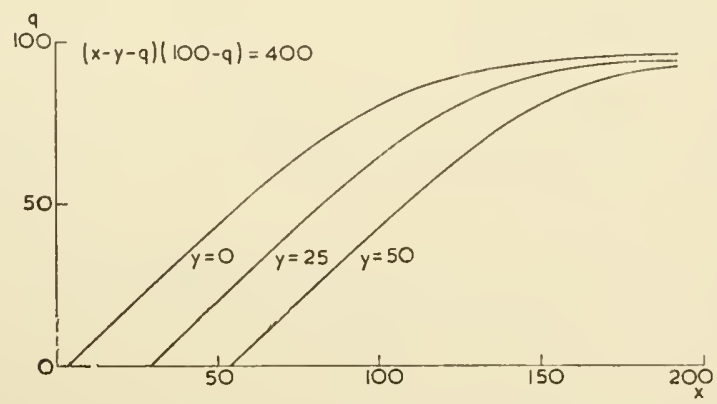

FIG. 6. Second solution of the differential equations of the type of $3.1 \mathrm{a}$ where the law of limiting factors is assumed. Case of substituting, or antagonistic, factors.

selection of the growth factors may not be considered equivalent to the result for the full solution.

The eqs. 3.4 and 3.5 are depicted in Figs. 5 and 6 . The curves in Fig. 5 bear no simple relation to each other. The curves in Fig. 6 are shifted in a horizontal direction. 


\section{The Use of the Growth Equation}

The correct use of the growth equation requires careful consideration about the nature of a growth factor and of the different solutions of the equation. Soil properties, as clay content or soil structure, are not growth factors. They are only in some ways related to them. Rainfall, for instance, is in itself not a growth factor, but it may constitute a part of the factor water. We will call these empirical productivity characteristics growth parameters. A definition of what a growth factor is seems hard to give. We will understand the meaning of such a designation here as an outside influence expressed in such a way that irrespective of the level of any other growth factor it exerts the same significance for the crop yield.

The aim of the construction of a growth equation is to describe how the level of a growth parameter, determined outside the plant, defines the actual importance of the factor as it acts inside the plant. If the observations of the value of the growth factors are made inside the plant, then the formulae may serve to define the activity of such factors. A further aim is to define how a growth factor influences the effect of other growth factors.

A growth factor now may be a function of the growth parameter and the growth parameter may constitute a part of the growth factor. Further, the growth parameter may bear a complex relation together with other parameters to the growth factor, but also the parameter may contribute to more than one growth factor.

If the parameter is indicated with $p$ and the factor with $f$, then in the formulae the following expressions may have to be used to obtain a good representation of the yield function. These linear or functional expressions should fit from a mathematical as well as from a plant physiological standpoint:

$$
\left.\begin{array}{c}
f=g(p)(4 . \mathrm{I}) \quad f=a p_{1}+b p_{2}(4.2) \quad f=g_{1}\left(p_{1}\right)+g_{2}\left(p_{2}\right)+g_{3}\left(p_{3}\right)+\ldots \\
f_{1}=g_{1}\left(p_{1}\right)+g_{2}\left(p_{2}\right)+\ldots \\
f_{2}=g_{3}\left(p_{1}\right)+g_{4}\left(p_{3}\right)+\ldots
\end{array}\right\} .
$$

An instance of formula 4.I with the factor a function of the parameter, might be the groundwater depth. The logarithm of that productivity parameter fits better into the growth equations than the depth itself. If this logarithm is inserted in formula 1.2 , this changes into formula 2.2.

Formula 4.2 represents cases as the combined influence of natural rain and sprinkling, where the artificial rain will be given in dry spells only and will be more efficient as a productivity factor, shown by a higher constant $a$, whilst natural rain is less effective because it also falls in wet periods and has to be given a lower constant $b$. 
Formula 4.3 may depict the growth factor water with parameters as clay and humus content, depth of water table and rainfall, each with its own characterising units and functions to express the part of the moisture factor which they each represent if their activity is expressed in the same scale of the growth factor.

Formula 4.4 represents the general case with empirical growth indicators where none of the parameters represent a theoretically pure growth factor. An instance is the optimum curve, which may be given by a formula:

$$
q=A\left(\mathrm{I}-\mathrm{e}^{-g_{1}\left(p_{1}\right)}\right)\left(\mathrm{I}-\mathrm{e}^{-p+g_{2}\left(p_{1}\right)}\right)
$$

Here a stimulating factor $x=g_{1}\left(p_{1}\right)$ is correlated positively with the parameter $p_{1}$, and an antagonistic growth factor $\mathrm{d} y=-p+g_{2}\left(p_{1}\right)$ is correlated negatively with $p_{1}$. Other growth parameters may be added or subtracted to the functions of $p$. Instead of a formula of the type of 1.4 , formulae of the type of 2.4 or 3.4 might just as well have been used here. The point to be stressed is, that if for one growth parameter an optimum curve is found, this means that two growth factors $x$ and $y$ are behind such a type of reaction, and that each of the formulae given can easily depict such an optimum reaction.

If two plant physiologically independent growth factors are influencing the yield, they may, however, comprise the same parameter. Humus, for instance, may bind nutritive cations as well as water. Now a yield, influenced by water and cations, may assume the following shape:

$$
q=A\left(\mathrm{I}-\mathrm{e}^{-g_{1}\left(p_{1}\right)-g_{2}\left(p_{2}\right)-\cdots}\right)\left(\mathrm{I}-\mathrm{e}^{-g_{3}\left(p_{1}\right)-g_{4}\left(p_{3}\right)-\cdots}\right)
$$

Here we see the expressions according to case 4.3 and 4.4 combined, as humus represented by $p_{1}$ appears in two factors. In each of them humus is combined with another parameter, with $p_{2}$ representing rainfall in the moisture factor and $p_{3}$ representing artificial manure in a nutritive factor.

The type of growth function depends on four considerations being, (I) what assumption is made with respect to the growth formula, (2) what expectations exist as to the component parts, which build up the separate growth factor, (3) what knowledge is available as to the functions, which reduce the parameters to the same scale and (4) what is the value of the constants ? These considerations should be mathematically, physically and physiologically sound. The number of parameters in ecological investigations may be very large. The number of growth factors, however, is much more restricted. It will be important to study how the parameters should add up to the relevant growth factor and how the growth factors co-operate in the yield. 


\section{SOME INSTANCES}

From field observations concerning the relation between groundwater depth and yicld, during a number of years, collected on different soil profiles, a graphical representation was made for advisory use. It was considered necessary to control whether the graphical representation agreed with the growth equations and growth functions as far as this might be expected from the superficial indications available.

In the inserted graph in Fig. 7 the curves are given, which represent all

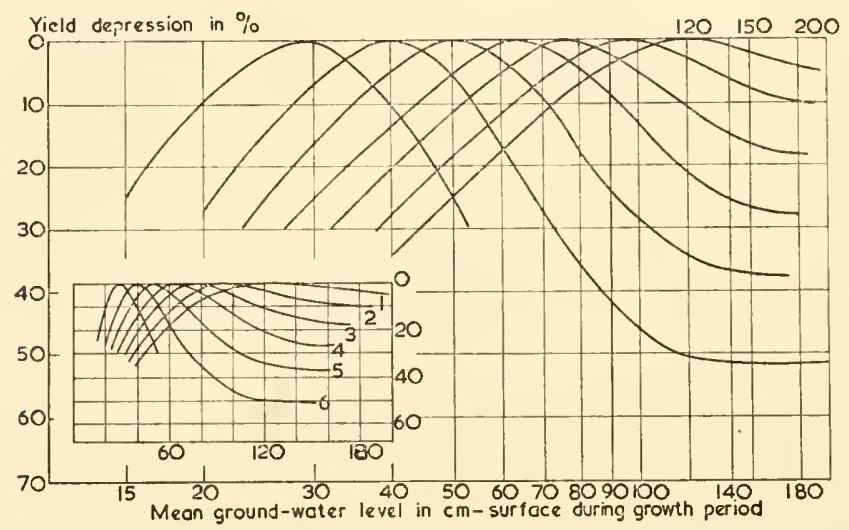

FIG. 7. The yield curves for increasing groundwater depth (sce inserted graph) were constructed with all data available in the Netherlands. By plotting against the logarithm of water depth the curves become to a certain extent parallel, pointing to formula I.5. The horizontal distance is a measure of the influence of water availability not related to groundwater depth.

the information then available on the relation of the yield to the groundwater depth. The convergent left-hand part of the curves seems to indicate that formula 2.4 might be applicable, or formula I.4 with a logarithmic scale for the groundwater depth. This logarithm furnishes a close parallel with the pF-concept for soil moisture and seems plausible. The logarithmic scale leads to the main curves of Fig. 7. The parallel left-hand ends of the curves suggest the additive solution of formula I.5, expressing that the soil moisture in the profile and the logarithm of the groundwater depth may be considered as additive parameters. By shifting the curves horizontally, they will coincide as far as they depict the influence on the yield of the growth factor which is described by the combined effect of ground water depth and profile type. 
By this horizontal shift the curve for the influence of the air is found as the envelope $A$ of the curves for the seven profiles. Because, however, not only a horizontal, but also a vertical shift is necessary, a relation with the second growth factor has to be taken into account. This relation is given by formula I. 4 which shows, that the logarithm of the yield has to be taken as vertical scale in order to obtain an additive relation between two growth factors.

The difference between the right-hand end of the curves and the envelope in Fig. 8 now gives quantitative information with respect to the second

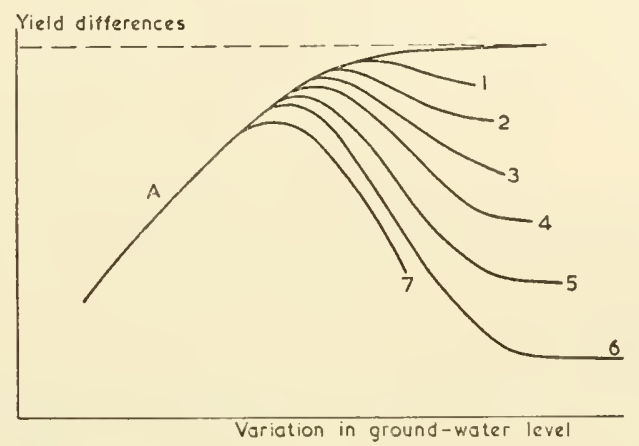

Fig. 8. The envelope $A$ of the curves, after shifting to part coincidence, depicts the influence of lack of aeration. The deviating branches, depicting the influence of water, give the influence of the factor water separately if subtracted from the envelope when, according to formula I.4, the yield is first plotted logarithmically.

growth factor, which obviously is the factor water. These curves are given in Fig. 9. In order to find out whether in this case also an additive relation according to formula I.S is present, the logarithm of the yield deficit, represented in Fig. 9, was plotted against the logarithm of the water depth. Figure Io depicts the result. If here the water depth was the exact growth factor, than the lines should, according to formula I.5, not only be parallel, but also straight. The first is true, the second point, however, is not. By shifting the line in an oblique way they coincide fairly accurately. The reaction curve $B$ shows how the growth factor water correlates with the logarithm of the water depth. If the logarithm of the vertical co-ordinates of curve $B$ is determined with the horizontal asymptote of line $B$ as zero point, and plotted against the logarithm of the water depth, then a straight line is obtained, showing that the growth function for water is an exponential function of the groundwater depth. This means that a close parallel exists with the capillary movement, which might be expected. 
The logarithm of the vertical co-ordinate of curve $A$ in Fig. 8, with the horizontal asymptote as zero line, also approaches a straight line and shows that there exists a close parallel between the growth factor governing the

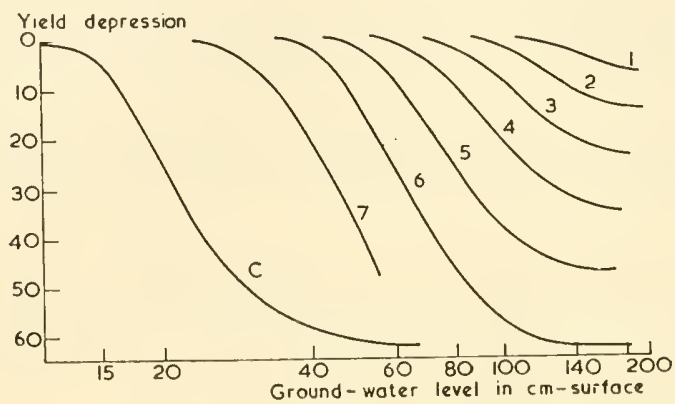

Fig. 9. The influence of the factor water, derived by the subtraction of the logarithms of the yields, plotted against the numerical value of the yield.

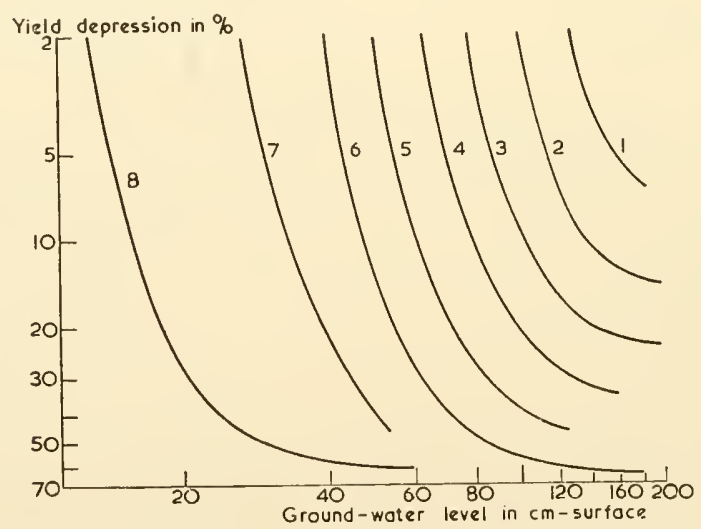

FIG. Io. The deficit in yield of Fig. 9, plotted logarithmically against the logarithm of the water depth, shows parallel lines pointing to the applicability of formula I.S. The curves may be shifted to coincidence, giving curve $B$ for the influence of the groundwater depth.

left-hand side of the curves and the air content in the soil profile, as is found by comparing with $\mathrm{pF}$-curve.

The relation between the yield and the groundwater depth, as derived from the available field observations, is not in contradiction to the yield formulae nor to experience with respect to soil physics and plant physiology. 
A second instance deals with the influence of sprinkling irrigation and nitrogen supply on the number of grazing days of cattle on perennial grassland. The original data were not very accurate and a reliable fitting of the yield curves was only possible if the functional relation between the yield, the nitrogen and the applied amount of water was given in advance (Fig. I I).

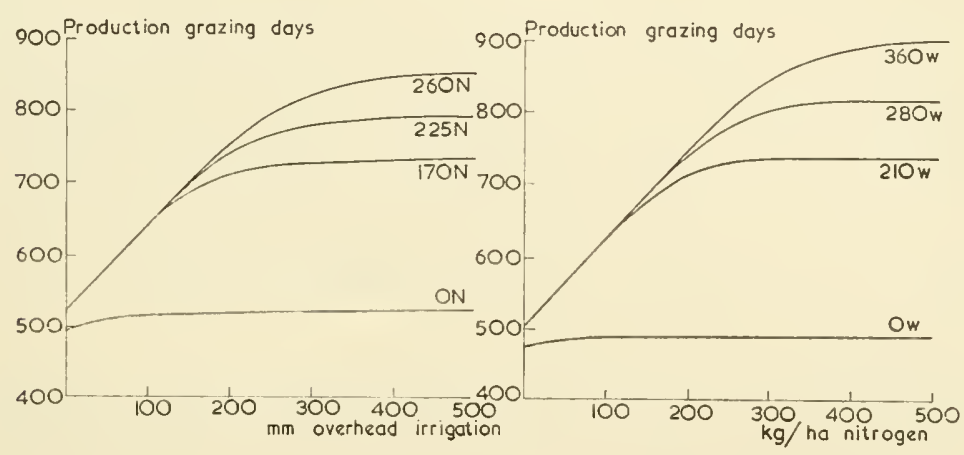

FIG. II. The influence of sprinkling irrigation and nitrogen on grazing days can best be described with formula 3.4 for the law of the limiting factors. The result for a dry year was found as depicted above.

It is well known that the yield function for the growth factors water and nitrogen may often be approximated by a straight line if quantities of water, nitrogen and yield are plotted against each other. This suggests that the law of limiting factors applies and formula $3 \cdot 4$ in the shape

$$
(x+A-a q)(y+B-b q)(Q-q)=D
$$

may be used. The constants $A$ and $B$ mean that part of the moisture and nitrogen, used by the plant, originate from rainfall, combined with soil moisture and from nitrification respectively. For the dry year, the value of $A$ was found to be $350 \mathrm{~mm}$ whereas $a$ appeared to be $500 \mathrm{l}$ water per $\mathrm{kg}$ dry material. $B$ was found to be $400 \mathrm{~kg}$ and $b$ equal to $20 \mathrm{~kg}$ dry material per $\mathrm{kg} \mathrm{N}$. The values for $A$ and $B$ correspond well with what might be expected. The rainfall may account for $220 \mathrm{~mm}$ of the value of $A$, and I $30 \mathrm{~mm}$ extracted water from the profile is not in contradiction with the 6 to I4 sprinklings given with an average of $280 \mathrm{~mm}$ applied water (Fig. I I).

It would have been difficult to find the relation between the yield and the two growth factors without an assumption as to what kind of relation might be expected. Reasoning about the model of the yield function to be 
considered valid leads to the formula for the law of limiting factors. Curve fitting without such a formula would not easily lead to results acceptable from a plant physiological standpoint. It should be mentioned here, that the exact mathematical treatment of the equation for the limiting factors does lead to considerable difficulties, if the aim should be to determine the unknown constants $a, b, A, B$ and $C$.

\section{Summary AND Conclusion}

Growth functions should be constructed with regard to plant physiological reasoning. Differential equations, giving the increase in yield per unit of the growth factor, supply the basic relations. Simple assumptions for the relation between the yield increase, the yicld and the growth factors already give useful formulae for the yicld patterns, but increased refmement of the assumptions are needed to obtain the flexibility to depict the different relations which may be encountered.

The growth equations are able to handle any number of ecological variables and allow the description of complex productivity situations. It is, however, necessary to know how these empirical productivity magnitudes should be inserted into the formulae. There are only a restricted number of growth factors, but only seldom will it be possible to obtain quantitative observations of a theoretically correct, uncontaminated growth factor, for which alone the simple solutions of the differential equations are valid. The value of the theoretically correct growth factor has to be built up from the values for the relevant ecological parameters.

This reconstruction of the value of the real growth factor may be attained by using a function of the ecological factor instead of the value itself. Also it may be necessary to construct the growth factor using a number of different yield parameters or the same parameter may be necessary to describe different growth factors. This makes the equations very fiexible, but it may be rather difficult to give empirical yield parameters their correct place in the equation.

It seems that the assumption 3.I provides the most acceptable basis for a yield equation, because the law of limiting factors is more easily justified than the law of diminishing returns, described by formula I.I. Also equation 3 gives a better account of what might be physiologically expected with regard to the interaction between growth factors.

The main problem in ecological research is, however, to translate the description of the ecological situation with many values into a description of the restricted number of well-defined but complex growth factors. Every growth factor should be constructed using the relevant ecological 
parameters and the proper function of each parameter should be determined. To find the functions of the parameters, often a reverse reasoning will as well be valuable. The object in that case is, given the yield and the growth equation, to construct the function of the combined ecological parameters in such a way that the observations fit well in the growth equation. The observation that the combination of functions of the parameter produces a relation similar to the simple growth equation, shows that the solution arrived at cannot be far from correct. In this way an insight into the interaction and the activity function of the parameters may be obtained. 


\title{
THE GROWTH RESPONSE OF SUGAR BEET TO SIMILAR IRRIGATION CYCLES UNDER DIFFERENT WEATHER CONDITIONS
}

\author{
B. Orchard \\ Rothamsted Experimental Station, Harpenden, Herts.
}

\section{INTRODUCTION}

OweN and Watson (1956) reported that when prolonged drought was broken by light rainfall, unirrigated sugar beet had a greater relative growth rate than irrigated controls and Gates (I955) reported a similar phenomenon in young tomato plants growing in pots. This paper describes an attempt to reproduce and analyse these effects by controlled watering of small field plots protected from rainfall by a static Dutch-light structure. Three similar experiments (two in summer and one in autumn) were done on the same variety of sugar beet growing on the same plots in three successive years so the effects of radiation and other weather factors on the development of the drought response and the recovery from it can be considered.

\section{EXPERIMENTAL}

\section{GenERAL}

Two treatments in which irrigation was withheld for a pcriod, brief drought $(B)$ and continued drought $(C)$ were compared with a freely available moisture treatment $(\mathrm{A})$. Before the drought and throughout treatment A the plots were maintained near field capacity by frequent watering. The plots were on a heavy clay loam, formerly a garden. The moisture content $-\mathrm{pF}$ relationship was determined by the method of Monteith and Owen (1958). Field capacity was about $28-30 \%$ of the oven dry weight and the permanent wilting percentage $\left(\mathrm{pF}_{4} \cdot 2\right)$ 13.8\%. The moisture content at $\mathrm{pF} 4 \cdot 2$ was greater than for a typical Rothamsted soil, possibly because of residual salts from tap-water used in previous irrigation experiments.

Sugar beet seed (Sharpe's Klein E) was washed for two hours in aerated running water, planted in soil blocks and covered with sand containing 'Harvesan' ( $120 \mathrm{mg}$ per $\mathrm{kg}$ ). One seedling per block was retained, and when the seedlings were well established the blocks were planted at a spacing of I $\mathrm{ft} \times$ I $\mathrm{ft}$ in plots of $\mathrm{I}_{4} \mathrm{ft} \times 9 \mathrm{ft}$. The soil was dry at planting and afterwards 
was watered freely. Metered quantities of tap-water were applied, with a hand-rose in Exp. I and with a mobile overhead sprayline in later experiments. Soil moisture was determined routinely on samples from the 0-I 2 in. layer. Flints made sampling at lower levels impracticable.

The crop was sampled on six occasions in Exps. I and 2 and on four occasions in Exp. 3. In Exps. I and 2, one $3 \mathrm{ft} \times 3 \mathrm{ft}$ area of crop (nine plants) and in Exp. 3, two $2 \mathrm{ft} \times 3 \mathrm{ft}$ areas (six plants each) were taken at each sampling.

The plants were separated into roots and tops, and the tops were subdivided into laminae and stem plus petioles. The fresh and dry weights of each part, the total leaf area and the number of living leaves were then determined. Leaf area was estimated by the method of Owen (1957) in Exp. I, and by the scanning planimeter (Orchard, I96I) in Exps. 2 and 3.

\section{Details of EXPERIMENTS}

EXPERIMENT I (1958) AND EXPERIMENT 2 (1959)

These experiments were similar in design and will be discussed together. The plots received ro cwt/acre of a compound fertiliser containing $7 \% \mathrm{~N}$, $7 \% \mathrm{P}_{2} \mathrm{O}_{5}$ and $10.5 \% \mathrm{~K}_{2} \mathrm{O}$. The seed was sown in mid-April. In 1958 , seedlings were planted on the plots $2 \mathrm{I}$ days after sowing, but in 1959 planting was delayed $\mathrm{I} 4$ days, so that an attack by Rhizoctonia spp. could be controlled. The A plots were maintained near field capacity throughout and no water was applied to the $\mathrm{C}$ plots after June 25 , except for $\mathrm{I}$ in. between the fifth and sixth samplings in 1958. These treatments were comparable in the two experiments, but the B treatments differed (Table I). The I958 regime was intended to produce water stress but no wilting; the plots were rewatered as soon as the soil moisture content reached $15 \%$. Two drought cycles of this type did not affect growth, and a third, more severe, cycle was given, so that the recovery from drought could be studied.

In 1959, therefore, drought was continued until growth was significantly affected. The drought was then broken by $\frac{1}{2}$ in. of water, but there was no further watering for 8 days; the plots were then returned to field capacity.

The three treatments were replicated in four randomised blocks.

\section{EXPERIMENT 3 (Autumn, 1960)}

The stubble left after an experiment on barley was burnt with a flame-gun and rotary cultivated. No fertiliser was added. Before sowing the barley, 2 $\mathrm{cwt} /$ acre of a compound fertiliser containing $\mathrm{I} 3 \% \mathrm{P}_{2} \mathrm{O}_{5}$ and $\mathrm{I} 3 \% \mathrm{~K}_{2} \mathrm{O}$ was 
TABLE I

Details of drought regimes

\begin{tabular}{|c|c|c|c|c|c|c|}
\hline \multirow[b]{3}{*}{ Expt. } & \multirow[b]{3}{*}{ Treatment } & \multirow[b]{3}{*}{ Cycle } & \multirow{2}{*}{\multicolumn{2}{|c|}{$\underbrace{\text { Date }}$}} & \multicolumn{2}{|c|}{ Water applied (in.) } \\
\hline & & & & & & To treated \\
\hline & & & From & To & A plots & plots \\
\hline \multirow[t]{3}{*}{ I } & B & Ist & $27 \cdot 5.58$ & I2. 6.58 & $2 \cdot 4$ & $\mathrm{I} \cdot 4$ \\
\hline & B & 2nd & I2. 6.58 & 3. 7.58 & $3 \cdot 0$ & $I \cdot I$ \\
\hline & B & $3 \mathrm{rd}$ & 3. 7.58 & 30. 7.58 & $3 \cdot 4$ & $2 \cdot 0$ \\
\hline \multirow[t]{2}{*}{2} & $\mathrm{~B}$ & Ist & 2. 6.59 & I. 7.59 & $5 \cdot 7$ & $(0.57)$ \\
\hline & $\mathrm{B}$ & 2nd & I. 7.59 & 13. 7.59 & $2 \cdot 9$ & $3 \cdot 4$ \\
\hline \multirow[t]{3}{*}{3} & $\mathrm{BL}$ & & 8. 9.60 & 3.11 .60 & $\mathbf{I} \cdot 7$ & $(0 \cdot 29)$ \\
\hline & $\mathrm{BH}$ & & 8. 9.60 & 3.11 .60 & $1 \cdot 7$ & $I \cdot 67$ \\
\hline & $\mathrm{BL}, \mathrm{BH}$ & & 3.11 .60 & 4. I.6I & nil & nil \\
\hline I & C & & $24 \cdot 6.58$ & $23 \cdot 9.58$ & $9^{-6}$ & $\left(0.5+0.5^{\star}\right)$ \\
\hline 2 & C & & $25 \cdot 6.59$ & I8. 9.59 & 14.5 & nil \\
\hline 3 & $\mathrm{C}$ & & 8. 9.60 & 4. I.6I & $\mathrm{I} \cdot 7$ & nil \\
\hline
\end{tabular}

The beet were transferred to the plots on $8.5 .58,22.5 .59,12.8 .60$ respectively. Applications of water insufficient to return the plots to field capacity shown in brackets.

* On 3.9 and 8.9.58.

applied to all plots and I. $5 \mathrm{cwt} /$ acre of nitro-chalk $(2 \mathrm{I} \% \mathrm{~N})$ to half of each plot. Seed was sown in soil blocks in late July and seedlings were transplanted 22 days later. Treatments $A$ and $C$ were the same as in Exps. I and 2. The $B$ and $C$ treatments started simultaneously in mid-September. In the B treatments the drought was broken in early November but half the plots $(\mathrm{BH})$ were then held at field capacity, while the others $(\mathrm{BL})$ received only $\frac{1}{4}$ in. of water and were not irrigated again.

Sampling was arranged so that the residual effects of the differential nitrogen treatment applied to the barley could be estimated. The number of plants per sample was decreased to six to provide four pairs of samples per plot.

The four water treatments were replicated in three randomised blocks.

\section{WEA THER}

Weather conditions differed during the three experiments. The total daily radiation (Kipp radiometer), hours of sunshine and evaporation from the standard I/1000 acre water surface showed similar time changes and only data on total daily radiation will be presented (Table 2 ). The radiometer 
TABle 2

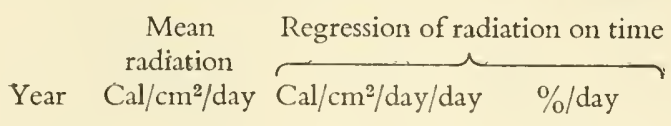

$\begin{array}{llll}\text { I958 } & 317 \cdot 4 & -I .75 & -0.55 \\ \text { I959 } & 40 I \cdot 2 & -I .75 & -0.44 \\ \text { I960 } & \text { II } 3 . I & -2.25 & -2.00\end{array}$

measured the radiation incident on the glasshouse, and the figures are not corrected for the transmission of the structure (about 70\%). The daily radiation fell significantly throughout each experiment.

During 1959 the experimental period had the greatest mean daily radiation and the smallest relative rate of decrease; 1958 had a smaller mean radiation and the same absolute rate of change as 1959. Although these time changes were significant they were not large and did not greatly change the growing conditions during the experiment. In I960 the experiment was done later in the year when the mean radiation was still less, and the change with time was greater; the growing conditions therefore changed appreciably during the experiment. In the final sampling interval temperature and illumination was unfavourable for growth.

\section{SoIL. MoIsture}

As only the top $\mathrm{I} 2$ in. of soil was sampled, the change in soil water content does not represent the total water loss during drought, when the relationship between the various soil layers was unpredictable. Under treatment A, soil water moves more freely, so that when the 0-12 in. layer is at field capacity the entire profile will usually be equally moist and changes in the O-I2 in. layer can then be used as a reliable guide to water requirements.

The water consumption of the A plots, which can be used as an estimate of the maximum deficit in the $B$ and $C$ plots, was about twice the amount of water required to regain field capacity in Exps. I and 2, but in Exp. 3 the amounts agreed to within $2 \%$. At least part of the discrepancy was caused by restriction of transpiration during drought on $\mathrm{B}$ and $\mathrm{C}$ plots. In I960 transpiration was already low and therefore insensitive to drought. The average moisture content of the A plots was higher in 1958 than in I959 so that there was more risk of drainage and the difference in water used (Table I) may underestimate the difference in transpiration. 


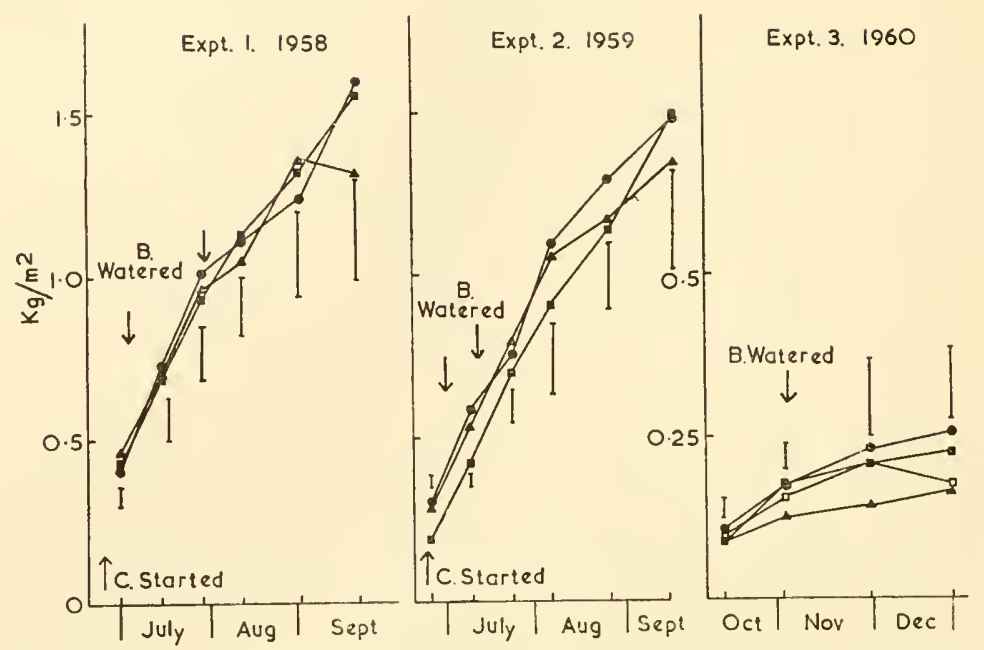

FiG. I. Total dry weight of plants. Circles-treatment A, squares-treatment B $(B H)$ (open squares treatment $\mathrm{BL}$ ), triangles-treatment C. A-frequent watering, B-intermittent drought, C-continuous drought, as detailed in Table I. Vertical lines, least significant differences $(P<0 \cdot 05)$.

\section{RESULTS}

The results of Exp. 3 are given as means of the two nitrogen levels. The nitrogen residues from the previous experiment had no important interaction with water regime, although they increased the dry weight and leaf area of the plants significantly they had no effect on the relative growth rates in the experimental period.

Effects of treatments have been expressed as percent of the value for the A plots.

\section{Dry Matter Production}

Dry matter production was significantly affected by drought in only one of the three experiments; in 1959, treatment B (Fig. I) decreased the yield by $38 \%$ after 23 days without watering. The corresponding treatment $\mathrm{C}$ caused a similar decrease but the relative response was smaller (10\%). The increase in dry weight during the second moist period of treatment $B$ was only slightly greater than with treatment $A$, and the difference in dry matter yield between $A$ and $B$ persisted for over 9 weeks.

The $1958 \mathrm{~B}$ plots gave no sign of a drought effect but the decreased dry weight of the $C$ plants at the final harvest was almost significant. This was 
mainly because dry matter was suddenly lost from the tops possibly as a response to the $I$ in. of water applied during the last sampling period, and not because of a steadily mounting drought effect. The treatments had no significant effect in Exp. 3 ; the large differences were the result of initial variation between plots. The relative growth rate was not affected except during the last interval when it was decreased by treatment $B$.

The dry matter contents of the various parts of the plant were not equally affected by drought. In Expts. I and 2 the top/root dry weight ratio (Fig. 2)

Expt. I. 1958

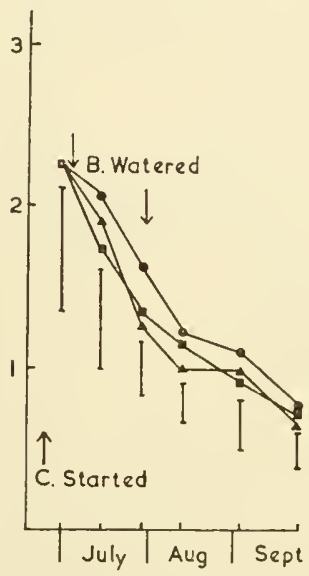

Expt. 2. 1959

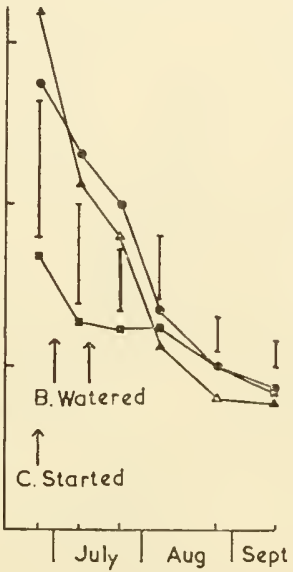

Expt. 3. 1960

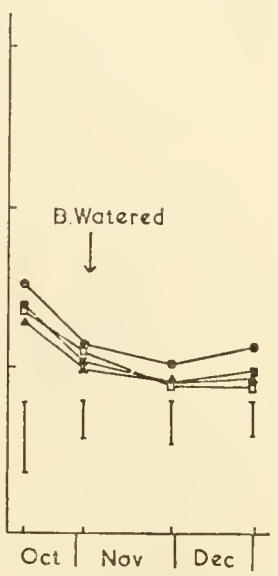

FIG. 2. Top/root dry weight ratio. Symbols as Fig. I.

and the lamina/petiole dry weight ratio (Fig. 3) fell uniformly with time. The effect of drought was small and acted oppositely on the two ratios. The decreased yields were entirely in the tops; the weight of roots was unaffected, so the decrease with time in top/root ratio was accentuated. In contrast, the time trend in lamina/petiole ratio was decreased by drought, the yield of lamina being decreased less than the yield of petioles. The results of the two experiments were consistent but in 1958 the drought effects were not significant. In 1959, whereas the effect of the C treatment was only just significant, treatment $\mathrm{B}$ had a highly significant effect on the top/root ratio, and increased the lamina/petiole ratio significantly during the recovery phase.

In Exp. 3 the top/root ratio fell at first and then became almost constant, the lamina/petiole ratio fell a little and then rose slightly. The lower growth rate of the $\mathrm{BL}$ plots during the final interval was not accompanied by 
changes in either ratio. The differences between experiments in the changes in dry matter distribution with time was probably caused by differences in the weather. Radiation and temperature were particularly unfavourable for growth during the final sampling interval in Exp. 3 .

\section{Leaf Area (Fig. 4)}

The changes with time in leaf area index $(\mathrm{L})$ were similar in all experiments; $\mathrm{L}$ reached a maximum when the plants were 3-4 months old and then decreased. Maximum $\mathrm{L}$ was slightly less in $1959(5 \cdot 3)$ than in $1958(6 \cdot 3)$ and

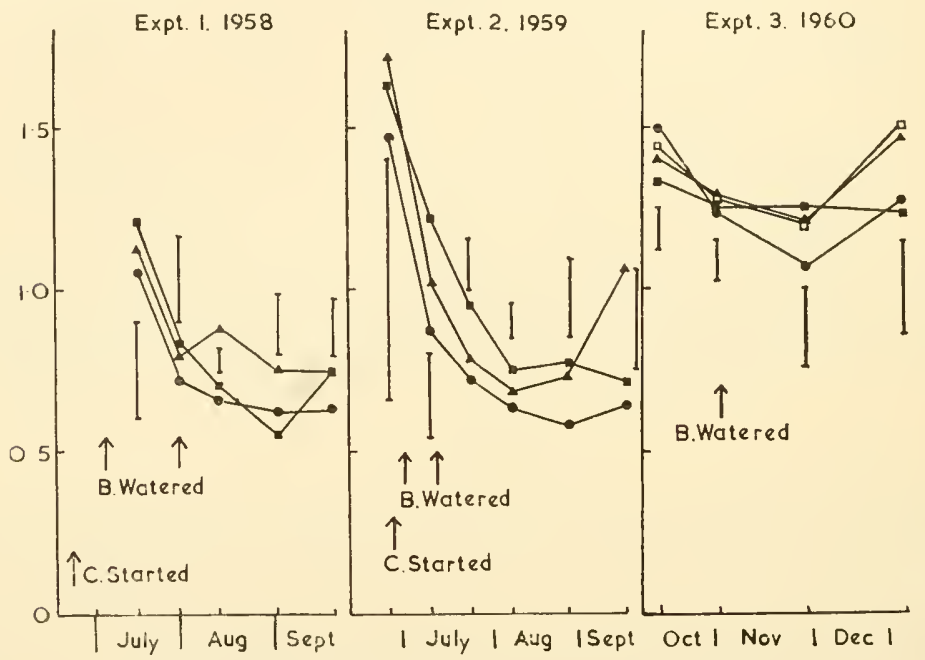

Fig. 3. Lamina/petiole dry weight ratio. Symbols as Fig. I.

much less in $1960(\mathrm{I} \cdot 3)$. Area per leaf was similar in Exps. I and 2, so the smaller maximum $\mathrm{L}$ was caused by a lower leaf number. In Exp. 3 low temperature and radiation decreased both leaf expansion and, less severely, leaf production. In all experiments the fall from the maximum was the result of decrease in area per leaf, and leaf number continued to increase with time (fig. 6).

Maximum L was less than that reported by Owen (1958) (7.8) for beet growing on the same plots but greater than that of sugar beet grown in the field at Rothamsted in 1958 (Orchard and Monteith, unpublished) or in previous years (Watson, 1947). Maximum L was attained slightly earlier under glass than in the open.

All drought treatments decreased L. The treatment B had the greatest 


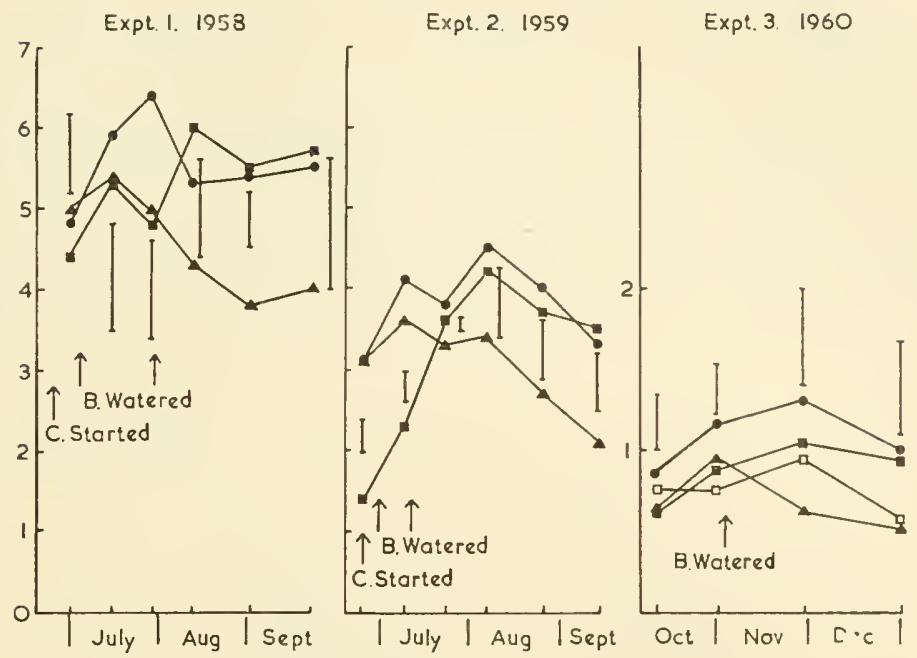

FIg. 4. Leaf area index. Symbols as Fig. I.
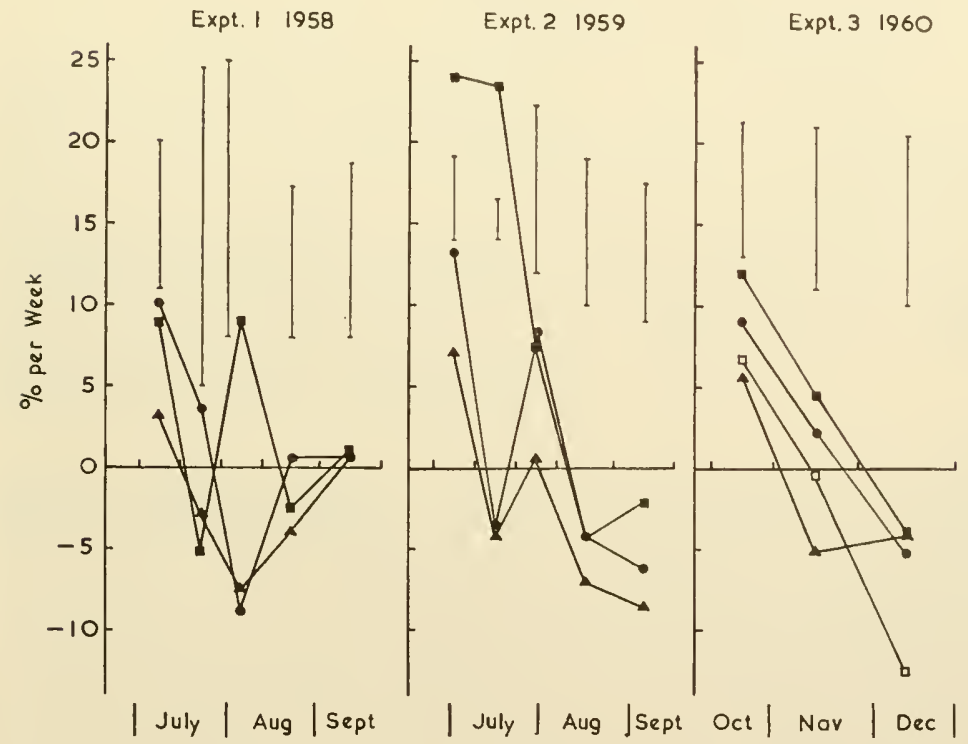

FIG. 5. Relative leaf growth rate. Symbols as Fig. I. 
effect $(54 \%)$ in 1959 and the least $(25 \%)$ in 1960 . The effect in 1960 was not significant, probably because of the large initial differences between plots but there was however a significant, positive corrclation between $\mathrm{L}$ and plant moisture content at the first sampling. Treatment $\mathrm{C}$ had very similar maximum effects upon leaf area index in different years $(30,36$ and $35 \%$ respectively). After watering, the decrease in $\mathrm{L}$ from treatment $\mathrm{B}$ disappeared within 2I days. The high relative leaf growth rates (Fig. 5) during the recovery period were transient and the $B$ plots never attained a
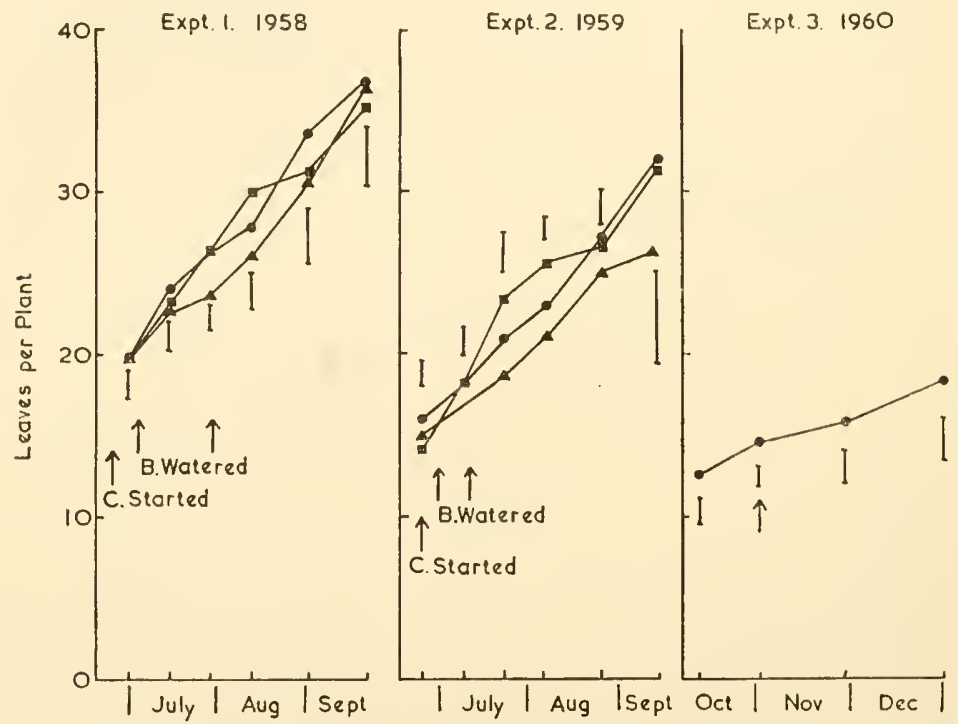

Fig. 6. Leaf number per plant. (i960 treatments B, C, not shown). Symbols as Fig. I.

significantly greater $\mathrm{L}$ than the A plots. Recovery from the BL drought in I960 was incomplete and temporary, as the leaf area decreased at the final harvest to that of treatment $\mathrm{C}$. The water applied during the eleventh week of treatment $\mathrm{C}$ in 1958 checked the decrease in $\mathrm{L}$.

In 1958 and 1959 , both treatments B and C decreased the area per leaf but only $\mathrm{C}$ decreased the leaf number significantly (Fig. 6). Leaf number also increased rapidly after watering and occasionally slightly exceeded that of treatment A, as in 1959 when with treatment B leaf number made a transient but just significant contribution to recovery. 


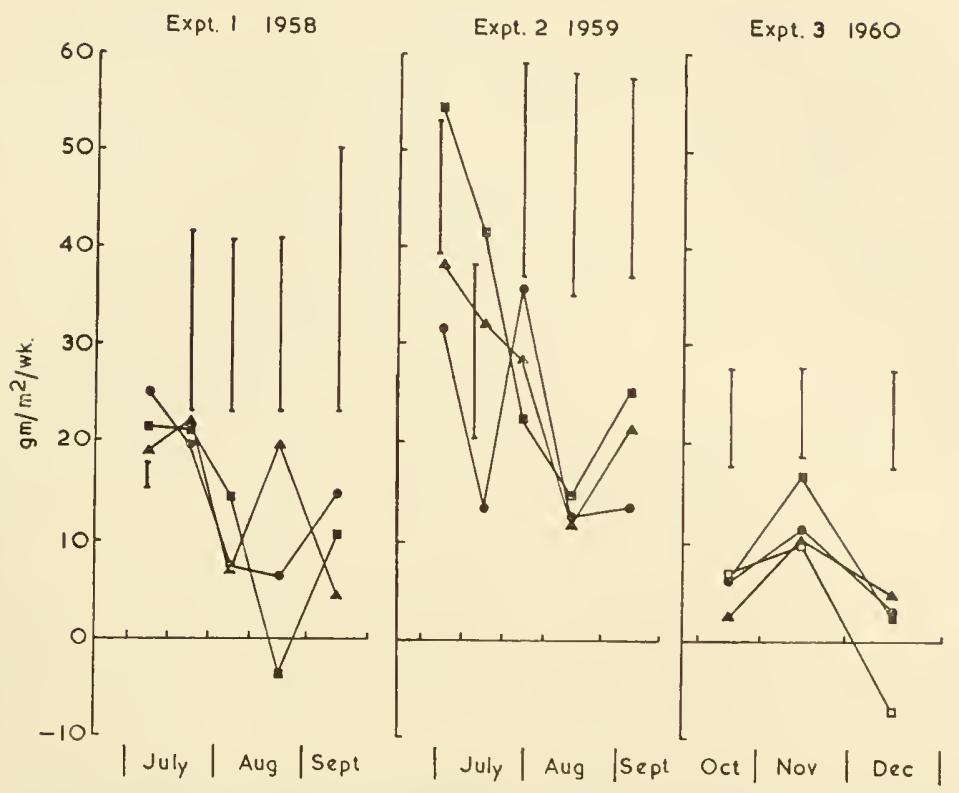

FIG. 7. Net assimilation rate. Symbols as Fig. I.

Net Assimilation Rate (Fig. 7)

The net assimilation rate (E) differed significantly between experiments, and was greatest in 1959 and least in 1960 , in accordance with the observed differences in total radiation. E was not depressed consistently by water shortage. The 1959 drought did, however, have a significant after effect on $\mathrm{E}$; when the drought was broken by $\frac{1}{2} \mathrm{in}$. of water, E was increased significantly. This increase persisted for a second I4-day period during which the plots were returned to field capacity.

Moisture Content (Fig. 8)

The moisture content fell with time, more slowly in Exp. 3 in which the mean moisture content was slightly less than in Exps. I and 2. The moisture content of the tops was greater than that of the roots and was affected more by treatment. The drought effect (relative to the A value) was similar in all three experiments; drought decreased the moisture content of the plants by $26-30 \%$ and restoring the plots to field capacity restored the moisture content to within $10 \%$ of the A value before the next sampling occasion. 
Expt. 1. 1958

Expt. 21959

Expt. 3. 1960
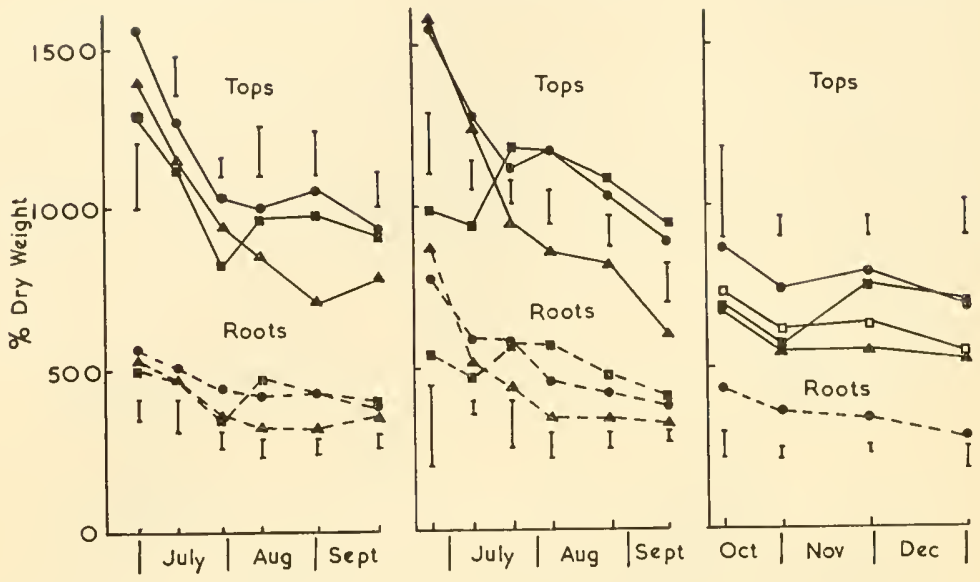

FIG. 8. Moisture content. (I960 roots, treatments B, C, not shown.) Symbols as Fig. I.

The action of small applications of water on moisture content was small even on the 1959 B plots where it affected leaf growth rate considerably.

The moisture content changes were almost certainly not correlated in a simple manner with turgor changes. The different response of tops and roots to treatment, and the small effect of light watering, indicate a change in composition of the dry matter of the plant rather than reversible loss of water.

\section{DISCUSSION}

The most interesting effect of weather was on the large stimulation of growth by watering after drought (after effect) which apparently required high radiation for its expression. The relative leaf growth rate during the recovery from drought was significantly greater than that of the A plots in both 1958 and 1959 , but the effect on net assimilation rate (E) was significant only in 1959 (Table 3). The increase in E, however, was associated with a decrease in $\mathrm{L}$ and was insufficient to increase the crop growth rate. The absence of a significant effect on $\mathrm{E}$ in 1958 might be explained by the small effect of drought on leaf area in that year. This does not, however, explain the absence of the phenomenon from the experiment in 1957 of Owen (1958). Owen's treatment B had almost the same effect on $L$ as the 1959 treatment but it had no after effect on E. Owen's B plants had twice the leaf area but received less radiation than the $1959 \mathrm{~B}$ plants. Although it is possible 
TABLE 3

The effects of watering on the growth of previously droughted sugar beets $(B)$ in comparison with freely watered plants (A)

\begin{tabular}{|c|c|c|c|c|c|c|}
\hline Year & Treatinent & $\begin{array}{r}\begin{array}{r}\text { Leaf ar } \\
\text { (leaf area/g }\end{array} \\
\end{array}$ & $\underbrace{\text { round area) }}_{\begin{array}{l}\text { I } 4 \text { days } \\
\text { after } \\
\text { watering }\end{array}}$ & $\begin{array}{l}\text { Relative } \\
\text { leaf } \\
\text { growth } \\
\text { rate } \\
\% / \\
\text { week }\end{array}$ & $\begin{array}{l}\text { Net } \\
\text { assimila- } \\
\text { tion } \\
\text { rate } \\
\mathrm{g} / \mathrm{m}^{2} / \\
\text { week }\end{array}$ & $\begin{array}{l}\text { Mean } \\
\text { radiation } \\
\mathrm{cal} / \mathrm{cm}^{2} / \\
\text { day }\end{array}$ \\
\hline 1955 & A & $2 \cdot 3$ & $2 \cdot 6$ & 5 & 34 & \\
\hline (Owen \& & B & $I \cdot O$ & $I \cdot 6$ & 20 & 96 & $480^{\star}$ \\
\hline Watson) & S.E. & \pm 0.12 & $\pm 0 \cdot 17$ & \pm 6 & $\pm \mathrm{I} 4$ & \\
\hline \multirow{3}{*}{$\begin{array}{r}1957 \\
\text { (Owen) }\end{array}$} & A & $5 \cdot 0$ & $6 \cdot 3$ & II $\cdot 5$ & 30 & \\
\hline & B & 2.5 & $4 \cdot 3$ & $27 \cdot 0$ & 38 & 298 \\
\hline & S.E. & \pm 0.12 & $\pm 0 \cdot 39$ & - & \pm 6.5 & \\
\hline \multirow[t]{3}{*}{1958} & A & 6.4 & $5 \cdot 3$ & $-8 \cdot 9$ & 7 & \\
\hline & B & $4 \cdot 8$ & $6 \cdot 0$ & I I $\cdot O$ & I 4 & 273 \\
\hline & S.E. & \pm 0.34 & \pm 0.39 & \pm 4.9 & $\pm 5 \cdot I$ & \\
\hline \multirow[t]{3}{*}{1959} & A & $3 \cdot I$ & $4 \cdot I$ & $\mathrm{I} 3 \cdot 3$ & 32 & \\
\hline & B & $I \cdot 4$ & $2 \cdot 3$ & $24^{\circ} \mathrm{O}$ & 54 & $4^{82}$ \\
\hline & S.E. & $\pm 0 \cdot$ I I & $\pm 0 \cdot 10$ & $\pm I \cdot 5$ & $\pm 3 \cdot 9$ & \\
\hline \multirow[t]{3}{*}{1960} & A & $I \cdot I S$ & $1 \cdot 30$ & $2 \cdot 2$ & 12 & \\
\hline & B & 0.88 & I.07 & $4 \cdot 5$ & I 7 & 60 \\
\hline & S.E. & \pm 0.088 & \pm 0.175 & $\pm 3 \cdot 0$ & $\pm 2 \cdot 7$ & J \\
\hline
\end{tabular}

* Assuming transmission of glasshouse $=70 \%$.

that the difference in leaf area may have been important (the after effect has only been observed in crops with $L$ less than $2 \cdot 5$ ), it cannot be the main factor otherwise a large after effect would have been observed in 1960 (maximum L I·3).

The maximum after effect of the $1959 \mathrm{~B}$ treatment on $\mathrm{E}$ (I $2 \%$ ) was somewhat smaller than that originally described by Owen and Watson (1956) (182\%), although $\mathrm{L}$, the drought effect on $\mathrm{L}$, and the effective radiation (taking the transmission of the glasshouse as $70 \%$ ) were closely similar in the two experiments.

Owen and Watson's plants were growing in an open field on light, sandy soil and so are not strictly comparable with those in my experiments. Further, the light transmission of the Dutch-light structure was not accurately known and may have been overestimated, so the large aftereffect they obtained may have been caused by a greater radiation intensity. 
The cause of the after-effect on $\mathrm{E}$ is still not clear; it is too large to be accounted for by the effect of $\mathrm{L}$ on $\mathrm{E}$ (Watson, I958). Drought may permit something to be stored which later promotes growth or the rapid expansion of the plant when the moisture content is increased may provide a sink for assimilates and so promote assimilation. Gates (I955) suggested that tomato plants become more juvenile as a result of wilting and so reversed the general trend for growth rates to fall with age, but this explanation does not apply to sugar beet in which the trend is small (Thorne, 1960). Gates (I957) later suggested that changes in phosphorus metabolism were important. The after-effect of drought on $E$ implies that $E$ is at least partially restricted by internal factors and that it should be possible to increase crop yicld by increasing $\mathrm{E}$.

The decrease in growth rate during drought (the direct effect) was only influenced by weather when the plants were small $(\mathrm{L}<\mathrm{I})$, although the effect itself was observed in the larger plants. The weather factor almost certainly operated through transpiration, which controls both the time required to remove the 'freely available' water from the root zone and the proportion of the soil moisture which is freely available (Bierhuizen, 1959; Kuiper and Bierhuizen, 1959). The effect of plant size is not unexpected considering the known interrelations between root growth, transpiration and water supply (Slatyer, I960). Water moves very slowly in unsaturated soils and root extension is essential to the maintenance of the water supply. Once the demand exceeds this supply, the plant turgor and hence root growth will fall, further restricting the supply. The larger the active root system and the greater the initial soil moisture content, the greater the water demand the system can sustain.

In I959, treatment B decreased both leaf area and dry matter production, but in 1960 the same treatment applied to plants with a similar number of leaves had no effect on dry matter production and only a small effect on leaf area. In 1959 transpiration was evidently rapid enough to exceed the critical demand and severe water stress developed. In 1960, transpiration was much slower and did not exceed the critical rate.

The significant positive correlation between plant moisture content and leaf area on the first sampling occasion in Exp. 3 indicates that the high initial variability of the plots was due to differences in soil moisture (remaining from the previous experiment). These appeared to interfere with the early growth of the plants and may have influenced the moisture content at the first sampling indirectly, either by decreasing the amount of stored water in the soil and so slightly hastening the onset of drought, or by affecting the composition of the plant. The significant negative correlation between 
moisture content at the first sampling and the subsequent relative leaf growth rate may indicate an after-effect of drought of the type already discussed. The water supplied before the start of the drought was probably cnough to relieve the water stress (without completely abolishing moisture content differences) but the weather did not permit the stunted plants to grow rapidly enough to overcome the check.

Weather may influence the drought response even when changes in root growth are not important. Bierhuizen (loc. cit.) showed that when transpiration is rapid, variation in soil moisture stress can influence transpiration rate at stresses as low as $\mathrm{pF}$ 2, although under conditions giving slow transpiration the rate is uninfluenced by soil conditions. According to Philip (1957) the permeability of the system must change. Although transpiration rate tends to a constant value independent of atmospheric conditions, at high soil moisture tension the change in permeability, and presumably the physiological change causing it, must increase when atmospheric conditions favour increased transpiration rates. Growth is usually more sensitive than transpiration to water stress so the growth of a plant in dry soil should interact with atmospheric conditions. This was not observed in my experiments; the effects of treatment C on L, net leaf number and moisture content were not significantly greater in I959 than in 1958 despite a $50 \%$ greater transpiration potential as estimated from the water consumption of the A plots.

There was no evidence that net assimilation rate (E) was decreased by drought; the $C$ plots had almost the same dry matter yield as the A plots, despite considerable differences in the leaf area index which implies that drought increased $\mathrm{E}$. This does not require a change in the internal physiology of the leaf. Watson (I958) showed that the rate of dry matter production (crop growth rate) of sugar beet increases with increasing $L$ and is greatest when $L$ is between 6 and 9, considerably above the values observed in my experiment. If the leaf area of the A plots was near or above the optimum, small changes in $\mathrm{L}$ would have no effect on dry matter production. Below optimal L, dry matter production is restricted because the crop fails to intercept all available radiation and above the optimum dry matter is lost by respiration of the leaves in heavy shade. At high levels of directional illumination (as on a clear summer day) dry matter production is also restricted because the upper leaves intercept light energy more rapidly than they can use it in carbon assimilation (the photosynthesis of sugar beet leaves reaches saturation at 0.3 of full sunlight, Gaastra, 1958). Watson and Witts (I959) ascribe the high optimum L (6-9) of cultivated beet as compared with wild beet or kale (optimum L 3-4) to its erect habit. Sunlight 
strikes the erect beet leaves obliquely and its effective intensity is brought to a level at which it is used efficiently and, at the same time, more leaf area can be illuminated by a given area of light beam. This mechanism, however, does not operate when the incident level does not greatly exceed saturation or when the light is diffuse, and the optimum for cultivated bect should then be the same as for kale. The Dutch-light structure intercepted at least $30 \%$ of the incident radiation and introduced some diffusion, and the optimum L for sugar beet should be considerably lower than in the open field.

In the first two experiments the $\mathrm{L}$ of the A plots was probably near the optimum, hence the decrease in $\mathrm{L}$ caused by drought did not influence dry matter production significantly.

In the third experiment $\mathrm{L}$ was below the optimum but the effect of the drought was obscured by the large experimental errors.

\section{REFERENCES}

Bierhuizen, J. F. (1959) Some observations on the relation between transpiration and soil moisture. Nether., J. agric. Sci. 6, 94-98.

GaAstrA, P. (1958) Light energy conversion in field crops in comparison with the photosynthetic efficiency under laboratory conditions. Meded. LandbHoogesch. Wageningen, 58, I-I2.

GATES, C.T. (I95S) The response of the young tomato plant to a brief period of water shortage. II: The individual leaves. Aust. J. biol. Sci. 8, 21 5-230.

Gates, C.T. (I957) The response of the young tomato plant to a brief period of water shortage. III: Drifts in nitrogen and phosphorus. Aust. J. biol. Sci. Io, I25-I46.

Kuiper, P.J. \& Bierhuizen, J. F. (I959) The effect of some environmental factors on the transpiration of plants under controlled conditions. Meded. LandbHoogesch. Wageningen, 58, I-I6.

MONTEtTh, J.L. \& OWen, P. C. (I958) A thermocouple method for measuring relative humidity in the range $95-100 \%$. J. Sci. Instrum. 35, 443-446.

OrChard, B. (I96I) An automatic device for measuring leaf area. J. exp. Bot. I2, 458464 .

OWen, P.C. (1957) Rapid estimation of the areas of the leaves of crop plants. Nature, Lond. 180, 6I I only.

OWEN, P.C. (1958) The growth of sugar beet under different water regimes. J. agric. Sci. 5I, I33-136.

OWEN, P.C. \& WATSON, D.J. (1956) Effect on crop growth of rain after prolonged drought. Nature, Lond. 177,847 only.

PHILIP, J. R. (I957) The physical principles of soil water movenent during the irrigation cycle. C.S.I.R.O. Inter. Comm. Irrigation Drainage, I25-I 54.

Statyer, R.O. (1960) Absorption of water by plants. C.S.I.R.O. Div. Land Res. Reg. Survey, Australia, 33I-339. 
Stanhili, G. (1957) The effect of differences in soil-moisture on plant growth: A review and analysis of soil moisture regime experiments. Soil Sci. 84, 205-2I4.

Thorne, G.N. (1960) Variations with age in NAR and other growth attributes of sugar beet, potato and barley in a controlled environment. Ann. Bot. Lond. N.S. 24, 356-371.

Watson, D.J. (1947) Comparative physiological studies on the growth of field crops. I. Variation in net assimilation rate and leaf area between species and varieties, and within and between years. Amm. Bot. Lond. N.S. II, 4 I-76.

Watson, D.J. (1958) The dependence of net assimilation rate on leaf area index. Amn. Bot. Lond. N.S. 22, 37-54.

Watson, D.J. \& Witts, K.J. (1959) The net assimilation rates of wild and cultivated beets. Ann. Bot. Lond. N.S. 23, 43 I-439. 


\title{
CROPPING PATTERN AND WATER RELATIONS
}

\author{
W. C. VISSER \\ Instituut voor Cultuurtechnick en Waterhuishouding, \\ Wageningen, Netherlands
}

\section{Aim OF THE InVESTIGATIONS}

WATER relations in the field not only influence the yield of crops, but also the kind of crops the farmer will grow. On dry soils rye is planted frequently. But if the water relations are improved and a larger yield per ha is obtained, there is, however, a good chance that the total amount of seed produced on the farm will decrease. If the field is better provided with moisture, this will induce the farmer to grow less rye and to increase the acreage sown with beet and potatoes. If one tries to predict the result of an increase in fertility of the soil, it will not only be necessary to predict the yield per unit area, but also the percentage of the area occupied by each crop. This proportion of the different crops in the total farm area will be called the cropping pattern.

\section{Nature of Problem}

Within rather wide limits the farmer is free to decide on what area of any crop should be planted. For that reason the frequency of occurrence of a certain crop is governed to a greater extent by the law of probability than by some more definite agricultural rule or necessity. Since the ecological situation will not be equally favourable however, not every crop will be grown to a same percentage and with a same probability. The less optimal this situation for a certain crop is, the smaller will be the probability of this crop being chosen by the farmer.

Generally it will be rather difficult to collect enough data to determine the frequency of occurrence of the crops accurately. Every field gives only one observation a year. Data for a number of years will be needed. But the crops grown in earlier years are often not too well remembered and the frequency data therefore will be less reliable. Moreover, cropping patterns of former years are liable to restrictions in comparability due to changes in the economy of agricultural production. Data from more than five years ago may become of suspect uniformity.

The number of data for calculation of the frequency decreases still more, 
because the unit of decision for the cropping pattern is not the field but the farm. The study of the influence of moisture relations on the cropping pattern will have to account for disturbing factors such as farm size, availability of labour, accessibility of the field, etc. A great many data of separate fields from a large number of farms will be needed. But the large number of farms may cover such a vast area, that the comparability of the farms to be included in the survey may be impaired, due to economic influences such as distance to markets or railheads.

This means that the data have to be collected from a relatively small area. The cropping pattern to be described has to be based upon a restricted number of observations, which are by their nature moreover, of a restricted accuracy. Therefore a method of treatment of the observations has to be devised, which enables a condensation of the information contained in the data as much as possible, and the elimination of random deviations as far as possible. This means a general formula has to be devised that is valid for every crop and fertility factor and requires the minimum amount of constants.

\section{The Formula for a Cropping Pattern}

An acceptable assumption is, that for every crop within the cropping system an optimal value for the production parameter will exist. The more the actual fertility level diverges from this optinum, the less frequently the crop will be planted. If the assumption is made that the frequency of occurrence is lincarly related to the difference $x-x_{0}$ between the actual and the optimal level of the production parameter $x$ this means that the probability of occurrence $F \%$ of the crop is governed by the normal probability distribution:

$$
F \%=A e^{-a^{2}\left(x-x_{0}\right)^{2}}
$$

This may be written as

$$
\ln F \%=-a^{2}\left(x-x_{0}\right)^{2}+\ln A
$$

Formula 2 expresses that by plotting the logarithm of the frequency against the production parameter a part of a parabola will be found, which is described by three constants, two of which $-\ln A$ and $x_{0}-$ may be accounted for by shifting the co-ordinate axes.

The value of $x_{0}$ and $\ln A$ depends on the crop and the production situation. If the value of $a$ were constant, then, by shifting the co-ordinate axes, the curves of every crop might be brought to coincidence with the curve for any other crop. 
The constant $x_{0}$ indicates at what level of the production parameter the optimum frequency is found. This optimum is the result of the combined effect of all the competing crops together within the farm economy. The constant $A$ indicates with what frequency the crop is planted under optimal conditions and depends therefore on the importance of the crop within the farm organisation and the farm economy.

The constant $a$ points out how the farmers react to decrease in profits and increase in costs under sub-optimal conditions and may be considered as a more sociological parameter. Can this parameter be independent of the soil and the crop?

Considering that according to the yield equation for the law of diminishing returns the yield depression $D$ may be described with

$$
D=B e^{-b(x-c)}
$$

and considering that $b$ is claimed to be constant, it may be assumed that the yield decrease for different soils and crops will not differ much by variation of the growth factor and it seems not too bold a step to assume that a same size of yield decrease will induce the farmer to react in the same way. If $b$ in formula 3 is near constant for the same growth parameter it makes sense also to take $a$ in formula 2 as constant for the same production parameter. This assumption is the more acceptable, because constancy or inconstancy cannot be proved statistically, due to the restricted accuracy of the data commonly available.

\section{The Clay Content and the Cropping Pattern}

The clay content is a useful parameter to indicate the moisture available in the soil profile. It governs rather strongly which crops will be grown. Potatoes and rye, for instance, are typical crops for dry profiles with low clay content.

To study the relation between cropping pattern and clay content the crops over five years of 2000 fields were collected. For successive groups of clay content the frequency of occurrence of the different crops was established. The logarithm of the frequency percentage, plotted against the clay content, yielded curves as given in Fig. I.

These curves now have to be fitted around a parabolic curve. This parabola is only partly covered by the longest curve which is possible in view of the variation in clay content. The relative unimportance of the value of the constant $a$ clearly results from the inaccurate determination of the degree of curvature, due to the relative shortness of these partial curves. The probability that the reaction curve is a parabola must to a greater 
extent be derived from reasoning about fundamental relations than from statistical evidence.

If for all the crops the curves are fitted around the parabola by applying a horizontal and a vertical shift, the partial curves coincide with the parabola and the frequency observations appear as a scatter of dots around

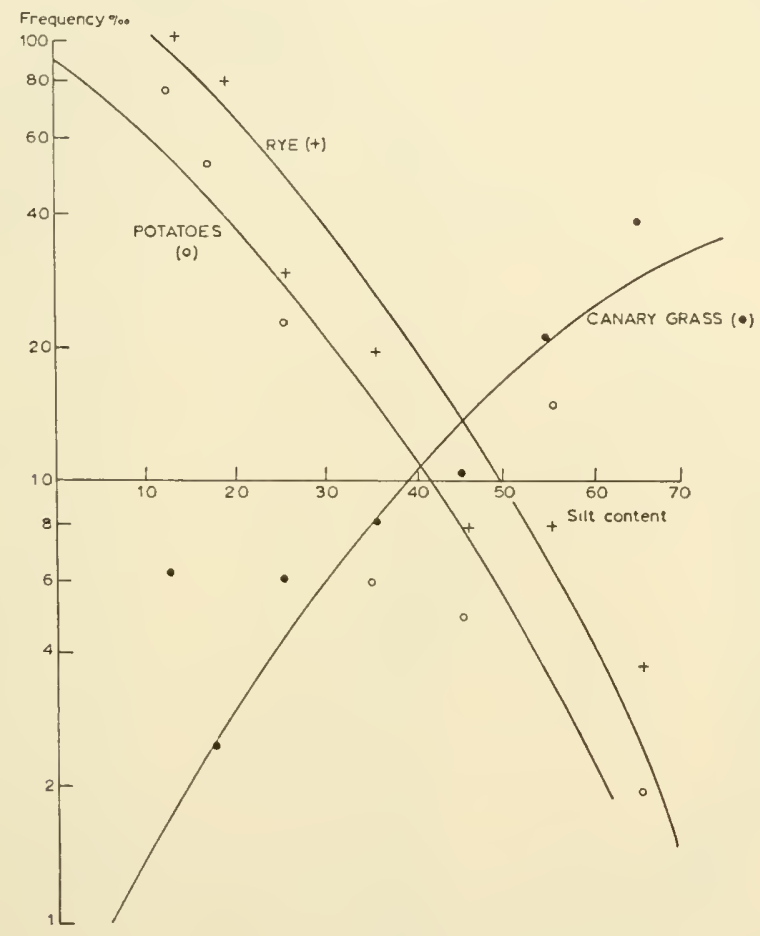

FIG. I. If the logarithm of the frequency of occurrence of a crop within the cropping pattern is plotted against the silt content, this gives curves of different shape, which may be considered as parts of parabolas.

the parabola. The result is given in Fig. 2. The object of interest now is not centred any more on the curve, but on the parameters $x_{0}$ and $A$ which appear in the graph as the distance of shifting of the co-ordinate axes. Figure 2 represents the entire cropping pattern of this clay soil and the effect of the clay content on this pattern.

If it were desirable to distinguish between more than one production parameter the formula to be used would be that of the normal multiple correlation. It may be mentioned that the sum of a number of single or 


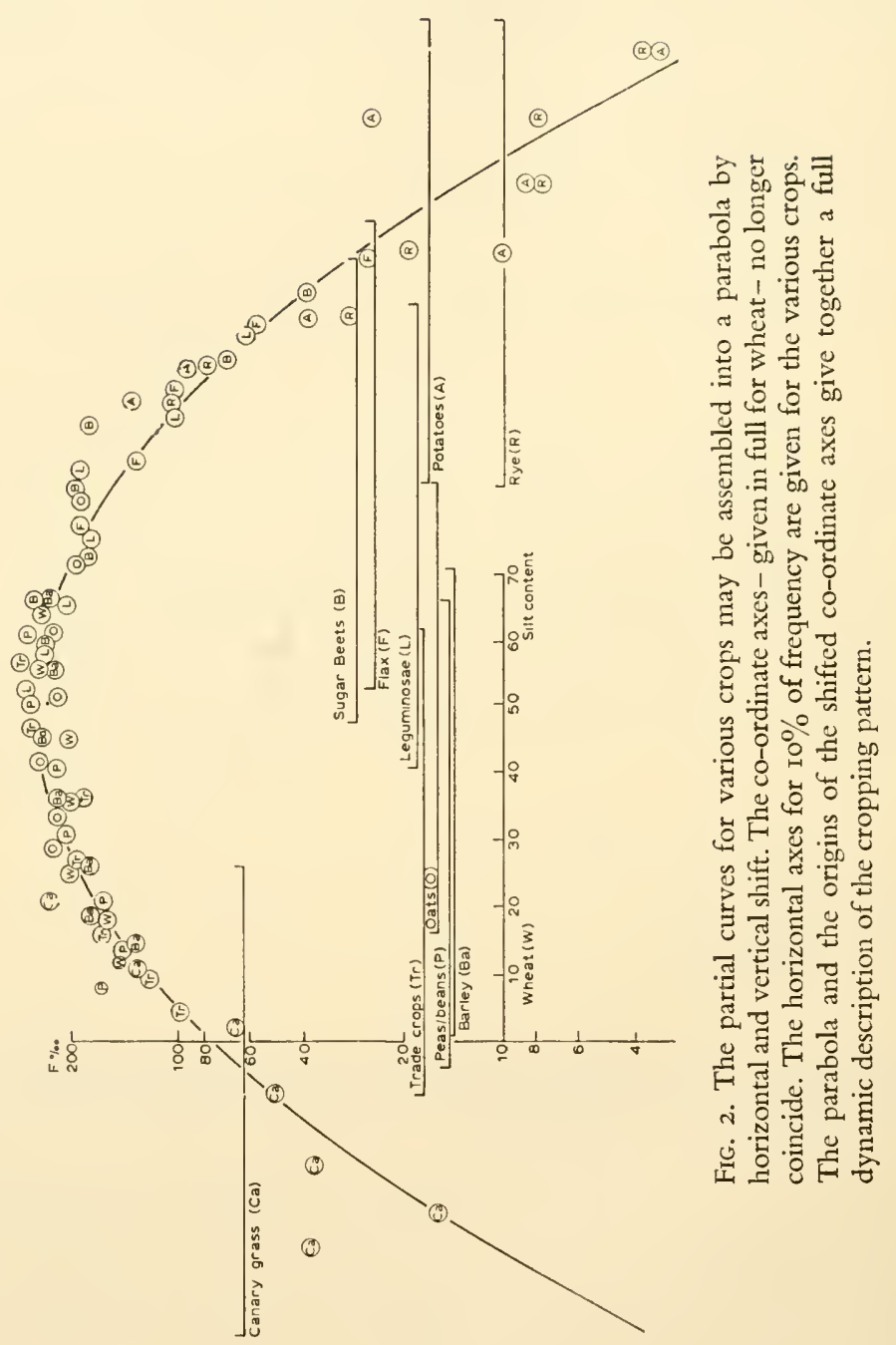


multiple correlation functions in fact does not make up the full 100\% for every value of the production parameters. The application of these formulae must be considered as an approximation.

\section{The Reliability of the Results}

If the reasoning about the fundamental properties of the cropping pattern is not convincing, then still a fitting of curves through the scatter diagrams remains, in which $x_{0}$ and $A$ give some information with respect to the position and slope of the curves, irrespective of any parabolic relation.

If the result of different areas is compared, this proves something about the reality of these parameters of the curves. In Fig. 3 for two areas the

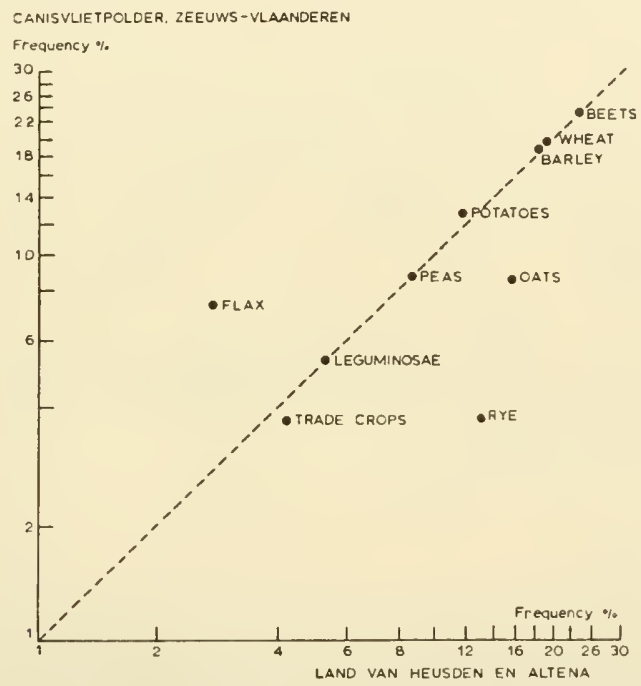

Fig. 3. The vertical component of shift $\log A$, expressed in a frequency scale, plotted against the same constant for another area, can apparently be determined rather accurately.

values for $x_{0}$ and $\log A$ are plotted against each other. The graph shows that within the margins of accuracy that may be expected in these investigations, the shift parameters $A$ and $x_{0}$ show in each area the same mutual relation.

This result shows that the parabola, as a principle to bring order in the independent choice of the crop to be grown by individual farmers, works out well, even if there exists a distinct difference in the type of farming in the two areas. 


\section{Groundwater Depth and Cropping Pattern}

In areas with a shallow water table, the question arises what influence the raising or lowering of the water table will have on the crops which one may expect will be grown.

In a sandy area differences in groundwater level promised workable data for an intended investigation. The crops grown on the fields of some 70 farms during the last five years, as well as the water table in summer, were established. These data supplied the frequency curves for each crop. In Fig. 4 the curves for a number of crops, plotted against the groundwater

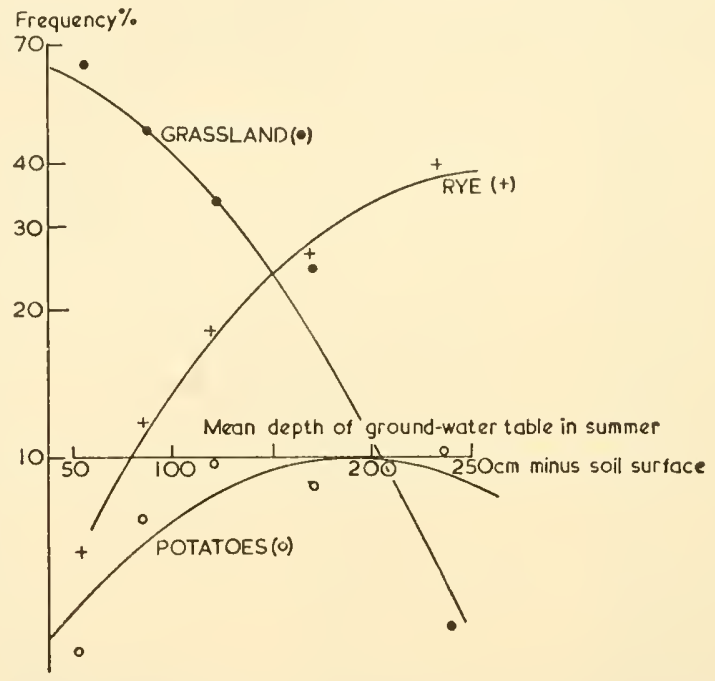

Fig. 4. For sandy soil and small farms the crop frequency has been determined and plotted against the groundwater depth in summer. Grass is clearly a wet-land crop, rye grows on dry fields and potatoes have an intermediate position.

depth are given. The difference in position of the crops in the cropping pattern is apparent and a change in groundwater depth will influence the type of farm considerably.

The data are fitted around a parabola by horizontal and vertical shifts. In Fig. 5 the result is given. For each crop the horizontal axis is given with endpoints $50 \mathrm{~cm}$ and $250 \mathrm{~cm}$ groundwater depth and this axis is drawn at a frequency value of $10 \%$. Where the shifted horizontal axes are situated well above the parabola, this means that at optimum conditions the frequency of occurrence remains below 10\%. The cropping system with respect to the influence of water is for every crop given by the parabola 
and the origin of the co-ordinate system for every crop separately. In Fig. 5 the horizontal axes are given to clarify the applicability of the graph, but they are superfluous because only the distances of shifting $\log A$ and $x_{0}$ matter.

The logarithmic scale may be changed back and the shifts undone to obtain a readable representation of the cropping pattern The frequency. is

REST CROPS (D)

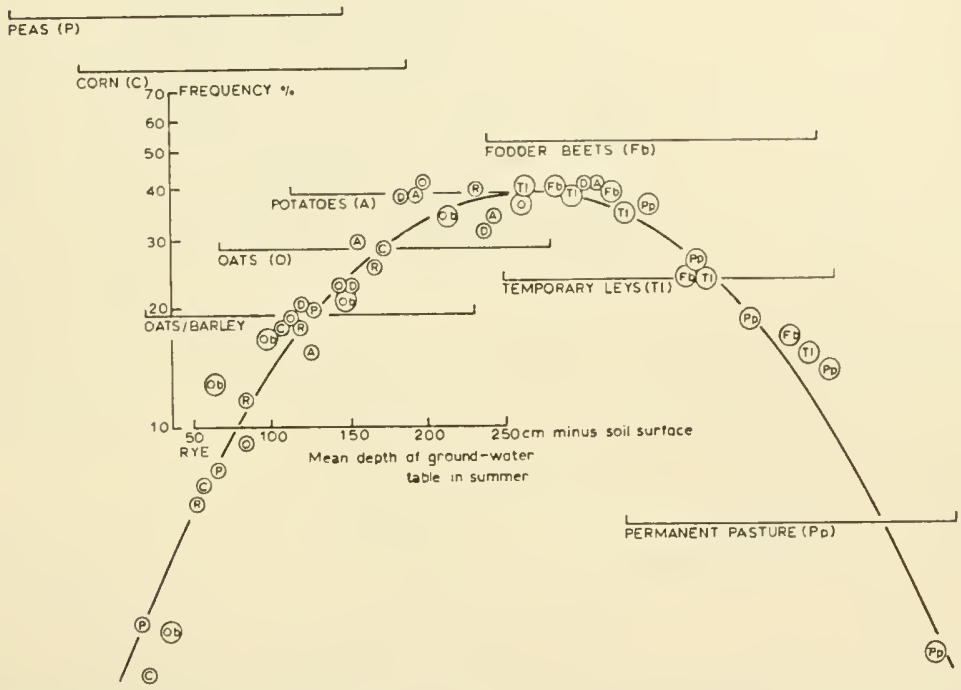

Fig. 5. The cropping pattern parabola gives the relative position of each crop clearly. The shifted co-ordinate axes are given in full for rye. It would be sufficient to give only the origin of the co-ordinate axes if a description of the cropping pattern is desired which is readily readable.

then plotted against the same co-ordinate scale for the groundwater depth. In Fig. 6 the result is given. The well-known facts that the wetter land is used for grassland and that also fodder beets increase in acreage and that cereals are crops for dryer soils is apparent. The continuous transition of the crop frequency curves point at a continuous change from cattle rearing to cereal culture.

\section{Summary and Conclusions}

The cropping pattern is a complex indication of the type of farming, described by the kind of crop and the percentage of occurrence. Important 
is a dynamic representation, in which the properties that influence the cropping pattern are variable. The type of farming depends on a great many internal and external factors, economic, organisational as well as physical. This complex relation may as a first approximation be described as a multiple probability distribution. Eventually skew chance distributions might be needed, but the nature of the data with respect to their restricted accuracy often make it unnecessary to introduce this complication.

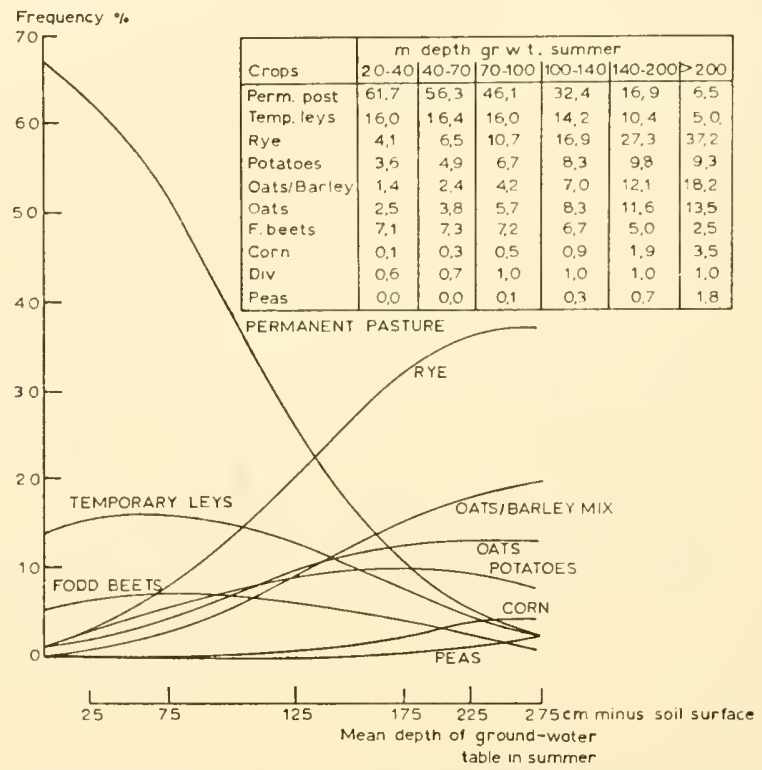

FIG. 6. The parabola for the cropping pattern makes possible a reconstruction of the frequency percentage-groundwater depth diagram by changing back the logarithmic scale and reversing the horizontal and vertical shifts. The graphical and numerical results of the influence of groundwater depth on the frequency of occurrence of each crop is given above.

One single probability distribution diagram is able to comprise the frequency curves for all the crops by choosing for every crop separately the right situation of the co-ordinate system for the frequency and for the production parameter. But this applies only if the logarithm of the frequency is used. Logarithmic plotting of the probability percentage transforms the frequency distribution curve into a parabola. The multiplication factor $a^{2}$ in the parabola - see formula 2- may be assumed to be constant for a certain area. This constant represents the reaction of the joint farmers to a decrease in productivity due to sub-optimal circumstances. 
The close relation between the probability distribution and the formula for diminishing returns as yield equation and the claim that the growth factor $b$-see formula 3 - is constant makes it plausible to assume also the constancy of $a^{2}$ in formula 2 .

By fitting the parabola through the frequency curves of the crops a representation of the cropping system is obtained, depicted by the parabola and the origin of the co-ordinate axes. Herewith the cropping pattern is condensed to a maximum of information with a minimum of constants. This will increase the accuracy of the result or reduce the quantity of needed data.

The curves show the well-known preference of different crops for lighter or heavier soils or lower or higher groundwater levels. The graphs may be useful for the prognosis of the change in farming type due to improvements in the ecological, organisational or economic situation. They also may be used for comparing cropping patterns in different areas after correcting for one or more factors that influence the cropping pattern most strongly.

The parabola method gives a fair basis for the study of the changes in crop frequency as a result of changes in the environment of agricultural production. 


\title{
WATER RELATIONS OF FOREST TREES
}

\author{
E. E. Gaertner \\ Professional Agrologist, Petawawa Forest, \\ Chalk River, Ontario, Canada
}

Seventy years have passed since R. Hartig (189I) in his Anatomie und Physiologie der Pflanzen considered the factors influencing the amount of growth in a tree. Under 'soil' he recognised depth, moisture, and mineral content; under 'climate', temperature and the humidity of the air; next was the area for crown and root development; the occurrence of seed years, and finally the inherited characteristics of the individual trees. Today we can still, to a degree, follow this outline to plot the relationship between a trec and its environment. In the present contribution we shall concentrate on the water relations of forest trees.

It is well recognised that water is an essential component of all living matter, yet its overall effect on the growth of forest trees is still not completely comprehended. It can be said that trees, through their nature, are subjected to a greater varicty of water stresses than any other plants, often more devastating because, due to their size, several of these stresses can be active simultaneously. While their roots are active in soil where the drying cycle acts slowly, the shoot tip, often fifty metres or more in the air is subjected to a rapidly changing environment.

Russell (1960) in the study of flow phenomena in plants has aptly pointed out the difficulties involved in this study. The technique of accurate measurements of the flux of material past a given point or of the space distribution of potentials in the flow system still remains to be developed, even for the flow of water through a single plant part such as a root, stem or a petiole.

Each species requires its own specific water supply for most favourable conditions of growth, and the quantity of water in the soil has a greater influence than any other factor on the distribution of plant species (Bowman, I9I I). This statement suggests in part, the vast variety of conditions affecting the relationship between the water content of the soil and the individual tree. It has been of concern not only to the forester, but also to the horticulturist and to those concerned with watershed management and irrigation. 
When considering the various sources of moisture to the tree, we might think of them in terms of ground water, or as precipitation which in turn becomes available to the plant through the roots, when it permeates the soil. The various types of soil moisture have been outlined by Kramer (I944). The alternative is moisture that becomes directly available from the atmosphere in the form of dew. Krečmer (195I) and Stone (1957a) have recently reviewed the literature on dew as an ecological factor. Stone and several co-workers explored the survival value of dew, though their experimental work has been restricted to seedling material of ponderosa pine (Pinus ponderosa Dougl.), (Stone and Fowells, I955; Stone, I957b) and coulter pine (Pintus conlteri D. Don.), (Stone, Went and Young, I950). They considered that dew and fog prolonged survival of trees in soil at or near the wilting point by causing a re-saturation of leaf tissue and concomitant reduction of moisture removed from the root system. Waisel (1958) in a study of dew absorption by evergreen trees and shrubs of arid zones stated that there was a negative correlation between soil humidity and dew absorption, but the amounts of dew taken up were completely inadequate to balance the daily transpiration loss.

The distribution and growth of tree species may be influenced by persistent dew and fog in areas of relatively low annual precipitation. The location of Sequoia sempervirens (Lamb.) Endl. along the foggy part of the California coast and of S. washingtoniana (Winsl.) Sudw. on the misty slopes of the Sicrras in inland southern California, is attributed to this climatic factor (Harlow and Harrar, I94I).

Although it is usual to think of fog in terms of moisture, Wilson (1948), while studying the increased apparent photosynthesis on Camellia japonica and Ligustrum lucidum, came to the conclusion that it was the $20-25 \%$ increase of carbon dioxide in the air on foggy days that was responsible for favourable plant growth.

Tree species may be found over a range of soil moisture sites which vary with latitude and altitude. For example beech's (Fagus grandifolia Ehrh.) amplitude is fairly wide in southern Ontario, but not as wide as in the southern United States where the population is also more diverse genetically (Camp, 1950). Frequently a species is limited to edaphic conditions by its intolerance to shade when it fits into niches where competition is less severe. Jack pine (Pinus banksiana Lamb.) is usually associated with dry soils although it does occur on very wet situations with black spruce (Picea mariana (Mill.) B.S.P.) as a codominant in areas south-east of Nighthawk Lake in northern Ontario. Similarly the same black spruce, which is usually found on wet soils, occurs on dry sites in north-western Ontario 
as a codominant with jack pine (Fraser, 1954). In both cases it may be partly intolerance to shade that forces each specics to edaphic extremes.

Soil moisture classification (Briggs, I897) includes gravitational, capillary and hygroscopic types as well as the vapour phase (Lebedeff, I928), the first two classes of which are available for tree growth. Condition of aeration (telluric and stagnant water (Hills, I953)) merits a special consideration for it is important not only for growth but even for selection of the tree species on different sites (Clements, 192I). In north-eastern North America yellow birch (Betula lutea Michx. f.) and black ash (Fraximus nigra Marsh.) are usually found on wet soils abundant with telluric (aerated) water, but they are replaced by black spruce and tamarack (Larix laricina (DuRoi) K. Koch.) if the soil water is stagnant with low oxygen content (Fraser, 1954).

Earlier workers have been interested in tolerance of trees both to light and water. Fricke (1904) showed that competition for moisture by roots of older trees could cause death of young growth under the shade of mother trees. His experiments were in a 70- to Ioo-year-old Scot's pine (Pimus sylvestris L.) stand on a dry sandy soil. Trenches $25 \mathrm{~cm}$ deep were cut around groups of ten-year-old $40 \mathrm{~cm}$ pines under this stand to isolate them from the mature trees. In the first year after trenching the young pines in the isolated groups doubled their terminal growth of the previous year. Similar changes were noted in the ecesis of a rich ground vegetation. Fricke (1904) found the soil moisture conditions in the experimental trenched plots two to three times greater than in untrenched areas. Björkman (1944-45), Surmač (1958), and others considered root competition for moisture and nutrients an important factor in limiting growth of tree seedlings in a closed stand. In other instances light was considered the limiting factor, for Moore (I926) showed that the addition of moisture to plots under the shade failed, in white pine (Pinus strobus L.), to counteract the shade effect. The seed in the experimental flats in shade showed markedly better germination than those in the open, because the soil surface was prevented from drying. However, the growth of the survivors in the open was many times that of the shaded seedlings in spite of ample moisture. Trenched and untrenched plot experiments were also conducted by Korstian and Coile (1938), who demonstrated that competition between individuals of the forest vegetation for soil moisture is a highly significant factor in growth, devclopment, and reproduction of loblolly and short-leaf pine in the Piedmont plateau.

Burns (1923) pointed out the variability of annulal ring width in New England forest trees, and stated that there was no direct correlation between 
rainfall and radial growth; rather, site conditions were of primary importance and Diller (1935) substantiated this conclusion by saying that soil moisture observations were better than precipitation records since the variable factors of run-off and seepage would be eliminated. Usually drought affected growth of the following year, whereas in wet years increase of growth occurred the same season. If trees are growing where drought or soil wilting conditions may occur, there may be a direct correlation of growth with precipitation. Bogue (I905) reported that this occurred in sugar maple (Acer saccharum Marsh.) where the effect of abnormally large or small precipitation on radial growth is evidenced the following year. Lodewick (1930) also correlated ring width of the longleaf pine (Pinus palustris Mill.) in Florida with precipitation during the March-October period. He indicated that vigorous trees were the best indicators with dry years useful for cross-identification. Various tests for reliability included the relative production of spring wood to summer wood.

The radial growth of short-leaf pine (Pinus echinata Mill.) and white oak (Quercus alba L.) was studied with a dial gauge dendrometer by Boggess (1953) who followed soil moisture at different depths (down to $60 \mathrm{~cm}$ ), rainfall inside and outside of the stand, air and soil temperature as well as evaporation. He found that both pine and oak completed $80 \%$ of their basal growth by the end of June, when available moisture through the profile became exhausted. The sporadic periods of diameter increase interspersed with periods of stem shrinkage in the latter part of the growing season were then directly related to the availability of soil moisture which becomes a limiting factor in diameter growth during most seasons, although other factors might affect the final cessation of growth (Boggess, 1956).

In the relative utilisation of soil moisture by various species, Shear and Stewart (1934) found that water was removed from the soil most rapidly by all species, white pine excepted, at about the time new foliage is produced. Larch, white oak and white pine removed more water from the first four feet of soil during the growing season than green ash (Fraxinus pennsylvanica var. lanceolata (Borkh.) Sarg.) and silver maple (Acer saccharinum L.). Soil moisture was affected to a depth of three and a half metres under white oak, three metres under larch, two and a half metres under maple and white pine and two metres under green ash. The water table fluctuated from about one metre down to these depths, thus the trees had a constant source of water from the water table.

Concerning the utilisation of soil water, Schopmeyer (I939) working with seedlings of short-leaf and loblolly pine (Pinus taeda Linn.) found that 
short-leaf pine absorbed more water from the soil than loblolly pine and at the same time maintained higher total water content in its leaves even when soil moisture was limiting. Short-leaf pine also maintained a higher solute concentration when recovering from the effect of drought; that is when $30 \%$ soil moisture was restored. Schopmeyer's data indicate that the greater drought resistance of short-leaf pine cannot be attributed to an ability to conserve water either by retarding transpiration or by forming bound water, or having a higher osmotic pressure. Yet the rate of transpiration of loblolly pine gradually diminished over a period of six weeks as decreased soil moisture approached and passed the 'wilting coefficient'. At the end of six weeks the transpiration rate was only $16 \%$ of that at $30 \%$ soil moisture. This does not agree with Veihmeyer and Hendrickson's (1936) data on fruit trees. Wilhelmi (1957) presented terminal growth data of young broad-leaved and coniferous trees growing on irrigated and control plots. His best species included Populus angulata and Salix purpurea, both considered suitable for dry sites, but both growing better on the irrigated site. Young conifers growing in the Rocky Mountains at low altitudes stand the lack of growth water for longer periods and their roots have a more rapid rate of penetration than those trees growing at high altitudes (Daubenmire, 1943).

Lyon (1940, I943) has studied the correlation of growth with seasonal rains and temperature in various conifers as well as red oak (Quercus borealis Michx.); only in red oak was there no correlation between the rain of the previous season and growth, though some effect of rains falling during the growing season was noted. His conclusions stressed the effect of variation of water supply on radial growth fluctuations. He found that white pine growth is sensitive to water supplied by rainfall. In white pine, terminal growth of the primary and secondary axes had the closest correlation with the amount of rainfall from the 'storage' May-November season of the preceding calendar year (Motley, 1949). Red pine did not show the same correlation but perhaps the material was too young and not yet established. Since food used for apical growth is manufactured the previous year (Kienholz, 1934; Kozlowski and Ward, 1957), one would expect apical growth to be correlated with the preceding summer's rainfall when the efficiency of photosynthesis could be affected by abnormal weather conditions. This is especially true in the temperate regions where an adequate supply of soil moisture is usually available from melting snows in spring and early summer when growth first occurs. Growth-rainfall trends in six species of hardwoods were studied by Friesner (1950) to obtain a growthrainfall trend coefficient. He found a definite correlation between rainfall 
and growth regardless of species concerned. The site under scrutiny had a minimum run-off and the rainfall data used were taken 20 kilometres from the experimental area.

Though we usually think of moisture in terms of availability, it should be remembered that an excess can be just as detrimental to most species. Soil aeration is intimately connected with soil moisture since surplus of the latter partly excludes the former. As previously indicated, the amount of oxygen to roots can become of paramount importance to healthy root survival. However, Kramer (I950) considers that soil aeration is seldom a serious problem in forests because natural selection tends to eliminate the trees not well adapted to poorly aerated (usually very wet) habitats. Such is the case in the great Clay Belt of northern Ontario (Fraser, 1954), where black spruce predominates in areas of high water table and represents an edaphic climax (Weaver and Clements, I938).

Cannon and Free (1917) showed that roots of mesquite cease to grow when oxygen is lacking or where there is more than $25 \%$ carbon dioxide. On the other hand, willow is very resistant to lack of oxygen in the soil atmosphere. In Java, the oxygen requirements of root systems in several hundreds of species of trees, shrubs, and herbs, were investigated by Verhoef (1943).

The gley horizon underlying the constantly or temporarily submerged soils in the forest of Chaux, at less than $35 \mathrm{~cm}$, can be penetrated only by alders, willows and American red oak (Quercus borealis v. maxima) (Lachausee, I950). This oak has a powerful tap root which pierces the gley horizon which the native $Q$. robur cannot do. The latter dies back at 80 to I00 years.

White (Picea glanca (Moench.) Voss.) and black spruce, red (Pinus resinosa Ait.), white and jack pine, as well as balsam fir (Abies balsamea (L.) Mill.) in naturally flooded areas, were both measured and classified according to health (Ahlgren and Hansen, 1957). Black spruce and balsam fir showed the greatest endurance and ability for recovery, although all trees were affected to a various degree. This varied not only with the species, but age of the tree as well as the duration of flooding. The $30-$ to $60-\mathrm{cm}$ class was most seriously affected and damage appeared to decrease progressively with size within the individual species. Some of the trees lost all their needles during flooding, but disease did not become evident in any of them until two years later. After 60 days of flooding, all sizes of balsam fir showed 80 to $100 \%$ mortality, and $4.5 \mathrm{~m}$ high white spruce showed $100 \%$ mortality; even 29 days of flooding affected the $30-$ to $60-\mathrm{cm}$ high white spruce. Of the hardwoods observed, paper birch was affected 
the most. Mikola (1950) in data from several hundred Scots pine and spruce (Picea abies (L.) Karst.) in central Finland, showed that in the i 8 years of agricultural crop failure since I 800 there was a correlation between these failures and tree growth, wherever crop failure was due to excessive moisture or frost (resulting in a cooler summer), but not where drought caused failure. During these i 8 periods the radial growth of these two species averaged $18 \%$ less than the growth in the preceding year. The floods in the marshy forests near Gabčikovo in July I954 were described by Farský (1957). Most of the younger plants were killed and the older ones lost their leaves when the flood water became warm and stagnant. Those species most severely affected included Fraximus excelsior, Quercus robur, Robinia psendoacacia, Prumus avium, Tilia cordata, Aesculus hippocastanmm and Acer spp.

Finally, Day (1946), commenting on root diseases in conifers, suggests that fungi might be of secondary importance as compared to adverse soil conditions of both drought and water-logging, which stimulate abnormal root growth consisting of unlignified collapsed tracheids. On a lesser scale, excess of seasonal moisture at Chalk River, Ontario, was found to retard growth of yellow birch (Betula lutea Michx, f.) (Fraser, I956, I96I). After extensive flooding in New Orleans, Bonck and Penfound (1944) measured terminal growth in two species of willow, sand bar willow (Salix interior Rowlee) and black willow (Salix nigra Marsh.), pecan (Carya illinoensis (Wang.) K. Koch) and hackberry (Celtis mississippiensis Bose). They have recorded that these species grew more rapidly during the April flood than at any other sector of their growth period, but elongated very little during the June flood. It is probable that the floods had little or no effect on the normal growth pattern of any of the four species studied.

It has been stated (Russell, I932) that an occasional extreme drought might affect vegetational boundaries more than normal climatic conditions. Late spring drought in Pennsylvania in 1935 and 1936 appeared to have caused stunted terminal growth and shorter needles in white pine (Craighead, I94I). Day (1950) on the other hand has found no injury to pine, but cracking of the stem, or dieback of younger trees of Sitka (Picea sitchensis (Bong.) Carr.) and Norway spruce (Picea abies (L.) Karst.) after a drought during the growing season in Wales and Scotland. These drought cracks result from internal shrinkage or collapse of wood as the water is withdrawn from the main stem and occur only in trees which are about 20 years old. The affected spruces were distinguished by low specific gravity of the wood produced and the marked absence of well-thickened late wood. A partial death of the root system appeared to be connected with the condition, which occurs on fertile but shallow soil where the rooting space is too 
limited for the potential need of the tree. In trees younger than 20 years, dieback rather than cracking, occurs.

It is obvious from the forgoing discussion that occasional drought affects trees differently at various stages of their development, and that we are dependent on natural occurrence for our data; exact duplication with mature material is nearly impossible without root disturbance. An exception to this might be found in the work of the salinity laboratory at Riverside, California, where, due to minimal rainfall, the water conditions of any tree under investigation can be closely regulated.

Many aspects of water relations of trees have been discussed by Kramer (1952). He has stated that, in winter, except during warm periods, transpiration of conifers is almost as low as that of bare branches of deciduous trees, probably because of the cold soil hindering water absorption. The question whether soil moisture is equally available between field capacity and wilting point has been approached by Stanhill (1957) who, in his comprehensive review, concluded that, in $80 \%$ of the experiments scrutinised, growth was affected by differences in the amounts of available water.

It is generally agreed that transpiration is affected by factors such as light intensity, humidity, temperature and species selection as long as soil moisture is above the wilting point (Pisek, I950; Veihmeyer and Hendrickson, 1955; Ladefoged, 1956). This is shown by an increase in sap flow from a morning low to a midday height, with further checking by sudden drops of temperature or showers (Huber and Schmidt, 1937; Schubert, I94I; Kuntz and Riker, I955). The maximum transpiration rate in July with a gradual subsequent decrease, would point both to the high temperature and long days as influential. Of course, even water availability might be affected by the physical characteristics of the tree studied, i.e., by the type and length of its root systems (Ladefoged, 1956). Kramer (I952) quotes Wiggans who recorded apple trees in Nebraska drawing on water to a depth of ten metres. An extreme of climatic effects on cvapotranspiration is suggested by Wilm (I957), who believes the dwarf 'rain forest' of the Puerto Rican mountains to be caused by suppressed transpiration rates in the saturated atmosphere.

The relation of forests to run-off and water storage in the soil was extensively reviewed by Zon (1927). Stålfelt (I944) studied water consumption of spruce and found that interception of precipitation by spruce crowns amounted to over $50 \%$. A much smaller, yet significant rainfall interception was found in forest stands at Chalk River (Fraser, 1956). Stålfelt (1944) also reported on considerable cuticular absorption, particularly where water in the soil was deficient. It is significant that younger 
trees consumed more water than older ones. This fact should be particularly pertinent to species establishment.

Adequate moisture and subsequent growth optimum might not be in the best interest of the tree if longevity is so considered. According to Schulman (I954) trees with great tolerance grown under adverse conditions and with extremely small annual increment $(4.6 \mathrm{~mm}$ radial increment per century of Fitzroya cupressoides (Molina) Johnston) live the longest.

The humidity aspects of the water cycle have been most thoroughly investigated by meteorologists (Geiger, 1950). However, Thornthwaite and Hare (I955) approached the problem from a climatological point of view and "expressed the hope that the conceptual framework of forest ecology will approach that of the climatologist more closely in the future'. Thornthwaite (1948) and Penman (1948, 1956) have independently developed methods of calculating potential evapotranspiration from meteorological records. Whereas Penman (1956) in his approximations utilises duration of bright sunshine, air temperature, air humidity, and wind speed, Thornthwaite (1948) calculates the potential evapotranspiration using nomograms derived from average temperatures and latitude. Fraser (I957, I96I) reported on fluctuations in soil moisture and potential evapotranspiration over a decade and indicated that although total annual rainfall at Chalk River, Canada, always exceeded potential evapotranspiration, periods of drought did occur in certan years when the evapotranspiration in summer months exceeded current rainfall. Consequently there was a gradual depletion of stored soil moisture with a resultant decrease in growth (Fraser, I958) of trees on sites that usually have adequate water. Trees on wet sites with seepage water were not affected to the same extent except where the root systems were shallow. Zahner (1955) in a study of soil water depletion by pine and hardwood stands during a dry season, noted little difference in the rate of loss of soil moisture between the two stands in southern Arkansas. His work supports the contention that evapotranspiration within a given climatic area is independent of the type of forest cover.

Daily and seasonal moisture changes in the leaves of yellow birch were elucidated by Fraser and Dirks (I959) in their study of the internal water relations of that species. They noted that wood moisture decreased from almost $100 \%$ in May to about $60 \%$ in late June when the leaves were fully unfolded. Relative turgidity of leaves was usually less during the day and during periods of drought it decreased even at night. Fraser and Gaertner (1959) outlined micro-environmental research in Canadian forests and emphasised the importance of using physiological techniques to 
evaluate the effect of various phases of the water cycle on tree growth. Although this paper has dealt almost exclusively with mature trees rather than seedling material in their relation to water economy and its effects on growth, it should not be forgotten that natural distributional patterns are often governed by factors affecting seed germination (Moore, 1926) or seedling tolerance as studied and discussed by Daubenmire (1943). Knowledge of such limiting factors, although essential in any forest management, does not necessarily prevent the cultivation of such trees. For now many of our agricultural or horticultural crops would have to be abandoned in many regions if natural regeneration was expected.

\section{REFERENCES}

Ahlgren, C.E. \& Hansen, H.L. (1957) Some effects of temporary flooding on coniferous trees. J. Forestry, 55, 647-650.

BJöRKMAN, E. (1944-45) Studier üver ljusets betydelse för föryngringens höjdtillväxt pä norrländska tallhedar. (Studies on the relation of light to the height growth of regeneration on Norrland pine heaths.) Medd. Skogs-försökanst. Stockh. 34, 497542.

Boggess, W.R. (1953) Diameter growth of shortleaf pine and white oak during a dry season. For. Note Ill. Agric. Expt. Sta. No. 37.7 pp.

Boggess, W.R. (1956) Weekly diameter growth of shortleaf pine and white oak as related to soil moisture. Proc. Soc. Amer. For. 83-89, Memphis, Tenu1.

Bogue, E.E. (1905) Annual rings of tree growth. U.S. Mo. Weath. Rev. 33, 250-25I. BoncK, J. \& Penfound, W.T. (1944) Seasonal growth of twigs of trees in the batture land of the New Orleans area. Ecology, 25, 473-475.

Bowman, I. (I9II) Forest Physiography. John Wiley and Sons, N.Y. p. 759.

Briggs, L.J. (I 897$)$ The mechanics of soil moisture. U.S. Dept. Agric., Bur. Soils, Bull. Io.

Burns, G.P. (1923) Studies in tolerance of New England forest species. IV : Minimum light requirement referred to a definite standard. Vt. Agric. Expt. Sta., Bul. 235. $32 \mathrm{pp}$.

CAMP, W.H. (1950) A biogeographic and paragenetic analysis of the American beech (Fagus). Yearbook of the Amer. Phil. Soc. I66-169.

Cannon, W.A. \& Free, E.E. (1917) The ecological significance of soil aeration. Science, N.S. 45, 178-180.

Clements, F.E. (I92I) Aeration and air content: the role of oxygen in root activity. Carnegie Inst. Wash., Pub. 3 I5. I 83 pp.

Craighead, F. S. (I94r) An effect of drought on white pine. J. Forestry, 39, 61 8-6r9.

DAUBENMIRE, R.F. (1943) Soil temperatures versus drought as the factor in determining lower altitudinal limits of trees in the Rocky Mountains. Bot. Gaz. 105, I-I3.

DAY, W.R. (1946) Root disease in conifers. Nature 158, 57-58.

DAY, W.R. (1950) The drought-crack of conifers. Rep. Imp. For. Inst., Oxf. x948-49. I2-13. 
DILLER, O.D. (I935) The relation of temperature and precipitation to the growth or beech in northern Indiana. Ecology, 16, 72-8I.

FARSKÝ, O. (1957) Škodlivé následky červencové povodně v lužních lesích na Gabšikovsku v roce I954. (The harmful results of the July 1954 floods in the marshy forests near Gabíčkovo.) Lesit. Čas. 3, Ino-I 57.

FrASER, D.A. (1954) Ecological studies of forest trees at Chalk River, Ontario, Canada. I. Tree species in relation to soil moisture sites. Ecology, 35, 406-4I4.

Fraser, D. A. (1956) Ecological studies of forest trees at Chalk River, Ontario, Canada. II: Ecological conditions and radial increment. Ecology, 37, 777-789.

Fraser, D. A. (1957) Ecological studies of forest trees at Chalk River, Ontario, Canada. III: Annual and seasonal march of soil moisture under a hardwood stand. Canad. Dept. Northern Affairs and National Resources, Forestry Branch, For. Res. Div. Techn. Note No. 55 .

Fraser, D.A. (1958) Growth mechanisms in hardwoods. Pulp Paper Mag. Canada, 59, 202-209.

Fraser, D. A. (I96I) Tree growth in relation to soil moisture. In: International Conference on Forest Tree Growth, Tucson, Arizona, Edited by T. T. Kozlowski, The Ronald Press, N.Y., pp. I 83-204.

FraSER, D.A. \& Dirks, H.T. (I959) Internal water relations of yellow birch at Chalk River. Canad. J. Bot. 37, 789-799.

Fraser, D.A. \& Gaertner, E.E. (1959) Concepts and instrumentation for microenvironmental studies in forest research. Proc. IX int. Bot. Congr., Montreal, p. 122 .

FRICKE, K. (1904) 'Licht-und Schattenholzarten', ein Wissenschaftlich nicht begriindetes Dogma. Centralblatt F.D.G. Forestwesen, 30, 3 I 5-325.

FrIESNER, R. C. (I950) Growth rainfall trend coefficient shown by six species of hardwoods in Brown Co., Ind. Butler Univ. Stud. 9, I 59-I66.

Geiger, R. (1950) The Climate Near the Ground. Engl. transl. by M. N. Stewart, Harvard Univ. Press, Cambridge, Mass. 482 pp.

Harlow, W.M. \& Harrar, E.S. (194I) A Textbook of Dendrology. McGraw-Hill Book Co., New York. 542 pp.

Hartig, R. (1891) Anatomie und Physiologie der Pflanzen. Verlag J. Springer, Berlin, p. 264 .

Hilıs, G. A. (1953) The identification and description of forest sites. Site Res. Man. No. 4, Ont. Dept. Lands and Forests, Res. Div. 71 pp.

HubER, B. \& SCHMIDT, E. (I937) Eine Kompensationsmethode zur thermoelektrischen Messung langsamer Safströme. Ber. dtsch. Ges. 55, 514-529.

Kienholz, R. (1934) Leader, needle, cambial, and root growth of certain conifers and their interrelations. Bot. Gaz.96, 7I-92.

Korstian, C.F. \& CoIle, T.S. (1938) Plant competition in forest stands. Duke Univ. School Forestry, Bul. 3. 125 pp.

Kozlowskr, T.T. \& WARD, R.C. (I957) Seasonal height growth of deciduous trees. For. Sci. 3, I68-I74.

Kramer, P.J. (1944) Soil moisture in relation to plant growth. Bot. Rev. Io, 529-559.

Kramer, P.J. (1950) Soil aeration and tree growth. Proc. 26th Nat. Shade Tree Conf. $S I-58$.

Kramer, P.J. (1952) Plant and soil water relations on the watershed. J. Forestry, 50, 92-95. 
KREČMER, V. (I9SI) Rosa jako činitel meteorologický, püdni, fysiologický, ekologický, a rosa $\mathrm{v}$ lesnictví (Dew as a meteorological, pedological, physiological and ccological factor, and dew in forestry.) Lesu. Práce, 30, 340-375.

KunTZ, J.E. \& RıKER, A.J. (1955) The use of radioactive isotopes to ascertain the role of root grafting in the translocation of water, nutricnts and diseasc-inducing organisms among forest trees. A-Conf. 8-P-I05, Geneva.

LACiAuUse, E. (I950) Les sols sous la dominance de l'eau et la foret. Rev. For. franç. $5,246-273$.

LADEFOGED, K. (1956) Undersogelser af træernes vandforbrug (Studies on water consumption by trecs.) Dansk Skonforen. Tidsskr. 4I, 48I-506.

Lebedeff, A.F. (1928) The movement of ground and soil waters. Proc. Ist int. Congr. Soil Sci. I, 459-494.

LODEW 1CK, J.E. (1930) Effect of ccrtain climatic factors on the diameter growth of longleaf pine in western Florida. J. Agric. Res. 41, 349-363.

Lyon, C. (1940) Tree growth beside a rain gaugc and thermometer. Ecology, 2I, $425-437$.

Lyon, C. (1943) Water supply and the growth rates of conifers around Boston. Ecology, 24, 329-344.

Mikola, P. (1950) Katovuodet ja metsien kasvu. (Tree growth in years of crop failure.) Mítsät. Aikak. 6, 204-205.

Moore, B. (1926) Influence of certain soil and light conditions on the establishment of reproduction in northeastern conifers. Ecology, 7, 191-220.

Motley, J.A. (1949) Correlation of elongation in white and red pine with rainfall. Butler Unin. Bot. Stud. 9, I-8.

P'ENMAN, H.L. (1948) The dependence of transpiration on weather and soil conditions. J. Soil Sci. I, 74-89.

Penman, H.L. (1956) Estimating evaporation. Trans. Amer. Geophys. Un .37, 43-50.

PISEK, A. (I950) Transpiration und Wasscrhaushalt der Fichte bei zunehmender Luftund Bodentrockenhiet. Proc. VII int. Bot. Congr., Stockholm, 229-230.

Russell, M.B. (1960) Some physical aspects of plant growth. Soil Sci. Soc. Proc. 24, 439-440.

Russell, R.J. (1932) Dry climates of the United States. II: Frequency of dry and desert years 1901-1920. Univ. Calit. Publ. Geog. 5, 245-274.

SChopmeyer, C.S. (I939) Transpiration and physiochemical properties of leaves as related to drought resistance in loblolly pine and shortleaf pine. Plan Pliysiol. I4, 447-462.

SCHUBert, A. (I94I) Untersuchungen über den Transpirationsstram der Nadelhölzer und den Wasserbedarf von Fichte und Lärche. Thar. Forstl. FB. 90, 821-\$8 3 ; (194I) Abstr. in Forstarchiv, I7, 165.

Schulman, E. (1954) Longevity under adversity in conifers. Scicnce, I19, 396-399.

Shear, G.M. \& Stewart, W.D. (1934) Moisture and pH studies of the soil under forest trees. Ecolog $\gamma, 15,145^{-1} 53$.

StÅlfelt, M.G. (1944) Grancıs vattenförbrukning och dess inverkan poa vattenomsättningen i marken. (The water consumption of spruce and its influence on the water regime of the soil.) K. Lantbr. Akad. Tidskr. 83, 425-505.

Stanin L, G. (1957) The effect of differences in soil moisture status on plant growth. Soil Sci. 84, 205-214. 
StONE, E. C. (1957a) Dew as an ecological factor. I: A review of the literature. Ecology' $38,407-413$.

Stone, E.C. (1957b) Dew as an ecological factor. II: The effect of artificial dew on the survival of Pinus ponderosa and associated species. Ecology, 38, 4I-422.

Stone, E.C. \& Fowerus, H.A. (1955) The survival value of dew as determined under laboratory conditions with Pimus ponderosa. Forest Sci. I, 183-188.

Stone, E.C., Went, F. W. \& Young, C.L. (1950) Water absorption from the atmosphere by plants growing in dry soil. Science, III, 546-548.

Surmač, G.P. (1958) The possibilities for natural regeneration of pine in the Kanyshin Massif. Lesn. Hoz. II, 71.

ThornthwaIte, C. W. (1948) An approach towards a rational classification of climate. Gcograph. Rev. 38, 55-94.

Thornthwatre, C.W. \& Hare, F.K. (1955) Climatic classification in forestry. Unasylva, 9, I-II.

Veihmeyer, F.J. \& Hendrickson, A.H. (1936) Essentials of irrigation and cultivation of orchards. Calif. Agric. Expt. Sta. E.vt. Serv. Circ. 50.

Veihmeyer, F.J. \&- Hendrickson, A.H. (1955) Does transpiration decrease as the soil moisture decreases? Traus. Amer. Geophys. Un. 36, 425-448.

Verhoef, L. (1943) Wortekstudien in de tropen. VI: Nadere gegevens omtrent de zuurstof bchocfte van det wortelstelsel. (Root studies in the tropics. VI: Further data on the oxygen requirement of the root system.) Korte Meded. Boschbonwprocfsta., Buitenzorg No. 8I. 65 pp.

WAIser, Y. (1958) Dew absorption by plants of arid zones. Bull. Res. Coum., Isracl, Sec. D. $180-186$.

Weaver, J.E. \& Clements, F.E. (1938) Plant Ecolog $\gamma$. 2nd ed. McGraw-Hill Book Co., New York. p. 601.

Wilhelni, T. (1957) Rhythums und Potenz des Höhenwachstums junger Nadel- und Laubhölzer. Allg. Forstzeitschr. I2, 4I-47.

WiLM, H.G. (1957) The influence of forest vegetation on water and soil. Untasyll'a, II, I60-I64.

WiLsON, C. (1948) Fog and atmospheric carbon dioxide as related to apparent photosynthetic rate of some broadleaf evergreens. Ecolog $\gamma, 29,507-508$.

ZahNer, R. (1955) Soil water depletion by pine and hardwood stands during a dry season. For. Sci. 1, 258-264.

ZoN, R. (1927) Forests and water in the light of scientific investigations. U.S. Govt. Print. Off., Wash. $106 \mathrm{pp}$.

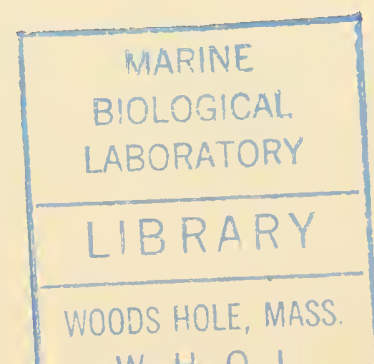




\section{AUTHOR INDEX}

The figures in bold type indicates the page on which the complete reference is given.

Ackley, W.M.B. I02, 107, III

Ahlgren, C.E. 371,375

Aitken, J. 37, 54

Aldrich, W. W. 323, 325

Alexeev, A. M. 226, 233

Allerup, S. I21, I22, I25

Alvin, P. de T. 17,18

Amer, F. A. 173,189

Anderson, A. B.C. 59,64

Andersson, N.E. 172,188

Angus, D.E. 43,54

Arisz, W.H. 86, 95, 99

Arvidsson, I. 53, 55, 102, 107, I I I

Ashbel, D. 46, 54

Ashton, P. S. 169,188

Aulitzky, H. I56, I57, 161, I62, 166

Ayres, A. D. 281, 286, 288

Babuschkin, L. N. $28 \mathrm{I}, 286$

Barrs, H.D. 98, 99

Bartoš, J. I08, I09, III

Bauman, L. 225, 233, 276, 278, 283, 287

Belik, V.F. 28I, 287

Berger, E. I $53,165,167,187,188$

Berger-Landefeldt, U. I 59,166

Bergman, H.F. 321, 324

Bernstein, L. 86, 99

Beskow. 8I

Beydemen, I.N. 9

Bierhuizen, J.F. 250, 252, 254, 256, $352,353,354$

Birch, H. F. 321,324

Björkman, E. 368,375

Bloemen, G. W. 254, 256

Boggess, W.R. 324, 324, 369, 375

Bogue, E. E. 369,375

Böhnig, R.H. 250,256

Bonck, J. 372, 375

Borhidi, A. 9

Bosian, G. I84, I85, 188

Bowen, I. S. 24, 35
Bowman, I. 366, 375

Boynton, D. 323, 324

Boysen-Jensen, P. I98, 198

Brawand, H. 66,82

Brewig, A. 97, 99

Briggs, L.J. 368, 375

Brilliant, V.A. 225, 226, 232, 233

Brouwer, R. 97, 100

Brown. 286

Burgy, R.H. I 38,140

Burns, G.P. $\quad 368,375$

Burnside, C. A. 250,256

Cain, S. A. 206, $22 \mathrm{r}$

Camp, W.H. 367,375

Cannon, W.A. 37I, 375

Carr, D.J. 98, 100

Cartellieri, E. I25, 125, 159, 166, 167

Čatský, J. 101, 102, 103, 111,227 , 233, 234, 300, 3II

Chaptal, L. 45, 8I

Childers, N. F. 322,325

Chrelashvili, M.N. 225, 233

Clements, F.E. $\quad 368,371,375$

Coile, T.S. 368,376

Cooil. 286

Craighead, F. S. 372,375

Currie, J.A. 63,64

Damagnez, J. $\quad 52,55$

Danilov, A. N. 225, 233

Daubenmire, R.F. $370,375,375$

Day, W. R. 372,375

Deacon, E. L. $28,30,32,35,46,55$

De Lavison, J. de R. 86, 100

Delfs, J. I 32, I38, 140

Deming, J.M. 64

Development Board, Baghdad 284, $285,286,287$

Diller, O.D. 369,376

Dirks, H.T. 374,376

Dixon, H.H. 99, 100 
Döring, B. 162,166

Dreibelbis, F. R. 42,55

Duvdevani, S. $42,43,53,55$

Dyer, A.J. 20,36

Eaton, F. M. $\quad 286,287$

Edlefsen, N.E. 59,64

Eger, G. II 9,125

Ellée, O. 225, 233

Ensgraber, A. 225, 232, 233

Evans, G.C. 170,188

Evenari, M. $44,56,184,188,206,221$

Fahn, A. 206, 222

Farský, O. 372,376

Feinbrumn. 207

Fisher, R.A. 317, 324

Folkes, B. F. $\quad$ I68, 189

Fowells, H. A. 367,378

Frankenberger, E. 49, 55

Fraser, D. A. 368, 371, 372, 373, 374, 376

Free, E. E. $\quad 371,375$

Fricke, K. 368,376

Friesner, R. C. 370,376

Fritz, M. I09, III

Fukuda, Y. 273, 287

Funk, J.P. 22, 35

Furr, J.R. 323, 325

Gaastra, P. 250, 256, 323, 354

Gaertner, E. E. 374,376

Gaff, D.F. $98, \mathbf{1 0 0}$

Gates, C. T. $340,352,354$

Gates, D.M. 39,55

Gauch, H. G. 286, 287, 309, 312

Gaussen, H. 9

Geiger, R. $65,79,80, \mathbf{8 2}, 374,376$

Gilead, M. 46, 55

Ginsburg, Ch. 219, 22 I

Glueck, N. 45, 55

Golubić, S. 9

Hahn, H. 54, 55

Halevy, A. 102, I09, III

Hansen, H. L. 371,375

Hardy, F. 323, 325

Hare, F. K. 374,378
Harlow, W.M. 367,376

Harrar, E. S. 367,376

Harrold, L. L. 42,55

Hartig, R. 366,376

Hatfield, H.S. 23,35

Hayward, H.E. $\quad 286,287$

Heath, O.V.S. $173,174,185,188$

Heilig, H. $79,8 \mathbf{2}$

Helder, R.J. $86,95,99$

Hendrickson, A.H. 323, 325, 370, 373,378

Hertz, C. H. I I2, I88

Hillel, D. 44,56

Hills, G. A. 368,376

Hiltner, E. 44, 55

Hitier, H. 45,55

Höfler, K. I64, I65, 166

Hofmann, G. $37,42,43,44,45,46,55$

Holdheide, W. 225, 232, 234

Holzman, B. I9, 26, 29, 30, 35, 4I, 56

Hope-Simpson, J. F. I68, I89

House, G.J. 33, 34, 35, 4I, 55

Huber, B. $273,287,373,376$

Hülsbruch, M. 85,100

Hygen, G. I68, I70, 17I, I72, I 84 , I 86,188

Iljin, W. S. I0I, I I I, 225, 233

Jackson, J. E. 94, 99, roo

Jarvis, M.S. 290, 3 I I, 3II, 319, 325

Jarvis, P. G. 3II, 3I4, 3I 5, 3I 6, 324, 325

Jones, R. L. 43,55

Kaltwasser, J. 225, 232, 233

Katti, M.S. 52,56

Kausch, W. 66, 73, 82, 202, 204, 205

Keilhack, K. 8I, 82

Kekkonen. $8 \mathrm{I}$

Kenworthy, A. L. 32I, 325

Kienholz, R. 370,376

Kittredge, J. 132,140

Kohnke, H. 66,82

Korczagyn, A. A. 9

Korstian, C. F. 368,376

Kozlowski, T. T. 370,376

Kramer, P.J. 86, 100, I84, I88, 367, $37 \mathrm{I}, 373,376$ 
Kraus, G. 79, 82

Krečmer, V. 367,377

Kreeb, K. 225, 233, 274, 275, 279, $280,283,284,287$

Kubín, S. 108. I09, I I I

Kuiper, P.J. 352,354

Kuntz, J.E. 373,377

Lachausee, E. 371, 377

Ladefoged, K. 373, 377

Larcher, W. I6I, I64, I65, I66, I67, 225,233

Law, F. I3 I, I36, I40

Lebedeff, A.F. $66,80,8$ I, 82, 368, 377

Lehmann, P. 53,55

Lejeune, G. 46, 55

Levitt, J. 85, 100, 304, 3 I I

Lieth, H. 9

Lindner, H. 66, 82

Linke. 44

Livingston, B. E. I 53, I66

Lloyd, F. E. I73, I88

Lobov, M. F. 275, 287

Lodewick, J. E. 369,377

Loftficld. J.V.G. I78, I 85, I88

Loneragan. $20 \mathrm{I}$

Long, I. F. $37,47,48,55$

Loughead, H.J. I $32, I_{40}$

Low, P.F. 59, 64

Luti, R. $\quad 237,245$

Lyon, C. 370,377

MacDowall, I. 22, 35

Magyar, P. IOI, I02, I07, III

Makkink, G.F. 248,256

Maximov, N.A. 220, 221

Mayer, A. 225, 233

Mazurak, A. I32, I40

Mcllroy. 50

Mees, G. C. $86,95,97,100$

Meusel, H. $\quad$ 197, I98, 198

Migsch, H. I64, I65, I66

Mikola, P. $\quad 372,377$

Milthorpe, F. L. $\quad$ I 72, I $85, \mathbf{I 8 8}$

Mohrmann, J. C. J. I5, I8

Monteith, J.L. $38,40,47,49,55,58$, 64, 340, 346, 354
Montford, C. 54,55

Montgomery, R. B. 29,36

Moore, B. $368,375,377$

Morris, L. G. 25, 35, 4I, 55

Motley, J. A. 370,377

Mïller-Stoll, W. R. 79, 82, I02, III

Nagel, A. 45,55

Negisi, K. 322,325

Nie, R. van $86,95,99$

Niederhof, C. H. I 3 I, I 36, I40, I4I

Nieman, R.H. 86,99

Nutman, F.J. I85, I88

Oksbjerg, E. B. I42, I44, I45, I52

Olberts, M. 8 I

Önal, M. 274, 287

Oppenheimer, H.R. I09, III, I 53, I67, I 84, I88, 220, 22 I

Orchard, B. $34 \mathrm{I}, 346,354$

Orshan, G. 206, 207, 219, 220, 22I, 222

Orshansky, G. 206, 207, 22 I

Owen, P. C. 58, 64, 340, 34I, 346, $350,35 \mathrm{I}, 354$

Pannier, F. 9

Pappenheimer, J.R. 95, roo

Parker, J. I I9, I22, I 25, I 72, I 88

Pasquill, F. 20, 27, 28, 35

Paterson, S.S. 9

Penfound, W. T. 372,375

Penman, H.L. $32,35,37,47,48,56$, I 47, I 52, 374, 377

Philip, J.R. 59, 64, 64, 353, 354

Pigott, C. D. 316,325

Pisek, A. 9, I25, I25, I53, I59, I64, I65, I67, I87, I88, 225, 233, 257, 27I, 373,377

Plantefol, L. 225, 233

Poel, L. W. 3I 5, 325

Poliakoff, A. 220, 22 I

Pomeroy, C. R. I 38,140

Prat, H. 226, 233

Priestley, C. H.B. 24, 29, 35, 46, 48, $49,55,56$

Priestley, J.H. 86, 100

Prutzer, E. I 57, I67 
Ramdas, L. A. 52,56

Rathschüler, E. I 54, I67

Raunkiaer, C. 206, 22 I

Rawitscher, F. I22, I25

Renner, O. 273, 287

Reuther, W. 323, 324

Richards, L. A. 59, 64, 290, 311, 323, 325

Richter, R. I 84, I88, 206, 221

Rider, N.E. 25, 27, 29, 30, 31, 33, 34, $35,36,4 \mathrm{I}, 55$

Ried, A. 225, 232, 234

Rijtema, P.E. $\quad 248,256$

Riker, A.J. 373,377

Robinson, G.D. 25, 30, 36

Robinson, R.A. 62, 64

Romose, V. 225, 234

Rosenan, N. 46, 55

Rossby, C. G. 29,36

Rottenburgh, W. I64, I65, 166

Rufelt,, H. I72, I88

Russel, J. C. 272

Russell, Sir J.E. 309, 31 I

Russell, M. B. 366,377

Russell, R.J. $\quad 372,377$

Rutter, A.J. I02, I03, III, I22, I 24, I $25,125,187,188,28 \mathrm{I}, 283,287$, 293, 302, 311, 312, 31 7, 321, 324, 325

Rychnovská-Soudková, M. I96, I97, 198, 198

Sabinin, D. A. $86,95,100$

Salisbury, E.J. I80, I88

Sands, K. I02, I03, III, I 25, I25, I 87 , I88, 28 I , 283, 287, 293, 302, 3 I I, 3 I 2, $317,321,324,325$

Satoo, T. 322,325

Savornin, J. $\quad 46,55$

Sayre, J.D. I78, I 85, 189

Schanderl, H. 53,55, IOI, II2

Schmidt, E. 373,376

Schneider, G. W. 32I, 325

Schofield, R. K. $\quad 58,59,64,64$

Schopmeyer, C.S. $369,370,377$

Shcubert, A. 373,377

Schulman, E. 374,377

Scott, J. F. $\quad$ I34

Scott, L. I. 86,100

Setlik, I. I08, I09, II I
Shanan, L. 44,56

Shaw, R.H. 43,56

Shear, G. M. 369, 377

Shmueli, E. 206, 222

Simonis, W. 202, 205

Simpson, G.C. $46,47,56$

Slatyer, R.O. $5 \mathrm{I}, 52,53,56, \mathrm{I} 86$, I89, 274, 287, 302, 309, 312, 322, 325, 352,354

Slavik, B. IO2, IIO, I12, 226, 227, 232, 234, 275, 287

Smith, W. O. $66,78,82$

Smyth, E. 225, 234

Sohm, H. I 59, 167

Spencer, E.J. I72, I85, 188

Stålfelt, M. G. I20, I2 I, I22, I25, 125, I 26, I $57,167,185, \mathbf{1} 89,225,226$, $232,234,373,377$

Stanhill, G. 313, 321, 325, 354, 373, 377

Stewart. 129

Stewart, W.D. 369,377

Stieglitz, H. $275, \mathbf{2 8 7}$

Stocker, O. 54, 56, IOI, I02, 103,104 , I 07, I 12, I 1 8, 1 26, 1 70, I 89, I96, $198,225,226,232,234,273,287$, 298, 3 I 2

Stokes, R. M. 62, 64

Stone, E. C. $52,53,56,367,378$

Strugger, S. 85 , 100

Surmač, G.P. $\quad 368,378$

Suzuki, C. 44,56

Swinbank, W.C. 20, 32, 35, 36, 46, 55

Tadmoor, N.H. 45,56

Tantraporn, W. 39, 55

Taylor, R.J. 20, 36

Taylor, S. A. 323, 325

Thompson, H. A. 323,325

Thorne, G. N. 352, 355

Thornthwaite, C. W. I9, 26, 36, 4I, 56, 374, 378

Tranquillini, W. I25, I25, I 56, I6I, I67, 257, 27I

Trénel, M. $66,79,80,8$ I, 82

Thren, R. 275, 288

Tugwell, C. P. $\quad 33$, 34, 35, 4I, 55

Turner, H. I55, I 56 , I 57 , I 58 , I60, I67 
Uhvits. 286

Vassiljev, I. M. IOI, II2

Veihmeyer, F.J. $65,66,72,82,313$ $323,325,370,373,378$

Venema, H.J. $\quad 39,56$

Verhoef, L. 37I, 378

Vine, H. 323,325

Visser, W. C. 254,256

Viswanath, B. $284,286,288$

Voigt, G. K. I $28,136,140$

Volk, O.H. 79,82

Vos, N.M. de 252, 256

Vries, D.A.de $39,56,258,271$

Vries, P.A. de 254,256

Wadleigh, C. H. 28I, 286, 287, 288, 309, 312, 323, 325

Waisel, Y. $53,54,56,367,378$

Walter, H. 9, 9, 65, 66, 79, 80, 82, I 44, I 52, I 53, I $57,167,200,205,225$, 234, 272, 273, 274, 275, 288

Ward, R.C. 370,376

Wassink, E. C. $250,254,256$

Watson, D.J. $340,346,35 \mathrm{I}, 352,353$, 355

Weatherley, P.E. $86,94,95,97,98$, 99, 99, I00, I02, I08, I12, I 70, I89

Weaver, J.E. 317,378

Weaver, L. R. 59,64

Weber, H. 66,82
Webster, I. F. $\quad 284,286,288$

Weck, J. 257, 27I

Welten, M. I02, II2

Went, F. W. 41, 52, 56, 367, 378

Whitehead, F.H. 235, 237, 241, 242, $243,244,244,245$

Wicht, C. L. 136,140

Wiggans. 373

Wilhelmi, T. 370,378

Wilkins, F.J. 23, 35

Williams, W. T. I73, I 74, I89

Willis, A.J. I02, I05, I09, II2, I68, I 70, I73, I74, I75, 189

Wilm, H. G. I 31,136, I3s, I40, I4I, 373,378

Wilson, C. 367,378

Winkler, E. I $87, \mathbf{I} 88, \mathbf{2 2 5}, \mathbf{2 3 3}$

Wit, C.T. de 246,256

Witts, K.J. 353, 355

Wormer, Th. M. I02, II2

Yemm, E. W. I02, 105, I09, III, I68, I70, I73, I74, I89

Young, C.L. $52,56,367,378$

Zahner, R. 374,378

Zand, G. 207, 219, 221

Zibold. 45

Zohary, M. 206, 207, 220, 222

Zon, R. 373,378 



\section{SUBJECT INDEX}

Abies balsamea, resistance to flooding, $37 \mathrm{I}$ Acer, killed by flooding, 372

Acer saccharimum, removal of water from soil, 369

Acer saccharum, 369

Acer tatriinm, 265

Achensee, precipitation, I 58

Achinagoichan, potential water deficit and surplus, 12

Aesculus lrippocastanmm, killed by flooding, 372

Alectorietum, distribution in relation to snow cover in Alps, 160

Alder, roots penetrating gley horizon, 371

Alfalfa, hydrature, 282

- osmotic value, $279,28 \mathrm{I}$

283

- salt content and yield, 286

Algae, 225

Allgäu, precipitation, 158

Alvine desert vegetation, 235-237

Alpine rose, distribution in relation to snow cover in Alps, I6o

- injury delay and drought stress, I 65

— water content, I65

- water loss, 166

Alps, climate, I 54

_- dew, I 59

__ potential water deficit, Is

Anmophila arenaria, I83

-

Allabasis articulata, 207

_— life cycle, 2I 2-2 I 3

_—_ seasonal body reduction, 215

—— transpiration, $2 \mathrm{I} 7$

213,216

Anagyris foctida, 221

Anatolia, 3, 4, 7, 8

Anemometers, 25, 33

Ankara, 3, 4, 8

- climatic diagram, 4

Apennines (Italy), 235-237
Apple, growth, 321, 322, 323

__ using water from great depths, 373

Artemisia campestris, transpiration, 184

Artemisia herba alba, 207

life cycle, 2IO-2 I I

seasonal body reduction.

2 IS

body, 213, 2 I 6

Artemisia monosperma, 207

life cycle, 2 r 2

- seasonal body reduction, 2 I5

transpiration, 2 I 7 weight of transpiring body,

213,216

Ash, distribution in North America, 368

- removal of water from soil, 369

(see also under Fraximus)

Atmospheric turbulence, 20-2I, 26-29

Australia, dew in Victoria, 50

Eucalyptus forest, 200-20I

Austria, climate at Obergurgl, 154

Azalias, distribution in relation to snow cover in Alps, 160

- injury delay and drought stress, I65

—_ water absorption, I 66

- water content, I65

Baghdad, 284

Baltic coast of Germany, dew, 43

Barley, cropping pattern, 360, 361, 363, 364

- osmotic value and hydration, 279

- osmotic value and yield, $276,277$.

278

_ salt content and yield, 286

Beans, 253

- condensation on, 45

- cropping pattern, 360

_- osmotic value and yield, 277, 283

- radiation and growth, 205

- salt content and yicld, 286

— water lack, 282-283

__ water use and growth, 25 I, 252 
Beech, distribution in Ontario and U.S.A., 367

Berlin, condensation in soil, 79

Betula lutea, Distribution in North America, 368

\section{—— growth, 372}

Betula pubescens, stomatal closure, 187

Birch, distribution in North America, 368

- effect of flooding, 37I-372

growth, 372

- moisture changes in leaves, 374

Blanket bog, 13, I7

Bodensee, precipitation, 158

Brachyblasts, 208-2 I 2

Brassica napus, water saturation deficit, I03, 107

___- wilting, I08

Brassica oleracea, water saturation deficit, I03, I04, 107

—— wilting, 108

Braunton Burrows, (North Devon), sand dune plants, I68-I 87

—— temperature, I77, I 79

British Isles, factors influencing distribution of certain species of plants, 289-3 I I

Bryophytes, 225

Cabbage, osmotic values and yield, 275,276

- water saturation deficit, 103,104, I07

— wilting, 108

Cairo, rainfall, I99

- root penetration of desert plants, 204

California, distribution of Sequoia, 367 Caltha palustris, dew and photosynthesis, 54

Cambridge, evaporation and dewfall, 25

¿ surface energy balance, 22

Camcllia japonica, photosynthesis, 367

Canary grass, cropping pattern, 359, 360

Carcx arcnaria, 183

transpiration, I 83, I 86
Carrots, 253

radiation and growth, 250

water use and growth, 25I, 252

Carya illinoensis, growth and flooding, 372

Cauliflower, 253

- growth and radiation, 250 water use and growth, 25 I

Celtis mississippiensis, growth and flooding, 372

Centaurea aegyptiaca, root penetration, 204

Ccrastium, 244

Ceratonia siliqua, absorption of dew, 54

Chamaephytes, seasonal dimorphism, 206-22I

- transpiration, 2 I 5-2I 8

Cistus salvifolius, 207

_-_ seasonal body reduction, 2 I5 - transpiration, 2I 7, 2 I8

$2 I 4,216$

Climatic diagrams, 3-9

Climatic types, 7

Coffec arabica, stomatal closure, is 5 transpiration, 122

Coffee, moisture stress and flowering, I7 Condensation, 37-46

— in soil, 65-82

Convolvulus lanatus, root penetration, 204

Corn, cropping pattern, 363,364

Cornus sanguinea, 289

(see also under Thelycrania sanguinea)

Coryncphorus canescens, 196

—_ stomatal closure, 197 transpiration, I90-I9I, I93-

195

— water content, I93-I95

Coshocton, Ohio, dewfall, 42

Cotton, 54

- transpiration, 302

Crimea, large heaps of stones as dew collectors 45

Crop yield, 326-339

Cropping patterus, 356-365

Cwm Dyli, potential water deficit and surplus, I 6

Cyanide, effect on permeability coefficients of tomato roots, $96-98$ 
Cynoglossum officinale, 169, I 74, I78-180

- Stomatal aperture, 179,185 transpiration, I 79, I 84 , I 86

Czechoslovakia, psammophytes, I90198

Dakar, dew collectors, 46

Deep percolation of water in the soil, I2 Denmark, spruce growth in Jutland, I 42-1 52

Derbyshire, 289, 290, 307, 310

Desert chamaephytes, 206-22I

Desert plants, I99-205, 206-22 I

Desert:, rainfall and run-off, 204

Deschampsia flexuosa, 315,320

Dew, 25, 34, 37-54

- absorption by plants, 53-54, 367

- on grass, $4 \mathrm{I}$ in relation to photosynthesis, 54 on sugar-beet, 4 I

- on wheat, 4 I

Dew collectors, 45

Dewfall, definition, 47

Dew gauges, 37, 42-44

Dew-point, 37

Diffusion cell, 59-63

Diffusion pressure deficit, 5 I

Distillation, defmition, 47

Dolichoblast, 208-219

Douala, 7 climatic diagram, 5

Drought damage to oak, I 52

Drought injury to spruce, I43, I44, I 45

Drought resistance, $57,302-308$

Drought stress, 165

Eddy diffusivity, 21, 28, 3 I

Enchytraeid worms, movements in relation to potential water surplus and deficit, I 7

Endive, 253

_- growth and radiation, 250

_- water use and growth, $25 \mathrm{I}$

Endymion, 3 i 5

England, dew, 43, 50

potential water deficit, is

Epipactis palustris, $\mathrm{I} 82$

Erica carnea, osmotic values, I 59
Eucalyptus, forest, 200-20I

Eucalyptus astringens, $20 \mathrm{I}$

- diversicolor, 201

- marginata, $20 \mathrm{I}$ redunca, $20 \mathrm{I}$

Euphorbia cornuta, root penetration, 204 Europe, water balance regions, I6

Evaporation, 6, I2, I9-35, 37

- in Alps, I 57

—_ measurement, 170

- in oats, 29

- in relation to radiation, 247,248 ,

254

— at Strážnice-Př́voz, 192

Evapo-transpiration, 3, I O, I I, I 2, I 6, I 47

- measurements, IO-I I

Exposure and plant growth, 235-244

Fagonia arabica, root penetration, 204

Fagus grandifolia, distribution in Ontario and U.S.A., 367

Farsetia callosa, root penetration, 204

Festuca dominii, stomatal closure, I96

I93, 195

Festuca dominii, water content, 192-193

Festucetum halleri, distribution in re-

lation to snow cover in Alps, I60

Field-balance (Morris's), 25, 26, 4 I

Filipendula ulmaria, I 82

——— transpiration, I 83

Filipendula vulgaris, 289 drought resistance, 302-308

- Growth, 290-296, 297, 310

- transpiration, 296-302, 309

Finland, crop failure of pine and spruce, 372

Fir, resistance to flooding, $37 \mathrm{I}$

Fitzroya cupressoides, longevity, 374

Flax, cropping pattern, 360, 36I

Flooding, effect on trees, 37 I, 372

Fog, absorption by Pitus, 367

- in Alps, I 59

Fog precipitation, 45

France, dew collectors, $45-46$ dewfall, 43

Fraxinus excelsior, in Hungary, 265 killed by flooding, 372 
Fraxinns nigra, distribution in North America, 368

__ peimsylvanica, removal of water from soil, 369

Frost injury, spruce, 142

Geranium, condensation, 45

Gernıany, dewfall, 43

Gibberellic acid, effect on growth of Helianthus, 243-244

Gobabis, climatic diagram, 4

Grape fruit, salt content and yield, 286

Grass, yield in relation to rainfall, 254

Grassland, cropping pattern, 362, 363

- productivity in relation to rainfall, I99-200, 202

Greenhouse growth of vegetables, 246256

Groundwater depth in relation to cropping pattern, 362,364

— yield of crops, 334, 335, 336

Growth function, 326-339

Gurgler valley, wind velocity, I 57

Guttation, 37

Hackberry, growth and flooding, 372 Halophytes, 204

Haloxylon articulatim, 207

life cycle, 2 I 3 seasonal body reduction, 2 I 5 transpiration, 2 I 7

213, 26I

Helianthemmin chamaecistus, transpiration, I 84

Helianthus anmuns, growth in wind tumnel, 237-243

Helichrysmm arenarimm, stomatal closure, 197

transpiration, I90-I9I, I94195, 196, 197

—_— water content, I94-I95

Holcus mollis, 3 I 5

Hungary, Alcali Steppe, Quercus cerris, $263,265-266,267$

Hydrature, definition, 272

—_ and plant production, 272-286

$H_{)^{\prime}}$ drocotyle vulgaris, I69, I 84
Hydrocotyle inlgaris, stomal behaviour, I $8 \mathrm{I}, \mathrm{I} 82$ I 85, I 86

transpiration, 173, I80-182,

Incident precipitation, measurement, I 36-I 37, pl. I

- on woodland, I36-138

India, water vapour uptake by soil, 52

Indole-acetic acid, effect on growth of Helianthins, 243

Innsbruck, osmotic value in plant conmmunities, I 59

Interception of precipitation, in spruce stand, II 7-II9 in woodland, 127-1 40

Iraq, 277, 28 I

Ireland, potential water deficit, I 5

Irrigation and grazing, 337

- effect on sugar beet growth, 340-354

Israel, 207, 208

_- dewfall, 43 stone heaps (dew collectors) in Negev, 45

Italy, 235-237

Jamaica, dewfall, 43

Java, oxygen requirements of tree roots. $37 \mathrm{I}$

Jerusalem, rainfall, 207, 213

Kabul, climate, 8

Kaiserstuhl (S.W. Germany) temperature gradient in soil, 79

Kale, growth, 353

Kompedal (Denmark) soil moisture, I 49-I S I soil profile, I49-I 50

Kraighgau, (S.W. Germany), temperature gradient in soil, 79

Larch, removal of water from soil, 369 Larix laricina, distribution in North Anerica, 368

Leaf tissue, hydration in relation to photosynthesis and respiration, 225233

Legumes, cropping pattern, 360, 36I 
Lettuce, 253

_- ismotic value, 2 So, $28 \mathrm{I}$

osmotic value and yield, $277,28_{3}$

radiation and growth, 250

water lack, 282-283

water use and growth, 251, 252, 255

Liche11, 225

-_ in relation to snow cover in Alps, 160

Ligustrum lucidum, photosynthesis, 367

Locndal (Delmmark), soil moisturc in spruce stand, I I I

—_ temperature and rainfall, I $42-143$

Loisclcuria procumbcns, injury delay and drought stress, I65

- water absorption, I66

- water content, I65

Loiseleurietum, distribution in relation to snow cover in Alps, I60

Lycimm, 22 I

Lycopsis arvousis, 183

Lysimeter, 42

- used to measure potential evaporatioll, IO-I I

Maple, growth, 369

- removal of water from soil, 369

Marram grass, 183

-_ transpiration, 183

Matric potential, $57,6 \mathrm{I}$

Mediterranean chamaephytes, 206-22I

Melon, 54

Meniscus as semi-permeable nembrane, 57,60

Mesquite, cessation of growth, 37 I

Meteorological data in relation to plant climate, 8

Mitscherlich equation, 326-328, 330

Moltkia callosa, root penetration, 204

Montpellier (France) dew collectors, $45-46$

- dewfall, 43

Moor House Nature Reserve, Wcstmorland, 17

Moravia, dewfall, 43

- psanmophytes, 190-19\$

Moscow, dewfall, 43

Munich, dewfall, 43
Negev, Dewfall, 46

—_ rainfall, 207

stone heaps as dew-collectors, 45

Netherlands, ground-water depth and crop yield, $334,335,336$

New England, 368

New Forest, 324

Nicotiana sanderac, photosynthesis and respiration, 226-233

- stomatal size, 228, 230, $23 \mathrm{I}$

Noca mucromata, 207

- life cycle, 2 I 2

- scasonal body reduction, 215

—- transpiration, 2 I 7

weight of transpiring body, 2 I3, 216

Norway, potential water deficit, I5, I6

Oak, 263, 265, 266, 267, 268, 27I

_- drought damage in Denmark, 152 growth, 370

- penetration of gley horizon by roots, $37 \mathrm{I}$

—_ radial growth, 369

(see also under Quercus)

Oats, cropping patterns, $360,361,363$, 364

- evaporation, 29

osmotic value and yicld, 276 , 278,283

Obergurgl, climate, 154

- precipitation, 158

- snow cover, I60

Odessa, 6

- clinatic diagram, 4

Olea europea, average saturation deficit, $53-54$

Orchis practemissa, $\mathbf{I} 82$

Onion, stomatal closurc, I85

Osmotic potential, 58

Osmotic value, 273-28I, 283, 284

- —. determination, 275

pine needles, 163 and yicld, 275,276

Orztal, precipitation, 158

Oxford, throughfall in spruce woodland, I $27-$ I 40 
Patscherkofel, sub-alpine plants-water content, I65

Pea, 67, 7i-78

__ cropping pattern, $360,361,363,364$ growth and radiation, 250 growth of seedlings, 201-202, 203

Peanuts, transpiration, 302

Peat, in Scotland, I3, I4

Pecan, growth and flooding, 372

Pelargonimm, stomatal behaviour, 173

— water movements in leaf, 90-93

Pennsylvania, growth of trees and drought, 372

Phaseolus murigo, salt content and yield, 286

Photometer, 169-170

Photosynthesis and growth of poplar, 257-270

- hydration of leaf tissue, 225-233

- radiation, 250 stomatal closure, 225

Picea abies, crop failure in Finland, 372

—_ dieback and drought, 372 growth, 257

—— growth in Denmark, I 42-I 52 throughfall beneath, 127

Picea excelsa, injury delay and drought stress, I65

—- precipitation in stand, I I 5I 25

—_ sub-lethal water content, I 65

Picea glanca, resistance to flooding, $37 \mathrm{r}$

Picea mariana, distribution in North

America, 368

Ontario, 367-378

Picea sitchensis, dieback and drought, 372

—_ throughfall beneath, I 3 I

Pimpinella saxifraga, growth, 2 Io

Pine, drought and growth, 372

- soil water depletion in Arkansas, 374

(see also under Piniss)

Pineapple, 54

Pinus, absorption of dew, 54

Pinns banksiana, distribution in Ontario, 367-368

Pimis cembra, injury delay and drought stress, I65
Pinus cembra, osmotic value of needles, $\mathrm{I}_{3}$

- snow cover and water balance, I $62-166$

temperature of needles, i 56

Pinus conlteri, survival value of dew, 367

- water vapour uptake, 52

Pinus densiflora, growth, 322

Pintss eclinata, radial growth, 369

- water vapour uptake, 52

Pinus halepensis, average saturation defi

cit, 53-54

Pinus palustris, ring width, 369

Pimus ponderosa, survival value of dew, 367

Pitus resinosa, resistance to flooding, 37 I throughfall beneath, 128

Pinus strobus, shade effect, 368

- - transpiration, 122

Pinus syluestris, competition for moisture, 368

- crop failure in Finland, 372

- growth, 257, 28I, 283, 293

- leaching in podsol beneath,

I 29

- transpiration, 122,302

— water consumption, I24, 187

IO2

Piims taeda, in Piedmont plateau, 368

- transpiration, 370

seedlings, $369-370$

Pisum satiunm, 67, 71-78

Piturantlus tortuosus, root penetration, 204

Poplar, photosynthesis and growth, 257-270

Populus angulata, growth, 370

Populus candicans, water movements in leaf, $90-93$

Potatoes, cropping pattern, 356, 359, $360,361,362,363,364$

osmotic values and yield, 275 . $276,278,283$

— water lack, 282-283

Potential evaporation, IO, I I, I2, I6 . — measurement, IO-I I 
Potential water deficit and surplus, IO-I 8

— at Achnagoichan, I2

- in Scotland, 15

Potentilla anserina, 183

Poterium spinosmm, 207

___ life cycle, 209-2IO, 2 I I

- _ seasonal body reduction, 2 I 5 transpiration, 2I7, 218

214,216 weight of transpiring body,

Potsdam, temperature gradient in soil, 79 Precipitation, Distribution: in Alps, I $57-158$

- - in spruce stand, I I 5-I25, I 27I 40

Precipitation distribution above woodland, I36-138, pl. I.

Prunus avium, killed by flooding, 372 Prumus padus, 289

___ drought resistance, 302-308

310 - growth, 290-296, 299, 309,
309

Prunus spinosa, 265

Psammophytes, in Czechoslovakia, 190198

Puerto Rico, dwarf rain forest, 373

Pyrus communis, 265

Quercus alba, radial growth, 369

Quercus borealis, growth, 370

_- roots penetrating gley horizoI1, 37 I

Quercus cerris, 265, $27 \mathrm{I}$

-_ assimilation, 266, 267

- - growth, $26_{3}$

- - transpiration, 267

Quetcus petraea, growtl, 313-324

Qucrcus robur, 37 I

—_— assimilation, 266, 268

mark, is 2 drought damage in 1)en-

___ killed by flooding, 372 transpiration, 268

Radiation, 3

—_ at Obergurgl, I 55, I 56
Radiation, at Wien, I 55 , I 56

- in relation to growth, 248-25I

Radioneters, 22

Radish, 253

- radiation and growth, 250

- water use and growth, $25 \mathrm{I}$

Rape, water saturation deficit, 103,107

- wilting, 108

Remscheid Dam (Germany), precipitation in drainage area, $8 \mathrm{I}$

Revivim, rainfall, 207, 213

Rlizoctonia, on sugar beet, 34I

Rhododendetum ferruginei, distribution in relation to snow cover in Alps, I6o Rhododendron ferruginem, injury delay and drought stress, 165

- water content, 165 water loss, I66

Ribes sanguineum, water movements in leaf, 90-93

Richardson number, 20, 21, 27, 28, 29, 30

Robinia psendoacaci, killed by flooding, 372

Rocky Mountains, growth of young conifers, $37^{\circ}$

Rosenholn (Deimark), soil moisture in spruce stand, ${ }^{4} 8$

- - soil profile, I 49

Rostock (E. Germany), soil moisture, 8 I

Rothamsted, absorption of water vapour by soil, 52

- dewfall and distillation, 49

- growth of sugar beet, 340-354

- weather, 342-343

Rumania, dewfall, 43

Rye, cropping pattern, 356, 359, 360, $361,362,363,364$

Salivi atrocinerea, 182

—_ transpiration, I83

Salix interior, growth and flooding, 372

Salix nigra, growth and flooding, 372

Salix purpurea, growth, 370

Sand dune plants, I68-I 87

Sarcostemma anstralis, 205

Saxifraga hypnoides, 289

_- drought resistance, 302-308

- - growth, 290-296, 3 Io 
Saxifraga hypuvides, transpiration, 296302, 303, 309

Scirpus holoschocnus, 182

Scotland, I2, I3, 14, I6, I 7

_ distribution of arable land, I4

Scnecio clegans, 237

Senecio jacobaca, I69, I 80, I 8 I

— stomatal aperture, I74, I75, I $77,178,185,187$

- transpiration, I7I, I72, I77, I 84, I 86

- water relations, I76-I 78

Sencio nebrodensis, growth in relation to wind speed, 237,238

Sequia sempervirens, distribution in relation to fog in California, 367

Sequoia n'ashingtonianta, distribution in relation to fog in California, 367

Silkeborg Sonderskov, oak and drought danage, 152

- soil moisture in spruce stand, I 5 I-I 52

Snow cover-influence on water relations, I 59- I66

- at Obergurgl, I60

Soil-balance (Morris's), 25, 26, 4I

Soil flux plates, 22, 23, 24

- in poplar stand, 258, 259

Soil moisture in relation to throtighfall, I 29

in spruce woodland, I 47-152

Solamm clacagnifolimm, osmotic valuc, 275

Solarimeters, 22

Solute potential, 58

Sorghum, transpiration, 302

South-West Africa, plant cover, 199-200

Spinach, 253

radiation and growth, 250

watcr use and growth, 25I, 252

Spruce, crop failure in Finland, 372

- dicback and drought, 372 distribution in North Amcrica, 368

distribution in Ontario, 367-368

effect of flooding, $37 \mathrm{I}$

growth, 257

growth in Denmark, I42-1 52
Spruce, growth in Ontario, 371

- injury delay and drought stress, I 6 ; interception of rainfall, is $5-125$,

I 27-I 40, 373

— stemflow, I28-I29, I34, I 36, I 37 , I 38, I 39

- stomatal regulation of transpiration, 125

sublethal water content, I65

Stcmflow, measurement, I34, I 36

- in spruce in relation in incident

rainfall, I 28-I 29, I 37, I 38, I 39

Stomatal aperturc, Cynoglossmm, 179

-_- Nicotiana, 228, 230, 23 I

I 85, I 87

Stomatol bchaviour, Hydrocotyle, I $\delta$ I, I 82

- Pelargonimm, 173

Stomatal closurc, 187, 196, I97

Stomatal closure, and photosynthesis, 225

Stomatal regulation of transpiration in spruce, 125

Stuttgart, 6

- climatic diagram, 4

Strážnice-Privoz (Moravia), I90-I92

_._ climatic conditions, I9I-I92

— evaporation, 192

- humidity, 192

- temperature, 192

Sub-alpine region, climate, I 53-I 66

Sublcthal deficit, I 53 , I 54

Succulents, 205

Sugar-beet, 226

- cropping pattern, 356, 360, 36I, 363,364

- growth and irrigation, 340-354

osmotic value and yield, 276,278 , 283

Surface energy balance, 19-35

Surface tension, 57

Sweden, spruce stands and precipitation, I 1 5-I25

Switzerland, I6

Table Mountain, fog precipitatisu, 45 
Tamarack, distribution in North America, 368

Temperature, of pine needles, I55, I56, I6I

__- of soil beneath snow, I6I, I62 of spruce needles, I45-I47

- measurement, I 45

Temperature gradients in soil, $65-82$

Teucrium chamaedrys, transpiration, I 84

Teucrium polium, 207

—_ life cycle, 208-209, 210

— - seasonal body reduction, 2 I 5

— transpiration, 217, 218

2I4, 216

Thelycrania sanguinea, 289

drought resistance, 302-308

growth, 290-296, 298, 309,

3 IO

transpiration, 296-302, 303,

309

Theodosia (Crimea) large heaps of stones as dew collectors, 45

Thermocouples, wet and dry bulb, 25,26

Throughfall, in forests, 127-I 40

- measurement, I3 I, I36

Thymus capitatus, 207

life cycle, 208, 209

seasonal body reduction, 215

transpiration, 217, 218

Weight of transpiring body,

214,216

Tilia cordata, killed by flooding, 372

Tobacco, photosynthesis and respiration, 226-233

- stomatal size, 228, 230, 23 I

Tomato, irrigation and growth, 340,352

— osmotic values and yield, 275, 276 salt content and yield, 286

water movements in roots, 94

Transpiration, 3 I-32, 85-99

- measurement in detached leaves,

I 70

- in psammophytes, $19 \mathrm{I}$

Trifolium incarnatum, growth, 202-204

Tsuga canadensis, throughfall, I 28

Turgor pressure, 273

Turkey, $3,4,7,8$
Turnip, osmotic value, 280

— osmotic value and yield, 277,283

- water lack, 282-283

Tyrol, climate, I 54

U.S.S.R. dewfall, 43

Vaccinietum, distribution in relation to snow cover in Alps, 160

Vaccinium vitis-idaea, transpiration, 186

Vegetation regions, in relation to climatic types, 8

Verbascum thrapsus, 174

Vivia faba, stomatal closure, 187

Victoria (Australia) dew, 50

Vietnam, condensation, 79

Viola hirta, transpiration, 183

Von Karaman's constant, 20

Wales, potential water deficit, 15,16

Water absorption, I 53

- by spruce at low temperatures, 162

Water consumption, Pinus, 124

- by spruce trees in relation to precipitation, I23-I25

Water content of soil, Braunton Burrows, 175-176

Water deficit, estimation in leaves, 170

Water loss, reduction, 153

Water movements, effect of dissolved salts, $57-64$

Water movements in roots and leaves, 85-99

Water potential of soil, $57-58$

Water saturation deficit, in leaves, IOIII I

Water use and growth, 25I-256

Water vapour, absorption by plants, 50-53

- movement in soil, $65-82$

Wheat, cropping pattern, 360, 361

- osmotic value, 275

—— and yield, 276, 284

- salt content and yield, 286 transpiration, I2I

Willow, 182

- growth and flooding, 372 
Willow, resistance to lack of oxygen in soil, 37I

- roots penetrating gley horizon, $37 \mathrm{I}$ transpiration, I 83

Wilting, 108 in relation to water saturation deficit, IOI-I I I

Wind and plant growth, 235-244

Wind tunnel-growth of $\mathrm{Zea}$ and Helianthus, 237-243

Wind velocity, in Gurgler valley, I 56, I 57

World Atlas of Climatic Diagrams, 7 , 8,9
Würzburg (Germany) temperature gradient in soil, 79

Zea mais, growth in wind tunnel, 237

Zilla spinosa, root penetration, 204 Zillertal, precipitation, I 59

Zygophyllum dumosum, 207

—— life cycle, 212

—— seasonal body reduction, 2 IS transpiration, 217

$2 \mathrm{I} 3,2 \mathrm{I} 6$ 



